


MICROBIAL ANTAGONISMS AND ANTIBIOTIC SUBSTANCES 
LONDON

GEOFFREY CUMBERLEGE OXFORD UNIVERSITY PRESS 



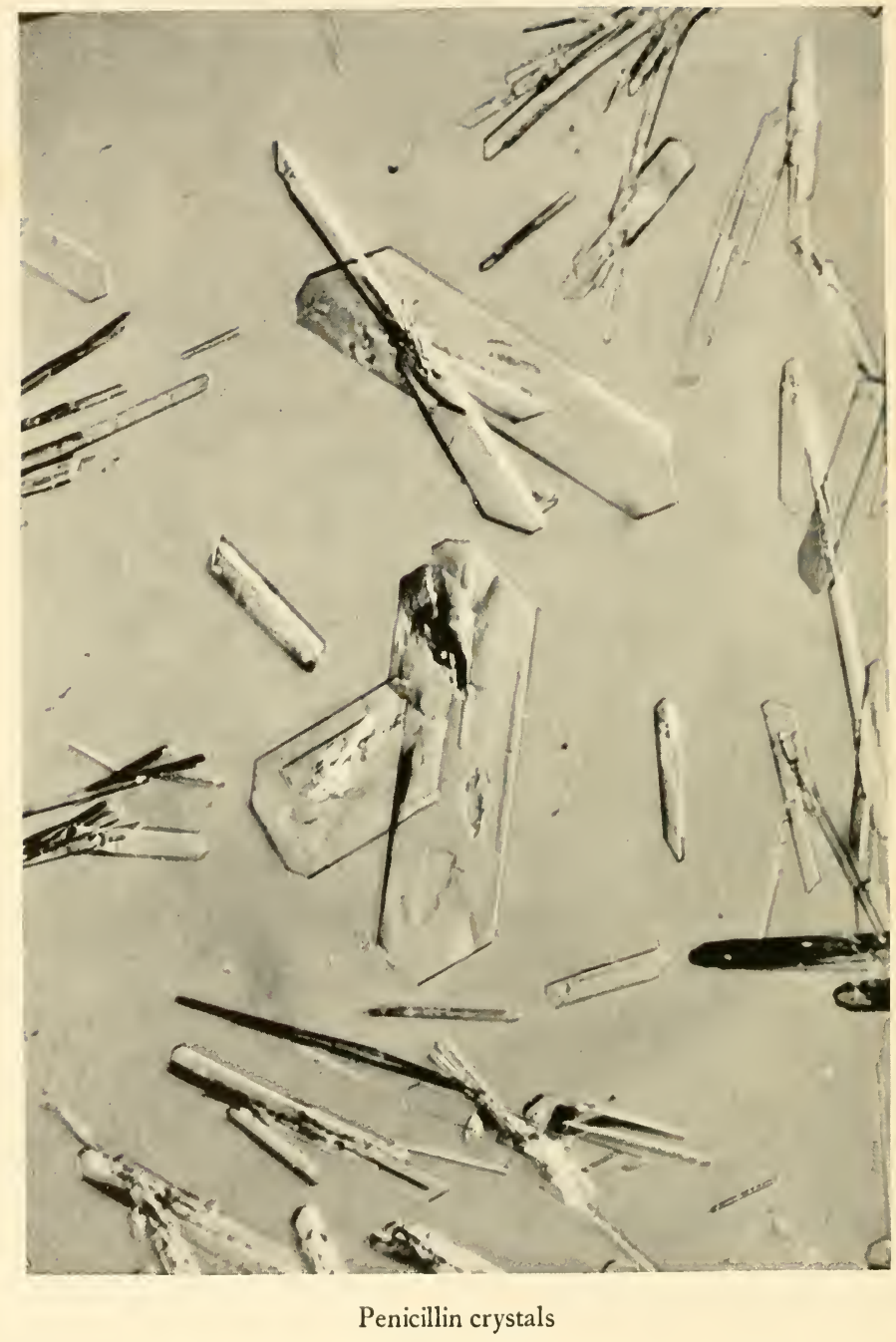




\title{
Microbial Antagonisms
}

\section{AND}

Antibiotic Substances

\author{
SELMAN A. WAKSMAN \\ PROFESSOR OF MICROBIOLOGY, RUTGERS \\ UNIVERSITY; MICROBIOLOGIST, NEW JERSEY \\ AGRICULTURAL EXPERIMENT STATION
}

"La vie empêche la vie"-Pasteur

\section{NEW YORK \\ THE COMMONWEALTH FUND}

I 947 


\section{COPYRIGHT, I945, BY \\ THE COMMONWEALTH FUND \\ FIRST PRINTING MARCH 1945 \\ SECOND PRINTING DECEMBER I 945}

SECOND EDITION, REVISED AND ENLARGED COPYRIGHT, I 947, BY THE COMMONWEALTH FUND

PUBLISHED BY THE COMMONWEALTH FUND

4I EAST 57 TH STREET, NEW YORK 22, N.Y.

PRINTED IN THE UNITED STATES OF AMERICA

BY E. L. HILDRETH \& COMPANY, INC. 


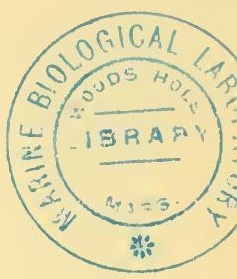

This book is affectionately dedicated to

\section{BOBILI}

who has stimulated me in moments of depression, who has been at all times an inspiration in the search for the unknown, my constant associate and antagonist 



\section{PREFACE TO THE FIRST EDITION}

ON the basis of their relation to man, the microscopic forms of life may be classified in two major groups: pathogenic forms that attack living systems, especially those useful to man and to his domesticated plants and animals; and saprophytic forms that attack inanimate matter, including the universal scavengers and the organisms utilized in industry and in the preparation of foodstuffs. Between true parasitism-one organism living in or upon the body of another-and true saprophytism -one organism merely destroying the waste products and the dead cells of another-are groups of relationships that may be designated as antagonistic and associative. In the first of these, one organism is injured or even destroyed by the other, whereas in the second, one organism assists the other and may in turn be benefited by it.

The antagonistic interrelationships among microorganisms have attracted attention since the early days of bacteriology. Following the discovery by Pasteur that microbes are responsible for certain human, animal, and plant diseases, it was established that other organisms, later designated as antagonists, are able to combat and even destroy the disease-producing agents. At first the soil was believed to be the natural habitat of the bacteria that cause epidemics and disease as a whole, but after careful study the fact was definitely established that very few of these bacteria survive for long in the soil. On the contrary, the soil was found to be the natural medium for the development of antagonists chiefly responsible for the destruction of pathogens. The saprophytic organisms that influence in various ways the disease-producing bacteria and fungi were found to inhabit, in addition to the soil, various other natural substrates, such as manure heaps and water basins.

The activities and potentialities of these antagonistic microbes still present many problems. Little is known about the nature and mode of formation of the antibiotic substances they produce, and even less about the mode of their action. The substances vary greatly in their physical and chemical properties. Some are soluble in water, others in ether, alcohol, or other solvents. Some are thermolabile, others are thermostable. Some are sensitive to alkalies or to acids, others are not. Some are 
readily oxidized and destroyed, others are not. Some are subject to destruction by specific enzymes. The substances are largely bacteriostatic in action, to a lesser extent bactericidal. They are selective in their action upon bacteria, some affecting largely gram-positive organisms and others acting alike upon certain gram-positive and certain gram-negative forms. Some are also fungistatic and fungicidal. Differences are largely quantitative rather than qualitative.

Some of the substances are highly toxic to animals. Others are either nontoxic or of limited toxicity and are active in vivo. Some hemolyze red blood cells, others do not. Those that are hemolytic and moderately toxic may be useful for application to local infections. Those that are neither hemolytic nor toxic and are active in vivo may have great importance in combating certain diseases in animals and man.

Some substances are formed by only a few specific organisms, others may be formed under proper conditions of nutrition by many different organisms. Some antagonists produce only one type of antibiotic substance, others form two or even more chemically and biologically different substances.

The ability of an antagonist or its products-antibiotic substances-to destroy a parasitic microorganism in vivo is influenced by the nature of the host as well as by the type and degree of the infection. The manner in which antagonists destroy or modify parasites varies greatly, depending frequently upon the nature of the antibiotic substances produced.

It is thus clear that the subject is extremely complicated, involving numerous interrelationships among different biological systems of both higher and lower forms of life.

In the following pages an attempt is made to present the broad interrelationships among microorganisms living in association, either in simple mixed cultures or in complex natural populations, with special attention to the antagonistic effects. Emphasis is laid upon the significance of these associations in natural processes and upon their relation to disease production in man and in his domesticated plants and animals. The chemical nature of the active-antibiotic-substances produced by various antagonists is described and the nature of the antagonistic action as well as its utilization for practical purposes of disease control is discussed. However, because concepts of the significance of these phenom- 
ena are changing so rapidly, no pretense has been made of examining completely the practical applications of this important subject.

Due to the fact that more detailed studies have been made on the production, nature, and utilization of penicillin, more information is presented about this than about any of the other substances. However, this should not be construed as desire on the author's part to emphasize this substance.

The subject of antagonistic effects of microorganisms has been reviewed in both general treatises $(706,944)$ and special papers $(268$, $440,443,449,580,62 \mathrm{I}, 730,836,867,986)$; special attention has been paid to the occurrence of such organisms in the soil (3I6, 670, 94I). Advantage was taken of these reviews in the preparation of the comprehensive bibliography presented at the end of this monograph. Attention is directed also to a recent complete review of the literature on the nature and formation of penicillin, the historical development of our knowledge of this agent, method of assaying, and clinical application (4IO).

The author expresses his sincere appreciation to the members of the staff of the Microbiology Department, New Jersey Agricultural Experiment Station; to members of the Department of Research and Development of Merck \& Co. and of the Merck Institute for permission to use reproductions of their work, especially the photograph of streptomycin crystals; to members of the staff of E. R. Squibb \& Sons for supplying the photograph of the penicillin-sodium crystals used as the frontispiece to this volume; to Mrs. Herminie B. Kitchen for her careful editing of the manuscript; and to the many investigators in the field whose work has been freely cited both in the form of text or tabular matter and as illustrative material.

S. A. W.

November ${ }^{2} 5,1944$ 



\section{PREFACE TO THE SECOND EDITION}

THE manuscript of the first edition of this book was completed less than three years ago. Since then the subject of antibiotics has made phenomenal progress. A number of new substances have been isolated. Several of those known previously as crude preparations have been purified, and some have been crystallized. Penicillin has risen from a metabolic product of certain fungi, promising but difficult to produce, to one of the most important chemotherapeutic agents now available to the medical world, and its yield has been increased a hundredfold by the selection of new strains and by the development of more suitable media and better conditions of growth. Its chemistry has been completely elucidated, and the existence of a number of different forms varying in chemical nature and biological activity has been established. Streptomycin was a laboratory curiosity late in 1943; now it occupies an important place as a promising chemotherapeutic agent for the treatment of certain diseases resistant to penicillin and the sulfa drugs.

This rapid progress of our knowledge of the formation, isolation, and utilization of antibiotics makes it advisable to bring out a revised edition of this book. A great deal of new material has been added, but in order to avoid enlarging the book excessively, it was decided to omit a number of references, mostly earlier articles of purely historical interest for which the reader is referred to the first edition, and those dealing with the clinical application of penicillin. Several excellent volumes on penicillin dealing with its use for disease control have recently been published.

S. A. W.

February 15, 1947

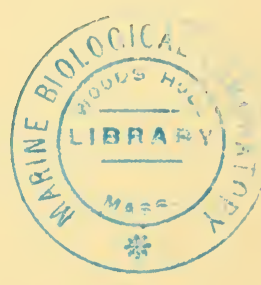





\section{CONTENTS}

I. Soils and Water Basins as Habitats of Microorganisms I

2. Human and Animal Wastes

3. Interrelationships among Microorganisms in Mixed Populations

4. Isolation and Cultivation of Antagonistic Microorganisms; Methods of Measuring Antibiotic Action

5. Bacteria as Antagonists

6. Actinomycetes as Antagonists

7. Fungi as Antagonists

8. Microscopic Animal Forms as Antagonists

9. Antagonistic Relationships between Microorganisms, Viruses, and Other Nonspecific Pathogenic Forms

10. Chemical Nature of Antibiotic Substances

I I. The Nature of Antibiotic Action

I2. Utilization of Antibiotic Substances for Disease Control

13. Microbiological Control of Soil-borne Plant Diseases

14. The Outlook for the Future

Classification of Antibiotic Substances

Glossary

Bibliography

Index of Microorganisms

General Index 



\section{SOILS AND WATER BASINS AS HABITATS OF MICROORGANISMS}

Although microorganisms inhabit a variety of substrates, from the dust in the atmosphere, the surface of living plants and plant residues, and numerous foodstuffs to the living systems of plants and animals, their natural habitations are soils and water basins.

The soil is by no means an inert mass of organic and inorganic debris. On the contrary, it fairly teems with life. The organisms inhabiting the soil range from those of ultramicroscopic size to those readily recognizable with the naked eye. Many thousands of species, capable of a great variety of activities, are represented in the soil. The physical nature and chemical composition of the soil, the climate, the plant vegetation, and the topography influence greatly both the composition of the microbiological population of the soil and its relative abundance. One gram of soil contains hundreds, even thousands, of millions of bacteria, fungi, actinomycetes, protozoa, and other groups of microorganisms. Under certain conditions, especially when the supply of fresh organic matter in the form of plant and animal residues is increased, the number may be much greater. This varied microbiological population renders the soil capable of bringing about a great variety of chemical and biological reactions.

Through its diverse activities, the microscopic population inhabiting soils and water basins forms one of the most important links in the chain of life on earth. However, its great influence upon numerous phases of human endeavor has been recognized only within recent years. All plants and all animals, including man himself, are dependent upon these organisms to bring about some of the processes essential to the continuation of life. The growth of annual and perennial plants, the supply of food for man and animals, and the provision of clothing and shelter depend largely upon the activities of these microorganisms, especially the transformations brought about in the state of such elements as carbon, nitrogen, sulfur, and phosphorus. 
Soils and water basins may be regarded as the primary reservoirs for all living systems inhabiting this planet. Whereas the great majority of microorganisms are saprophytic in nature, living upon inorganic elements and compounds and upon the dead residues of plant and animal life, others have become adapted to a parasitic form of existence and have learned to thrive upon the living tissues of plants and animals. Many of these parasites find their way into the soil and into water basins and may be able to survive there for long periods of time or even indefinitely.

Although the following discussion is limited primarily to the microbiological population of the soil, it also applies, to a greater or lesser extent, to the microorganisms that inhabit manures made up of animal excreta, household wastes, and artificially prepared composts and to those that inhabit water basins, including rivers, lakes, and seas. There are, however, marked differences in the nature of the microbial population of waters and of soils because of the physical and chemical differences in the composition of these two substrates. Nevertheless, some of the underlying principles apply to all substrates. There are, for example, marked differences in the nature and abundance of the populations of soil and water and those of milk, sewage, and foodstuffs. Whereas microorganisms multiply in the latter substrates at a very rapid rate, those in the soil and in water basins are more nearly static, since the rate of their multiplication is much slower except under very special conditions, such as the addition of fresh, undecomposed plant and animal residues or a change in the environment or in the chemical nature of the substrate.

\section{PHYSICAL PROPERTIES OF THE SOIL}

The soil-the surface layer of the earth's crust-comprises three distinct phases, the gaseous, the liquid, and the solid. The last is largely inorganic in nature, with varying concentrations of organic constituents originating from plant and animal residues and found in the soil in different stages of decomposition. The organic substances together with the living and dead cells of microorganisms that inhabit the soil make up what is known as soil organic matter or, more often, soil humus. The soil as a medium for the development of microorganisms is thus mark- 
edly different from the common artificial laboratory media, whether these be synthetic or consist of products of animal or plant life, upon which these organisms are grown.

The inorganic soil particles are surrounded by films of colloidal materials, which are both inorganic and organic in nature. As a rule, the microorganisms inhabiting the soil adhere to these films, although some move freely in the water surrounding the particles. Water and air play essential roles in the soil system and control the nature and extent of the soil population. The nature and size of the mineral and organic soil fractions, as well as the phenomena of adsorption, also influence the abundance, nature, and distribution of microorganisms in the soil. Sandy soils are better aerated than heavy clay soils; they are, therefore, more favorable for the growth of aerobic bacteria and fungi. However, since such soils lack the high water-holding capacity of the heavier soils, they are more readily subject to the process of drying out, which may result in a reduction in microbial activities.

Oxygen, another important factor in microbial development in the soil, becomes available to microorganisms by gaseous diffusion. The oxygen supply diminishes with increase in depth of the soil. When an excess of free water is present in the soil, gaseous oxygen cannot penetrate very deeply and soil organisms then become dependent upon the dissolved oxygen which diffuses into the soil solution. Since the rate of oxygen diffusion is extremely slow, waterlogged soils tend to become depleted of oxygen. Under these conditions, there are marked changes in the microbiological population of the soil: the fungi and actinomycetes tend to decrease, and the bacteria, especially anaerobic types, predominate. Peat bogs are examples of soils in a perpetual anaerobic state; the microbial population is quite distinct from that of mineral soils. Semiarid soils, with a much greater diffusion of oxygen into the deeper soil layers, possess a population which is largely aerobic; in these and other mineral soils the abundance and nature of the organic matter exert a decided influence upon the abundance and nature of the microorganisms present.

The microbiological populations of soils, composts, and water basins are also influenced markedly by seasonal and temperature changes. Certain microorganisms are capable of active life at temperatures ap- 
proaching the freezing point of water; others, known as thermophilic forms, can withstand very high temperatures, some being active even at $60^{\circ}$ to $70^{\circ} \mathrm{C}$.

The reaction of the soil is also a factor influencing the nature of the population. Many microorganisms are active within a very limited range of $p H$ values; others, notably many of the fungi, are adapted to much wider ranges of reaction. In acid soils, larger numbers of fungi are present, because of the fact that they tolerate more readily the more acid reactions, which limit bacterial competition. On the other hand, actinomycetes comprise a large percentage of the microbial population of dry and alkaline soils.

\section{CHEMICAL COMPOSITION OF THE SOIL}

The solid part of the upper or surface layer $(20$ to $30 \mathrm{~cm}$.) of the soil commonly is made up of I to Io per cent organic matter and 90 to 99 per cent inorganic or mineral matter. The concentration of organic matter may be even less than I per cent, as in desert and poor sandy soils, or more than ro per cent, as in certain virgin prairie soils and, especially, peat lands which consist of 50 to 99 per cent organic matter, on a dry basis.

The organic matter of the soil is markedly different in chemical nature from that of plant and animal materials. It contains much less cellulose and hemicelluloses than the majority of plants and is higher in lignins and proteins. It is characterized by a narrow ratio of the two important elements carbon and nitrogen, usually about IO: I ; it is much more resistant to microbial decomposition than are plant and animal residues. It is black, is soluble to a considerable extent in alkalies, and is partly reprecipitated by acids. These alkali-soluble constituents have often been designated as "humic acids" or "humic bodies," thus imparting the idea that soil organic matter is made up largely of these "acids" (942).

The inorganic constituents of the soil comprise largely sand, silt, clay, and, to a more limited extent, a number of soluble and insoluble salts, notably phosphates, sulfates, and silicates of calcium, magnesium, potassium, iron, aluminum, manganese, zinc, copper, and others. Some of 
the chemical elements comprise the framework of the soil and are used to only a limited extent by plant and microbial life. Others form important nutrients (for example, C, N, S, P, H, and O) or serve as catalysts for the continuation of life $(\mathrm{Zn}, \mathrm{Fe}, \mathrm{Mn}, \mathrm{Cu}, \mathrm{Mo}, \mathrm{B}$, and even $\mathrm{K}$ are often considered as belonging in this category). The function of most of these elements in the life of microorganisms is not fully understood. In view of the fact that some of the elements in the latter group have been found to form important constituents of certain enzyme systems, the difference between the two functions is not significant.

\section{BIOLOGICAL STATE OF THE SOIL}

The abundance of higher plant and animal life in and upon the surface of the soil influences considerably the nature and extent of the microbiological population. Certain plants harbor in their roots specific microorganisms that act as symbionts; this is true of the root nodule bacteria of leguminous plants and the mycorrhiza-forming fungi found in orchids, evergreens, and many other plants. Higher plants also offer a favorable environment for the growth of certain other types of bacteria and fungi, this specific environment being designated as the rhizosphere. The bacterial population of the rhizosphere is not very different qualitatively from that found some distance away from the plants, except that certain types of bacteria are more prominently represented.

The growth of plants results in the production of waste materials and residues left in and upon the soil in the form of roots, leaves, needles, and other products, all of which offer favorable nutrients for microbial development. The root systems of plants also bring about better aeration of the soil, thus making conditions more favorable for the development of aerobic organisms. The presence of higher plants often leads to the development of certain types of bacteria, fungi, and nematodes that are pathogenic to the plants, such as the causative agents of root rots, damping-off diseases, root-galls, and various others. Some of the pathogens may become well established in the soil and may persist there long after the specific host plants have been removed. They may even be able to attack other hosts. Plant life thus exerts a variety of in- 
fluences upon the nature and abundance of the soil-inhabiting microorganisms.

Higher animals also influence the soil microbiological population. Cattle and horses on pastures contribute, through their droppings, energy sources and various other essential nutrients for the development of microorganisms. After death, the bodies of animals, from the smallest insects to man, the lord of creation, also offer available nutrients for the growth of numerous microorganisms. Many animals living in the soil, such as insects and rodents, become carriers of certain bacteria and fungi that are destructive to their hosts; this phenomenon is often utilized for combating injurious animals. Finally, the numerous animals living on the surface of the soil leave waste products rich in bacteria, fungi, and invertebrate animals, some of which are capable of causing serious animal diseases (945).

\section{NATURE AND COMPOSITION OF THE SOIL MICROBIOLOGICAL POPULATION}

The microorganisms inhabiting the soil can be divided, on the basis of their systematic position in the biological kingdom, into the following eight groups: bacteria, actinomycetes, fungi, algae, protozoa, worms, insects and other near-microscopic animals, and ultramicroscopic forms. The last group comprises bodies that range from living systems to products of living organisms; they possess the property of activating similar substances and imparting to them their specific activities, as in the case of phages and viruses.

Five methods are commonly employed for determining the abundance of the various groups of microorganisms inhabiting the soil; namely, plate culture, selective culture, direct microscopic methods, contact slide, and mechanical separation. Each of these has certain advantages and certain limitations. In many cases, special methods have been devised to supplement the more common methods.

The plate method is based upon principles similar to those employed in other branches of bacteriology. Various media are used, both organic and synthetic. The soil microbiologist has attempted to produce media that either allow the development of the greatest number and the great- 
est variety of organisms or are particularly favorable for the growth of certain special types of organisms. None of the media so far employed allows the growth of the total soil population. The plate method is often supplemented by the selective culture method, in which a great variety of media are used in order to obtain a representative picture of the soil population. Since the number of media required to enable all soil microorganisms to develop is virtually limitless, the enrichment methods can only give a proximate idea of the nature and abundance of the microbiological population. Because of the development on the plate of certain organisms that exert a toxic effect upon others, the plate method often shows excessive variation in the numbers of bacteria and fungi (256).

The microscopic methods have been introduced to fill this gap, since by them the relative abundance of the various groups of organisms found in soils, composts, or other natural substrates can be established. Unfortunately, these methods do not allow any differentiation between living and dead cells, nor do they permit a differentiation between the various physiological types of microorganisms such as pathogens and nonpathogens. A further limitation, especially of the contact slide, is that the fast-growing forms cannot be prevented from overgrowing the slide and repressing the slow-growing types.

The mechanical separation methods are based upon the use of special sieves or water emulsions and are utilized for the study of the larger forms such as insect larvae and nematodes.

The relative abundance of the different groups of microorganisms in a given soil, as determined by any one of the foregoing methods, varies with the nature of the soil, amount of organic matter, oxygen supply, moisture content, temperature, acidity, and buffering capacity (Table I), as well as with the nature of the higher plants growing in the given soil (Table 2). Despite all these factors, the microbiological population of the soil throughout the world has certain definite and common characteristics and comprises certain well-defined, specific types. The bacteria usually range in number from a few hundred thousand to several hundred million per gram of soil, though many species do not develop on the common plate. Fungi are found in the form of mycelial filaments and as spores and may therefore constitute as large 
a mass of living matter as do the bacteria; their actual number, as determined by the plate method, may vary from a few thousand to several hundred thousand per gram of soil. The significance of these results is

TABLE I. INFLUENCE OF SOIL TREATMENT ON NUMBER OF MICROORGANISMS

\begin{tabular}{|c|c|c|c|c|}
\hline \multirow{2}{*}{ TREATMENT OF SOIL } & \multirow{2}{*}{$\begin{array}{c}\text { REACTION } \\
\text { OF SOIL } \\
p H\end{array}$} & \multicolumn{3}{|c|}{ MICROORGANISMS FOUND* } \\
\hline & & Bacteria & Actinomycetes & Fungi \\
\hline Unfertilized and unlimed & 4.6 & 3,000 & 1,150 & 60 \\
\hline Lime only added & 6.4 & 5,410 & 2,410 & 23 \\
\hline Potassium salts and phosphates & & & & \\
\hline added & $5 \cdot 5$ & 5,360 & 1,520 & 38 \\
\hline Salts and ammonium sulfate & & & & \\
\hline added & $4 \cdot I$ & 2,690 & 370 & 112 \\
\hline Salts, ammonium sulfate, and & & & & \\
\hline lime added & 5.8 & 6,990 & 2,520 & 39 \\
\hline Salts and sodium nitrate added & $5 \cdot 5$ & 7,600 & 2,530 & 47 \\
\hline Stable manure and salts added & $5 \cdot 4$ & 8,800 & 2,920 & 73 \\
\hline
\end{tabular}

From Waksman (945).

* In thousands per gram of soil as determined by plate method.

TABLE 2. INFLUENCE OF GROWING PLANTS ON NUMBER OF MICROORGANISMS IN THE SOIL

\begin{tabular}{|c|c|c|c|c|}
\hline \multirow{3}{*}{ PLANT } & \multirow{3}{*}{$\begin{array}{l}\text { SAM PLE OF } \\
\text { SOIL TAKEN }\end{array}$} & \multirow{2}{*}{\multicolumn{3}{|c|}{ MICROORGANISMS FOUND* }} \\
\hline & & & & \\
\hline & & Bacteria & Actinomycetes & Fungi \\
\hline \multirow[t]{2}{*}{ Rye } & Near roots & 28,600 & 4,400 & 216 \\
\hline & Away from roots & 13,200 & 3,200 & 162 \\
\hline \multirow[t]{2}{*}{ Corn } & Near roots & 41,000 & 13,400 & 178 \\
\hline & Away from roots & 24,300 & 8,800 & 134 \\
\hline \multirow[t]{2}{*}{ Sugar beet } & Near roots & 57,800 & 15,000 & 222 \\
\hline & Away from roots & 32,100 & 12,200 & 176 \\
\hline \multirow[t]{2}{*}{ Alfalfa } & Near roots & 93,800 & 9,000 & 268 \\
\hline & Away from roots & I 7,800 & 3,300 & 254 \\
\hline
\end{tabular}

From Starkey (877).

* In thousands per gram of soil. 
not always clear, since a given colony may have originated from a hyphal filament, a mass of mycelium, or a single spore. Determination by the plate method of the number of actinomycetes is subject to the same limitations; these organisms usually constitute from ro to 50 per cent of the colonies appearing on common bacterial agar plates.

Algae are numerous in the surface layers of soil only. Protozoa are present in the soil in an active vegetative or trophic state and in the form of cysts. The active cells appear when excessive water is present, even for a few hours; in dry soil, the cysts predominate. Flagellates are represented by the largest numbers, sometimes approaching a million individuals per gram of soil; amebae are next in abundance; ciliates are usually found to the extent of a few hundred to several thousand per gram of soil. Nematodes, rotifers, earthworms, and larvae of numerous insects are also abundant, often forming a large part of the bulk of the living mass of cell substance.

By means of the selective and enrichment culture methods, several physiological classifications of bacteria have been recognized. The following descriptive terms are commonly used to designate these groups: autotrophic vs. heterotrophic, aerobic vs. anaerobic, motile vs. nonmotile, pathogenic vs. saprophytic, psychrophilic and mesophylic vs. thermophilic, symbiotic vs. nonsymbiotic, and antagonistic vs. nonantagonistic.

The fungi may be classified into three types: saprophytic and freeliving, mycorrhiza-producing, and plant pathogenic. The most common groups of soil fungi are found in the genera Rhizopus, Mucor, Penicillium, Aspergillus, Trichoderma, Fusarium, Cladosporium, and Cephalosporium. The soil often harbors an abundant population of yeasts and fleshy or mushroom fungi. The latter may produce an extensive mycelium in the soil, binding the particles together and preventing their falling apart.

Various bacteriolytic agents, including specific phages, have also been demonstrated in the soil. The phage of root-nodule bacteria is of particular interest. It is readily adsorbed by the soil, but its presence can easily be established. The repression of spore-forming bacteria and the abundance of Pseudomonas fluorescens may be due to the antagonistic action of the latter. 


\section{SOILS AND WATER BASINS AS CULTURE MEDIA}

Microorganisms require for their growth and respiration certain energy sources and certain nutrients, as well as certain conditions favorable for their development. Different organisms show considerable variation in this respect. The mineral elements required for growth and multiplication are almost invariably present in the soil and to a large extent also in many water basins. The available energy supply may be limited, however, and thus usually becomes the most important factor regulating the abundance and activities of microorganisms in natural substrates. The autotrophic bacteria depend on the supply of oxidizable minerals such as ammonium salts, nitrite, sulfur, iron, and manganese, the oxidation of which makes energy available for their growth. The heterotrophic organisms are dependent on the carbon compounds brought into the soil in the form of plant and animal residues as well as the bodies of many insects, earthworms, and other small animals. The roots of plants also supply an abundance of easily available substances for microbial nutrition.

Every organic compound produced in nature finds its way, sooner or later, into the soil or into lakes and rivers, where it serves as a source of energy for microorganisms. This energy becomes available to some of the organisms through anaerobic or fermentative transformation and to others through aerobic or oxidative processes. The net change in the energy produced by any one organism or group of organisms is accompanied by a loss of free energy by the system to which the culture is

TABLE 3. MULTIPLICATION OF COLIFORM BACTERIA IN STERILE SOIL

\begin{tabular}{|c|c|c|c|}
\hline \multirow{3}{*}{ ORGANISM } & \multirow{3}{*}{$\begin{array}{c}\text { BACTERIA } \\
\text { INOCULATED* }\end{array}$} & \multirow{2}{*}{\multicolumn{2}{|c|}{ BACTERIA RECOVERED* }} \\
\hline & & & \\
\hline & & After ro days & After 26 days \\
\hline \multicolumn{4}{|l|}{ Escherichia coli } \\
\hline in soil alone & 2,600 & $149,000,000$ & I $38,000,000$ \\
\hline \multicolumn{4}{|l|}{ Aerobacter aerogenes } \\
\hline in soil alone & 109,000 & $48,000,000$ & $42,600,000$ \\
\hline in soil and glucose & I09,000 & $1,660,000$ & $240,000,000$ \\
\hline
\end{tabular}

From Waksman and Woodruff (978).

* Per gram of soil. 
confined. The synthesis of new cell material by microorganisms is accompanied by a gain of free energy, which must be supplied by other chemical transformations. Ordinary soils, however, contain microbial nutrients in concentrations sufficient to support a large number of living cells. This can be illustrated by the fact that when a soil is sterilized and then inoculated with a pure culture of bacteria rapid multiplication takes place (Table 3 ). When fresh water taken from a lake or the sea is kept in the laboratory for one or two days, a great increase in its bacterial population occurs.

There is considerable variation in the ease with which a specific organism can be isolated from a natural substrate and consequently in the techniques employed. Some microorganisms may be present in abundance and can be readily isolated. Others are found only in limited numbers and can be obtained only with considerable difficulty and by the use of special procedures. Still others can be isolated only after the natural substrate is treated in such a manner as to favor the multiplication of the specific organism; this can be done by enriching the soil with a nutrient or substance which the particular organism is able to utilize, or by changing conditions of reaction, by aeration, or by other treatment. Such treatment sometimes results in the development of special strains or races adapted to the special conditions.

\section{NUTRITION OF MICROORGANISMS IN NATURAL SUBSTRATES}

It was at first assumed that bacteria and other microorganisms possess a simpler type of metabolism than do higher plants and animals; although some can obtain all the nutrients required for cell synthesis and energy from simple elements and compounds, others need for their nutrition certain highly complicated organic substances. Recently it has been recognized that various "growth-promoting" substances or vitamins play an important role in the nutrition of many microorganisms. It has also been established that highly complicated enzyme systems are produced by these lower forms of life, and that many interrelationships exist among their metabolic processes, the composition of the medium, and the environmental conditions. One thus begins to realize that the 
metabolism of these microbes is also highly complicated. Most of the information on their nutrition is based upon their growth on artificial culture media. In nature, however, these organisms live in associations and vary considerably in the degree of their interdependence. As yet no laboratory method has been developed that duplicates these conditions.

Microorganisms vary considerably in their nutrition and energy utilization, as well as in the breakdown and transformation of the available nutrients. Certain elements or compounds are required for cell synthesis. In some cases, certain trace elements as well as varying concentrations of growth-promoting substances are also essential. Among the nutrient elements, nitrogen occupies a prominent place. Considerable variation exists in the ability of microorganisms to utilize different types of nitrogen compounds: some can obtain their nitrogen from a wide variety of substances; others are restricted to the use of a single group of compounds such as proteins, amino acids, urea, ammonia, or nitrate; a few are able to use atmospheric nitrogen. The variety of organic nitrogenous bodies supplied to microorganisms in soils and in water basins is limited only by the number of such compounds synthesized by plants and animals. The complex forms of nitrogen are broken down to simpler compounds; these may be assimilated by organisms and again built up into complex forms, or they may be utilized only by other organisms. Microbial activity thus regulates the state of the nitrogen in natural substrates and is responsible for the continuous stream of ammonia and nitrate forming the available sources of nitrogen that make possible the growth of higher plants.

THE GROW'TH OF THE MICROBIAL CELL IN PURE CULTURE AND IN MIXED POPULATIONS

When nutrients are available in sufficient concentration and when the environmental conditions are favorable for the development of the microbial cell in pure culture, growth follows a definite sigmoid-shaped curve. Slow multiplication is followed by rapid development, until a certain maximum number of cells within a given volume of medium is reached; the rate of growth then diminishes. The maximum population of Aerobacter aerogenes grown in a medium containing lactose and 
ammonium tartrate increases at first in proportion to the concentrations of these nutrients but later becomes independent of them. The onset of the stationary phase may be due to several factors: exhaustion of substances necessary for growth, change in the reaction of the medium to one unfavorable for further development, accumulation of toxic products. When the nutrients in the medium are exhausted, addition will restore growth. When an unfavorable change in reaction has taken place, the addition of acid or alkali will render the medium again favorable. The production of toxic substances in the medium can be counteracted usually by the use of heat or by treatment with charcoal, though some of the injurious bodies may be heat-resistant.

In the presence of other microorganisms, a certain organism may show reactions markedly different from those obtained in pure culture: it may produce substances that are either favorable or injurious to the other cells, it may compete with the other organisms for the available nutrients or it may render the medium more favorable for their development. Some bacteria like Bacillus cereus can attack native proteins but not amino acids, whereas others like Ps. fuorescens can attack amino acids but not proteins; when these two organisms are placed together in the same medium, their activities supplement one another. Numerous other instances are found in soil and water of an organism preparing the substrate for another, ranging from distinct symbioticism, where one organism depends absolutely for its living processes upon the activities of another (symbiosis), to association, where one organism merely is favored by the growth of another (metabiosis), to the injury of one organism by another (antagonism), and finally, to the actual destruction of one by another (parasitism).

\section{INTRODUCTION OF DISEASE-PRODUCING}

ORGANISMS INTO THE SOIL

Ever since higher forms of life first made their appearance on this planet they have been subject to attack by microbes. These microscopic organisms must have gained, at an early stage in the development of the higher forms, the capacity of attacking them in one manner or another. There is no plant or animal now living that is not subject to in- 
fection by different bacteria, fungi, and protozoa. The more advanced the animal body is in the stage of evolution, the more numerous are its ills, most of which are caused directly or indirectly by microorganisms.

The microbial agents causing thousands of diseases of plant and animal life have now been recognized and even isolated and described. In many cases these disease-producing agents are closely related morphologically to others that lead a harmless existence in soils or water basins; many of the saprophytes, for instance, are found to be of great benefit to man and to his domesticated plants and animals. This suggests the probability that pathogenic microorganisms represent certain strains of soil and water-inhabiting types that have become adjusted to a parasitic existence. During their life in the host, they multiply at a rapid rate and produce substances toxic to the body of the host. The result is that the host is incapacitated for a certain period of time, until it succeeds in building up resistance against the invading organisms. It may thus overcome the injurious effect of the pathogen or it may be killed if such resistance cannot be effected. In the first instance, a temporary or permanent immunity against the specific disease-producing microbe or its close relatives may result. The host is often able to survive the attack without being able to destroy the invading microbes; if it again attains a normal form of life, it is designated as a carrier of the disease-producing agent.

Pathogenic organisms pass their existence in the living body of the plant or animal. They spread from one host to another by contact or through a neutral medium, such as water, milk, or dust where they may remain alive and active for varying lengths of time, or they reach the soil or water basins in the excreta of the host. If the host is killed by the infecting microbes, they may survive for some time upon the remnants of what was once a living animal or plant and thus find their way into the soil and water basins.

Considering the millions of years that animals and plants have existed on this planet, one can only surmise the great numbers of microbes causing the numerous diseases of all forms of life that must have found their way into the soil or into streams and rivers. What has become of all these pathogenic bacteria? This question was first raised by medical bacteriologists in the eighties of the last century. The soil was searched 
for bacterial agents of infectious diseases. It was soon found that, with very few exceptions, organisms pathogenic to man and animals do not survive very long. This was at first believed to be due to the filtration effect of the soil upon the bacteria. It came to be recognized, however, that certain biological agents are responsible for the destruction of the pathogenic organisms. These investigations led to the conclusion that the soil can hardly be considered as a carrier of most of the infectious diseases of man and animals. The fact that many pathogens can grow readily in sterilized soil but do not survive long in normal fresh soil tends to add weight to the theory of the destructive effect upon pathogens of the microbiological population in normal soil.

\section{INTRODUCTION OF SAPROPHYTIC ORGANISMS} INTO THE SOIL

It often becomes necessary to inoculate the soil with organisms not usually found there. The common practice of inoculating soil with bacteria capable of forming root nodules on leguminous plants is a case in point. It is essential, therefore, to know how long these organisms will survive. The survival period is influenced greatly by the presence of a host plant that protects the specific bacteria from attack by antagonistic organisms. In the absence of the host plant, the bacteria seem to disappear gradually, and reinoculation becomes advisable when the host is again planted in the given soil. It has been observed also that specific strains of bacteria tend to deteriorate in the soil, and that it is necessary to reinoculate the soil with more vigorous strains of the organisms in question.

Some bacteria, notably members of the Azotobacter group, are able to fix nitrogen independently of host plants but these organisms are absent from many soils. The suggestion was made that such soils might benefit from inoculation. However, it has been found that when soils and peats are inoculated with $A$. chroococcum large-scale destruction of the latter often occurs (8I4), due, it is believed, to the presence in the soil of antagonistic organisms as well as toxic substances $(492,687$, 980).

Certain fungi are unable to grow in fresh nonsterilized soil but are 
capable of growing in heated soil. This was found to be due to the fact that normal soils contain certain substances that render the growth of the fungus impossible; these substances are destroyed by heating. An extract of fresh soil acts injuriously upon the growth of the fungus Pyronema; the injurious effect is partly removed on boiling. Certain forest soils contain not only antifungal but also antibacterial factors (630a) which are dialyzable and thermostable; other thermolabile and nonfilterable substances may be present which neutralize the effect of the antibiotics.

The survival of microorganisms added to soil or water is thus influenced by the nature of the native soil or water population, the organisms added, the composition of the substrate, and various environmental conditions.

\section{SAPROPHYTIC AND PATHOGENIC NATURE OF CERTAIN SOIL MICROORGANISMS}

Various fungi and actinomycetes causing animal diseases, notably skin infections, appear to resemble very closely the corresponding soil saprophytes. It was therefore suggested that many of the dermatophytic fungi normally lead a saprophytic existence in the soil but are also capable of developing on epidermal tissue and bringing about infection of the tissues. This was found to be true especially of species of Sporotrichum, various actinomycetes such as those causing lumpy jaw of cattle, and certain other organisms. Henrici (406) divided fungus infections of animals into two groups: first, superficial mycoses, comprising moniliases and dermatomycoses, that are caused by a variety of fungi widely distributed in nature; and, second, deep-seated infections, namely, aspergillosis, sporotrichosis, and blastomycosis, with a marked tendency to restricted distribution. The latter were said to be caused primarily by saprophytic forms, including varieties capable of chance survival and of multiplication when accidentally introduced into animal tissues.

Walker (98I) suggested that the partly acid-fast coccoid, diphtheroid, and actinomycoid organisms that have been cultivated repeatedly from leprosy are merely different stages in the life cycle of the 
same form. The causative agent of leprosy, like certain pathogenic actinomycetes, is believed to be a facultatively parasitic soil organism, probably of wide but irregular distribution. Leprosy was thus looked upon primarily as a soil infection, brought about presumably through wounds; a secondary means of infection by contagion was not excluded. A comparison of cultures obtained from rat leprosy, human leprosy, and bacteria of soil origin led to the conclusion that the strains from all three sources were identical; human and rat leprosy were said to have the same etiology and endemiology, finding a normal habitat in the soil.

An interesting relationship has been shown to exist between Texas fever and the capacity of cattle tick (Boophilus bovis), the parasite carrier, to persist in the soil (865). The causative agent is an organism with protozoan characteristics. It persists in southern pastures where the carriers survive from one season to the next and keep the cattle continuously infected. The disease is of little importance in northern regions, the ticks being destroyed during the winter. When northern cattle are moved to southern pastures, they become subject to the disease.

Pathogenic microorganisms capable of surviving in the soil have presented important economic problems to farmers raising hogs, cattle, poultry, and other domestic animals, but disease incidence through this source has been greatly diminished by the proper practice of sanitation. The rotation of crops has been utilized for the purpose of overcoming these conditions, several years usually being required to render infected pastures safe for use. The fact that most pathogenic organisms rapidly disappear when added to the soil makes this problem rather simple; the prevention of infectious diseases would have presented far more difficult problems were the infecting agents to remain indefinitely virulent in the soil. The few disease-producing agents that are capable of persisting, such as anthrax, blackleg, and coccidiosis, have been the cause, however, of considerable damage to animals.

Of greater economic importance than the survival in the soil of human and animal pathogenic agents is the fact that the soil harbors a number of plant pathogens, including not only fungi, bacteria, and actinomycetes, but also nematodes and insects. Fortunately, the continued development of these organisms in the soil also leads to the accumulation of saprophytic organisms destructive to them. 
The extent to which virus diseases persist in the soil is still a matter for speculation. It has been demonstrated that the phage of legume bacteria may persist and become responsible for a condition designated as "alfalfa-sick soils" and "clover-sick soils" ( 178,490$)$. In order to overcome this condition, the breeding of resistant varieties of plants has been recommended. 


\title{
HUMAN AND ANIMAL WASTES
}

\begin{abstract}
And a place shalt thou have without the camp, whither thou shalt go forth abroad: and a spade shalt thou have with thy weapons; and it shall be, when thou sittest abroad, thou shalt dig therewith, and shalt afterward cover that which cometh from thee.Deuteronomy 23:13 and 14.
\end{abstract}

Human and animal excreta and other waste products, which are or frequently become both offensive and dangerous to public health, sooner or later find their way into the soil and water basins. The soil also receives the many residues of growing crops that are annually left on the land, together with the waste materials of the farm and the home (942). These wastes contain substances partly digested by man and animals, and their metabolic waste products, as well as freshly synthesized material in the form of microbial cells. The microbial population of such waste materials comprises agents of digestion, some microbes that are present accidentally, and some that possess the capacity of causing human, animal, and plant diseases.

These waste materials do not remain long in an unaltered form and do not accumulate in or on the surface of the soil or in water basins; otherwise both soil and water long ago would have been rendered unsightly, disagreeable bodies, which man would not dare to tread upon or enter. On the contrary, the soil and the water are capable of digesting all these cast-off materials and of completely destroying their undesirable characteristics. Through all past ages, the waste products of plant and animal life have disappeared, whereas the soil and the water in the rivers, lakes, and seas have remained essentially the same, except under very special conditions such as those that brought about the production of peat in water-saturated basins and, in past geological ages, the formation of coal. The capacity of soil and water to destroy these offensive wastes is due entirely to the microorganisms that inhabit the substrates. The important ultimate products of destruction are ammonia, carbon dioxide, and water; often hydrogen and methane are 
produced; various mineral compounds, such as phosphates, sulfates, and potassium salts are also liberated. These mineralized substances are essential for the continuation of plant and animal life on this earth.

Largely because of the activities of the microorganisms inhabiting soils and water systems, man does not need to worry about the disposal of plant and animal wastes. These activities need only be regulated, in order to accomplish the breakdown of complex substances with the greatest efficiency and the least loss of valuable nutrient elements. The following principal objectives are usually to be attained: first, the destruction of plant and animal pathogens, including pathogenic bacteria and fungi and disease-producing protozoa, worms, and insects; second, the liberation of the essential elements required for plant nutrition in available forms, especially carbon, nitrogen, and phosphorus; and, third, the formation of certain resistant organic substances, known collectively as humus, which are essential for the improvement of the physical, chemical, and biological condition of the soil.

\section{STABLE MANURES AND FECAL RESIDUES}

\section{Microbial Population}

Fresh excreta of animals and man are rich in fecal bacteria, consisting, on the average, of 5 to 20 per cent bacterial cells. Lissauer (575) calculated that the bacterial substance of feces ranges from 2.5 to I 5.7 per cent of the dry weight, with an average of 9 per cent. Bacteria were reported to make up 9 to 42 per cent of the bulk of animal stools, the percentage depending on the composition of the foodstuffs, the nature of the animal and its condition of health, and other factors (366). Since I mg. of dry bacterial substance contains about 4 billion bacterial cells, the number of these organisms in fecal excreta can be seen to be very large, although many, if not most, of the cells are no longer in a living state.

By suitable methods of cultivation, human feces were found (626) to contain I 8 billion bacteria per gram. About Ioo billion bacteria may be produced daily in the human intestine. Human feces are made up, on an average, of 32.4 per cent bacterial cells amounting to 2,410 million bacteria per milligram of moist material. Feces of healthy 
persons were shown (30I) to contain 8.2 to 24.2 per cent bacterial cells; in those of persons suffering from intestinal disturbances the percentage was 20.I to 40.2. With the development of the microscopic technique for counting bacteria, much larger numbers of cells were shown to be present than could be determined by the plate method.

The urine of healthy persons is sterile or very low in bacteria. Because of the ability of many bacteria to utilize the chemical constituents of urine, rapid bacterial multiplication takes place in fresh urine, especially when mixed with animal feces and bedding (8I I).

The microbiological population of animal excreta is characteristic. In addition to the common fecal bacteria, it contains fungi, thermophilic bacteria, and, in herbivorous animals, anaerobic cellulose-decomposing bacteria (58I).

The bacterial population of fresh cow manure was found (833) to consist of 47.5 per cent cocci (Streptococcus pyogenes, Sarcina sp., and Micrococcus candicans), 2 I.2 per cent coli-like colonies (Escherichia coli, $A$. aerogenes, and $S$. septicemiae), and many dark colony-forming types. Other groups represented were Bacteroides, Flavobacterium, Pseudomonas, Bacillus, various anaerobic bacteria, Oidium, and many others. When the manure was allowed to decompose, yellow rods, fluorescent bacteria, and mesentericus types took the place of the streptococci.

The following heterotrophic bacteria have been demonstrated (8 I I) in manure: Bacillus subtilis, Bacillus mesentericus, Bacillus cereus, $\mathrm{Ba}$ cillus tumescens, Bacillus petasites, Pseudomonas fluorescens, Pseudomonas putida, Salmonella enteritidis, Escherichia coli, Proteus vulgaris, Micrococcus luteus, Micrococcus candicans, Staphylococcus albus, Sarcina flava, Streptococcus pyogenes, and others. Anaerobic bacteria are also abundant (337).

Pathogenic bacteria may also occur frequently in human feces and in stable manure; Mycobacterium tuberculosis and various hemolytic streptococci (860), as well as pathogenic anaerobes including Clostridium welchii, $\mathrm{Cl}$. septicum, $\mathrm{Cl}$. oedematis, and $\mathrm{Cl}$. fallax have been found (484).

The protozoa capable of developing in manure and in urine include not only saprophytic forms but also certain parasites, such as Tricho- 
mastric and Trichomonas, capable of living and even of multiplying in excreta. The coprophilic protozoa comprise various flagellates, certain amebae, and ciliates. The liquid part of the manure is considerably richer than the solid in total number of protozoa as well as in species, including Polytoma uvella, Cryptochilum nigricans, and Tetramitus rostratus. These protozoa nearly all feed upon bacteria. The infusoria may feed upon smaller protozoa, so that forms like Colpidium may not destroy bacteria at all.

Human and animal excreta also contain a large population of fungi, chiefly in a spore state. Schmidt (837) divided the manure-inhabiting fungi into three groups:

Those found only in manure; their spores are swallowed with the feed, and they pass unchanged through the digestive tract, though they are favorably influenced toward germination by the body heat and digestive fluids of the animal. Their natural multiplication by spores is impossible without the physiological action of the digestive processes.

Those that do not have to pass through the digestive tract of an animal in order to germinate and develop. The representatives of this group occur in nature only in manure, although some are able to grow also on other substrates. They can be cultivated both on manure and on other media, mostly at ordinary temperatures.

Organisms found both in manure and on other substrates. They grow readily at room temperature on a number of media.

\section{Composition and Decomposition}

The chemical composition of human and animal excreta, and of stable manures in general, varies considerably, depending on the nature of the animal, its age, mode of nutrition, and composition of foodstuffs (463). As soon as voided, manure begins to undergo rapid decomposition. This results in the formation of ammonia and various other nitrogenous degradation products. These give rise to offensive smells, which are controlled by the conditions of decomposition. From a sanitary point of view, it is essential that decomposition should be accompanied by the destruction of the injurious organisms present in the manure. The fecal organisms gradually disappear and their place 
is taken by a population concerned in the decomposition of cellulose, hemicelluloses, and proteins.

The decomposition of complex plant and animal residues leads to a rapid reduction in carbohydrates and is accompanied by the evolution of considerable heat, the temperature of the compost reaching as high as $75^{\circ} \mathrm{C}$., as shown in Figure $\mathrm{I}$.

In order to hasten the decomposition of manure, conditions must be favorable to the activities of microorganisms. It must be properly

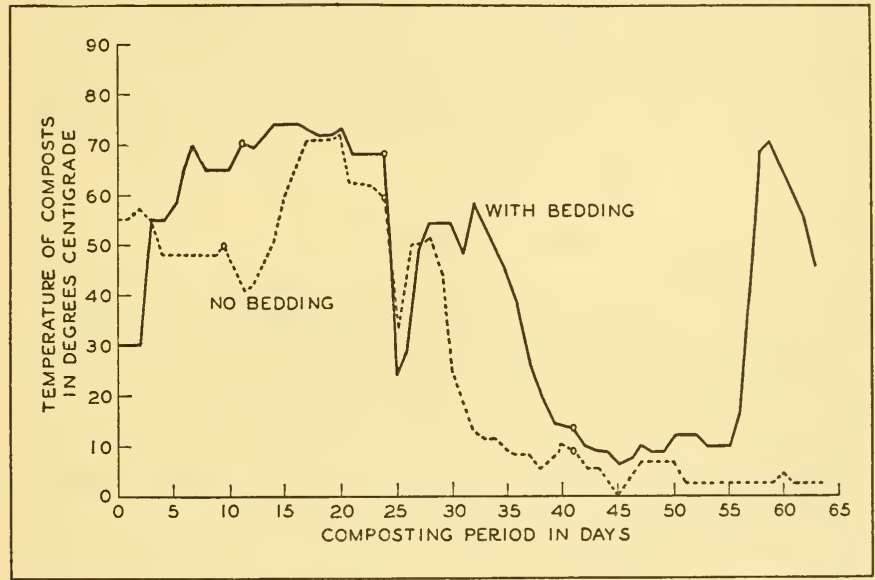

FIGURE I. Influence of straw bedding upon temperature changes in the composting of manure. Circles indicate times of turning composts. From Waksman and Nissen (96I).

aerated and well moistened but not saturated with water. By placing the manure, together with the waste materials of the farm and the home, in heaps, designated as composts, the decomposition processes can be controlled so as to lead to heat liberation; this results in the destruction of the injurious organisms and the conservation of the plant nutrient elements. When not properly regulated, the decomposition processes may be wasteful, unsanitary, and unsightly, and may even become a source of infection to man and his domesticated animals. 


\section{SEWAGE}

Disposal of sewage and other home wastes is one of the important sanitary problems of men living in industrial and residential centers. Haphazard methods of disposing of sewage not only lead to conditions most unpleasant to human habitation but they are dangerous from the standpoint of infectious diseases.

Sewage abounds in microorganisms that originate not only from human excreta but also from other household and industrial wastes. The various saprophytic bacteria present in sewage rapidly attack the organic constituents and bring about their gradual mineralization. The destructive action of saprophytic organisms greatly reduces the number of pathogens $(342,343)$. Activated sludge, for example, has been shown (882) to possess a definite and consistent bactericidal action against the colon bacteria. In addition to antagonistic organisms, active bacteriophages against nearly all types of intestinal bacteria are present in sewage. The destruction of pathogens by bacteriolysis thus readily finds a place in the activated-sludge method of sewage purification.

Dissolved oxygen is generally present when sewage is diluted with water. As the destruction of the organic matter proceeds rapidly, the oxygen becomes depleted, so that none is left after a few hours. The predominant bacterial flora of the water may then become anaerobic, with the result that the chemical processes of decomposition are completely changed; hydrogen sulfide, mercaptans, and other foul-smelling substances are then formed. This is accompanied by a typical anaerobic breakdown of carbohydrates, leading to the formation of various organic acids, carbon dioxide, hydrogen, and methane. The nitrogen in the protein and urea is transformed to ammonia and various amines. When sewage is aerated, the anaerobic processes gradually give way to aerobic processes, as the oxygen diffuses into the liquids or as the sewage is diluted with water containing dissolved oxygen.

When sewage is freed from solids by sedimentation before discharge, or when it is aerated sufficiently to maintain the concentration of dissolved oxygen, decomposition proceeds rapidly without the production of the bad odors usually associated with the anaerobic breakdown. The destruction of the pathogenic bacteria results largely through the ac- 
tivities of the saprophytes (809, 1008). For the purpose of promoting the development of aerobic bacteria, processes employing the use of intermittent sand filters, broad irrigation, contact beds, trickling filters, and activated sludge are applied.

The modern methods of sewage purification are based on the longknown fact that the soil is a destroyer of offensive wastes. In early days, in fact, the soil handled all sewage problems. Sewage disposal plants in modern cities are so operated that microorganisms found to be so efficient in the soil are able to act under optimum conditions, resulting in rapid purification. Sewage freed from most of its organic constituents can be discharged into a stream and will not deplete the water of its dissolved oxygen. Chlorine is frequently employed in the final treatment to assure the complete destruction of the pathogens.

\section{GAR BA GE}

The processes involved in the disposal of garbage from the home are similar to those utilized in the disposal of stable manure rather than of sewage. At present, garbage usually is destroyed by burning, which results in great economic waste, or is dumped outside cities, thus creating centers of infection and unpleasant appearance. More logical and less wasteful processes are based upon the principle of composting. Several of these processes are now utilized in India and China, where economic pressure is greatest. By proper handling, a product is formed that is free from injurious insects, parasitic worms, and bacteria, and that conserves all the valuable elements essential for plant growth.

\section{DESTRUCTION OF INJURIOUS MICROORGANISMS}

Improper methods of disposal of human and animal wastes were responsible, in the early history of mankind, for many epidemics of cholera, typhoid, plague, and other diseases. Only in recent years, after man learned the nature of the spread of these diseases, were proper methods developed for disposing of human wastes.

' Fecal-borne diseases rank with venereal disease and tuberculosis as the most important infectious diseases of China, because the people 
do not maintain proper sanitation and because human excreta are used as fertilizers. Any successful system for the control of these diseases must be sanitary and at the same time profitable. Of I, I90 persons examined, $8 \mathrm{I}$ per cent were positive for ascaris, with an average egg count of I 4,000 per cubic centimeter. Children had a higher count than adults, and females a higher count than males. The life habits of the Chinese people are highly favorable for the spread of ascaris. By a special process of composting of feces, sufficient heat was produced to destroy disease-producing organisms and their reproductive bodies. The compost thus produced is highly effective as a fertilizer (IO23).

\section{SURVIVAL OF HUMAN AND ANIMAL PATHOGENS IN SOIL AND WATER}

During the period I 878 to 1890 following the brilliant work of Pasteur, when bacteriology was still in its infancy, medical bacteriologists took much interest in soil microbes. This was due largely to the belief that causative agents of disease that find their way into the soil may survive there and thus become a constant and important source of infection. The introduction by Koch, in $188 \mathrm{I}$, of the gelatin plate method placed in the hands of the investigator a convenient procedure for measuring the abundance of the soil population and determining the survival in the soil of agents causing serious human diseases. In spite of the fact that this method revealed only a very small part of the soil population, it enabled the medical bacteriologist to establish beyond doubt that such organisms tend to disappear in the soil. This resulted in definite conviction on the part of the public health and medical world that the soil is seldom a source of infection. It was soon demonstrated that disease-producing agents die out in the soil at a rather rapid rate, depending on the nature of the organisms, the soil, climate, and other conditions.

\section{Organisms that Survive for Long Periods}

Only a few disease-producing microorganisms are able to survive in the soil for any considerable periods of time. These few include the organisms causing tetanus, gas gangrene, anthrax, certain skin infections, 
actinomycosis in cattle, coccidiosis in poultry, hookworm infections, trichinosis, enteric disorders in man, blackleg in cattle, and Texas fever. To these may be added the botulinus organism and others producing toxic substances, as well as bacteria, actinomycetes, and fungi that cause plant diseases such as potato scab, root rots, take-all disease of cereals, and damping-off diseases.

Anthrax, a scourge of cattle and sheep, is a persistent survivor in soil; spores of this organism are known to retain their vitality and virulence for fifteen years. Anthrax survives particularly well in damp regions, especially in soils rich in decomposing organic matter; the hay and feed from these lands may transmit the disease to animals. The fact that certain fields carry anthrax infection ("anthrax pastures") was recognized in Europe long before the nature of the disease was known. Human infection results from contact with diseased animals or animal products.

The anaerobic, spore-forming bacteria that cause gas gangrene are widely distributed in nature. They are found extensively in soils and in decomposing plant and animal residues. The causation of disease by these organisms received particular attention during the first world war, which was fought chiefly in trenches.

Another important pathogenic anaerobe able to survive in soil for long periods of time is $\mathrm{Cl}$. chawvoei, the causative agent of blackleg in cattle; southern pastures are said to be better carriers of blackleg than northern pastures. Cl. tetani is also widely distributed in the soil and appears to be associated with the use of stable manures. Wounds infected with soil may lead, therefore, to the development of tetanus or gas gangrene and must be treated accordingly.

The botulinus organism not only may remain alive in the soil for a long time (642), but it may also produce there a potent toxin that causes much loss of water fowl and other wild life. Aeration of the soil results in the destruction of this toxin by aerobic bacteria (742).

\section{Organisms that Survive for Brief Periods}

Other pathogenic bacteria, however, are able to survive in the soil only for limited periods of time. They are eliminated sooner or later from the soil, either because of their inability to compete with the soil 
population or because of their actual destruction by the latter. Although the pathogens seem to possess considerable resistance toward unfavorable soil conditions, they are unable to multiply at rates permitting their indefinite survival in the soil. The anthrax bacillus and certain other parasites infesting domesticated and wild animals belong to this group. Certain insect and animal carriers make possible the survival and spread of many pathogens in the soil.

The great majority of disease-producing bacteria, however, are able to survive only for very brief periods outside their respective hosts, especially in soil and water. It is sufficient to cite the fact that typhoid and dysentery bacteria, which are known to contaminate watersheds and water supplies, disappear sooner or later. It has been estimated, for example, that in sewage sludge free to undergo normal digestion, typhoid bacteria probably survive for less than 7 days. It was suggested, therefore, that sludge held in a digestion tank for about Io days might be applied to the soil for fertilizer purposes without detriment to public health.

The gram-negative bacteria of the typhoid-dysentery group die out rapidly in septic material; the typhoid bacteria survive for about 5 days, the Flexner type of dysentery for about 3 days, and the Shiga bacillus dies out even in a shorter period. If decomposition in the tank has not advanced far enough, as shown by low alkalinity, the organisms may survive for a much longer period. The efficiency of ripe tank effluent to destroy bacteria is believed to be due to both the alkaline reaction and the presence of antagonistic metabolic products. The destruction of typhoid and dysentery bacteria in the soil depends on a number of factors, chief among which are the moisture content and reaction, and the nature and abundance of the microbiological population. In moist or dry soils, most of the pathogenic bacteria were found to die within ro days ( 5 IO).

Numerous other pathogenic agents, including those causing some of the most deadly human and animal scourges-tuberculosis, leprosy, diphtheria, pneumonia, bubonic plague, cholera, influenza, mastitis and abortion in cattle, the many poxes-constantly find their way into the soil in large numbers. They disappear sooner or later, and no one now 
ever raises the question concerning the role of the soil as the carrier of these disease-producing agents or as the cause of epidemics.

This rapid disappearance of disease-producing bacteria in the soil may be due to a number of factors: (a) unfavorable environment; (b) lack of sufficient or proper food supply; (c) destruction by predacious agents such as protozoa and other animals; (d) destruction by various saprophytic bacteria and fungi considered as antagonists; (e) formation by these antagonists of specific toxic or antibiotic substances destructive to the pathogens; (f) in the case of some organisms at least, increase of the bacteriophage content of the soil resulting in the lysis of some bacteria, especially certain spore-formers (50).

The course of survival of only a few disease-producing organisms outside the host has been studied in detail. Sufficient information has been accumulated, however, to justify certain general conclusions. When $E$. coli is added to sterile soil, it multiplies at a rapid rate (Table 3, p. 10), but when added to fresh, nonsterile soil it tends to die out quickly (Table 4). The rate of its disappearance is independent of reaction of the soil and of incubation temperature.

In order to illustrate the fate of certain important disease-producing

TABLE 4. SURVIVAL OF BACTERIA ADDED TO SOIL AND THEIR EFFECT UPON THE SOIL MICROBIOLOGICAL POPULATION

\begin{tabular}{|c|c|c|c|c|}
\hline \multirow[t]{2}{*}{ INOCULUM } & \multicolumn{2}{|c|}{ INCUBATION } & \multicolumn{2}{|c|}{ ORGANISMS RECOVERED* } \\
\hline & $\begin{array}{l}\text { Number } \\
\text { of days }\end{array}$ & $\begin{array}{c}\text { Tem- } \\
\text { perature }\end{array}$ & Total & $\begin{array}{c}\text { Coliform } \\
\text { bacteria }\end{array}$ \\
\hline Control soil & 5 & $28^{\circ} \mathrm{C}$. & 21,400 & $<200$ \\
\hline E. coli added $\dagger$ & 5 & $28^{\circ} \mathrm{C}$ & 25,600 & 6,800 \\
\hline E. coli added $\dagger$ & 5 & $28^{\circ} \mathrm{C}$ & 39,700 & 3,500 \\
\hline E. coli added & 5 & $37^{\circ} \mathrm{C}$ & 22,800 & 4,700 \\
\hline Control soil & 33 & $28^{\circ} \mathrm{C}$. & 5,900 & $<10$ \\
\hline E. coli added & 33 & $28^{\circ} \mathrm{C}$ & 22,100 & 130 \\
\hline E. coli added $\dagger$ & 33 & $28^{\circ} \mathrm{C}$ & 17,600 & 140 \\
\hline$E$. coli added & 33 & $37^{\circ} \mathrm{C}$ & 23,000 & $<10$ \\
\hline
\end{tabular}

From Waksman and Woodruff (980).

* In thousands per gram of soil.

$\dagger$ Washed suspension of $E$. coli cells added at start and after 5 days.

$¥ \mathrm{CaCO}_{\mathrm{a}}$ added to soil. 
bacteria which find their way into the soil or into natural water basins, it is sufficient to draw attention to reports of experiments made on a few typical pathogens.

\section{The Colon-Typhoid Group of Bacteria}

Frankland $(293,294)$ was the first to establish that Eberthella typhosa may survive in sterilized polluted water or in pure deep-well water for 20 to 5 I days although it dies out in 9 to 13 days in unsterile surface water. In other studies (48I) it was found that the typhoid organism was able to survive in sterilized tap water for 15 to 25 days, as against 4 to 7 days in fresh water; the bacteria died off even more rapidly in raw river or canal water, the survival time being reduced to I to 4 days. The degree of survival of the typhoid organism in water was found to be in inverse ratio to the degree of contamination of the water, the saprophytic bacteria in the water apparently being responsible for the destruction of the pathogen. These conclusions were later confirmed. Freshly isolated cultures of E. typhosa survived a shorter time than laboratory cultures, high temperatures $\left(37^{\circ}\right.$ C. $)$ being more destructive than low ones. Sedgwick and Winslow (846) reported that cells of $E$. coli rapidly died out in the soil, 99 per cent destruction occurring in dry soil in 2 weeks, with a longer survival in moist soil.

In general E. typhosa is able to survive only a short time in unsterilized soil, much longer in sterile soil. S. Martin (623), for example, observed that typhoid bacteria survived and grew readily in sterile soil but when added to well-moistened and cultivated soil they were rapidly destroyed. The same phenomenon occurred when the pathogens were added to a culture of a soil organism in a nutrient medium. Only in certain soils were conditions favorable for the prolonged survival of the pathogen. The conclusion was reached that the typhoid organism is destroyed by the products of decomposition taking place in the soil. It was further concluded that an antagonistic relation appears to exist in some soils but not in others and that this is due to the action of specific antagonistic bacteria present in the particular soils.

Frost (303) also reported that typhoid bacteria were rapidly destroyed when added to the soil. In 6 days, 98 per cent of the cells were 
killed, and in the course of a few more days all the cells tended to disappear entirely from the soil. Under conditions less favorable to the growth of antagonists, the typhoid organism survived not only for many days, but even for months. The conclusion was reached that when soil bacteria are given a chance to develop by-products, there results a marked destruction of typhoid organisms brought into contact with them.

Among the factors responsible for the disappearance of E. typhosa in water, the presence of certain water bacteria was found to be of special importance (924). Rochaix and Vieux (798) demonstrated that when an achromogenic strain of Pseudomonas aeruginosa was present in drinking water, it was not accompanied by any other bacteria. Media inoculated with this organism and $E$. coli gave, after i 3 days' incubation, only cultures of the former. That the two organisms could coexist, however, was shown by inoculation into sterilized water. Only the actual development of the antagonist led to the repression of the fecal organism. The supply of oxygen in the water is important. E. typhosa added to activated sludge increased within the first 4 to 6 hours; this was followed by a reduction in 24 hours, and a 99 per cent destruction in several days (422). The survival period was shorter in sewage-polluted than in unpolluted waters, especially when the sewage was aerated. About 80 per cent reduction of typhoid bacteria was obtained in the Netherlands East Indies by the passage of sewage through Imhoff tanks. Digestion of sludge reduced the number further but did not eliminate the bacteria completely; after the sludge was dried no typhoid bacteria could be found (653).

A study of microorganisms antagonistic to E. coli resulted in the isolation of organisms from 5 of 44 samples of well water, I of I 2 samples of spring water, and 6 of 16 samples of surface water. The antagonists included 3 strains of Pseudomonas, I each of Sarcina, Micrococcus, Flavobacterium, and yeast, 2 actinomycetes, and 3 unidentified nonspore-forming, gram-negative rods (455).

The survival of E. typhosa in manure and in soil is known to be affected decidedly by various saprophytic bacteria. When a carrier was induced to urinate on a soil, E. typhosa could be recovered within 
6 hours from the washings of the soil; however, after 30 hours the organism could no longer be demonstrated, although the soil was still moist with the urine (655). In the absence of sunlight, the organism was recovered after 24 hours but not later. When the urine was allowed to dry on towels, the bacterial cells survived for Io days because saprophytic microorganisms failed to develop on the dry towels. Other evidence was submitted that $E$. typhosa is destroyed by bacteria grown in association with it. Moisture was found to be the most important factor influencing the longevity of typhoid bacteria in the soil; 50 per cent of the bacteria died during the first 48 hours, the survival of the remainder extending over a period of months. Even in those investigations where E. typhosa was detected after 70 or 80 days, the evidence pointed to a lack of multiplication of these bacteria in the soil; when the organism survived for a shorter time in sterilized than in natural soil, it was found $(6,6)$ to be due to the fact that steam heating of soil results in the formation of bactericidal substances.

$E$. coli was rapidly crowded out by other organisms in manure piles. The addition of 9 million cells of $E$. coli and I 3 million cells of $A$. aerogenes to a soil resulted, in 106 days, in reductions to 6,000 and 25,000 respectively; in 248 days, both organisms had completely disappeared (856). The occurrence of coliform bacteria in soil depends entirely on the degree of pollution; soil relatively free from pollution contains no coliform bacteria or only a small number. No evidence of multiplication of these bacteria in the soil could be detected (899).

Sea water, as well, appears to have a bactericidal effect upon organisms added to it $(959$, I050). This is believed to be due to the presence of some substance other than salt. Dysentery and typhoid organisms were found to disappear from sea water in 12 and 16 hours, whereas paratyphoid organisms survived for $2 \mathrm{I}$ and 23 days (9I5). Harvey (386) concluded that sea water contains a substance that is inhibitory to the growth of diatoms; this substance is adsorbed on precipitated phosphate or animal charcoal, and is destroyed by treatment with $\mathrm{H}_{2} \mathrm{O}_{2}$.

Protozoa were found to be at least partly responsible for the destruction of the typhoid organism added to water systems (452, 74I). 


\section{Mycobacterium tuberculosis}

The fate outside the hosts of the bacteria causing tuberculosis in man and in animals has also been studied extensively. Considerable difficulty has often been encountered, however, in demonstrating the presence of this pathogen, which must be detected usually by guinea pig inoculation methods. The organism was found to be alive in a dark room after I 57 to I 70 days, but not after I 72 to I 88 days; in diffused light, the longevity was only I 24 days. In the incubator, the organism retained its virulence for 33 days, but not for 100 days; on ice, virulence was still evident after IO2 days but not after I 53 days (657).

Pure cultures of the bovine organism mixed with cow manure and exposed in a 2-inch layer in a pasture remained virulent for 2 months in sunlight and longer in the shade. Tubercle bacteria were still alive in a garden soil on the 2 I $3^{\text {th }}$ day and dead on the 230 th day. They were alive in buried tuberculous guinea pigs on the 7 Ist day, and dead on the 99th day. In running water, they survived for more than a year (86). Mycobacterium tuberculosis survived for 309 days in sputum kept in darkness, even when completely desiccated; in decomposing sputum, living organisms could be isolated after 20 days but not after 25 days (871a). Under conditions prevailing in southern England, it was found ( $\mathrm{IO} 2 \mathrm{O}$ ) that the tubercle organism may remain alive and virulent in cow's feces exposed on pasture land for at least 5 months during winter, 2 months during spring, and 4 months during autumn; in summer, no living organisms were demonstrated even after 2 months. Under protection from direct sunlight, the survival period was longer. Feces protected from earthworms yielded viable cells even after 5 months. Virulent bacteria were still present in stored liquid manure at least 4 months after infection, though during this time a gradual reduction in virulence of the organism was observed.

The addition of manure to soil was found to favor the survival of the tubercle bacteria, as indicated by a higher proportion of test animals becoming tuberculous when the amount of manure added to the soil was increased (6 13 ). Positive tests were obtained for soil and manure after I 78 days but not later. The organism survived on grass for at least 49 days. Rhines ( 780 ) found that $M$. tuberculosis multiplied in sterile soil 
as well as in the presence of certain pure cultures of bacteria; however, a fungus was found to check the development of the pathogen, especially in manured soil. In nonsterile soil, the pathogen was slowly destroyed, the plate count being reduced to about one sixth of the original in I month. In a study of the survival of avian tubercle bacteria in sewage and in stream water, there was a reduction, in 73 days, from 48,000 to I 400 per milliliter in sewage and to 4,200 in water (779).

\section{Other Disease-producing Microorganisms}

A study of the viability of Brucella melitensis in soil and in water in Malta brought out the fact that the organism survived in sterile tap water 42 days and in unsterile tap water only 7 days. It survived 25 days in soil and 69 days in dry sterile soil, but only 20 days in unsterile manured soil, 28 days in dry natural road dust, 20 days in dry sterile sand, and 80 days on dry cloth $(334,446)$.

The rapid destruction of cholera bacteria added to soil was first pointed out by Houston (45 I). Similar rapid destruction of the diphtheria organism was also noted. Serratia, however, retained its vitality for 158 days. Vibrio comma also survived for a short time only in feces (362), different strains showing considerable variability; temperature was an important factor. During the hot season in Calcutta, the viable period was somewhat longer than a day, as compared to 7 or 8 days during the cold season; the critical cholera months were found to follow directly the cool months. The organism did not survive very long in fresh water, although the time appeared to be long enough to cause occasional serious epidemics. It remained alive for 47 days in sea water (459). The conclusion was reached that although the organism is ordinarily destroyed rapidly in water as a result of competition with other microbes, it may survive in certain instances for some time.

As a result of the evidence presented above and of other information not reported here, it has gradually become established that the soil has an enormous purification or sanitation effect upon the pathogenic bacteria brought into it either by direct excreta, in sewage, or in otherwise contaminated waters. This effect is of a double kind: (a) physical adsorption of the bacteria upon the soil, light, porous, sandy soils being 
far less efficient in removing the bacteria than heavy loam or clay soils; (b) biological effect, resulting in the destruction of the bacteria in the soil. As a result of early studies on the survival of the cholera organism in the soil, certain soils became recognized as "cholera immune" or as "cholera destroying" (736). 


\title{
INTERRELATIONSHIPS AMONG MICROORGAN- ISMS IN MIXED POPULATIONS
}

\begin{abstract}
It must not be forgotten that there are extremes in another direction, where one of the two associated organisms is injuring the other, as exemplified by many parasites, but these cases I leave out of account here. This state of affairs has been termed antibiosis.-H. M. Ward.
\end{abstract}

THE antagonistic effects of one organism upon another were observed by many of the early microbiologists. It is sufficient to cite here three striking examples based upon totally different approaches to the subject.

In I 876, Tyndall (919), on the basis of the growth of wild cultures of bacteria and fungi in organic media, spoke of "the struggle for existence between the Bacteria and the Penicillium. In some tubes the former were triumphant; in other tubes of the same infusion the latter was triumphant. The Bacteria which manufacture a green pigment appear to be uniformly victorious in their fight with the Penicillium."

In 1877 , Pasteur (710) noted that the production of anthrax in susceptible animals can be repressed by the simultaneous inoculation with $B$. anthracis and various other bacteria. This led him to make the following significant suggestion: “. . . on peut introduire à profusion dans un animal la bactéridie charbonneuse sans que celui-ci contracte le charbon: il suffit qu'au liquide qui tient en suspension la bactéridie on ait associé en même temps des bactéries communes."

In 1879, DeBary ( 172 ) emphasized the significance of the antagonistic interrelations among microorganisms; when two organisms are grown on the same substrate, sooner or later one overcomes the other and even kills it.

These and other observations thus laid the basis for a study of mutualistic effects of microorganisms in natural and in artificial environments. 


\section{SYMBIOSIS AND ANTIBIOSIS}

Microbes grow and bring about many metabolic reactions in natural substrates, such as soils and water basins, in a manner quite different from those in pure cultures where they are not influenced by the growth of other organisms. In artificial and natural media, whether these be synthetic materials, complex organic mashes and infusions used for the preparation of industrially essential products, or the bodies of plants and animals, pure cultures of microbes are free from the associative and competitive effects of other microbes found in natural substrates. In mixed populations, a number of reactions that do not commonly take place in pure cultures are involved. Even in the case of mixed infections, a pathogen may be preceded or followed by one or more saprophytes, whereby the processes of destruction brought about in the living animal or plant body are alleviated or hastened. In the mixed populations found in natural substrates, the ecological relationships are largely responsible for many of the essential differences in the behavior and metabolism of the microbes, as compared with the same organisms growing in pure culture.

Almost all microorganisms inhabiting a natural milieu, such as soil or water, are subject to numerous antagonistic as well as associative, or even symbiotic, interrelations. Every organism is influenced, directly or indirectly, by one or more of the other constituent members of the complex population. These influences were at first visualized as due primarily to competition for nutrients. This was well expressed by Pfeffer, who said that "the entire world and all the friendly and antagonistic relationships of different organisms are primarily regulated by the necessity of obtaining food." It was soon recognized, however, that this explanation does not account fully for all the complex interrelations among microorganisms in nature.

Symbiotic, or mutualistic, and antagonistic relationships among microorganisms indicate whether advantages or disadvantages will result to the organisms from the particular association; the first are beneficial and the second are injurious and may even be parasitic (4I, 982). When two organisms are capable of utilizing the same nutrients but are differently affected by environmental conditions such as reaction, air 
supply, and temperature, the one that finds conditions more suitable for its development will grow more rapidly and in time be able to suppress the other. According to Porter (729), the effects produced by fungi in mixed culture are due either to exhaustion of nutrients or to the formation of detrimental or beneficial products. When two or more organisms live in close proximity they may exert antagonistic, indifferent, or favorable effects upon one another. These potentialities were later enlarged (1046) to include stimulating, inhibiting, overgrowing, and noninfluencing effects. After considerable experimentation and speculation, Lasseur (548) came to the conclusion that antagonism is a very complex phenomenon and is a result of numerous and often little-known activities. Antagonism influences the morphology of the organisms, their capacity for pigment production, and other physiological processes.

No sharp lines of demarcation can be drawn between associative and antagonistic effects. Well-defined effects of two symbionts may change during the various stages of their life cycles or as a result of changes in the environment. It is often difficult to separate strictly symbiotic phenomena from associations of less intimate nature, frequently designated as commensalisms. The various stages of transition from obligate parasitism to true saprophytism can be represented as follows:

Obligate parasitism (cer- Facultative parasitism (spe- Modified parasitism; tain bacteria, smut fungi) $\rightarrow$ cies of Fusarium, Rhizoc- $\rightarrow$ hosts may derive some $\rightarrow$ tonia, and Actinomyces) benefit (certain mycorrhiza)

Balanced parasitism (vari- True symbiosis (rootous mycorrhiza) $\rightarrow$ nodule bacteria, lichen formations)

True saprophytism (auto$\rightarrow$ trophic and heterotrophic bacteria and fungi).

The phenomena of antagonism do not fit exactly into the above scheme but are parallel with it: the injurious effects of one organism upon another range from antagonism of varying degrees of intensity to the actual living or preying of one organism upon another. The latter may be classified with the phenomena of parasitism and disease production.

Microorganisms inhabiting the soil live in a state of equilibrium 
and any disturbance of this equilibrium results in a number of changes in the microbial population, both qualitative and quantitative. The ecological nature of this population found under certain specific conditions, as well as the resulting activities, can be understood only when the particular interrelationships among the microorganisms are recognized. Because of its complexity, the soil population cannot be treated as a whole, but some of the processes as well as some of the interrelations of specific groups of organisms can be examined as separate entities. Some have received particular attention, as the relations between the nonspore-forming bacteria and the spore-formers, the actinomycetes and the bacteria, the bacteria and the fungi, the protozoa and the bacteria, and the relations of the bacteria and the fungi to the insects.

The term "synergism" has been used to designate the living together of two organisms, resulting in a change that could not be brought about by either organism alone (440). Microbes living in association frequently develop characteristics which they do not possess when living in pure culture. For example, Schiller (835) found that when beer yeasts are placed together with tubercle bacteria in a sugar-containing but nitrogen-free medium, the yeasts develop antagonistic properties toward the bacteria and use the latter as a source of nitrogen by secreting a bacteriolytic subtance that is also active outside their cells. Various bacteria are able to kill yeasts when they are inoculated into suspensions of the latter in distilled water. The destruction of the fungus $O$ phiobolus, the causative agent of the take-all disease of cereals, by soil organisms was believed to be a result of the need of a source of nitrogen by the latter.

Papacostas and Gaté (706) suggested applying the term "antibiosis" to interactions in mixed cultures in vitro and "antagonism" to mixed infections in vivo. In order to obviate a possible concept that the two types of interaction, namely in the test tube and in the living body, are different, it is more appropriate to apply the term "antagonism" to the unfavorable effects of one living system upon another and "antibiosis" to the production by one organism of specific chemical substances which have an injurious effect upon another organism. 


\section{THE NATURE OF A MIXED MICROBIAL POPULATION}

A mixed microbial population is made up of a great variety of bacteria, and often also of fungi, actinomycetes, and protozoa; to these are added, under certain conditions, various algae, diatoms, nematodes and other worms, and insects. The specific nature and relative abundance of the various microorganisms making up a complex population in either a natural or an artificial environment depend upon a number of factors, which can be briefly summarized as follows:

The physical nature of the medium in which the population lives: soil, compost, or manure pile; river, lake, or ocean; sewage system; or peat bog.

The nature, concentration, and availability of the chemical constituents of the medium used by the microbes as nutrients, especially the materials used as sources of energy and for the building of cell substance. Various organic and inorganic substances, whether complex or simple in chemical composition, favor the development of specific groups of microorganisms capable of utilizing them. For example, sulfur favors the development of specific sulfur bacteria, and cellulose favors such organisms as are capable of attacking this complex carbohydrate as a source of energy. In many instances there is considerable competition for the available food material. Organisms that possess a greater capacity for attacking the particular compound, or are capable of preventing the development of other organisms by the formation of substances injurious to the latter, usually become predominant. Proteins, starches, and sugars can be acted upon by a great variety of microorganisms. The predominance of one group may depend not only upon the chance presence of the particular organism or its capacity for more rapid growth, but also upon its ability to form alcohols, acids, and other products that influence the growth of other organisms.

Environmental conditions favorable or unfavorable to the development of specific organisms. Of particular importance in this connection are temperature (thermophilic vs. mesophilic organisms), oxygen supply (aerobic vs. anaerobic organisms), moisture content (bacteria and fungi vs. actinomycetes), reaction (acid-sensitive vs. acid- 
tolerant forms), as well as the physical conditions of the substrate as a whole.

The presence and abundance of organisms that produce substances having a favorable and stimulating or an injurious and toxic effect upon other organisms, or that may compete for the available nutrients. The equilibrium in the microbiological population in a natural medium such as soil or water may be upset by the introduction of specific nutrients, as well as by treatment with chemical and physical agents whereby certain organisms are destroyed and others stimulated.

The presence of specific microorganisms in a natural medium may be considerably influenced by the presence of certain parasitic or phagocytic agents. The role of protozoa in controlling bacterial activities by consuming the cells of the bacteria has been a subject of much speculation. The presence of bacteria, fungi, and nematodes capable of destroying insects is of great importance in human economy. Many other relationships, such as the presence of phages against specific organisms, are often found greatly to influence the nature and composition of a specific population.

\section{ASSOCIATIVE INTERRELATIONSHIPS}

Numerous instances of associative interrelationships among microorganisms are found in nature. These may be grouped as follows:

Preparation or modification of the substrate by one organism whereby it is rendered more favorable or more readily available for the growth of another organism. As an illustration one may cite the breakdown of cellulose by specific bacteria, thereby making the particular energy source available to noncellulose-decomposing organisms, including not only certain bacteria and fungi but also higher forms of life such as ruminant animals (herbivores) and insects (termites, cockroaches), which carry an extensive cellulose-decomposing microbiological population in their digestive systems. Another illustration is the breakdown of complex proteins by proteolytic bacteria, resulting in the formation of amino acids and polypeptides, which form favorable substrates for peptolytic bacteria. The ammonia liberated from proteins and amino acids supplies a source of energy for nitrify- 
ing bacteria and a source of nitrogen for many fungi. The ability of bacteria to concentrate in solution those nutrients that are present only in mere traces enables animal forms (protozoa) to exist at the expense of the bacteria (106).

Influence upon the oxygen concentration available for respiration. This involves the phenomenon first observed by Pasteur (709) of consumption of oxygen by aerobic bacteria, thus making conditions favorable for the development of anaerobes.

Symbiotic interrelationships, where both organisms benefit from the association. The three most important examples found in nature are: (a) the phenomenon of symbiosis between root-nodule bacteria and leguminous plants; (b) mycorrhiza formations between certain fungi and higher plants; (c) lichen formation between algae and fungi. Certain other interrelations are not strictly symbiotic, but are found to fall between groups a and $c$; here belong nitrate reduction accompanied by cellulose decomposition and nitrogen-fixation with cellulose decomposition, carried out in each case by two specific groups of organisms.

Production by one organism of growth-promoting substances that favor the development of other organisms. The formation of riboflavin by anaerobic bacteria in the digestive tract of herbivorous animals is an interesting and highly important phenomenon in the nutrition of such animals. The production of bacterial growth stimulants by yeasts and the beneficial action of mixed populations upon nitrogen-fixation by $A$ zotobacter are other illustrations of this general phenomenon. The presence of specific bacteria has been found necessary for the sporulation of certain yeasts and for the formation of perithecia by various Aspergilli (825). Various other processes of association have also been recognized (940).

Destruction by one microorganism of toxic substances produced by another, thereby enabling the continued development of various members of the microbiological population.

Modification of the physiology of one organism by another. In the presence of certain bacteria, Clostridium gramulobacter-pectinovorum forms lactic acid instead of butyl alcohol (873). The presence of Clostridium acetobutylicum in cultures of bacteria producing dextro-lactic acid and laevo-lactic acid causes such bacteria to form the inactive lactic acid (897); intimate contact of the bacteria is essential, the use of membranes preventing this effect. Pigment formation by $P_{s}$. 
aeruginosa may be weakened when the latter is grown together with other organisms. E. coli may lose the property of fermenting sugars when grown in the presence of paratyphoid organisms (462).

Some associations of microorganisms are not so simple. The complex system of animal infection by more than one organism, with the resulting complex reactions in the animal body, is a case in point.

The effect of one organism upon the activities of another can be illustrated by the results of the decomposition of complex plant material by pure and mixed cultures of microbes (Table 5). Trichoderma, a fungus

TABLE 5. DECOMPOSITION OF ALFALFA BY PURE AND MIXED

CULTURES OF MICROORGANISMS

\begin{tabular}{|c|c|c|c|c|}
\hline ALI & $\begin{array}{c}\text { TOTAL } \\
\text { ALFALFA DE- } \\
\text { COMPOSED } \\
\text { Per cent }\end{array}$ & $\begin{array}{l}\text { HEMICELLU- } \\
\text { LOSES DE- } \\
\text { COMPOSED } \\
\text { Per cent }\end{array}$ & $\begin{array}{l}\text { CELLU- } \\
\text { LOSE DE- } \\
\text { COM POSED } \\
\text { Per cent }\end{array}$ & $\begin{array}{c}\mathrm{NH}_{3}-\mathrm{N} \\
\text { PRODUCED } \\
\text { mgm. }\end{array}$ \\
\hline Trichoderma & $9 \cdot 3$ & $4 \cdot 7$ & 0 & 61 \\
\hline Rhizopus & 6.6 & 12.8 & 2.9 & 53 \\
\hline Trichoderma + Rhizopus & I 3.7 & 22.6 & 10.6 & 63 \\
\hline Trichoderma + Cunninghamella & la $\quad 15.0$ & 15.4 & $5 \cdot 7$ & 47 \\
\hline Trichoderma + Ps. fuorescens & 10.5 & 14.5 & 6.4 & 32 \\
\hline Streptomyces 3065 & 16.6 & 43.0 & 23.2 & 52 \\
\hline \multicolumn{5}{|l|}{ Trichoderma + Streptomyces } \\
\hline 3065 & 12.5 & I 4.6 & 4.8 & 56 \\
\hline Soil infusion & 28.4 & 40.9 & 50.8 & 21 \\
\hline
\end{tabular}

From Waksman and Hutchings (960).

known to be an active cellulose-decomposing organism, did not attack at all the cellulose of alfalfa and decomposed the hemicelluloses only to a limited extent; however, the organism utilized the proteins rapidly, as illustrated by the amount of ammonia liberated. Rhizopus, a noncellulose-decomposing fungus, attacked largely the hemicelluloses in the alfalfa and some of the protein; a small reduction in cellulose was recorded, probably because of an analytical error. When Trichoderma was combined with $R$ hizopus, the former attacked readily both the cellulose and the hemicelluloses. The same effect upon the activity of Trichoderma was exerted by other noncellulose-decomposing organ- 
isms, such as the fungus Cunninghamella and the bacterium Ps. fluorescens. On the other hand, when Trichoderma was combined with a cellulose-decomposing Streptomyces, there was considerable reduction in the decomposition of the total plant material as well as of the cellulose and hemicelluloses. These results further emphasize the fact that two organisms may either supplement and stimulate each other or exert antagonistic effects. The total soil population is far more active than any of the simple combinations of microorganisms.

\section{COMPETITIVE INTERRELATIONSHIPS}

The following competitive relations among the microscopic forms of life inhabiting the sea have been recognized (15):

Competition among chlorophyll-bearing diatoms for the available nutrient elements in the water

Competition among the copepods for the available particulate food materials, notably the diatoms

Competition between individuals belonging to one species and individuals belonging to another

Competition between young, growing, and reproducing cells and older, respiring cells

Food competition and space competition

Competition between transitory and permanent populations

Competition between sedentary or sessile organisms and free-moving forms

This list has been enlarged (943) to include other factors that are particularly prominent in nonaquatic environments:

Degree of tolerance of the immune or resistant varieties and of the less resistant or more sensitive forms to attack by disease-producing organisms

Fitness for survival of microbes that are able to adapt to a symbiotic form of life, such as leguminous plants or mycorrhiza-producing plants, and those that are not so adapted

Survival of parasitic forms that require living hosts for their development, as contrasted with saprophytes that obtain their nutrients from mineral elements or from dead plant, animal, and microbial residues 
Various special types of competition, for example, competition between strains of root-nodule bacteria (Rhizobium), whereby one strain checks completely the multiplication of other strains, even outside the plant, the dominant strain then becoming responsible for all the nodules produced (679).

These phenomena of competition are found not only in natural substrates, such as soil and water, but also in artificial media. When several microbes are growing in the same culture medium, some will be repressed in course of time whereas others will survive and take their place. This is due to the fact that these microbes compete for the use of the same nutrients or that conditions, such as reaction, oxygen supply, and temperature, are more favorable to some organisms than to others. Another phenomenon may also be involved, that some organisms may produce toxic substances that repress the growth of others. In artificial media, slowly growing tubercle bacteria, diphtheria organisms, and others will be repressed by the rapidly growing saprophytes. Under aerobic conditions, aerobic bacteria and fungi will repress yeasts and anaerobic bacteria, whereas under anaerobic conditions the reverse will take place. An alkaline reaction will favor the development of bacteria, an acid reaction will favor the growth of fungi.

\section{ANTAGONISTIC INTERRELATIONSHIPS}

When two or more organisms live together, one may become antagonistic to the others. The composition of the medium and the conditions of growth influence the nature and the action of the antagonist; the metabolism and cell structure of the antagonized organism may be modified or the cell itself may be destroyed (184). In urine, for example, staphylococci may become antagonistic to $E$. coli or vice versa, depending on the initial numbers of the two groups, on the formation of metabolic products, or on the exhaustion of nutrients (246). The toxic substances produced by the antagonists comprise a variety of compounds, ranging from simple organic acids and alcohols to highly complex bodies of protein or polypeptide nature.

Various types of antagonism are recognized. Nakhimovskaia (670) 
concluded that all phenomena of antagonism among microorganisms can be conveniently classified into four groups:

I. Antagonism in vivo vs. antagonism in vitro. According to some investigators, only the inhibitive forms of antagonism (in vitro) may be designated as true antagonisms; the in vivo forms were designated as phenomena of antibiosis. As pointed out above (p. $3^{8}$ ), this differentiation is no longer recognized.

2. Repressive, bactericidal, and lytic forms of antagonism. One may further distinguish between bacteriostatic and bactericidal, fungistatic and fungicidal forms of antagonism, as well as between antagonism of function and antagonism of growth.

3. Direct, indirect, and true antagonism.

4. One-sided and two-sided antagonism; antagonism between strains of the same species and antagonism among strains of different species.

Duclaux (212) was the first to demonstrate that the growth of a fungus upon a certain medium renders the medium unfavorable for the further growth of the same organism. Küster (54I) has shown that culture solutions in which fungi have grown are not suitable for the germination of freshly inoculated spores but are improved by boiling. This effect was observed as a result of the growth not only of the same organism but also of other species. Similar observations were made for bacteria: Marmorek (620) reported, in 1902, that the growth of hemolytic streptococci in broth rendered the medium unsuitable for subsequent growth of the same organism. The production of spores by bacteria was believed to be caused by the formation of toxic, thermolabile organic substances; upon the destruction of these by boiling, the medium was again made favorable for the growth of bacteria and bacterial spores were once more able to germinate. Some of the toxic substances appeared to be thermostable (668).

Fungi are capable of producing not only growth-inhibiting but also growth-promoting substances. By means of certain procedures, it was found possible to separate the two (690). The tendency of fungus hyphae to turn away from the region in which other hyphae of the same fungus were growing was explained as a negative reaction to chemical substances produced by the growing fungus (306). This nega- 
tive chemotropism was shown to be due to thermolabile staling substances (358). The phenomenon of staling was often spoken of as vaccination of medium (45), and was ascribed to the action of protein degradation products.

These and other experiments led to the conclusion that many microorganisms are capable of producing substances that are injurious to their own development (iso-antagonistic) or, and sometimes much more so, to other organisms growing close to them (hetero-antagonistic). The growth of certain fungi and bacteria in practically pure culture, even in a nonsterile environment, was believed to be due to this phenomenon. It is sufficient to mention the lactic and butyric acid bacteria, the citricacid-producing species of Aspergillus, the lactic and fumaric-acidproducing species of Rhizopus, and the alcohol-producing yeasts. The chemical substances produced by these organisms in natural substrates may be looked upon as protective metabolic products of microorganisms in their struggle for existence. Such products play a highly significant part in the metabolism of various organisms, especially those that grow parasitically upon living plant and animal bodies.

Among the various types of antagonism, the one resulting in the production of active substances that can be isolated and purified has received the greatest consideration recently. These substances have been designated as toxins, poisons, antagonistic agents, bacteriostatics, and antibiotics. The chemical nature of some has been elucidated, but that of many others is still unknown. Some of these substances are destroyed by boiling, by exposure to light, or by filtration, whereas others are resistant to heat and to ultraviolet rays; some are readily adsorbed by certain filters, from which they can be removed by the use of special solvents such as ether, alcohol, chloroform, and acetone. The concentration of the antagonistic substances produced by many fungi and bacteria is greatly influenced by the energy and nitrogen sources in the medium and by environmental conditions, such as temperature and aeration.

The three important types of antagonism are (a) the repressive, inhibitive, or bacteriostatic, (b) the bactericidal, and (c) the bacteriolytic. When one bacterium is inoculated into the filtrate of another, the growth of the first is slower than that of the control. Certain types of 
antagonism express themselves in the destruction by the antagonist of the other organisms present in the mixed culture, with or without lysis. $B$. mesentericus, for example, is capable not only of depressing but also of killing the cells of diphtheria and pseudodiphtheria (IO52). The lytic form of antagonism is illustrated by the action of Ps. aeruginosa, $B$. brevis, and certain other antagonists upon micrococci and various spore-forming bacteria.

In differentiating between "direct antagonism" and "passive antagonism," attention was directed (670) to the fact that the latter depends not upon the direct action of the antagonist but upon the changed conditions of culture under the influence of the antagonist's growth. This may comprise a change in $\mathrm{pH}$ and $r \mathrm{H}$ of medium or an impoverishment of some of the nutrient constituents. "Direct antagonism" was often distinguished (677) from "indirect antagonism," the first being limited to those phenomena in which the antagonistic action is connected with the direct action of the living cell, whereas in the second the metabolic products produced by one organism are injurious to others. Intestinal bacteria were found $(367,369)$ to repress the anthrax organism only when the former were in an active living state. Other investigators (4I8) designated the action of the living cell itself as "true antagonism."

Bail (32) suggested that for every bacterium there is a typical constant number of cells capable of living in a given space. When this concentration $(M)$ is reached, multiplication comes to a standstill, independently of exhaustion of the nutrients or formation of toxic substances. The same phenomenon was believed to hold true when two bacteria live together (гог 3 ): if the limiting cell-in-space concentrations are different for the two organisms, the one with a higher $M$ value represses the other; however, the weaker species may check the stronger when planted in sufficient excess (243). It has been suggested (370) that certain physiological properties of the individual organisms, designated as "biological activity" and "competitive capacity," must also be taken into consideration in evaluating this relationship. The fact that the number of yeast cells reaches a maximum independently of the initial number of cells added or the concentration of nutrients in a given 
volume of medium has been explained (9I) by the amount of oxygen originally present.

Garré (315) deserves the credit for having first noted that antagonism may be either one-sided or two-sided. In the first case, one organism represses another that is not antagonistic to it; in the second case, both organisms repress each other. A one-sided antagonism may become two-sided under certain conditions of culture. E. coli is antagonistic to $E$. typhosa; however, if the latter is inoculated into a medium somewhat earlier than the former, $E$. typhosa becomes antagonistic to $E$. coli (936).

Although the most common antagonisms are between organisms of different species, there are numerous instances where one strain of a species may be antagonistic toward another strain of the same species $(53,370,651)$. Certain strains may develop antagonistic properties in the presence of other strains (74). Nonflagellated variants of typhoid bacteria were repressed by a flagellated form, smooth variants of paratyphoid bacteria by rough forms, and so on. The fact that all bacterial cultures stop growing after a certain period of time has been interpreted to be a result of the antagonistic action of some cells upon others. When the filtrates of such cultures are added to fresh nutrient media they may stop the growth of the same species as well as that of other species.

Certain organisms produce pigments in the presence of others; these pigments are believed to be in some way associated with the phenomenon of antagonism. In the presence of $S$. lutea, V. comma forms a dark violet pigment that is accompanied by an increase in agglutination and in virulence (670). The destruction of Dictyostelium mucoroides by a red-pigment-forming bacterium was accompanied by an increase in intensity of the pigment (723); the blue pigment of Bacterium violaceum, however, only delayed the growth of the fungus. Penicillium africanum produces a more intense pigment in contact with other fungi such as Aspergillus niger; this pigment accumulates in the mycelium of the latter, which may thereby be killed (I86). P. luteum and Spicaria purpurogenes produce a pigment that is used not only for purposes of protection, but also for attack upon other organisms, whereby the latter are killed and stained (669). 


\section{THEORIES OF THE NATURE OF ANTAGONISTIC ACTION}

The various theories proposed to explain the mechanism of antagonistic effects of microorganisms may be summarized under the following processes:

\section{Exhaustion of nutrients}

Physicochemical changes in medium

Pigment action

Action at a distance

\section{Space antagonism}

Enzyme action, either directly by the antagonist or as a result of cell autolysis, under the influence of the antagonist

Production and liberation of antibiotic substances

Pasteur (710) ascribed the antagonistic effect that aerobic bacteria have upon the anthrax organism to the consumption of the oxygen by the former; the unfavorable influence of normal blood upon the growth of anthrax was believed to be due to competition for the oxygen by the red blood corpuscles. Freudenreich (298) considered the antagonism between Ps. aeruginosa and Bacillus anthracis as due to exhaustion of nutrients by the former. These studies were soon followed by numerous other investigations in which the exhaustion of nutrients in the media was believed to be responsible for the phenomenon of antagonism; the onset of the stationary phase in bacterial growth was believed (579) to belong here. Change in $p \mathrm{H}$ of medium, exhaustion of nutrients, and accumulation of toxic products were also found to be limiting factors.

It thus became apparent, even in the early days of bacteriology, that certain changes are produced by microbes in the medium in which they grow which render it unfit for the growth of other organisms. It also was soon recognized that the problem is more complicated than the mere exhaustion of nutrients. The changes in relationship produced by changes in surface tension, in oxidation-reduction potential, in reaction, and in osmotic pressure were suggested as explanations. Among the classical examples of the effect of reaction upon the growth of other organisms is the acidification of milk by lactic acid bacteria. Metchnikov emphasized the fact that Lactobacillus bulgaricus acts antagonistically 
not only by means of the lactic acid that it produces but also by the formation of special substances. The production by bacteria of alkalireaction products that have an injurious effect upon the further growth of the organisms has also been demonstrated (342). These substances were found to correspond to amino compounds, liberated in the process of cellular disintegration. Numerous other physical and physicochemical factors influence the growth of an organism in an artificial medium. It is to be recalled that the rate of survival of bacterial cells in water or in salt solution is markedly influenced by the colloids present, the concentration of electrolytes, the reaction, and the temperature.

Microbial antagonism was thus looked upon largely as a result of a series of physical factors, including various radiations such as mytogenetic rays, $p \mathrm{H}$ changes, conductivity, electric charge, and surface ten$\operatorname{sion}(525)$.

Most antagonisms, however, can be explained by the production of antibiotic substances by the antagonists. Because of the thermolability of some, sensitivity to chemical reagents, or adsorption on bacterial filters, considerable difficulty has been experienced in isolating the active substances. Many of these substances are iso-antagonistic, whereas others are able to act upon different bacteria. Most of them have been found to be thermostable.

The first antibiotic recognized as such was pyocyanase, produced by Ps. aeruginosa (235). Other organisms that produce such substances are Serratia marcescens (229), Ps. fuorescens (566), B. mesentericus (I052), B. mycoides, B. subtilis, and other spore-forming bacteria. Since the early work at the turn of the century and especially during the last five or six years, many new antibiotics have been isolated or demonstrated. These will be discussed in detail later.

The production of these antibiotics by microorganisms is greatly influenced by reaction, temperature, and aeration of substrate, as well as by the presence of other organisms. Evidence is still lacking as to whether these substances may accumulate in the soil and in water, whether the antagonized organisms are able to overcome their effect, and whether they are destroyed by other members of the soil or water microbiological population $(365,976)$.

Different organisms possess different degrees as well as different 
mechanisms of antagonism. Often one organism may completely check the growth of another; later, growth may be resumed, although it will not be quite normal. Antagonism stimulates spore-production and brings about deformed growth of the mycelium in fungi or the formation of gigantic cells in bacteria. The morphological effects produced by the antagonists comprise changes in form, size, and structure of hyphae, direction of growth, complete cessation of growth, and abbreviation of hyphal segments. 


\section{ISOLATION AND CULTIVATION OF ANTAGONISTIC MICROORGANISMS; METHODS OF MEASURING ANTIBIOTIC ACTION}

IN nearly all the earlier work and even in many recent investigations on the antagonistic properties of microorganisms and the production of antibiotic substances, two procedures were employed: indiscriminate testing of pure cultures of bacteria and fungi, commonly taken from culture collections, for antagonistic effects against one another or against certain specific or test organisms; and isolation of occasional antagonistic organisms from old plate cultures, as air contaminants, or from mixed infections. These studies were carried out either by medical bacteriologists interested in agents capable of suppressing bacterial pathogens or by plant pathologists interested in organisms capable of inhibiting the growth of fungi, principally those concerned in the causation of plant disease. They resulted in the accumulation of considerable information concerning antagonistic organisms, the nature of the phenomenon of antagonism, and, to a more limited extent, the mechanisms involved. Neither of these methods, however, is suitable for a systematic study of antagonism as a natural process.

The last decade has witnessed a number of systematic attempts to determine the distribution of antagonists in nature, to isolate specific organisms capable of bringing about the desired reactions, and to establish the mechanism involved in these reactions. These studies were undertaken by a group of Russian investigators interested largely in fungi and actinomycetes as agents antagonistic to other microorganisms chiefly causing plant diseases, and by American and British investigators interested in agents active against bacterial pathogens of man.

The early significant, but unrecognized, investigations of Schiller (835) on forced antagonisms and the studies of Gratia and his associates $(356,357)$ on mycolysates were in direct line of the more recent studies of Dubos (20I), who made a systematic attempt to isolate from specially enriched soils bacteria capable of destroying specific 
pathogenic organisms. Although it had been previously established that many spore-forming bacteria are capable of producing substances that have antibacterial properties, as shown by the work of Pringsheim (738), Much (664), and others, Dubos was the first to succeed in isolating in crystalline form the active substances involved and in demonstrating their chemical nature. He utilized for the isolation of the organisms the soil enrichment culture method. This consisted in adding repeatedly various pathogenic bacteria to a soil in which, as a result, antagonistic organisms developed that were capable of destroying the bacteria; these organisms were then isolated by appropriate procedures.

These investigations, as well as the work of Fleming (26I) later followed by other British investigators ( 5 ) on the antibacterial properties of molds belonging to the Penicillium notatum group, served as the direct stimulus to numerous studies. The entire series of studies led to the development of simple methods for the systematic isolation of microorganisms capable of inhibiting the growth of fungi and bacteria, both pathogenic and saprophytic, and for separating many of the antibiotic substances produced by these organisms.

\section{METHODS OF ISOLATING ANTAGONISTIC MICROORGANISMS}

Several methods are now available for the isolation of antagonistic microorganisms from natural substrates such as soil, stable manure, composts, sewage, water, and food products. These methods are different in nature, but they are all based on the same principle, that of bringing a living culture of a bacterium or fungus into close contact with a mixed natural population, thereby allowing certain members of this population to develop at the expense of the added culture.

\section{Soil Enrichment Method}

By this method a soil is enriched with known living pathogenic bacteria. Fresh garden or field soil is placed in glass beakers or pots, and the moisture of the soil is adjusted to optimum for the growth of aerobic bacteria, which is about 65 per cent of the water-holding capacity of the soil ( 20 to 50 per cent of the moist soil); the containers are covered 
with glass plates and placed in an incubator at $28^{\circ}$ or $37^{\circ} \mathrm{C}$. Washed suspensions of living bacteria are added to the soil at frequent intervals, care being taken to avoid puddling it with an excess of the fluid, so conditions will not be made anaerobic. Samples of the enriched soil are removed at intervals and tested for the presence of organisms antagonistic to the bacteria added. Fresh washed suspensions of the living bacteria are inoculated with the enriched soil as soon as the presence of antagonistic organisms is demonstrated; this results in the development of the antagonistic organisms and the destruction of the bacteria in suspension. Transfers are then made to fresh suspensions of the bacteria, resulting in an enrichment of the antagonist, which can finally be isolated in pure culture $(201,207,442)$.

The significance of the soil enrichment method and its application to the isolation of specific antagonistic organisms has been questioned (969). It was suggested that whereas there is no question concerning the multiplication of microorganisms capable of decomposing a given substance or of secreting enzymes active upon such a substance in response to its introduction into the soil, there is still doubt whether specific antagonistic organisms develop as a result of the introduction of living cells into the soil. The reason for this was based upon the fact that antibiotic reactions produced by antagonistic organisms do not affect bacteria by simple digestive or oxidative mechanisms.

\section{Bacterial Agar Plate Method}

This method was first used by Gratia and Dath (357) for the isolation of antagonistic agents, actinomycetes having been found readily by it.

To isolate antagonistic bacteria, agar ( 1.5 per cent) is washed in distilled water, then dissolved in water supplemented by I per cent glucose and 0.2 per cent $\mathrm{K}_{2} \mathrm{HPO}_{4}$. Ten-milliliter portions of the sugarphosphate agar are placed in glass tubes and sterilized. The sterile agar is melted, and the tubes are placed in a water bath kept at $42^{\circ} \mathrm{C}$. A washed, centrifuged suspension of living bacteria, grown on solid or in liquid media, is then added and thoroughly mixed with the agar. This "bacterial agar" is poured into a series of Petri plates containing onemilliliter portions of fresh or enriched soil, diluted $\mathrm{I}: 100$ to $\mathrm{I}: \mathrm{I0,000}$ 
times with sterile water. The contents of the plates are thoroughly mixed in order to distribute the diluted soil suspension in the bacterial agar. The plates are inverted and incubated at $28^{\circ}$ or $37^{\circ} \mathrm{C}$.

After I to Io days' incubation, depending on the nature of the organism used for the preparation of the plates, the presence of antagonists is manifested by the formation of clear zones surrounding their colonies (Figure 2). The organisms are isolated from these colonies and are retested for antagonistic properties, either by transfer to fresh bacterial agar plates or by inoculating solidified agar plates and crossstreaking with test organisms $(956,978)$.

In the isolation of antagonistic fungi the same method is followed, except that it is preferable to make the bacterial agar acid by using $\mathrm{KH}_{2} \mathrm{PO}_{4}$ in place of $\mathrm{K}_{2} \mathrm{HPO}_{4}$. The resulting acidity $(p \mathrm{H} 4.5)$ inhibits the growth of bacteria and actinomycetes. Since the soil contains fewer fungi than bacteria, lower dilutions of soil are employed for this purpose ( $I$ : IO to I : I,000).

This method, like the soil enrichment method, does not always yield desirable results. As shown in Table 6, some of the most important antagonists, such as $P$ s. aeruginosa, $S$. antibioticus, $A$. flavus, and $P$. notatum, do not develop on such a plate since they cause only limited lysis of bacteria. On the other hand, B. brevis, S. griseus, A. fumigatus, and $A$. clavatus cause extensive lysis of gram-positive bacteria and so can readily be isolated.

\section{Crowded Plate Method}

Ordinary field or garden soil is plated out on common nutrient (beefpeptone) agar, very low dilutions ( $\mathrm{I}:$ IO to $\mathrm{I}: \mathrm{I}, 000$ ) being used to enable a large number of bacterial colonies to grow on the plate. The resultant crowding of these colonies allows the development on the plate of potential antagonists that are normally present in the soil. The production of antibacterial substances by these antagonists inhibits the growth of bacteria in close proximity to them and, in consequence, clear zones are formed around the colonies (Figure 3 ). It is possible, by means of this method, to demonstrate that many strains of spore-forming bacteria possessing antagonistic properties are present in the soil and can readily be isolated from it. 
TABLE 6. GROWTH OF ANTAGONISTIC ORGANISMS ON BACTERIAL WASHED AGAR MEDIA AND LYSIS OF BACTERIA

\begin{tabular}{|c|c|c|c|c|c|c|}
\hline \multirow{3}{*}{$\begin{array}{l}\text { ANTAGONISTIC } \\
\text { ORGANISM }\end{array}$} & \multicolumn{6}{|c|}{ MEDIUM CONTAINING WASHED CELLS OF } \\
\hline & \multicolumn{2}{|c|}{ E. coli } & \multicolumn{2}{|c|}{ S. lutea } & \multicolumn{2}{|c|}{ B. subtilis } \\
\hline & Growth & Lysis & Growth & Lysis & Growth & Lysis \\
\hline \multicolumn{7}{|l|}{ Bacteria: } \\
\hline B. brevis & o & 0 & $H+$ & $H$ & $\mathrm{HH}$ & $H+1$ \\
\hline B. simplex & o & o & ++ & + & $+H$ & ++ \\
\hline Ps. aeruginosa & 0 & o & $H+$ & o & $+H$ & 0 \\
\hline \multicolumn{7}{|l|}{ Actinomycetes: } \\
\hline S. antibioticus & 0 & o & $H H$ & o & $H$ & 0 \\
\hline S. griseus & 0 & o & $+1+$ & + & + & + \\
\hline S. lavendulae & o & o & $\mathrm{HH}$ & + & $++t$ & ++ \\
\hline Micromonospora sp. & o & 0 & $\mathrm{HH}$ & $H+$ & 0 & 0 \\
\hline N. gardneri & 0 & 0 & & & $++t$ & $\mathrm{HH}$ \\
\hline \multicolumn{7}{|l|}{ Fungi: } \\
\hline A. clavatus & $H+$ & o & $H+H$ & $H+H$ & $+1+$ & $H+$ \\
\hline A. flavus & $+H$ & 0 & ++ & o & ++ & 0 \\
\hline A. fumigatus & $+H$ & 0 & ++ & $H$ & $H+$ & $+H$ \\
\hline Gliocladium sp. & $+H$ & 0 & $+1+$ & + & $H+$ & 0 \\
\hline P. notatum & $H+$ & 0 & 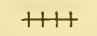 & \pm & 0 & 0 \\
\hline
\end{tabular}

From Waksman and Schatz (969).

Note. $\mathrm{o}$ indicates no growth of antagonist or lysis of test bacterium as shown by formation of clear zone on plate; \pm indicates trace; + to $+1+$ indicates increasing amounts of growth or lysis.

\section{Direct Soil Inoculation Method}

Nutrient agar plates are inoculated with the bacteria or fungi for which antagonists are to be found, and the plates are incubated for 24 to 48 hours at $28^{\circ}$ or $37^{\circ} \mathrm{C}$. Particles of fresh or enriched soil placed on the surface of the bacterial or fungus growth on the plate will give rise to antagonistic organisms that will bring about the killing or even the lysis of the original culture. By this method, organisms antagonistic to many bacteria and fungi causing plant and animal diseases have been isolated $(683,685)$.

For the isolation of bacteria antagonistic to fungi, the latter are grown on potato agars until they have spread over the plate; particles of moist soil are then placed on the surface of the mycelium, and the plates are incubated in a moist chamber. Bacteria lysogenic to the fungi 
grow out of the soil and gradually dissolve the mycelium until the entire surface of the plate becomes free of the hyphae of the fungus. By transferring some of the material from the lysed spots, pure cultures of bacteria have been obtained that are capable of producing destructive effects upon the fungi, similar to the action of the particles of soil.

To these four methods may be added the "forced antagonism" method of Schiller (835), previously referred to, which consists in feeding a culture of an organism with another one, thereby forcing the second to develop the capacity of destroying the first.

By means of the foregoing methods, as well as various modifications of them, it was possible to demonstrate that soils, composts, and water basins contain an extensive population of microorganisms possessing antibacterial and antifungal properties. When $E$. coli was used as the test organism, it was found that although this organism was capable not only of surviving but actually of multiplying in sterile soil, it died off very rapidly when added to fresh soil. The rate of its destruction was greatly increased with every subsequent addition of washed bacterial cells to the soil. This was accompanied by the development of certain antagonistic microbes capable of destroying $E$. coli in pure culture.

A large number of fungi, actinomycetes, and bacteria possessing antagonistic properties have thus been isolated. The nature of the test organism was found to be of great importance in this connection. When Staphylococcus aureus, S. lutea, and B. subtilis were used, a large number of antagonists could readily be isolated. With $E$. coli, however, a much smaller number of microbes thus isolated possessed antagonistic properties. Certain other gram-negative bacteria, like Brucella abortus, were more sensitive than $E$. coli, whereas certain gram-positive bacteria, like $B$. mycoides and $B$. cereus, were less sensitive than $B$. subtilis $(956,958)$.

Bacteria destructive to fungi, or possessing fungistatic and fungicidal properties, have also been isolated from soils as well as from the surface of plants, such as flax, by transferring small sections of soil or plant stem to plates of fungi growing on potato agar; transfers made from the lytic spots yielded antagonistic bacteria (686). By the use of this 


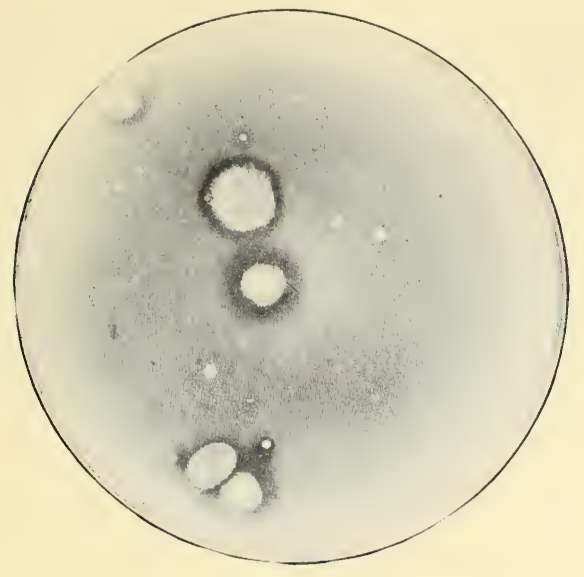

Figure 2. Development of antagonistic fungi on bacterial-agar plate. From Waksman and Horning (956).
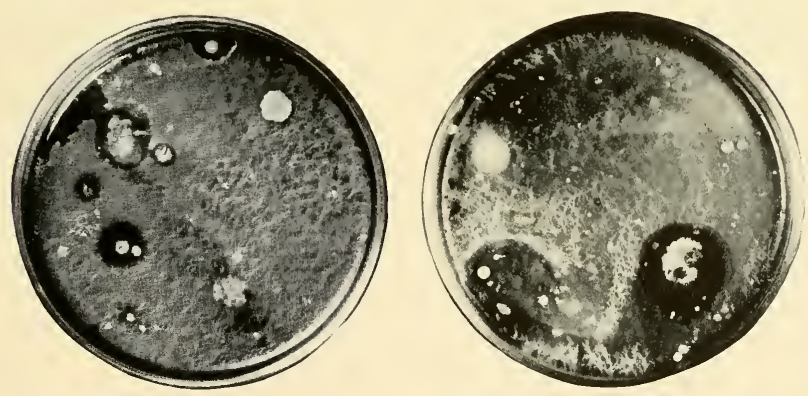

FigURE 3. Bacterial plates made from soil, showing clear zones surrounding colonies of antagonistic organisms. From Stokes and Woodward (885). 


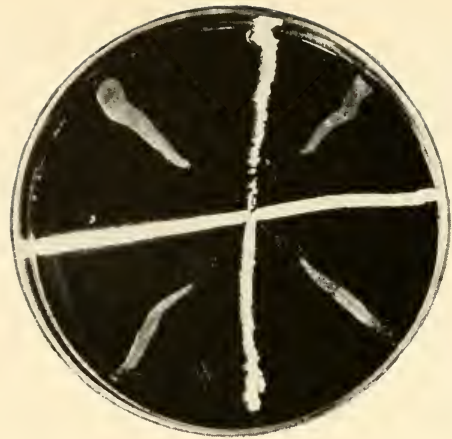

Antagonistic action of $S$. antibioticus upon S. lutea

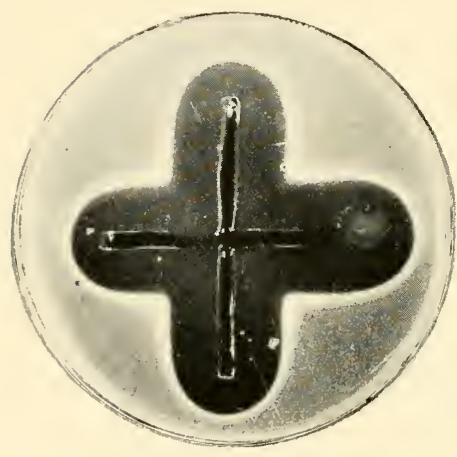

Bacteriostatic action of actinomycin upon $S$. lutea

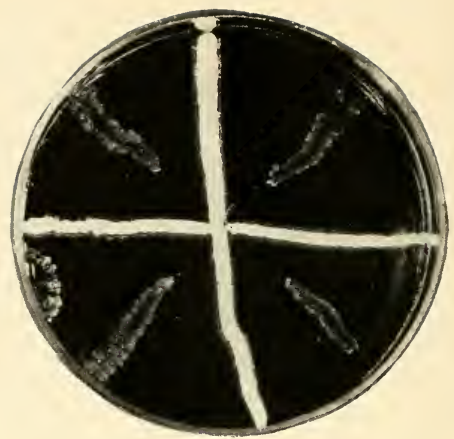

Antagonistic action of $S$, antibioticus upon B. mycoides

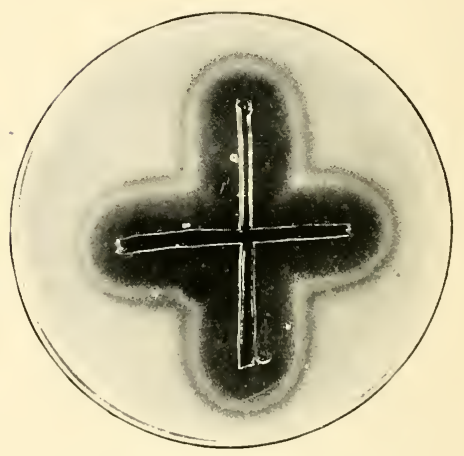

Bacteriostatic action of actinomycin upon B. mycoides

Figure 4. Antagonistic effects of living organisms and their products. From Waksman and Woodruff (974). 
method, Chudiakov (I43) isolated various bacteria antagonistic to Fusarium. The antagonists were found abundantly in cultivated soils, but not in flax-sick soils rich in Fusarium. Bamberg (35) demonstrated, in the soil, bacteria capable of bringing about in Io days complete destruction of Ustiliago zeae and other fungi. Myxobacterium was also found (473) capable of bringing about the disintegration of fungus mycelium. Nonspore-forming bacteria, similar to the cultures of Chudiakov, were isolated and shown to be able to attack a number of fungi, including species of Fusarium, Sclerotinia, Gleosporium, Acrostalagmus, Alternaria, and Zygorhynchus (729).

\section{METHODS OF TESTING THE ANTAGONISTIC} ACTION OF MICROORGANISMS

Once antagonistic organisms have been isolated, it is essential to establish their bacteriostatic spectrum-that is, their ability to inhibit the growth of various specific microorganisms. Usually these antagonists do not affect alike all bacteria and fungi, some acting primarily against gram-positive bacteria and against only a few gram-negative forms (mostly cocci), others acting upon certain bacteria within each of these two groups.

A considerable number of methods have been developed for measuring these antagonistic effects. They measure the selective nature of the antagonistic action and they can also give quantitative information concerning the intensity of this activity. Because of the great differences in the degree of sensitivity of bacteria to the action of the antagonists, the proper selection of one or more test organisms is highly essential. $S$. aureus has been employed most commonly, different strains of this organism having been found to vary greatly in their sensitivity even to the same substance. Streptococcus viridans, B. subtilis, Micrococcus lysodeikticus, $S$. lutea, $E$. coli, and $E$. typhosa are other organisms that are frequently employed for testing the activity of antagonists. Although for purposes of concentration and purification of a known substance a single test organism is sufficient, it has been found advisable during the isolation of antagonistic organisms and the study of the na- 
ture of the antibiotic substance or substances that they produce to use more than one test bacterium, including one or more gram-positive and one or more gram-negative bacteria.

Most of the methods for testing antagonistic action are based upon the growth of the test organisms in the presence of the living antagonists or of the antibiotic substances produced by them in liquid and on solid nutrient media. Only a few of these methods are now utilized, most of them being chiefly of historical interest.

\section{Liquid Media}

Several methods using liquid media have been proposed for testing the antagonistic activities of microorganisms:

Simultaneous inoculation of the medium with the antagonist and the test organism.

Inoculation of the medium with the antagonist first, followed after 6 to 48 hours by inoculation with the test organism.

Inoculation of the medium with the test organism first, followed, after a certain interval, by the antagonist.

Effect of the metabolic products of the antagonist upon various microorganisms. In I888, Freudenreich (298) first filtered the culture through a Chamberland candle and inoculated the filtrate with the test organisms. The culture filtrate is usually added to the fresh medium, either previously inoculated with the test organism for the purpose of establishing the lytic effect of the filtrate, or followed by the test organism, whereby the bacteriostatic action is measured.

Placing a porcelain filter or cellophane membrane between the cultures of the antagonist and of the test organism. Frankland and Ward (295) used a filter of the Pasteur-Chamberland type partly filled with broth and placed in a beaker containing the same kind of broth; the antagonist and test organism were inoculated into the two lots of broth, and the effect of each upon the growth of the other was determined. Frost (303) emphasized, however, that, although theoretically this is an ideal method, it is open to criticism since motile bacteria are usually able to grow through the filter after a certain lapse of time.

Collodion sac method. Collodion sacs, prepared by means of test tubes from which the bottoms have been cut out, are partly filled with 
broth and placed in a flask containing the same kind of broth. The test organism is inoculated into the medium inside the sac, and the antagonist into the flask $(3 \circ 3)$.

\section{Solid Media}

Solid media have also been used extensively for testing the action of antagonists. These media offer certain advantages over liquid media. The following methods are most commonly used:

Simultaneous inoculation of antagonist and test organism. This method, introduced by Garré (315) in 1887, consists in streaking the antagonist and the test organism on the surface of a solidified agar or gelatin medium. The streaks are alternate and may be parallel, radiating from a common center, or intersecting at right angles (Figure 4). If the active substance produced by the antagonist does not diffuse for any considerable distance into the medium, the method is not satisfactory. Frost (303) modified this method by inoculating the whole medium with the test organism and, when the medium had hardened, streaking the antagonist across the surface. The first of these came to be known as the anaxogramic method; the second is often spoken of as the implantation method. The spotting of the two organisms on the plate is illustrated in Figure 5.

Successive inoculation of the test organism, after the antagonist has already made some growth, so as to enable the active substance to diffuse.

Double plate methods ( 303 ). A Petri dish is divided into two parts by means of a small glass tube or rod. After sterilization, one tube of molten agar is heavily inoculated with the antagonist and poured into one half of the plate. When the agar has hardened, another tube of sterile agar is poured into the other half of the plate. Both sides are then streaked with the test organism, each side being equally inoculated by separate streaking. This can be done by using a loop bent at nearly right angles; the charged loop is moved from the circumference toward the glass rod. The loop is then sterilized, recharged with the test culture, and the streak continued on the other side of the plate. The inoculation with the test organism may be made soon after the plate is poured, or the antagonist may be given an opportunity to develop before the test organism is streaked thus making the 


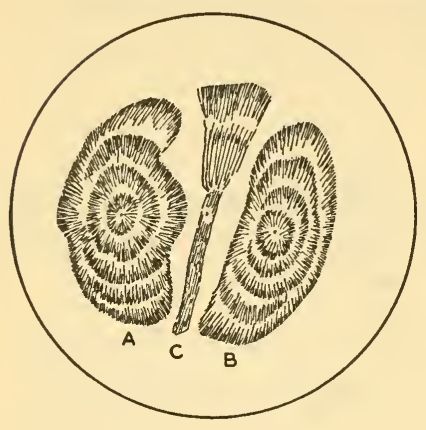

Helminthosporium (A and B) inhibited by Fusarium (C)

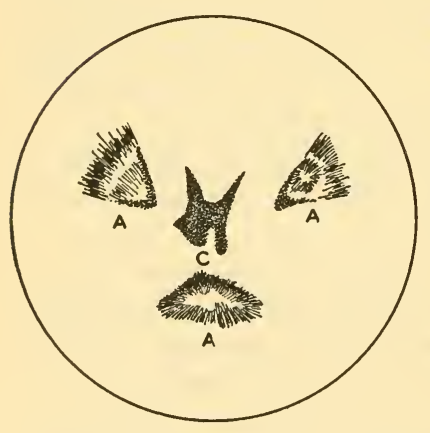

Helminthosporium (A) inhibited by a bacterium (C)

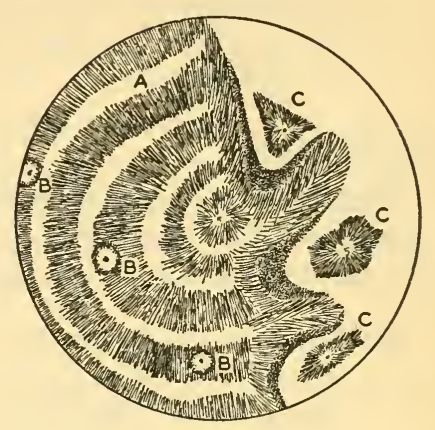

Pestalozzia (A) inhibited by one species of Penicillium (C) but not by another (B)

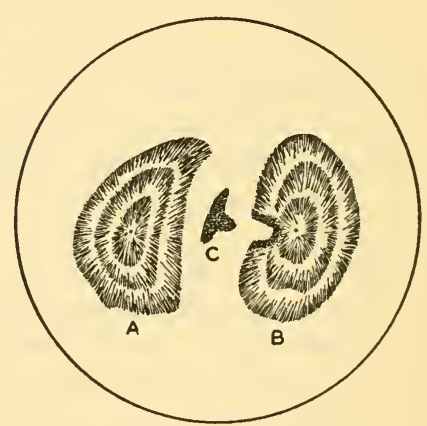

Helminthosporium (A and B) inhibited by a white yeast (C)

FIgURe 5. Inhibition of fungus development by antagonists. From Porter (729). 
antagonistic effect more striking. This method has also been used

(258) for testing the antibiotic properties of fungus cultures.

Mixed culture inoculation. The cultures of the antagonist and the test organism are mixed and inoculated upon the surface of the solidified agar or before the molten agar has been added to the plate. The colonies of the antagonist will be surrounded by clear sterile zones, free from any growth of the test organism.

Spot inoculation of the antagonist upon an actively growing culture of a bacterium or fungus on an agar plate. This method is particularly convenient for detecting antagonists that possess lytic properties.

A layer of molten sterile agar is used to cover the surface of an antagonist that has made some growth in a plate, and the surface of the agar layer is then inoculated with the test organism. The active substance produced by the antagonist will diffuse through the agar and reduce the growth of the test bacterium (609).

Semisolid media are used for testing the action of antagonists upon the motility of bacteria ( 182 ).

A number of other methods, usually modifications of those outlined above, have been used for testing the ability of fungi to produce antibiotic substances (724, 1016). Some of these methods, notably the agar diffusion (cup, paper disc, cylinder) test, are used for the quantitative estimation of the concentration of the antibiotic in the medium and for isolation purposes. These methods can indicate the formation not only of growth-inhibiting but also of growth-promoting substances (99).

Raper et al. (765) removed plugs of agar of constant dimensions from the fungus cultures being tested and placed them on the surface of plates seeded with $S$. aureus. The plates were incubated at $37^{\circ} \mathrm{C}$., and the amount of penicillin present was estimated by the size of the zones of inhibition. For the purpose of screening many cultures, a modified Czapek's solution agar, I per cent by volume of corn steep liquor ( 55 per cent solids) was used; the solution was adjusted to $p \mathrm{H}$ 7.0 , and 2 per cent agar was added. Twenty-milliliter portions were placed in tubes, sterilized, and poured into sterile Petri dishes. The plates were selected to insure that the agar layers were of uniform depth. Single colonies were established by suspending spores of the culture to be tested in melted agar at $45^{\circ} \mathrm{C}$. The agar was allowed to so- 
lidify and small amounts were placed with an inoculating needle in the centers of the agar plates. The plates were incubated at $24^{\circ} \mathrm{C}$. for 6 days; then 4 or 5 plugs were removed radially from the agar, the first being adjacent to the colony margin, and tested as described above (838).

Various other methods have been proposed for measuring the rate of production or secretion of antibiotic substances by fungi $(726,963)$.

\section{METHODS OF GROWING ANTAGONISTIC ORGANISMS FOR THE PRODUCTION OF ANTIBIOTIC SUBSTANCES}

Once the antagonistic action of any organism has been established, the next step is to determine the nature of the substance produced and to measure quantitatively its antibiotic action. Before this can be done, however, the organism must be grown upon suitable media under conditions favorable for the maximum production of the antibiotic substance.

The media used for the production of antibiotics can be classified into two groups: synthetic and complex organic media. The first contain a source of carbon, usually glucose, sucrose, or starch ( 2 to 6 per cent); a source of nitrogen, usually nitrate or ammonia sulfate ( 0.2 to 0.6 per cent) ; several salts, namely, $\mathrm{K}_{2} \mathrm{HPO}_{4}$ or $\mathrm{KH}_{2} \mathrm{PO}_{4}$ (O.I to 0.2 percent), $\mathrm{MgSO}_{4} \cdot 7 \mathrm{H}_{2} \mathrm{O}$ (0.05 per cent), $\mathrm{KCl}$ (0.05 per cent), and $\mathrm{FeSO}_{4} \cdot 7 \mathrm{H}_{2} \mathrm{O}$ (o.ooI per cent). Certain supplementary materials such as yeast extract, meat extract, or corn steep, or trace elements such as $\mathrm{ZnSO}_{4}$, $\mathrm{MnSO}_{4}$, or $\mathrm{CuSO}_{4}$ ( I to 2 ppm.) may also be added. The organic media contain a complex form of nitrogen, such as tryptone, peptone, casein digest; either no other source of carbon is used or a carbohydrate is added in the form of lactose, glucose, dextrin, starch, brown sugar, molasses, or similar products as well as several salts similar to those listed above. Some media are supplemented with $\mathrm{CaCO}_{3}$, others are not, depending upon the extent of acidity produced by the organism.

The medium may be solid (agar or bran) or liquid, the latter being the more common. Several types of culture vessels are used, depending on the condition of aeration. Since so far as is known all the micro- 
organisms capable of producing antibiotic substances are aerobic, either shallow layers of medium ( $\mathrm{I} .5$ to $2 \mathrm{~cm}$. in depth) are placed in stationary vessels (flasks or trays), or shaken cultures are used. In the case of deep vessels or tanks, the medium is properly stirred and aerated by forced draft with sterilized and filtered air.

The optimum temperature required for the growth of the antagonistic organisms and the production of antibiotic substances ranges between $20^{\circ}$ and $30^{\circ} \mathrm{C}$. The length of incubation varies from 2 to 6 days for submerged cultures and from 3 to 20 days for stationary cultures.

A knowledge of the preliminary treatment of the inoculum or spore material is essential. For the growth of spore-forming bacteria, the use of a pasteurized spore suspension is advisable in order to avoid the variable factor due to vegetative cells. Actinomycetes and fungi are grown on agar slants in order to obtain abundant spore material for the inoculation of stationary cultures. For submerged cultures, special spore suspensions are produced by growing the organisms in shaken cultures.

The cultures must be tested carefully in order to establish the optimum activity when the culture filtrate is cooled and extraction of active substance is started.

\section{Tyrothricin}

For the production of tyrothricin, shallow layers of medium are used most frequently. The media contain complex sources of nitrogen, such as tryptone, casein hydrolysate, soybean meal digest, and pressed juice of waste asparagus. Simple substances, such as glutamic acid, asparagine, ammonium salt, plucid citric or malic acid, are also effective in presence of 0.2 per cent tryptone. Glucose, mannitol, or glycerol (3 to 5 per cent) can be used as the source of carbon, and calcium, magnesium, and manganese as required mineral. Maximum yields of more than $2 \mathrm{gm}$. per liter are obtained in Io to I 6 days' incubation at $35^{\circ} \mathrm{C}$. (564).

\section{Penicillin}

For the production of penicillin, the composition of the medium is highly important. At first a simple glucose-nitrate solution known as Czapek-Dox medium was used. It was later found that when yeast ex- 
tract or corn steep liquor was added and brown sugar was used in place of glucose, the growth of the organism and the production of penicillin were greatly facilitated $(5,28 \mathrm{I})$. The ratio of $\mathrm{C}$ and $\mathrm{N}$ sources is significant. It has been shown, for example, that penicillin is produced in organic media when the ratio sucrose-peptone is less than I.O, and in inorganic media when sugar- $\mathrm{NaNO}_{3}$ ratio is I.O or I0.0 (59I).

The following was found $(838)$ to be a suitable medium for maximum production of penicillin:

$\begin{array}{lr}\text { Lactose } & 40.00 \mathrm{gm} . \\ \mathrm{NaNO}_{3} & 3.00 \mathrm{gm} . \\ \mathrm{MgSO}_{4} \cdot 7 \mathrm{H}_{2} \mathrm{O} & 0.25 \mathrm{gm} . \\ \mathrm{KH}_{2} \mathrm{PO}_{4} & 0.50 \mathrm{gm} . \\ \mathrm{ZnSO}_{3} & 0.0 \mathrm{Im} . \\ \text { Corn steep liquor } & 90 \quad \mathrm{ml} . \\ \text { Distilled water to make } & \text { I000 } \mathrm{ml} .\end{array}$

This medium has been variously modified, as by reducing the lactose to $20 \mathrm{mg}$. per liter and the corn steep to $40 \mathrm{ml}$. or by using in its place $25 \mathrm{mg}$. of dried steep liquor solids (764).

The need for a specific penicillin-promoting substance, such as might be found in corn steep or in other plant extracts (555), in order to increase appreciably the yield of the antibiotic agent is of particular interest. Certain amino acids, namely, arginine, histidine, and glutamic acid, in concentrations of $0.3,0.3$, and $0.4 \mathrm{gm}$. per liter, respectively, appear to provide a large part of this stimulating effect (I004). A proper balance of the concentration of the ions $\mathrm{PO} \overline{\overline{4}}, \mathrm{SO}_{\overline{4}}, \mathrm{NO}_{\overline{3}}$, and $\mathrm{Mg}++$ is also essential. The proportions of the essential three salts in optimum solution were found (733) to be $\mathrm{KH}_{2} \mathrm{PO}_{4}-0.475$, $\mathrm{MgSO}_{4} \cdot 7 \mathrm{H}_{2} \mathrm{O}-0.05$, and $\mathrm{NaNO}_{3}-0.475$; different strains show marked differences in their response to a change in balance of these three salts.

This led to the development of different synthetic media, such as the following (735); the amounts are given on a liter basis:

$\begin{array}{lrl}\text { Starch } & 5.0 & \mathrm{gm} . \\ \text { Lactose } & 25.0 & \mathrm{gm} . \\ \text { Glucose, crude } & 5.0 & \mathrm{gm} .\end{array}$




$\begin{array}{lll}\text { Glacial acetic acid } & 6.0 & \mathrm{gm} . \\ \mathrm{Na}_{2} \mathrm{HPO}_{4} & \text { I.6 } & \mathrm{gm} . \\ \mathrm{K}_{2} \mathrm{PO}_{4} & 2.0 & \mathrm{gm} . \\ \mathrm{NH}_{4} \mathrm{NO}_{3} & 4.0 & \mathrm{gm} . \\ \left(\mathrm{NH}_{4}\right)_{2} \mathrm{SO}_{3} & \text { I.0 } & \mathrm{gm} . \\ \mathrm{KNO}_{3} & \text { I.O } & \mathrm{gm} . \\ \mathrm{MgSO}_{4} \cdot 7 \mathrm{H}_{2} \mathrm{O} & 0.25 & \mathrm{gm} . \\ \mathrm{FeSO}_{4} \cdot 7 \mathrm{H}_{2} \mathrm{O} & 0.2 & \mathrm{gm} . \\ \mathrm{MnSO}_{4} \cdot 7 \mathrm{H}_{2} \mathrm{O} & 0.04 & \mathrm{gm} . \\ \mathrm{CuSO}_{4} \cdot 5 \mathrm{H}_{2} \mathrm{O} & 0.005 \mathrm{gm} . \\ \mathrm{Cr}\left(\text { as } \mathrm{K}_{2} \mathrm{Cr}_{2} \mathrm{O}_{7}\right) & 3 & \mu \mathrm{g}\end{array}$

Phenylacetic acid and its derivatives have a marked effect upon penicillin yields; frequently amide derivatives are just as effective as the corresponding acids (887).

With the introduction of the submerged process for the production of penicillin, it became necessary to find a simple means of obtaining large numbers of spores. For this purpose, a medium high in calcium salt appears to be essential (282). Such a medium is as follows:

$\begin{array}{lr}\text { Sucrose or brown sugar } & 20.0 \mathrm{gm} . \\ \mathrm{NaNO}_{3} & 6.0 \mathrm{gm} . \\ \mathrm{KH}_{2} \mathrm{PO}_{4} & \mathrm{I} .6 \mathrm{gm} . \\ \mathrm{MgSO}_{4} \cdot 7 \mathrm{H}_{2} \mathrm{O} & 0.5 \mathrm{gm} . \\ \mathrm{CaCl}_{2} & 25.0 \mathrm{gm} .\end{array}$

Tap or distilled water to make $1000 \mathrm{ml}$.

The culture is grown for 4 to 6 days with continuous aeration and agitation.

Various other methods are used for spore production, for the purpose of inoculating large batches of medium. For surface growth, dry spores are mixed with a floating and spreading agent, such as whole wheat flour.

Other media, such as bran ( 762$)$, have been utilized to a limited extent for the production of penicillin. However, the submerged process, accompanied by agitation and aeration, using one of the above liquid media has now come into general use for large-scale production of penicillin. 


\section{Streptothricin and Streptomycin}

For the production of streptothricin, a tryptone medium with starch or glucose is used. A typical medium is given here:

$\begin{array}{ll}\text { Glucose or starch } & \text { I0.00 gm. } \\ \text { Tryptone } & 5.00 \mathrm{gm} . \\ \mathrm{K}_{2} \mathrm{HPO}_{4} & 2.00 \mathrm{gm} . \\ \mathrm{NaCl} & 2.00 \mathrm{gm} . \\ \mathrm{FeSO}_{4} & 0.0 \mathrm{Im} . \\ \text { Tap water to make } & \text { I000 ml. }\end{array}$

For stationary cultures, 0.25 per cent agar may be added.

For streptomycin, certain specific organic precursors are required. The precursors are present in meat extract, in corn steep, and in the cells of certain microorganisms such as yeasts and actinomycetes. A typical medium, on a liter basis, consists of:

$\begin{array}{lr}\text { Glucose } & \text { IO.0 gm. } \\ \text { Peptone } & 5.0 \mathrm{gm} . \\ \text { Meat extract } & 5.0 \mathrm{gm} . \\ \mathrm{NaCl} & 5.0 \mathrm{gm} . \\ \text { Final } \mathrm{pH} & 6.5 \text { to } 7.0 \\ \text { Tap water to make } & \text { I000 } \mathrm{ml} .\end{array}$

For spore production, a simple synthetic medium may be used, such as glucose-asparagine agar, consisting of:

$\begin{array}{lr}\text { Glucose } & \text { I0.0 gm. } \\ \text { Asparagine } & 0.5 \mathrm{gm} . \\ \mathrm{K}_{2} \mathrm{HPO}_{4} & 0.5 \mathrm{gm} . \\ \text { Agar } & \text { I } 5.0 \mathrm{gm} . \\ \text { Distilled water to make } & \text { I } 000 \mathrm{ml} .\end{array}$

A synthetic medium has also been suggested (905a) for streptomycin production, consisting of:

Glucose

$7 \cdot 4 \mathrm{gm}$.

Ammonium lactate

$5.4 \mathrm{gm}$.

$\mathrm{KH}_{2} \mathrm{PO}_{4}$

$2.38 \mathrm{gm}$. 


$\begin{array}{ll}\mathrm{K}_{2} \mathrm{HPO}_{4} & 5.65 \mathrm{gm} . \\ \mathrm{MgSO}_{4} \cdot 7 \mathrm{H}_{2} \mathrm{O} & 0.98 \mathrm{gm} . \\ \mathrm{ZnSO}_{4} \cdot 7 \mathrm{H}_{2} \mathrm{O} & 0.0 \text { I I } 5 \mathrm{gm} . \\ \mathrm{FeSO}_{4} \cdot 7 \mathrm{H}_{2} \mathrm{O} & 0.0 \text { I I I gm. } \\ \mathrm{CuSO}_{4} \cdot 5 \mathrm{H}_{2} \mathrm{O} & 0.0064 \mathrm{gm} . \\ \mathrm{MnCl}_{2} \cdot 4 \mathrm{H}_{2} \mathrm{O} & 0.0079 \mathrm{gm} . \\ \text { Distilled water to make } & 1000 \mathrm{ml} . \\ p \mathrm{H} & 6.95\end{array}$

METHODS OF MEASURING THE ACTIVITY OF ANTIBIOTIC SUBSTANCES

It has long been recognized that the evaluation of bacteriostatic and bactericidal substances is controlled to a considerable extent by the methods employed. These methods are based upon the following factors: (a) proper selection of the test organism, (b) composition of the medium used for testing activity, (c) time of action, (d) conditions of carrying out the test, and (e) nature of the active substance. The results obtained in a comparison of substances containing the same active principle may not be very reliable when different agents are compared, since these vary greatly in their specific action upon different bacteria. This is especially true of antibiotics.

In most of the work on chemical disinfectants, which are primarily bactericidal agents, the death rate of the viable cells has been used as a basis for evaluation. Different substances have been compared with a standard, ordinarily phenol. Since antibiotic and chemotherapeutic substances are primarily bacteriostatic in action, the inhibition of the growth and multiplication of the test organism is commonly used as a basis for their evaluation.

In any attempt to select a single standard method for measuring quantitatively the activity or potency of an antibiotic substance, it is essential to recognize several pertinent facts, which may be briefly summarized as follows:

Antibiotic (antibacterial, antimicrobial) substances are primarily bacteriostatic (or fungistatic) in their action; some substances are also markedly bactericidal (or fungicidal). 
Antibiotic substances are selective in their action; they are able to inhibit the growth of some bacteria in very low concentrations, whereas much larger amounts are required to affect other bacteria and some organisms may not be inhibited at all by the particular substance even in very high concentrations.

Conditions for the bacteriostatic activity of different antibiotic substances vary greatly. Some substances are not active at all, or their activity is greatly reduced in some media because of the neutralizing effect of certain constituents of the media, such as peptone, $p$-amino-benzoic acid, or glucose. Other agents require the presence in the medium of specific constituents for their activity to become effective. The activity of some is reduced at an acid reaction, whereas that of others is not affected.

The mechanism of the action of different antibiotic agents is different. Some agents interfere with bacterial cell division, others with bacterial respiration, and still others with utilization by the bacteria of essential metabolites.

Many antagonistic organisms produce more than one antibiotic substance. Ps. aeruginosa produces pyocyanase and pyocyanin; $B$. brevis, gramicidin and tyrocidine; $P$. notatum, penicillin and notatin; $A$. fumigatus, spinulosin, fumigatin, fumigacin, and gliotoxin; $A$. flavus, aspergillic acid and penicillin. The culture filtrate of an antagonistic organism often differs, therefore, in its activity from that of the isolated active substance.

The course of production of antibiotic substances by two typical antagonistic organisms is illustrated in Figures 6 and 7 .

In view of the bacteriostatic nature of antibiotic substances, few of the methods commonly used for testing the efficiency of antiseptics and germicides can be employed. This is particularly true of the "phenol coefficient test," which measures the germicidal action of phenol upon E. typhosa. The limitations of this method, based on the bactericidal action of a single substance on a single organism, even as applied to chemical antiseptics have long been recognized (810).

A number of methods have been developed for determining the activity of antibiotic substances. They vary greatly, each having its limitations and advantages. Because of lack of uniformity in the methods, the results obtained by one are not always comparable with those obtained 
Sa3117וาרIN 001 d3d sw6
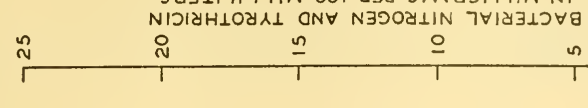

ㅇ.

$\underline{n}$

$\stackrel{1}{1}$

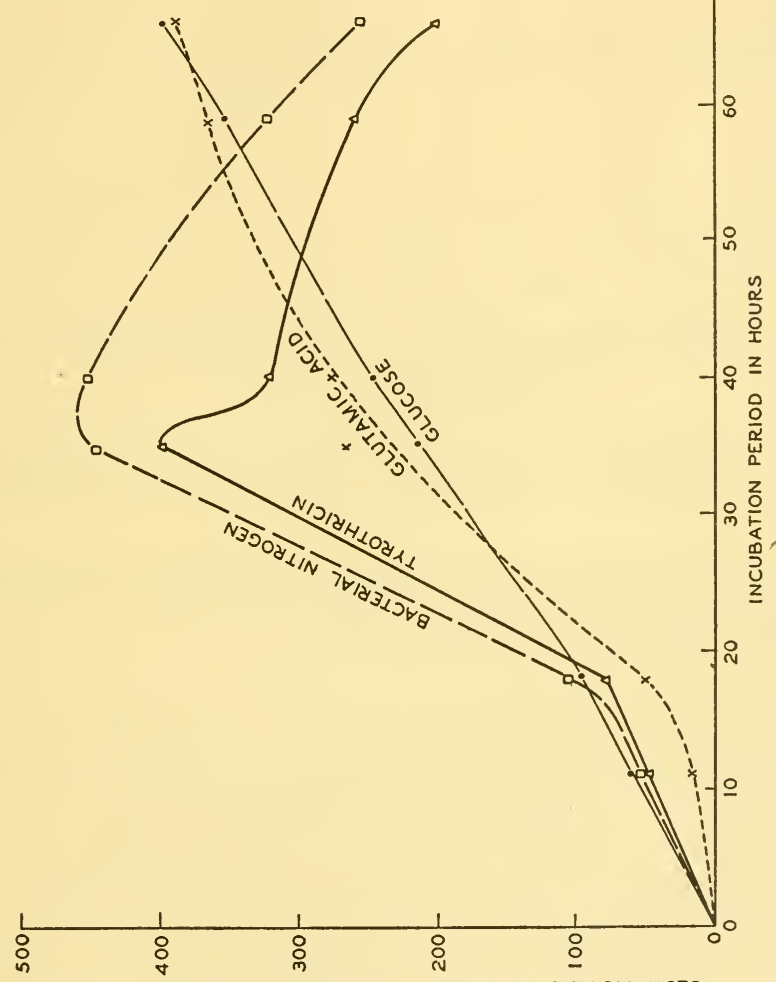

Sม31

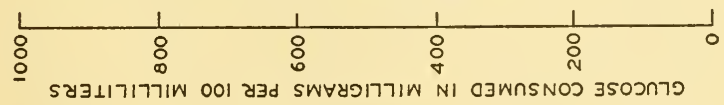




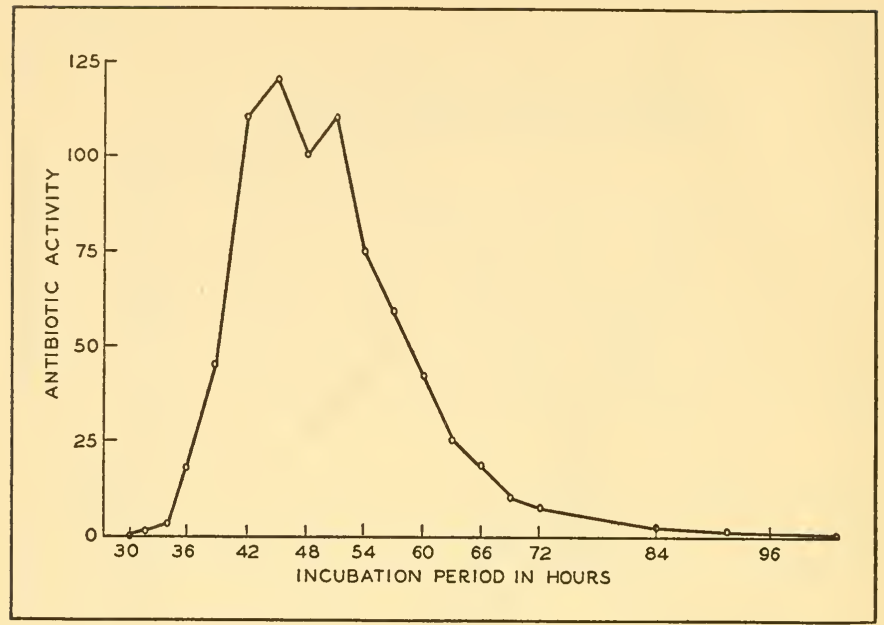

Figure 7. Production of gliotoxin by Trichoderma. From Weindling (989).

by another. The most important methods at present in use are briefly summarized in the following pages (583).

\section{Agar Streak-Dilution Method}

If an unknown antibiotic substance is tested, it is essential to employ several test organisms in order to throw light upon the selective activity of the substance on different bacteria, and thus to determine the antibiotic spectrum characteristic of each substance. Nutrient agar media have usually been employed. Sterility is not absolutely essential for this method, although it is desirable. The unknown substance is diluted to various concentrations ( $\mathrm{I}, \mathrm{0} .3, \mathrm{O} . \mathrm{I}$, etc.; or $\mathrm{I}, 0.5,0.25$, etc.) ; these dilutions are added and thoroughly mixed with definite volumes ( $10 \mathrm{ml}$.) of sterile agar medium, melted and cooled to $42^{\circ}$ to $45^{\circ} \mathrm{C}$. The agar is allowed to solidify, and is streaked with three or four test bacteria, among the most common of which are $E$. coli, B. mycoides, $B$. subtilis, $S$. aureus, $M$. lysodeikticus, $S$. lutea, $M$. phlei, as well as various other bacteria and fungi. The age of the cultures ( 6 to 
24 hours) is important. The plates are incubated at $28^{\circ}$ or $37^{\circ} \mathrm{C}$. for I 6 to 24 hours, and readings are made. The highest dilution at which the test organism fails to grow is taken as the end point. Activity is expressed in units, using the ratio between the volume of the medium and the end point of growth or the dilution at which growth is inhibited (964).

The bacteriostatic and fungistatic activity of several antibiotic substances is shown in Table 7 .

\section{Serial Dilution Method}

Once a substance is characterized as regards its selective action upon specific bacteria, its activity or concentration can be measured more accurately by the liquid dilution or titration method. One test organism is selected, usually a strain of $S$. aureus. Different strains may vary in their action. Definite volumes of the test medium are placed in test tubes and sterilized (sterility is essential in this method), and various dilutions of the active substance are added. The dilutions can range in order of $3: I$, $2: I$, or even narrower, namely in series of $1.2: I, I .5: I$, etc. The tubes are inoculated with the test organism and incubated for 16 to 24 hours. In some cases the medium is inoculated before it is distributed into the tubes. The highest dilution of the antibiotic giving complete inhibition of growth, as expressed by a lack of turbidity of medium, is taken as the end point. Activity is expressed in units as above.

The dilution method has several disadvantages: every assay takes much time; during chemical fractionation, the substance may become contaminated with bacteria not sensitive to the active substances; only one organism can be used in a single series of tests.

One modification of the method has been adapted for measuring the activity of penicillin. Several dilutions of the active agent are prepared and $0.5 \mathrm{ml}$. portions added to $4.5 \mathrm{~cm}$. quantities of liquid medium in test tubes. These are inoculated with a standard drop $(0.04 \mathrm{ml}$.) of a 24-hour culture of the test organisms. Complete or partial inhibition is shown by the absence of turbidity after 24 hours of incubation at $37^{\circ} \mathrm{C}$. Dilutions higher than those required for complete or partial inhibition gave, after 24 hours of incubation, only a retarding effect $(I, 5)$; a microscopic examination ( $3 \mathrm{II}$ ) indicated defective fission of the bacteria, 


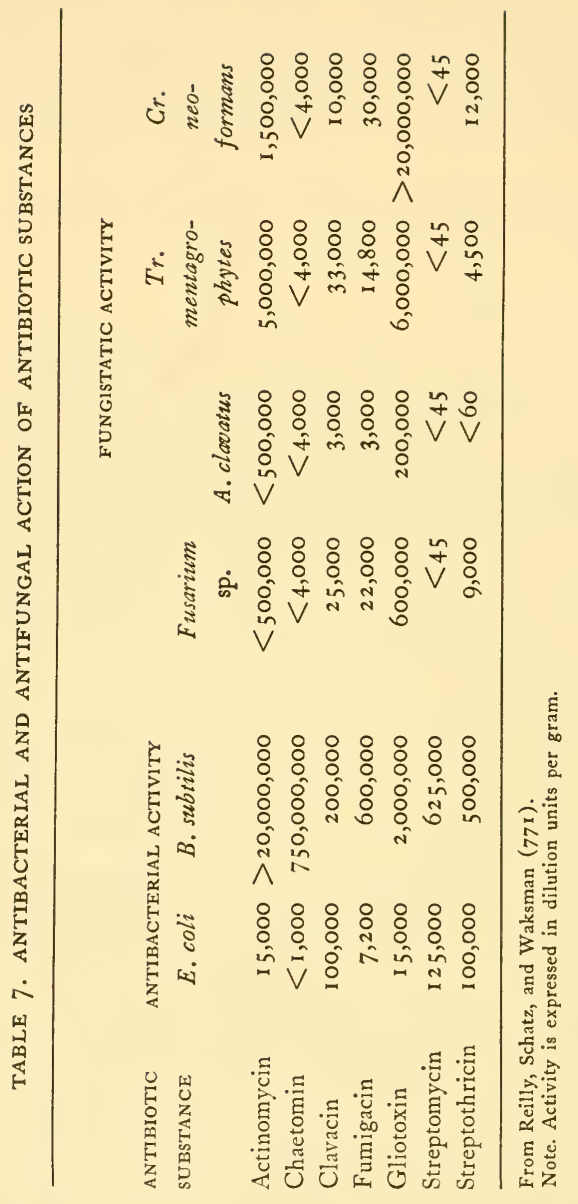


even though the macroscopic appearance of the culture did not show any inhibition. Pneumococci and $S$. viridans show marked strain differences by this method. In one experiment with Salmonella typhi, partial inhibition was obtained in a dilution of 1 : 10,000; however, elongation of the cells was detected in a dilution of $\mathrm{r}: 60,000$, a concentration which was considered as a therapeutic possibility (Table 8 ).

The other modifications of this method either use different test cultures, such as $B$. subtilis (285), or have been developed to meet the requirements of the clinician when only small amounts of blood or other body fluids are available, in which case a very sensitive strain of $S$. hemolyticus is used (75 I). The use of Klebsiella pneumoniae for assaying streptothrycin and streptomycin permits the determination of as little as $0.05 \mu \mathrm{g} / \mathrm{ml}$., giving somewhat more rapid and more accurate results (I9I).

Agar Diffusion (Cup, Paper Disc, Cylinder) Method (5, I 73, 283, $285,390)$

This method, first employed for measuring antiseptics qualitatively (8I0), was later developed for quantitative use. A suitable agar medium is inoculated with a test organism ( $S$. aureus or B. subtilis), the active agent being placed upon the agar within a groove or in a special small glass cup with an open bottom from which the substance diffuses into the medium. The rate of diffusion of the antibiotic is parallel to its concentration. Potency can be calculated by measuring the zone of inhibition and comparing it with that of a known standard preparation. Various modifications of this method have recently been introduced $(286,937)$. This method has the advantage of simplicity and convenience, since it does not require sterile material and several preparations or duplicates can be tested on the same plate. The method also possesses certain disadvantages, however, since it cannot be used for comparing different substances but is limited to the measurement of activity of only one type of substance; it cannot be used for the study of unknowns until a standard has been established for each; it cannot be used for substances that are not water soluble.

Nutrient agar containing $5 \mathrm{gm} . \mathrm{NaCl}, 3 \mathrm{gm}$. meat extract, $5 \mathrm{gm}$. 
TABLE 8. BACTERIOSTATIC SPECTRUM OF PENICILLIN

\section{ORGANISM AFFECTED}

N. gonorrhoeae*

$N$. meningitidis

$S$. aureus

S. pyogenes

$B$. anthracis

A. bovis

Cl. tetanit

Cl. welchii

Cl. septicum

Cl. oedematiens

S. viridanst

Pneumococcust

C. diphtheriae (mitis)

C. diphtheriae (gravis)

S. gärtneri

S. typhi

Pneumococcust!

Anaerobic streptococcus $\ddagger$

$P$. vulgaris

S. viridanst

$P$. pestis

S. typhimurium

S. paratyphi $B$

Sh. dysenteriae

$\mathrm{Br}$. abortus

$\mathrm{Br}$. melitensis

Anaerobic streptococcus

V. comma

E. coli

$K$. pneumoniae

Ps. aeruginosa

$M$. tuberculosis

L. icterohaemorrhagiae
DILUTIONS AT WHICH INHIBITORY

EFFECTS WERE OBSERVED

Complete

Partial

None

2,000,000

$>2,000,000$

$>2,000,000$

I, $, 000,000$

2,000,000

I, $, 000,000$

2,000,000

4,000,000

4,000,000

I, $, 000,000$

2,000,000

I, 000,000

2,000,000

4,000,000

I, $, 000,000$

I,000,000

I, 500,000

300,000

300,000

625,000

250,000

I 25,000

32,000

20,000

I 0,000

9,000

4,000

2,000,000

$4,000,000$

4,000,000
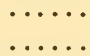

I, 500,000

7,500,000

......

I, 500,000

3, I 2 5,000

500,000

I,000,000

625,000

64,000

I 28,000

40,000

80,000

30,000

90,000

......

27,000

8,000

I 6,000

32,000

60,000

8,000

I 6,000

4,000

I, 000

$<\mathrm{I}, \mathrm{OOO}$

100,000

8,000

500,000

I 6,000

5,000

10,000

4,000

8,000

4,000

8,000

2,500

I 0,000

$<4,000$

4,000

I,, 00

2,000

$<\mathrm{I}, \mathrm{OOO}$

I,, 000

$<\mathrm{I}, \mathrm{OOO}$

I, 000

$<\mathrm{I}, \mathrm{OOO}$

1,000

$<\mathrm{I}, \mathrm{OOO}$

I, 000

$<3,600$

3,600

From Abraham et al. (5). Crude penicillin preparation was used.

* Another strain was inhibited only up to 32,000 .

† Grown in Lemco broth; in beef broth complete inhibition reached only 100,000.

+. In Pneumococcus, S. viridans, and anaerobic streptococci, different strains appear at different levels in the table. 
peptone, I 5 gm. agar, I,000 $\mathrm{ml}$. tap water, and adjusted to $\mathrm{pH} 6.8$, is poured into plates to a depth of 3 to $5 \mathrm{~mm}$. The plates are seeded thoroughly with the test organism ( $S$. aureus) by flooding with I: Io or I : 50 dilution of I 6-to-24-hour-old broth culture in sterile water. The excess fluid may be removed with a pipette. The surface of the agar is allowed to dry somewhat in the $37^{\circ} \mathrm{C}$. incubator for I to 2 hours, the lids of the plates being raised about $\mathrm{I} \mathrm{cm}$. above the bottoms of the dishes. Sterile short glass cylinders ( $5 \mathrm{~mm}$. inside diameter) are placed on the agar, the lower edge of the cylinder sinking into the agar, and are filled with the test solution. Several cylinders may be placed in one dish.

For measuring the activity of penicillin, the plates are incubated for I 2 to 16 hours at $37^{\circ} \mathrm{C}$. The diameter of the clear zone around the cylinder is measured with pointed dividers to the nearest $0.5 \mathrm{~mm}$. The relation of concentration of penicillin in the solution to the zone of inhibition, or the "assay value," is expressed by a curve which is obtained with standard solutions. This curve tends to flatten out above 2 units of penicillin per milliliter. The assay value is not influenced by the $p H$ of the test material, thickness of the agar, or sterility of the material.

The Oxford unit (O.U.), as determined by this method, is the amount of penicillin that will just inhibit completely the growth of the test strain of $S$. aureus in $50 \mathrm{ml}$. of medium. Thus, a preparation containing one unit of penicillin per milligram of material just inhibits the growth of the test organism in a dilution of $1: 50,000$.

An international standard for penicillin, based upon crystalline material, has been adopted.

In one of the modifications of the agar diffusion method, a spore suspension of $B$. subtilis is used as the test organism. It is grown for several days under forced aeration, and the cultures are pasteurized in order to destroy the vegetative cells. The spore suspension is stored in the cold and used as the stock inoculum; it is titrated in order to determine the optimum amount for seeding purposes. The lowest level (usually O.I to $0.2 \mathrm{ml}$. per Ioo milliliters of agar) that gives a dense, continuous growth of the organism under the assay conditions is selected as the optimum.

It has been reported (839) that when $B$. subtilis changes from the 
smooth to the rough phase there is a marked increase in resistance to certain penicillins but not to others. This has a bearing upon a knowledge of the chemical entities present in the penicillin preparations.

This method is also very convenient for measuring the activity of streptothricin and streptomycin. A standard curve is obtained by filling the cups in quadruplicate with dilutions of the standard containing ro, $20,40,60,80$, and $100 \mu \mathrm{g} / \mathrm{ml}$. The dilution of the unknown contains about $50 \mu \mathrm{g} / \mathrm{ml}$. After overnight incubation at $30^{\circ} \mathrm{C}$., the inhibition zones around the cups are measured and plotted to give a standard curve. The concentrations of the unknowns are read off this curve by projecting the value of the inhibition zones.

A standard streptomycin agar was developed (582) consisting of $6 \mathrm{gm}$. peptone, $\mathrm{r} .5 \mathrm{gm}$. beef extract, $3.0 \mathrm{gm}$. yeast extract, $15.0 \mathrm{gm}$. agar, $\mathrm{I}, 000 \mathrm{ml}$. distilled water, $p \mathrm{H}$ after sterilization $7.9 \pm 0 . \mathrm{I}$. The test strain $B$. subtilis is grown on agar or in submerged liquid medium. The cells are suspended in sterile $0.5 \mathrm{M}$ potassium phosphate buffer, $p \mathrm{H} 7.0$, and pasteurized to kill the vegetative cells. The spore suspension is counted by plating and is stored at $2^{\circ}$ to $4^{\circ} \mathrm{C}$. Twenty-milliliter portions of sterile agar are first poured into the plates; the agar is allowed to harden and is then covered with $4 \mathrm{ml}$. of the seeded agar containing about 250,000 spores per $\mathrm{ml}$. of agar. The plates may be stored at $2^{\circ}$ to $4^{\circ} \mathrm{C}$. for several days. The test sample is diluted with equal volume of $0.2 \mathrm{M}$ potassium phosphate buffer, $p \mathrm{H} 7.9$, and all subsequent dilutions are made with $0.1 \mathrm{M}$ buffers. Either paper discs or cups may be used, 4 to 6 per plate; in the case of discs $0.08 \mathrm{ml}$. of sample is added rapidly to each disc after it has been placed on the agar. A standard is used on each plate. The plates are incubated at $30^{\circ} \mathrm{C}$. for 15 to 30 hours. At $37^{\circ} \mathrm{C}$. the zones develop after 4 to 6 hours' incubation. A typical curve is shown in Figure 8.

\section{Turbidimetric Method}

End-point methods have long been recognized as having many limitations. Since it is difficult to determine accurately the end point and since it takes a relatively much larger amount of an antibiotic substance to inhibit completely the growth of the test organism as compared with only 50 or 99 per cent inhibition, the suggestion has been made that 


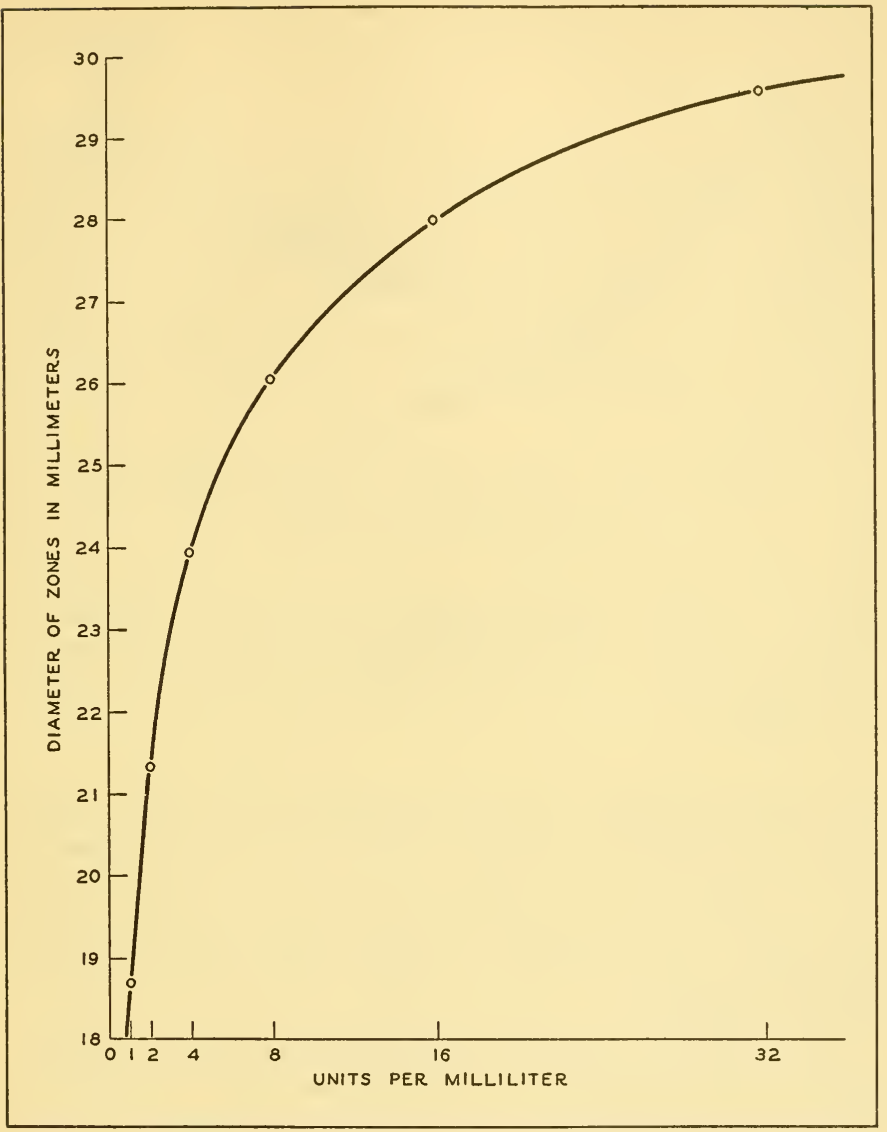

FIGURE 8. Daily standard curve of streptomycin on streptomycin assay agar, incubation $30^{\circ} \mathrm{C}$. From Loo et al. $(582)$.

partial inhibition of growth be measured and, from this, the concentration of the active substance be calculated in a manner similar to the measurement of the potency of bactericidal agents. Partial inhibition can be determined by plating for the number of viable bacteria, as com- 


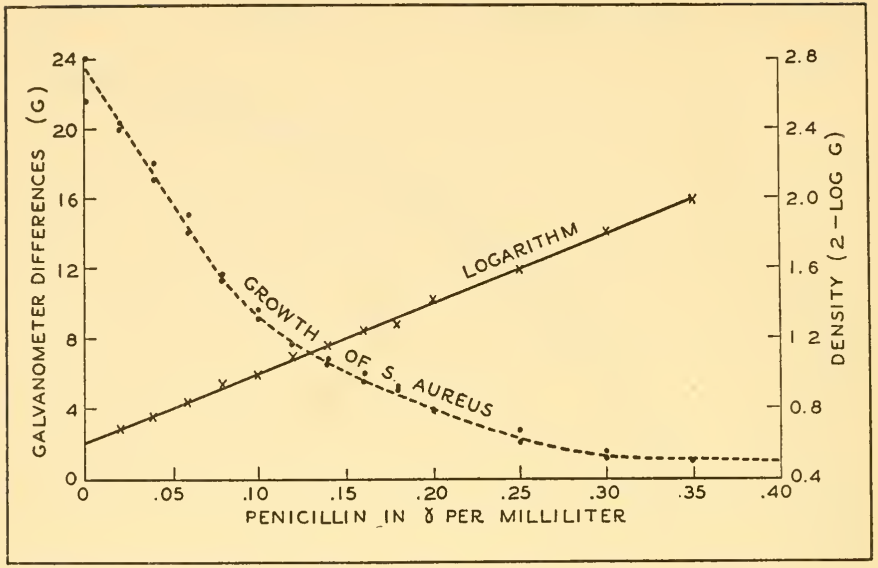

FIGURE 9. Relation between penicillin concentration and inhibition of Staphylococcus aureus. The penicillin preparation contained 42 Oxford units per milligram, and the incubation period was sixteen hours at $37^{\circ} \mathrm{C}$. From Foster (280).

pared with the control, or it can be measured by a convenient turbidimeter. The results obtained by this method are more nearly quantitative than those obtained by other methods, as shown in Figure 9. By proper modifications, the length of time required to obtain a satisfactory reading can be reduced to four hours $(482,610)$, or even to 90 minutes $(280,554)$.

The turbidimetric method has also found application in the standardization of streptomycin. For this purpose, certain noncapsulated cultures of $K$. pneumoniae are used. Nutrient broth is inoculated from a slant and incubated at $37^{\circ} \mathrm{C}$. for 22 to 24 hours. A series of dilutions of streptomycin in nutrient broth is prepared and one-milliliter portions are added in duplicate to tubes containing $9 \mathrm{cc}$. of broth inoculated with 2 per cent of the culture. The tubes are incubated at $37^{\circ} \mathrm{C}$. for 3 hours, 3 drops of formalin are added to stop growth, and turbidity is determined in a photoelectric colorimeter. The turbidity measurements are 
plotted against the concentrations of streptomycin and compared with the standard.

\section{Special Methods}

Special methods were found to be specific for measuring the action of certain substances. The ability of tyrothricin to hemolyze red blood cells served as the basis for measuring the potency of this substance ( $18 \mathrm{I}$ ): the tyrothricin content is calculated from the amount of hemolysis by the unknown and is read from a standard curve. The inhibition of growth of a $\beta$-hemolytic streptococcus, group A, as measured by hemolysin production has been used for assaying the potency of penicillin (747, 1022). Penicillin can also be estimated by its inhibition of nitrite production by $S$. aureus cultures (350). The antiluminescent test has been utilized not only for measuring the activity of certain substances but also for determining their possible usefulness. The results of a comparative study of a number of antibiotic substances by this and the dilution method are brought out in Table 9.

Other methods suggested for measuring the activity of antibiotic substances are based upon interference with a given physiological function of the test organism such as dehydrogenase activity and respiration (562) upon the prevention of growth of the test organism (pneumococcus) in semisolid tissue culture medium (392), or upon the diffusion of the antibiotic placed upon the surface of inoculated semisolid in tubes and measurement of the depth of clear zone (27). Although only a single method is usually employed in the concentration and standardization of a given antibiotic such as penicillin or streptomycin, it is often advisable to check the results by another method, especially where several test organisms are used, in order to obtain an antibacterial spectrum that will demonstrate that one is still dealing with the same type of chemical compound.

The results obtained by the various methods for determining the relative potency of different antibiotics lend themselves readily to statistical analysis $(68,5 \mathrm{I} 3,5 \mathrm{I} 4)$.

Methods have also been developed for detection of chemotherapeu- 
TABLE 9. ANTILUMINESCENT AND ANTIBACTERIAL ACTIVITIES OF VARIOUS ANTIBIOTIC SUBSTANCES

SMALLEST AMOUNT SHOWING ACTIVITY, IN MICROGRAMS

Antiluminescent test

Tolu-p-quinone

Pyocyanase

Clavacin I

Aspergillic acid

Gliotoxin

Clavacin II

Pyocyanin

Actinomycin

Streptothricin

Sodium clavacinate

Flavatin

Fumigacin

Lauryl sulfate

Phenol

Penicillin 1

Sùlfanilamide

Gramicidin

Gramidinic acid

Tyrothricin

$\mathrm{AP}_{2}$ I

Penicillin II

0.11
3
I I

Antibacterial test*

\section{Gramicidin}

Tyrothricin

Penicillin II

Penicillin I

Flavatin

15 Gramidinic acid

$17 \quad \mathrm{AP}_{21} \dagger$

22 Actinomycin

47 Aspergillic acid

54 Gliotoxin

56 Streptothricin

94 Fumigacin

256

273

273

I 170

Pyocyanin

Pyocyanase

Tolu-p-quinone

27.0

42.0

55.0

1650

3940

$>500$

$>500$

Lauryl sulfate

Clavacin I

Clavacin II

Sodium

clavacinate

$>500$

Phenol

$>500$

$>5000$
AL/AB RATIO

$\begin{array}{ll}.002 & \text { Tolu-p-quinone } \\ .008 & \text { Pyocyanase } \\ .0156 & \text { Clavacin I } \\ .06 & \\ .256 & \end{array}$

.002

.07

.18

.23 Sodium clavacinate .18

.31 Clavacin II

.54

Sulfanilamide

$<.56$

Phenol

Pyocyanin

1.7

4.6

$7 \cdot 5$

8.0

Gliotoxin

20.0

Streptothricin

21.0

Fumigacin

100.0

Actinomycin

Flavatin

1000.0

$\mathrm{AP}_{2} \mathrm{I} \dagger$

$>1630$

Gramidinic acid

$>2175$

Penicillin I

27,500

Tyrothricin

$>62,500$

Gramicidin $>250,000$

Penicillin II >325,000

From Rake, Jones, and McKee $(748)$.

* Streptococcus pyogenes used as test organism.

† A tyrothricin-like preparation.

tic substances in tissues and their secretions, as by the use of fluorescent microscopy, penicillin giving a green fluorescence (403). By utilizing the inactivating effect of penicillinase upon penicillin, it was possible to work out a method for the evaluation of different forms of penicillin in blood serum ( 130 ).

Several methods are commonly employed for measuring bactericidal 
action of antibiotic substances. A suspension of washed bacterial cells in saline or other suitable solution, or a 5-to-I2-hour-old broth culture of the test organism, is treated with various dilutions or concentrations of the active substance. After incubation at $37^{\circ} \mathrm{C}$. for I to 24 hours, the number of living cells is determined. If the active substance has lytic properties or if the test organism undergoes lysis readily, the readings are simplified. If no lysis occurs, the treated bacterial suspension or culture is streaked or plated out. The streaking procedure gives only a relative idea of the extent of bactericidal action. If 50 to 90 per cent killing of cells is to be taken as a unit of measurement, the culture is plated on a suitable medium and the actual number of surviving cells are determined.

Some of the foregoing methods can also be utilized for measuring the fungistatic and fungicidal properties of antibiotic substances. Protective fungicides may first function as fungistatic agents, others function better either as fungicidal or as fungistatic agents, and still others show either a high or a low for both. The growth of Ceratostomella $u l m i$ was inhibited by actinomycin, clavacin, and hemipyocyanin in concentration of $\mathrm{I}: 100,000(77 \mathrm{I}, 949)$.

\section{METHODS OF TESTING THE IN VIVO ACTIVITIES OF ANTIBIOTIC SUBSTANCES}

Ordinary pharmacological, bacteriological, and pathological procedures are used for testing the toxicity and activity of antibiotic substances in the animal body.

In order to determine the amount of an antibiotic required for the treatment of a certain infection, it is essential to know not only the response of the organism causing the infection but also the sensitivity of the particular strain involved. It is also essential to determine the concentration of the antibiotic in the body fluids. A number of methods have been proposed for this purpose, especially for penicillin and streptomycin.

Most of these represent various modifications of the agar diffusion and serial dilution methods, using a hemolytic streptococcus or some other suitable test organism, such as $S$. aureus or $B$. subtilis. In some 
cases the serial dilution has been combined with the turbidimetric method. The ability of penicillin to inhibit hemolysin production by streptococci has also been utilized (800a). A comparison of the agar diffusion, turbidimetric, and serial dilution methods led to the conclusion that the last is the most suitable for routine clinical work (508). Penicillin-containing material may also be spread over a given area of a nutrient agar surface, allowing time for absorption of the liquid, and streaking the surface with standard strains of $S$. aureus of known sensitivity; on comparing with standard penicillin preparation, it is possible to determine both the concentration of penicillin and the degree of sensitivity to penicillin of the infecting agent ( 152 ).

Fleming (266) proposed a method using a hemolytic streptococcus as test organism and blood (preferably group $\mathrm{O}$ ) from which leucocytes have been removed or inactivated and treated with a clot-inhibiting substance as a medium. Hemolysis of blood is measured either in a slide cell or in a capillary tube. The penicillin concentration in the blood is estimated by the serial dilution method. This method has been variously modified for clinical assays of penicillin.

A convenient method for measuring the concentration of streptomycin in body fluids is to use the agar diffusion method with an alkaline medium, low in salt, and a carefully selected test organism $(582,879)$. 


\section{CHAPTER 5}

\section{BACTERIA AS ANTAGONISTS}

Following the work of Pasteur in 1877 on the antagonistic effects of bacteria against the anthrax organism, considerable attention has been centered upon bacteria as agents possessing antibacterial properties. A systematic study of this phenomenon was first made by Babes in 1885 ( 155 ), who demonstrated that this antibacterial action is due to the formation of definite chemical substances. Garré (315) first introduced, in 1887 , suitable methods, such as the streak test, for demonstrating the antagonistic effect of one organism upon another. The first antibiotic substance, pyocyanase, was isolated in I 899 by Emmerich and Löw (235).

Freudenreich (298) found in 1888 that when certain bacteria were grown in a liquid medium, the filtrate obtained by passing the culture through a porcelain candle supported the growth of the typhoid organism not at all or only very feebly. Garré (315) observed that Ps. putida inhibited the growth of $S$. aureus, E. typhosa, and Bacillus mucosus-capsulatus but not of $B$. anthracis and other bacteria. It was soon reported (563), however, that $B$. anthracis was also killed by the Pseudomonas antagonist, whereas the growth of $S$. aureus and $V$. comma was only retarded; no effect at all was exerted upon $E$. typhosa or $E$. coli. In consequence, the antagonist was claimed to be active against $B$. anthracis but not against other bacteria. Olitsky (69r) concluded that Ps. fuorescens inhibited the growth not only of $E$. typhosa but also of $B$. anthracis, $V$. comma, $S$. marcescens, and $S$. aureus. These and other apparently contradictory results were undoubtedly due to differences in the specific nature of the strains of the organisms used by the various investigators and to different methods of cultivation.

The presence of Ps. fluorescens in sewage was found (55 I) to reduce greatly the period of survival of the typhoid organism. The latter did not develop even in gelatin upon which Ps. fuorescens had previously grown, and it could not be detected in sterile sewage in which the antagonist was present for seven days. According to Frost (303), E. ty- 
phosa can be antagonized by a number of different soil bacteria, of which Ps. fluorescens exhibits the strongest effect. He observed that although $P$. vulgaris acted more rapidly, the active substance did not diffuse to so great a distance in the medium, thus pointing to a different inhibition mechanism. Mixed cultures showed greater activity than pure cultures, either because the latter lost their antibiotic property when grown for a long time on artificial media or because mixed cultures comprise two or more species with a greater combined action. The antagonistic substances produced by these bacteria were active at $37^{\circ} \mathrm{C}$., whereas at ice-chest temperature the action was delayed so that the pathogen had an opportunity to develop. This was believed to offer a possible explanation for the fact that when water supplies become contaminated in cold weather, their power of producing infection is retained for a longer time than when the contamination takes place in warm weather.

Frost concluded that the phenomenon of antagonism results in checking the growth of E. typhosa as well as in killing the pathogen. Evidence that antagonistic substances exist in an active state in the soil or in water appeared to be lacking; rather, the results suggested that formation of such substances depends on the actual development of specific antagonistic organisms. Changes in environment, such as temperature, oxygen supply and reaction of the medium, and nature and concentration of nutrients, were believed to have little or no influence on the production of the antibiotic substances; these were produced under conditions favoring growth of the antagonists.

The activity of the influenza organism was found (1025) to be largely dependent on the presence of accompanying bacteria. Some of these, especially micrococci, are favorable to the growth of this organism whereas others, such as Ps.aeruginosa and $B$. subtilis, are injurious.

According to Lewis (566), luxuriant growth of Ps. fluorescens in manured soil and in protein solution containing $B$. cereus is due to antagonistic action of the former organism against the latter. Ps. fluorescens also inhibits the growth of $B$. anthracis, $B$. megatherium, $V$. comma, Chromobacterium violaceum, and Rhodococcus. Other species of the genera Bacillus, Eberthella, Sarcina, Neisseria, and Phytomonas are somewhat more resistant to the action of Ps. fuorescens. Salmonella species are less sensitive, whereas $E$. coli, $A$. aerogenes, and $S$. marces- 
cens are highly resistant. Ps. fuorescens produces a thermostable substance which is toxic to all bacteria except the green fluorescent forms and which is active against actinomycetes but not against fungi. This substance is water-soluble and dialyzable through collodion and other membranes.

In addition to the aforementioned bacteria, numerous other groups were found to contain strains which had strong antagonistic properties toward bacteria as well as fungi. Some of the antagonists were highly specific, such as those acting upon the various types of pneumococci; others were less selective, such as certain soil bacteria that can bring about the lysis of living staphylococci and inhibit the growth of various gram-positive and gram-negative bacteria. S. marcescens was antagonistic to various spore-forming bacteria. These, in turn, were antagonistic to sarcinae, bringing about their lysis, to V. comma, and to various other bacteria. It was further found that the antagonists modified the physiology of the antagonized organism. When two bacteria were planted, for example, in the same medium, metabolic products were formed that were not produced in the culture of either organism alone, whereas certain decomposition processes were either hastened or retarded (674).

The various antagonistic bacteria can be divided into several groups, on the basis of their morphological and physiological properties.

\section{SPORE-FORMING BACTERIA}

Many aerobic spore-forming bacteria possessing antagonistic properties have been isolated from a great variety of sources, such as soil, sewage, manure, and cheese. Among these, B. subtilis, B. mycoides, $B$. mesentericus, and $B$. brevis occupy a prominent place, as shown in Table iо.

Duclaux (212) isolated antagonistic spore-forming bacteria from cantal cheese, the organisms having been designated as Tyrothrix. Nicolle (680) obtained from the dust in Constantinople a strain of $B$. subtilis that had decided bacteriolytic properties against members of the pneumococcus group and various other bacteria such as the typhoid, anthrax, and Shiga organisms. E. coli and V. comma were most readily 
TABLE IO. SPORE-FORMING BACTERIA ANTAGONISTIC TO OTHER BACTERIA

\begin{tabular}{|c|c|c|c|}
\hline ANTAGONIST & ORGANISM AFFECTED & KNOWN PROPERTY & REFERENCES \\
\hline B. anthracis & $\begin{array}{c}\text { Anthrax, typhoid, and } \\
\text { lactic acid bacteria }\end{array}$ & & 298,819 \\
\hline B. brevis & Gram-positive bacteria & Produces tyrothricin & $201,202,208$ \\
\hline B. mesentericus & Many bacteria & Bacteriolytic & 419 \\
\hline B. mesentericus & Diphtheria bacteria & Bactericidal & 31,984 \\
\hline $\begin{array}{l}\text { B. mesentericus } \\
\text { vulgatus }\end{array}$ & C. diphtheriae & $\begin{array}{l}\text { Substance thermola- } \\
\text { bile, nonfilterable }\end{array}$ & 738 \\
\hline B. mycoides & $\begin{array}{l}7 \text { to } 20 \text { species of } \\
\text { bacteria }\end{array}$ & Lytic & 664 \\
\hline $\begin{array}{l}\text { B. mycoides, } \\
\text { var. cytolyticus }\end{array}$ & $\begin{array}{l}\text { Most pathogens and } \\
\text { many nonpathogens }\end{array}$ & & 292 \\
\hline B. subtilis & Various bacteria & Bacteriolytic & 680 \\
\hline B. subtilis & $\begin{array}{l}\text { Various bacteria, espe- } \\
\text { cially certain plant } \\
\text { pathogens }\end{array}$ & Produces subtilin & 453,460 \\
\hline B. subtilis & $\begin{array}{l}\text { M. tuberculosis, } E \text {. } \\
\text { typhosa, etc. }\end{array}$ & & 927 \\
\hline B. subtilis & $\begin{array}{l}\text { M. tuberculosis } \\
\text { and other bacteria }\end{array}$ & $\begin{array}{l}\text { Thermostable sub- } \\
\text { stance produced }\end{array}$ & 693,816 \\
\hline $\begin{array}{l}\text { B. subtilis- } \\
\text { mesentericus }\end{array}$ & $\begin{array}{l}\text { Mostly living gram- } \\
\text { positive bacteria and } \\
\text { dead gram-negative } \\
\text { bacteria }\end{array}$ & Lytic & 806,808 \\
\hline B. thermophilus & S. lutea & Suppresses growth & 864 \\
\hline
\end{tabular}

acted upon, staphylococci were less affected, and B. suipestifer least. The filtrate of the organism grown in peptone broth had strong antibiotic properties; it liquefied gelatin and hemolyzed red blood corpuscles. When various bacteria cultivated on a solid medium were suspended in physiological salt solution and seeded with the antagonist, the latter developed abundantly and the bacterial suspensions became 
clarified. The lysed solutions of pneumococcus prepared by the use of the filtrate of $B$. subtilis could be used for purposes of vaccination. In this connection, Nicolle spoke of the work of Metchnikoff who had proved, in 1897 , that organisms belonging to the B. subtilis group are capable of destroying various bacterial toxins.

Rosenthal (806) isolated, from soil and from fecal matter, facultative thermophilic antagonistic bacteria belonging to the $B$. mesentericus group capable of dissolving both living and dead bacteria. The simultaneous growth of the antagonist with $V$. comma and other bacteria brought about the clarification of the culture of the latter in about 5 or 6 days. These bacteriolytic organisms were designated as "lysobacteria." It was recognized that the action of antagonists is different from that of phage in several respects: (a) the filtrate of the antagonist is active against other bacteria; (b) both living and dead cultures of bacteria are dissolved; (c) antagonistic action is not so specific as that of phage; (d) races of $E$. coli resistant to phage are dissolved by the filtrate of the antagonist. The active substance was believed to be of the nature of an enzyme. Friedländer's bacillus was not acted upon, possibly because of the formation of a pellicle by the bacillus. The active substance was formed in 4 to 5 days but increased in activity after 2 to 3 weeks. It was essential that a surface pellicle of the organism be maintained. Submerged growth was less favorable. Fresh filtrates had the greatest activity, the property being lost after storage for 3 months. The substance was thermolabile, activity being destroyed at $70^{\circ} \mathrm{C}$. The filtrate of an organism dissolved by the action of the antagonist proved to be as active as the filtrate of the culture of the antagonist. It acted injuriously upon intestinal bacteria not only in vitro but also in vivo.

Much and associates (664) isolated several strains of B. mycoides that possessed strong antagonistic properties. The active strains were said to be found only rarely in nature. They gave a mesentericus-like growth, producing a pellicle and no turbidity in bouillon. One strain was able to lyse 20 species of bacteria, another acted upon 18 , a third on 12 , and a fourth on only 7. Marked differences were shown to exist in the degree of antagonistic activity of the different strains. $P$. vulgaris, E. typhosa, and V. comma were lysed in 24-hour bouillon cultures as a result of adding pieces of agar containing colonies of the 
antagonist. A lytic effect was also exerted upon staphylococci (824) and gram-negative bacteria (504, 505). The substance was precipitated by Io per cent tungstic acid and lead acetate and was thermostable.

Much and Sartorius (664) came to the conclusion that B. mycoides Flügge comprises two groups of organisms. One produces branching colonies on agar and forms no pellicle in meat broth, the flaky growth dropping to the bottom and the medium remaining more or less clear. The second group forms flat surface growth similar to that of $B$. mesentericus on agar and a pellicle on the surface of liquid media. Many of the pellicle-forming strains have the capacity, in varying degrees, of dissolving various cultures of bacteria. This is not due to their proteolytic activity, since members of the first group may be more actively proteolytic. The culture filtrate of the antagonist dissolves the bacteria but does not destroy their antigenic properties. The lytic substance, designated as Much-lysin, was said to have a double effect: one, bound to the living cells of the organism, had nothing to do with phage, and the other, found in the bacteria-free filtrate, had an apparent similarity to phage but was distinct from it.

The idea that in the case of bacterial antagonists one is dealing with specific strains rather than with distinct species was further emphasized by Franke and Ismet (292). Various strains of B. mycoides, designated as cytoliticus, were shown to be able to lyse many pathogenic and nonpathogenic bacteria but not their own cells; the same action was exerted by the culture filtrate (Table I I). The lytic action of strains of $B$. subtilis upon different bacteria, including $M$. tuberculosis (927), pneumococci, typhoid, diphtheria, and other organisms, has also been definitely established.

Pringsheim (738) isolated a strain of $B$. mesentericus-vulgatus that had a decided inhibiting effect upon a variety of bacteria, particularly Corynebacterium diphtheriae. On agar plates the antagonist produced a circular zone of inhibition, just beyond which was a ring of larger colonies, indicating a stimulating effect. It was suggested that the antagonist produced a toxin that was stimulating in small doses and injurious in larger concentrations. The active substance was thermolabile and nonfilterable. The antagonistic properties appeared to be inherent in the particular strain of an organism and were not increased by serial 
passage. The action of filtrates of $B$. mesentericus against diphtheria organisms was considered (984) as highly specific. Other strains of this organism were reported to be active against Pasteurella pestis (244). Living gram-positive bacteria were found (806) to be more susceptible than gram-negative organisms to the antagonistic action of spore-forming aerobes; in the case of dead organisms, the reverse was true. Plates were heavily seeded with the test bacteria and the centers of the plates

TABLE I I. LYSIS OF PATHOGENIC BACTERIA BY VARIOUS STRAINS OF A SPORE-FORMING ANTAGONIST (CYTOLYTICUS)

\section{ORGANISM IYSED}

E. typhosa

Paratyphoid A

Paratyphoid B

Shigella

$\mathrm{Y}$ bacillus

E. coli

C. diphtheriae

Ps. pyocyaneus

S. aureus

S. albus

S. citreus

$S$. viridis

S. haemolyticus

S. mucosus

$P$. vulgaris (Weil-Felix)

Pneumococcus

\section{STRAIN NUMBER OF CYTOLYTICUS}

I II III VI VII VIII IV

$\mathrm{H}+\mathrm{H}+\mathrm{H}+\mathrm{H}+\mathrm{H}$ o

$+\mathrm{H}+\mathrm{H}+\mathrm{H}+\mathrm{H}+\mathrm{H}$

$0+\mathrm{H}+\mathrm{H}+\mathrm{H} 0$

$\mathrm{H}+\mathrm{H}+\mathrm{H}+\mathrm{H} 0$

$+\mathrm{H}+\mathrm{H}+\mathrm{H}$ o

$\mathrm{H}+\mathrm{H} \mathrm{H}+\mathrm{H}+\mathrm{H} 00$

$\mathrm{H}+\mathrm{H}+\mathrm{H}+\mathrm{H}+\mathrm{H}+$

$0+\mathrm{H}+\mathrm{H}+\mathrm{H}$ H

$+0 \mathrm{H}+\mathrm{H}+\mathrm{H}+\mathrm{H}$

$+\mathrm{H}+\mathrm{H}+\mathrm{H}+\mathrm{H}+$

$\mathrm{H}+\mathrm{H}+\mathrm{H}$ O $\mathrm{H}+\mathrm{H}+\mathrm{H}$

$+\mathrm{H}+\mathrm{H}+\mathrm{H}+\mathrm{H}+\mathrm{H}$

$\mathrm{H}+\mathrm{H}+\mathrm{H}+\mathrm{H}+\mathrm{H}+\mathrm{H}$

$\mathrm{H}+\mathrm{H}+\mathrm{H}+\mathrm{H}+\mathrm{H}+\mathrm{H}$

$\mathrm{H}+\mathrm{H}+\mathrm{H}+\mathrm{H}+\mathrm{H}$

$\mathrm{H}+\mathrm{H}+\mathrm{H} H \mathrm{H}$ H $\mathrm{H}$

From Franke and Ismet (292).

o no clearing.

+ trace but no true clearing.

inoculated with the antagonist. Inhibition of growth and lysis were used as measures of antagonistic action.

Hettche and Weber (4I9) isolated 4I strains of B. mesentericus from 25 samples of soil. These were streaked on blood agar, and the diphtheria organism was used for testing their effect. In 18 strains the antagonistic action was detected in 24 hours; there was no parallelism 
between inhibition and hemolysis. Of the I 8 active strains, I I lost the property after two transfers and 2 were exceedingly active.

More recently, beginning with the work of Dubos, considerable attention has been devoted to spore-forming bacteria, resulting in the isolation of a number of substances or preparations that have been designated as tyrothricin, gramicidin S, subtilin, bacitracin, bacillin, simplexin, subtilysin, and endo-subtilysin (8 I 5a). These substances are largely active against gram-positive bacteria; however, some also affect gram-negative bacteria and fungi.

Dubos (2Or) obtained from a soil enriched with various living bacteria a gram-negative, spore-bearing bacillus ( $B$. brevis) that had a marked lytic effect against gram-positive bacteria, including staphylococci and pneumococci. The antagonist was grown for 3 to 4 days in shallow layers of peptone media at $37^{\circ} \mathrm{C}$. The bacterial cells were removed by centrifuging, and the filtrate was acidified, giving a precipitate from which a highly active substance (tyrothricin) was isolated. On crystallization, two preparations were obtained, namely gramicidin and tyrocidine, these making up only a fraction of the tyrothricin complex.

Natural substrates, such as soil, sewage, manure, and cheese, were found (209) to contain various spore-forming bacteria that have marked antagonistic properties against various gram-positive and gramnegative bacteria. Hoogerheide (442) obtained from the soil an aerobic, spore-forming bacterium that produced a highly active bactericidal substance; it also prevented the formation of capsules by Friedländer's bacterium. This substance appeared to be similar to gramicidin. Gramicidin $\mathrm{S}$ is, however, more like tyrocidine.

Further studies definitely established that strains of spore-forming bacteria possessing antagonistic properties are widely distributed in the soil and possess certain physiological characteristics that differentiate them from the inactive strains. This is brought out in Table I2. The production of the antibiotic is a function of the growth of the bacterial cell. The yield of the antibiotic is influenced by the composition of the medium; the substance is bound to a protein, the bond between the two being destroyed by trypsin ( 523 ).

$B$. subtilis has been reported by many investigators to exert an an- 
tagonistic effect upon many pathogenic bacteria, bringing about their complete lysis. The time required for such lysis was 48 hours for grampositive cocci, 5 days for the typhoid and paratyphoid organisms, and 8 to 12 days for $E$. coli and $M$. tuberculosis (693). The action of $B$.

TABLE I2. BIOCHEMICAL CHARACTERISTICS OF ACTIVE AND INACTIVE STRAINS OF SPORE-FORMING SOIL BACTERIA

\begin{tabular}{ccccccc}
\hline & & & LIQUE- & HY- & \\
STRAIN & ACID PRODUCTION FROM & PRO- & FAC- & DROLY- & \\
& DUCTION & TION OF & SIS OF & GRAM \\
& Dextrose Lactose Sucrose & OF $\mathrm{H}_{2} S$ & GELATIN & STARCH & STAIN
\end{tabular}

Active Strains

\begin{tabular}{llllllll} 
A-2 & - & - & - & + & + & - & - \\
A-5 & - & - & - & + & + & - & - \\
A-IO & - & - & - & + & + & - & - \\
A-2 I & - & - & - & + & + & - & - \\
A-23 & - & - & - & + & + & - & - \\
A-27 & - & - & + & + & - & - & - \\
A-34 & - & - & - & + & + & - & - \\
INACTIVE STRAINS & & & & & & & \\
A-I5 & - & - & + & - & - & + & + \\
A-31 & - & + & + & - & + & + & + \\
A-32 & + & + & + & - & + & + & + \\
\hline
\end{tabular}

From Stokes and Woodward (885).

- reaction becoming alkaline.

+ acid produced.

subtilis upon various bacteria is also growth-inhibiting. This property is due to the formation of one or more antibiotics which have been described in the literature under several different names.

Cultures of $B$. subtilis found (453) to have a high activity against plant pathogenic bacteria yield an antibiotic that was designated (460) subtilin. Other preparations designated by the same name (759) have a strong bacteriostatic, bactericidal, and lytic effect upon a variety of bacteria, including $B$. anthracis, $C$. diphtheriae, and $S h$. dysenteriae; the activity of the culture filtrate was about 4 to 16 units and there was a marked parallelism between the antibacterial properties of the filtrate and its proteolytic action.

A water-soluble, nontoxic, relatively heat-stable compound was iso- 
lated from other strains of $B$. subtilis and named bacitracin (469). Still another strain of $B$. subtilis isolated from soil enriched with $M$. tuberculosis yielded an antibiotic designated bacillin (284). This substance is produced in manganese-containing media and is mostly found in the cell-free filtrate of the culture. It is adsorbed on norite and eluted with 90 per cent ethyl alcohol, concentrated in vacuo and taken up in water. It is active against both gram-positive and gram-negative bacteria. Blood and certain other complex organic materials reduce or destroy its activity. This is due to the presence of a substance which was designated antibacillin and which was found to be a peptide (I030).

$B$. licheniformis, related to $B$. subtilis, was found ( 107 ) to produce an effect against $M$. tuberculosis. The active substance was present in the cells of the organism when grown on a synthetic medium. The culture was acidified to $p \mathrm{H}_{2} .5$ and treated with 3 volumes of 95 per cent ethanol. The coagulum was autoclaved and extracted on boiling with 0.5 volume of 0.4 per cent acetic acid for 45 minutes. The substance had an activity against $M$. phlei and $S$. aureus in $I: 80,000$ dilution, but not against $E$. coli. $M$. tuberculosis hominis was inhibited in $1: 20,000$ dilution. Preparations of greater purity had an activity of $1: 80,000 /$ gm. The preparation, which was not very toxic to mice, was considered as a mixture of several substances.

Various other antibiotics have been reported for aerobic spore-forming bacteria. Some of these substances are active against both grampositive and gram-negative bacteria. This is true, for example, of colistatin (323a).

Spore-forming bacteria are also able to produce antibiotics antagonistic to fungi. $B$. simplex was found (154) to be antagonistic to Rhizoctonia solani, an important plant pathogen. It produced a thermostable agent that inhibited the growth and even caused the death of the fungus. When the active substance was added to the soil it controlled to some extent seed decay and damping-off disease of cucumbers and peas. It was also active against bacteria (49I). It is adsorbed on norite and eluted with methyl alcohol; the latter is evaporated in vacuo and the residue is taken up in water. This preparation was designated as simplexin (287).

$B$. mesentericus produced on artificial media an antibiotic that sup- 
pressed the growth of Helminthosporium sativum. It increased sporulation of the fungus, inhibited or retarded spore germination, caused abnormal hyphal development, and induced mutations in certain strains of the fungus. The substance was thermostable and diffusible. It passed through a Berkfeld filter, was absorbed by infusorial earth, withstood freezing and desiccation, and did not deteriorate readily. It was destroyed by alkalies but not by acids. It was inactivated or destroyed, however, by certain fungi and bacteria (142).

Various other spore-forming bacteria were found capable of inhibiting the growth of bacteria, fungi, and other lower forms of life. In many instances, only little is known of the nature of the active agent involved. It is sufficient to illustrate this by an observation that B. hirudenses, growing abundantly in the digestive fluids of leeches and considered as a symbiont of these animals, exerted a marked inhibitory effect upon the growth of various bacteria and fungi (845).

Antagonistic relations among entomogenous bacteria have been demonstrated for the foul brood of the honeybee (44I). This interaction between $B$. popilliae and $B$. lentimorbus was believed to explain the mutually exclusive development of the two types of milky disease in Japanese beetle groups.

NONSPORE-FORMING BACTERIA: PS. AERUGINOSA, PS. FLUORESCENS, AND S. MARCESCENS

Among the nonspore-forming bacteria, those belonging to the fluorescent, green-pigment and red-pigment producing groups have probably received the greatest attention as antagonists. Bouchard (78) was the first to report, in I 888, that the pyocyaneus organism (Ps. aerugi nosa) was antagonistic to the anthrax bacillus. It was soon found (I 3 I, 298 ) that when grown on artificial media, this organism affected bacteria, including E. typhosa, Pfeifferella mallei, V. comma, and Bacterium tyrogenes. The growth of staphylococci, micrococci, diplococci, and spore-forming rods was also reduced. The antagonist inhibited its own growth as well.

These early observations were amply substantiated (Table 13). Ps. aeruginosa was shown to be active against $E$. coli, $M$. tuberculosis, and 
a variety of other bacteria. The addition of top minnows (Gambusia) to water polluted with $E$. coli caused the disappearance of the bacteria; this was shown to be due to the inhibiting effect of the pyocyaneus organism present in the intestinal flora of Gambusia. The presence of this antagonist in water renders the colon index of the water an unreliable guide to pollution (388). When a mixture of the antagonist and the colon organism was incubated, the former tended to outgrow the latter after 24 hours. Even after sterilization, media in which Ps. aeruginosa had grown depressed the growth of other microorganisms including

TABLE I 3. NONSPORE-FORMING BACTERIA AS ANTAGONISTS TO BACTERIA

\begin{tabular}{|c|c|c|c|}
\hline ANTAGONIST & ORGANISMS AFFECTED & KNOWN PROPERTY & REFERENCES \\
\hline Ps. aeruginosa & $\begin{array}{l}\text { B. anthracis, E. typhosa, } V \text {. } \\
\text { comma, etc. }\end{array}$ & $\begin{array}{l}\text { Thermostable, filter- } \\
\text { able substance }\end{array}$ & $\begin{array}{l}64,78, \text { I } 31,235 \\
236,298,557\end{array}$ \\
\hline Ps. aeruginosa & $\begin{array}{c}\text { Gram-negative bacteria, } M . \\
\text { tuberculosis, and yeasts }\end{array}$ & Depresses growth & $\begin{array}{l}45 \mathrm{Ia}, 798,800 \\
801\end{array}$ \\
\hline Ps. fluorescens & $\begin{array}{l}\text { E. coli, S. marcescons, } C \text {. } \\
\text { diphtheriae, B. anthracis, } \\
\text { etc. }\end{array}$ & $\begin{array}{l}\text { Thermostable, filter- } \\
\text { able substance }\end{array}$ & $\begin{array}{l}244,303,315,334, \\
417,418,420,421, \\
446,563,566,692\end{array}$ \\
\hline Ps. fluorescens & Actinomycetes & Lytic action & 593 \\
\hline S. marcescens & $\begin{array}{l}\text { Cl. chauroei, } B \text {. anthracis, } \\
\text { staphylococci, micrococci }\end{array}$ & $\begin{array}{l}\text { Colorless, thermo- } \\
\text { stable, lytic sub- } \\
\text { stance }\end{array}$ & $51,229,777$ \\
\hline S. marcescens & $\begin{array}{l}\text { Gram-positive but not gram- } \\
\text { negative bacteria }\end{array}$ & $\begin{array}{l}\text { Alcohol-soluble } \\
\text { pigment }\end{array}$ & 420 \\
\hline E. coli & $\begin{array}{c}\text { Typhoid, paratyphoid, diph- } \\
\text { theria, staphylococci, and } \\
\text { proteolytic bacteria }\end{array}$ & Growth-inhibiting & $\begin{array}{l}53,55,132,368, \\
515,685,769,912, \\
983\end{array}$ \\
\hline E. coli & Other $E$. coli strains & & $357^{a}, 681$ \\
\hline E. coli & $\begin{array}{l}\text { B. anthracis and other spore- } \\
\text { forming bacteria }\end{array}$ & & $\begin{array}{l}110,344,367,369, \\
457,485,819,923\end{array}$ \\
\hline A. aerogenes & B. anthracis, $P$. pestis & & $244,367,369$ \\
\hline E. typhosa & $\begin{array}{c}\text { E. typhosa, Ps. fluorescens, } \\
\text { E. coli, B. anthracis }\end{array}$ & & $\begin{array}{l}315,354,923 \\
936\end{array}$ \\
\hline S. paratyphi & $E$. coli, B. anthracis, $P$. pestis & & $244,462,810,923$ \\
\hline
\end{tabular}


TABLE I 3 (continued)

ANTAGONIST

Streptococci

Streptococci

Staphylococci

Micrococci

Diplococci and pneumococci

$K$. pneumoniae

P. vulgaris

P. avicida

Myxobacteria

Anaerobic bacteria
ORGANISMS AFFECTED

$B$. anthracis, $C$. diphtheriae

B. anthracis, Ph.tumefaciens, Thermostable, nonS. lactis, P. pestis, L. bulgaricus

filterable substance

$70,244,802,1007$

Activity not associated with hemoly- $303,670,7$ I I, 836 sis or virulence

Gram-positive bacteria, $C$. diphtheriae, $P$. pestis

V. comma, M. tuberculosis, E. typhosa, Br. melitensis

Various bacteria

$B$. anthracis, $C$. diphtheriae, $P$. pestis

$B$. anthracis, $P$. pestis, $C l$. sporogenes

B. anthracis, E. typhosa

Plant-disease-producing bacteria

Thermolabile substance

Active filtrate

$53,155,215,244$, 247

$213,214,580,625$, 670

2 I 3,2 I 4, 243, 244, $370,580,677,766$

$53,55,244,303$, 677,7 I I, 853 $36,244,923,985$

298

Thermostable lytic $\quad 869$ substance

S. marcescens, Ps. fuorescens, and Saccharomyces cereviseae; spore formation by the last was favored (800).

The specific antagonistic action of $P_{\text {s. aeruginosa upon various bac- }}$ teria was found by early investigators to be due to the production of an active heat-resistant substance. By filtering the culture through a Berkfeld, evaporating to a small volume, dialyzing through a parchment membrane, precipitating with alcohol, and drying over sulfuric acid, a preparation was obtained which was designated as pyocyanase (see p. 5 I). It had, even in very low concentrations, a marked destructive effect upon diphtheria, cholera, typhus, and plague organisms, as well as on pyogenic streptococci and staphylococci. It rapidly dissolved $V$. 
comma cells and in a few seconds rendered inactive such bacterial toxins as that of diphtheria. Since the bacteriolytic action of pyocyanase was in direct proportion to the time of its action and concentration, and in inverse proportion to the numbers of bacteria acted upon, its enzymatic nature was believed to be substantiated. The preparation withstood heating in flowing steam for 2 hours.

It has been established that pyocyanase has a lytic effect against the diphtheria organism, streptococci, meningococci, the typhoid organism, pneumococci, $P$. pestis, Vibrio metchnikovi, V. comma, and many other bacteria. There has been considerable disagreement, however, concerning the chemical nature and therapeutic action of pyocyanase, due largely to the variation in the nature of the preparations obtained. Kramer, for example, has shown (529) that the activity of the substance depends on three factors: nature of strain, not all strains being equally effective; composition of medium, glycerol-containing media being most favorable; and method of extraction of active substance from culture media. The enzymatic nature of pyocyanase was not universally accepted, largely because of the thermostability of the substance, its solubility in organic solvents, and the fact that temperatures of o to $37^{\circ} \mathrm{C}$. fail to influence its activity $(59,420,737)$.

$P_{s}$ aeruginosa produces, in addition to pyocyanase, a blue pigment, pyocyanin. Both substances possess lytic properties, I : I, ooo dilution of the pigment being able to lyse $E$. coli in 6 hours. Pyocyanin was said to be more effective in younger cultures, and pyocyanase in older. Pyocyanin had a bactericidal action also upon $S$. hemolyticus, $S$. albus, $S$. aureus, $C$. diphtheriae, $M$. tuberculosis, V. metchnikovi, and the Y-Ruhr bacillus, but not upon $P$. vulgaris, E. coli, or the typhoid organism. In general, gram-positive bacteria were largely affected. Numerous other substances have been isolated from the cells of the organism or from the culture medium of Ps. aeruginosa. It is sufficient to mention the pyo-compounds and pyolipic acid.

In order to test the action of Ps. aeruginosa upon other bacteria, Kramer (529) placed a drop of a suspension of this organism upon a plate inoculated with $M$. tuberculosis or with $V$. metchnikovi. In 24 hours, a sterile zone surrounded the colony of the antagonist, the width 
of the zone depending upon the moisture content of the medium, the degree of diffusion of the active substance, its concentration, and the resistance of the test bacteria. When either of the two pathogens was inoculated into liquid media and the antagonist was introduced simultaneously or within 24 hours, the latter had a decided bactericidal effect.

No less extensive is the literature on the antagonistic action of the fluorescent group of bacteria, first established by Garré (315) in I 887 and later by others. Its bacteriostatic spectrum is illustrated in Table I4. The active substance is thermostable, dialyzes through a membrane, passes through Seitz and Berkfeld filters and is said to be soluble in chloroform $(418,566)$. Aerobic culture conditions are favorable to its accumulation. Members of this chromogenic group of bacteria were also found to be able to bring about the lysis of infusoria (I 34 ).

$S$. marcescens exerts antagonistic effects against a number of bacteria, including diphtheria, gonococci, anthrax, and $\mathrm{Cl}$. chauvoei, as well as fungi causing insect diseases (624). The formation of antibiotic substances by this organism has been demonstrated by various investigators. These substances are active not only in vitro but also in vivo. Their formation was believed not to be associated with the production of the pigment by the organism. Hettche (420), however, asserted that the bactericidal action of Serratia is closely related to pigment production. The pigment was extracted with alcohol and was found capable of dissolving dead gram-positive bacteria but not gram-negative organisms. Eisler and Jacobsohn (229) ascribed the antagonistic action of Serratia not to the pigment but to certain water-soluble, thermostable ( $70^{\circ} \mathrm{C}$. for 30 minutes) lytic substances.

\section{THE COLON-TYPHOID BACTERIA}

Members of the colon-typhoid group are not typical soil inhabitants, although they find their way continuously into the soil and into water basins. Various organisms belonging to this group have been said to possess antagonistic properties (440). Bienstock (55) reported, in I899, that proteolytic bacteria are repressed by the presence of $E$. coli and $A$. aerogenes. Tissier and Martelly (912) emphasized that this phenomenon occurs only in the presence of sugar, the effect being due 
TABLE I 4. ANTAGONISTIC ACTION OF PS. FLUORESCENS UPON VARIOUS MICROORGANISMS

\begin{tabular}{|c|c|c|c|c|c|c|c|c|c|c|}
\hline \multirow[t]{2}{*}{ ORGANISM } & \multicolumn{10}{|c|}{ PERCENTAGE OF AGED MEDIUM IN THE AGAR } \\
\hline & 0.5 & I.O & 2.5 & 5.0 & IO & I 5 & 20 & 30 & 40 & 50 \\
\hline B. cereus & - & - & + & & & & & & & \\
\hline B. mycoides & - & - & + & & & & & & & \\
\hline B. anthracis & - & + & & & & & & & & \\
\hline B. vulgatus & - & - & + & & & & & & & \\
\hline B. subtilis & - & - & + & & & & & & & \\
\hline B. megatherium & - & + & & & & & & & & \\
\hline R. cinnebareus & - & + & & & & & & & & \\
\hline$R$. roseus & - & - & + & & & & & & & \\
\hline M. floous & - & - & - & + & & & & & & \\
\hline N. catarrhalis & - & - & - & + & & & & & & \\
\hline Ps. aeruginosa & - & - & - & - & - & - & - & - & - & - \\
\hline Ps. fluorescens & - & - & - & - & - & - & - & - & - & - \\
\hline S. lutea & - & - & - & + & & & & & & \\
\hline S. marcescens & - & - & - & - & - & + & & & & \\
\hline S. albus & - & - & + & & & & & & & \\
\hline S. aureus & - & - & - & + & & & & & & \\
\hline S. citreus & - & - & + & & & & & & & \\
\hline$K \cdot$ pneumoniae & - & - & - & + & & & & & & \\
\hline V. comma & - & + & & & & & & & & \\
\hline Ch. violaceum & - & + & & & & & & & & \\
\hline E. typhi & - & - & + & & & & & & & \\
\hline Sh. paradysenteriae & - & - & + & & & & & & & \\
\hline S. enteritidis & - & - & - & + & & & & & & \\
\hline S. suispestifer & - & - & - & + & & & & & & \\
\hline S. pullorum & - & - & - & + & & & & & & \\
\hline E. coli & - & - & - & - & - & - & + & & & \\
\hline A. aerogenes & - & - & - & - & - & - & + & & & \\
\hline Ph. bowlesii & - & - & + & & & & & & & \\
\hline Sac. marianus & - & - & - & - & - & - & - & - & - & - \\
\hline Sac. ellipsoideus & - & - & - & - & - & - & - & + & & \\
\hline Sac. pastorianus & - & - & - & - & - & - & - & - & + & \\
\hline Zygosac. prioriamus & - & - & - & - & - & - & - & + & & \\
\hline Torula sphaerica & - & - & - & - & - & - & - & - & - & - \\
\hline A. niger & - & - & - & - & - & - & - & - & - & - \\
\hline
\end{tabular}

From Lewis ( 566 ).

+ denotes complete inhibition. 
to the fermentation of the sugar by E. coli, resulting in the production of acid.

Wathelet (983) observed in 1895 that in mixed culture the colon bacterium gradually replaces the typhoid organism and this was later fully confirmed. The occurrence of slowly growing lactose-fermenting strains of $E$. coli in stools has been ascribed to the phenomenon of antagonism (462), and the inhibitory action upon E. typhosa added to certain stools was also ascribed to the antagonistic action of $E$. coli (68I). Different strains of $E$. coli repress the typhoid organism to a different extent. The ratio of the two organisms developing on agar was designated as the antagonistic index; an index of 100:20 means that for every 100 colonies of the colon organism, 20 colonies of typhoid developed.

Active colon strains may be inhibitive to other strains of the same organism. The existence of strong and weak antagonistic strains has been questioned frequently ( 1034 ). Many of these strains were observed to have a strong antagonistic action against the pathogenic intestinal flora; these results were contested, however $(97,543)$. The action of $E$. coli of different origin varies, freshly isolated strains being more active than stock cultures $(783,866)$. It has also been reported that fresh, actively growing cultures of $E$. typhosa inhibit the growth of $E$. coli, but that older cultures are not antagonistic (936).

The production by smooth strains of $E$. coli of a highly specific bacteriolytic substance which lyses the cells of a rough strain of this organism has also been indicated (1045); this substance was ineffective against other rough and smooth strains, whereas the filtrates of the rough strains were inactive upon the smooth strain. The substance is readily destroyed by heating at $70^{\circ}$ to $80^{\circ} \mathrm{C}$. E. coli antagonism has also been correlated $(632)$ with the greater resistance of the strains to environmental factors, their greater rate of multiplication, and their greater adaptation to nutrient media.

A bacteriophage was found (574) to develop as a result of the antagonistic action of $E$. coli against the Shiga bacillus and was said to occur in the intestines where antagonistic conditions are always present. Gratia (355) found that the filtrates of one race of E. coli inhibited 
another race and caused an agglutination of the latter in fluid media. The weakest antagonists were said (387) to belong to the paracolon group, the strains of medium activity to the colon group, and the strongest antagonists to the colon-immobilis type. Whenever the feces were found to contain large numbers of $E$. coli, no typhoid organisms were present. The resistance of certain persons to intestinal diseases was, therefore, ascribed to the high antagonistic colon index. By utilizing the principle of antagonism of some strains of $E$. coli against others, two types of $E$. coli resistant to the antagonistic substance were isolated ( 176 ): one produced giant colonies, the other small punctiform, translucent colonies.

More recently it was established (357a) that various strains of $E$. coli produce a complex mixture of antibiotics, designated as colicines, which are mostly bacteriostatic against certain other strains of this organism as well as against other pathogenic enterobacteria. On the basis of their selective action, concentration, diffusibility, thermostability, and sensitivity to antagonistic organisms, eight groups of substances were listed. They represent polypeptides readily destroyed by trypsin.

$E$. coli exerts an antagonistic action also upon $S$. schottmülleri, $C$. diphtheriae, staphylococci, $M$. tuberculosis, B. anthracis, various sporeforming soil bacteria, and putrefactive water bacteria. The action against anthrax was said to be only temporary (344). It was also suggested (457) that only living cultures of $E$. coli are active. The simultaneous inoculation of $S$. aureus and $E$. coli was found (769) to be injurious to the first and not to the second organism; this effect was increased by an increase in the number of $E$. coli cells in the inoculum. Gundel and Himstedt (368) have shown that E. coli, but not A. aerogenes, is antagonistic to $S$. aureus and $S$. albus.

The term autophage has been used (342) to designate the process of clearing a water emulsion of dead cells by a culture of an antagonist such as $E$. coli. This clearing effect was said to be due to the fact that the dead cells are used as nutrients by the living organism. The mechanism of the action was variously explained by a change in the $\mathrm{pH}$ value of the medium or in the oxidation-reduction potential or by a direct enzymatic effect. In some cases thermolabile, filterable substances were dem- 
onstrated $(369,618)$. These substances have been considered to be either autotoxins (148) or proteolytic enzymes (719). The filtrate of $E$. coli was reported (836) to be highly selective in its action, depressing only the dysentery organism of Shiga. Gundel (372) isolated from a bouillon culture of $E$. coli thermostable lipoids capable of bringing about the lysis of the colon organism and other bacteria. The antagonistic relations between $E$. coli and $V$. comma are well established. The cholera organism also possesses antagonistic properties $(308,499)$.

The typhoid organism is also capable of exerting an antagonistic action against itself as well as against $P$ s. fluorescens, $E$. coli, and various other bacteria, including $B$. anthracis. The nature of the action is not clearly understood. Salmonella paraty $p h i$ possesses antagonistic properties against $E$. coli, $B$. anthracis, $P$. pestis, and various other bacteria.

\section{$\mathrm{COCCI}$}

Numerous cocci have been found to possess antagonistic properties against other bacteria. Doehle ( I 87) first demonstrated in I 889 that streptococci are able to antagonize $B$. anthracis, especially on solid media. Similar action was exerted against diphtheria bacteria; this action was not correlated with the hemolytic properties or the virulence of the antagonist. Further studies established the effect of various streptococci against anthrax. This effect was found (IIO) to be more pronounced in liquid than in solid media, and to be highly specific as regards the strain. $S$. pyogenes was shown to be antagonistic, in vivo, to B. anthracis and to Phytomonas tumefaciens, even to the extent of suppressing vegetative malformations brought about by the last named (70). S. cremoris was active against $S$. lactis (1007), S. mastidis against $S$. lactis and L. acidophilus, and Streptococcus mucosus against $P$. pestis. Rogers (802) reported an antagonistic effect of $S$. lactis against $L$. bulgaricus; the active substance was thermostable and would not pass through a bacterial filter. More recently, certain streptococci were found $(625)$ to produce a very potent antibiotic which was thermostable and dialyzable; it was active against various gram-positive but not gram-negative bacteria; it was well tolerated on subcutaneous and 
intravenous injection, and was believed to offer promise as a chemotherapeutic agent.

Freudenreich (298) first emphasized the antagonistic action of staphylococci against various bacteria. The list was later enlarged to include gram-positive acid-resisting forms, corynebacteria, and the plague organism. Some of these antagonists were found to be able to lyse the dead cells of their own kind as well as those of various other organisms. Gundel (372) isolated from staphylococci an active lipoid which had bactericidal properties. A water-soluble, alcohol-insoluble substance, said to be an enzyme capable of bringing about the lysis of corynebacteria, was also isolated from a strain of staphylococcus (2 I 5 ).

Various micrococci possess strong antagonistic properties. Löde (580) isolated a micrococcus which affected a variety of microorganisms three or more centimeters away, the active substances being dialyzable. An organism related to Micrococcus tetragenus and described as $M$. antibioticus was found to possess a strong antagonistic action against $V$. comma, M. tuberculosis, E. typhosa, Ph. tumefaciens, Br. melitensis, various spore-forming bacteria, numerous cocci, and others.

Diplococci exerted an antagonistic action against various bacteria, including pyogenic staphylococci and streptococci in the sputum, sporeformers, and gram-negative bacteria. They produced, under aerobic conditions only, a filterable substance that was heat resistant.

The antagonistic action of pneumococci has definitely been established. The active substance of these organisms was said to be thermolabile, since it was destroyed at $80^{\circ}$ to $85^{\circ} \mathrm{C}$.; it was produced only under aerobic conditions. In reviewing the literature on the longevity of streptococci in symbiosis, Holman (440) observed that many chances of error are inherent in mixed cultures, particularly with closely similar organisms; pneumococci, for example, were found to be able to live for long periods in association with nonhemolytic streptococci. Peculiar antagonistic relations between pneumococci and staphylococci were also reported ( 13 ). Adaptive alterations could be expected in the growth of bacteria in mixed cultures $(32)$. Which of the two organisms antagonizes the other was believed to depend frequently upon the numerical abundance of one or the other (243). 
OTHER AEROBIC AND ANAEROBIC BACTERIA

The antagonistic action of $K$. pneumoniae against $B$. anthracis has been reported. Freudenreich (298) found that the filtrate of this antagonist repressed the growth of a number of bacteria, including the diphtheria and plague organisms.

Other aerobic bacteria were found capable of exerting antagonistic effects against one or more organisms, these effects varying considerably in nature and intensity. It is sufficient to mention the action of $P$. vulgaris against $B$. anthracis and $P$. pestis; of $P$ s. aviseptica against $B$. anthracis and $E$. typhosa; of Bacterium lactis aerogenes against $B$. anthracis and $P$. pestis. $B$. anthracis is capable of iso-antagonism and of antagonizing certain other organisms, including $E$. typhosa and Bacterium acidi lactici (786). Certain Myxobacteriales have been shown to be capable of bringing about the lysis of various plant-disease-producing bacteria; a thermostable lytic substance, passing through cellophane but not through a Seitz filter, was obtained. Although certain bacteria like Achromobacter lipolyticum were found capable of reducing the pathogenicity of $M$. tuberculosis, no active cell-free extract could be obtained (79).

$M$. tuberculosis produces a water-soluble substance, designated phthiocol, which in concentrations of 0.05 to 0.1 per cent inhibited the growth of various gram-positive and gram-negative bacteria, but not Ps. aeruginosa (568a).

Bacillus larvae, a gram-negative rod, was found (44I) capable of inhibiting the growth of various gram-positive and gram-negative bacteria. The human and bovine strains of $M$. tuberculosis were also inhibited but not the avian strain. The antibiotic was soluble in water but not in organic solvents. It was adsorbed on activated charcoal but no eluent could be found. It was moderately heat stable. Its antibiotic activity was inhibited by glucose but not by cysteine or sucrose.

The morphology of one bacterium may be considerably modified by the presence of another. Living cultures of $L$. bulgaricus influenced the variation of $E$. coli from the " $S$ " to the " $R$ " phase, inhibited development of the organism, and even brought about its lysis. No active sub- 
stance could be demonstrated; the lactic acid itself had only a limited effect (9). Korolev (528) has shown that when a yellow sarcina was added to solid media a stimulating effect was exerted on the growth of species of Brucella ( $\mathrm{Br}$. melitensis, $\mathrm{Br}$. abortus, $\mathrm{Br}$. suis); in liquid media, however, the activities of these species were repressed, the sarcina thus acting as an antagonist. A white staphylococcus exerted an antagonistic action on Brucella species both in liquid and on solid media.

Certain acid-producing aerobes were found capable of inhibiting toxin production by Clostridium botulinum in glucose but not in noncarbohydrate media (373). Since acid itself cannot bring about this effect, Holman (440) suggested that the acid must be active in a nascent state. A mixture of a Clostridium sporogenes and Cl. botulinum also interfered with the development of the toxin; it was even thought possible that the first anaerobe might cause the disappearance of toxin already produced (164, 165). S. aureus, E. coli, P. vulgaris, and other bacteria permitted the growth of $\mathrm{Cl}$. botulinum in aerobic cultures, accompanied by toxin production (290). However, Streptococcus thermophilus inhibited the growth of $\mathrm{Cl}$. botulinum, the toxin of the latter being gradually destroyed (493).

Passini (708) claimed that Bacillus putrificus verrucosus destroyed $M$. tuberculosis in nine days. The effect of other anaerobes on the survival of anthrax spores in dead animals has been extensively studied (440). Novy (688) reported that the injection into guinea pigs of $P$. vulgaris and Clostridium oedematiens resulted in rapid death of the animals and extensive growth of the anaerobe in the animal bodies; however, the simultaneous inoculation of $\mathrm{Cl}$. sporogenes and $P$. vulgaris did not result in putrid lesions. According to Barrieu (36), the presence of $P$. vulgaris and certain nonpathogenic spore-bearing aerobes in wounds favors, through their proteolytic activity, the virulence of pathogenic bacteria. Pringsheim (738) grew Cl. welchii with Alkaligenes fecalis for ten generations on agar slants and could easily detect in the growth of the latter the opaque colonies of the anaerobe. A liquefying sarcina allowed $\mathrm{Cl}$. welchii and $\mathrm{Cl}$. butyricum to grow in open tubes. Many war-wound infections were believed (985) to be due to an association of $P$. vulgaris with anaerobes, since the former increased the virulence of $C l$. perfringens and others. 
The antagonistic effects of lactic acid bacteria of the L. bulgaricus and L. acidophilus groups have received considerable attention, especially in regard to their action against intestinal bacteria. This was believed to be due to the production of acid by the bacteria rather than to the formation of specific antagonistic substances. This phenomenon aroused particular interest because of the function of some of these organisms in replacing bacterial inhabitants of the human digestive system (526).

Various bacteria also have a marked destructive effect upon plant pathogenic fungi, as will be shown later. Some produce stable, heatresistant, antifungal substances (73I).

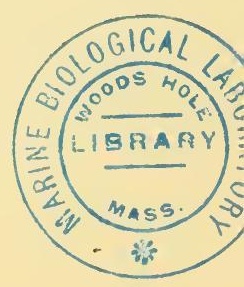




\section{ACTINOMYCETES AS ANTAGONISTS}

Actinomycetes are found in large numbers in many natural substrates. They occur abundantly in soils, composts, river and lake bottoms, in dust particles, and upon plant surfaces. Certain species are capable of causing serious animal and plant diseases.

Actinomycetes, like fungi, produce a mycelium, but they are largely unicellular organisms of dimensions similar to those of bacteria. Some of the constituent groups are closely related to the bacteria, others to the fungi. On the basis of their morphology, the order Actinomycetales has been divided into three families, Mycobacteriaceae, Actinomycetaceae, and Streptomycetaceae, comprising the genera Mycobacterium, Actinomyces, Nocardia, Streptomyces, and Micromonospora. These genera are represented in nature by many thousands of species, of which several hundreds have been described. A few are shown in Figure Io.

Comparatively little is known of the physiology of actinomycetes. Some produce certain organic acids from carbohydrates; others prefer proteins and amino acids as sources of energy, many species being strongly proteolytic. Some are able to attack starch, with the production of dextrins and sugar, accompanied by the formation of diastatic enzymes. Many reduce nitrates to nitrites. Some attack sucrose and form the enzyme invertase; others, however, do not. Certain species are able to utilize such resistant compounds as rubber and lignin. Synthetic media are favorable for the production of a characteristic growth and pigmentation. Among the pigments, the melanins have received particular attention. They range from the characteristic brown to various shades of black and deep green and are formed in protein-containing and in some cases also in protein-free media. The other pigments range from blue, yellow, and orange to various shades of grey.

According to Beijerinck (4I), the process of pigment production by actinomycetes in gelatin media is associated with the formation of a 


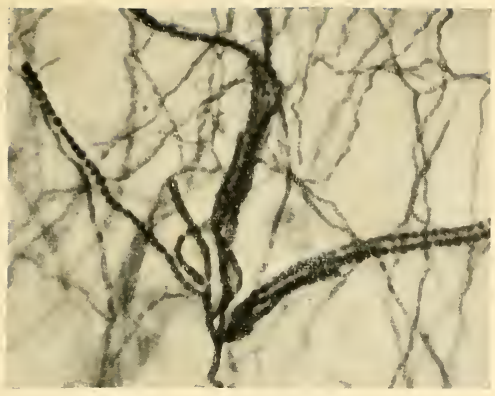

S. antibioticus, important antagonist.

From Waksman and Woodruff (974)

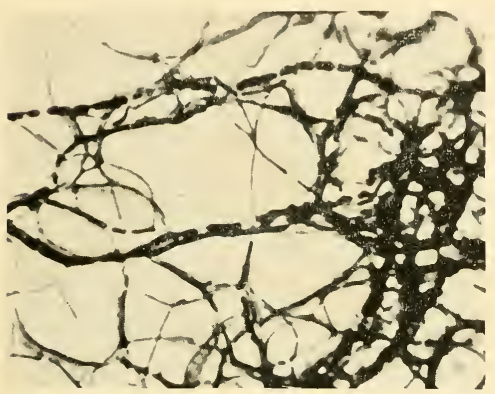

Submerged growth of S. lavendulae.

From Woodruff and Foster ( IO3I)

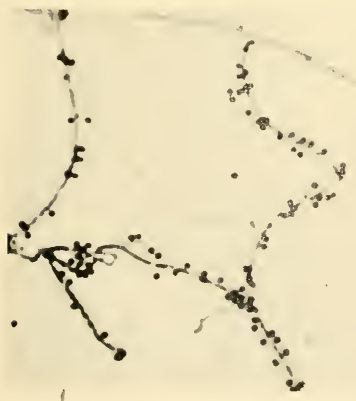

M. vulgaris. From Waksman,

Cordon, and Hulpoi (953)

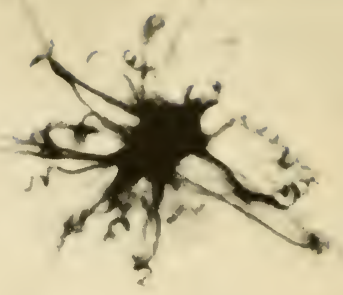

S. lavendulae, important antagonist

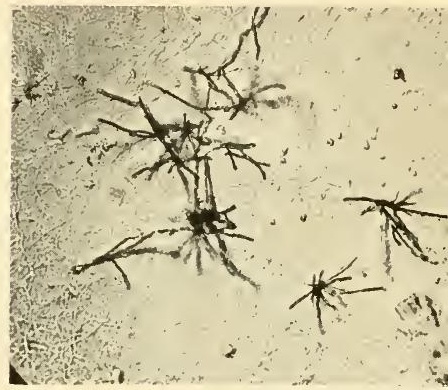

S. griseus, streptomycin-producing str: Prepared by Waksman and Schatz

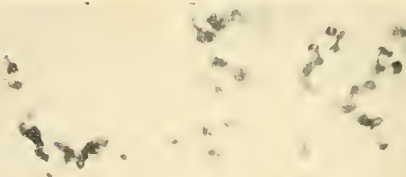

-

$-$

Streptomyces 3042 , showing close spi type of branching. Prepared by Stark

Figure io. Types of actinomycetes. 

quinone, which turns brown at an alkaline reaction and in the presence of oxygen. The action of quinone in the presence of iron was found to be similar to that of the enzyme tyrosinase. Since an excess of oxygen is required for the formation of quinone, only limited amounts are found in deep cultures. The quinone is believed to be formed from the peptone in the medium; although good growth was produced on media containing asparagine, $\mathrm{KNO}_{3}$, and ammonium sulfate as sources of nitrogen, only traces of quinone, if any, were found. The tyrosinase reaction is not involved in the production of all black pigments by actinomycetes; some species produce such pigments in purely synthetic media, in the complete absence of peptone.

Actinomycetes grow in liquid media in the form of flakes or small colonies, usually distributed either on the bottom and walls of the container or throughout the liquid; often a ring is formed on the surface of the medium around the wall of the vessel. In many cases, a full surface pellicle is produced, which may be covered with aerial mycelium. As a rule, the liquid medium does not become turbid, even in the presence of abundant growth. When grown on solid media, actinomycetes form small, compact, soft to leathery colonies; a heavy lichen-shaped mat is produced that may become covered by an aerial mycelium. The addition of a small amount of agar ( 0.25 per cent) to a liquid medium is highly favorable to growth, especially in large stationary containers.

Actinomycetes can also be grown in liquid media in a submerged condition, with suitable agitation and aeration in order to supply oxygen; the medium may also be kept in shaken state. Growth occurs in the form of a homogeneous suspension of discrete colonies and mycelial fragments throughout the liquid. Responses in growth and biochemical activities as a result of treatments may thus be obtained under more homogeneous physiological conditions.

Although most actinomycetes are aerobic, some are anaerobic, and many can grow st a reduced oxygen tension. The aerobic actinomycetes commonly found on grasses and in soil are said (5 I I) never to have been isolated from animal infections. Mixed infections consisting of anąerobes growing at body temperature together with aerobes have often been demonstrated. Certain aerobic species also are capable of 
causing infections in man and other animals, and certain plant diseases (potato scab, sweet potato pox) are caused by aerobic species of actinomycetes.

\section{ANTAGONISTIC PROPERTIES}

Many actinomycetes have the ability to antagonize the growth of other microorganisms, notably bacteria, fungi, and other actinomycetes; this is brought out in Tables 15 and I6. The antagonistic species are not limited to any one genus but are found among three genera, Nocardia, Streptomyces, and Micromonospora.

Gasperini (322) first demonstrated, in I 890, that certain species of the genus Streptomyces had a marked lytic effect upon other microorganisms. He emphasized that "Streptothrix develops habitually in a spontaneous manner upon the surface of bacteria and fungi, upon which it lives to a limited extent in the form of a parasite, due to the faculty that its mycelium possesses to digest the membrane from these lower fungi." Greig-Smith $(364,365)$ found that soil actinomycetes are antagonistic to not only bacteria but also certain fungi; since actinomycetes grow abundantly in normal soils, it was suggested that they may become an important factor in limiting bacterial development. Lieske established (57I) that specific actinomycetes are able to bring about the lysis of many dead and living bacterial cells; they are selective in their action, affecting only certain bacteria such as $S$. aureus and $S$. pyogenes, but not S. lutea, $S$. marcescens, or Ps. aeruginosa.

Rosenthal (805) isolated from the air an actinomyces species which he designated as the true biological antagonist of the diphtheria organism. He inoculated the surface of an agar plate with an emulsion of the bacteria and inoculated the actinomyces into several spots. At the end of two days, the plate was covered with the diphtheria organisms, but the colonies of the actinomyces were surrounded by large transparent zones. In another method utilized, agar was mixed with an emulsion of the diphtheria bacteria killed by heat, and the mixture was poured into plates. After solidification of the medium, the antagonist was inoculated in several spots on the plates. Its colonies gradually became surrounded by clear zones, thus proving that it produced a lytic 
TABLE I 5. ANTAGONISTIC PROPERTIES OF VARIOUS ACTINOMYCETES

\begin{tabular}{|c|c|c|c|}
\hline ANTAGONIST & ORGANISMS AFFECTED & KNOWN PROPERTY & REFERENCES \\
\hline S. albus & $\begin{array}{l}\text { Pneumococci, strepto- } \\
\text { cocci, staphylococci, } \\
\text { Ps. aeruginosa, etc. }\end{array}$ & $\begin{array}{l}\text { Thermolabile sub- } \\
\text { stance, causes lysis } \\
\text { of dead cells }\end{array}$ & $\begin{array}{l}354,357 \\
1001,1002\end{array}$ \\
\hline S. albus & Various fungi & $\begin{array}{l}\text { Protein, enzyme, } \\
\text { causes lysis of dead } \\
\text { and certain living } \\
\text { bacteria }\end{array}$ & $10-12$ \\
\hline S. antibioticus & $\begin{array}{l}\text { All bacteria and fungi, } \\
\text { especially gram-posi- } \\
\text { tive types }\end{array}$ & $\begin{array}{l}\text { Thermostable sub- } \\
\text { stance, bacterio- } \\
\text { static }\end{array}$ & 976 \\
\hline S. griseus & $\begin{array}{l}\text { Gram-positive and gram- } \\
\text { negative bacteria, not } \\
\text { fungi or anaerobic } \\
\text { bacteria }\end{array}$ & $\begin{array}{l}\text { Produces streptomy- } \\
\quad \text { cin }\end{array}$ & 830 \\
\hline S. lavendulae & $\begin{array}{l}\text { Various gram-positive } \\
\text { and gram-negative } \\
\text { bacteria }\end{array}$ & $\begin{array}{l}\text { Produces streptothri- } \\
\text { cin }\end{array}$ & 979 \\
\hline S. praecox & S. scabies & & 644 \\
\hline Streptomyces sp. & Bacteria and fungi & Lytic action & 322 \\
\hline Streptomyces sp. & Diphtheria & Growth inhibition & 805 \\
\hline Streptomyces sp. & $\begin{array}{l}\text { B. mycoides, proactino- } \\
\text { mycetes, mycobacteria }\end{array}$ & $\begin{array}{l}\text { Bactericidal action, } \\
\text { with or without } \\
\text { lysis }\end{array}$ & 76,534 \\
\hline Streptomyces sp. & Fusarium & Lytic action & 633 \\
\hline N. gardneri & Gram-positive bacteria & Bacteriostatic action & 313,958 \\
\hline Micromonospora & Gram-positive bacteria & $\begin{array}{l}\text { Thermostable active } \\
\text { substance produced }\end{array}$ & 958 \\
\hline Actinomycetes & Dead and living bacteria & Lysis & 571 \\
\hline Actinomycetes & Spore-forming bacteria & Repression of growth & 364,1000 \\
\hline Actinomycetes & Gram-positive bacteria & $\begin{array}{l}\text { Thermostable sub- } \\
\text { stance, produced on } \\
\text { synthetic media, } \\
\text { resembles lysozyme }\end{array}$ & 536,671 \\
\hline Actinomycetes & Pythium & $\begin{array}{l}\text { Thermostable sub- } \\
\text { stance }\end{array}$ & 908 \\
\hline
\end{tabular}


TABLE I6. ANTIBACTERIAL SPECTRUM OF CERTAIN ANTAGONISTIC ACTINOMYCETES

TEST ORGANISM

N. rubra

$N$. corallina

N. alba

M. rubrum

$M$. citreum

$M$. tuberculosis

$M$. smegmae

M. phlei

Corynebacterium sp.

E. coli

$S$. aureus

M. ruber

B. mycoides

$B$. megatherium

$B$. mesentericus

B. subtilis

B. tumescens

Ps. fluorescens

Ps. aeruginosa

$P$. vulgaris

$S$. marcescens

$M$. luteus

$M$. condicans

$M$. roseus

M. lysodeikticus

S. lutea

$A z$. vinelandii

Az. chroococcum

Rh. leguminosarum

Radiobacter
ZONE OF INHIBITION, IN MILLIMETERS

S. violaceus $S$. aurantiacus S. griseus

S. globisporus

\begin{tabular}{|c|c|c|c|}
\hline 35 & 32 & 0 & 0 \\
\hline 40 & 45 & 22 & 10 \\
\hline 40 & 25 & 0 & 0 \\
\hline 40 & 33 & 10 & 0 \\
\hline 38 & 37 & 0 & 0 \\
\hline 8 & 10 & 0 & 0 \\
\hline Io & 8 & 0 & 0 \\
\hline 20 & 25 & 0 & 0 \\
\hline 12 & IO & 0 & 0 \\
\hline 0 & 0 & 0 & 0 \\
\hline 25 & 19 & 0 & 0 \\
\hline 35 & 28 & 0 & 0 \\
\hline 30 & 10 & 0 & 0 \\
\hline 33 & 5 & 0 & 0 \\
\hline 30 & 2 & 0 & 0 \\
\hline 23 & I & 0 & 0 \\
\hline 22 & 0 & 0 & 0 \\
\hline 0 & 0 & 0 & 0 \\
\hline 0 & 0 & 0 & 0 \\
\hline 0 & 0 & 0 & 0 \\
\hline 0 & 0 & 0 & 0 \\
\hline 30 & 25 & 0 & 0 \\
\hline 37 & 22 & 0 & 0 \\
\hline 42 & 27 & 0 & 0 \\
\hline 38 & 33 & 0 & 0 \\
\hline 30 & 27 & 0 & 0 \\
\hline 3 & 0 & 0 & 0 \\
\hline 5 & 0 & 0 & 0 \\
\hline 0 & 0 & 0 & 0 \\
\hline 0 & 0 & 0 & 0 \\
\hline
\end{tabular}

From Krassilnikov and Koreniako (534).

substance that diffused through the agar and dissolved the diphtheria cells.

Gratia and Dath (357) suspended dead cells of staphylococci and other bacteria in 2 per cent agar and exposed the plates to the air. A cul- 
ture of a white actinomyces developed on the plates, each colony being surrounded by a clear zone of dissolved bacterial cells. By transferring this culture to a suspension of dead staphylococci in sterile saline, a characteristic flaky growth was produced, the bacterial suspension becoming clarified in 36 hours. When the lysed emulsion was filtered, the filtrate could again dissolve a fresh suspension of dead staphylococci. This culture was found able to attack all staphylococci tested as well as certain gram-negative bacteria, such as Ps. aeruginosa; however, it was inactive against $M$. tuberculosis and $E$. coli. Some antagonistic strains could also attack $E$. coli, though this property was readily lost.

This type of antagonism was believed to be widely distributed in nature and to be directed against many bacteria, pathogenic and saprophytic. The culture of the antagonist in bouillon gave a very active agent, whereas the lysed bacterial suspension was weaker in its action. The active substance was present extensively in old cultures and was fairly stable. The material obtained by lysing the suspension of bacteria by means of an antagonist was designated as "mycolysate." It did not possess the toxicity of the nonlysed suspension but it preserved its antigenic properties (356). Gratia (354) also reported that actinomycetes were able to attack living cells of bacteria, except $E$. coli and $E$. typhosa which had to be first killed by heat before they could be dissolved.

Welsch (IOOI, IOO2) made a detailed study of the lytic activity of an actinomyces culture, presumably identical with that employed by Gratia and later described as Actinomyces albus. The culture was grown in different media, the best results being obtained in very shallow layers of ordinary bouillon. The active substance present in the filtrate was designated as "actinomycetin." It was able to dissolve, at least partly, all dead bacteria, whether killed by heat or by chemicals, gram-positive or gram-negative, though gram-negative bacteria were, as a rule, more susceptible. The growing culture of the antagonist brought about better clarification (lysis) of the bacterial suspension than the filtrate. The solubilizing properties of the active agent, its susceptibility to heat and to ultraviolet rays, its size as measured by ultrafiltration, suggested its protein nature. The kinetics of its action pointed to its being an enzyme. It was precipitated by acetone, alcohol, and ammonium sulfate. Most of the gram-negative bacteria were not attacked either by actinomycetin 
or by the living culture of the antagonist. Only a few of the grampositive bacteria, including certain pneumococci and streptococci, could be dissolved by sterile actinomycetin. A definite parallelism in the activity of the preparation against dead bacteria and of the living culture against living bacteria suggested that the same substance is concerned in both cases. The bacteria were therefore divided ( 1000 ), on the basis of their relation to actinomycetin, into three groups:

Bacteria that were lysed by the culture filtrate; these included pneumococci and hemolytic streptococci

Bacteria that were not dissolved even by the most active soluble substance, but which were depressed by the mycelium of the living actinomyces; these comprised various sarcinae and fluorescens types

Bacteria that were not acted upon by either the living culture or the actinomycetin preparation; these included the colon-typhoid and the pyocyaneus groups, though when the latter were killed by heat or inactivated by radium emanations, as in the case of $E$. coli, or were placed under conditions unfavorable to multiplication, they were dissolved by the lytic substance.

The first detailed survey of the distribution of antagonistic organisms among actinomycetes was made by a group of Russian investigators. According to Borodulina (76), actinomycetes are able to antagonize various spore-forming bacteria and to bring about the lysis of their living cells. A thermostable substance was produced on agar media. The activity of this substance was greatly reduced at an alkaline reaction, whereas an acid reaction favored it. When $B$. mycoides and an antagonist were inoculated simultaneously into peptone media, no inhibitive effect was obtained, because the bacterium changed the reaction of the medium to alkaline, thereby making conditions unfavorable for the production of the antibiotic substance by the antagonist. When the antagonist was first allowed to develop in the medium, before the bacterium was inoculated, a strong antagonistic effect resulted, which led to the elongation of the vegetative cells of $B$. mycoides; this was due to a delay in fission and was accompanied by the suppression of spore formation.

Krassilnikov and Koreniako (534) found that many species of actinomycetes belonging to the genus Streptomyces but not Nocardia pro- 
duced a substance that possessed a strong bactericidal action against a large number of microorganisms. This substance was particularly active against nocardias, mycobacteria, and micrococci; it was less active upon spore-bearing bacteria and had no action at all on nonspore-forming bacteria, as illustrated in Table I6. Under the influence of the antibiotic factor, the microbial cells were either entirely lysed or killed without subsequent lysis. The action upon spore-bearing bacteria was bacteriostatic but not bactericidal. The nonspore-forming bacteria, including species of Rhizobium and Azotobacter, not only were not inhibited but were actually able to develop in filtrates of the antagonists.

Of 80 cultures of actinomycetes isolated from different soils, 47 possessed antagonistic properties, but only 27 of them secreted antibiotic substances into the medium (Table I 7). These agents were capable of inhibiting the growth of gram-positive but not of gram-negative bacteria or fungi. The nature of the action of the various antagonists was

TABLE I7. OCCURRENCE OF ANTAGONISTIC ACTINOMYCETES IN DIFFERENT SOILS

\begin{tabular}{|c|c|c|c|}
\hline & $\begin{array}{l}\text { TOTAL STRAINS } \\
\text { OF ACTINOMY- }\end{array}$ & $\begin{array}{l}\text { NUMBER OF } \\
\text { ANTAGONISTIC }\end{array}$ & $\begin{array}{l}\text { STRAINS WHICH } \\
\text { LIBERATED TOXIC }\end{array}$ \\
\hline NATURE OF SOIL & CETES TESTED & STRAINS & SUBSTANCES \\
\hline Chernozem & 24 & 10 & 9 \\
\hline Podzol & II & 7 & 3 \\
\hline Solonets & 4 & 4 & 4 \\
\hline High altitude soil & 9 & 6 & 5 \\
\hline Sandy soil & 6 & 5 & I \\
\hline Dry desert soil & 5 & 4 & I \\
\hline River bank meadow & 14 & 7 & 2 \\
\hline \multirow[t]{2}{*}{ Cultivated soil } & 7 & 4 & 2 \\
\hline & - & - & - \\
\hline Total & 80 & 47 & 27 \\
\hline
\end{tabular}

From Nakhimovskaia (671).

found not to be identical. Some excreted water-soluble substances into the medium, others did not. All the antibiotic agents were thermostable, since heating for 30 minutes at 1.5 atmospheres only reduced somewhat their activity. For those antagonists which did not excrete 
any substance into the medium, the presence of the growing antagonist was essential in order to bring about an inhibition of bacterial development. On the basis of their sensitivity to the antibiotic substance of actinomycetes, mycobacteria could be differentiated from nonsporeforming, especially nodule-forming, bacteria. The production of the antibiotic substance was highest in synthetic media and was rather weak or even totally absent in media that contained proteins. The substance was filterable and was able to resist the effect of radiation.

It was further reported (67I) that the antagonistic effects of actinomycetes were manifested not only in artificial media but also in soil, the interrelations here being much more complex. Some of the strains that produced antagonistic effects in artificial nutrient media were ineffective under soil conditions. The antagonistic action was more intense in light podzol soils and was greatly reduced in heavy or chernozem soils. One of the factors that resulted in a decrease in the antagonistic properties of actinomycetes in the heavy soils was apparently the high content of organic matter. By adding peptone to a light soil, the antagonistic action of the actinomycetes was greatly weakened. When actinomycetes were allowed to multiply in the soil before inoculation with $B$. mycoides, the antagonistic effect was highly pronounced even in the presence of high concentrations of peptone.

An attempt to isolate an antibiotic substance from some of the soil actinomycetes was made by Kriss (536). On the basis of its properties he was led to conclude that this substance could be classified definitely with lysozyme. It was insoluble in ether, petroleum ether, benzol, and chloroform, and was resistant to the effects of light, air, and high temperatures. The optimum reaction for the production of this substance by Streptomyces violaceus was found to be $\mathrm{pH} 7 . \mathrm{I}$ to 7.8 , the activity not being increased by selective cultivation. On the basis of its properties, this substance could hardly be classified with egg-white lysozyme. It must be concluded also that the differences in the antibiotic properties of the various antagonistic actinomycetes isolated by the Russian investigators definitely point to the fact that more than one antibiotic substance was involved.

In a more recent survey (958) of the distribution of antagonistic actinomycetes in soils and in composts, it was found that of 244 cultures 
isolated at random from different soils, 49 , or 20 per cent, of the cultures were actively antagonistic; 57, or 23 per cent, showed some antagonistic properties; and 138 , or 57 per cent, possessed no antagonistic action at all (Table I 8). A somewhat similar distribution of antagonistic properties was observed among a group of well-identified species taken from a type culture collection, embracing I6I pure strains. Only one of the members of the genus Nocardia proved to be antagonistic; only one of the Micromonospora forms was active. Most of the antagonists were found among the members of the genus Streptomyces. These cultures were also examined for bacteriolytic properties, living $S$. aureus being

TABLE I 8. ISOLATION OF ANTAGONISTIC ACTINOMYCETES FROM VARIOUS SUBSTRATES

\begin{tabular}{|c|c|c|c|c|c|c|c|c|c|}
\hline $\begin{array}{l}\text { SOURCE OF } \\
\text { ORGANISMS }\end{array}$ & $\begin{array}{l}\text { TOTAL } \\
\text { CULTURES } \\
\text { ISOLATED }\end{array}$ & $\begin{array}{l}\text { Cul- } \\
\text { tures }\end{array}$ & $\begin{array}{l}\text { Percent- } \\
\text { age of } \\
\text { total }\end{array}$ & $\begin{array}{l}\text { GRC } \\
\text { Cul- } \\
\text { tures }\end{array}$ & $\begin{array}{l}\text { Percent- } \\
\text { age of } \\
\text { total }\end{array}$ & $\begin{array}{l}\text { GRC } \\
\text { Cul- } \\
\text { tures }\end{array}$ & $\begin{array}{l}\text { UP In } \\
\text { Percent- } \\
\text { age of } \\
\text { total }\end{array}$ & $\begin{array}{l}\text { Cul- } \\
\text { tures }\end{array}$ & $\begin{array}{l}\text { UP IV } \\
\text { Percent- } \\
\text { age of } \\
\text { total }\end{array}$ \\
\hline \multicolumn{10}{|l|}{$\begin{array}{l}\text { Fertile, ma- } \\
\text { nured, and }\end{array}$} \\
\hline $\begin{array}{l}\text { limed soil } \\
\text { Infertile, un- } \\
\text { manured, }\end{array}$ & 74 & 20 & 27.0 & 5 & 6.8 & I & I. 3 & 48 & 64.9 \\
\hline limed soil & 75 & II & $14 \cdot 7$ & 8 & 10.7 & 4 & 5.2 & 52 & 69.3 \\
\hline $\begin{array}{l}\text { Potted soil } \\
\text { Potted soil, en- } \\
\quad \text { riched with }\end{array}$ & $1-$ & I & $7 \cdot 7$ & $\mathbf{I}$ & $7 \cdot 7$ & 0 & 0 & I I & 84.6 \\
\hline E. coli & 21 & I & 4.8 & 4 & 19.0 & 4 & 19.0 & 12 & 57.2 \\
\hline $\begin{array}{l}\text { Potted soil, en- } \\
\text { riched with } \\
\text { mixtures of }\end{array}$ & 1- & & & & 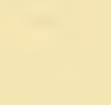 & & & & \\
\hline bacteria & I 5 & I 2 & 80.0 & 2 & I $3 \cdot 3$ & 0 & 0 & I & 6.7 \\
\hline $\begin{array}{l}\text { Lake mud } \\
\text { Stable-manure }\end{array}$ & 9 & 3 & $33 \cdot 3$ & 4 & $44 \cdot 4$ & 0 & 0 & 2 & 22.2 \\
\hline compost & 37 & $\begin{array}{r}I \\
-\end{array}$ & 2.7 & 20 & 54.0 & $\begin{array}{r}4 \\
-\end{array}$ & 10.8 & 12 & 32.4 \\
\hline Total & 244 & 49 & 20.I & 44 & I 8.0 & I 3 & $5 \cdot 3$ & 138 & 56.6 \\
\hline
\end{tabular}

From Waksman, Horning, Welsch, and Woodruff (958).

Note. The organisms in group I were the most active antagonists, those in groups II and III had more limited antagonistic properties, and those in group IV showed no antibacterial effects with the methods used. 
used as the test organism. On this basis, 87 cultures (53.I per cent) were found to be inactive, 53 cultures ( 32.3 per cent) were moderately active, and 24 cultures ( 14.6 per cent) were highly active. The conclusion was reached ( 1000 ) that bacteriolytic activities against killed bacteria and living gram-positive bacteria are widely distributed among the actinomycetes. Growth-inhibiting properties of actinomycetes were found to be significantly associated with bacteriolytic action upon living gram-positive bacteria.

Certain actinomycetes also show antagonistic activities against fungi (IO-I 2, 908). S. albus was capable of inhibiting the growth of all the species of fungi tested, an effect shown to be due to the production of an active substance. By the use of a culture of Colletotrichum gloeosporioides, the antagonistic activities of 80 type cultures of actinomycetes were measured. The antagonist was allowed to grow for 5 days

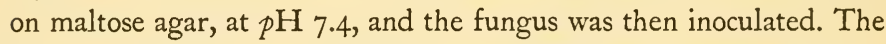
cultures of actinomycetes were divided, on this basis, into three groups: strong, weak, and noninhibitors. The first group comprised I 7.5 per cent of the cultures; the second, 38.8 per cent; and the third, 43.7 per cent. These results are surprisingly similar to those reported for the distribution of actinomycetes possessing antibacterial properties, including those that were isolated at random from the soil and those taken from a culture collection.

Meredith (633) made a survey of the distribution of organisms antagonistic to Fusarium oxysporum cubense in Jamaica soils; most of these antagonists belong to the actinomycetes. The antagonists were not evenly distributed in the various soil samples, Io of the 66 samples giving 44 per cent of the antagonistic organisms. Those actinomycetes that were antagonistic to Fusarium when grown in their own soil-solution agar were not always antagonistic when tested in soil-solution agar prepared from other soil. A culture of actinomyces isolated from a compost produced lysis of the Fusarium. When spores of both organisms were mixed in an agar medium, the fungus developed normally for two days but began to undergo lysis on the fifth day, large sections of the mycelium disappearing. On the seventh day only chlamydospores were observed. In 9 days the fungus completely disappeared, the actinomyces making a normal growth. 


\section{NATURE OF ANTIBIOTIC SUBSTANCES}

It has already been established that antagonistic actinomycetes readily produce a variety of different types of antibiotic substances. Some of these have been isolated and even crystallized and information has been gained concerning their chemical nature. Others have been obtained in the form of crude but highly active preparations. Still others are known but they have not been isolated as yet and have, therefore, been rather insufficiently studied. So far, eight substances have been definitely recognized: actinomycetin, actinomycin, streptothricin, streptomycin, proactinomycin, micromonosporin, litmocidin, and mycetin.

Among the various antagonistic actinomycetes, five species have been studied in detail and, therefore, deserve particular attention, namely, S. antibioticus (974), S. lavendulae (979), S. griseus (830), $N$. gardneri (313), and $S$. albus (1000).

$S$. antibioticus produces a highly active antibiotic substance that has been isolated and described as actinomycin. It was shown to be antagonistic to all species of bacteria tested as well as to many fungi (Table 19). Actinomycin is not affected by heat. It is soluble in ether and in alcohol as well as in other solvents, but in water only in very high dilutions. It is highly toxic to animals.

Several species of actinomycetes are capable of producing actinomycin in both organic and synthetic media, the yield varying with the organism (955a, 1002a). The addition of 0.25 per cent agar to stationary cultures increases considerably the growth of the organism and the production of actinomycin. The presence of a small amount of starch, phosphate, and sodium chloride was also found to be favorable. Actinomycin-producing forms are strictly aerobic, and are able to produce actinomycin only when grown either in very shallow layers or under aerated or agitated submerged conditions.

$S$. lavendulae is capable of inhibiting the growth of many gramnegative and gram-positive bacteria. It produces an antibiotic substance designated as streptothricin.

For the production of streptothricin, the tryptone can be replaced by a variety of simple nitrogenous compounds, such as glycine (Table 20), alanine, aspartic acid, asparagine, and glutamic acid; the carbo- 
TABLE I9. BACTERIOSTATIC SPECTRUM OF ACTINOMYCIN

\begin{tabular}{|c|c|c|c|c|c|}
\hline \multirow[t]{2}{*}{ ORGANISM } & \multirow[t]{2}{*}{ GRAM STAIN } & \multicolumn{4}{|c|}{$\begin{array}{l}\text { ACTINOMYCIN ADDED, MILLIGRAMS } \\
\text { PER LITER OF MEDIUM }\end{array}$} \\
\hline & & 0.1 & 1.0 & 10 & 100 \\
\hline S. marcescens & - & 3 & 3 & 3 & 3 \\
\hline A. aerogenes & - & 3 & 3 & 3 & $3^{*}$ \\
\hline E. coli (intermediate) & - & 3 & 3 & 3 & $3 *$ \\
\hline E. coli & - & 3 & 3 & 3 & $1 *$ \\
\hline Ps. aeruginosa & - & 3 & 3 & 3 & 0 \\
\hline Ps. fluorescens & - & 3 & 3 & 3 & 0 \\
\hline Br. abortus & - & 3 & 3 & 3 & 0 \\
\hline N. catarrhalis & - & 3 & 3 & 2 & 0 \\
\hline E. carotovora & - & 3 & 3 & 2 & 0 \\
\hline Sh. gallinarum & - & 3 & 2 & 2 & 0 \\
\hline A. stutzeri & - & 3 & 2 & $\mathbf{I}$ & 0 \\
\hline$H$. pertussis & - & 3 & 3 & 0 & 0 \\
\hline Az. vinelandii & - & 3 & o & 0 & o \\
\hline S. cellulosae & + & 3 & 2 & I & o \\
\hline S. californicus & + & 3 & 3 & 2 & o \\
\hline M. tuberculosis & + & 3 & 3 & o & o \\
\hline Cl. welchii & + & 3 & 0 & 0 & o \\
\hline B. macerans & + & 3 & 3 & 0 & $\circ$ \\
\hline B. megatherium & + & 3 & 0 & 0 & $\circ$ \\
\hline B. polymyxa & + & 3 & 0 & 0 & $\circ$ \\
\hline B. mycoides & + & I & o & 0 & o \\
\hline B. mesentericus & + & $\mathbf{I}$ & 0 & 0 & o \\
\hline B. cereus & + & $\mathbf{I}$ & o & 0 & o \\
\hline B. subtilis I & + & 0 & 0 & 0 & 0 \\
\hline B. subtilis II & + & 0 & 0 & 0 & 0 \\
\hline G. tetragena & + & 0 & 0 & 0 & o \\
\hline S. lutea & + & 0 & 0 & 0 & o \\
\hline Streptococci and staphylococci & + & 0 & 0 & 0 & 0 \\
\hline
\end{tabular}

From Waksman and Woodruff (975).

Note. $O$ indicates no growth; 1 , trace of growth; 2, fair growth; 3, good growth.

* If $200 \mathrm{mg}$. per liter were added the results were usually as follows: for $A$. aerogenes, fair; for $E$. coli (intermediate), trace; for $E$. coli, no growth.

hydrate may be left out completely, with only limited reduction in activity. No growth of the organism is obtained on tryptophane, phenyl alanine, and certain other forms of nitrogen. Good growth may be obtained with ammonium sulfate or sodium nitrate, but the production of 
TABLE 2O. GROWTH AND PRODUCTION OF STREPTOTHRICIN BY

S. LAVENDULAE

\begin{tabular}{lccccc}
\hline & & & \multicolumn{2}{c}{ GROWTH } & \multicolumn{2}{c}{ ACTIVITY } \\
SOURCE OF & MREAT- & MANT OF & OF INCU- PER IOO ML. & \multicolumn{1}{c}{ E. } & B. sub- \\
NITROGEN & CULTURE & BATION & OF MEDIUM & coli & tilis \\
Tryptone & Shaken & 2 & 346 & 150 & 1,000 \\
Tryptone & Shaken & 5 & 253 & 100 & 1,000 \\
Glycine & Shaken & 2 & 162 & 30 & 30 \\
Glycine & Shaken & 5 & 266 & 100 & 500 \\
Tryptone & Stationary & 8 & 245 & 20 & 200 \\
Glycine & Stationary & 8 & 239 & 25 & 150 \\
\hline
\end{tabular}

From Waksman (946).

Note. The organism was grown in I per cent starch medium.

the active substance is limited unless the organism is grown under submerged conditions. Iron appears to play an essential role in the production of the active substance. An increase in growth as a result of an increase in the amino-acid concentration, with the same amount of carbohydrate, causes an increase in the production of streptothricin. An increase in growth as a result of an increase in carbohydrate concentration does not.

When the medium contains one amino acid as the only source of carbon and nitrogen, there is gradual increase in the alkalinity of the medium, resulting in the destruction of the streptothricin. Neither the growth of the organism nor the production of the streptothricin, however, is influenced by the reaction of the medium, within certain limits, even between $\mathrm{pH}_{4.4}$ and 8.0 ( 1028 ). The metabolism of $S$. lavendulae and the course of production of streptothricin under stationary and submerged conditions are illustrated in Figure I I. The bacteriostatic spectrum of streptothricin is shown in Table $2 \mathrm{I}$. It has a certain delayed, even if limited, toxicity to animals and is active in vivo against both gram-positive and gram-negative bacteria (792).

Different strains of $S$. lavendulae differ greatly in their ability to produce streptothricin. The possibility that other species of Streptomyces are also capable of producing streptothricin or closely related compounds, as indicated by somewhat different antibiotic spectra, has also 


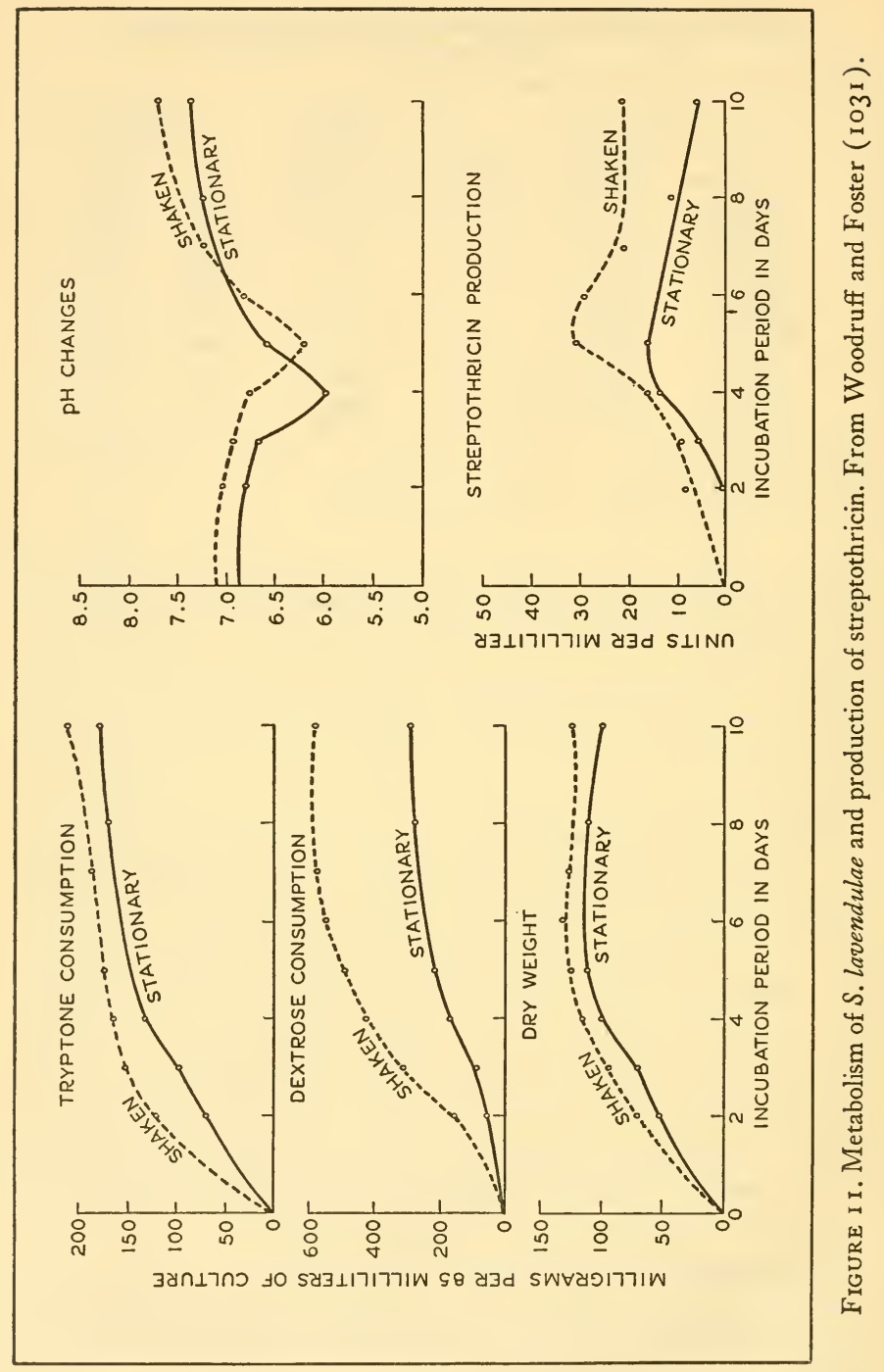


ORGANISM

$B$ subtilis

B. mycoides

B. macerans

B. megatherium

$B$. polymyxa

B. cereus

$M$. lysodeikticus

S. muscae

S. lutea

A. aerogenes*

$A$. aerogenes

E. coli $\dagger$

E. coli (4348)

S. marcescens

S. marcescens

Ps. fluorescens

Sh. gallinarum

$P$. pseudotuberculosis

$B r$ abortus

S. cholerasuis

S. schottmülleri

S. abortivoequina

S. typhimurium

$H$. suis

$H$. influenzae

$B r$ abortus

Az. agile

$A z$. vinelandii

Az. chroococcum

$A z$. indicum

M. phlei

Cl. butyricum $\S$

L. casei§

S. albus

S. violaceus-ruber

S. lavendulae
CRUDE STREPTOTHRICIN ADDED, MILLIGRAMS PER 10 CUBIC CENTIMETERS AGAR

$\begin{array}{llll}0.3 & 0.1 & 0.03 & 0.01\end{array}$

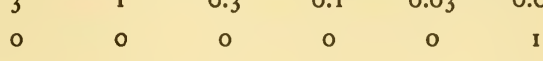

22

2

2

2

2

2.

2

2

2

\section{2}

2

\section{2}

2

2

2

$$
2
$$

From Waksman and Woodruff (979).

Note. 0 indicates no growth; 1 , limited growth; 2, good growth; $\mathrm{Tr}$, trace of growth.

* Representing 3 distinct strains.

$\dagger$ Representing 5 strains of $E$. coli obtained from different sources.

$\ddagger$ Representing 4 strains.

$\$$ Cultured anaerobically. 
been established (969). Other members of the genus are capable of forming different antibiotics (498).

$S$. griseus produces an antibiotic substance, designated as streptomycin, that is also active against both gram-positive and gram-negative bacteria. It is similar in its solubility and certain chemical properties to streptothricin; however, it acts readily against $B$. mycoides and is more active than streptothricin against certain gram-negative bacteria, such as $M$. tuberculosis, $S$. marcescens, and Ps. aeruginosa. The bacteriostatic spectrum of streptomycin is given in Table 22. Streptomycin is also active in vivo against a variety of other bacteria, as shown later. It is also active against spirochetes, but it is not active against fungi, anaerobic bacteria or viruses (79I).

TABLE 22. BACTERIOSTATIC SPECTRUM OF STREPTOMYCIN

\begin{tabular}{|c|c|c|c|}
\hline ORGANISM & $\mu g$ & ORGANISM & $\mu g$ \\
\hline A. aerogenes & $0.5-2.5$ & M. tuberculosis, hominis & 0.15 \\
\hline B. anthracis & 0.375 & N. gonorrhoeae & 5.0 \\
\hline B. megatherium & $0.25-3.0$ & $P$. pestis & $0.75^{-1.5}$ \\
\hline B. mycoides & $0.1-3.8$ & P. tularensis & $0.15-0.3$ \\
\hline B. subtilis & $0.12-1.0$ & Ph. pruni & 0.25 \\
\hline$B r$. abortus & $0.5-3.75$ & Pr. vulgaris & $0.4-3.0$ \\
\hline$B r$. suis & 0.5 & Ps. aeruginosa & $2.5-25.0$ \\
\hline Cl. butyricum & 8.0 & Ps. fluorescens & I 2.5 \\
\hline Cl. tetani & $>104$ & S. lutea & 0.25 \\
\hline C. diphtheriae & $0.375-3.75$ & S. marcescens & I.O \\
\hline D. pneumoniae & 8.0 & S. enteritidis & 0.5 \\
\hline E. typhi & $1.0-37.5$ & S. schottmülleri & 2.0 \\
\hline Er. muriseptica & 2.5 & Sh. paradysenteriae & $0.25-3.75$ \\
\hline E. coli & $0.3-3.75$ & S. aureus & $0.5^{->}>16.0$ \\
\hline H. influenzae & $1.56-5.0$ & S. hemolyticus & $2.0->16.0$ \\
\hline H. pertussis & $1.25-3.0$ & S. viridans & $>\mathrm{I} 6$ \\
\hline L. monocytogenes & 2.5 & V. comma & $6.0-37 \cdot 5$ \\
\hline K. pneumoniae & $0.625-8.0$ & A. bovis & 3.75 \\
\hline M. mallei & $10->10.0$ & $N$. asteroides & I 2.5 \\
\hline M. avium & 10.0 & S. antibioticus & $<0.4$ \\
\hline M. phlei & 0.12 & S. lavendulae & 1.25 \\
\hline
\end{tabular}

From Waksman and Schatz (970).

Note. Unit of activity is the number of micrograms of streptomycin per milliliter of suitable medium required to inhibit growth. 
One of the important cultural characteristics of the production of streptomycin is the need for a specific substance in the medium, as found in meat extract, corn steep, or the mycelium of the actinomyces. On a medium containing sodium nitrate or an amino acid as a source of nitrogen, the organism produces good growth but little antibiotic activity. However, when the mycelium thus formed in the culture is added to fresh medium, streptomycin production takes place. This indicates that the organism is capable of synthesizing the streptomycin "precursor," but not in sufficient amounts to influence the production of the antibiotic in the culture. For rapid and abundant formation of streptomycin, the presence of a "precursor" in the medium is required. The presence of a small amount of carbohydrate, such as glucose, is also favorable to growth and the production of the streptomycin. The reaction of the medium changes first to acid and later to alkaline, the highest alkalinity ( $p \mathrm{H} 8.2$ to 8.6 ) corresponding to the maximum production of the streptomycin. When the culture begins to undergo lysis, there is another increase in acidity of the culture, accompanied by an increase in viscosity, due to the formation of slimy material.

Growth and activity reach a maximum in stationary cultures in 8 to Io days, at $28^{\circ} \mathrm{C}$., and in submerged cultures in 2 to 3 days. The latter depends largely on the nature and amount of inoculum: with a heavy inoculation of pregerminated spore material the maximum may be reached in 36 to 48 hours.

Streptomycin is produced only by certain strains of $S$. griseus. Even the active culture may gradually deteriorate $(832)$ due to the formation of inactive strains or spore-free variants, which are unable to form the antibiotic. For the successful production of streptomycin, it is essential, therefore, continuously to select active strains from the mother culture.

The streptomycin is found in the culture filtrate, from which it can be isolated by suitable methods. However, the mycelium of the organism appears to contain small amounts of a second antibiotic factor which is soluble in ether, and which has a bacteriostatic spectrum distinct from that of streptomycin. This second factor has not been sufficiently studied.

$N$. gardneri produces an active bacteriostatic substance that has been 
designated as proactinomycin ( 313$)$. Its bacteriostatic spectrum is shown in Table 23. It is produced on both synthetic and organic media. It is effective chiefly against gram-positive bacteria, although to a more limited extent than actinomycin.

$S$. violaceus produces on synthetic media a substance partly soluble in water, and largely soluble in alcohol, benzene, chloroform, and dichlorethane, but not in ether. It gives a deep violet color in alcoholic solution and is active against gram-positive bacteria, less so against mycobacteria and corynebacteria, and not at all against gram-negative bacteria. It was designated as mycetin $(245,533 a)$. Various gram-negative bacteria, as well as pus, reduce its activity.

$N$. cyanea (Pr. cyaneus) produces a pigment, designated litmocidin, which is related to the anthocyanins and inhibits the growth of various bacteria in vitro but not in vivo (80a, 323b).

TABLE 23. BACTERIOSTATIC EFFECT OF PROACTINOMYCIN

\begin{tabular}{|c|c|}
\hline ORGANISM & $\begin{array}{l}\text { APPROXIMATE DILUTION OF } \\
\text { MATERIAL IN MILLILITERS } \\
\text { GIVING HIGHEST EFFECT }\end{array}$ \\
\hline D. pneumoniae & $1,500,000$ \\
\hline S. pyogenes & 500,000 \\
\hline S. aureus & 500,000 \\
\hline N. meningitidis & 500,000 \\
\hline$B$. anthracis & 500,000 \\
\hline V. comma & 6,000 \\
\hline S. typhi, S. paratyphi B, Shigella, E. coli & 2,000 \\
\hline
\end{tabular}

From Gardner and Chain (313).

S. albus forms a bacteriolytic substance designated as actinomycetin, which is a protein and is enzymatic in nature. Its lytic action upon bacteria was visualized by Welsch (IOOO) as a two-step reaction: first, the susceptible cells are killed by the selectively bactericidal lipoid; second, those dead cells are dissolved by the bacteriolytic enzyme, which alone is responsible for the lysis of heat-killed bacteria. The phenomenon does not take place in complex culture media, since the bactericidal 
action of the lipoid is greatly impaired under those conditions; the presence of the living actinomyces is generally necessary, since free lipoid should be secreted in the susceptible suspension.

Certain actinomycetes can produce agents that are capable of exerting a lytic effect not only upon the organisms that produce them but also upon other organisms (IOI I). The formation of an autolytic substance by a thermophilic actinomyces was also demonstrated $(492,531)$. The filtrates of such lysed cultures were said to offer promise in the treatment of actinomycosis caused by Actinomyces bovis (185).

In the case of some actinomycetes, like $S$. griseus, the lysis of the cells appears to be a definite stage in the life cycle of the organism. This is observed particularly in rapidly growing submerged cultures, especially when they are inoculated not with fresh spores but with cell growth previously obtained under submerged conditions. The production of streptomycin is definitely associated with the lysis of the culture; when lysis progresses, not only does streptomycin formation cease completely but the substance already formed may be rapidly destroyed.

Despite a seeming similarity in their growth characteristics, and despite the fact that some investigators (356) assumed that all actinomycetes are able to act as antagonists, it is now definitely established (534, 971,974 ) that one is dealing here with highly specific types or strains. Although many actinomycetes yield, either in the culture filtrate or in the mycelium, an ether-soluble substance that has some bacteriostatic activity, only certain species, such as $S$. antibioticus, are capable of producing the typical actinomycin.

Both the quantitative production of the substance and the presence of other substances depend entirely upon the culture of the organism. One is dealing here both with strain specificity and with species characteristics.

Strains can be isolated from antagonistic actinomycetes that are completely inactive. This phenomenon seems to be correlated with the type of growth of the organism; nonsporulating strains of $S$. griseus, for example, do not produce streptomycin. The formation of this antibiotic agent is associated definitely with the growth of certain sporulating strains of this organism (832). 


\section{ANTAGONISTIC EFFECTS OF ACTINOMYCETES}

\section{AGAINST AGENTS PRODUCING}

\section{PLANT DISEASES}

Various species of Streptomyces are also strongly antagonistic against bacteria causing plant diseases, such as Bacterium solanacearum (426). According to McCormack (593), aerobic conditions are necessary for the development of the antagonistic properties of actinomycetes; those requiring less oxidized conditions are themselves antagonized. B. megatherium, for example, was said to be antagonistic to certain species but was antagonized by others. Ps. fluorescens, however, was antagonistic to actinomycetes as a whole, causing their lysis.

Actinomycetes possess antagonistic properties not only against bacteria but also against some other actinomycetes. The more aerobic species are antagonistic to the less aerobic types. Millard (644) believed that he succeeded in controlling potato scab caused by Streptomyces scabies by the use of green manures such as grass cuttings. The development of scab on potatoes grown in sterilized soil and inoculated with $S$. scabies was reduced by the simultaneous inoculation of the soil with Streptomyces praecox, an obligate saprophyte. By increasing the proportion of the latter organism to the pathogen, the degree of scabbing on the test potatoes was reduced from roo per cent to nil. The sterilized soil provided sufficient nutrients for the development of the antagonist and only a small increase in the control was obtained when grass cuttings were added and sterilized along with the soil.

Sanford (820) was unable, however, to control potato scab by the inoculation, with $S$. scabies and $S$. praecox, of both steam-sterilized and natural soil containing different amounts of green plant materials. These organisms were perfectly compatible on potato dextrose agar, as well as in a steam-sterilized soil medium. The control of scab, therefore, was said to have been due not to the direct action of $S$. praecox but to certain other undetermined microorganisms favored by the presence of the green manure. $S$. scabies is very sensitive to various products of fungi and bacteria. When grown in close proximity to various bacteria, the acid production of the latter inhibited S. scabies to a considerable degree. Its complete inhibition was not due to the acid reaction 
alone, however, since a certain bacterium was isolated from the soil which definitely inhibited the growth of this plant pathogen.

Goss (347) observed that the severity of scab is dependent on the amount of $S$. scabies present in the soil, which was believed to be controlled by the soil microflora. No evidence was obtained as to whether the effect of the soil flora on $S$. scabies was due to specific organisms. Kieszling ( 502 ) isolated two cultures of bacteria which were antagonistic to $S$. scabies; when added to the soil, these bacteria prevented the development of scab on potatoes.

\section{IN VIVO ACTIVITY OF SUBSTANCES PRODUCED BY ACTINOMYCETES}

Just as the chemical nature of the antibiotic agents produced by actinomycetes varies, so does the action of these agents in the animal body. Some, like actinomycin, are very toxic, whereas others, like streptothricin and streptomycin, have low toxicity and give great promise of practical application. Because of the activity of streptothricin and streptomycin against gram-negative bacteria and because of the lack of reliable chemotherapeutic agents active against these bacteria, the utilization of these substances in the treatment of certain diseases caused by such bacteria has become very significant. Some preparations, like actinomycetin, have been utilized in the preparation of a bacterial hydrolysate (mycolysate) for vaccination purposes. Streptomycin has come to be recognized as an important chemotherapeutic agent in the treatment of a number of infectious diseases. 


\section{FUNGI AS ANTAGONISTS}

THE antagonistic interrelationships in which fungi are involved comprise the following reactions: (a) the antibacterial activities of fungi; (b) the antagonistic effects of fungi upon fungi; (c) the effects of bacteria and actinomycetes upon fungi; (d) the action of fungi upon insects and other animal forms. From the point of view of practical utilization, two aspects deserve special consideration: (a) the utilization of fungi for combating human and animal diseases; (b) the antagonistic interrelationships of fungi with other organisms, since fungi comprise the most important group of microorganisms that cause plant diseases.

\section{ANTIBACTERIAL EFFECTS OF FUNGI}

Apparently Gosio is to be credited (268) with having first demonstrated that a crystalline material produced by a species of Penicillium has the capacity of inhibiting the growth of a bacterium, namely $B$. anthracis; this substance is now known as mycophenolic acid. Soon afterward, in 1897, Duchesne (21 I) reported that certain green Penicillia are capable of repressing the growth of various bacteria or of bringing about their attenuation. Vaudremer (934) demonstrated in 1913 that the presence of $A$. fumigatus results in the attenuation of the cells of M. tuberculosis.

Vaudremer (934) was the first to attempt the clinical utilization of a fungus product. He treated "more than 200 patients" suffering from tuberculosis with extracts of the fungus; although no toxic effects were observed, the curative properties of the preparation were such as not to justify any significant conclusions.

Since these early studies a number of fungi have been found to possess antibacterial properties; this phenomenon has sometimes been spoken of as mycophagy (935a). Several fungi have been studied in detail, and in some cases one or more antibiotic substances have been isolated (Figure I2). The property of inhibiting the growth of bacteria is 


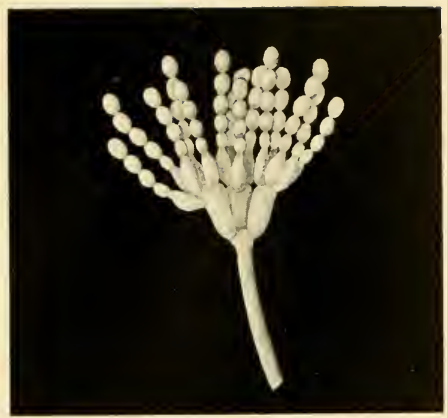

Typical conidial structure of $P$. notatum NRRL 832. From Raper and Alexander (764)

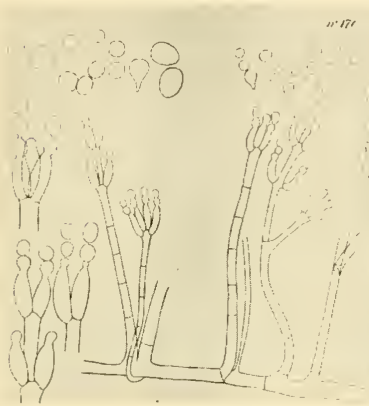

P. citrinum. From Biourge (56)

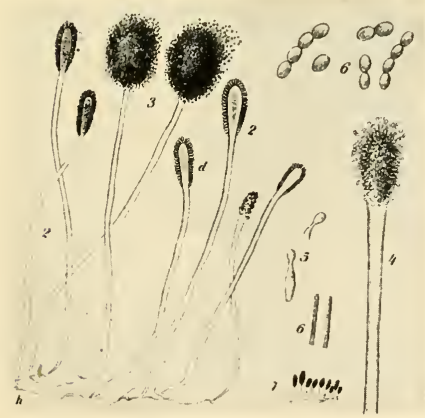

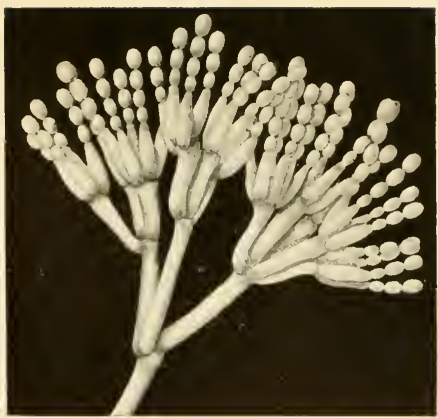

Typical penicillus of NRRL 1951. From Raper and Alexander (764)

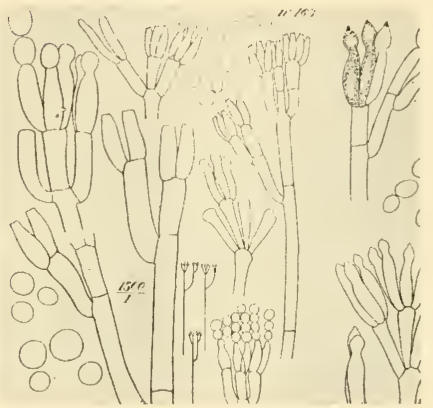

P. chrysogenum. From Biourge (56)

A. clavatus. From Wehmer (983a) A. fumigatus. From Wehmer (983a)

Figure 12. Some typical fungi that produce antibiotic substances. 

not characteristic of any one genus or even species, but of certain strains within a given species. Different strains may produce distinct variants of a given antibiotic. This is true especially of penicillin, of which a number of types have now been isolated, varying both chemically and in their selective antibacterial properties.

Some organisms produce more than one antibiotic. Two genera, Penicillium and Aspergillus, have been found to comprise a large number of antagonistic forms. Several other genera are also known to contain organisms that possess antibacterial properties; very few of these, however, were ever found among the Phycomycetes; the Basidiomycetes also include a large number of organisms capable of producing antibiotics.

The active fungi may be divided (956) into the following eleven groups:

Aspergillus clavatus

A. flarus-oryzae

Penicillium luteum-purpurogenum

Penicillium notatum-chrysogenum

Trichoderma-Gliocladium

Miscellaneous other fungi
A. fumigatus

Penicillium cyclopium-claviforme

Fusarium-Cephalosporium

Chaetomium and other Ascomycetes Basidiomycetes

A comparative study of a number of fungi taken from a culture collection brought out (IOI 7 ) the fact that about 40 per cent of the Aspergilli (Aspergillus fumaricus, A. fumigatus, Aspergillus schiemannii, Aspergillus terreus) and 25 per cent of the Penicillia (Penicillium chrysogenum, Penicillium claviforme, Penicillium funiculosum, Penicillium expansum) possessed antagonistic properties. In a study of 100 strains of Aspergilli ( IOI 8 ), 28 were found to be active against $S$. aureus, 16 against $E$. coli, and 9 against $P$ s. aeruginosa; strains of $A$. niger were most positive and those of $A$. versicolor were negative. Among the Penicillia, in addition to $P$. notatum, the following were shown (IOIO) to produce considerable antibiotic action: $P$. brunneoviolaceum, $P$. chloro-leucon, $P$. citrinum, $P$. chrysogenum, and $P$. griseo-roseum, the last two species producing the penicillin-type of action. The composition of the medium and the nature of the strain are of great importance. The active producers of antibiotic substances belong to the group of 
Asymmetrica. Of many Phycomycetes tested, only Phythophthora erythroseptica showed some activity. A few Ascomycetes were also found to be active. Next in importance to the Aspergilli and Penicillia as producers of bacteriostatic substances are the Basidiomycetes.

A summary of the antibacterial properties of various fungi and of the antibiotic substances produced by them is given in Table 24. In addition to the specific strain of the organism, the composition of the medium and the conditions of growth, especially aeration, are most important in controlling the amount and nature of the antibiotic substance produced by the organism. Different strains of the same organism when grown under identical conditions vary greatly in the production of the antibiotic substance, as shown for A. clavatus (968) and other fungi (497).

\section{Penicillium notatum-chrysogenum Group}

Because of the production by these organisms of penicillin, which has already found a wide practical application, this group of fungi deserves special attention. Fleming (26I) first observed that a fungus culture growing on a staphylococcus plate brought about destruction of the bacteria, as shown by the fact that the colonies became transparent and were undergoing lysis. The fungus was isolated in pure culture and was later identified as $P$. notatum. It was found to possess marked bacteriostatic and bactericidal properties for some of the common pathogenic bacteria, largely the gram-positive cocci and the staphylococci, the streptococci, the diphtheria organism, and the gonococci and meningococci; bacteria belonging to the colon-typhoid-dysentery group were not affected. The culture filtrate of the fungus was found to contain an active substance, which was designated as penicillin.

The selected culture of the fungus is grown on one of the media described earlier (pp. 65-69). The reaction of the medium changes from slight initial acidity ( $p \mathrm{H} 6$ to 7 ) to distinct acidity ( $p \mathrm{H} 3.0$ ), followed later by alkalinity, finally reaching a $p H$ of 8.0 or even 8.8 . A faint to deep yellow color is produced in the medium. Penicillin production is usually at its maximum at about $p \mathrm{H}_{7}$ and may remain constant for several days or may fall again rapidly. In stationary cultures, once a fungus pellicle has been produced, the medium can be replaced several times, 
ANTAGONIST

A. clavatus

A. floous

A. flavus

A. fumigatus

A. fumigatus

A. fumigatus

and $A$. albus

A. niger

Chaetomium sp.

Gliocladium and

Trichoderma

$P$. citrinum

P. claviforme

$P$. notatum and

$P$. chrysogenum

$P$. notatum

\section{$P$. puberulum} and $P$. cyclopium
$P$. resticulosum
Various bacteria

Penicillium sp.
ORGANISMS AFFECTED

Gram-negative and grampositive bacteria

Streptococci, staphylococci, and certain grampositive bacteria

Mostly gram-positive bacteria

Gram-positive bacteria

Various bacteria

M. tuberculosis

Gram-positive and gramnegative bacteria

Various gram-positive bacteria

Various gram-positive and gram-negative bacteria

Various bacteria

Gram-positive and gramnegative bacteria

Mostly gram-positive and also certain gram-negative (Neisseria, Gonococcus) bacteria

All bacteria tested, in presence of glucose

Various bacteria

Gram-negative as well as gram-positive bacteria
ACTIVE SUBSTANCE

REFERENCES

Clavacin, highly

$957,968,1012$ bactericidal

Aspergillic acid $480,740,1006$

Flavicin, similar to, $103,605,950$ if not identical with, penicillin

Fumigacin, gliotoxin

Fumigatin, spinu- $\quad 702$ losin

Active filtrate

I 05 I

Aspergillin

Chaetomin

956

Gliotoxin, highly bacteriostatic

Citrinin 745

Claviformin

I 24, 125

Penicillin, active

$5,75,146$, in vivo, low tox- $262,437,770$, icity

956

Notatin, penatin, penicillin B, $E$. coli factor

Penicillic acid

Crude metabolic product

Penicidin $61,698,703$

62

$157,517,521$, 786,956

$61,698,703$ 9 
giving fresh lots of penicillin in about half the time required for the initial growth. Crude penicillin cultures are capable of inhibiting the growth of staphylococci in dilutions of $\mathrm{I}: 800$. Recently, much more active preparations have been obtained ( $\mathrm{I}: \mathrm{I0}, 000$ ).

Chain et al. (123) were the first to succeed in isolating from the culture medium of $P$. notatum a water-soluble, stable, brown powder which had marked antibacterial activity. This preparation inhibited, in dilutions of I to several hundred thousand, the growth of many aerobic and anaerobic bacteria. The active material was relatively nontoxic to laboratory animals. Intravenous and subcutaneous injections of $10 \mathrm{mg}$. or more to mice had little or no effect. The material was active in vivo, subcutaneous injections saving the lives of mice injected intraperitoneally with $S$. pyogenes or $S$. aureus. Intramuscular infections of mice with $C l$. septicum were also successfully treated by repeated subcutaneous injections of penicillin.

An extensive literature soon began to accumulate on the production ( $127, \mathrm{r} 28,17 \mathrm{r}, 28 \mathrm{I}$ ), isolation, and identification of penicillin. The course of its formation in the culture of the organism is illustrated in Figure 13. Conditions of nutrition were found to be particularly important. Preparations having an activity of 2,000 Oxford units or 100,000,000 dilution units have been obtained. The importance of the dual nature of $P$. notatum (the culture being composed of two distinct cell constituents) must be recognized for maximum penicillin production $(34,377)$. The low toxicity of penicillin, its solubility in water, and its in vivo activity make it an ideal agent for combating disease caused by gram-positive bacteria.

$P$. notatum represents an extremely variable group of organisms, some strains producing considerable penicillin, others producing little penicillin but large amounts of a second factor, designated as penatin or notatin. Some strains of a closely related fungus, $P$. chrysogenum, are also capable of producing penicillin that is apparently the same as the penicillin of $P$. notatum. The $P$. notatum-chrysogenum group of fungi is widely distributed in nature, having been isolated from different soils and from various moldy food products; however, only a few strains produce enough penicillin to justify their use for the commercial production of this substance. 


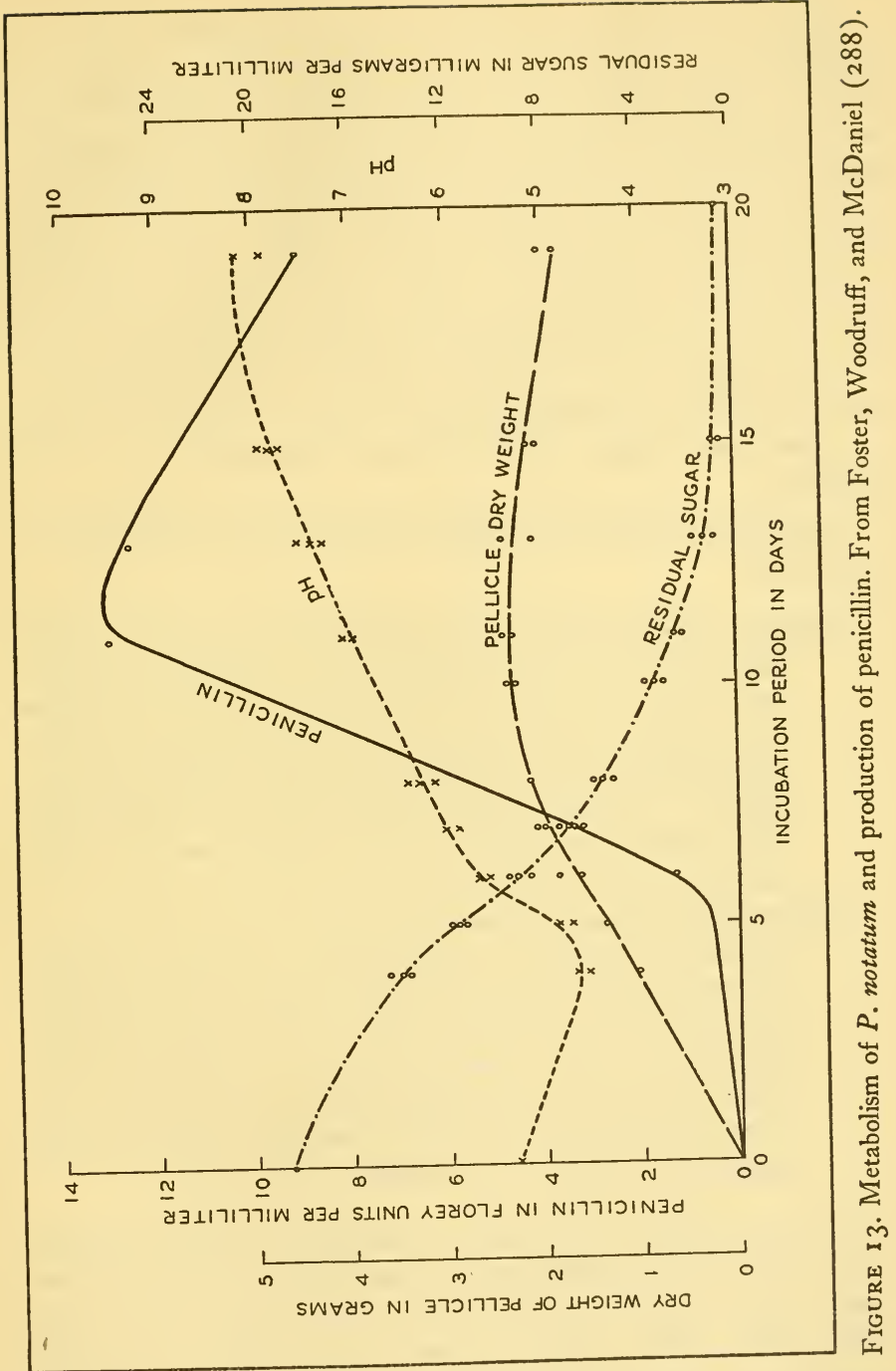


Raper et al. (765) summarized the principal characters which distinguish the $P$. notatum-chrysogenum group as follows: (a) colonies, at 10 to 2 days, velvety or loose-textured, plane or radially furrowed, with sporing areas in blue-green shades; (b) the colonies are generally characterized by abundant yellow exudate, often collecting in conspicuous droplets; (c) reverse of colony yellow, usually becoming brown with age; the agar medium becomes yellow; (d) the penicillus usually consists of from 2 to 5 more or less divergent columns of spores; it represents an asymmetric, biverticillate structure with smooth walls throughout; (e) the conidia or spores are smooth walled, varying from globose and sub-globose $(P$. notatum) to elliptical $(P$. chrysogenum), and ranging in size from approximately 2.5 to $4.0 \mu$ in diameter.

Among a large number of cultures investigated, two subgroups were recognized.

Subgroup I comprises those that are characterized by penicillin yields ranging from about 20 to $35 \mathrm{O} . \mathrm{U} . / \mathrm{ml}$; the colonies are loose textured, comparatively deep, heavily sporing, at first pale blue-green but becoming darker with age; conidiophores often comparatively long and rather coarse, bearing large penicilli; conidia typically subglobose to definitely elliptical, characteristic of $P$. chrysogenum. These strains are common in soil and also occur in considerable abundance in a wide variety of other natural substrates.

Subgroup II comprises the strains that produce 50 to 80 O.U./ml. of penicillin; the colonies are fairly compact or even close textured, velvety throughout, dark green with abundant yellow exudate; conidiophores bear penicilli somewhat smaller than those of Subgroup I, typical of $P$. notatum. These strains have been isolated from soil, cheese, fruits, and bread. Different isolations were found to vary greatly in their capacity to produce penicillin; substrains derived from these also show marked variation in productivity.

$P$. notatum lends itself readily to the study of sectorial mutants. These either can arise spontaneously or can be induced by special treatments, such as irradiation with x-rays or bombardment of the culture with neutrons (667). This phenomenon can be utilized for genetic studies (727). Mutants have thus been obtained which produce un- 


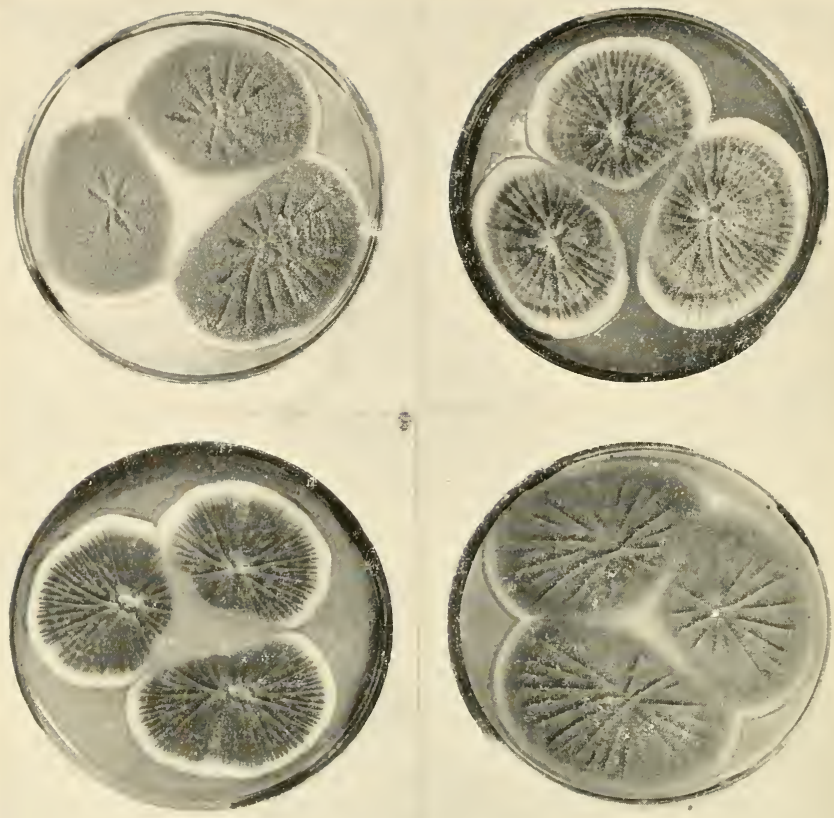

है
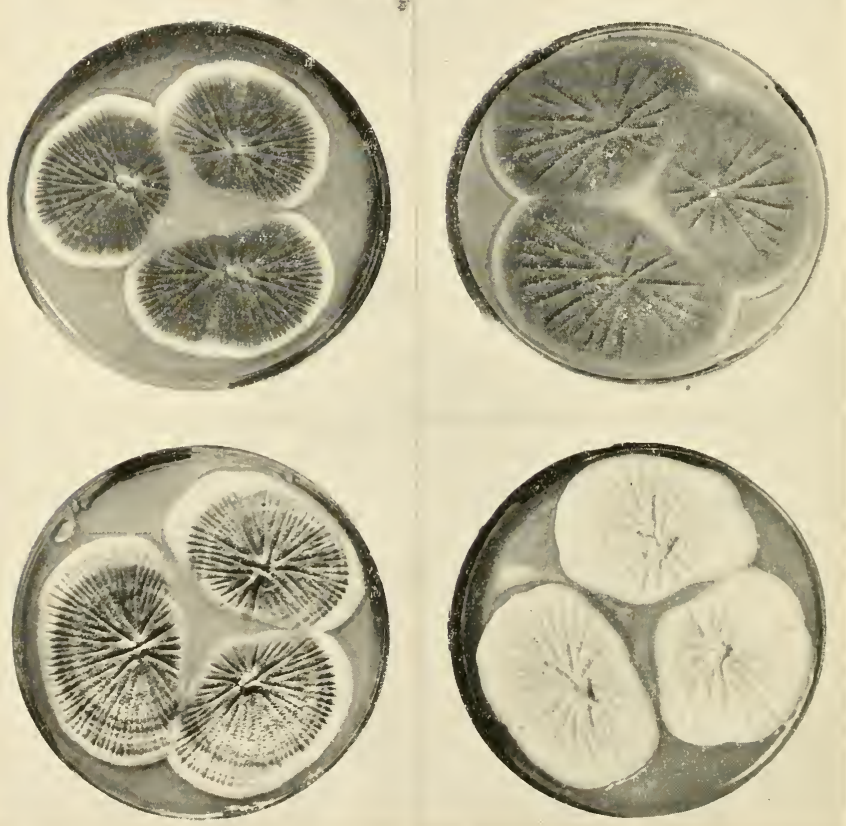

Figure I f. P. chrysogenum, NRRL 1951, and derivative strains. From Raper and Alexander $(764)$. 
usually high yields of penicillin in submerged culture (475). On examination in plate culture as well as microscopically, these high-penicillin-yielding mutants resembled the parent strains from which they were isolated. Some of the high-yielding cultures are relatively stable; others, however, are quite unstable, giving substrains with substantially greater yields of penicillin. Light-sporing substrains give reduced yields; white nonsporulating strains are characterized by low yields (764). Some of the most productive strains were found to vary primarily in biochemical activity, and only little in cultural or structural details. Some of the variations are brought out in Tables 25 and 26 and in Figures 14 and 15.

TABLE 25. PRODUCTION OF PENICILLIN IN SUBMERGED CULTURE BY NRRL 832 AND THREE SELECTED SUBSTRAINS

\begin{tabular}{|c|c|c|c|c|c|c|c|c|}
\hline \multirow[b]{2}{*}{ CULTURE } & \multicolumn{2}{|c|}{ THIRD DAY } & \multicolumn{2}{|c|}{ FOURTH DAY } & \multicolumn{2}{|c|}{ FIFTH DAY } & \multicolumn{2}{|c|}{ SIXTH DAY } \\
\hline & $\begin{array}{l}\text { Penicillin } \\
\text { O.U./ml. }\end{array}$ & $p \mathrm{H}$ & $\begin{array}{l}\text { Penicillin } \\
\text { O.U./ml. }\end{array}$ & $p \mathrm{H}$ & $\begin{array}{l}\text { Penicillin } \\
\text { O.U./ml. }\end{array}$ & $p \mathrm{H}$ & $\begin{array}{l}\text { Penicillin } \\
\text { O.U./ml. }\end{array}$ & $p \mathrm{H}$ \\
\hline 832 stock & 35 & $7 \cdot 9$ & 65 & 8.1 & $6 I$ & 8.3 & 40 & 8.5 \\
\hline $832 . A_{2}$ & 47 & $7 \cdot 9$ & 92 & 8.0 & 83 & 8.3 & 50 & 8.4 \\
\hline $8_{32 .} A_{2}(6)$ & 37 & 8.1 & 62 & 8.0 & 75 & 8.2 & 52 & 8.4 \\
\hline $832 . B_{2}$ & 29 & 8.2 & 37 & $7 \cdot 7$ & 42 & 8.1 & 35 & 8.4 \\
\hline
\end{tabular}

From Raper and Alexander (764).

TABLE 26. PRODUCTION OF PENICILLIN IN SURFACE CULTURE BY NRRL I 249.B2 I, I950, I978, AND TWO SUBSTRAINS OF I978, A AND B

\begin{tabular}{|c|c|c|c|c|c|c|c|c|}
\hline \multirow[b]{2}{*}{ CULTURE } & \multicolumn{2}{|c|}{ FOURTH DAY } & \multicolumn{2}{|c|}{ FIFTH DAY } & \multicolumn{2}{|c|}{ SIXTH DAY } & \multicolumn{2}{|c|}{ SEVENTH DAY } \\
\hline & $\begin{array}{l}\text { Penicillin } \\
\text { O.U./ml. }\end{array}$ & $p \mathrm{H}$ & $\begin{array}{l}\text { Penicillin } \\
\text { O.U./ml. }\end{array}$ & $p H$ & $\begin{array}{l}\text { Penicillin } \\
\text { O.U./ml. }\end{array}$ & $p \mathrm{H}$ & $\begin{array}{l}\text { Penicillin } \\
\text { O.U./ml. }\end{array}$ & $p \mathrm{H}$ \\
\hline I 249. B 2 I & 76 & 6.4 & 185 & $7 \cdot 2$ & 177 & $7 \cdot 9$ & 135 & 8.2 \\
\hline I 950 stock & 98 & $7 \cdot 3$ & 139 & $7 \cdot 7$ & 103 & 8.0 & 81 & 8.3 \\
\hline 1978 stock & 120 & 6.9 & 233 & $7 \cdot 4$ & I 14 & 7.9 & 162 & 8.3 \\
\hline $1978 \mathrm{~A}$ & 109 & $7 \cdot 3$ & I 54 & 7.6 & I 31 & 8.0 & 85 & 8.3 \\
\hline $1978 \mathrm{~B}$ & 124 & 6.9 & 262 & $7 \cdot 3$ & 246 & 7.8 & 190 & 8.2 \\
\hline
\end{tabular}

From Raper and Alexander (764). 


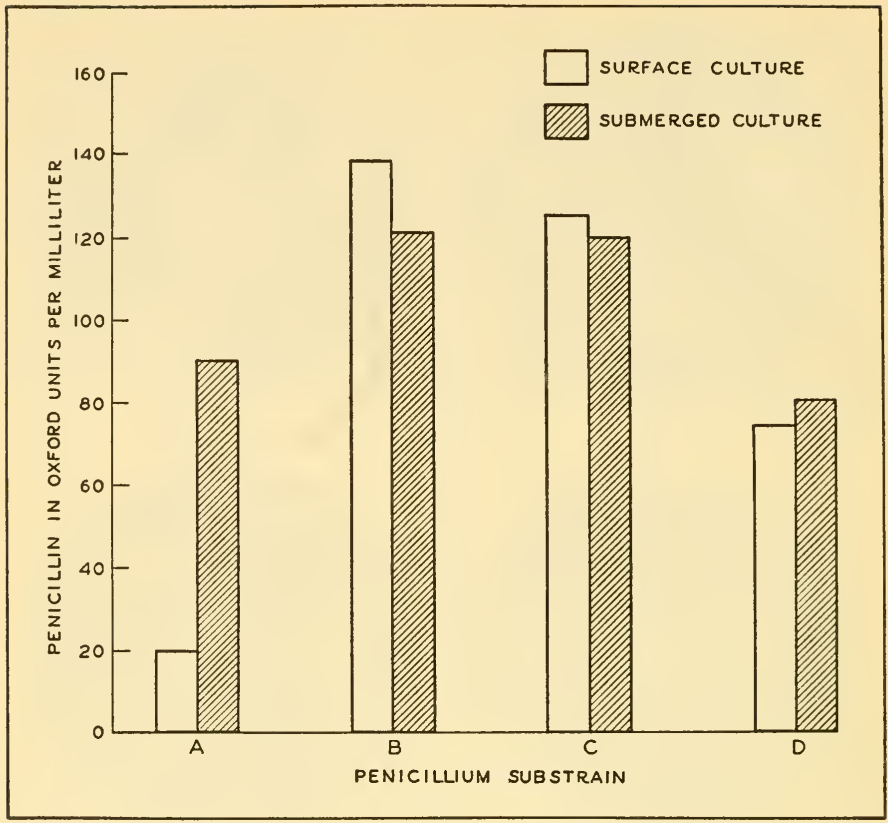

FIgURe 15. Comparative production of penicillin by substrains of $P$. chrysogenum $1951 . \mathrm{B}_{25}$ in surface culture and submerged culture. From Raper and Alexander (764).

As a result of these studies the following conclusions were reached $(763,764)$ :

I. The capacity to produce penicillin as a metabolic product is a groupspecific rather than a strain-specific character.

2. Different members of the $P$. notatum-chrysogenum group vary greatly in their capacity to produce penicillin.

3. Special strains are particularly suited for certain types of penicillin production.

For surface production of penicillin, no strain was found to be better than the original Fleming culture that has been freed from degenerate, 
mutant strains. This freeing of mutants must be carried out continuously, in order to avoid the degeneration of the culture. By strain selection and improvement of medium (addition of corn steep liquor, use of lactose), the penicillin yield of such cultures has been increased from 2 to 6 to more than 200 O.U./ml. (662). For submerged cultures, however, strains of $P$. notatum and $P$. chrysogenum are used which are not related to the Fleming strain. The best medium for tank production is about half the concentration of the nutrients used for surface culture. Pregerminated inocula are used (663).

In a study of the metabolism of the penicillin-producing fungi (308a) it was established that the most important factors for high yields of penicillin are the nature of the culture, aeration, temperature, and proper balance among the nutrients of the medium, especially the relation between the carbon and nitrogen sources (59I). Specific amino acids have an influence on the yield of penicillin, especially in submerged culture (375). Yields ranging from 90 to 900 units of penicillin were obtained under submerged conditions of growth.

The rate of utilization of different sugars and oxygen consumption by penicillin-producing strains of a submerged culture is brought out in the following summary (519):

$\begin{array}{ccc}\text { RUGAR } & \begin{array}{c}\text { RATE OF UTILIZATION } \\ \text { GM./L/HOUR }\end{array} & \mathrm{O}_{2} \text { UPTAKE } \\ \text { ML./L/HOUR }\end{array}$

The lactose is more slowly utilized than the glucose, and less oxygen is required for penicillin production. The addition of boron to the medium favors lactose utilization and results in a higher rate of respiration and nitrogen utilization, with a less abundant mycelium, lower ammonia levels, and higher penicillin yields (520).

At least four different penicillins have been isolated, namely, F, G, $\mathrm{X}$, and $\mathrm{K}$, two or more being found in the same culture broth. These penicillins differ in their chemical characteristics, in their antibacterial spectra, and also in their chemotherapeutic utilization. For example, penicillin $\mathrm{X}$ is more effective in the treatment of gonorrhea than $\mathrm{G}$. 
Various cocci are 6 to 8 times more sensitive to $\mathrm{X}$ than to commercial penicillin, which is largely $G$ (695).

Penicillin or penicillin-like substances are also produced by $A$. flavus, A. parasiticus (149), A. giganteus (722), and a variety of other fungi, largely species of Aspergillus and Penicillium, including $A$. niger, $A$. nidulans, $A$. oryzae, $P$. citreo-roseum (28I), P. crustosum (1039), and others, such as $A$. flavipes (1005).

Certain species of Penicillium are also capable of producing other antibacterial substances, namely, citrinin, penicillic acid, and clavacin, the first of which is also produced by species of Aspergillus belonging to the candidus group (906).

Atkinson (29) tested 68 cultures of Penicillium and found that 18 possessed antibacterial properties. These cultures were divided into two groups: first, those largely active against gram-positive bacteria and producing substances like penicillin and citrinin; second, those active also against gram-negative bacteria and producing substances of the penicillic acid and penicidin types.

\section{Aspergillus flavus-oryzae Group}

The $A$. oryzae members of this group possess only limited antagonistic properties. Many of the $A$. flavus strains, however, apparently have the property of producing at least two antibacterial substances when grown on suitable media and under suitable conditions.

White and Hill ( I006) isolated from cultures of a strain of $A$. flavus grown on tryptone media a crystalline substance, aspergillic acid, that showed antibacterial activity against certain gram-negative as well as gram-positive bacteria. The substance was produced when the organism was grown on organic media, but not on synthetic. It was soluble in ether, alcohol, acetone, or acetic acid, but not in petroleum ether; it was soluble in dilute acid or alkaline aqueous solutions, and was precipitated by phosphotungstic acid. Aspergillic acid proved to have relatively high toxicity, and showed no protective action against hemolytic streptococci or pneumococci infections in mice.

Glister isolated a culture (338) that also produced an antibacterial agent with a wide range of activity, both gram-positive and gram-negative bacteria being inhibited by the culture filtrate. An extract was ob- 
tained that inhibited the growth of these bacteria in a dilution of approximately I : 200,000 .

A. flavus was found (46) to produce frequent variants; two of these consistently gave far higher yields of aspergillic acid than those reported by White. The substance was found to have wide activity, especially against gram-positive cocci, but was less active against the anaerobes of gas gangrene and the gram-negative bacteria.

Bush and Goth ( $\mathrm{IO}_{3}$ ) isolated from $A$. flavus a second substance designated as flavicin. They grew the organism for 6 to 8 days on a nitrate-glucose medium containing 2 per cent corn steep. The filtrate was acidified to $p \mathrm{H}_{2} 2.5$ to 3.0 with phosphoric acid and extracted with purified isopropyl ether. The ether was treated with a slight excess of $0.2 \mathrm{~N} \mathrm{NaHCO}_{3}$ ( 5 to Io cc. per liter of culture), giving a yield of 75 to roo per cent of active material obtained. Purification was obtained by acidification of the $\mathrm{NaHCO}_{3}$ extract with $\mathrm{H}_{3} \mathrm{PO}_{4}$ to $\mathrm{pH}$ 2 to 3 and removal of the precipitate, the latter containing most of the toxicity (due no doubt to aspergillic acid) and the filtrate most of the activity. The filtrate was treated with ice-cold isopropyl ether, saturated with $\mathrm{CO}_{2}$, washed with cold distilled water, and reextracted. The combined extracts were distilled at $0^{\circ} \mathrm{C}$. to dryness under $\mathrm{CO}_{22}$. A yellow-orange glassy residue was obtained. It had a low toxicity and was active in vivo.

The similarity to penicillin of the second antibiotic substance produced by $A$. flavus has been definitely established $(605,606)$ by chemical isolation and composition, solubility and stability, biological behavior, low toxicity to animals, and therapeutic activity. A sodium salt assaying $240 \mathrm{O} . \mathrm{U} . / \mathrm{mg}$. was obtained chromatographically and gave the following composition: 45.36 per cent $\mathrm{C}$, 4 . I 6 per cent $\mathrm{H}, 3.02$ per cent $\mathrm{N}$, and 13.36 per cent $\mathrm{Na},[a]_{\mathrm{D}}=+108^{\circ}$ (in water).

Under submerged conditions, $A$. flavus thus produces two substances, one of the aspergillic acid type and the other of the penicillin type. Some strains produce little or no activity in submerged cultures, and most strains produce very little activity in stationary cultures. No activity is produced in synthetic media (950). The culture filtrate of $A$. flavus grown on lactose-peptone media was active against $M$. tuberculosis and other acid-fast bacteria in vitro. 


\section{Aspergillus fumigatus Group}

Four antibacterial substances were isolated from strains of $A$. fumigatus: the two pigments, spinulosin and fumigatin (702), which are not selective in their action against bacteria, the colorless fumigacin that is active largely against gram-positive organisms (957), and gliotoxin $(339,63 \mathrm{I})$. Helvolic acid, isolated from a strain of $A$. fumigatus ( 126, I6I), was found $(63 \mathrm{I}, 955)$ to be identical with purified fumigacin.

Fumigacin is active against $S$. aureus in dilutions of $\mathrm{I}: 200,000$ to I : 750,000 and is very stable. The pigment fumigatin, however, was said to deteriorate on standing, inhibition of $S$. aureus being reduced from $I: 50,000$ to $I: 25,000$ in 7 days. Fumigacin has a certain degree of resistance to high temperatures. Boiling in aqueous solution for 5 to Io minutes reduced but did not destroy completely its activity. Heating at $80^{\circ} \mathrm{C}$. for $\mathrm{I} 5$ minutes reduced the activity only slightly. When fumigacin was dissolved in alcohol and precipitated by addition of nine volumes of water, the alcohol-water solution was found to contain 0.25 $\mathrm{mg}$. per $\mathrm{ml}$. A comparison of the antibacterial activity of fumigacin with that of the other substances produced by $A$. fumigatus is given in Table 27.

A number of fungi, largely Aspergilli and usually members of the $A$. fumigatus group, have been found to be able to inhibit the growth

TABLE 27. CHEMICAL PROPERTIES AND BACTERIOSTATIC ACTIVITY OF FOUR ANTIBIOTIC SUBSTANCES PRODUCED BY ASPERGILLUS FUMIGATUS

\begin{tabular}{|c|c|c|c|c|c|c|}
\hline \multirow[b]{2}{*}{ SUBSTANCE } & \multicolumn{3}{|c|}{ MELTING } & \multicolumn{3}{|c|}{$\begin{array}{l}\text { BACTERIOSTATIC ACTIVITY } \\
\text { IN DILUTION UNITS }\end{array}$} \\
\hline & $\begin{array}{l}\text { CRYSTALLI- } \\
\text { ZATION }\end{array}$ & $\begin{array}{l}\text { POINT } \\
{ }^{\circ} \mathrm{C} .\end{array}$ & FORM ULA & E. coli & S. aureus & $\begin{array}{c}\text { B. sub- } \\
\text { tilis }\end{array}$ \\
\hline Spinulosin & $\begin{array}{l}\text { Purplish-bronze } \\
\text { plates }\end{array}$ & 201 & $\mathrm{C}_{8} \mathrm{H}_{8} \mathrm{O}_{5}$ & - & - & - \\
\hline Fumigatin & $\begin{array}{l}\text { Maroon-colored } \\
\text { needles }\end{array}$ & 116 & $\mathrm{C}_{8} \mathrm{H}_{8} \mathrm{O}_{4}$ & 1,200 & 200,000 & 40,000 \\
\hline Fumigacin & $\begin{array}{l}\text { Very fine white } \\
\text { needles }\end{array}$ & $215-220$ & $\mathrm{C}_{32} \mathrm{H}_{44} \mathrm{O}_{8}$ & 1,200 & $2,000,000$ & 100,000 \\
\hline Gliotoxin & $\begin{array}{c}\text { Elongated } \\
\text { plates }\end{array}$ & 195 & $\mathrm{C}_{13} \mathrm{H}_{14} \mathrm{O}_{4} \mathrm{~N}_{2} \mathrm{~S}_{2}$ & 6,000 & $1,500,000$ & 750,000 \\
\hline
\end{tabular}


of $M$. tuberculosis. As pointed out previously, Vaudremer recorded in I9I 3 (934) that the fungus produces a thermostable substance which is responsible for the antituberculosis effect. Zorzoli ( $105 \mathrm{I}$ ) reported in I 940 that $A$. fumigatus produces a thermostable substance $\left(100^{\circ} \mathrm{C}\right.$. for I hour) which interferes with the growth of $M$. tuberculosis. Asheshov and Strelitz (27) observed a marked action of $A$. fumigatus preparations upon the B.C.G. but not upon the avian strain of $M$. tuberculosis; the bacteriostatic activity was greater against $M$. tuberculosis B.C.G. than against staphylococci, although the bactericidal activity was lower. Culture filtrates and extracts of various unidentified fungi were found capable of inhibiting the growth of the organism (647). One such extract was designated as mycocidin; its effect upon the human tubercle bacillus was both bacteriostatic and bactericidal (328). Jennings (464) reported that helvolic acid (fumigacin), one of the antibiotics produced by $A$. fumigatus, in concentrations of $\mathrm{r}: \mathrm{I0}, 000$ inhibited completely and in $\mathrm{r}: 100,000$ only partly, the growth of the tuberculosis organism isolated from sputum.

A. ustus produces in ordinary Czapek-Dox medium with 4 per cent glucose and O.I per cent yeast extract, after I 4 to I 9 days' incubation, a substance that inhibits the growth of $M$. tuberculosis and $M$. ranae (539). This antibiotic can be extracted from the medium with ether and other organic solvents. The ether residue is dissolved in phosphate buffer of $p H$ i I.o. On acidification of the alkaline solvent, a yellow flocculent precipitate is obtained. This substance inhibited the growth of $M$. ranae in a dilution of $1: 150,000$, and the acid precipitate in I $: 300,000$ dilution. By means of a "countercurrent distribution" the active agent was separated into two crystalline and one partially crystalline preparations (438).

The mycelium of $A$. ustus was found (I88) to contain a group of antibiotics, one of which was designated as ustin. This substance was active against gram-positive, including acid-fast, bacteria $(\mathrm{I}: 500,000)$. It is inhibited by serum albumins and by lipids.

\section{Aspergillus clavatus Group}

'This comprises a number of strains that produce highly active antibiotic substances. By treating the culture filtrate with charcoal and 
eluting the active substance with ether, Wiesner (IOI2) obtained a preparation having a bactericidal potency in dilutions of $\mathrm{I}: \mathrm{IO0}, 000$. This activity was not inhibited by serum, pus, or urine; strains of bacteria that proved to be resistant to sulfonamides or mandelic acid were inhibited by this material.

The active substance was designated (957) clavacin. It is active against $E$. coli and other gram-negative bacteria, as well as against gram-positive bacteria. It is different in this respect from fumigacin. Whereas the latter acts much more readily upon $B$. mycoides than $B$. subtilis, clavacin shows the opposite effect-greater activity against $B$. subtilis than against $B$. mycoides. Clavacin possesses a high bactericidal action, as compared with other antibiotic substances.

A detailed study of its production by a variety of strains of $A$. clavatus was made (968). The marked differences in the physiology of the different strains of $A$. clavatus were said to explain the differences in the production of clavacin by different strains. Those that change the reaction of the medium to alkaline, for instance, tend to inactivate the clavacin.

Since clavacin is produced by a number of different fungi, it has received a number of designations, including patulin formed by $P$. patulum (744), claviformin by $P$. claviforme (124, 125), and clavatin (47). It is also produced by strains of $P$. expansum, $P$. urticae, $A$. terreus, $A$. giganteus, Gymnoascus, and others $(24,486,501)$. For species of Penicillium it was found (578) that glucose as a source of carbon, an incubation temperature of $20^{\circ} \mathrm{C}$., stationary culture, and a source of iron offer optimum conditions.

\section{Trichoderma and Gliocladium Group}

Certain strains of fungi of the genera Trichoderma and Gliocladium were found to exert a marked antagonistic action against various fungi and bacteria. An antibiotic substance designated as gliotoxin was isolated and found $(82,989)$ to be highly bactericidal. In order to produce this substance, the fungus is grown in a submerged condition in shakecultures. An abundant supply of oxygen and a high acidity ( $p \mathrm{H} 5.0$ or lower) are essential. Ammonium salts as nitrogen sources give better results than peptone or nitrates. Glucose and sucrose were found to be 
good carbon sources. It is of particular interest to note that whereas penicillin and flavicin are produced in media containing complex organic materials as sources of nitrogen, fumigacin, clavacin, and gliotoxin are produced in synthetic media, the presence of complex nitrogen sources often being deleterious.

Gliotoxin was isolated from the culture filtrate by the use of lipoid solvents, chloroform being most effective. Nonsterilized media adjusted to $p \mathrm{H}_{2} .5$ to 3.0 could be used for large-scale production, the high acidity reducing the effect of contaminants (992). Gliotoxin is stable in neutral and acid solutions at room temperature; at alkaline reactions, it is very unstable, the rate of decomposition increasing with increasing alkalinity and temperature. At $\mathrm{pH} 2.4$, heating to $122^{\circ} \mathrm{C}$. for $30 \mathrm{~min}$ utes did not affect the active substance. With decreasing acidity, especially at $p \mathrm{H} 5.0$, it became less thermostable.

Gliotoxin is also produced by a number of other fungi, including $P$. obscurum (665) and $A$. fumigatus (63I).

Certain species of Trichoderma, including $T$. viridis, produce another antibiotic substance that is particularly active against fungi, designated as viridin (84). It is produced when the organism is grown in shallow layers of nitrate-containing media for 4 to 6 days at $25^{\circ} \mathrm{C}$.; the cultures are characterized by a bright yellow color. It is isolated from the culture filtrate by extraction with chloroform, evaporation, and recrystallization from alcohol or benzene. It is stable only in acid solution.

\section{Fusarium Group}

The ability of species of Fusarium to produce antibiotic substances was first observed in a survey of the antibacterial properties of fungi, as pointed out above (p. I3I). F. oxysporum was found (II2) to possess antibacterial properties. One of the organisms, namely $F$. javanicum, was studied in detail. A substance, designated as javanicin, was isolated (26) from the medium by the use of ether or benzene. It was removed from the solvent by extraction with aqueous $\mathrm{Na}_{2} \mathrm{CO}_{3}$. It contained a quinone group but no carboxyl. It was active against grampositive, including acid-fast, bacteria in concentrations of $I: 50,000$ to I 4000,000 but had little activity against gram-negative bacteria. It was relatively nontoxic. 


\section{Basidiomycetes}

The larger Basidiomycetes produce bacteriostatic substances that compare favorably with those formed by Aspergilli and Penicillia. The testing of the sporophore extract alone may be indicative, but it is not a fully reliable test for a positive result; the fungus must be cultured and a strip test made (IOI4). Of 700 species tested, about 70 gave a strong positive reaction and 100 a weak reaction against $S$. aureus and/or E. coli (IOI9). In a comparison of 72 genera, one or more species of 43 genera produced some antibiotic activity; none, however, was more active than $P$. notatum and none affected gram-negative forms $(785,785 \mathrm{a})$.

Polyporin, produced in the culture filtrate and in the sporophores of Polystictus sanguineus, is a thermostable substance not affected by $\mathrm{pH}$ changes between 2.0 and 8.0. It passes through a Seitz filter, is not affected by body fluids, is nontoxic, and is active in vitro and in vivo against various gram-positive ( $S$. aureus, $S$. viridans) and gram-negative bacteria ( $E$. typhosa, $V$. comma, etc.). Clitocybe gigantea var. candida, a member of the Agaricus group, contains in its cell material a substance, designated as clitocybin, which is soluble in water, chloroform, acetone, and ether. It is destroyed on heating at $70^{\circ}$ to $80^{\circ} \mathrm{C}$. It inhibits the growth of various gram-negative bacteria, such as $E$. coli, Ps. aeruginosa, E. typhosa, and Br. abortus, various gram-positive bacteria, and $M$.tuberculosis. It is fairly toxic to animals: I gm. of the dry fungus substance is treated for 24 hours with Io $\mathrm{ml}$. water; $\mathrm{I} \mathrm{ml}$. of this extract will kill a $300 \mathrm{gm}$. guinea pig in 48 hours. It is effective in arresting the development of tuberculosis in guinea pigs (439). Several species of Cortinarius and one of Psalliota inhibited various gram-positive and gram-negative bacteria (30).

\section{Other Groups}

Various other fungi, including $A$. albus, $A$. niger, and Monilia albicans, were found ( IO5I) to exert a marked antibacterial action against human and bovine tubercle bacteria; active filtrates were obtained, but the specific agents were not isolated. Certain dermatophytes, especially strains of Trichophyton mentagrophytes, also produce an antibiotic 
substance when grown in glucose-peptone media. This substance is similar to penicillin in that it is favored by the addition of corn steep, and in its antibiotic spectrum, its sensitivity to reaction and temperature, and its destruction by penicillinase preparations ( 7 I 4 ).

A number of unidentified molds have been reported to produce pigments which have antibiotic activity against various bacteria (807). This is true, for example, of $P$. cinnabarimus. The red pigment extracted from the mycelium of this fungus inhibited $S$. aureus and $S$. pyogenes in a dilution of $\mathrm{I}: 5,000$. The extract was slightly hemolytic, although not very toxic (637).

A study of the distribution of antibiotic properties among the fungi revealed the fact that the Aspergilli and Penicillia are most active and the Phycomycetes least (Table 28).

TABLE 28. DISTRIBUTION OF ANTAGONISTIC PROPERTIES AMONG THE FUNGI

\begin{tabular}{lcccc}
\hline & TOTAL & \multicolumn{3}{c}{ PERCENTAGE } \\
\multicolumn{1}{c}{ ORDER OR } & NUMBER & PERCENTAGE & WEAKLy & PERCENTAGE \\
Phycomycetes & EXAMINED & ACTIVE & ACTIVE & INACTIVE \\
Ascomycetes & 30 & - & - & 100 \\
Aspergillus & 20 & - & - & 100 \\
Penicillium & 150 & 30 & 20 & 50 \\
Basidiomycetes & 200 & 20 & 30 & 50 \\
\hline
\end{tabular}

From Wilkins and Harris (1017, 1018, 1019).

\section{ANTAGONISTIC ACTION OF FUNGI AGAINST FUNGI}

Numerous fungi were found to exert antagonistic effects either against fungi belonging to the same species or against other fungi (Table 29). This phenomenon is particularly important in connection with the study of plant diseases. The effects are selective. The hyphae of Peziza will kill various Mucorales, whereas different species of Aspergillus and Penicillium are able to kill Peziza. A single spore of $P$. luteum was found capable of germinating in cultures of Citromyces 
TABLE 29. ANTAGONISTIC INTERRELATIONSHIPS AMONG DIFFERENT FUNGI

\begin{tabular}{|c|c|c|}
\hline ANTAGONIST & ORGANISMS AFFECTED & REFERENCES \\
\hline Acrostalagmus sp. & Rhizoctonia & 990 \\
\hline Alternaria tenuis & Ophiobolus & 89 \\
\hline A. clavatus & Various fungi & 949 \\
\hline A. flavus & Peziza & 773 \\
\hline A. niger & Peziza, Rhizoctonia & $773,933,990$ \\
\hline Botrytis allii & Monilia, Botrytis, etc. & 933 \\
\hline Botrytis cinerea & Rhizoctonia & 990 \\
\hline Cephalothecium roseum & Helminthosporium & 359 \\
\hline Cunninghamella elegans & Monilia & 933 \\
\hline Fusarium lateritium & Rhizocionia & 990 \\
\hline Fusarium sp. & Deuterophoma & 827 \\
\hline Gliocladium sp. & Helminthosporium, Mucor, etc. & 729 \\
\hline Helminthosporium sp. & $\begin{array}{l}\text { Colletotrichum, Fusarium, } \\
\text { Botrytis, etc. }\end{array}$ & 729 \\
\hline$H$. teres & $\begin{array}{l}\text { Fusarium, Ustilago, Helmintho- } \\
\text { sporium, etc. }\end{array}$ & 729 \\
\hline H. sativum & Ophiobolus & 89 \\
\hline Mucor sp. & Ophiobolus, Mucor & 89,837 \\
\hline Penicillium sp. & Peziza, Rhizoctonia, etc. & 773 \\
\hline Penicillium sp. & Ophiobolus, Fusarium, etc. & 89 \\
\hline Peziza sclerotiorum & $\begin{array}{l}\text { Mucor, Trichothecium, Dematium, } \\
\text { etc. }\end{array}$ & 773 \\
\hline Peziza trifoliorum & Peziza & 773 \\
\hline Sclerotium rolfsii & Helminthosporium & 729 \\
\hline Sterigmatocystis sp. & Alternaria & 729 \\
\hline Thamnidium elegans & Mucor & 837 \\
\hline Torula suganii & Aspergillus, Monascus, etc. & 690 \\
\hline Torulopsis sp. & Blue-staining fungi & 630 \\
\hline Trichoderma lignorum & $\begin{array}{l}\text { Rhizoctonia, Armillaria, Phy- } \\
\text { tophthora, etc. }\end{array}$ & 989,990 \\
\hline$T$. lignorum & Rhizoctonia, Pythium, etc. & $14,63,933$ \\
\hline Verticillium sp. & Rhizoctonia & 990 \\
\hline
\end{tabular}

From Novogrudsky $\left(68_{3}\right)$.

and of bringing about their destruction. $P$. luteum-purpurogenum produces a thermostable substance, soluble in ether and in chloroform, that is antagonistic to the growth and acid production of A. niger (705). 
Coniophora cerebella was inhibited by a species of Penicillium, its mycelium being considerably modified; however, in time the former organism adapted itself to the latter and overgrew it, its rate of growth being eventually more rapid than that of a pure culture (380). Certain fungi are able to parasitize other fungi. The germination of the spores of one fungus may be reduced by the presence of spores of another (553).

Different fungi produce different types of fungistatic and fungicidal substances, some of which are stable, others unstable. These are formed particularly by the lower fungi or the molds, with the exception of the Phycomycetes that have so far not been found to produce any antibiotic substances. Their action consists in modifying or killing the mycelium of the other fungus, or merely in preventing spore germination. Brömmelhues (89), studying the effects of $H$. sativum and Penicillium sp. against $O$ phiobolus graminis, emphasized that the inhibitory action was due to a toxic substance that was thermostable and diffusible in agar. In some cases, no relation could be observed between the acidity produced by one organism and its ability to influence the growth of another (1046); in other cases, as in the mutualistic effects of Sclerotium rolfsii and $F$ usarium vasinfectum, the first overgrew completely the second at $p \mathrm{H}$ 6.9, whereas in alkaline ranges the reverse took place (804).

Random isolations of $P$ enicillium cultures and of other soil-inhabiting fungi were tested for their effects on the virulence of $H$. sativum on wheat seedlings grown in steam-sterilized soil (823). Some forms exerted a marked degree of suppression, some had no effect, and others increased the virulence of the pathogen; marked variations in activity were observed among the different species of Penicillium. Because Hyphomycetes were found to be capable of parasitizing the oospores of Pythium (196), Hyphomycetes were believed to serve as effective agents in promoting soil sanitation. Various species of Torulopsis, in addition to certain bacteria, are capable of inhibiting the growth of Dematiaceae, fungi that cause the blue staining of wood pulp (630). A species of Penicillium ( $P$. gladioli) was found (8ra) to produce an antibiotic (gladiolic acid) which is actively fungistatic but only weakly bacteriostatic.

Certain fungi may affect the reproduction of others. Melanospora 
pampeana, for example, normally does not form any perithecia in culture but is able to do so in the presence of Basisporium gallarum or Fusarium moniliforme. This effect was ascribed to a special substance that resists heating at $110^{\circ} \mathrm{C}$. Different fungi have a special influence on the germination of spores of various ascomycetes and of other fungi $(28,776)$, these effects being characteristic of the antagonists.

The edible mushroom Psalliota campestris exerts a definite antagonism against the parasitic fungus $M y \operatorname{cog} o n e$ (135). This phenomenon has been looked upon as a case of antibody formation. Species of Fusarium are able to antagonize the mushroom fungus; however, an actively growing culture of the latter may become antagonistic to the former (I026). In the destruction of paper pulp by fungi, a marked antagonism was shown (34I) to take place between different organisms, especially by Trichoderma lignorum against various species of Fusarium and other fungi, as illustrated in Figures 16 and 17 .

Certain species of Trichoderma and Gliocladium are able to inhibit the growth of various plant pathogenic fungi, especially $R$. solani, as well as of Blastomycoides dermatitidis, a causative agent of human skin diseases. The active substance, gliotoxin, is liberated during the early stages of growth. The mycelium of older cultures contains another substance that is soluble in acetone; this has only an inhibiting effect and is not fungicidal as is gliotoxin. The fungicidal effect of gliotoxin upon the germinating spores of Sclerotinia americana and hyphae of $R$. solani was found to be greater than that of $\mathrm{CuSO}_{4}$ and less than that of $\mathrm{HgCl}_{2}$.

Various other fungi are able to exert antagonistic effects against plant pathogens. $T$. lignorum and $A$. niger restricted the growth of the fungi Macrophomina phaseoli and $R$. solani, which produce cotton root rot, and reduced the activity of the filtrates of the pathogens causing wilting of the plants.

Satoh $(826)$ has shown that Ophiobolus miyabeanus produces both growth-promoting and growth-retarding substances, the first of which is heat stable and passes through a Chamberland filter; the second is inactivated at $100^{\circ} \mathrm{C}$. and does not pass through a filter. The formation of two substances by Torula suganii, both of which were thermostable, however, was also demonstrated (690). 


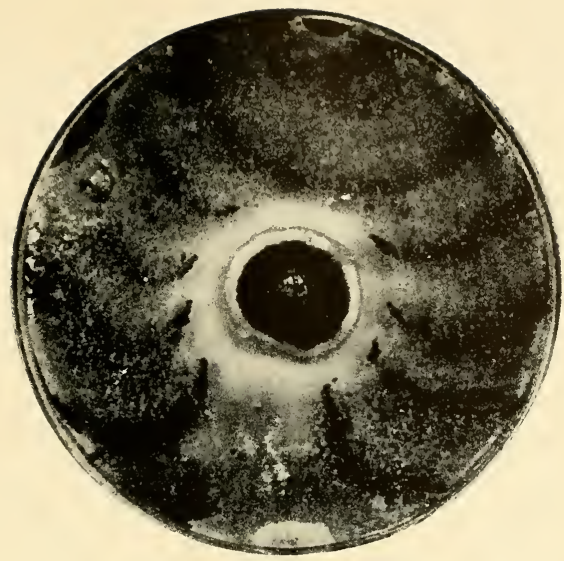

Figure 16. Antagonistic effect of one fungus, Ps. zonatum (in center), upon another, T. lignorum. From Goidanich et al. (34 I).

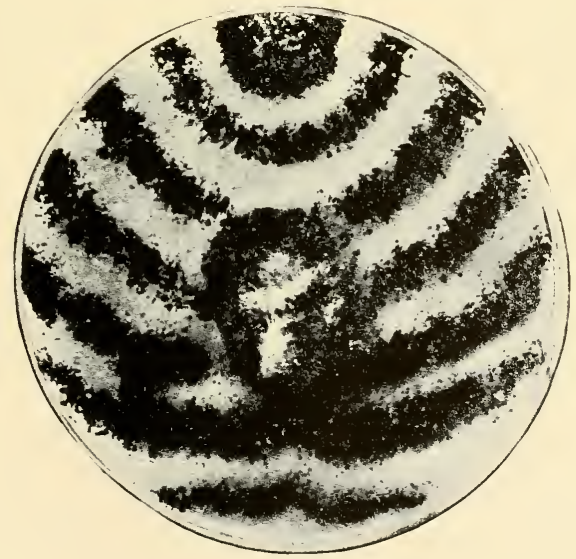

Figure 17. Attack of an antagonistic fungus. T. lignorum, upon another fungus, $F$. sambucinum (in center). From Goidanich et al. (34 I). 

ANTAGONISTIC EFFECTS OF BACTERIA AND ACTINOMYCETES AGAINST FUNGI

Various bacteria and actinomycetes have marked selective fungistatic and fungicidal effects (Table 30). Bacteria active against $U$. zeae were isolated from corn, these bacteria being capable of destroying the colonies of the smut fungi. The widespread distribution of such bacteria in the soil was believed to check the multiplication of the pathogenic fungi. Four types of bacteria antagonistic to smuts and to certain other fungi have been described (470). Some of these bacteria produce enzymes that are able to dissolve the chemical constituents of the cell walls of the fungus sporidia; they were also found to be active in the soil against the specific fungi. Brown (93) observed that $H$. sativum and a certain bacterium produced thermostable, mutually inhibiting substances. The bacterium as well as its metabolic products inhibited the

TABLE 30. ANTAGONISTIC EFFECTS OF BACTERIA AGAINST FUNGI

\begin{tabular}{lll}
\hline ANTAGonist & ORGANiSMS AFFECTED & REFERENCES \\
Achromobacter sp. & Fusarium, Sclerotinia & 143 \\
Al. faecalis & Helminthosporium & 729 \\
Bacillus "D" & Ustilago, Penicillium & 35 \\
B. anthracis & S. cerevisiae & 525 \\
B. mesentericus & Helminthosporium & 142,729 \\
B. mycoides & Helminthosporium & 729 \\
B. simplex & Rhizoctonia & 154 \\
B. subtilis & Cephalothecium roseum & 11 \\
Bacterium sp. & Fusarium, Sclerotinia, etc. & 729 \\
Bacterium sp. & Ustilago & 470 \\
Myxobacterium & Ustilago & 247,470 \\
P. vulgaris & Basisporum, Phytophthora, etc. & 506,729 \\
Ps. aeruginosa & Saccharomyces & 525 \\
Ps. juglandis & Dothiorella & 247 \\
Ps. phaseoli & Fusarium & 63,247 \\
Ps. translucens & Ophiobolus & 87 \\
Ps. vulgaris & Ophiobolus & 87 \\
S. marcescens & Beauveria, etc. & $10,1 \mathrm{I}, \mathrm{12}, 624$ \\
Spore-forming bacteria & Fungi & 35,729 \\
\hline
\end{tabular}

From Novogrudsky $\left(68_{3}\right)$. 
growth not only of the particular fungus but also of other members of the same genus, but not of Fusarium conglutinans. These bacteria produced a diffusible agent that inhibited the growth of $H$. sativum ( I I 5a). The active substance was not destroyed by autoclaving; it diffused into fresh agar and water, producing "stale water" that was inhibitory to the fungus.

Chudiakov ( I 43) isolated from the soil two bacteria that were capable of bringing about the lysis of different species of Fusarium as well as other fungi. These bacteria were found to be widely distributed in most soils; they were absent, however, in flax-sick soils, in spite of the abundance of Fusarium. When this fungus was added to the soil containing antagonistic bacteria, it did not develop, and the plants did not become diseased. The antagonistic action of a variety of other bacteria against plant pathogenic fungi has been definitely established, as in the case of $B$. simplex against Rhizoctonia, $P$. vulgaris against Phytophthora (488), and B. mesentericus against Helminthosporium ( I 42). B. simplex was grown (49I) for 7 days at $28^{\circ} \mathrm{C}$. in potato-dextrose medium containing I per cent peptone, and the active substance was removed by charcoal and dissolved in alcohol. Different fungi differed in the degree of tolerance to this substance. The majority were repressed when Io per cent concentration of the stale medium was added to fresh medium.

The ability to produce a thermostable substance toxic to the plantdisease-producing fungus Rhizoctonia is widespread among spore-forming bacteria. The toxic substance is insoluble in ether, chloroform, and benzol, but is soluble in ethyl alcohol. It passes through collodion, cellophane, and parchment membranes. It is readily destroyed on boiling in alkaline media but is more resistant in acid media.

Nakhimovskaia (672) found that various bacteria are able to inhibit the germination of rust spores. Nonspore-forming bacteria, such as $P$ s. fluorescens and $S$. marcescens, prevented the germination of the spores of Ustilaga avenae, Ustilaga hordei, Ustilaga muda, and Ustilaga reae. Spore-forming bacteria, including $B$. mycoides and $B$. mesentericus, as well as sarcinae ( $S$. ureae, $S$. lutea), exerted no antagonistic action on the rust spores. The presence of these bacteria, however, influenced the nature of the germination of the spores, which gave rise to mycelium 
like forms with great numbers of copulating filaments, whereas in the control cultures yeast-like forms prevailed and copulating cells were rarely encountered. The presence of a certain concentration of bacterial cell substance was essential to this antagonistic effect. With a more limited amount of cell material, the bacteria ceased to inhibit the germination of the spores but influenced the germination process in the same manner as do nonantagonistic bacteria, that is, they stimulated the sexual process. An increase in concentration of cell substance, even of nonantagonistic organisms, would inhibit spore germination.

The common occurrence of the fungus Pyronema confluens in freshly burned-over soils, but not in natural soils, was explained (684) as due to the destruction of the bacterial antagonists by heating of the soil. Ps. fluorescens was particularly effective as an antagonizing agent. A comparative study of the fungistatic action of substances of bacterial origin (883) has shown these to be more active than common disinfectants. Tyrothricin inhibited the growth of animal pathogens in dilutions of $I: 5,000$ to $I: 20,000$, pyocyanin in $I: 2,000$ to $I: 5,000$, and hemipyocyanin in $\mathrm{I}: 20,000$ to $\mathrm{I}: 60,000$.

Actinomycetes may also exert a marked depressive effect upon the growth of fungi. The active substances produced by these organisms show considerable selective action just as in the case of the bacteria. Actinomycin was found (974) to inhibit the growth of Penicillium, Aspergillus, Ceratostomella, and yeasts in concentrations of I:50,000; larger amounts ( $1: 10,000)$ were required to inhibit other fungi, including Rhizopus and Trichoderma. Streptothricin is less effective against fungi, although it inhibits the growth of certain yeasts (IO3I).

In general, antibiotics vary as much in their antifungal as in their antibacterial effects. Some, like gliotoxin and actinomycin, were found to be highly active against both parasitic and saprophytic fungi, whereas others, like chaetomin and streptomycin, had little if any activity. Since some of the substances, like actinomycin, have a highly toxic effect upon animal tissues, the selection of a suitable antifungal agent for chemotherapeutic purposes is limited to a very few promising materials; among these gliotoxin and streptothricin were mentioned (77I). 


\section{MICROSCOPIC ANIMAL FORMS AS ANTAGONISTS}

THE microscopic animal world inhabiting the soil and water basins comprises protozoa, insects and insect larvae, nematodes and other worms. Their relationships to the microbiological flora of soils and waters are varied. Many, if not most, of these animals feed upon the bacteria and fungi, as well as upon the smaller animal forms. Some carry a bacterial population in their digestive tract and appear to depend upon these bacteria for some of the digestion processes. Many of the animal forms are parasitized by bacteria and fungi. Some of these forms are subject to the action of specific substances produced by microbial antagonists. No detailed discussion will be presented of these varied relationships, but attention will be directed to a few specific phenomena which have a bearing on the subject under consideration. The ability of higher animals to produce antibacterial substances has been amply established. Some of these substances are well characterized, as in the case of lysozyme found in mammalian tissues and secretions and inhibins found in fresh human urine (I89).

\section{RELATIONS OF PROTOZOA TO BACTERIA}

The lower animal forms inhabiting the soil, manure piles, and water basins often utilize bacteria in the synthesis of their foodstuffs. Although many of the smallest organisms, namely the protozoa, are able to obtain their nutrients from simple organic compounds and mineral salts, they frequently depend upon the bacteria to concentrate the nutrients present in dilute forms in the natural substrate. It has been shown (I06), for example, that when carbohydrates are present in water in very low concentration, the protozoa may not be able to use them in that dilute form; however, the bacteria can assimilate these carbohydrates and can build up extensive cell substance, and the protozoa are then able to multiply by consuming the bacteria. Protozoa are apparently also able to destroy pathogenic bacteria (78I). 
The fact that some of the protozoa feed upon bacteria served as the basis for a theory designated as the "protozoan theory of soil fertility" (8I2). According to this theory, the capacity of protozoa to consume bacteria is responsible for the limited fertility of certain soils. The bacteria were viewed as the sole agents responsible for the liberation of nutrients in the decomposition of soil organic matter and for the transformation of these nutrients into forms available to higher plants. The protozoa, because of their capacity to digest bacteria, were looked upon, therefore, as the agents injurious to soil fertility. The increased fertility which results from the treatment of soil with heat and with certain chemicals was believed to be due to the destruction of the protozoa, considered as the "natural enemies of the bacteria."

Subsequent investigations did not support this theory. When protozoa were added to cultures of bacteria responsible for certain specific processes they did not exert any detrimental effect upon the particular reactions brought about by the bacteria, despite the fact that they fed upon and thereby considerably reduced the numbers of these bacteria. In many cases, the effect of protozoa upon bacterial activities may actually be considered beneficial ( 163 ). This was found to be true for such processes as the fixation of atmospheric nitrogen, the liberation of ammonia from proteins, and the formation of carbon dioxide from carbohydrates.

Failure to confirm the protozoan theory of soil fertility was due primarily to the fact that several assumptions were made that were not fully justified, namely, (a) that bacteria are the only important soil organisms responsible for the decomposition of the soil organic matter; (b) that protozoa, by consuming some of these bacteria, are capable of restricting bacterial development and, ipso facto, organic matter decomposition. The fact was overlooked that the soil harbors, in addition to the bacteria, many fungi and actinomycetes capable of bringing about the decomposition of plant and animal residues, resulting in the liberation of ammonia, and that this could take place even if all the bacteria were completely eliminated from the soil.

The favorable effect of partial sterilization of soil upon fertility still remains to be explained. Various other theories have been proposed, the most logical of which is one based upon a soil condition designated as 
"microbiological equilibrium" (972). It has also been suggested (527) that the phenomenon is due to the disappearance of the bacterial antagonists in the soil as a result of partial sterilization.

In many cases, however, protozoa are responsible for bringing about extensive destruction of bacteria. This may find a practical application in the purification of water and sewage. The action of the protozoa is due in this case to the actual ingestion of the bacteria (452).

The theory that protozoa may favor soil processes because of the stimulation of bacterial development and hence the accelerated transformation of soil materials is not always justified. The assumption is usually made that these processes take place in the soil in a manner similar to those brought about in artificial culture media, a generalization that may be justified only in very special cases. No consideration is given to the fact that the presence of numerous other organisms in the soil may modify considerably the activities of the protozoa. The use of artificial media gives only a one-sided conception of the significance of protozoa in soil processes. Although the more recent claim concerning the function of protozoa in the soil is based upon more direct experimental evidence, it is still inadequate, because it gives insufficient consideration to the numerous elements involved in the complex soil population.

The protozoa make up only a small portion of the soil population, both in numbers and in the actual amount of cell substance synthesized. Their ability to reduce bacterial numbers in normal soil is not very significant. The indirect method of studying protozoa in solution media, whereby the types observed and the activities obtained are quite different from those occurring in the natural soil, has been largely responsible for the exaggerated importance attached to these organisms.

One may conclude that the protozoa, by consuming some of the bacteria, keep these organisms at a high state of efficiency, thus assisting in the breakdown of the plant and animal residues in the soil. In other words, the rate of energy transformation brought about by bacteria and even the total amount of change produced in the substrate are increased by the presence of protozoa. Thus, an interrelationship among microorganisms which was at first thought to be antagonistic actually has proved to be associative. The protozoan Oikomonas termo was found to be capable of living at the expense of a large number of bacteria, 
namely 83 per cent of those tested. The fact that Oikomonas causes many species of bacteria to flocculate was suggested as explanation for the ability of the protozoa to digest these bacteria (38I).

The ability of protozoa to destroy bacteria was said (426) to be responsible for the protection of certain plants against attack by plant pathogenic bacteria and fungi. This was said to hold true of attack of potatoes by Bacterium aroideae and of other plants by Pseudomonas hyacinthi and Pseudomonas citri, as well as by species of Fusarium and Penicillium.

Various bacteria may exert a toxic action upon protozoa, thus limiting the development or bringing about the destruction of the latter ( 133 , 584). Certain plant pathogenic bacteria inedible by amebae were found to produce a toxin that was harmful to these amebae. In some cases, the protozoa were capable of developing a certain resistance to specific bacterial products (72I). The toxic action of some bacteria against Paramecium could be overcome by the presence of a flagellated protozoan Oikomonas (382).

On the basis of the ability of protozoa to utilize bacteria as food, Singh classified (855) the latter into 3 groups: (a) edible forms, (b) inedible but harmless to protozoa, (c) forms toxic to protozoa. Pigment-producing bacteria are inedible and some are toxic; these comprise the $P$ s. aeruginosa and the $S$. marcescens groups.

Since some amebae, like Hartmanella castellanii, function as phagocytes, they are believed (545) to offer excellent material for the study of the effect of antibiotic substances upon pathogenic bacteria in the presence of these amebae, the latter not being affected, as by penicillin, for example.

Certain factors in the medium seem to affect the encystment of protozoa ( $9 \mathrm{co})$; it remains to be determined to what extent these factors can be classified with antibiotic substances.

Myxamoebae of the slime mold Dictyostileum discoideum also live upon bacteria. They are able to utilize the gram-negative somewhat better than the gram-positive types, with certain few exceptions. Bacterial spores are also ingested by these organisms, but they are not digested. 


\section{RELATIONS OF PROTOZOA TO FUNGI}

The presence of Colpoda and other infusoria in an active form was found to repress the growth of Verticillium dahliae in culture media and to prevent infection of tomato plants by this pathogen; Colpoda was also active in soils and reduced the incidence of wilting (88).

The ability of various fungi to destroy protozoa and nematodes has been studied in detail by Drechsler (194, 195).

\section{MALARIAL AND TRYPANOSOME PARASITES}

In connection with the recent interest in antibiotic substances, considerable work has also been done on the effect of these substances upon different strains of Plasmodium causing malaria and upon different trypanosomes causing various tropical diseases.

Weinman found (993) that the general correlation between the gram-stain of bacteria and their sensitivity to gramicidin also extends to protozoa (Leishmania, Trypanosoma) and to the Leptospira tested. Tyrocidine had a marked effect, in concentration of $5 \mu \mathrm{g} / \mathrm{ml}$., upon the flagellates; they remained active for many hours, gradually losing their motility; a few escaped, giving rise to delayed growth.

Levaditi and Twort (56I) demonstrated that trypanosomes are destroyed by $B$. subtilis and are also partly destroyed by $E$. coli, but not by $B$. prodigiosus, $B$. mesentericus, $B$. pyocyaneus. The active substance, designated as trypanotoxin, was found to be produced by $B$. subtilis in the culture filtrates and in centrifugates. The washed cells of the organism were inactive. The substance is thermolabile and is destroyed at $70^{\circ} \mathrm{C}$. in 20 minutes. It does not pass collodion dialysis membranes. It is also active in high concentrations against the tic-fever Spirillum and Leishmania, but not against Borrelia gallinarum. It is apparently not very active in vivo, since it did not protect mice against trypanosomes. Contact between trypanotoxin and trypanosomes in vitro led to the development of toxo-resistant strains of the latter. This resistance was maintained for many generations; however, the new strains do not become more resistant to pyocyanase and other anti-trypanosome reagents.

Further studies (560) brought out the following facts: resistant 
strains did not adsorb the toxin, as did the susceptible strains; the susceptible trypanosomes were destroyed completely by antiserum, whereas the resistant forms were also resistant to this antiserum.

A lipid-like substance produced by species of Phycomyces was active against Trypanosoma equiperdum in vitro but not in vivo (830a).

\section{MICROBIAL CONTROL OF INSECT DISEASES}

Insects are subject to attack by various groups of microorganisms, including bacteria, fungi, protozoa, nematodes, and other insects. Many attempts have been made to control insect pests by the use of pure or mixed cultures of microorganisms. In this connection the following relationships must be considered: the receptivity of the insect to microbial attack during its various stages of development; the environmental conditions favoring the attack on the insect by the disease-producing organism; the influence of environment upon the virulence of the attacking microbe; the manner in which the parasite attacks the host; the coordination of the optimum activity of the disease-producing agent with the abundance of the host and the proper stage of its development.

The microbial agents that keep in check the spread of insects, some of which are highly injurious to plants and animals, are far more important than any other methods of control. These microbial agents can be classified into three groups, depending upon the nature of the host: (a) microbes that attack economically useful insects and that must be controlled in order to avoid important losses from disease; (b) microbes that attack injurious insects and that must therefore be favored and encouraged; (c) microbial agents infectious to plants, animals, and man that are spread by insects.

Various bacterial diseases that formerly caused considerable destruction of silkworms and bees have been controlled, once the nature of the organisms concerned was established. One of Pasteur's important contributions to microbiology was the control of Flacheria among silkworms. However, most of the problems of control of injurious insects have been difficult to solve. A great number of bacterial, fungus, and virus diseases of insects are now known, but the many attempts to em- 
ploy these pathogens in combating the insect hosts have not always been successful. The investigations so far carried out in this important field may be considered as at a very primitive stage.

Metalnikoff (634) compared the bacterial treatment of caterpillars of Pectinophora gossypiella with the action of arsenical poisoning. The dry spores of Bacterium ephestiae, Bacterium gelechiae, Bacterium 5, and Bacterium cazaubon, in powder form, were mixed with water at the rate of $\mathrm{I}$ to 4 ounces to $2 \mathrm{I} / 2$ gallons of water, with the addition of 4 per cent of molasses; this preparation was sprayed on the plants two to four times, at regular intervals, at the rate of 196 gallons or less per acre. The best results were obtained for plants treated with $B$. ephestiae, the infestation being reduced by about 50 per cent as compared with the controls. A slightly smaller reduction occurred on plots sprayed with $B$. cazaubon, while $B$. gelechine reduced the infestation by less than 40 per cent. Those plants that were treated with the arsenical spray showed a reduction of only i 8 per cent.

Recently microorganisms have been used for the control of the larvae of Japanese and other beetles in the soil. A variety of bacteria, fungi, and nematodes were found capable of destroying these larvae. Once the attacking microorganisms have become established in the soil, the larvae and the beetles themselves tend to disappear. Glaser (335) utilized for this purpose Neoaplectona glaseri. This parasite possesses great reproductive capacity and is capable of destroying large numbers of grubs. Glaser demonstrated the presence of this nematode also in localities where the grub was not present.

Dutky (222) described two spore-forming bacteria (Bacillus popilliae and Bacillus lentimorbus) which cause the milky disease of the larvae of the Japanese beetle. These bacteria are grown in the larvae and then inoculated into soil. They are capable of infecting the grub, and are said to be responsible for the reduction in the beetle population. Bacteria pathogenic to the citrus red scale have also been isolated from the soil (868).

Fungi have also been utilized for the control of insects. Sweetman (89 I) emphasized the importance of entomogenous fungi as destructive enemies of insects. A limitation to their practical importance in the fight against insects is that the fungi require special conditions for develop- 
ment, especially high humidity and favorable temperature, which are not always found under natural conditions.

Glasgow (336) established that some of the caecal bacteria of Heteroptera show a marked antagonism toward other bacteria and protozoan parasites that occur in the intestines of these insects. The caecal system of the insects was removed and dropped into nutrient bouillon, where it remained for a month or more without showing any bacterial growth. This was believed to be proof of the fact that the caecal bacteria are antagonistic to ordinary saprophytic and parasitic bacteria and prevent their development; also they apparently kill these bacteria when they invade the alimentary canal of the insect.

According to Duncan (2I6), the bactericidal principle found in different insects and ticks shows differences in regard to the types of bacteria affected and the degree of their susceptibility. The gut-contents of Argas and Stomoxys show the widest range of action; that of bugs, the least. Spore-forming bacteria are especially affected by material from Stomoxys, whereas staphylococci appear to be more susceptible to the action of Argas material. The gut-contents of ticks was found to have a weak activity upon $P$. pestis, whereas the contents of certain insects favored the growth of the latter. This phenomenon may have a bearing upon the function of the plague flea. The action of the lethal principle is greater and more rapid at $37^{\circ} \mathrm{C}$. than at room temperature. The lethal principle has been found to be active for at least six months when kept in a dry state. It is thermostable, resisting temperatures as high as $\mathrm{I} 20^{\circ} \mathrm{C}$, and is not destroyed by proteolytic enzymes. It appears to be bound to proteins, since it is precipitated from solution by alcohol and acetone, but it is not affected by these reagents. It is insoluble in the common fat solvents. It becomes inactivated when allowed to act upon bacteria and appears to be adsorbed by killed bacteria, even by species that are not destroyed by it. This substance does not have the properties of either bacteriophage or lysozyme.

The presence in certain insects of a variety of other substances, such as allantoin, which affect bacterial activities has also been established. These observations give rise to the hope that man may in time succeed in developing and utilizing microorganisms for the biological control of injurious insects (88I). 


\section{RELATION OF NEMATODES TO SOIL MICROORGANISMS}

Nematode worms are represented in the soil by a number of saprophytes as well as by many plant and animal parasites. The latter vary greatly in their relation to the host. The larvae of the cereal parasite Tylenchus tritici penetrate the wheat seedlings between the leaf sheaths, near the growing or apical points. When the head is formed, the larvae enter the flowering parts and form galls. They become sexually mature, mate, and lay eggs which hatch in the galls, and then become dormant. When the galls fall to the ground and decompose, the larvae are liberated and proceed to find and attack new plants. Other nematodes attack plants by feeding upon the roots. The methods of control require, therefore, a knowledge of their life history. Some species produce resistant forms or cysts that may survive in the soil for many years, even in the absence of the host plant. Soil sterilization by steam or by chemicals is frequently employed as a measure of nematode extermination.

Antagonistic relationships may be utilized for the control of nematodes. Linford et al. ( 572 ) found that the root-knot nematode of pineapple (Heterodera marioni) may be controlled by heavy applications of organic material. The decomposition of this material results in a greatly increased population of saprophytic nematodes in the soil. The decomposed organic residues also support large numbers of such other soil microorganisms destructive to the parasitic nematodes as the nemacapturing fungi ( 180,196 ), the nontrapping fungal parasites, the predaceous nematodes, the predaceous mites, and different bacteria capable of destroying nematodes.

\section{BACTERICIDAL ACTION OF MAGGOTS}

Surgical maggots are said to have a bactericidal effect in wounds, in addition to removing necrotic debris. The presence of an active bactericidal substance which is thermostable and active against $S$. aureus, hemolytic streptococci, and $\mathrm{Cl}$. welchii has been demonstrated (854) in the maggot Lucilia sericata. 


\section{ANTAGONISTIC RELATIONSHIPS BETWEEN MICROORGANISMS, VIRUSES, AND OTHER NONSPECIFIC PATHOGENIC FORMS}

Antagonistic phenomena in relation to viruses have been but little investigated. It has been established, however, that certain microorganisms are capable of destroying viruses, and particularly that some viruses possess the capacity of antagonizing other viruses. The rapid inactivation of poliomyelitis virus in the process of aeration of sewage sludge has also been indicated ( I I I).

\section{BACTERIA AND VIRUSES}

The ability of certain strains of $B$. subtilis to inactivate the virus of rabies has long been recognized. The activity was found to be due to a substance produced in the culture filtrate; limited experimental evidence pointed to the effectiveness of this substance not only in vitro but also in vivo (619). When a mixture of the culture filtrate of $B$. subtilis and the virus was injected into rabbits, the activity of the virus was suppressed (619). It has been suggested (774a) that this action upon the virus of rabies and of equine encephalitis is due not to a true antibiotic but to a proteinase similar to the one which destroys bacterial toxins.

An inactivating effect of $B$. subtilis upon the virus of vesicular stomatitis as well as staphylococcus phage, when in contact with them for I 5 to 8 hours at $35^{\circ} \mathrm{C}$., was also reported (750). This phenomenon has been explained as due to the process of adsorption. The facts that it is selective, that the phage cannot be reactivated, and that the virus is rendered impotent by the action of the bacterium also point to a possible antagonistic effect. However, different specific antibiotics, including penicillin, tyrothricin, and subtilin, when used either alone or in combination with sulfonamides or acridine, have failed to prevent infection of mice with influenza virus (537).

A "nontoxic" inactivator has been defined (307) as a substance that 
inactivates plant viruses and is not detrimental to most forms of life. Various microorganisms are capable of producing such inactivators. Plant viruses differ in their sensitivity to "nontoxic" inactivators. According to Johnson (473) various microorganisms are capable of forming such inactivators against tobacco-mosaic virus. The inactivators produced by $A$. aerogenes and $A$. niger are particularly effective against a variety of plant viruses, but not against all of them; the inactivators produced by the two organisms appear to be similar. They are comparatively heat stable but are slowly destroyed by certain organisms. They can be concentrated by evaporation of medium. A substance which was capable of rapidly inactivating the tobacco-mosaic virus was isolated (895) from yeast. A chemical reaction between the inactivating principle and the virus was therefore suggested. The inactivator in this instance was destroyed by heating with I $N \mathrm{NaOH}$ solution, but not by $2 N \mathrm{HCl}$. It was not a protein and gave on analysis 39.7 per cent $\mathrm{C}$ and 5.85 per cent $H$. The substance was said to be a polysaccharide. $A$. niger was also found (307) to form in the medium a substance capable of inactivating a number of different plant viruses; the effect of the inactivator was found to be exerted upon the virus itself and not upon the plant.

Of I 50 organisms, comprising bacteria, fungi, and actinomycetes, isolated from different natural substrates as well as from soil enriched with virus concentrates, only three showed some inactivation of the fowl pox virus, and, in one case, of the laryngotracheitis virus. The active principle of one of these organisms was actinomycin, an antibacterial substance known to be highly toxic to animals (477).

\section{ANTIBIOTIC SUBSTANCES, VIRUSES, AND}

\section{PHAGES}

The first recorded observation on the effect of antibiotics upon viruses is that of Fukuhara (304) who demonstrated that pyocyanase, after having been in contact with the viruses of vaccinia, rabies, and chicken pest, brought about their inactivation, as shown by the fact that when viruses so treated were inoculated into experimental animals the respective diseases did not develop.

Most of the viruses, however, appear to be resistant to the action of 
antibiotics; this was found to be true of penicillin and clavacin against fowl pox inoculated into the chorioallantoic membrane of the chick embryo (784). Penicillin was also found (707) to be without effect on the virus of vaccinia, encephalitis, and equine encephalonigelitis; however, it had an effect, when used in large doses, on the course of infection of chick embryos with psittacosis and meningopneumonitis. The possible effect of other antibiotics, such as aspergillin, upon certain viruses has also been indicated (375).

In a study of phage inactivation, it was found that streptothricin, streptomycin, and clavacin exerted an effect, whereas penicillin and actinomycin did not. There was no correlation between the susceptibility of the host cells and that of the phage to an antibiotic agent. In the case of $E$. coli host and phage, a concentration of the antibiotic great enough to inactivate all the viable cells showed progressive decrease in 24 hours of phage added to such mixtures. With lower concentrations of the antibiotic, the phage multiplied only when the cells were increasing. Phage in suspensions of streptomycin-treated cells was not

TABLE 3 I. EFFECT OF PENICILLIN AND STREPTOMYCIN ON S. AUREUS PHAGE AND ITS HOST. RESULTS $\mathrm{X} 1 \mathrm{O}^{5}$

\begin{tabular}{|c|c|c|c|c|c|c|c|}
\hline \multirow[t]{2}{*}{ TREATMENT } & \multirow[t]{2}{*}{ UNITS/ML. } & \multicolumn{3}{|c|}{$\begin{array}{l}\text { BACTERIAL CELLS/ML. } \\
\text { AFTER TIME SPECIFIED } \\
\text { AT } 37^{\circ} \mathrm{C.}^{*}\end{array}$} & \multicolumn{3}{|c|}{$\begin{array}{l}\text { PLAQUES } / \text { ML. } \\
\text { AFTER TIME SPECI- } \\
\text { FIED AT } 37^{\circ} \mathrm{C} \text {. }\end{array}$} \\
\hline & & $\begin{array}{c}3 \\
\text { hours }\end{array}$ & $\begin{array}{c}24 \\
\text { hours }\end{array}$ & $\begin{array}{c}48 \\
\text { hours }\end{array}$ & $\stackrel{3}{3}$ & $\begin{array}{c}24 \\
\text { hours }\end{array}$ & $\begin{array}{c}4^{8} \\
\text { hours }\end{array}$ \\
\hline Culture control & 0 & 320 & 3300 & 570 & & & \\
\hline Cells + streptomycin & 2 & .01 & 4.25 & 4200 & & & \\
\hline Cells + penicillin & 10 & .15 & .275 & 55 & & & \\
\hline Cells + phage & 0 & & .01 & & & 4700 & \\
\hline Phage + broth & 0 & & & & $7 \cdot 5$ & 3.7 & .001 \\
\hline Phage + streptomycin & 2 & & & & & 120 & .04 \\
\hline Phage + penicillin & 10 & & & & & 100 & .98 \\
\hline $\begin{array}{c}\text { Cells }+ \text { phage }+ \\
\text { streptomycin }\end{array}$ & 2 & .01 & .001 & .294 & & .41 & .2 \\
\hline $\begin{array}{l}\text { Cells }+ \text { phage }+ \\
\text { penicillin }\end{array}$ & 10 & .09 & .001 & .025 & & & \\
\hline
\end{tabular}

From Jones (476).

* Number of cells at start, 114 . 
reactivated by dilution after prolonged incubation (Table $3 \mathrm{I}$ ). Penicillin and streptomycin acting on $S$. aureus phage and its host, at concentrations of the substances which had no destructive effect on the phage alone, showed that no reduction of the phage occurred when placed in the presence of penicillin-treated cells, whereas a definite decrease took place in the case of streptomycin-treated cells (476).

A mixture of phage and penicillin caused more rapid killing and lysis of staphylococci than either alone, thus indicating that the penicillinresistant organisms were killed by the phage and vice versa. Penicillin itself did not affect phage multiplication and did not interfere with its lytic action (425).

The formation of antiphage agents can be studied by a group of methods, making use of the phage agar plate, phage streak, and agardiffusion or cup tests. Growth of the antagonist upon the phage-seeded agar, or the diffusion of the antiphage agent into the agar, is followed by flooding the surface with host-seeded agar. Antiphage action is indicated by a reduced number of plaques or by a zone of bacterial growth surrounding either the antagonist or the cup containing the antiphage substance (466).

The use of antibiotics in combating true viruses has so far given only little encouragement. However, the inhibition of growth of typhus rickettsiae by penicillin has been established (36I).

\section{RELATIONSHIPS AMONG VIRUSES}

The cultivation of influenza virus in a simple tissue-culture was found (20) to render the culture unable to support the growth of a biologically distinct strain of the virus added 24 hours later. The tissueculture, however, was still capable of supporting multiplication of a related virus such as that of lymphogranuloma venereum. When two strains of the influenza virus were added to the tissue-culture simultaneously, the one added in larger concentration suppressed the growth of the other.

Numerous reports have been made concerning the interference of one virus by another, and even of inactivated bacteriophage with the active agent of the same strain (1047, I048). Henle and Henle (404) have 
shown that even an inactivated virus, whether a homologous or a heterologous strain, is capable of suppressing the development of the influenza virus.

Jungeblut and Sanders (483) suggested that poliomyelitis in animals may be aborted by the injection of another virus. A strong antagonism was observed between a murine virus mutant (virus passed through mice for many generations) and the parent strain of the virus. The murine virus was capable of counteracting large paralytic doses of poliomyelitis; the two viruses virtually counterbalanced each other.

Other types of antagonism between viruses include that of canine distemper or lymphocytic chorio-meningitis virus against experimental poliomyelitis ( I69). An intramuscular injection of a neurotropic strain of yellow fever virus was found to protect animals against simultaneous infection with a highly pathogenic viscerotropic strain (447). The antagonistic agent was believed to be a chemical substance produced by the murine virus, for which the term "poliomyelitis inhibition" was proposed by Jungeblut. The "interference phenomenon" of two viruses can be used to advantage in bringing about immunity reactions.

The suppression of one strain of yellow fever virus by another, as well as of equine encephalomyelitis virus and of influenza $A$ by yellow fever virus, belongs to the same group of phenomena. No neutralizing antibodies or nonspecific antiviral substances were found in the yellow fever virus (558).

A similar type of antagonism is frequently observed also among plant viruses. Yellow mosaic virus will not grow in the tobacco tissue cells already infected with the agent causing common mosaic disease (608). Other antagonistic phenomena between plant viruses have been reported (6I2). The virus of peach-yellow prevented invasion by the virus of little-peach and the latter prevented invasion by the former (540). The conclusion was reached (608), therefore, that virus domination in a plant may be looked upon as a type of antagonism, quantitative in nature, the degree of domination by a given virus being influenced by the host.

Many other instances of virus antagonism have been reported, as when one virus prevents the multiplication of another and actually replaces it in plants in which it is established (37). Certain vitamins, such 
as ascorbic acid and thiamin, and certain other organic compounds, such as cysteine, inhibit the formation of necrosis produced by tobacco-mosaic virus. This reaction is reversible, since necroses begin to develop when the tobacco leaves thus treated are placed in pure water (8I5).

The ability of bacterial phages to interfere with the development of other phages has been studied in detail by Delbrück and Luria ( 175 , 586). They have shown that a certain phage, after inactivation by ultraviolet radiation, retained its ability to interfere with the growth of another phage acting upon the same host. The partly inactivated first phage is adsorbed by the sensitive bacteria and inhibits their growth without producing lysis. The partly inactivated phage interferes also with the growth of the active phage. This interference between bacterial phages was explained as due to competition for a "key-enzyme" present in limited amount in each bacterial cell. This enzyme was also believed to be essential for bacterial growth.

In order to explain the "mutual exclusion effect" of one virus by another, a "penetration hypothesis" was proposed (I 74). According to this hypothesis, the penetration of one virus into the cell renders the cell membrane impermeable to any other virus; each virus has a characteristic penetration time, and a change of permeability occurs at the end of this time. The depressor effect consists in competition between the two viruses for the same substrate.

The function of a co-factor, like tryptophane, was considered to be either that of a cement substance acting in a specific combination between virus and host receptive spots or as a coenzyme which enables the virus particles, during their encounters with the host cells, to become attached to them and attack them (2I).

\section{MICROBES AND TUMORS}

The ability of certain microbes to bring about hemorrhage in tumors (455a, 1044) may also be classed among the antagonistic phenomena. The hemorrhage-producing agent is a polysaccharide and is isolated only from gram-negative bacteria.

Laszlo and Leuchtenberger (549) described a rapid test for the detection of tumor-growth inhibitors. Inhibition was judged by comparing 
tumor sizes and weights in treated and untreated groups of mice bearing sarcoma, after a period of 48 hours of growth. The groups were matched as to initial size of the tumors. The selective damage said to be caused by penicillin to sarcoma cells as compared with normal cells ( 156$)$ was later shown (567) to be due not to the pure penicillin itself but to some impurity present in crude penicillin preparations.

The hemorrhagic effect upon the tumors is highly selective, being characteristic of the sarcoma cells only and does not occur in normal tissues, with a few minor and slight exceptions. The phenomena of hemorrhage and necrosis are followed in some cases by a complete and permanent regression of the tumor. The curative effects of such treatments are still open to question, however (94). The same may be said of the effect upon tumors of trypanosomes or of the "factors" produced by them.

The effect of penatin upon sarcoma has been tested and found to be negative ( 1 I 13 ).

\section{ANTITOXIC PROPERTIES OF ANTIBIOTICS}

The ability of various microorganisms to destroy or neutralize bacterial toxins has been definitely established. The substance involved was designated as an antidotic (759). It is produced by $B$. subtilis and $P$. notatum; however, isolated penicillin had no such effect, although large doses of this antibiotic protected mice against the action of gonococcal endotoxin (685). Clavacin was also found (675) capable of neutralizing tetanus toxin. 


\section{CHEMICAL NATURE OF ANTIBIOTIC SUBSTANCES}

Antimicrobial agents are of either chemical or biological origin. The first comprise inorganic (heavy metals, halogens) and organic (phenols, arsenicals, dyes, aromatic oils) compounds. The second include a variety of products of higher plants (quinine, chaulmoogra oil, wheat flour protein, allicin), higher animals (lactenin, lysozyme), and microorganisms, to which the term "antibiotic" is specifically applied.

The property possessed by culture filtrates of many bacteria of inhibiting the growth of bacterial cells has long been recognized. The suggestion has even been made that all bacteria, when tested at the right age and under proper conditions of culture, are able to produce antibacterial substances (7I). It is now definitely established, however, that this property is characteristic of only certain strains of specific bacteria, fungi, and actinomycetes.

The production of antibiotic substances by microorganisms is influenced by the strain of the organism, composition of the medium, incubation temperature, age of the culture, aeration, and certain other factors.

The more important antibiotic substances are described briefly in Table 32. They may be classified on the basis of their origin from specific microorganisms, their chemical properties, or their biological action. Differences between various compounds may often be in degree rather than in kind. Different organisms may produce the same antibiotic; frequently the substance may show minor variations from the general type, these variations being both chemical and biological. Some organisms are able to produce more than one antibiotic: $B$. brevis produces tyrocidine and gramicidin; $P$. notatum, penicillin and penatin; $A$. fumigatus, fumigatin, fumigacin, spinulosin, and gliotoxin; $A$. flavus, aspergillic acid and penicillin.

Since the name of an antibiotic often designates only a crude preparation, considerable confusion has arisen because different names have been given to the same preparation, or the same name has been applied 


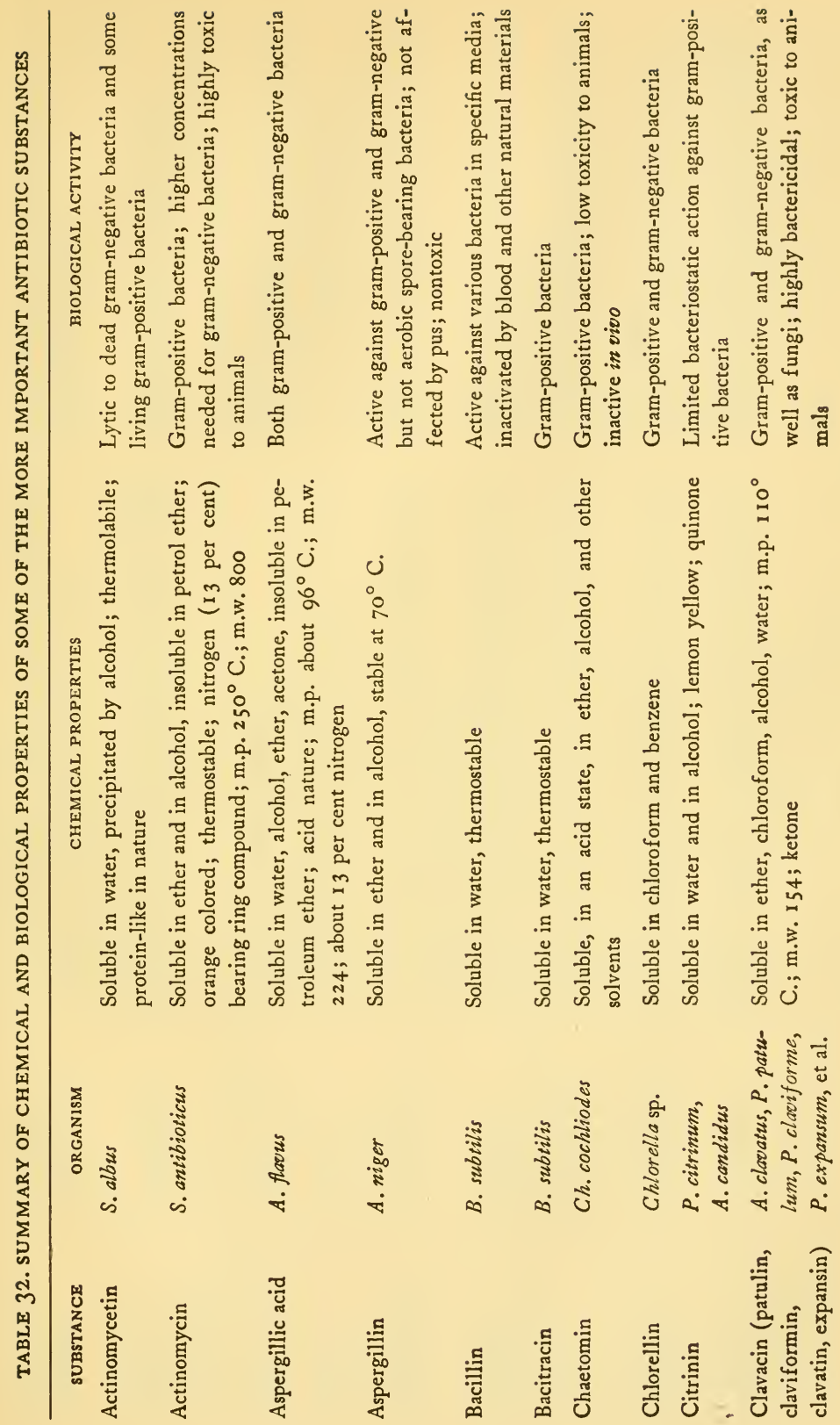




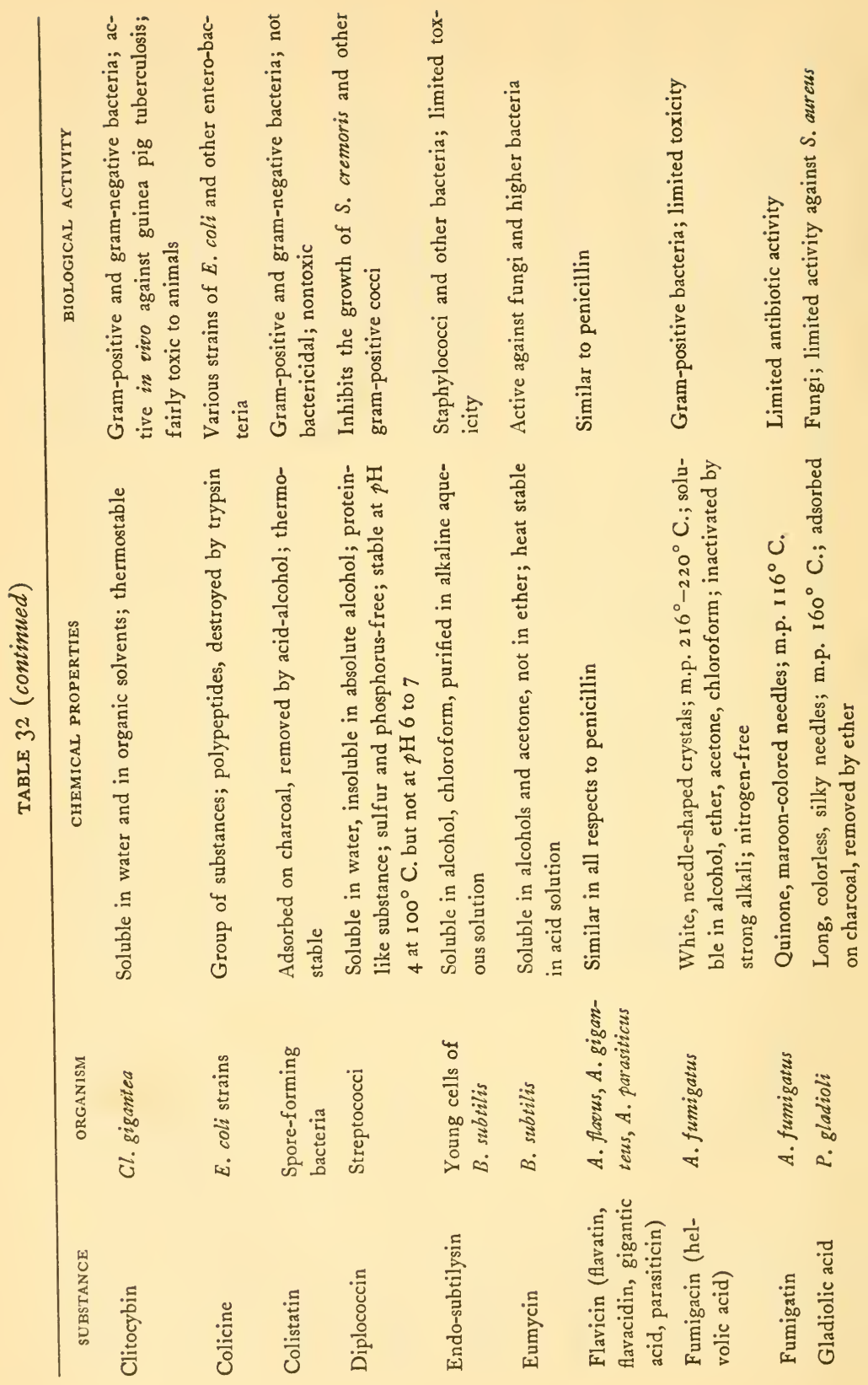




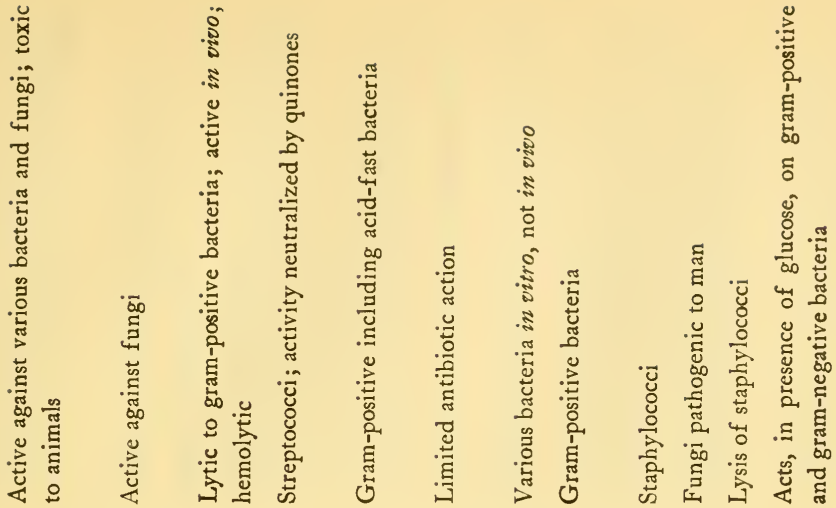

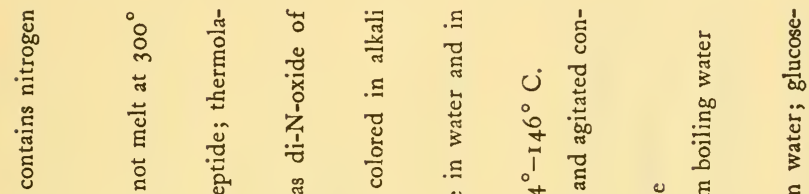

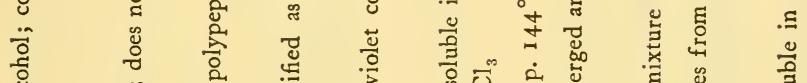

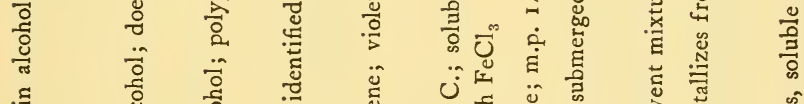

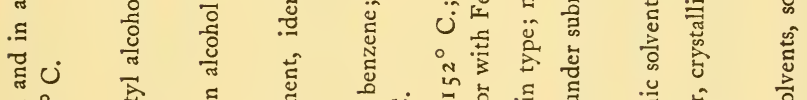

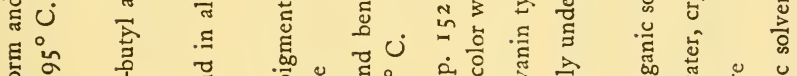

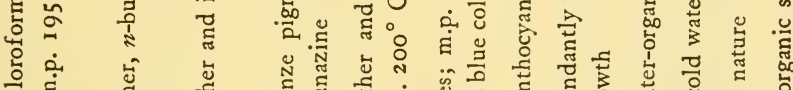

趈

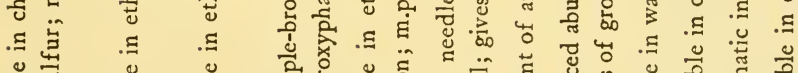

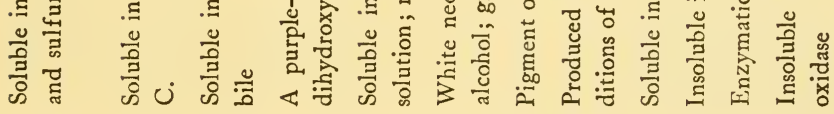

过

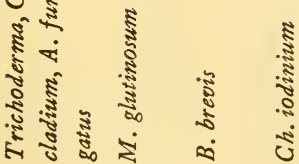

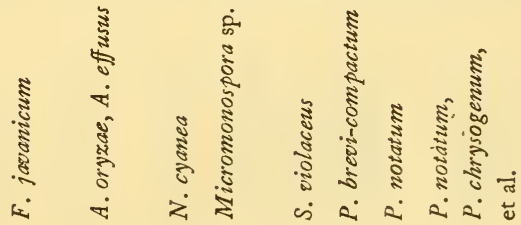

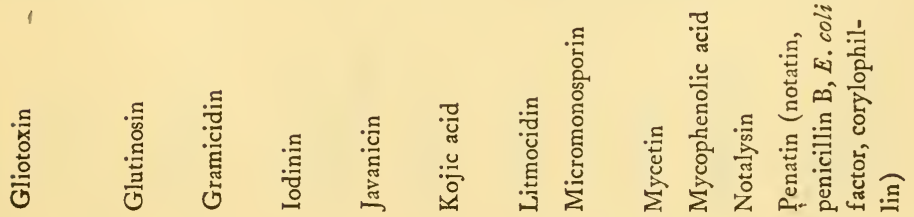




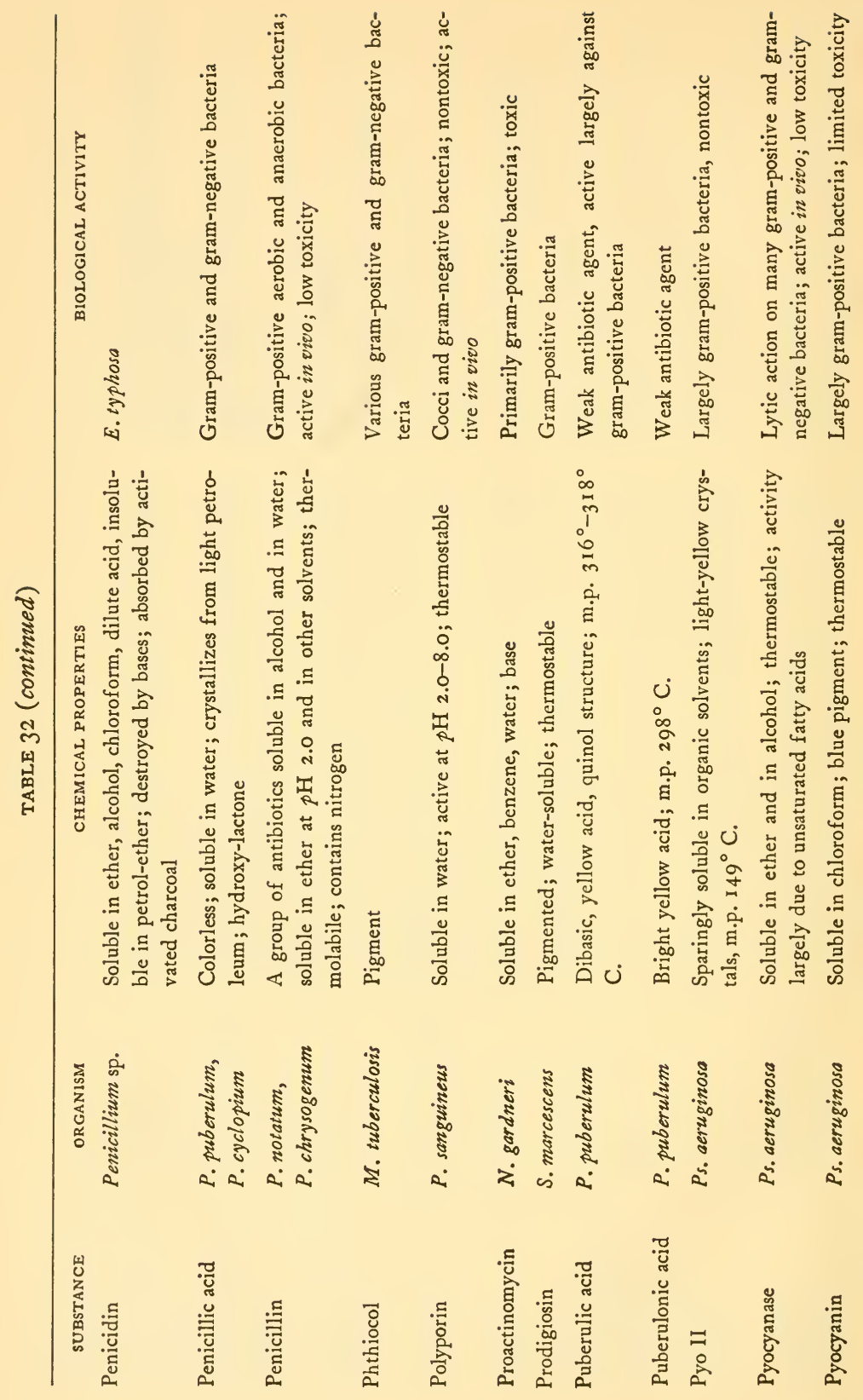




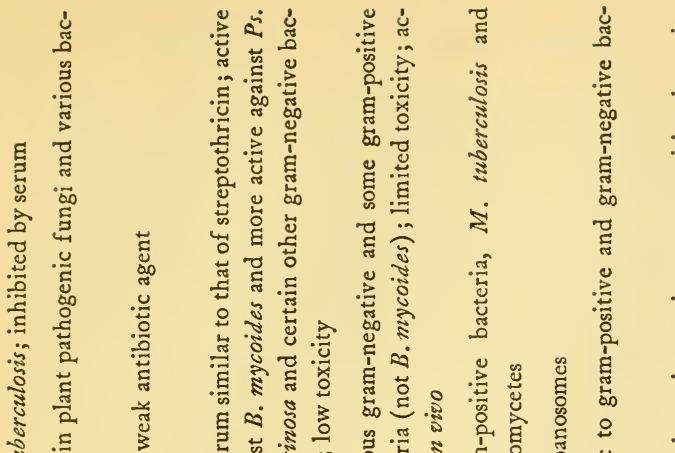

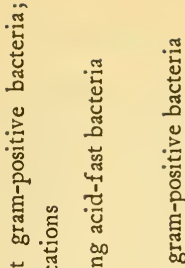

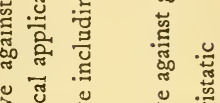

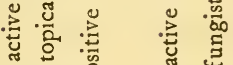

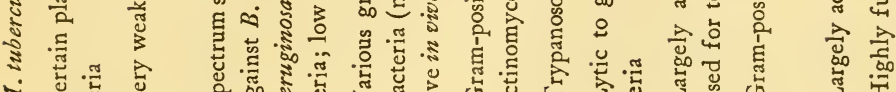
¿

¿

ठํㅀ

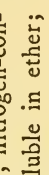

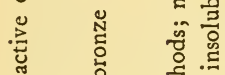

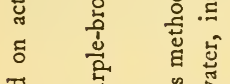

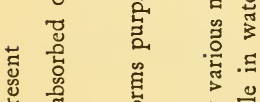

मे ले क्षे

용 च

क

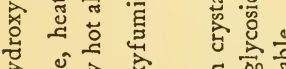

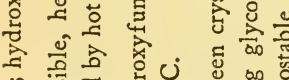

ठ艹

:

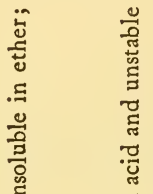

.

क्ष

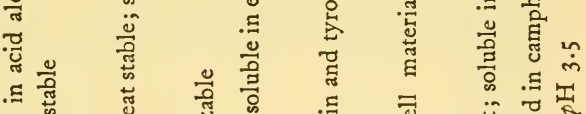

ฮั

त 出

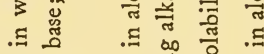

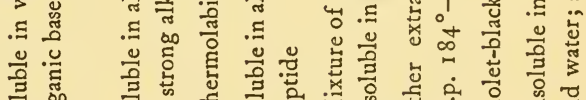

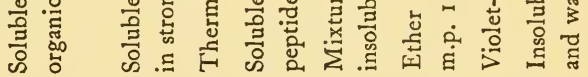
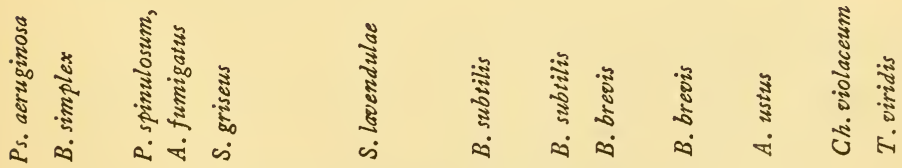

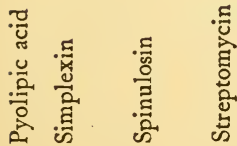



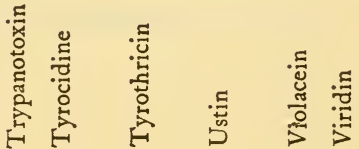


by different workers to different preparations even when these have been obtained from the same organism. Witness, for example, the designation "subtilin" that has been applied in different countries to preparations obtained from different strains of members of the $B$. subtilis group grown on media of different composition. The fact that other names, like "bacitracin," "subtilysin," "endo-subtilysin," and "bacillin," are given to certain preparations of $B$. subtilis does not necessarily indicate that the substances are different. We must await further information concerning the chemical and biological properties of these preparations before their identity can be definitely established. The name "aspergillin" has been applied to at least four preparations, in spite of the fact that it was first used to designate the black pigment of $A$. niger.

Various names have been used to designate indefinite preparations produced by unknown organisms. This is true, for example, of "mycocidin" produced by certain fungi and active against $M$. tuberculosis (328), and of "fungin" and "mycoin," terms used to designate antibiotics of fungi and actinomycetes, as well as of the term "inhibin" to designate antibacterial substances present in honey.

On the basis of their solubility, antibiotics may be divided into four groups:

Group A. Soluble in water at different reactions, and insoluble in ether. These substances usually represent proteins, organic bases, or adsorption compounds on protein molecules. Some have been isolated in a pure state. They comprise the bacterial enzymes acting upon microbial polysaccharides, actinomycetin, microbial lysozyme, streptothricin, streptomycin, penatin, and pyocyanin.

Group B. Soluble in ether and in water at proper reactions. Here belong many of the important antibiotic substances so far isolated and described, namely, penicillin, flavicin, citrinin, clavacin, proactinomycin, penicillic acid, and aspergillic acid.

Group C. Insoluble in ether and in water. These include gramicidin, tyrocidine, subtilin, and simplexin.

Group D. Soluble in ether and insoluble in water. These include fumigacin, fumigatin, gliotoxin, actinomycin, pyocyanase, and others.

Some of the antibiotic substances have been crystallized, and infor- 
mation has been gained concerning the approximate chemical nature of others; many others are still imperfectly known. On the basis of their chemical nature, the antibiotic substances may be divided as follows:

Lipoids and various microbial extracts removed by organic solvents, such as pyocyanase, pyolipic acid, and others

Pigments, namely pyocyanin, hemipyocyanin, prodigiosin, fumigatin, chlororaphin, toxoflavin, actinomycin, litmocidin, and others

Polypeptides, comprising tyrothricin, gramicidin, tyrocidine, colicines, subtilin, bacillin, and actinomycetin

Sulfur-bearing compounds, namely the different penicillins, gliotoxin, and chaetomin

Quinones and ketones, namely, citrinin, spinulosin, clavacin, and penicillic acid

Organic bases, including streptothricin, streptomycin, and proactinomycin

Oxford (7OI) classified the known antibiotic substances on the basis of their chemical structure. Most of the antibiotic substances can thus be grouped as follows:

I. Compounds containing $\mathrm{C}, \mathrm{H}$, and $\mathrm{O}$ only

1. $\mathrm{C}_{6}$ group: $\mathrm{C}_{6} \mathrm{H}_{6} \mathrm{O}_{4}$ - kojic acid

2. $\mathrm{C}_{7}$ group: $\mathrm{C}_{7} \mathrm{H}_{6} \mathrm{O}_{4}$-clavacin

3. $\mathrm{C}_{8}$ group: $\mathrm{C}_{8} \mathrm{H}_{6} \mathrm{O}_{6}$-puberulic acid

$\mathrm{C}_{8} \mathrm{H}_{8} \mathrm{O}_{4}$-fumigatin

$\mathrm{C}_{8} \mathrm{H}_{10} \mathrm{O}_{4}$-penicillic acid

4. $\mathrm{C}_{10}$ group: $\mathrm{C}_{10} \mathrm{H}_{20} \mathrm{O}_{3}$-pyolipic acid

5. $\mathrm{C}_{13}$ group: $\mathrm{C}_{13} \mathrm{H}_{14} \mathrm{O}_{5}$ - citrinin

6. $\mathrm{C}_{15}$ group: $\mathrm{C}_{15} \mathrm{H}_{14} \mathrm{O}_{6}$ - javanicin

7. $\mathrm{C}_{17}$ group: $\mathrm{C}_{17} \mathrm{H}_{20} \mathrm{O}_{6}$-mycophenolic acid

8. $\mathrm{C}_{20}$ group: $\mathrm{C}_{20} \mathrm{H}_{16} \mathrm{O}_{6}$-viridin

9. $\mathrm{C}_{32}$ group: $\mathrm{C}_{32} \mathrm{H}_{44} \mathrm{O}_{8}$-fumigacin, helvolic acid

Various other compounds belonging to this group have been isolated, such as gladiolic acid, $\mathrm{C}_{11} \mathrm{H}_{10} \mathrm{O}_{5}$.

II. Compounds containing $\mathrm{C}, \mathrm{H}, \mathrm{O}$, and $\mathrm{N}$

I. $\mathrm{C}_{12}$ group: $\mathrm{C}_{12} \mathrm{H}_{8} \mathrm{ON}_{2}$-hemipyocyanin

$\mathrm{C}_{12} \mathrm{H}_{8} \mathrm{O}_{4} \mathrm{~N}_{2}$-iodinin

$\mathrm{C}_{12} \mathrm{H}_{20} \mathrm{O}_{2} \mathrm{~N}_{2}$-aspergillic acid 
2. $\mathrm{C}_{13}$ group: $\mathrm{C}_{13} \mathrm{H}_{10} \mathrm{ON}_{2}$ - pyocyanin

3. $\mathrm{C}_{21}$ group: $\mathrm{C}_{21} \mathrm{H}_{37-39} \mathrm{O}_{12} \mathrm{~N}_{7}$-streptomycin

4. $\mathrm{C}_{34}$ group: $\mathrm{C}_{34} \mathrm{H}_{46} \mathrm{O}_{4} \mathrm{~N}_{2}$-pyo II

5. $\mathrm{C}_{41}$ group: $\mathrm{C}_{41} \mathrm{H}_{56} \mathrm{O}_{11} \mathrm{~N}_{8}$-actinomycin

6. $\mathrm{C}_{146}$ group: High molecular weight compounds, such as gramicidin and tyrocidine; diplococcin may also be included in this group

III. Compounds containing $\mathrm{C}, \mathrm{H}, \mathrm{O}, \mathrm{N}$, and $\mathrm{S}$

I. $\mathrm{C}_{9}+$, namely the penicillin group of compounds which is designated by the formula $\mathrm{C}_{9} \mathrm{H}_{11} \mathrm{O}_{4} \mathrm{SN}_{2}$. R

2. $\mathrm{C}_{13}$ group: $\mathrm{C}_{13} \mathrm{H}_{14} \mathrm{O}_{4} \mathrm{~N}_{2} \mathrm{~S}_{2}$-gliotoxin

IV. Other compounds, many of which have as yet not been fully identified. Here belongs ustin, $\mathrm{C}_{19} \mathrm{H}_{15} \mathrm{O}_{5} \mathrm{Cl}_{3}$.

On the basis of their toxicity to animals, antibiotic substances may also be divided into three groups:

Compounds that are nontoxic or but slightly toxic; here belong penicillin, streptomycin, flavicin, polyporin, and actinomycetin

Compounds of limited toxicity, including gramicidin, tyrocidine, citrinin, streptothricin, and fumigacin

Highly toxic compounds, such as actinomycin, gliotoxin, aspergillic acid, and clavacin

Many of the antibiotic substances are thermostable, others are thermolabile; some pass readily through Seitz and other filters, others are adsorbed. The various methods of isolation of these substances are based upon their chemical nature, solubility, and properties of adsorption.

\section{SUBSTANCES PRODUCED BY BACTERIA}

\section{Lipoids and Pigments}

Ps. aeruginosa, discovered by Gessard in I 882 (329), and formerly known under the names of Bacterium pyocyaneum and Bacillus pyocyaneus, produces several antibiotic agents, the colorless lipid pyocyanase, the pigment pyocyanin, and an alcoholic extract of the bacterial cells.

Pyocyanase, the first antibiotic substance to be isolated, has had a 
rather interesting history. Emmerich believed that it is an enzyme $(233,236)$. Later it was found $(766)$ that all the active substance could be extracted with lipid solvents; the extraction of the cells of $P$ s. aeruginosa with alcohol also gave active antibacterial preparations. A crystalline product was finally obtained (448); it was soluble in organic solvents and had a bactericidal effect upon $B$. anthracis, $S$. albus, $C$. diphtheriae, and a number of other organisms.

In the course of time it was recognized that all the antibacterial activity of the lipoid extracted from the medium was due to the presence of fatty acids, so that the term pyocyanase is now used to designate the antibiotic lipid, found in the medium and containing unsaturated fatty acids. Certain well-defined compounds have recently been isolated, such as pyolipic acid (50a).

Schoenthal (843) obtained three compounds that possessed antibacterial properties, namely, pyocyanin, oxyphenazine, and an active oil that formed insoluble salts with calcium, barium, and heavy metals. The last appeared to be similar to what had previously been described as pyocyanic acid, a substance highly active against $V$.comma. All three compounds were isolated by extraction with chloroform.

Different strains of Ps.aeruginosa may produce either pyocyanase or pyocyanin or both, the production of the two not proceeding in a parallel manner. Among the amino acids, alanine and tyrosine were found to be favorable to pyocyanin production (346), although the effect of tyrosine is not very significant $(346,46 \mathrm{I}, 573)$.

The determination of the nature of the antibacterial substances of Ps. aeruginosa can be carried out in the following manner (4I8): the organism is grown in bouillon for 14 days; the cultures are heated for a half hour at $75^{\circ} \mathrm{C}$. to kill the living cells; they are then centrifuged, the liquid is treated with chloroform which extracts the pigment, and the chloroform solution is concentrated in vacuo at $50^{\circ} \mathrm{C}$.; the aqueous solution remaining after chloroform extraction is acidified with hydrochloric acid and again shaken five times with chloroform, thus extracting the fatty acids. It was found that the antibacterial properties are yery little diminished by removal of the pigment; however, when both the pigment and the fatty acids are removed, no antibacterial action is left in the culture. $S$. aureus is commonly used as the test bacterium. 
The broth culture of the organism may also be first extracted with ether, giving pyocyanase, and the residue treated with chloroform, yielding pyocyanin. The solution left after the removal of the blue chloroform extract may be again treated with ether, giving a yellow pigment, which also has some activity (529). This pigment is a derivative of pyocyanin and is often designated (1036) as hemipyocyanin. It may also be obtained by acidifying pyocyanin with acetic acid and heating. The fluorescin remaining in the culture after the ether and chloroform extraction was found to be inactive. In old cultures, pyocyanin is changed into a brown pigment, pyoxanthose. A fourth pigment, which is yellow in transmissible light and fluorescent-green in reflected light, is produced under certain conditions. It was excreted into the medium as a leuco base.

Pyocyanase is soluble in ether, benzol, benzene, and petrol ether (766). It can be separated into several lipoids, the action of which shows slight variation. This preparation consists of a phosphatide, a neutral fat, and a free fatty acid. The antibacterial properties have been attributed to the last constituent (42 I). A definite relation has been observed between the number of double bonds and the activity of the substance $(59,420)$. According to Dressel (197), most fatty acids exert bactericidal and bacteriolytic effects upon gram-positive bacteria, whereas gram-negative organisms are not lysed. Pyocyanase acts upon various bacteria, including the colon-typhoid group, though the ability of the substance to inhibit the growth of this group of bacteria has been denied by some workers ( 372 ).

$B$. mesentericus and other spore-forming bacteria also produce antibiotic agents of a lipoid nature. The substance is not affected by heating for 30 seconds at $100^{\circ} \mathrm{C}$. but is weakened at $115^{\circ} \mathrm{C}$. for Io minutes. It is considered similar in its bactericidal properties to pyocyanase.

Alcohol and acetone extracted from $B$. mesentericus a weakly active substance (4I9) that diffused through a cellophane membrane and could be partly absorbed on a Berkfeld filter. When shaken directly with ether, the culture lost its antibacterial properties. The ether extract was concentrated and ammonia added, and the solution was treated with 50 per cent alcohol. The alcohol was then removed, and the residue was acidified and treated with petrol ether, which brought the active sub- 
stance into solution. The active substance was again dissolved in alcohol and taken up in ether. The ether solution was washed with water, evaporated, and dried. One liter of a 30-day-old culture of $B$. mesentericus gave $162 \mathrm{mg}$. of petrol-ether-soluble fatty acids and an oily substance of a brownish color. It was neutralized with $\mathrm{NaOH}$ solution and tested. The extract diluted to I : 7,500 killed diphtheria; a I : I,000 dilution was required to kill staphylococci. Iso-valerianic acid and oleic acid, isolated from this material, had a similar bactericidal action. Weakening of the substance by heating was demonstrated and was believed to be due to a break in the double bond of the oleic acid.

$E$. coli exerts an antagonistic effect in vivo when injected subcutaneously or when used for feeding. It produces $(367,369)$ a thermolabile substance that was considered to be a lipoid in character. However, some of the antibiotics of $E$. coli, namely the colicines, appear to be definitely proteins or polypeptides.

Pyocyanin is a dark blue pigment, red in acid solution, m.p. $133^{\circ} \mathrm{C}$., water soluble and amphotheric. It is extracted with chloroform, then reextracted by acidulated water. It is characterized by a wide antibiotic spectrum and high toxicity to animals. This pigment was first studied by Fordos in 1860 (277). Since then many contributions have appeared dealing with formation and nature of this pigment. Several formulae have been suggested for pyocyanin (46I, 935, I036), one of which is shown in Figure I 8 . The structure of pyocyanin has considerable similarity to chlororaphin and iodinin, obtained from Chromobacterium (596), and two synthetic compounds, phenazine and acridine (939). Since $P$ s. aeruginosa is an extremely variable organism, the nature and abundance of the pigment are variable. Keeping the organism for 5 minutes at $57^{\circ} \mathrm{C}$. or cultivating it in liquid egg-albumin has been found to result in destruction of some of its pigment-producing properties (330, 557).

Hemipyocyanin is found in old cultures of Ps. aeruginosa (843) and is synthesized (1036) from pyocyanin. It is a yellow pigment, m.p. I $58^{\circ} \mathrm{C}$., with basic and phenolic properties. It is moderately bacteriostatic and strongly fungistatic (883).

Prodigiosin is produced by $S$. marcescens. It is insoluble in water and is active against $B$. anthracis ( 1035 ). 
<smiles>C=C(C)C(=O)C(C)=CC(=O)O</smiles>

PENICILLIC ACID<smiles>O=C1COC2COCC12</smiles>

CLAVACIN<smiles>O=c1ccoc(=O)cc1</smiles>

KOJIC ACID<smiles>COC(=O)C=CC(=O)O</smiles>

FUMIGATIN

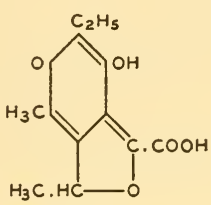

CITRININ

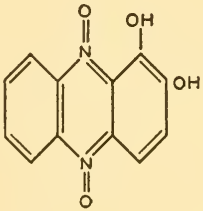

IODININ

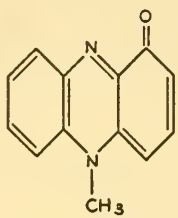

PYOCYANIN

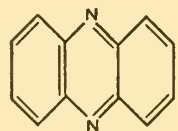

PHENAZINE

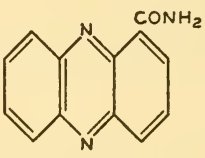

CHLORORAPHIN

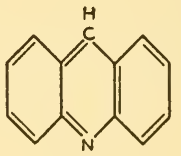

ACRIDINE

FigURE I 8. Structural formulae of some antibiotic substances.

Iodinin is a deep purple-bronze pigment, m.p. $236^{\circ} \mathrm{C}$. (Figure I 8 ). It is produced by $C h$.iodinum (597) and is excreted into the medium. It is insoluble in water and in acids but soluble in alkali, and is phenolic in character. It is dissolved in chloroform. It is active against $S$. hemolyticus, less so against $S$. aureus and other bacteria.

Violacein, a purple pigment, is produced by $C h$. violaceum. This pigment is active against gram-positive bacteria, except $\mathrm{Cl}$. welchii; it 
has little effect upon the gram-negative bacteria, except the meningococci. Among the fungi, only Blastomyces dermatiditis is susceptible. The action of the pigment is greatly affected by serum (569).

It may be added here that certain aromatic oils and various fatty acids possess marked bactericidal properties ( 518$)$. Unsaturated acids are more active than saturated acids (1040). Ordinary peptones have also been found to contain a substance that is active against various bacteria, especially when small amounts of inoculum are used (202). The active substance is thermostable and is associated with an acid-precipitated fraction that is pigmented and changes color upon oxidation and reduction. The bacteriostatic effect of this material can be corrected by the addition of reducing agents, such as thioglycollic acid. The bacteriostatic action of dyes is well known and need hardly be discussed here. It is sufficient to mention, for example, methylene blue and indophenols in oxidized forms.

Pyo-compounds. Doisy and his collaborators (389) centered their attention upon the antibiotics present in the Ps. aeruginosa cells. This group of compounds was designated as Pyo I, Pyo II, Pyo III, and Pyo IV. The culture of the organism was incubated for 5 weeks, cooled, and acidified with $\mathrm{HCl}$ to $p \mathrm{H}_{3.5}$; it was centrifuged, and the precipitate was extracted with hot 95 per cent ethyl alcohol. The alcohol extract was diluted with water to 80 per cent alcohol and treated with petroleum ether, to remove the fats and fatty acids. The alcoholic solution was evaporated and the aqueous residue extracted with ether. The extract was separated into the four fractions listed above, which represented pure, crystalline, active substances. These fractions were structurally related and were more active against the gram-positive than the gram-negative bacteria. They were nontoxic to animals.

\section{Polysaccharidases}

Among the antibiotic substances of microbial origin may also be included the enzyme systems that have the capacity of decomposing the capsular substance of certain bacteria, thereby rendering them more readily subject to destruction in the blood stream or in other substrates. The first enzyme of this type was isolated by Dubos and Avery (204, 
205, 207) from certain soil bacteria. These enzymes are highly specific, some being able to act only upon one type of pneumococci. As a result of their action, the pneumococcus cell is rendered susceptible to destruction by phagocytosis. This enzyme was produced by the soil bacteria under selective conditions of culture, that is, when the capsular polysaccharide of the pneumococcus was present in the medium; the only other substance that could be used for its production was aldobionic acid, which was derived from the above polysaccharide. Yields of the enzyme were increased by increasing the concentrations of the specific substrate in the medium from O.OI to O.I per cent. Above O.I per cent, the yields decreased, 0.3 to 0.4 per cent inhibiting the growth of the bacterium. The addition of 0.1 per cent yeast extract favored the production of the enzyme; proper aeration was essential, the bacterium making the best growth in shallow layers of medium. The enzyme was concentrated by distillation in vacuo and by ultrafiltration. Toxic substances accompanying the active preparation could be largely removed by the use of an aluminum gel. The enzyme is associated with a protein which passes through a collodion membrane with an average pore size of $10.6 \mu$, but is held back by pores having a diameter of $8.2 \mu$. After filtration, the enzyme can be recovered in solution by immersing the membrane in distilled water or in physiological salt solution.

Dubos (199) believed that it is possible to develop "adaptive" bacterial enzymes against many organic substances. These enzymes exhibit a great degree of specificity, as in the case of the enzyme that hydrolyzes the capsular polysaccharide of the pneumococcus. The cell of this organism contains an enzyme that changes the cell from the gram-positive to the gram-negative state, but is ineffective against streptococci or staphylococci.

Active preparations of the enzyme protected mice against infection with as many as $\mathrm{I}, 000,000$ lethal doses of the specific pneumococcus. The enzyme retained its activity for 24 to 48 hours after its injection into normal mice; it also exerted a favorable influence on the outcome of an infection already established at the time of treatment. A definite relationship was found to exist between the activity of the enzyme in vitro and its protective power in the animal body. 


\section{Polypeptides and Proteins}

From the tyrothricin complex group of antibiotics produced by $B$. brevis, two crystalline compounds have been isolated. They are polypeptides resistant to the action of proteolytic enzymes (20I, 208, 450, 909). The organism is grown in shallow layers of a suitable medium, such as one containing I per cent casein digest or tryptone and 0.5 per cent $\mathrm{NaCl}$ in tap water, adjusted to $\mathrm{pH}$ 7.0. After inoculation, the medium is heated for 20 minutes at $70^{\circ} \mathrm{C}$., in order to kill the vegetative cells of the bacteria, leaving only the spores to develop. The culture is allowed to grow for 72 hours. The reaction of the culture is then adjusted to $\mathrm{pH} 4.5$ by the use of about 3 or $4 \mathrm{cc}$. concentrated $\mathrm{HCl}$ per liter of culture. A precipitate is formed which is removed by filtration through paper; it is then suspended in 95 per cent alcohol (20 cc. of alcohol per liter of culture) and allowed to stand 24 hours. The active substance is dissolved and is separated from the residue by filtration; when the alcoholic solution is diluted with Io volumes of I per cent $\mathrm{NaCl}$, the substance is precipitated out. It carries all the activity and can be desiccated in vacuo, over $\mathrm{P}_{2} \mathrm{O}_{5}$, giving a yield of about $100 \mathrm{mg}$. of final dry substance per liter of culture medium. The protein-free, alcohol-soluble active material is tyrothricin. When an attempt was made to produce tyrothricin in aerated submerged cultures, none was obtained in complex nitrogenous media; however, simple amino compounds, like asparagine, gave good growth and yielded the antibiotic substance. The presence of cystine in the mixture of amino acids appeared to inhibit growth (884).

Gramicidin is obtained by treating tyrothricin with a mixture of equal volumes of acetone and ether, evaporating, and dissolving in boiling acetone. On cooling, it crystallizes out as spear-shaped colorless platelets, melting at $228^{\circ}$ to $230^{\circ} \mathrm{C}$., with a yield of about Io to I 5 grams from IoO grams of the crude material. Gramicidin is soluble in lower alcohols, acetic acid, and pyridine, and moderately soluble in dry acetone and dioxane; it is almost insoluble in water, ether, and hydrocarbons. When a solution containing 20 to $50 \mathrm{mg}$. per milliliter alcohol is diluted to I mg. per milliliter, with distilled water or with glucose solution, an opalescent solution is produced without flocculation. On dilution with electrolyte solutions, an immediate flocculation occurs. 
The specific rotation of gramicidin in 95 per cent alcohol solution is approximately $[\alpha]_{D}^{25}=+5^{\circ}$. On analysis, it gives 62.7 per cent $\mathrm{C}$, 7.5 per cent $H$, and 13.9 per cent $N$. The molecular weight, as determined in camphor, is about $\mathrm{I}, 400$. The empirical formula of $\mathrm{C}_{74} \mathrm{H}_{106} \mathrm{O}_{14} \mathrm{~N}_{14}$ has been suggested. On further study, the molecular weight of gramicidin was found (9I I) to present an anomaly in that it appeared to depend on the nature of the solvent and on the concentration of the solute, giving values from 600 to I,200; isothermal distillation in methanol, however, indicated a molecular weight of 2,700 to 3,100 , with an approximate formula of $\mathrm{C}_{146} \mathrm{H}_{202} \mathrm{O}_{2} \mathrm{~N}_{30}$. It gave neither free amino nor carboxyl groups; it contained ro molecules of a-amino acids, of which two or three were tryptophane residues. These and a saturated aliphatic acid, with 14 to 16 carbons, account for about 85 to 90 per cent of the weight of the substance. Amino acids that have definitely been identified are $l$-tryptophane, $d$-leucine, $l$-alanine, $d l$ valine, and glycine $(345,892)$. A study of the configuration of the dipeptide valyvaline separated from gramicidin brought out the fact that only valines of like configuration have been joined together by the bacterium ( 137). About 45 per cent of the $\alpha$-amino acids gave the $d$ configuration $(449,450)$. An unknown hydroxyamino compound has also been indicated.

The presence of ethanolamine (2-aminoethanol-1) as a component of gramicidin hydrolysates, which reacts with periodate to yield formaldehyde and $\mathrm{NH}_{3}$, has been definitely indicated (893). Actually two ethanolamine residues may occur in gramicidin, since their destruction during acid hydrolysis of gramicidin is considerable. The liberation of some of these amino acids during hydrolysis, such as valine and tryptophane, can be measured by their availability to L. arabinosus (I39).

Tyrocidine hydrochloride is moderately soluble in alcohol, acetic acid, and pyridine; it is sparingly soluble in water, acetone, and dioxane, and is insoluble in ether and hydrocarbon solvents. An alcohol solution can be diluted with water to give a clear solution containing 5 to $10 \mathrm{mg}$. per milliliter; electrolytes produce an immediate precipitate. A solution in distilled water containing I $\mathrm{mg}$. or even less per milliliter has a low surface tension and behaves like a soap or detergent solution. Un- 
like gramicidin, it precipitates a number of soluble proteins in a manner similar to some of the cationic detergents.

Tyrocidine is dissolved in four times its weight of boiling absolute alcohol, to which is added alcoholic $\mathrm{HCl}$ (O.I mol. per liter). On cooling, a precipitate is formed. This is recrystallized from absolute methanol plus small amounts of $\mathrm{HCl}$; clusters of microscopic needles are obtained, melting at $237-239^{\circ} \mathrm{C}$., with decomposition; the specific rotation is $[\alpha]_{D}^{25}=-{ }_{102}{ }^{\circ}$ ( $\mathrm{I}$ per cent in 95 per cent alcohol). Tyrocidine analyzes: 59.4 per cent $C$, 6.8 per cent $H, 13.5$ per cent $N, 2.7$ per cent $\mathrm{Cl}$. The molecular weight is about $\mathrm{I}, 260$ or a multiple of this number. Tyrocidine is a salt of a polypeptide having free basic amino groups. The $d$-amino acids make up 20 per cent of its $\alpha$-amino groups. The most probable molecule was shown to contain two amino groups, three amide groups, and one weakly acidic carboxyl or phenolic group, with a molecular weight of 2,534. Among the amino acids, tryptophane, tyrosine, and dicarboxylic-amino acids have been detected; concentration of some of these acids has been established: aspartic acid, 5.1 per cent; valine, 7.6 per cent; and leucine, 8.2 per cent (138, I 40). Summaries of the chemical and biological properties of gramicidin and tyrocidine were made by Hotchkiss (449) and Hoogerheide (443).

The tyrothricin-type of antibiotic substance appears to be widely distributed among spore-forming aerobic soil bacteria (442, 444, 885). Preparations obtained from different bacteria appear to be markedly different in chemical nature and biological activity. This is true, for example, of the preparation obtained by the following method: A seven-day-old bacterial culture was treated with 2 to 5 per cent of an electrolyte and $\mathrm{HCl}$ added to give a $\mathrm{pH}$ of 4.0. A precipitate was formed which was centrifuged and extracted with 95 per cent alcohol, until no more turbidity could be observed after dilution with an equal volume of water. The alcoholic extracts were evaporated to dryness and extracted with ether, petroleum ether, and benzol, in which the active substances are insoluble. The residue was then dissolved in absolute alcohol, and the concentrated solution dialyzed for 24 hours against running tap-water and for 24 hours against distilled water. The active substance was obtained partly in a precipitated form and partly in a 
colloidal solution in the dialysis bag. Upon evaporation of the water, a highly active, grayish-white powder was obtained. One hundred liters of medium gave I 5 grams of purified active substance. The activity could be tested by inhibition of encapsulation of Friedländer's bacterium; this was brought about by the addition of $4 \mathrm{mg}$. to I ml. of culture medium. This preparation was later found to be identical with gramicidin $(443,9$ I I ).

Gramicidin S $(43,324)$ is related to the tyrothricin complex, being tyrocidine in nature. It was found (894) to be a cyclopeptide, with a stoiochiometric minimum unit formed from one residue each of $l$-ornithine, $l$-proline, $l$-valine, $l$-leucine, and $d$-phenylalanine. The unit possesses one free amino group, no free carboxyl groups, and one residue of chloride.

Bacitracin is formed by certain strains of $B$. subtilis grown in shallow layers of media. A heavy surface pellicle is produced after 3 to 5 days' incubation at $37^{\circ} \mathrm{C}$. The medium is extracted with normal butanol and concentrated by steam distillation in vacuo, giving a grayish-white powder. The substance is neutral and water soluble and withstands heating for 15 minutes at $100^{\circ} \mathrm{C}$. without significant loss of activity. It is stable in acid solution but unstable in alkaline solution above $p \mathrm{H} 9$, and is not digested by proteolytic enzymes. It is active chiefly against grampositive organisms, but the gonococcus and meningococcus are also susceptible to it. It is active in vivo against experimentally produced hemolytic streptococcus and gas gangrene infections (469).

Subtilin is produced by certain strains of $B$. subtilis. It is a polypeptide and is readily digested by proteolytic enzymes. It is most active at pH 2.2 and gradually becomes inactivated with decreasing acidity. It is active against various gram-positive bacteria, acid-fast bacteria, and certain pathogenic fungi ( 816$)$. Eumycin, produced by certain strains of $B$. subtilis and active largely against fungi, actinomycetes, and mycobacteria, although showing little effect against staphylococci may also belong to this group (47I). Subtilysin was reported to have a lytic action against gram-negative bacteria, none against cocci (925). Some of the subtilin preparations also have the capacity of inactivating bacterial toxins, such as diphtheria, tetanus, and others. This property was as- 
cribed to the presence of a heat-stable substance designated as antidotic (759).

Diplococcin is produced by certain lactic acid streptococci. It is a protein synthesized in the bacterial cells from the amino acids in the medium, and is extracted with cold dilute acetic acid. The active protein is precipitated by 60 per cent saturation with ammonium sulphate (70I). It is active against gram-positive cocci and Lactobacillus species, but not against gram-negative bacteria.

A thermostable substance was obtained (I 54) from B. simplex, an organism capable of bringing about the destruction of various pathogenic fungi. This antibiotic was later designated as simplexin. It was produced by the bacterium grown both on synthetic and on organic media. It can be adsorbed on activated charcoal and recovered from the latter by the use of hot alcohol.

To what extent substances of bacterial origin that are toxic to brain tissues, like toxoflavin $\left(\mathrm{C}_{6} \mathrm{H}_{6} \mathrm{~N}_{4} \mathrm{O}_{2}\right)$, are also effective against bacteria and other microorganisms still remains to be determined. Toxoflavin, formed by Bacterium cocovenenans, is extracted from the culture saturated with salt by means of chloroform; from this it is recovered by an aqueous solution and purified (931, 932).

Other bacterial toxins, like botulinus toxin, various amines and purine bases, and numerous toxins produced by bacteria in living plant and animal systems, are beyond the scope of this treatise.

\section{SUBSTANCES PRODUCED BY ACTINOMYCETES}

\section{Actinomycin}

Actinomycin is an ether-soluble and alcohol-soluble pigmented substance produced by certain actinomycetes, notably $S$. antibioticus. The culture medium is treated with ether, giving an orange-colored extract. The residue is evaporated and treated with petrol ether (975).

The purification of actinomycin was effected by chromatographic adsorption, followed by fractionation of eluate. The orange-brown residue left after treatment with petroleum ether was dissolved in benzene, filtered, and allowed to pass through a tower packed with aluminum oxide. On washing the tower with large amounts of benzene, a chro- 
matogram slowly developed. The column was then washed with a solution of $\mathrm{r} 5$ parts acetone to 85 parts benzene until the yellow-orange band approached the bottom of the column. The elution of the pigment from the column was accomplished finally by further washing with 30 per cent acetone in benzene until the eluate was faintly yellow in color. The later eluates were found by assays to contain all the active pigment, whereas all previous eluates, as well as the fractions remaining on the adsorbent, showed no bacteriostatic or bactericidal activity.

Pure actinomycin was obtained by concentrating the 30 per cent acetone-benzene eluates to dryness, then recrystallizing the red solid residue from acetone-ether mixtures or from ethyl acetate. From these solvents, the pigment separated as vermilion-red platelets which melted at $250^{\circ} \mathrm{C}$, with slow decomposition. The pigment is readily soluble in chloroform, benzene, and ethanol; moderately in acetone and hot ethyl acetate; and slightly in water and ether. The color of the solid pigment depends on its state of subdivision; when ground very fine, its color is orange-red (910).

Actinomycin is optically active, a solution of $5 \mathrm{mg}$. in $2 \mathrm{cc}$. ethanol in a $\mathrm{I} \mathrm{dm}$. tube having a rotation $-\mathrm{I} .60^{\circ} ;[\alpha]_{\mathrm{D}}^{25}=-320^{\circ} \pm 5$. Its molecular weight was found to be around I,000. Cryoscopic measurements in cyclohexanol and in phenol gave molecular weights of 768 to 780 and 813 , respectively. The approximate molecular formula was found to be $\mathrm{C}_{41} \mathrm{H}_{56} \mathrm{O}_{11} \mathrm{~N}_{8}$. Actinomycin exhibits characteristic absorption in the visible and ultraviolet regions. In ethyl alcohol, it shows strong absorption at $450\left(\mathrm{E}_{\mathrm{r} \mathrm{cm}}^{\mathrm{x} \%}=200\right)$ and between 230 and 250 .

Actinomycin is not soluble in dilute aqueous alkali or in dilute mineral acids. It is soluble in Io per cent hydrochloric acid and appears to be regenerated by diluting such solutions with water. With strong alcoholic alkali a purple color is formed, which rapidly disappears. Actinomycin is readily reduced by sodium hydrosulfite and by stannous chloride, but is unaffected by sodium bisulfite. With sodium hydrosulfite the reduction is characterized by a change in color from red to pale yellow. The color change is reversed by exposing the reduced pigment to air. The same reversibility of color occurs when the pigment is subjected to catalytic hydrogenation in the presence of platinum oxide. The pigment has one or more functional groups capable of re- 
versible reduction-oxidation (probably quinone in nature) and several others capable of acetylation (probably hydroxyls). The quinone-like structure of the pigment is borne out by its sensitivity to alcoholic alkali, and to hydrogen peroxide in the presence of sodium carbonate. In the latter instance, the color rapidly disappears and a cleavage seems to occur.

Actinomycin in alcohol-water solutions is resistant to the action of heat, being able to withstand boiling for 30 minutes. When such solutions are made acid, however, boiling has a destructive effect upon the activity of the substance, the extent of destruction being directly proportional to the concentration of acid. The effect of alkali, however, is much greater. Dilute alkali changes the color of the substance to light brown, accompanied by a reduction in activity, which can be largely restored when the solution is made neutral again. At a higher alkalinity $(0.25 \mathrm{~N})$, especially at boiling temperature, the activity and reversibility are destroyed. Exposure of solutions to light for I to 3 months reduces the activity of the pigment very little.

\section{Streptothricin}

Streptothricin is produced by Streptomyces lavendulae grown in a medium containing glucose or starch ( I per cent) as a source of energy, and tryptone, glycocoll, glutamic acid, or other organic nitrogenous compound ( 0.3 to 0.5 per cent) as a source of nitrogen. Sodium nitrate is a somewhat less favorable source of nitrogen. The organism is grown in stationary, shallow cultures containing starch as a source of carbon or glucose and a small amount of agar, or in submerged cultures. The optimum temperature for the production of streptothricin is $23^{\circ}$ to $25^{\circ} \mathrm{C}$. (946). The relation between growth of the organism and production of the antibiotic substance is brought out in Table 33 .

Streptothricin is soluble in water and in dilute mineral acids, but is destroyed by concentrated acids. It is insoluble in ether, petrol ether, and chloroform. In the crude culture-filtrate and in the alcohol-precipitated form, streptothricin is thermolabile, whereas in the purified state it is thermostable, withstanding $100^{\circ} \mathrm{C}$. for 15 minutes. Treatment with proteolytic enzymes does not reduce its activity. On adjusting the reaction of the medium, when growth is completed, to $p \mathrm{H} 3.5$ with 
TABLE 33. GROWTH OF STREPTOMYCES LAVENDULAE AND PRODUCTION OF STREPTOTHRICIN ON TRYPTONE-STARCH MEDIUM

\begin{tabular}{|c|c|c|c|c|c|c|}
\hline \multirow[b]{3}{*}{ AERATION } & \multirow{2}{*}{$\begin{array}{l}\text { INCU- } \\
\text { BATION }\end{array}$} & \multirow[b]{2}{*}{ STARCH } & \multirow{2}{*}{$\begin{array}{l}\text { DRY WEIGHT } \\
\text { OF MYCE- } \\
\text { LIUM IN }\end{array}$} & \multirow{2}{*}{$\begin{array}{l}\text { NITROGEN } \\
\text { IN MYCE- } \\
\text { LIUM IN }\end{array}$} & \multicolumn{2}{|c|}{$\begin{array}{l}\text { ACTIVITY } \\
\text { IN UNITS }\end{array}$} \\
\hline & & & & & $E$ & B. sub- \\
\hline & IN DAYS & LEFT & MILLIGRAMS & MILLIGRAMS & coli & tilis \\
\hline Shaken & 2 & $+H$ & & & 10 & 5 \\
\hline Shaken & 3 & + & 225 & I 8.2 & 10 & 50 \\
\hline Shaken & 4 & 0 & 293 & 26.2 & 75 & 250 \\
\hline Shaken & 6 & 0 & 231 & $17 \cdot 3$ & 100 & 300 \\
\hline Shaken & 8 & 0 & & & 75 & 200 \\
\hline Shaken & 12 & 0 & 142 & 9.6 & 30 & 50 \\
\hline Stationary & 7 & H+ & & & 50 & 200 \\
\hline Stationary & 10 & $\operatorname{Tr}$ & 235 & I 8.8 & 50 & 300 \\
\hline Stationary & 14 & $\operatorname{Tr}$ & & & 60 & 250 \\
\hline
\end{tabular}

From Waksman (946).

acid, a precipitate is produced, the filtrate containing virtually all the activity.

Streptothricin is completely adsorbed, at neutrality, on charcoal, from which it can be removed by treatment for 8 to I 2 hours with dilute mineral acid or acid alcohol. The acid extract is neutralized and concentrated in vacuo, at $50^{\circ} \mathrm{C}$., just to dryness; the residue is extracted with absolute alcohol, filtered, evaporated, and taken up in water. It can also be precipitated from the neutralized solution with ether or acetone. Further concentration and reduction in ash content can be obtained by subsequent treatments. On electrodialysis, the active substance moves to the cathode at $\mathrm{pH}$ 7.0.

Streptothricin has been crystallized as the Reinecke salt (300). The crystals consist of a cluster of fine platelets which decompose at $192^{\circ}$ to $194^{\circ} \mathrm{C}$. after sintering at $184^{\circ} \mathrm{C}$. The molecule was found to correspond to the di-reineckate of a base $\mathrm{C}_{13} \mathrm{H}_{25} \mathrm{O}_{7} \mathrm{~N}_{5}$; the $\alpha$-amino nitrogen was 20 to 22 per cent of the total nitrogen. The molecule of streptothricin is thus believed to contain at least five nitrogen atoms, two of which are present as salt-forming basic groups; it is free of O-methyl, Nmethyl, and hydrolyzable acetyl groups. Streptothricin is stable between $p \mathrm{H}$ I and 8.5, but is destroyed by high alkalinity. The activity of 
the sulfate is $500-530 \mu \mathrm{g} / \mathrm{mg}$. One of the more recent modifications (7I $3 a$ ) of the method of isolation of streptothricin comprises the following steps: charcoal adsorption, elution with formic acid in methyl alcohol-water, partial concentration in vacuo, precipitation with picric acid, conversion to hydrochloride, chromatography over aluminum oxide, and precipitation with methyl orange as helianthate. This preparation had an activity of $830 \mathrm{\mu g} / \mathrm{mgl}$, with a specific rotation $[a]_{0}^{25}-5 \mathrm{I} \cdot 3^{\circ}$.

\section{Streptomycin}

Streptomycin is produced, in stationary and shaken cultures, in a medium containing meat extract, corn steep, soy bean meal, or some other suitable material. Its maximum production occurs in shaken cultures in 2 to 3 days, and in stationary cultures in 7 to ro days (830, 971), as shown in Table 34 .

TABLE 34. GROWTH OF S. GRISEUS AND PRODUCTION OF STREPTOMYCIN

\begin{tabular}{lrcr}
\hline Incubation & $\mu \mathrm{g}$ & $\begin{array}{c}p \mathrm{H} \text { of } \\
\text { medium }\end{array}$ & $\begin{array}{r}\text { Growth } \\
\text { in mg.* }\end{array}$ \\
Shaken cultures & 10 & 7.8 & 270 \\
2 days & 70 & $7 \cdot 7$ & 185 \\
3 days & 60 & 7.8 & - \\
4 days & 70 & 8.2 & - \\
7 days & & & 73 \\
Stationary cultures' & 6 & 7.7 & 171 \\
3 days & 12 & 7.8 & 163 \\
5 days & 53 & 7.9 & 264 \\
7 days & - & 8.3 & - \\
9 days & 55 & - & \\
I days & 5 & & \\
\hline
\end{tabular}

From Schatz, Bugie, and Waksman (830).

* Weight of dry mycelium produced by $S$. griseus.

Streptomycin is also a base, like streptothricin, but differs from it in chemical composition, antibacterial spectrum, and lower toxicity for animals $(830,952)$. It is highly active against the gram-negative enteric group of bacteria and related organisms. A detailed discussion of 
the nature of the antibiotic action of streptomycin and its utilization for chemotherapeutic purposes is presented elsewhere (pp. 287-296).

It was at first suggested (947) that 3 units of activity be recognized for measuring streptomycin: an S unit, or the amount of material that will inhibit the growth of a standard strain of $E$. coli in I ml. of glucose-free nutrient agar or broth; an L unit, inhibition on a liter basis; a $\mathrm{G}$ unit, inhibition on a dry weight basis of crystalline material. Since streptomycin base was found to be $\mathrm{I}, 000 \mathrm{~S}$ units per I mg., it was decided to accept the weight of streptomycin as a basis of standardization: I $\mathrm{S}$ unit is thus equivalent to I microgram of the pure base.

Streptomycin can be isolated from the medium by several procedures. In one method ( I I 5), culture filtrates of $S$. griseus assaying 100 to $\mathrm{I} 80$ units of streptomycin per $\mathrm{ml}$. served as the starting material. Several common adsorption agents, such as charcoal, can be used to remove the active material from the culture. The substance is then eluted with hydrochloric acid in 95 per cent ethanol. Anhydrous hydrogen chloride in methanol is a more convenient reagent, since the crude streptomycin can be precipitated directly from the methanol solution with ether. The filtrate is clarified at $p \mathrm{H}_{2}$ with 0.5 per cent carbon; this is followed by removal of the streptomycin, at $p \mathrm{H} 7$, with I per cent carbon, which is washed successively with water, neutral ethanol, and neutral methanol, and the streptomycin is eluted by two or three extractions with O.I $\mathrm{N}$ methanolic hydrogen chloride. The alcoholic extracts are combined and 2 to 3 volumes of ether added, precipitating the crude streptomycin chloride as a light-brown amorphous powder. When the methanol solution contains much water, a sticky gum results. The recovery of the streptomycin by this method varies from 30 to 50 per cent, the product assaying from I 50 to 300 micrograms.

For further purification, a faintly acid solution of crude streptomycin chloride in 70 to 80 per cent methanol is percolated over a sulfuric acid-washed alumina column ( $p \mathrm{H}_{5}$ to 6$)$; an inactive fraction giving a positive Sakaguchi test first appears, followed by a Sakaguchi-negative fraction. This test parallels the antibiotic action of the fractions. A small amount of active material remains on the column and can be washed through by lowering the methanol content of the solvent. This material contains sulfate ion but no chloride. The streptomycin sulfate 
passes through the column less rapidly, since it is less soluble than the chloride in methanol.

The various streptomycin fractions obtained from the column are concentrated and lyophilized, giving white amorphous powders. The most active fractions range from 600 to $900 \mu \mathrm{g} / \mathrm{mg}$., and amount to approximately 80 per cent of the total. Satisfactory results are obtained only if the crude streptomycin has an activity of about $200 \mu \mathrm{g} / \mathrm{mg}$. or higher. Preparations of lesser purity contain substances which interfere with the development of the chromatogram. The chloride is soluble in methanol, less soluble in ethanol, practically insoluble in butyl alcohol, acetic acid, and pyridine. The sulfate is only slightly soluble in methanol and practically insoluble in the other solvents.

Streptomycin gives a positive Sakaguchi test, the presence of a guanidine group being indicated by the fact that alkaline hydrolysis results in the formation of ammonia and the disappearance of the Sakaguchi test. Streptomycin also gives a positive test for an hydroxyl group. Negative tests are obtained in the amino nitrogen, Hopkins-Cole, Millon, xanthoproteic, biuret, and Pauly diazo tests. The presence of a carboxyl group is considered as questionable, since the streptomycin chloride, obtained by precipitation from methanolic hydrogen chloride with ether, gives approximately neutral solution. The ultraviolet spectrum of streptomycin showed only end-absorption below $230 \mathrm{m \mu}$, which makes improbable the presence of an aromatic ring or conjugated double bonds.

Streptomycin is inactivated rapidly by o.I $\mathrm{N}$ sodium hydroxide at room temperature. It is relatively stable over a $p \mathrm{H}$ range of $\mathrm{I}$ to Io but is inactivated by I $\mathrm{N}$ hydrochloric acid.

Streptomycin was first crystallized as the reineckate salt from water, in the form of thin plates which decomposed at $162^{\circ}-164^{\circ} \mathrm{C}$., the basic component being $\left(\mathrm{C}_{10} \mathrm{H}_{19} \mathrm{O}_{7-8} \mathrm{~N}_{3}\right)_{n}$. The antibiotic potency of pure streptomycin lies between 800 and 9 Io $\mu$ g per mg. (299). Streptomycin can also be isolated ( $537 \mathrm{a}$ ) by the method described above for streptothricin. This includes charcoal adsorption, elution with methanolic formic acid, precipitation with picric acid, conversion to the hydrochloride, chromatography with aluminum oxide, and final conversion to the crystalline helianthate. 
In another procedure (538) the crystalline salt of streptomycin and p-(2-hydroxy-l-naphthylazo)-benzenesulfonic acid is prepared from streptomycin $\mathrm{HCl}$, and orange II. The salt has an activity of 300 $\mu \mathrm{g} / \mathrm{mg}$. Crystalline streptomycin sulfate was found to have an activity of $520 \mu \mathrm{g} / \mathrm{mg}$.

On chromatographic purifications, streptomycin concentrates yielded a crystalline double salt of streptomycin trihydrochloride and calcium chloride (Figure I9). This preparation showed that streptomycin has the composition $\mathrm{C}_{21} \mathrm{H}_{37-39} \mathrm{~N}_{7} \mathrm{O}_{12}$. The double salt is characterized by constant biological, chemical, and physical properties. It is more satisfactory than the hydrochloride which is obtained by precipitation. The double salt can be prepared from streptomycin hydrochloride or from the crystalline streptomycin helianthate. A cryoscopic molecular weight determination on streptomycin trihydrochloride in water gave about 800 for the free base, necessary corrections having been made for the chloride ion and the non-ideal cryoscopic behavior of the trivalent streptomycin ion (712).

Further studies on the chemistry of streptomycin revealed the fact that it has the general constitution of a hydroxylated base (streptidine) attached through a glycosidic linkage to a nitrogen-containing disaccharide-like molecule. The latter group of the streptomycin molecule contains a free or potential carbonyl group and a methyl-amino group (85).

The reaction of the streptomycin with one molecule of water can be presented as follows:

$$
\begin{array}{ccc}
\mathrm{C}_{21} \mathrm{H}_{37-39} \mathrm{~N}_{7} \mathrm{O}_{12}+\mathrm{H}_{2} \mathrm{O} \rightarrow & \mathrm{C}_{8} \mathrm{H}_{18} \mathrm{~N}_{6} \mathrm{O}_{4}+\mathrm{C}_{13} \mathrm{H}_{21-23} \mathrm{NO}_{9} \\
\text { Streptomycin } & \text { Streptidine } & \text { Streptobiosamine } \\
\mathrm{C}_{13} \mathrm{H}_{23} \mathrm{NO}_{9}+\mathrm{H}_{2} \mathrm{O} \rightarrow & \mathrm{C}_{6} \mathrm{H}_{10} \mathrm{O}_{5}+\mathrm{C}_{7} \mathrm{H}_{15} \mathrm{NO}_{5} \\
\text { Streptobiosamine } & \text { Streptose } & \text { N-methyl- } \alpha- \\
& & \text { l-glucosamine }
\end{array}
$$

The basic nitrogen atom in the streptobiosamine is not present as a primary amino group. The streptomycin molecule was presented graphically as follows: 


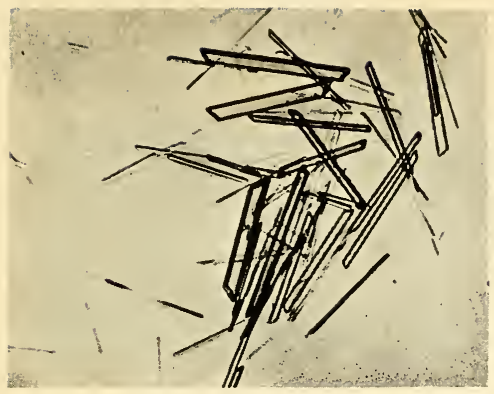

Tyrocidine hydrochloride. From Hotchkiss (449)

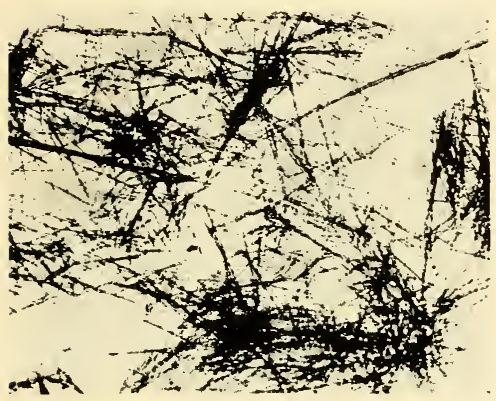

Fumigacin. From Waksman and Geiger (955)

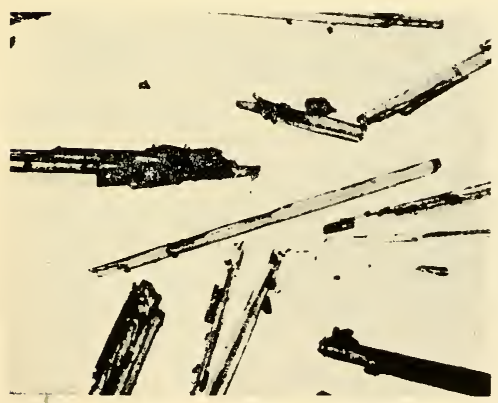

Citrinin. Prepared by Timonin

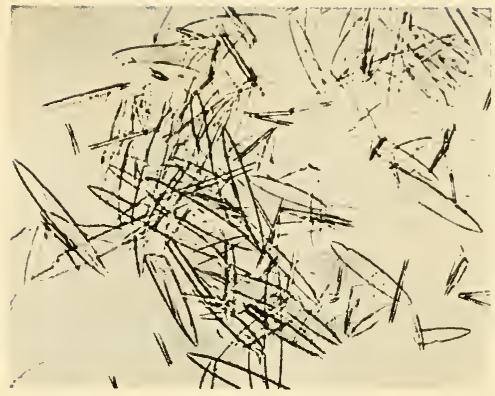

Gramicidin. From Hotchkiss (449)

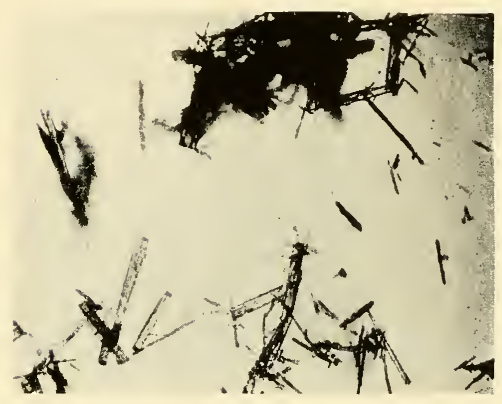

Gliotoxin. From Waksman and Geiger (955)

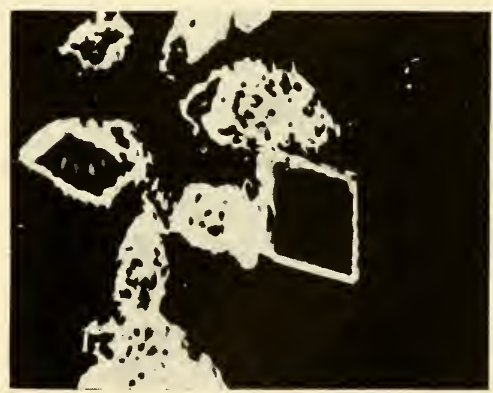

Actinomycin. Prepared by Tischler

FigURE I 9. Crystalline preparations of antibiotic substances. 


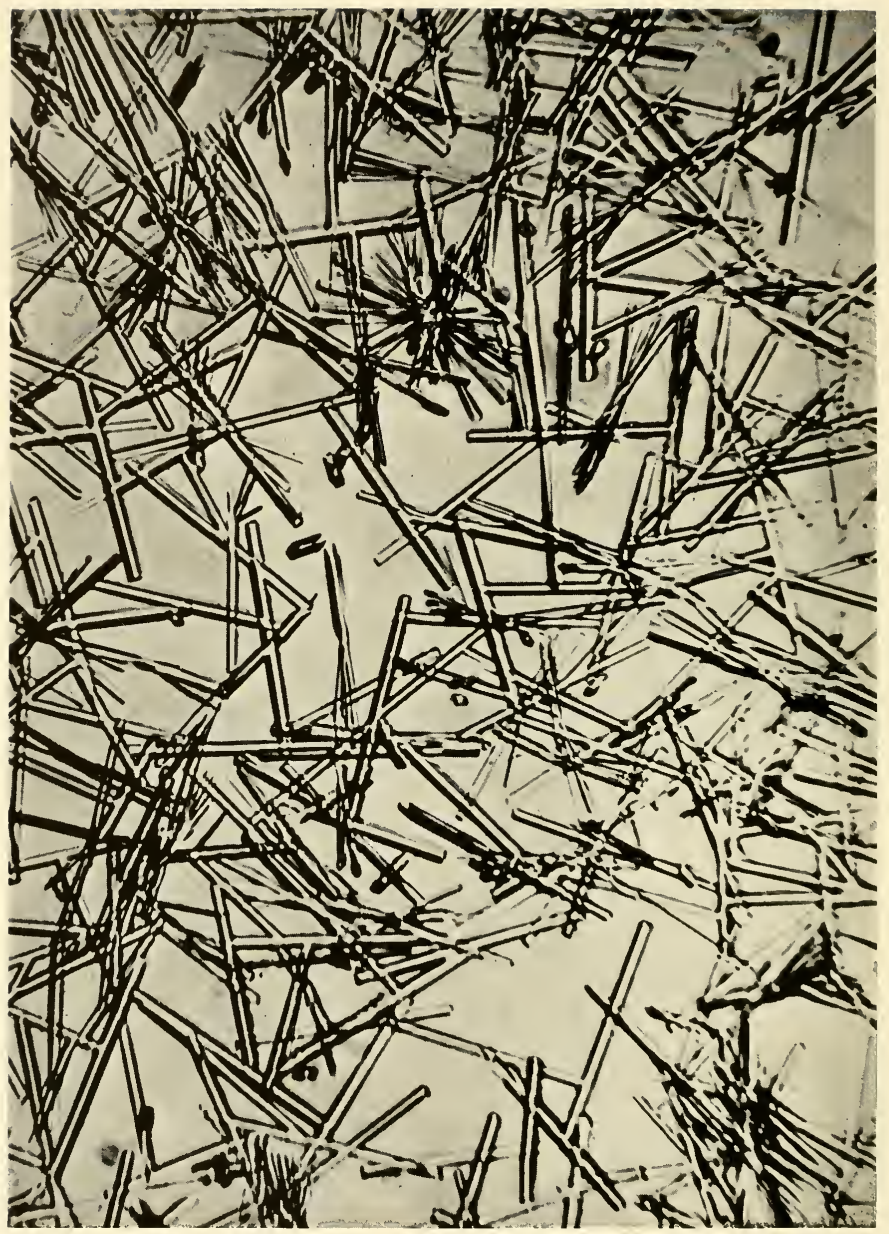

Figure 20. Streptomycin crystals. 


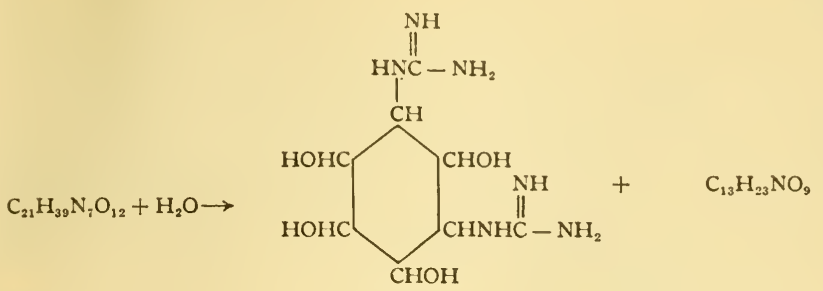

Streptomycin $\longrightarrow$ Streptidine $\quad+\quad$ Streptobiosamine

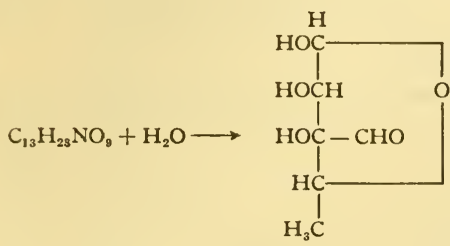

Streptobiosamine $\longrightarrow$ Streptose

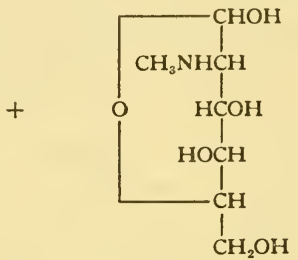

$+\quad$ N-methyl-l-glucosamine

Streptidine was characterized by the following crystalline salts: dipicrate, sulfate, carbonate, dihydrochloride, dihydroiodide, dihelianthate, di- $d$-camphorsulfonate, and chloroplatinate. Streptidine appears to contain one or more hydroxyl groups, but no primary amino, carboxy, methoxy, or carbonyl groups. It formed an octaacetyl derivative (713).

Streptidine has the molecular formula $\mathrm{C}_{8} \mathrm{H}_{18} \mathrm{~N}_{6} \mathrm{O}_{4}$. A further study of this compound has been made by Carter et al. (I I4). Streptomycin hydrochloride was completely inactivated on standing 24 hours in anhydrous $1.0 \mathrm{~N}$ methanolic hydrogen chloride without forming a new basic group. The addition of two volumes of ether completely precipitated the guanidine, which was previously reported by Carter et al. (I I5) as one of the functional groups of streptomycin. From the supernatant solution there is readily obtained an amorphous, optically active hydrochloride of a nonguanidine base whose properties agree 
with those of the methyl streptobiosaminide dimethyl acetal hydrochloride reported by Brink et al. (85). The addition of picric or sulfuric acid to an aqueous solution of the guanidine hydrochloride gives insoluble crystalline salts that are readily recrystallized from hot water. The analytical data for the salts agree with those of a diguanidine base of the composition $\mathrm{C}_{8} \mathrm{H}_{18} \mathrm{~N}_{6} \mathrm{O}_{4}$. This compound has the same empirical formula as that suggested by Brink et al. for streptidine, and is presumed to be identical with it.

Streptidine sulfate was also obtained by allowing a solution of streptomycin chloride in I N sulfuric acid to stand at $37^{\circ} \mathrm{C}$. for 45 hours. The sulfate was precipitated in crystalline form by adding 3 to $5 \mathrm{vol}$ umes of acetone to the reaction mixture.

Streptidine was hydrolyzed by refluxing for 48 hours with $6 \mathrm{~N}$ alkali yielding four moles of ammonia and a new base, for which the name streptamine was proposed. This base was isolated as the slightly soluble sulfate by neutralizing the hydrolysis mixture with sulfuric acid and adding an equal volume of methanol. The sulfate was purified by recrystallization from aqueous methanol. The hydrolysis of streptidine proceeded as follows:

$$
\begin{aligned}
& \mathrm{C}_{8} \mathrm{H}_{18} \mathrm{~N}_{6} \mathrm{O}_{4}+{ }_{4} \mathrm{H}_{2} \mathrm{O} \rightarrow \underset{\text { Streptidine }}{\mathrm{C}_{6} \mathrm{H}_{14} \mathrm{~N}_{2} \mathrm{O}_{4}+{ }_{4} \mathrm{NH}_{3}+{ }_{2} \mathrm{CO}_{2}} \\
& \text { Streptamine }
\end{aligned}
$$

These results appeared to establish the fact that the six nitrogen atoms of streptidine are present as two monosubstituted guanidine groups which are replaced by two primary amino groups in streptamine. Further treatment with benzoyl chloride in pyridine yielded a product melting at $350^{\circ}$ to $35 \mathrm{I}^{\circ} \mathrm{C}$., the analyses of which agreed fairly well for hexabenzoylstreptamine.

Streptidine reduced two moles of periodate; streptamine, six; dibenzoylstreptamine, two; no formaldehyde was formed from any of these compounds. The fact that streptamine required six moles of periodate suggested to Carter et al. ( I I 4) that the four hydroxyl and two amino groups are located on adjacent carbon atoms, pointing to a cyclic structure, since an open chain molecule should have yielded at least two moles of formaldehyde and required only five moles of periodate. Streptidine and streptamine were assigned the following formula: 


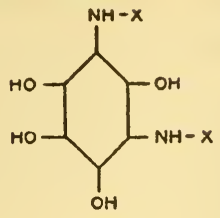

\section{Streptamine $\mathrm{X}=\mathrm{H}$ \\ Streptidine $\mathrm{X}=-\mathrm{C} / / \mathrm{NH}_{2}$}

When streptomycin chloride is hydrolyzed with $\mathrm{I} .0 \mathrm{~N}$ sodium hydroxide, for three minutes at $100^{\circ} \mathrm{C}$. or for eighteen hours at $40^{\circ} \mathrm{C}$., a weakly acidic substance, m.p. $161^{\circ}-162^{\circ} \mathrm{C}$. is obtained. It has been characterized as maltol, namely,

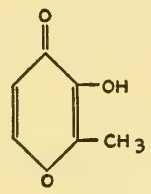

The maltol gives a brilliant violet color with ferric chloride and a positive iodoform test; it reacts rapidly with nitric acid, and sublimes readily, even at $100^{\circ} \mathrm{C}$. The benzoate melts at $114^{\circ}-115^{\circ} \mathrm{C}$. It has been isolated from hydrolyzates of streptomycin salts ranging in purity from 280 to $800 \mu \mathrm{g} / \mathrm{mg}$. The yields of maltol were about 30 per cent if one mole was derived from one mole of streptomycin.

It was suggested that the formation of maltol by alkaline hydrolysis of streptomycin, measuring the ultraviolet absorption in acid solution, be used as an assay procedure, for the absorption produced is proportional to the initial antibiotic activity in preparations having a potency of 50 to $800 \mu \mathrm{g} / \mathrm{mg}$. The ferric chloride color reaction also appeared to be useful for this purpose.

Streptomycin can be distinguished from streptothricin by inactivation with cysteine. This property is not due to the sulfhydryl group alone. On oxidation of the cysteine, the substance is reactivated (I79). In view of the specific sensitivity of different bacteria to streptothricin 
and streptomycin, not only can they be readily differentiated from one another by their bacteriostatic spectra, but the admixture of one with the other can actually be measured quantitatively. B. mycoides can be used to measure the presence of a small amount of streptomycin with streptothricin, whereas bacteria resistant to streptomycin can be utilized for detecting the presence of a small amount of streptothricin or other antibiotic (858).

Proactinomycin is produced by $N$. gardneri grown in soft agar media, from which it is extracted by organic solvents, such as ether, amyl acetate, benzene, and carbon tetrachloride. It can be re-extracted in water by adjusting the $p \mathrm{H}$ to 4.0 with $\mathrm{HCl}$ or $\mathrm{H}_{2} \mathrm{SO}_{4}$. The aqueous extract is concentrated in vacuo and evaporated to dryness from the frozen state. A white powder, very easily soluble in water, is obtained. The yield of the material is $60 \mathrm{mg}$. from I liter of culture. The substance is fairly stable, though boiling for Io minutes at $p \mathrm{H} 2.0$ or $p H$ 7.0 results in a small loss of activity. Boiling at $p \mathrm{H}$ I0.0 destroys the greater part of the antibacterial activity. Proactinomycin has basic properties and is precipitated from aqueous solution by such base precipitants as picric acid, picrolonic acid, and flavianic acid.

Proactinomycin is active in a dilution of $\mathrm{I}: 500,000$ or more against gram-positive cocci, $B$. anthracis, and $N$. meningitidis; it is much less active against gram-negative bacteria and is not very toxic to animal tissues, but definitely more so than penicillin or streptomycin. When given by mouth it can confer a considerable degree of protection against intraperitoneal infection with hemolytic streptococci. It is excreted in the urine and bile, and is absorbed from the alimentary canal. Repeated injections cause fatty changes in the livers of mice (273).

\section{SUBSTANCES PRODUCED BY FUNGI}

\section{Penicillin}

Penicillin is produced by various strains of $P$. notatum and $P$. chrysogenum, as well as by a variety of other fungi. The penicillin-like nature of an antibiotic substance is usually established by its chemical and biological properties: extraction in organic solvents at $p \mathrm{H} 2$ and re-extraction in water at $\mathrm{pH} 7$; inactivation by acid and alkali; partial inactivation by heating at $100^{\circ} \mathrm{C}$. and $p \mathrm{H} 7$ for 15 minutes; complete 
inactivation by penicillinase and by copper ions; inactivation by methyl alcohol; characteristic antibiotic spectrum, such as activity against $S$. aureus and not against $E$. coli (270).

The strain of the organism used, the composition of the medium, and the conditions of growth greatly influence not only the yield of penicillin but also its chemical nature. Complex organic media containing glucose or brown sugar as a source of carbon are essential. Nitrate is used as a source of nitrogen; the medium also must contain a phosphate and certain other minerals. The supplementary addition of a stimulating substance in the form of yeast extract, corn steep, or certain vegetable juices is essential for the maximum production of penicillin. Since the organism produces an acid, probably gluconic, in the medium, some $\mathrm{CaCO}_{3}$ must also be added. The metabolism of $P$. notatum in relation to penicillin production is illustrated in Figure 13 (p. I 35 ).

Four methods have been proposed for the growth of the fungus and the production of penicillin. These are:

Surface growth in shallow liquid media; usually flasks, bottles, and other containers are employed, the depth of the medium being 1.5 to $2.0 \mathrm{~cm}$.

Submerged growth in liquid media; the vessels must be provided with proper stirrers and aeration

Surface growth upon semi-solid media, including grain and bran (762)

Circulation of medium through a column, the supporting material being made up of wood shavings or pebbles; the rate of flow of the medium is very important

Since the various strains of penicillin-producing organisms vary greatly in their optimum conditions for the production of this antibiotic substance, different strains must be used for different conditions of cultivation.

Penicillin is formed in the medium when active growth begins and reaches a maximum soon after the growth maximum, which occurs in 7 to 14 days in stationary cultures and in 3 to 7 days in submerged cultures, at $20^{\circ}$ to $25^{\circ} \mathrm{C}$.

Penicillin is soluble in ether, acetone, esters, and dioxane; it is mod- 
erately soluble in chloroform, slightly soluble in benzene and in carbon tetrachloride. It is soluble in water to the extent of $5 \mathrm{mg} . / \mathrm{ml}$.

It is inactivated by oxidation and by evaporation at $40^{\circ}$ to $45^{\circ} \mathrm{C}$. in acid and in alkaline solutions, although it is fairly stable at $p \mathrm{H} 5$ to 6 . If the solutions are adjusted to $p \mathrm{H} 6.8$, it retains its potency for 3 months. The crude penicillin does not dialyze through a collodion membrane and resists heating at $60^{\circ}$ to $90^{\circ} \mathrm{C}$. for short periods; it remains active when heated at $100^{\circ} \mathrm{C}$. for 5 minutes but not for $10 \mathrm{~min}$ utes.

The methods of isolation of penicillin from the culture media can be classified under the extraction and adsorption procedures.

Fleming first reported that penicillin is insoluble in ether. This was found ( 146 ) to be due to the alkaline reaction of the filtrate; for at $p \mathrm{H}$ 2.0 ether removes completely the antibacterial substance. The ether extract is evaporated with some water in vacuo at $40^{\circ}$ to $45^{\circ} \mathrm{C}$., the residual water containing the active substance, which is extremely labile.

For practical purposes, penicillin is extracted from the acidified culture by means of different organic solvents, such as ether or amyl acetate (6). It is then removed from the solvent by shaking with phosphate buffer or with water at $p \mathrm{H}$ 6.7. Since penicillin is rapidly destroyed at a high acidity, the first extraction must be carried out very quickly and at a low temperature. In the presence of the solvents, penicillin is stable for several days. The aqueous extract may be partly decolorized by shaking with charcoal and filtering. The solution is cooled, acidified, and extracted several times with ether or amyl acetate; the extracts are passed through an adsorption alumina column, or through a 2.5 per cent precipitate of an alkaline earth carbonate on silica gel. Water may often contain a pyrogenic or heat-producing substance that must be removed from the penicillin.

The following four main zones were recognized in the chromatograms, beginning from the top:

I. A dark brownish-orange layer, the depth of which is inversely proportional to the amount of charcoal used for the decolorization; this zone contains some penicillin

2. A light yellow layer containing most of the penicillin but none of the pyrogen 
3. An orange layer which contains some penicillin and some or all of the pyrogen

4. A brownish or reddish-violet layer which contains almost no penicillin; the pigment disappears on exposure to light

The fourth fraction is discarded, and the others are eluted with $\mathrm{M} / \mathrm{I} 5$ phosphate buffer ( $p \mathrm{H} 7.2$ ). The penicillin is again extracted with ether, then with water, sodium hydroxide being used to adjust the $p \mathrm{H}$. Since penicillin is destroyed readily in alkaline solution, care must be taken in adding the alkali. The "nonpyrogenic" or "therapeutic" fraction, which contains about 80 per cent of the penicillin, is extracted with pyrogen-free water. It is a deep reddish-orange liquid, yellow in dilute solution, with a characteristic smell and bitter taste.

Another method for obtaining penicillin has been suggested (638). In this method, the culture medium was adjusted to $\mathrm{pH} 3$ to 4 , saturated with ammonium sulfate and extracted with chloroform. The concentrated chloroform extract was treated with phosphate buffer at $p H$ 7.2 to remove the active substance. This process was repeated, the less active substance being separated from the active fraction by extraction with chloroform at different ranges. By precipitating the concentrated extracts from petroleum ether, the free acid form of penicillin was obtained. By saturating the chloroform-benzol solution with dry ammonia gas, an ammonium salt was obtained which gave a dark yellow microcrystalline powder. The salt was more stable than the acid form. By acetylating or benzoylating the ammonium salt a further increase in stability was obtained. This penicillin was strongly dextrorotatory and had an adsorption maximum of $2,750 \mathrm{~A}^{\circ}$. The preparation had an activity of $32,000,000$ dilution units against hemolytic streptococci, which corresponds to about 240 Oxford units per milligram.

When ether is used, the medium is adjusted to $p \mathrm{H}_{3}$, extracted several times, the ether extract treated with dilute $\mathrm{NaHCO}_{3}$, the aqueous solution acidified and again extracted with ether; this is followed by shaking with excess of $\mathrm{BaCO}_{3}$, separating aqueous phase, filtering, and evaporating in frozen state (145).

By the adsorption method, activated charcoal or fuller's earth is used (20 gm./L). The solution is first acidified to $\mathrm{pH} 3.6$, filtered, neutralized, treated with charcoal, and filtered. Ethanol is used to remove the 
penicillin from the charcoal; the extract is evaporated, acidified, and treated with ether. Various procedures for large-scale production and recovery of penicillin have been described $(503,607,768)$.

Various modifications of these methods may be employed. In some cases, $n$-butyl alcohol is used for extraction. The culture filtrate is adjusted to $p \mathrm{H} 6.4$ and ammonium sulfate added, and the penicillin is extracted. When light petroleum ether and dilute sodium bicarbonate solution are added to the butyl alcohol extract, the penicillin is brought back into aqueous solution (48). The problem of drying is very important (276).

The barium salt was at first considered as the most suitable form for general use. In this form, penicillin retains its antibacterial activity for an indefinite period. It is soluble in absolute methyl alcohol but insoluble in absolute ethyl alcohol. However, the $\mathrm{Na}$ and $\mathrm{Ca}$ salts are the common forms now used. Penicillin forms water-soluble salts with most heavy metals, except $\mathrm{Fe}^{+++}$.

Penicillin is unstable and readily inactivated by a number of reagents, including heavy metal ions, especially $\mathrm{Cu}, \mathrm{Pb}, \mathrm{Zn}$, and $\mathrm{Cd}$. Penicillin is stable toward light and atmospheric oxygen, but is oxidized by $\mathrm{H}_{2} \mathrm{O}_{2}$ and $\mathrm{KMnO}_{4}$, the antibacterial activity being lost.

In assaying penicillin, both biological and chemical tests are used. Of the former, the cup assay method is most commonly employed, although the turbidimetric and other tests are also frequently used. The different forms of penicillin are recognized by the differences in their effect upon various bacteria, notably $S$. aureus and $B$. subtilis.

The world standard for penicillin has been defined as that activity which is present in 0.6 micrograms of the international penicillin standard (384). One mg. of crystalline penicillin will thus contain $\mathrm{I}, 667$ Oxford units (O.U.) and will be comparable to 84 million dilution units against $S$. aureus ( I 68, 454).

The chemical method for assaying penicillin is based upon the acidity produced by the action of a standard penicillinase solution upon the penicillin preparation and titrated to $\mathrm{pH} 8.0$ (666). The colorimetric method is based upon its interaction with an intensely colored primary amine, $\mathrm{N}$-(1-naphthyl-4-azobenzene)-ethylenediamine to give amidic products containing acidic groups (845a). 
Tests are also made for sterility, moisture content, presence of pyrogenic substances, and toxicity (248).

By means of adsorption, distribution between solvents, and reduction, a barium salt or penicillin was at first obtained $(5,6)$ which was homogeneous by chromatographic analysis and gave 450 to 500 Oxford units per milligram of dry material. The active substance was found to be a salt of a strong dibasic acid with $p \mathrm{H}$ values approximately 2.3 and 3.5. The molecule contained one carboxyl, one latent carboxylic, two acetylatable, at least five $\mathrm{C}-\mathrm{Me}$ groups, and no easily reducible double bond. The penicillin thus prepared was more sensitive to oxidizing agents than to reducing agents; it was unstable toward dilute acids and alkalies, and to heat (loss of $\mathrm{CO}_{2}$ ), primary alcohols, and various heavy metal ions. Tentative suggestions were made concerning its chemical nature as follows: (a) a polysubstituted hydroaromatic ring structure; (b) the acidic groups (carboxyl) not conjugated with the chromophore responsible for the absorption; (c) the possible presence of a trisubstituted $\alpha$-unsaturated ketone grouping.

With the introduction of new cultures for the production of penicillin, with the development of new methods for the growth of the organism, as submerged vs. stationary, and especially with the employment of synthetic media, it was found that several forms of penicillin are produced (735).

P. chrysogenum $\mathrm{x} \mathrm{1,612} \mathrm{was} \mathrm{found} \mathrm{to} \mathrm{yield} \mathrm{about} \mathrm{roo} \mathrm{O.U./ml.} \mathrm{The}$ penicillin molecule is readily synthesized, especially when a phenyl linkage has been supplied. The addition of $3.3 \mathrm{gm} . / \mathrm{L}$ of phenylacetic acid to the medium gave a maximum yield of 244 O.U. $/ \mathrm{ml}$.

$P$. notatum $\mathrm{I}, 984$-A yields 40 to $50 \mathrm{O} . \mathrm{U} . / \mathrm{ml}$. of penicillin on a purely synthetic medium, in presence of such factors as indole acetic acid or naphthalene acetic acid. The production of penicillin takes place in the presence of the following groups:

I. Cysteine (or cystine in presence of a suitable reducing agent such as sulfite waste liquor)

2. The $-\mathrm{C}-\mathrm{C}-\mathrm{N}-$ chain with the proper linkage at each end

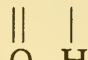

$\mathrm{O} \mathrm{H}$ 
3. The phenyl ring, or preferably 2 and 3 combined as phenylaceturates, $\alpha$-phenylacetamide or $\beta$-phenylethylamine.

Several forms of penicillin or "natural penicillins" have been isolated (715). They were all found to have the empirical formula $\mathrm{C}_{9} \mathrm{H}_{11} \mathrm{O}_{4} \mathrm{SN}_{2} \cdot \mathrm{R}$. These forms may be presented as follows:

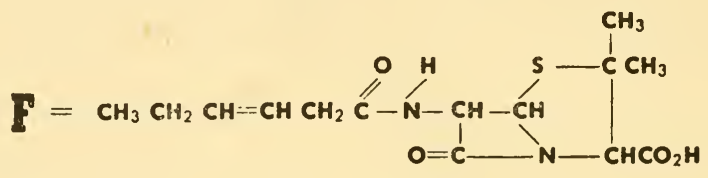<smiles></smiles><smiles>CC1(C)SC2C(NC(=O)CO)C(=O)N2C1C(=O)O</smiles><smiles>CCCC(=O)NC1C(=O)N2C1SC(C)(C)C2C(=O)O</smiles>

In accordance with the nomenclature employed in the forthcoming monograph on the chemistry of penicillin, which is being prepared under the auspices of the National Academy of Sciences, penicillin $G$ is designated benzylpenicillin; penicillin $\mathrm{K}, \mathrm{F}$, and $\mathrm{X}$ are designated, respectively, $n$-heptylpenicillin, $\Delta^{2}$-pentenylpenicillin, and $p$-hydroxybenzylpenicillin. 
The penicillins are strong monobasic acids of $p \mathrm{~K}$ about 2.8. On treatment with hot dilute mineral acids, penicillins give I molecule of $\mathrm{CO}_{2}$, an amino acid (penicillamine) and other products. The penicillamine ( $d$ - $\beta, \beta$-dimethylcysteine) belongs to the $d$ or "unnatural" series of $\alpha$-amino acids. Penicillin $G$ yields on hydrolysis phenaceturic acid, phenylacetamide, and an aldehyde, $\mathrm{C}_{10} \mathrm{H}_{11} \mathrm{O}_{2} \mathrm{~N}$. Phenylacetic acid was also identified as a hydrolytic product.

The acidic group of penicillin was found to be identical with the carboxyl group in penicillamine; the addition of water to penicillin gives a second carboxyl; the new carboxyl breaks down to $\mathrm{CO}_{2}$ by the action of hot dilute mineral acid. The dicarboxylic acid thus produced, designated as penicilloic acid, is presumably the product of the action of penicillinase on penicillin.

The molecular weight of penicillin ranges from 490 to 510 .

Penicillin is very unstable, especially in acid solutions and in an isolated form.

\section{Penatin}

$P$. notatum produces, in addition to penicillin, a second antibacterial substance designated as $E$. coli factor, penatin, notatin, and penicillin $B$. This substance is a flavo-protein and acts as a glucose-oxidase, oxygen being required. It is characterized by its action not only upon grampositive but also upon many gram-negative bacteria, and by the fact that the presence of glucose is required for its activity. Its action is inhibited by the presence of catalase $(157,517,786)$.

\section{Flavicin}

Flavicin, a substance similar in every respect to penicillin, is produced by $A$. flavus (950); another substance, gigantic acid, is produced by $A$. giganteus ( 722 ). Preparations of flavicin have also been designated as flavatin (748), aspergillin ( 103,876$)$, and flavacidin (606). This substance was found to be largely penicillin $F$, with a potency of $\mathrm{I}, 400$ O.U./mg. against $S$. aureus and a $B$. subtilis-S. aureus ratio of 0.72 . The variable $\mathrm{R}$ group in the general penicillin formula is represented by $-\mathrm{CH}_{2} \cdot \mathrm{CH}_{2} \cdot \mathrm{CH}=\mathrm{CH} . \mathrm{CH}_{3}$. A small amount of penicillin $\mathrm{G}(\mathrm{R}=$ $-\mathrm{CH}_{2} \cdot \mathrm{C}_{6} \mathrm{H}_{5}$ ) was also detected (299). 


\section{Aspergillic Acid}

Aspergillic acid is produced by A. flavus. It is extracted from the tryptone medium by adsorption on norite and elution with ether. The pure acid has an m.p. of $93^{\circ} \mathrm{C}$. $\left(84^{\circ}\right.$ to $96^{\circ} \mathrm{C}$.) and an optical activity of $[\alpha]_{\mathrm{D}}=+14^{\circ}$. The formula $\mathrm{C}_{12} \mathrm{H}_{20} \mathrm{O}_{2} \mathrm{~N}_{2}$ has been proposed for this substance. It possesses a hydroxyl group which gives it its acid nature $(p \mathrm{~K} 5.5)$. It is stable under acid and alkaline conditions and can be distilled with steam or in vacuo without loss of activity. When grown in brown-sugar-containing media, a closely related substance is formed, having the formula $\mathrm{C}_{12} \mathrm{H}_{20} \mathrm{O}_{3} \mathrm{~N}_{2}$ and an m.p. of $\mathrm{I} 49^{\circ} \mathrm{C}$., with lower biological activity. It can also be extracted from the medium, at low $p \mathrm{H}$, by organic solvents (benzene or heptane). The pure aspergillic acid (m.p. $96.5^{\circ}$ to $97.5^{\circ} \mathrm{C}$.) was found to account for only 5 per cent of the yield, whereas another fraction (m.p. II $8^{\circ}$ to $12 \mathrm{I}^{\circ}$ C.) had about 75 per cent of the antibiotic activity of the medium (IO2, 220).

Aspergillic acid is moderately active against various gram-positive and gram-negative bacteria, including $S$. aureus, $E$. coli, and $M$. tuberculosis, as well as fungi. The addition of blood to the medium greatly reduces this activity. However, the antibiotic potency and the toxic effect rapidly disappear after systemic or intrathecal administration, the material being excreted in the urine in very small amounts (IO2). The addition of cobaltous ions ( $1: 100,000$ ) greatly enhances the tuberculostatic properties of aspergillic acid, especially in media low in iron (349).

Bromo-aspergillic acid is 8 to Io times as active against $S$. hemolyticus as aspergillic acid. Further studies of the chemical nature of the material showed it to be a pyrazine derivative (220).

\section{Citrinin}

Citrinin is produced by $P$. citrinum and other fungi ( 745 ) on a synthetic medium, with inorganic salts of nitrogen and with glucose as a source of carbon. The culture filtrate is acidified with $\mathrm{HCl}$, and the substance crystallized from boiling alcohol. Citrinin forms a monosodium salt which, at $p \mathrm{H} 7.0$ to 7.2 , gives a virtually colorless solution in water. It is a yellow crystalline solid, m.p. $170^{\circ}$ to $17 \mathrm{I}^{\circ} \mathrm{C}$. (decomp.). It is 
l-rotatory (in alcohol) and nearly insoluble in water. It changes in color from lemon-yellow at $p \mathrm{H} 4.6$ to orange-pink at $p \mathrm{H} 5.6$ to 5.8 and to cherry-red at $p \mathrm{H}$ 9.9. The addition of $\mathrm{FeCl}_{3}$ to the culture solution gives a heavy buff-colored precipitate, which dissolves in an excess of reagent to give an intense iodine-brown solution. Citrinin has little if any activity against gram-negative bacteria and about 50,000 dilution units against $B$. subtilis and $S$. aureus $(33,907)$.

\section{Penicillic Acid}

Penicillic acid was first isolated in 1913 by Alsberg and Black (I6) as a metabolic product of $P$. puberulum. It is also produced by $P$. cyclopium. A limited air supply and an acid reaction of the medium favor the production of this acid. It is isolated $(698,703)$ by evaporation of the culture solution, the crude acid crystallizing on cooling. It is purified by recrystallization from hot water. Yields greater than 2 gm. per liter of culture were obtained. It is a monobasic acid, stable, colorless, appreciably soluble in cold water, giving a series of colorless and readily soluble salts $(6 \mathrm{I}, 487)$. It is optically inactive, and its m.p. is $87^{\circ} \mathrm{C}$. (anhydrons), $64^{\circ}$ to $65^{\circ} \mathrm{C}$. $\left(+\mathrm{H}_{2} \mathrm{O}\right)$. It has limited activity against gram-positive and gram-negative bacteria. It is also active against yeasts, and is toxic to animals when injected subcutaneously in concentrations of 0.2 to $0.3 \mathrm{gm}$. per kilogram weight.

\section{Fumigatin}

Fumigatin is a 3-hydroxy-4-methoxy-2,5-toluquinone or $\mathrm{C}_{8} \mathrm{H}_{8} \mathrm{O}_{4}$ (Figure I8). It forms maroon-colored crystals, has an m.p. of I I $6^{\circ} \mathrm{C}$., and is water-soluble $(23,743)$. It is extracted with chloroform from acidified medium. It has limited activity against gram-positive bacteria.

All quinones have been divided into three groups on the basis of their action on Staphylococcus: (a) those that have a markedly weaker antibacterial action than fumigatin, including toluquinone and some of its derivatives; (b) those that are somewhat more effective than fumigatin, including 3:4 dimethoxytoluquinone; (c) those with activity perceptibly greater than that of fumigatin (methoxytoluquinones). The introduction of $-\mathrm{OCH}_{3}$ into the quinone nucleus results in an in- 
crease in antibacterial activity. The introduction of an $\mathrm{OH}$ or the replacement of $-\mathrm{OCH}_{3}$ by $\mathrm{OH}$ results in a decrease in activity. None of these quinones, however, has any very striking action on gram-negative bacteria, such as $E$. coli $(325,697)$.

\section{Clavacin}

Clavacin is anhydro-3-hydroxy-methylene-tetrahydro- $\gamma$-pyrone-2carboxylic acid (Figure I 8 ). It is produced by a number of fungi, and has also been designated claviformin, patulin, clavatin, and expansin. It is colorless, optically inactive, neutral, and readily soluble in water and most common organic solvents $(445,489)$; it has an m.p. of I I ${ }^{\circ} \mathrm{C}$. It is isolated either by preliminary adsorption on norite followed by removal with ether or chloroform, or by the direct treatment of the culture with ether. The extract is evaporated, leaving a brown substance; this is treated with a small amount of water, and the aqueous solution again extracted with ether. Clavacin crystallizes when the ether solution is concentrated, or after preliminary purification over a silica gel column.

Clavacin is about equally active against gram-positive and gramnegative bacteria, its growth inhibition being about 200,000 dilution units. It is also strongly fungistatic. It is toxic to animal tissues, its lethal action upon mice being about $25 \mathrm{mg}$. per kilogram body weight when given intravenously or subcutaneously.

Clavacin neutralizes the action of tetanus toxin and can thus be distinguished from isoclavacin and its derivatives. This specific action was ascribed (739a) to the position of one double bond in clavacin.

\section{Fumigacin}

Fumigacin is produced by different strains of $A$. fumigatus. It is a colorless, monobasic acid, m.p. $212^{\circ} \mathrm{C}$., l-rotatory in chloroform. It is insoluble in water except as sodium salt, sparingly soluble in methyl and ethyl alcohols, and readily soluble in acetone, ether, chloroform, and other organic solvents. It is extracted from the medium either by preliminary adsorption on charcoal followed by treatment with ether and alcohol, or by direct extraction of culture in accordance with the following method (63I): The culture filtrate is acidified to $\mathrm{pH} 2$ with 
phosphoric acid and extracted three times with ether, the combined extracts equalling the volume of the filtrate. The ether is evaporated to one-tenth of its volume and the concentrate is shaken repeatedly with saturated sodium bicarbonate solution, which removes a dark-red pigment. The solution is then exhaustively extracted with 6 per cent sodium carbonate solution. The ether phase, on evaporation, yields gliotoxin. The sodium carbonate solution is acidified and distributed several times with benzene; the partly crystalline residue from the benzene (7-I $2 \mathrm{mg}$. per I $\mathrm{L}$ of culture filtrate), on repeated recrystallization from methanol, yields pure fumigacin in the form of filamentous needles. Fumigacin melts with some decomposition at $215^{\circ}-220^{\circ} \mathrm{C}$, depending on the rate of heating. $[\alpha]_{\mathrm{D}}^{25}=-\mathrm{I} 32 \pm 2^{\circ}$ (0.4I per cent in chloroform). The ultraviolet absorption curve shows only strong end absorption below $260 \mathrm{~m} \mu$ with $\mathrm{E}_{1 \mathrm{~cm} .}^{\mathrm{r} \%}=298$ at $234 \mathrm{m \mu}$.

Fumigacin is markedly bacteriostatic against gram-positive bacteria, but not against the gram-negative forms. It is also active against tubercle bacilli, giving complete inhibition in a dilution of $\mathrm{I}: \mathrm{I} 0,000$, and partial inhibition in $\mathrm{I}: \mathrm{I00}, 000$ dilutions (464). It is not very toxic to animals ( 126 ).

\section{Gliotoxin}

Gliotoxin is produced by various species of Trichoderma, Gliocladium, Aspergillus (A.fumigatus) and Penicillium (P.obscurum), as well as various other fungi. It has been analyzed as $\mathrm{C}_{13} \mathrm{H}_{14} \mathrm{O}_{4} \mathrm{~N}_{2} \mathrm{~S}_{2}$ (474). It is rapidly produced in an acidified $(p \mathrm{H} 3.0$ to 3.5$)$ synthetic medium when grown in a submerged or shaken condition for 2 to 4 days. It is extracted from the culture medium by the use of chloroform. The latter is distilled off, and the residue is taken up in a small amount of hot benzene or 95 per cent alcohol, from which, on cooling, silky white needles crystallize. It is recrystallized from benzene or alcohol. It has an optical rotation of $[\alpha]_{\mathrm{D}}^{19}=-239^{\circ}$, and an m.p. of $\mathrm{I} 2 \mathrm{I}^{\circ}$ to I $22^{\circ} \mathrm{C}$. (99I).

Gliotoxin is frequently accompanied by one or more other antibiotic substances, $A$. fumigatus producing as many as three others. $P$. obscurum also produces one other. The removal of both from the medium is brought about by extraction, at $p \mathrm{H}_{2}$, with benzene. The addition of 
equal parts of petroleum ether to the concentrated extract results in the separation of a crude preparation of gliotoxin. Purification is accomplished by repeated crystallizations (665).

Gliotoxin is sparingly soluble in water and readily soluble in alcohol. It is unstable, particularly in alkaline solutions, and is sensitive to oxidation and to heating (988); it is inactivated by heating for $10 \mathrm{~min}$ utes at $100^{\circ} \mathrm{C}$. ( 14 ). Its potency was found to be destroyed by bubbling oxygen for 5 minutes.

Gliotoxin is active against various bacteria and fungi. It is toxic to Rhizoctonia hyphae in a dilution of $1: 300,000$, which is about twothirds of the toxicity of $\mathrm{HgCl}_{2}$. The crystals, as well as the crude material, were found to be toxic also to Trichoderma, but the minimum lethal dose was about 40 times greater than that required for Rhizoctonia.

\section{Viridin}

Viridin is produced by Trichoderma viride. It crystallizes in the form of colorless rod-like prisms, which decompose without melting at $217^{\circ}$ to $223^{\circ} \mathrm{C}$. It is extracted from the medium with chloroform, evaporated under reduced pressures, and crystallized from ethyl alcohol. It is optically active; a I per cent solution in chloroform gives $[a]_{\mathrm{D}}^{19}=-222^{\circ}$. The addition of phloroglucinol and $\mathrm{HCl}$ to a dilute alcoholic solution gives a deep reddish-violet color. It is unstable in aqueous solutions, but stable at $p \mathrm{H}_{3.5}$. It is highly fungistatic but not very bacteriostatic (84).

\section{Other Substances}

A number of other antibacterial substances have been isolated from fungi, but have not been adequately studied either chemically or biologically. It is sufficient to mention the following:

Puberulic acid, a colorless, optically inactive, water-suluble dibasic acid, with an m.p. of $316^{\circ}$ to $318^{\circ} \mathrm{C}$., and puberulonic acid, a brightyellow acid with an m.p. of $298^{\circ} \mathrm{C}$., are produced $(62,704)$ by various species of Penicillium ( $P$. puberulum). The first is a quinol and the second is quinonoid. They have moderate activity against gram-positive bacteria. $P$. puberulum also produces a photosensitive compound. 
$\mathrm{C}_{17} \mathrm{H}_{12} \mathrm{~N}_{2} \mathrm{O}_{2}$, with an m.p. of $220^{\circ} \mathrm{C}$.; it appears in the mycelium after 5 weeks' incubation and has certain antibiotic properties ( 108 ).

Penicidin was isolated (29) from a species of Penicillium. It is soluble in ether, alcohol, chloroform, and dilute acids, but not in petrol ether. It is destroyed by bases, and is adsorbed on active charcoal. It is similar to aspergillic acid in its antiluminescent properties. It is active against $E$. typhosa.

Chaetomin is produced by a species of Chaetomium ( $C$. cochliodes) grown in complex organic media. It is active largely against gram-positive bacteria (948). Much larger concentrations of the material are found in the mycelium of the organism than in the culture filtrate; it is extracted from the former with acetone and from the latter with ethyl acetate. It is purified by washing with sodium carbonate, treated with petroleum ether, followed by chromatographic absorption. Chaetomin contains nitrogen and sulfur, but it differs in biological activity from penicillin and from gliotoxin (326).

Kojic acid (Figure I 8 ) is produced by various species ( $A$. oryzae and A. effusus). It possesses definite, even if limited, antibacterial properties and is more active against gram-negative than gram-positive bacteria; its antibiotic activity is not inhibited by serum ( 150,465 ). It is particularly active against species of Leptospira (660).

Polyporin is produced by Polystictus sanguineus grown for two to three weeks in various synthetic media. It is present in both the culture filtrate and the sporophores of the fungus. It is water soluble, and is active (bacteriolytic) against various gram-negative (E. typhosa, V. comma) and gram-positive ( $S$. aureus) bacteria. It is nontoxic and nonhemolytic (77). Its activity is not affected by oral administration, by passage through a Seitz filter, or by pus and other body fluids and tissues. It protected animals against $V$. comma and $E$. typhosa infections, and neutralized typhoid vaccine (77a).

Mycophenolic acid is produced by $P$. brevi-compactum. It was so named by Alsberg and Black (16) in I9I3, although it was first isolated by Gosio in 1896 and is said (268) to be the first antibiotic to have been crystallized. It has only limited activity upon certain gram-positive bacteria, but it has a considerable effect in inhibiting the growth of 
fungi, especially those pathogenic to man and to plants. This effect is largely fungistatic, giving titers up to I :80,000 (27I).

Glutinosin is produced by Metarrhizium glutinosum grown on synthetic media ( $83 a$ ). The substance is extracted with ether, $n$-butyl alcohol, or petroleum ether. The solvent is evaporated and the material crystallized from ethyl alcohol in the form of thin, colorless plates, free from $\mathrm{S}$ and $\mathrm{N}$. It does not melt at $300^{\circ} \mathrm{C}$. It has specific antifungal activity, inhibiting spore germination, but does not possess any antibacterial properties.

\section{SUBSTANCES PRODUCED BY YEASTS}

According to Fernbach (252), certain yeasts produce volatile substances which are toxic not only to other yeasts but also to bacteria. Rose yeasts (Torula suganii), either fresh or heated to $\mathrm{I} 20$ to $\mathrm{I} 30^{\circ} \mathrm{C}$., were found (690) to contain a substance which has an antagonistic action against fungi, especially in the young mycelial stage, but not against yeasts; the growth of $A$. niger was reduced by 60 to 70 per cent and that of $A$. oryzae by 25 to 30 per cent. The substance was not found in the ash of the organism and was not secreted in the filtrate, but remained in the yeast cells. An alkaline reaction was unfavorable to its formation and action. The active substance was soluble in acetone, alcohol, ether, and chloroform, and was adsorbed by kaolin, Seitz filter, paper, and by the fungus mycelium. It could be removed from the kaolin by treatment with ether or acetone. Acetone-treated yeast no longer had an antagonistic effect, but only a stimulating one.

According to Schiller ( 835 ), yeasts produce a bacteriolytic substance only in a state of "forced antagonism," that is, in the presence of staphylococci and certain other bacteria. The substance is thermolabile, since it is destroyed at $60^{\circ} \mathrm{C}$. It is active also outside the cell. More recently ( 15 I ), the active substance of yeast was concentrated. In a crude state, the active material was found to be nonvolatile and readily soluble in water, in 95 per cent alcohol, and in acetone containing a trace of water. It was stable at $100^{\circ} \mathrm{C}$. at $p \mathrm{H} 7.3$. It contained nitrogen but no sulfur. Although a positive biuret reaction was obtained, it appeared that the protein was present as an impurity. 
The ability of Torulospora utilis var. major to inhibit the growth of various gram-negative and other bacteria has also been demonstrated (II2).

\section{SUBSTANCES PRODUCED BY ANIMALS}

To what extent antibacterial substances produced by animals and plants should be classified with the true antibiotics is open to question. In view of the fact, however, that these substances behave in a manner similar to antibiotics, they can be mentioned here.

\section{Lysozyme}

Fleming (260) found that egg white contains an enzyme, designated as lysozyme, that is active against certain bacteria, notably micrococci, bringing about their lysis. It is soluble in water and in dilute $\mathrm{NaCl}$ solution. It is precipitated by chloroform, acetone, ether, alcohol, and toluene. It is not acted upon by pepsin or trypsin.

Lysozyme has been demonstrated in most mammalian tissues and secretions, in certain vegetables, and in bacteria (905). It was found to be a polypeptide containing 16 per cent nitrogen and 2 to 3 per cent sulfur and having a molecular weight of I 8,000 to 25,000 . It is soluble and stable in acid solution, insoluble and inactivated in alkaline solutions, and inactivated by oxidizing agents (641). It diffuses in agar and through cellophane, and thus is markedly different from bacteriophage (332). It is fixed on the bacterial cells. It acts primarily upon the cell membrane of bacteria, the highly viscous component of the bacterial cell (the mucoids), especially the sugar linkages of the complex amino-carbohydrates, being disintegrated by the enzyme. The degradation of the bacterial polysaccharide to water-soluble products ( $\mathrm{N}$-acetylated amino-hexose and a keto-hexose) by lysozyme is accompanied by complete lysis of some of the bacteria. In the case of other lysozymesensitive bacteria, such as $B$. subtilis, no lysis occurs; apparently the morphological structure of these bacteria does not depend exclusively on the unaltered state of the substrate for lysozyme (242).

1 The formation of a lysozyme-like material was also demonstrated (259) for a coccus isolated from dust. A sarcina susceptible to egg-white 
lysozyme also was found (64I) to produce an autolytic enzyme similar to it. It has been suggested that the antibacterial action of saliva may be due to the presence in it of antagonistic bacteria. The lysozyme of saliva is known to act primarily upon gram-positive bacteria. A large number of bacteria were tested (3I) for their ability to antagonize diphtheria and pseudo-diphtheria organisms. Only the spore-forming $B$. mesentericus and $B$. subtilis groups produced antagonistic substances, but these bacteria were not found in the saliva. Cultures of bacteria isolated from the saliva had no antagonistic effect, thus proving that the action of saliva need not be due to its bacterial content.

\section{Milk}

Milk was found (694) to contain several thermolabile bactericidal substances and two thermostable compounds which acted injuriously upon lactic acid bacteria. Orla-Jensen emphasized that the growth of bacteria in milk is influenced by a combination of activators or growthpromoting substances and of inhibitors, the predominance of one or the other being determined by various conditions. These substances influence the development of specific lactic acid bacteria during the spontaneous souring of milk.

\section{Other Substances}

Various other animal tissues and fluids contain substances which produce a bacteriostatic effect upon gram-positive bacteria. The method of isolation of these substances and their selective action are similar to those of tyrothricin (523a).

\section{SUBSTANCES PRODUCED BY HIGHER PLANTS}

It has been known for a long time that certain alkaloids and other plant extracts possess bactericidal properties. Sherman and Hodge (85 I) demonstrated in 1936 that the raw juices of cabbage, turnips, and horseradish possess antibacterial properties. The active substance in the juice could be adsorbed on activated carbon and by passage through fine Berkfeld filters. The substance was thermolabile, being destroyed at $60^{\circ} \mathrm{C}$. in 10 minutes. 
Osborn (696) examined as many as 2,300 different flowering plants, of which 134 species gave positive results. The activity against grampositive bacteria was far greater than against gram-negative forms; cabbage, cauliflower, broccoli, and kohlrabi gave the greatest effect upon both groups of bacteria. The Ranunculaceae were most active of all the plants. The stability of the substances as regards wilting and drying varied greatly. Extracts of honeysuckles (Lonicera tartarjia), especially of the roots, are very active (583).

Antibacterial substances are thus found to be widely distributed among higher plants. Some of these substances have been isolated and even crystallized. Allicin, a diallyl sulfoxide, was isolated from Allium sativum (II7). Crepin, an aß-unsaturated lactone, has been isolated from Crepis taraxacifolia; the empirical formula $\mathrm{C}_{14} \mathrm{H}_{16} \mathrm{O}_{4}$ has been suggested for it. It is active against both gram-positive and gramnegative bacteria (39I). Protoanemonin, obtained from buttercups, Ranunculus, is active against various bacteria and fungi (847). Tomatin, an antibiotic occurring in the tomato plant, was found ( $456 \mathrm{a})$ to be active against a variety of gram-positive bacteria and fungi, including both plant and animal pathogens.

Lichens were also found capable of producing antibacterial activity. Of about 100 forms tested, 52 could inhibit either $B$. subtilis or $S$. aureus or both; gram-negative bacteria are generally not susceptible. Although certain lichen constituents were found to possess antibiotic properties, no specific agent has been isolated ( 100 ). Spanish moss also produces an antibiotic effect (999).

Unbleached wheat flour was shown (889) to contain a protein which had bacteriostatic and bactericidal activity in vitro; although its activity was greater against gram-positive organisms, it also had some activity against gram-negative types. The antimicrobial action of this protein can be neutralized by means of a phosphatide (I033), a reaction which may be due to the formation of a lipoprotein that has no longer any antibiotic activity. 


\section{THE NATURE OF ANTIBIOTIC ACTION}

Sulfanilamide, penicillin, and gramicidin can be clearly set apart from the classical antiseptics which are general protoplasmic poisons. All three substances are primarily bacteriostatic rather than bactericidal in their action. Since they do not destroy the respiration of bacteria, one may assume that the inhibition of growth which they cause depends not upon interruption of the cellular metabolism as a whole, but rather upon some subtle interference with certain individual reactions. To interrupt the pathogenic career of an infectious agent, therefore, it is not necessary to kill the invading cell, but only to block one step in its metabolic path by some specific inhibitor. - Dubos.

\section{ANTIBIOTIC SUBSTANCES AND CHEMICAL}

\section{DISINFECTANTS}

SINCE antibiotic substances vary greatly in their origin and in their chemical nature, they may be expected to vary also in their mode of action upon the cells of bacteria and other microorganisms, and in the effect upon the animal tissues when these agents are used for chemotherapeutic purposes. Comparatively little is known concerning these mechanisms. It is known, however, that antibiotic substances act chiefly by interfering with the growth of the bacterial cell, although in many cases they are able to bring about the lysis of the cell as well. Because of the first effect, it has been assumed that antibacterial agents are structurally related to bacterial metabolites that usually function as coenzymes (600). In this connection, the following properties of antibiotic agents are of particular significance:

Most antibiotics are strongly bacteriostatic and only weakly bactericidal, though a few are also strongly bactericidal and some are even bacteriolytic.

Some substances act primarily in vitro and only to a limited extent in vivo because of interference of the body tissues with their action; others, however, act readily upon bacteria in vivo. 
A few antibiotic agents are fairly nontoxic to the animal body; others are somewhat more toxic but can still be utilized; and some are so highly toxic that they offer little promise as chemotherapeutic agents.

Antibiotic agents differ greatly in their solubility: some are water soluble; others are alcohol soluble and only slightly soluble in water; and some are acids and react with alkali solution to form soluble salts.

Some antibiotic agents are stable under a variety of conditions, whereas others are unstable.

Some antibiotic substances are hemolytic, others have apparently no injurious effect upon blood cells. The latter can be used for general body treatment, whereas the former are suitable only for local applications.

Since antibiotic substances are selective in their action upon microorganisms, none can be expected to be utilized as general agents against all bacteria. This also points to the remarkable physiological differences in the morphology and physiology of bacterial cells, and to the differences in mode of action of the different antibiotics upon various bacteria.

A comparison of the antibacterial action of the antibiotic substances produced by two bacteria will serve to illustrate some of the foregoing points. Pyocyanin, produced by $P_{s}$. aeruginosa, inhibits the growth of many gram-positive and gram-negative bacteria in dilutions as high as I : I00,000; pyocyanase and hemipyocyanin have less activity upon the bacteria, but yeasts are more sensitive to them than to pyocyanin. Tyrothricin, produced by $B$. brevis, is far more specific in its action, which is limited largely to gram-positive bacteria. The sensitivity of pathogenic fungi to these compounds also differs markedly. Some other striking differences are found on comparing two types of antibiotic substances produced by fungi, namely, penicillin and clavacin, and two substances produced by actinomycetes, namely, streptothricin and actinomycin. The bacteriostatic spectra of these four substances are recorded in Table 35. The first of each pair has limited toxicity to animals, and the second is highly toxic. Whereas penicillin acts largely upon gram-positive bacteria and only upon a few gram-negative organisms, streptothricin acts alike upon certain bacteria within each group. Clavacin and actinomycin, both of which are highly toxic, differ similarly in their action upon bacteria, the first being largely active against 
gram-positive and the second active against members of both groups. These four compounds show various other differences in the nature of their antibacterial action. Differences in the bactericidal properties of other antibiotic substances are brought out in Table 36.

Various attempts have been made to compare the antibacterial action of antibiotic substances with that of organic antiseptics. According to Suter (890), the bactericidal action of a compound depends upon certain physical and chemical characters; a property that determines the bactericidal action of the compound upon $E$. typhosa may be relatively unimportant in the case of another organism such as $S$. aureus. A substance may have the same activity, as expressed by the phenol coeffcient, against two organisms and still differ markedly in its relative

TABLE 35. BACTERIOSTATIC SPECTRA OF FOUR ANTIBIOTIC SUBSTANCES

\begin{tabular}{|c|c|c|c|c|c|}
\hline TEST ORGANISM & $\begin{array}{l}\text { GRAM } \\
\text { STAIN }\end{array}$ & $\begin{array}{l}\text { PENI- } \\
\text { CILLIN }\end{array}$ & $\begin{array}{l}\text { ACTINO- } \\
\text { MYCIN }\end{array}$ & $\begin{array}{l}\text { STREPTO- } \\
\text { THRICIN }\end{array}$ & CLAVACIN \\
\hline S. aureus & + & $9,500 *$ & 20,000 & 200 & 100 \\
\hline S. aureus & + & $1,000 \dagger$ & - & - & - \\
\hline S. lutea & + & $38,000^{*}$ & 60,000 & 100 & 500 \\
\hline B. subtilis & + & $19,000 *$ & 60,000 & 750 & 200 \\
\hline B. megatherium & + & I,900* & 40,000 & 200 & 100 \\
\hline B. mycoides & + & $5^{*}$ & 40,000 & $<3$ & 200 \\
\hline Cl. welchii & + & I,500† & 1,000 & - & - \\
\hline Actinomyces sp. & + & I,ooo† & 10 & $10-50$ & - \\
\hline Neisseria sp. & - & $2,000 \dagger$ & 20 & - & - \\
\hline Br. abortus & - & $2 \dagger$ & 10 & 100 & - \\
\hline Sh. gallinarum & - & $2 \dagger$ & 20 & 300 & - \\
\hline Pasteurella sp. & - & It & $<10$ & 100 & - \\
\hline Hemophilus sp. & - & - & 50 & 30 & - \\
\hline S. schottmülleri & - & $<\mathrm{I} \dagger$ & $<10$ & 200 & 60 \\
\hline S. aertrycke & - & $10 *$ & - & - & - \\
\hline Ps. fluorescens & - & $<5^{*}$ & 10 & $<3$ & 6 \\
\hline S. marcescens & - & $<I^{*}$ & $<5$ & 5 & 60 \\
\hline A. aerogenes & - & $<5^{*}$ & $<5$ & 30 & 50 \\
\hline E. coli & - & $\langle I \dagger$ & - & - & - \\
\hline E. coli & - & $<5^{*}$ & 5 & 100 & 100 \\
\hline
\end{tabular}

Note. Activity is indicated in thousands of dilution units per gram.

- Data based on a sample having 470 Oxford units.

$\dagger$ Data reported by Abraham et al. (5), based on a less active preparation. 
TABLE 36. BACTERICIDAL EFFECTS OF PENICILLIN, GRAMICIDIN, AND TYROCIDINE UPON S. HEMOLYTICUS

\begin{tabular}{|c|c|c|c|c|c|}
\hline \multirow[b]{2}{*}{$\begin{array}{l}\text { 1NHIBITING } \\
\text { AGENT* }\end{array}$} & \multicolumn{5}{|c|}{ NUMBER OF VIABLE ORGANISMS $†$} \\
\hline & At start & At I hour & $\begin{array}{c}\text { At } \\
3 \text { hours }\end{array}$ & $\begin{array}{c}\text { At } \\
7 \text { hours }\end{array}$ & $\begin{array}{c}\text { At } \\
24 \text { hours }\end{array}$ \\
\hline Penicillin & 1,500 & 4,300 & 2,650 & 420 & 0 \\
\hline Gramicidin & 1,500 & 2,430 & 1,140 & 7 & 2.4 \\
\hline Tyrocidine & 1,500 & 0.1 & 0 & 0 & 0 \\
\hline
\end{tabular}

From Dawson, Hobby, Meyer, and Chaffee (171).

* $10 \mu \mathrm{g}$ of each preparation was added to I milliliter of culture.

$\dagger$ In thousands per milliliter.

lethal effects. The conclusion was reached that the mechanism of bactericidal action must be considered as a separate problem for each type of organism, and, one may add, for each type of compound.

Although the major difference in the action of antibiotic substances and chemical antiseptics is based upon the selective antibacterial nature of the former, still an attempt may be made to correlate the two types of compounds. Marshall and Hrenoff (62 I) constructed a disinfectant spectrum for antibacterial substances with a flexible blending of differentiated degrees of activity. The first, or ineffective, band covers a range of dilutions of an agent between zero concentration and the highest dilution which still exerts no action on bacteria. The second, or stimulative, band comprises a range of relatively high dilutions in which there is a slight stimulation of bacterial multiplication; this range is ordinarily narrow, but it may become broad. The third, or inhibiting, and the fourth, or bactericidal, bands merge indistinguishably. The fifth, or impractical, band covers a range of concentrations of the disinfectant that are too great for practical purposes (Figure $2 \mathrm{I}$ ).

By establishing the normal rate of multiplication of bacterial cells in a given culture without the disinfectant, one can determine the retardation of that rate by the disinfectant. This rate approaches zero at complete inhibition with no multiplication and no deaths. A further increase in the concentration of disinfectant results in the death of some organisms per unit of time, and eventually a concentration is reached at which all organisms die rapidly. Any rate of multiplication greater than zero but less than normal can be considered as the bacteriostatic zone, and 

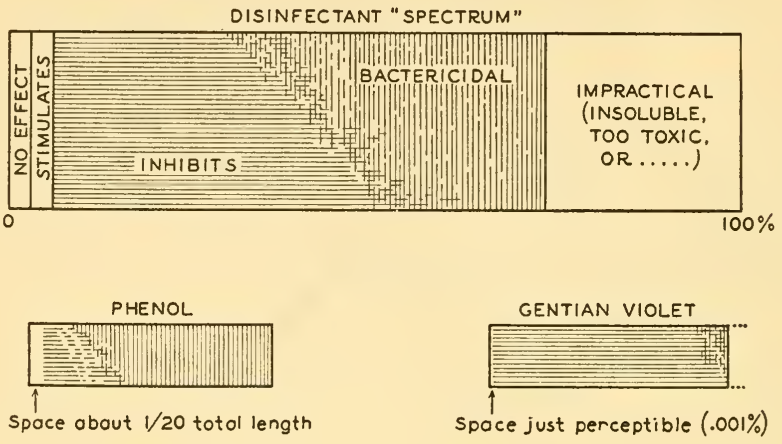

Figure 21. Disinfectant spectrum. From Marshall and Hrenoff (621).

the rate less than zero as the bactericidal zone. According to this concept of bacteriostasis, bacterial growth may be delayed under the influence of a disinfectant for many days or for many hours; or the bacteria may progressively die over a period of many days.

The following factors influence the selective action of an antibiotic agent upon bacteria (200): the acidic and basic properties of the bacterial cell, the nature and property of its membrane, its permeability, the relative importance for metabolism and viability of the specific biochemical systems affected by the agent, the activity of autolytic enzymes in the bacterial cell, as well as others.

Marked differences exist in the degree of sensitivity of various bacteria to different antibiotic substances and chemical agents. Gramicidin is most specific in its action, being limited to the cocci and acting upon actinomycetes to only a limited extent. Penicillin is next in its selective action. Actinomycin, tyrocidine, and gliotoxin act primarily upon the gram-positive organisms and actinomycetes, and much less upon gramnegative bacteria. The selective action is in contrast to the generalized, even if more limited, action of phenol and quinone, which act alike on both gram-positive and gram-negative organisms. Pyocyanase, pyo- 
cyanin, and the culture filtrate of $P$. notatum (due to the presence of notatin) are similar in some respects but not in others to the chemical compound in their action; they are found to be generally bacteriostatic over a wide range of test organisms, no sharp division being obtained upon the basis of the gram stain. Streptothricin is unique in its action; the gram-positive spore-former $B$. subtilis is most sensitive, but the other spore-former $B$. mycoides is not affected at all. The gram-negative $E$. coli is more sensitive to streptothricin than either $M$. lysodeikticus or $S$. lutea. Streptomycin is almost as active against $B$. mycoides as against $B$. subtilis but is less active against fungi. The antibiotics of microbial origin are generally found to be stronger bacteriostatic agents than the chemicals tested. A high bacteriostatic effect is not necessarily accompanied by a correspondingly high bactericidal action. Gliotoxin, one of the most active bacteriostatic substances among those tested, possesses lower bactericidal properties than other preparations. Streptothricin and streptomycin, on the other hand, are highly bacteriostatic and bactericidal against certain gram-negative bacteria.

The specific morphological differences among the bacteria, based upon the gram stain, as shown by their sensitivity to antibiotic substances, are thus found to be relative rather than absolute. Most grampositive bacteria are more sensitive to the majority of antibiotics than are gram-negative bacteria. But other antibiotics, such as streptothricin, streptomycin, and clavacin, act quite differently and show marked variations within each group.

\section{MECHANISM OF ANTIBIOTIC ACTION}

In an attempt to interpret the antibacterial properties of antibiotic substances, one may benefit from a comparison of the action of these substances and that of other antibacterial agents. Recent studies of the mechanism of antibacterial action of chemotherapeutic agents led to rather definite concepts concerning the nature of this action. The action was believed to consist in depriving the bacteria of the use of enzymes or metabolites by various types of interference. When the organisms are thus inhibited their nutritional requirements are more exacting than in their normal state. E. coli and $S$. hemolyticus, when inhibited by acri- 
flavine components, were found to require for further growth two types of material not normally added, one of which could best be replaced by nucleotides, and the other by a concentrate of amino acids, especially phenylalanine $(598,599)$.

On the basis of the information now available, the following mechanisms may be tentatively presented here:

The antibiotic substance interferes with bacterial cell division, thus preventing further growth of the organism. The cell, unable to divide, gradually dies. It has been shown $\left(3^{6} 3\right)$, by the use of the manometric method, that certain bactericidal agents in bacteriostatic concentrations have no effect on the metabolic rates of bacteria, though they do inhibit cell multiplication.

The antibiotic interferes with the metabolic processes of the microbial cells by substituting for one of the essential nutrients. A specific inhibitory effect may be exerted by those substances that are structurally related to normal cell metabolites; such substances are taken up by the cell in competition with normal nutrients but since they are useless to the cell for further reactions they block the process of growth (253, 596-600). The antibiotic effect of certain polypeptides, such as gramicidin, may be due to the presence of a $d$-amino-acid isomer of a natural amino acid, $l$-leucine, required for bacterial growth (289).

The antibiotic, such as aspergillic acid, interferes with the utilization of iron or with the functioning of the iron-containing enzyme system (348).

The antibiotic may interfere with the production and utilization of an essential growth-factor required by the cell. The staling effect of a medium, frequently spoken of in connection with protozoa as "biological conditioning" of the organism, may serve as an illustration. Such effects have been overcome by the addition of a mixture of thiamine, riboflavin, and nicotinamide (374).

The antibiotic agent brings about the oxidation of a metabolic substance which must be reduced in the process of bacterial nutrition, or otherwise modifies the intermediary metabolism of the bacterial cell.

The agent combines with the substrate or with one of its constituents, which is thereby rendered inactive for bacterial utilization.

The agent competes for an enzyme needed by the bacteria to carry out an essential metabolic process. 
The agent interferes with various enzymatic systems, such as the respiratory mechanism of the bacterial cell, especially the hydrogenase system (449) and the phosphate uptake by the bacteria accompanying glucose oxidation, as in the action of gramicidin. Penicillin, for example, inhibits the production of coagulase by staphylococci in vitro (590).

The antibiotic substance may inhibit directly cellular oxidations, particularly those involving nitrogenous compounds, an action similar to that of propamidine (52I).

The antibiotic substance acts as an enzyme system and produces, in the medium, oxidation products, such as peroxides, injurious to the bacterial cell. The glucose oxidase produced by $P$. notatum catalyzes the following reaction:

Glucose $+\mathrm{H}_{2} \mathrm{O}+\mathrm{O}_{2} \rightarrow$ Gluconic acid $+\mathrm{H}_{2} \mathrm{O}_{2}$.

The antibiotic substance favors certain lytic mechanisms in the cell, whereby the latter is destroyed; this mechanism may be either secondary or primary in nature.

The antibiotic substance affects the surface tension of the bacteria, acting as a detergent; tyrocidine lowers the surface tension of the bacterial cell, thereby causing its death, possibly by forming a stable complex with it (200).

The antibiotic substance may interfere with the sulfhydryl group which is essential for cell multiplication. This was shown by Fildes (254) to hold true for mercurials and other chemical antiseptics as well as for true antibiotics such as clavacin and penicillic acid (325).

The interaction of sulfhydryl-containing compounds with antibiotics depends on the nature and concentration of the latter. It has been suggested (I I 8) that the activity and specificity of an antibiotic are functions of several factors, such as its diffusibility into the microbial cell, its adsorption by various enzyme systems, its reaction with sulfhydryl groups of the enzymes or with other sulfhydryl-containing substances adsorbed by the enzyme. Gliotoxin and the active principles of Allium sativum and Arctium minus showed little specificity in reactivity toward the thiols, whereas penicillin, streptomycin, and the Asarum canadense antibiotic reacted more readily with those sulfhydryl compounds which contained basic amino groups in the vicinity of the - $\mathrm{SH}$. Pyocyanin had intermediate properties ( I I 5 b). 
The theory of inner antagonism has been suggested (509). The bacterial cell is said to contain two antagonistic groups, namely coagulants and lysins; when the correlation between these two groups is disturbed the result is either agglutination and precipitation by the first or lysis by the second. The phage is given as an example of a free inner antagonist, the lysin; reproduction of the phage is thus explained by the formation of lysins in multiplying cells. The action of antibiotic substances and resulting cell lysis were also explained by the inner antagonism.

It has been postulated ( 170 ) that the action of growth-inhibiting substances may consist in prolongation of the lag phase, reduction of the growth rate, lowering of stationary population, or hastening the death of the bacteria. A bactericide has all these effects, whereas a bacteriostatic agent may affect one stage selectively. When organisms are allowed to grow in the presence of an antibacterial agent, a greater concentration of the latter is required to bring about a given effect upon the bacterial culture.

On the other hand, bacteria subjected to the action of an antibiotic substance may develop mechanisms that render them resistant to the action of the substance, and some bacteria and fungi even may produce an enzyme, such as penicillinase, that brings about the destruction of the antibiotic substance.

The antibacterial action of gramicidin was found (4I2) to be inhibited by a cationic detergent, phemerol, whereas penicillin was not affected by either gramicidin or two cationic detergents, phemerol and zephiran. When gramicidin and penicillin were used together, their effect was only slightly additive (394); however, penicillin and streptothricin exerted a marked additive effect upon bacteria sensitive to both of these substances (287).

The inhibition of the antibacterial action of sulfanilamide by $p$-amino-benzoic acid has been explained by the fact that the latter is a growth factor in bacterial nutrition. Competition for this growth factor between the bacterial cell and the bacteriostatic agent is responsible for the inhibition of the agent. In a similar manner pantoyltaurine, which is related to pantothenic acid as sulfanilamide is to p-amino-benzoic acid, will inhibit the growth of hemolytic streptococci, pneumococci, 
and $C$. diphtheriae, by preventing the utilization of pantothenic acid by these bacteria, for which it is an essential metabolite. Fildes (253) emphasized that "chemotherapeutic research might reasonably be directed to modification of the structure of known essential metabolites to form products which can block the enzyme without exhibiting the specific action of the metabolite." Since $p$-amino-benzoic acid has no such action on penicillin, it is assumed that its mode of action upon bacteria is different from that of sulfanilamide. However, it was suggested that penicillin as well acts by inhibiting directly one or more enzymes, the difference being merely one of degree (648).

The antibacterial activity of iodinin is neutralized by quinones; this is probably due to the destruction of the iodinin, since the N-oxide is reduced by the organism (596, 597, I009). Different anti-inhibitors are known for other antibiotic substances, as shown later.

Numerous other examples of metabolite-antagonism can be cited. Since the nature and function of the various metabolites are so diverse, and there are so many ways of modifying their structure, the principle of interference with biological processes through the use of analogs of essential metabolites is considered as established (994). The interference is sometimes explained as a direct competition between the metabolite and its analog for some cellular component for which they both have great affinity. However, in addition to competition, other factors also operate. The majority of the interferences involve organisms that are unable to synthesize the essential metabolite the function of which is disturbed.

McIlwain recommended the use of an antibacterial index to represent the minimal value of $\mathrm{C}_{\mathrm{I}} / \mathrm{C}_{\mathrm{M}}$, or the ratio of concentration of inhibitor $\left(C_{I}\right)$ just sufficient to prevent the growth of the organism, to the concentration of metabolite $\left(\mathrm{C}_{\mathrm{M}}\right)$ present. The smaller the antibacterial index the more effective is the compound, therefore, as an inhibitor. With $S$. hemolyticus, the homopantoyltaurine was found to have an index of 20,000, the pantoyltauramide 2,000, and the pantoyltaurine 500. The indices vary for different organisms. E. coli and $P$. vulgaris synthesize their own pantothenate and are not inhibited by these analogs of pantothenic acid. The mechanism of the resistance is at present unknown. 
The concentration of the active substance and the composition of the medium are highly important in modifying the activity of the substance. Some antibiotic substances, like penicillic acid, lose considerable bacteriostatic activity when incubated with sterile broth or with sterile peptone water at $\mathrm{pH} 7$ and $37^{\circ} \mathrm{C}$. for I to 3 days (700); a similar effect was observed with certain simple amines and amino acids. The concentration of the substances reacting with penicillic acid is diminished on autoclaving the peptone broth in the presence of 2 per cent glucose. The neutralizing or anti-inhibiting agent interacts with the antibiotic substance and neutralizes its antibacterial effect either in the absence or in the presence of the organism.

Since not all antibiotics of microbial origin have been isolated in a crystalline state, confusion often resulted from the use of crude preparations. Concentrated and partly purified actinomycetin had no appreciable lytic action upon living cells; however, the presence of a small amount of a highly bactericidal substance, which was especially active against gram-positive bacteria, resulted in the lysis of living bacteria by actinomycetin. This action was thus a result of the activity of at least two different agents present in one preparation ( $\mathrm{IOO}_{2}$ ).

\section{ANTIBACTERIAL ACTION}

Chain and Florey (122) divided all antibiotic substances into two groups:

I. Antibiotics which react with protoplasmic constituents and kill both bacterial and animal cells, comparable to the action of "antiseptics." These antibiotics can be further subdivided into (a) those that are active against both gram-positive and gram-negative bacteria, and (b) those that exert a selective antibiotic action, usually against gram-positive organisms, such as gramicidin and actinomycin. The selectivity is not absolute, since gramicidin acquires strong bactericidal activity against gram-negative bacteria in the presence of protamines, due to the fact that protamines remove phospholipids, which inhibit the antibacterial action of gramicidin.

2. Antibiotics which react with substances having a specific significance in the bacterial cell only. Some of these substances are largely 
growth inhibiting and can, therefore, be designated as "bacteriostatics." The bacteriostatics may be expected to be relatively nontoxic to animal cells. Antibiotics of this class have possibilities as chemotherapeutic agents for general administration and for the treatment of systemic infections.

In order to determine whether an antibacterial substance has chemotherapeutic potentialities, the effect of the antibiotic on bacterial respiration can be determined by using the Barcroft-Warburg apparatus. If respiration is stopped by addition of the antibiotic in dilution of I : I,O00, the organisms may be said to have been killed, the substance being an antiseptic which will be toxic to animal tissues. If, however, the antibiotic produces little or no effect on respiration of the bacteria, there is a probability that the substance has chemotherapeutic possibilities.

Chain and Florey further suggested that observations be made on: (a) the toxicity of the antibacterial substance to leucocytes, a wide gap between a toxic concentration and a bacteriostatic effect suggesting that the substance may be useful, at least for local application; (b) the effect of blood, pus, and tissue extracts on the bacteriostatic activity, inhibition of activity being due to chemical combination between the active substance and a tissue constituent or to an inhibitory mechanism similar to that of $p$-amino-benzoic acid for the sulfonamides; (c) the toxicity of the substance to mice when injected intravenously. Any therapeutically active substance will be excreted unchanged or little changed in the urine, since it does not combine with the tissue cells.

Although Dubos (206) believed that none of the in vitro metabolic screening methods at present available is satisfactory in a search for new chemotherapeutic agents, Chain and Florey emphasized that those antibiotics which pass the above biological tests can be expected to be effective as general chemotherapeutic agents and to be worth further investigation with mouse protection tests.

\section{Tyrothricin}

The phenomenon of antibiotic action by a specific substance can best be illustrated by the action of tyrothricin upon bacterial cells. Five distinct stages have been described (2OI): 
1. Inhibition of growth. Certain gram-positive bacteria are inhibited by as little as I microgram or less of the substance per Io milliliters of nutrient broth or agar, thus giving an activity of $1: 10,000,000$ or more.

2. Bactericidal action consists in the killing of the bacterial cells, either in a washed state and suspended in saline, or in a growing state in broth culture.

3. Lytic activity comprises the rate of lysis of a suspension of bacterial cells. Streptococci, for example, are readily lysed by gramicidin, whereas staphylococci are acted upon more slowly and less completely.

4. Inhibition of enzyme activity includes dehydrogenases or enzymes of respiration. Gram-positive cocci, incubated at $37^{\circ} \mathrm{C}$., lose their ability to reduce methylene blue in the presence of glucose, upon addition of gramicidin. Since inactivation of the dehydrogenase takes place before any morphological changes are observed in the cells, lysis was believed to be a secondary process, following cell injury; hydrolytic enzymes, however, remained unaffected.

5. Protection of animals by the antibiotic substance against infection.

Gramicidin and tyrocidine differ in chemical properties and in biological activity. Gramicidin acts only against gram-positive bacteria, including pneumococci, streptococci, staphylococci, diphtheria bacteria, and aerobic spore-forming bacilli; meningococci and gonococci are not readily acted upon. Tyrocidine affects both gram-positive and gramnegative organisms. Gramicidin causes hemolysis of washed red cells, this hemolytic action being destroyed on heating. Tyrocidine causes lysis of many bacterial species. This action, however, is secondary, autolysis following the death of the cells. Peptones and serum inhibit the action of tyrocidine, but gramicidin is affected only to a limited extent by these agents $(6 \mathrm{I} 7)$.

Tyrocidine behaves as a general protoplasmic poison. The effect of gramicidin, on the other hand, is reversible. Staphylococci "killed" with gramicidin and no longer able to grow on organic media can be made to grow in the presence of certain tissue components. Gramicidin is, therefore, not considered as a gross protoplasmic poison, but retains a good deal of its activity in animal tissues. When applied locally at the site of infection, gramicidin exhibits definite action against pneumococci 
and streptococci. When injected intravenously, however, it is almost completely inactive against systemic infection.

It was demonstrated by tissue culture technique (4I2) that the hemolytic effect of tyrothricin was due to the presence of gramicidin. When tyrothricin or gramicidin was heated in an aqueous suspension there was a loss of hemolytic and bactericidal activity. Tyrocidine, which is not very hemolytic, showed no marked toxic effect upon the leucocytic elements of the human blood in amounts up to roo mg. per milliliter for 8 hours. Other investigators ( 757 ) have reported that the hemolytic activity of tyrothricin is inherent rather in the tyrocidine fraction, although gramicidin also exhibits a definite hemolytic action. The addition of glucose causes only slight inhibition of the hemolytic effect.

Treatment with formaldehyde results in the lowering of the hemolytic and toxic activity of gramicidin, without reduction of antibacterial properties; this was interpreted as signifying that these properties do not necessarily depend upon the same molecular configuration (565).

Gramicidin was found to be effective, in amounts as low as I mg., upon a billion gram-positive organisms, whereas tyrocidine acted in 25 to 50 times that concentration in the absence of inhibitors $(449,450)$. Tyrocidine appeared to block all the oxidative systems of the bacteria studied, whereas gramicidin seemed to affect only certain individual reactions.

Tyrothricin was reported (67) to inhibit enzymatic dehydrogenation not only of glucose but also of a number of other compounds, such as lactic acid, fumaric acid, and glutamic acid. Inhibition of dehydrogenase was parallel to inhibition of growth.

Both substances were found to exert a protective antibacterial action in mice infected intraperitoneally with susceptible bacteria; gramicidin protected the animals at a level one-fiftieth as high as that required for tyrocidine. Both substances are toxic to animals when injected into the blood stream; they show little toxicity when applied locally by the subcutaneous, the intramuscular, or the intrapleural route; oral administration is not accompanied by toxic effects, but such treatment is ineffective (758).

Gramicidin remains active in the blood stream, but it has only weak 
bacteriostatic properties and no bactericidal action. Tyrocidine is strongly bactericidal but it is inactivated by blood serum, hence it is limited to local applications. No specific effect was exerted by these substances on respiratory or circulatory systems (793).

According to Dubos (200), the retention of the stain by gram-positive bacteria indicates a peculiar property of the cell wall of these organisms. The addition of one microgram of gramicidin to a billion pneumococci, streptococci, and staphylococci is considered sufficient to inhibit the growth of these organisms on subsequent transfers. This effect was said to be due not to an alteration of the protoplasm but to some specific interference with an essential metabolic function. Bacterial cells which have been inhibited by the action of gramicidin become viable again when cephalin is added to the medium. It was suggested that the ineffectiveness of gramicidin against gram-negative bacteria may be due to the presence of a phospholipid in these organisms.

Different strains of $S$. aureus differ in their susceptibility to the action of tyrothricin. There is apparent adaptation of the organism to increasing concentrations of the substance. A marked increase in resistance of the infecting organism, after several weeks of therapy, was observed (752). Staphylococci grown in the presence of increasing concentrations of gramicidin become resistant to inhibition by this substance $(8 \mathrm{I}, 720)$.

Both gramicidin and tyrocidine are said (206) to be surface-active compounds, their antibacterial action being inhibited by phospholipids. Tyrocidine behaves like a cationic detergent; it is bactericidal in buffer solutions for all bacterial species so far tested, with the exception of the tubercle bacillus. Gramicidin influences some energy-using process which would normally allow carbohydrate and phosphate storage. This effect is specific, since penicillin and sulfanilamide do not have the same effect upon the phosphate metabolism of staphylococci. On the other hand, like many surface detergents, tyrocidine modifies the surface of the bacterial cell in such a manner that vital soluble metabolites, such as nitrogen compounds, inorganic phosphate, and phosphate esters are washed out of the cell. Hotchkiss (449) concluded that although tyrothricin and its constituents are more active against gram-positive than gram-negative organisms, Neisseriae respond more like gram-positive 
cocci, and gram-positive, spore-forming bacteria are insensitive to gramicidin; tyrocidine has more activity against gram-negative organisms and is more bactericidal, whereas gramicidin is primarily bacteriostatic.

Tyrocidine destroys immediately and irreversibly the metabolic activity of the bacteria, such as oxygen uptake and acid production. For most tissue cells, with the exception of spermatozoa, gramicidin is much less toxic than tyrocidine. It behaves like a specific inhibitor of certain metabolic reactions. It retains much of its activity in vivo.

Tyrocidine brings about rapid cytolysis of the cells. There is a quantitative relation between the concentration of the antibiotic and the number of cells lysed, namely $\mathrm{I} \mathrm{mg}$. for $10^{9}$ and $0.1 \mathrm{mg}$. for $10^{8}$ cells. The amino acid decarboxylases are not inhibited even by concentrations of tyrocidine of $0.3 \mathrm{mg} . / \mathrm{ml}$. (309).

\section{Other Antibiotics from Spore-forming Bacteria}

The other antibiotic substances isolated from spore-forming bacteria are characterized by bacteriostatic spectra quite different from that of tyrothricin. This is brought out in Table 37. Some of these substances,

TABLE 37. COM PARATIVE ANTIBIOTIC SPECTRA OF SUBSTANCES PRODUCED BY AEROBIC SPORE-FORMING BACTERIA

\begin{tabular}{lccc}
\hline \multicolumn{1}{c}{ TEST ORGANISM } & BACILLIN & SUBTILIN & SIMPLEXIN \\
S. aureus & 1.0 & 1.0 & 96.0 \\
M. conglomeratus & 2.0 & 1.0 & - \\
D. pneumoniae III & 3.0 & - & 0.4 \\
S. paratyphi & 0.25 & 10.0 & 96.0 \\
Pasteurella sp. & 1.0 & - & 0.4 \\
E. coli & 2.7 & 10.0 & 2.7 \\
E. typhosa & 1.4 & 10.0 & 2.7 \\
\hline
\end{tabular}

From Foster and Woodruff $(284)$.

Note. Unit of activity is the amount of antibiotic required to inhibit $S$. aureus as test bacterium.

like subtilin, are capable of destroying various bacterial toxins, such as diphtheria, tetanus, and others, as well as hemolysin (759).

Subtilin was found to be similar to gramicidin in its effect upon surface tension, in producing hemolysis, even if more delayed, in killing 
Entamoeba histolytica in I :400,000 dilution, and in cytolyzing T. equiperdum in $\mathrm{I}: 2,000$ dilution (20). Extracts of cells of $B$. subtilis with ether or chloroform in an acid medium $\left(p \mathrm{H}_{2.5}\right)$, redissolved in an

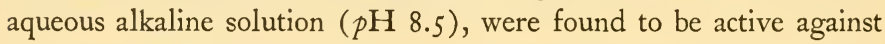
staphylococci, E. coli, and $M$. tuberculosis (693).

\section{Penicillin}

In his first description of penicillin, Fleming recorded (26I) that "it was noticed that around a large colony of a contaminating mould the staphylococcus colonies became transparent and were obviously undergoing lysis." Penicillin was referred to by Fleming as a bactericidal agent and the conclusion was reached that it belonged to the group of slow-acting antiseptics, since staphylococci were completely killed only after an interval of $4 \frac{1}{2}$ hours, even in a concentration 30 to 40 times that required for complete inhibition of the culture in broth. Florey and Florey (275), however, concluded, as a result of in vitro experiments, that penicillin is bacteriostatic and not bactericidal, at least in concentrations suitable for chemotherapeutic purposes. This led Garrod to state that "penicillin is in a true sense an antiseptic rather than a germicide: it does not kill bacteria quickly." The action of penicillin was found to be affected by changes in temperature, reaction of the substrate, and age of the bacterial culture $(320,321)$.

In addition to its marked bacteriostatic effect, penicillin has also been found to be decidedly bactericidal; this is accelerated by an increase in temperature from $4^{\circ}$ to $42^{\circ} \mathrm{C}$. but is impaired by an increase in acidity of medium between $\mathrm{pH} 7.0$ and 5.0. The rapid drop in the number of bacteria within the first I 5 minutes after application of the penicillin was interpreted (594) as indicative of its bactericidal action in vivo. Young cells are particularly susceptible, whereas mature cells are neither lysed nor readily killed. The bacteriolytic action of penicillin upon sensitive organisms is greatest at the maximum rate of multiplication $(507,5$ I 2$)$. The lysis of bacteria by penicillin depends upon their ability to produce autolysin. Bacteria are resistant to the lysin when living and become sensitive to it after the cells have been killed by penicillin or by other agents. The rate of bacteriolysis is thus controlled by bacterial multiplication and production of autolysin (913). 
Penicillin is markedly sporicidal against sensitive organisms; this action is greater in milk than in water, especially if preceded by sublethal heating of the spores ( 162 ). Penicillin is active against spirochetes (399), including Treponema pallidum $(225,296)$.

Penicillin is thus found to be actively bactericidal in a medium and an environment in which active multiplication of the bacteria occurs, since it acts best in good culture media such as broth or serum and poorly in water or saline solutions. Although penicillin kills large numbers of sensitive bacteria, it does not always kill all the bacteria present, but leaves a few cells that are resistant to its action. These soon begin to multiply, giving rise to a resistant culture.

Penicillin affects a metabolic function of the bacteria during the early stages of their development. Certain antibacterial substances, like helvolic acid, neutralize the effect of penicillin on the bacteria, whereas others, like sulfanilamide, have a synergistic effect. The latter is especially well marked with strains of staphylococci that are naturally resistant to penicillin ( $12 \mathrm{I}$ ).

Although penicillin is active primarily on gram-positive bacteria, it also has an effect on certain gram-negative bacteria, but not on the colon organism, Hemophilus, or Brucella. The gram-negative cocci can be divided into two groups, on the basis of their sensitivity to penicillin: $N$. gonorrhoeae, $N$. intracellular, and $N$. catarrhalis, which are sensitive; and $N$. flava and other nonpathogenic Neisseriae, which are not sensitive.

Some species of Hemophilus, such as $H$. ducreyi, are as sensitive to penicillin as is $S$. aureus, although less so than $S$. hemolyticus (659). High potency preparations of penicillin were found (43I) to have an inhibitive effect even on $E$. coli. The susceptibility of gram-negative bacteria to penicillin is much greater in synthetic than in complex organic media; in the case of the latter, various polypeptides and possibly some amino acids appear to neutralize the effect of penicillin upon $E$. coli, the antagonism being partly removed by methionine $(852)$. In studies on the effect of penicillin on bacteria in urine, it was shown (4.02) that 90 times the dose required to eliminate $S$. aureus will affect $S$. faecalis, 240-fold increase will act on $P$. vulgaris, and 90o-fold will act on $E$. coli (880). Although Salmonella strains were inhibited by 
only 2 units of penicillin per I ml. and $P$. vulgaris, E. typhosa, Shigella, Escherichia, and Aerobacter showed even greater resistance, it was still believed that concentrations of penicillin in the urine can be attained to inhibit the growth of these organisms (904).

Penicillin is not active against pathogenic fungi, the growth of which may actually be stimulated by this antibiotic. However, it has some activity against $A$. bovis, the growth of which was inhibited by $0.0 \mathrm{I}$ O.U./ml. (496), and against certain other actinomycetes (I93).

Various forms of penicillin differ in their action upon specific bacteria. Welch et al. (998) have shown that penicillin $\mathrm{X}$ is more effective than commercial penicillin against certain bacteria but not against others, not only in the test tube but also in the animal body. These results have been confirmed, as shown in Table 38. S. aureus and B. subtilis are more sensitive to penicillin $\mathrm{G}$ than to $\mathrm{X}$, on a weight basis; however, penicillin $\mathrm{X}$ is more effective than $\mathrm{G}$ on certain other bacteria.

TABLE 38. INHIBITION OF GROWTH OF DIFFERENT BACTERIA BY TWO FORMS OF PENICILLIN (MICROGRAMS OF PENICILLIN PER ML)

\begin{tabular}{|c|c|c|c|}
\hline & & & $\begin{array}{c}\text { RATIO } \\
\text { G }\end{array}$ \\
\hline ORGANISM & PENICILLIN G & PENICILLIN $\mathrm{X}$ & $\mathbf{x}$ \\
\hline S. oureus & .040 & .060 & 0.7 \\
\hline B. subtilis & .059 & .098 & 0.6 \\
\hline Pneumococcus Type I & .019 & .016 & 1.2 \\
\hline Pneumococcus Type II & .007 & .005 & 1.4 \\
\hline Streptococcus Group D & 2.400 & 1.700 & 1.4 \\
\hline Streptococcus Group B & .120 & .066 & 1.8 \\
\hline Streptococcus Group A & .010 & .006 & 1.7 \\
\hline Er. rhusipathiae & .097 & .049 & 2.0 \\
\hline E. coli & 81.000 & 46.900 & 1.7 \\
\hline
\end{tabular}

From Libby and Holmberg (568).

Note. Unit of activity calculated on the basis of 1,650 units $/ \mathrm{mg}$. for pure penicillin $\mathrm{G}$, and $\mathrm{I}, 000$ units/mg. for pure penicillin X.

Different strains of the same organism show marked variations in their sensitivity to penicillin. For example, a study of 40 strains of hemolytic $S$. aureus isolated from patients in an Army hospital (725) gave a range of sensitivity from complete tolerance of $4 \mathrm{O} . \mathrm{U} . / \mathrm{ml}$. to 
inhibition by $0.0020 . \mathrm{U} . / \mathrm{ml}$. More than 40 per cent of the strains thus isolated could be called resistant; this was especially true of the strains isolated from patients who received penicillin.

The oxygen uptake of suspensions of staphylococci was not inhibited to any extent by the action of penicillin for 3 hours. In a concentration of $\mathrm{I}: \mathrm{I}, 000$, after incubation for 24 hours at $37^{\circ} \mathrm{C}$., the bacteria gave larger numbers of colonies on plating (5). Although o.or to o.r mg. of penicillin per milliliter was found $(432-437)$ to be sufficient to inhibit the growth of $2,500,000$ hemolytic streptococci (Group A), no conclusion could be reached as to whether its action is truly bactericidal or merely bacteriostatic.

Penicillin inhibits fibrinolysis by sensitive strains of $S$. pyogenes; this phenomenon is believed to be connected with growth inhibition (183).

A comparison was made of the amounts of crude penicillin and gramicidin required to bring about total inhibition of growth of bacteria, on the basis of micrograms per milliliter of culture medium (rabbit's plasma and a serum extract of chick embryo). The results were as follows:

Penicillin Gramicidin

$\begin{array}{lrr}D . \text { pneumoniae } & 2.5-5.0 & 0.5-1.0 \\ \text { S. pyogenes } & 2.5 & 5.0 \\ \text { S. salivarius } & 20-40 & 2.5-60 \\ \text { S. faecalis } & 200^{*} & 40-60 \\ \text { S. aureus } & 2.5-10 & 300^{*}\end{array}$

* Inhibition not complete at these figures.

The two substances appeared to be as effective against bacteria in cultures containing growth tissue as in cultures in which no tissue was present $(394,395)$.

Inhibition of growth of 2 to 4 million hemolytic streptococci was obtained by the use of $0.03 \mu \mathrm{g}$ penicillin with an activity of 240 to 250 O.U./mg. (432, 437). No inhibition was obtained with peptone, p-amino-benzoic acid, blood, or serum. The fact that both penicillin and sulfonamides act upon some bacteria and are ineffective upon others suggests a similarity in their mode of action (648). A marked difference was found, however, in the action of penicillin and sulfonamides, 

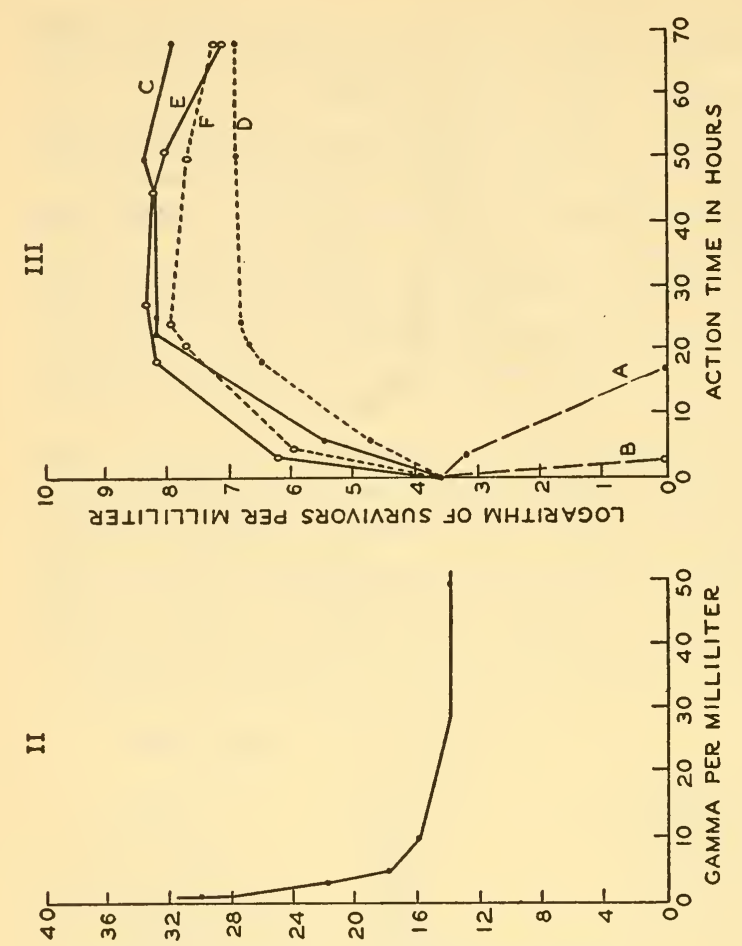

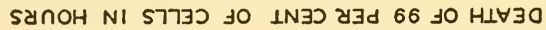

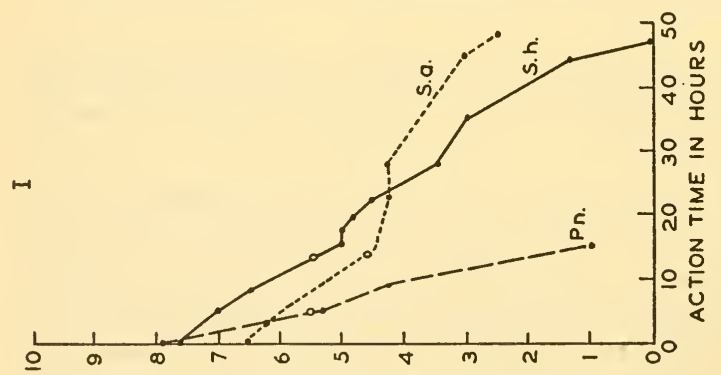

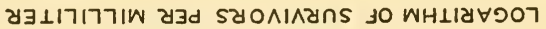

ミ

流

ริ

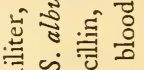

灵宅 范

¿ 2 .

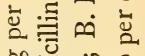

bo

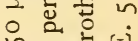

넹혀 떠

ఏ出.芯

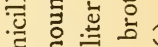

घี ఏ

- bo 元 寸

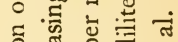

.

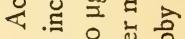

⺊

ن पू

었 뇌

.들 되 음

䒿四 苍

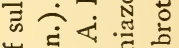

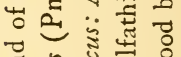

चี

. $0 \overrightarrow{0} \dot{0} . \Xi$

일

है

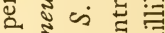

फू ठี ठี

ฮี ฮี

岇. त् क क

.

苂

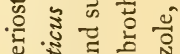

芩

ต

त क न

ง 4.7 .5

ब के है

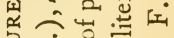
它 
the latter merely decreasing the rate of multiplication and the former actually bringing about a decrease in the number of organisms present. This is shown in Figure 22. The rates of activity of penicillin, gramicidin, and tyrocidine are compared in Table 35 (p. 220). The bactericidal action of penicillin is greatly influenced by the age of the culture, young cultures being readily killed whereas older cultures are only little affected. No penicillin is absorbed or destroyed by the bacteria.

Penicillin is not very stable (760). It is sensitive to reaction and temperature changes. The effect of reaction upon the stability of penicillin is shown in Figure 23. The thermostability of pyrogens and their removal from penicillin preparations are also important (996).

Para-amino-benzoic acid and sulfapyridine were found to have a synergistic effect on penicillin. A solution of sodium penicillin with I,200 units per milliliter gave roo $B$. subtilis units in a synthetic casein

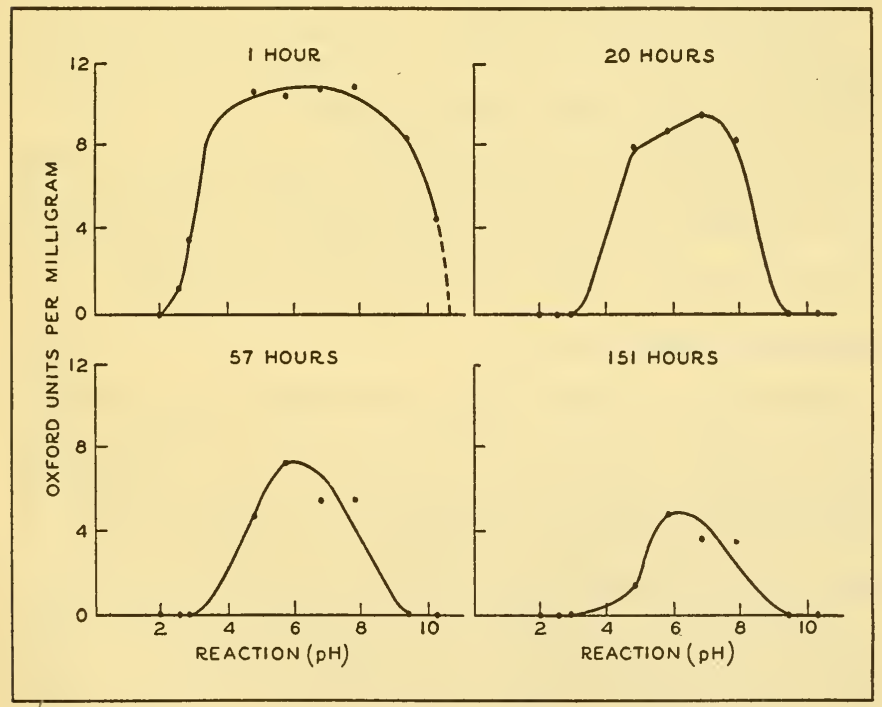

FIGURE 23. Inactivating effect of reaction upon penicillin. From Foster and Wilker (283). 
hydrolyzate medium; the activity was increased to 6,000 by addition of $p$-amino-benzoic acid in dilution of $\mathrm{I}: 2,500$ to $\mathrm{I}: \mathrm{I0}, 000$; this was also true in presence of glucose in test medium. A similar, although somewhat lower, increase took place with $S$. aureus; no effect was obtained with $S$. hemolyticus. The addition of a dilute solution of sulfapyridine, which in itself had little inhibiting effect, exerted an even greater synergistic action upon penicillin. This effect was exerted not only in vitro but also in vivo (92 I).

Various gram-negative bacteria have been found to be susceptible to penicillin in a medium devoid of amino acids; the action of these apparently consists in neutralizing the action of penicillin upon these bacteria (43I). Various bacteria are capable of producing penicillin-destroying or penicillin-inhibiting substances. Penicillinase is an enzyme; it is produced by $E$. coli and other bacteria; it is inactivated by heat and at $p \mathrm{H} 3.0$ and 9.0. Anti-penicillin is not an enzyme; it is produced by B. subtilis (715a); it is heat stable.

The ability of penicillin to destroy the bacteroids in cockroaches was interpreted (95) as indicative of the fact that these bacteroids are not parasitic but rather symbiotic microorganisms.

Penicillin was also found (409) to be able to inhibit the rate of cell division of fertilized sea urchin eggs when used in concentrations of 250 to 2,500 O.U./ml. It inhibits the adsorption of methylene blue on activated charcoal, in concentrations as low as IOo O.U. $/ \mathrm{ml}$.

\section{Streptothricin and Streptomycin}

Streptothricin and streptomycin are active against both gram-positive and gram-negative bacteria, although they differ in antibiotic spectra and in toxicity to animals. They are soluble in water but insoluble in alcohol and other organic solvents. Both have an optimum reaction at pH 8.0, and both are repressed by glucose and by acid salts. Both are stable compounds and are highly resistant to the action of microorganisms. However, the two substances can be differentiated in their relation to cysteine. Streptomycin becomes inactivated by the addition of 3 to 5 mg. of this compound to $100 \mu \mathrm{g}$ of the antibiotic, whereas streptothricin is not affected by it ( 179 ).

The antibacterial activity of streptomycin can be largely or com- 
pletely neutralized or antagonized by various chemical agents. These include glucose and certain other sugars, an anaerobic environment, certain sulfhydryl compounds, and ketone reagents. In some cases, as in the action of sugars or the anaerobic environment, the effect on streptomycin may be traced to the acidity produced under these particular conditions. However, in the effect of cysteine, of cevitamic acid, and of ketone reagents the inhibition of streptomycin activity may be associated with the blocking of the active grouping in the molecule of the streptomycin. Streptomycin represents too large a molecule to explain the inactivation of its antibacterial properties by the blocking of a single group in its molecule. Until the chemistry of streptomycin is more clearly elucidated, it is difficult to present a suitable theory that would explain the various effects of streptomycin inactivation (327).

The ability of various bacteria to give rise to strains which are more resistant to the action of streptothricin and streptomycin has been definitely established. Certain strains have been obtained that are a hundred or more times as resistant to streptomycin as the original culture. Such strains are only slightly more resistant to streptothricin, and show no difference from the mother culture in their sensitivity to penicillin, clavacin, or antibiotics of spore-forming bacteria. Variations in sensitivity to streptomycin by natural strains of the same organism have also been obtained (965). This phenomenon has an important bearing upon the chemotherapeutic utilization of the material.

Streptothricin-resistant strains of $L$. casei show differences in pantothenic acid and biotin sensitivity from the susceptible parent strains (716).

\section{Actinomycin}

Actinomycin is a bacteriostatic agent, active primarily against grampositive bacteria. It is extremely toxic to animals, a factor which limits its practical utilization. One milligram of actinomycin given to mice, rats, or rabbits intravenously, intraperitoneally, subcutaneously, or orally proved (796) to be lethal for I kilogram weight of the animals. Doses as small as $50 \mu \mathrm{g}$ per kilogram injected intraperitoneally daily for 6 days caused death accompanied by severe gross pathological changes, notably a marked shrinkage of the spleen. Actinomycin is 
rapidly removed from the blood and excreted. It has no effect upon bacteriophage or staphylococci, although o. I milligram per cent inhibits growth as well as blood coagulation by these organisms (675).

A comparison of the effect of actinomycin with that of tyrothricin and its constituents, tyrocidine and gramicidin, upon the growth of rhizobia (9I7) showed that, whereas gramicidin inhibited all strains alike, the other three substances inhibited the slow-growing rhizobia much more than the fast-growing ones. Effective and ineffective strains behaved alike. Of the four antibiotic substances, tyrocidine was usually bactericidal, actinomycin was bacteriostatic, and the other two possessed both properties. Some strains of rhizobia were stimulated by limited concentrations of actinomycin.

\section{Proactinomycin}

Proactinomycin, in low concentrations, lengthens the lag phase of staphylococci, this increase in lag becoming greater in certain media as the size of the inoculum is reduced. One of the primary effects of this antibiotic is believed to be the interference with the synthesis or use of diffusible substances produced by the cells and concerned with the ending of the lag. When the concentration of proactinomycin is increased above a certain value, the effect is different: after a period of incipient growth, the cells begin to die. There is thus a qualitative similarity between the effect of proactinomycin and of penicillin (3).

\section{Clavacin}

Clavacin not only is bacteriostatic on gram-negative bacteria but also possesses marked bactericidal properties, as is brought out in Figure 24. Clavacin has an inhibiting effect upon the following respiratory enzyme systems: glucose dehydrogenase, succinoxidase, malic acid dehydrogenase, glycerophosphate dehydrogenase, and tryptophanase (379). Various animal fluids and organs (serum, liver) contain an enzyme which converts clavacin into an acid, due to the hydrolysis of the lactose ring; a marked reduction in its antibiotic action results (535). Clavacin is also active against fungi, including species of Pythium (24) and C. ulmi (949). 


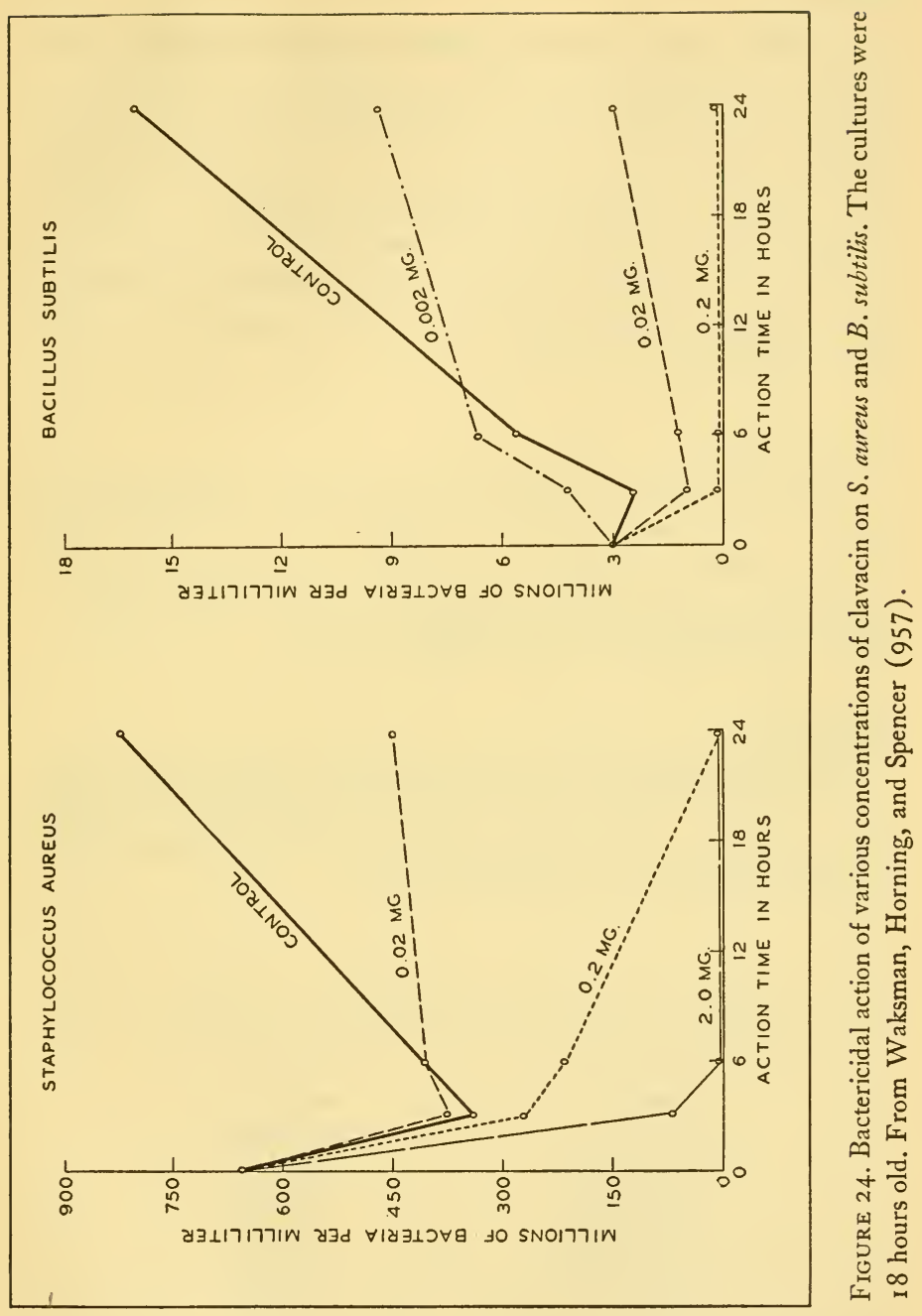




\section{Fumigacin}

Fumigacin is active only upon gram-positive bacteria and has a rather limited bactericidal effect. Its action upon tubercle bacteria has recently attracted considerable attention (27). Partially purified preparations inhibited multiplication of the human strain of $M$. tuberculosis in dilutions as high as $I$ : I,400,000. Killing effect was exerted by a dilution of I : 500,000; this was measured by incubation of a heavy suspension of the bacteria with different dilutions of the substance, incubating 24 hours, and measuring for viability. The avian type of $M$. tuberculosis was not affected.

\section{Aspergillic Acid}

Aspergillic acid is active against various bacteria, including the human strains of $M$. tuberculosis. It was suggested that its mode of action is due to interference with the utilization of iron by this organism (348). The favorable effect of cobaltous ion on the tuberculostatic action of this antibiotic has been established (349).

\section{Gliotoxin}

Gliotoxin is active against both gram-positive and gram-negative bacteria (Table 39). The substance is rather toxic to animals, the minimum lethal dose being 45 to $65 \mathrm{mg}$. per kilogram body weight; hematuria is caused by even lower concentrations (474).

TABLE 39. BACTERIOSTATIC ACTION OF GLIOTOXIN

\begin{tabular}{lr}
\hline TEST ORGANISM & ACTIVITY \\
S. aureus & $4,000,000$ \\
S. pyogenes & $1,000,000$ \\
Pneumococci & $4,000,000$ \\
S. enteritidis & 250,000 \\
A. aerogenes & 200,000 \\
$K$. pneumoniae & 250,000 \\
E. coli & 80,000 \\
\hline
\end{tabular}

From Johnson, Bruce, and Dutcher (475).

Note. Units of activity by dilution method. 


\section{Other Antibiotic Agents}

On comparing the action of citrinin with penicillic acid, the first was found (698) to act largely upon gram-positive bacteria; the second, like quinones, had a more widespread action, especially against the colon-typhoid group.

Considerable speculation has been focused upon the ability of various organisms to inhibit the growth of $M$. tuberculosis. These comprise various fungi, such as $A$. fumigatus $(27,870)$ and $P$. notatum (863), bacteria, and a number of actinomycetes including species of Nocardia and Streptomyces (83I, I029). The antibacterial action of some of these organisms is believed to be due to the formation of substances spoken of as tuberculocidins. The specific effects of some of the substances, which are now recognized, are described in detail elsewhere (pp. 294-296).

\section{BACTERIOSTATIC AND BACTERICIDAL AGENTS}

Fleming (263) divided all selective bacteriostatic agents, exclusive of the action of oxygen on anaerobic bacteria, into three groups: (a) physiological agents, including bile, serum, proteolytic enzymes, and lysozyme; (b) microbiological products, comprising the antibiotic substances; (c) chemicals of known composition, including dyes, salts (potassium, tellurite, mercuric salts), and other agents.

Most of the antibiotics are characterized not only by their bacteriostatic action but also by marked bactericidal properties, the two usually being parallel (963). Concentrations of an antibiotic substance smaller than those needed to cause inhibition often stimulate the growth or metabolic processes of the organism. In this respect these agents are similar in action to synthetic detergents and to other chemical disinfectants, as discussed previously. It may also be of interest to note here that the antibacterial action of straight-chain mono-amines and diamines, amidines, guanidines, and quaternary bases increases with the length of the chain up to a maximum and then decreases, the grampositive bacteria being more sensitive than the gram-negative organisms. Serum increases the activity of the shorter-chain compounds and decreases that of the longer-chain compounds, depending to a considerable extent upon the test bacteria (305). 
The bactericidal action of antibiotic agents, as influenced by their concentration, can be illustrated by the action of pyocyanase (Table 40). In a study of the bactericidal action of actinomycin (975) it was found that the addition of $0.5 \mathrm{mg}$. of actinomycin to a $10 \mathrm{ml}$. suspension of $E$. coli reduced the number of viable cells from $6,400,000$ to 493,000 , the methylene blue reduction test remaining positive; I $\mathrm{mg}$. actinomycin reduced the number of cells to 4,800 , the reduction test becoming negative; $2 \mathrm{mg}$. of the agent brought about complete de-

TABLE 4O. BACTERICIDAL ACTION OF PYOCYANASE UPON THREE BACTERIA

\begin{tabular}{|c|c|c|c|c|c|}
\hline \multicolumn{2}{|c|}{ B. ANTHRACIS } & \multicolumn{2}{|c|}{ E. TYPHOSA } & \multicolumn{2}{|c|}{ C. DIPHTHERIAE } \\
\hline Hours & $\begin{array}{c}\text { Bacteria per } \\
\text { milliliter }\end{array}$ & Hours & $\begin{array}{c}\text { Bacteria per } \\
\text { milliliter }\end{array}$ & Minutes & $\begin{array}{c}\text { Bacteria per } \\
\text { milliliter }\end{array}$ \\
\hline Start & I I ,060,000 & Start & $13,125,000$ & Start & $24,150,000$ \\
\hline 24 & $6,890,000$ & 3 & $1,242,000$ & 2 & I $7,850,000$ \\
\hline 72 & $1,360,000$ & 9 & 105,000 & 180 & o \\
\hline 96 & 654,000 & & & & \\
\hline 120 & 329,000 & & & & \\
\hline 144 & 0 & & & & \\
\hline
\end{tabular}

From Emmerich, Löw, and Korschun (237).

struction of all the cells. The bactericidal action of actinomycin seems to be a result of a chemical interaction similar to that of other antiseptics. On adding O.I mg. actinomycin to a suspension of $E$. coli cells in a ro $\mathrm{ml}$. buffer solution, the value of the constant $K$ was found to vary from $0.02 \mathrm{I}$ to 0.026 for different periods of incubation. Figure 25 illustrates graphically the effect of different concentrations of actinomycin on the death rate of $E$. coli in buffer solution.

Quinones have a high bactericidal power ( 153,977 ), due not to their chemical interaction with the cell proteins but to their reactivity with the simpler cell constituents such as some of the amino acids. Only a slight difference was found in the apparent activity of quinones toward yeasts, bacteria, proteins, peptones, peptides, and certain amino acids. Alcohol increases the germicidal power of the quinones. Actinomycin contains a quinone group; however, it acts differently toward gram-positive and gram-negative bacteria; alcohol has no effect upon its action, thus pointing to marked differences in chemical and biologi- 


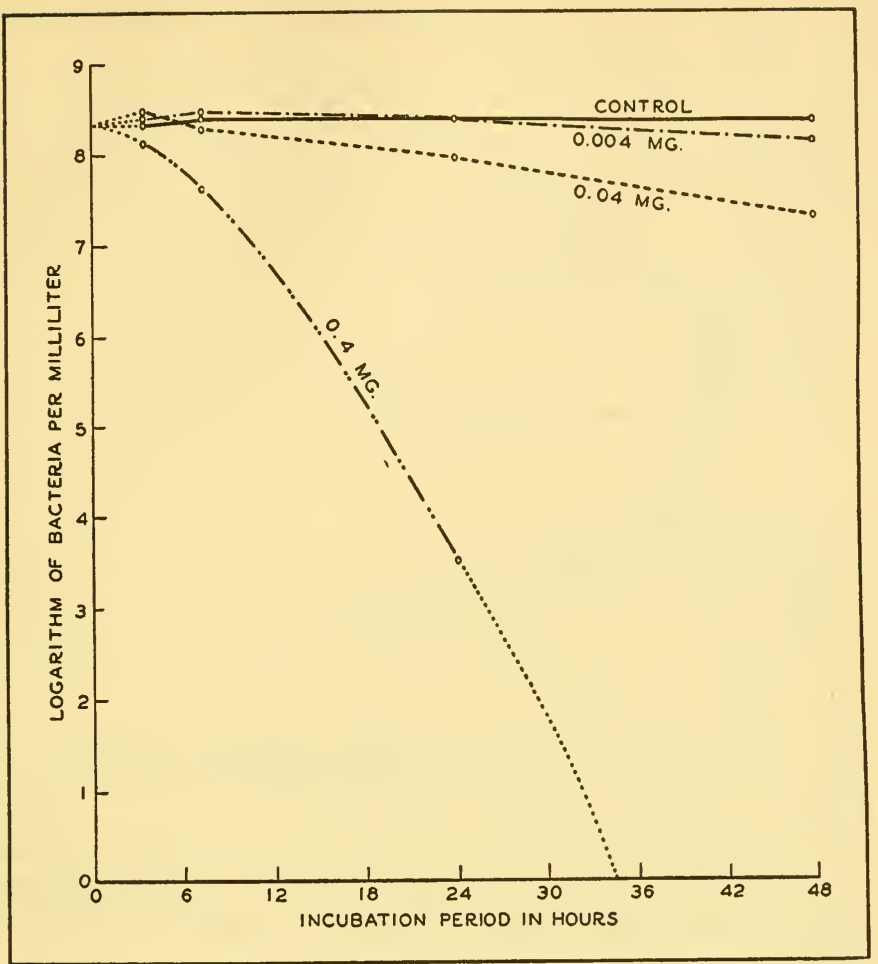

FIgURE 25. Action of actinomycin on $E$. coli; death rate in buffer solution. Amounts are given in milligrams of actinomycin per 10 milliliters of solution. From Waksman and Woodruff (977).

cal nature of this antibiotic agent and of quinones. On the other hand, many of the antibiotic substances produced by fungi are typical quinones and act as such.

By varying the concentrations of disinfectants, the types of curves of destruction of bacterial cells were found (728) to range from linear to an abrupt drop to zero at critical concentrations. This is brought out in a study of the spirocheticidal action of penicillin (Figure 26). 


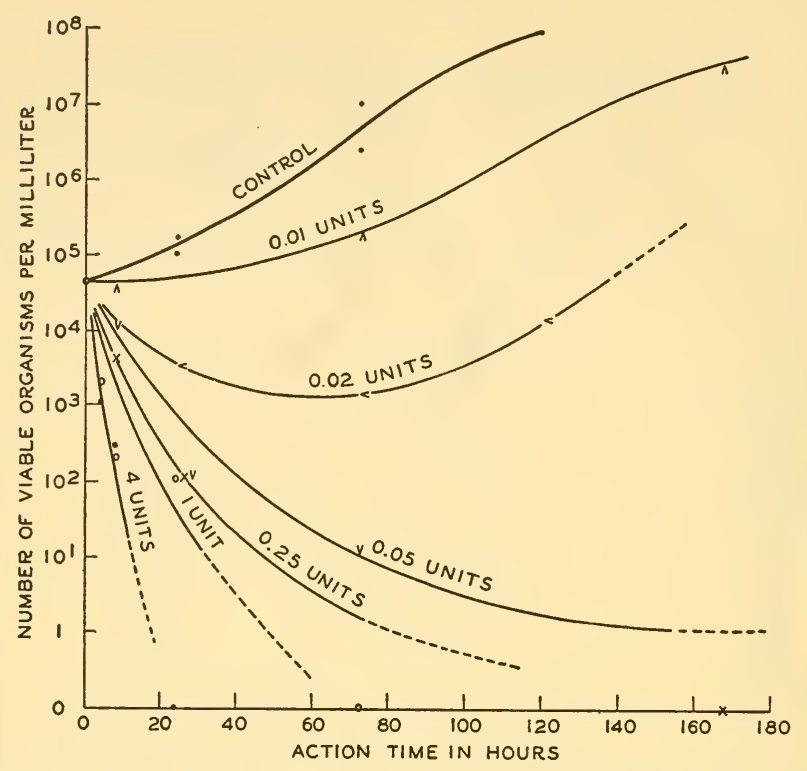

FIGURE 26. Spirocheticidal action of various amounts of penicillin in vitro. Inoculum, $4 \times 10^{4}$ organisms per milliliter. From Eagle and Musselman (225).

In general, chemical disinfectants act upon bacteria in four different ways: (a) some affect the lag phase of the growth period, (b) some influence the mechanism of cell division, (c) some influence the metabolic processes, and (d) some affect the death rate of the microbes. Similar, if not greater, variations are found in the nature of the action of antibiotic substances of microbial origin upon the bacterial cell.

Gramicidin inhibited dehydrogenase activity, since the antagonized bacteria rapidly lost their capacity to reduce methylene blue in the presence of glucose. E. coli suspension treated with actinomycin lost its capacity to reduce methylene blue before the cells were completely killed. The oxidation of succinic acid by tissue preparations, which re- 
quire the cooperation of succinic dehydrogenase and a cytochrome system, was strongly inhibited by pyocyanin. This inhibition exhibited certain interesting peculiarities: in low concentrations, pyocyanin strongly inhibited the activity of the complete succinic cytochrome system but had no effect on the oxidation of succinic acid through methylene blue; in the presence of $\mathrm{KCN}$, pyocyanin acted as an autoxidizable hydrogen acceptor similar to methylene blue; glutaminic acid did not affect the inhibitory action of pyocyanin. This inhibitory action was found to be due not to the formation of oxalacetic acid but to a direct effect on succinic dehydrogenase. The influence of pyocyanin on bacterial respiration, as well as its ability to function as an accessory respiratory enzyme, has aroused much interest $(228,302)$.

A strong lytic action of some of the antibiotic substances, similar in some cases to the action of enzymes, has also been indicated. This lytic mechanism may be a product of the antagonized cell itself. Autolysis is usually defined as the destruction of some of the essential chemical constituents of the cell by enzymes originating within the cell.

The lytic effect does not hold true, however, for most of the antibiotic substances and for most of the bacterial cells. Since the greatest bactericidal effect of penicillin occurs during the maximum rate of bacterial multiplication and since cells producing autolysin lyse rapidly it must be concluded that lysis of the cells follows the killing effect of penicillin (9I3).

Chain and Duthie ( 12 I ) called attention to the fact that Fleming recorded the slow bactericidal effect of penicillin on Staphylococcus and its lytic action only under certain conditions. The original statement by Florey, Chain, and associates that penicillin was mainly bacteriostatic was based on the fact that it did not influence the oxygen uptake of resting Staphylococcus, for large numbers of viable colonies were found after incubation with penicillin for 24 hours. Penicillin was later found to be definitely bactericidal, but not under unfavorable conditions such as low temperature or exhausted media. The bactericidal effect can be increased by substances which favor bacterial growth or decreased by substances which interfere with bacterial growth, such as sulfadiazine. During the resting phase of Staphylococcus, even large concentrations of penicillin have no effect on the oxygen uptake. However, during the 
early lag phase and the logarithmic phase of multiplication, penicillin has a strong inhibitory effect, completely stopping oxygen uptake, even in small concentrations. It was concluded that penicillin exerts a bactericidal effect on Staphylococcus before actual division occurs, or after one division during the logarithmic phase. It appears to interfere with some metabolic function of the early stages of bacterial development.

Bonét-Maury and Pérault (73), using the differential photometer, suggested that penicillin stops proliferation of $S$. aureus almost immediately and lysis follows. A second proliferation occurs regularly, followed by a second partial lysis and then a second post-lytic growth. Gardner (3I2) reported that high penicillin concentrations ( 50 to 100 O.U./ml.) slowly kill bacterial spores. $B$. anthracis spores were more susceptible than those of $B$. subtilis, although neither were completely eliminated by penicillin.

The relation between antibiotics and bacteriophage has attracted considerable attention. Gratia (353) observed a definite relation between the action of lysozyme and the liberation of bacteriophage. The action of antibiotic agents, however, is usually quite different from that of bacteriophage $(352,677)$. Filtrates of cultures of homologous bacteria are able to inactivate the anti-coli phage; at $27^{\circ} \mathrm{C}$., the inactivation is proportional to the phage and filtrate concentration; at $\mathrm{O}^{\circ} \mathrm{C}$., to the square root of the latter (23I). Based upon the formation of iso-antagonistic substances, a method has been suggested ( 132 ) for the differentiation of bacteria belonging to the typhoid group.

\section{EFFECT OF ANTIBIOTIC SUBSTANCES UPON THE MORPHOLOGY OF MICROORGANISMS}

Emmerich and Saida (238) were the first to report that anthrax bacteria undergo morphological changes as a result of the action of pyocyanase. Since that early work, the effect of bacterial filtrates upon cell multiplication and cell growth has been made the subject of many investigations. It was reported ( $38 \mathrm{I}$ ), for example, that no complete cessation of the fission process of bacteria results from the action of the substance, but that growth itself is checked, the action being nonspecific as far as bacterial species are concerned. The conclusion was reached that 



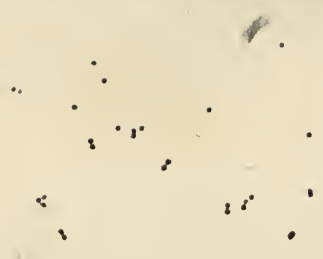

S. aureus, normal cells. Prepared by Foster and Woodruff 1

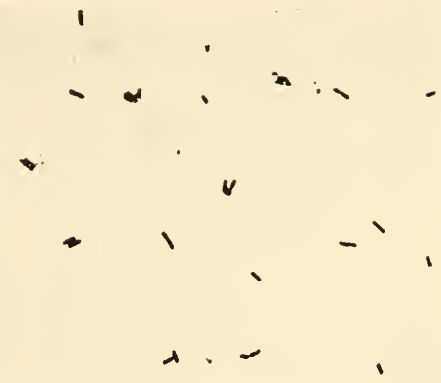

B. subtilis, normal cells. Prepared by Foster and Woodruff

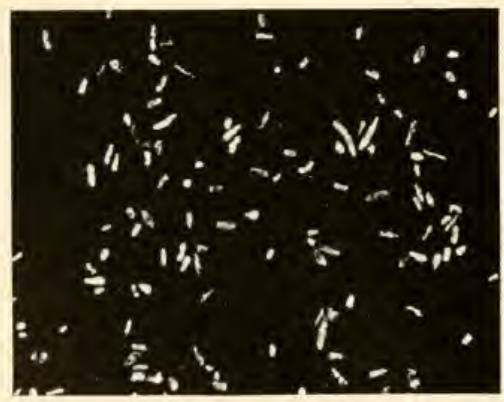

Az. vinelandii, normal cells. Prepared by Starkey

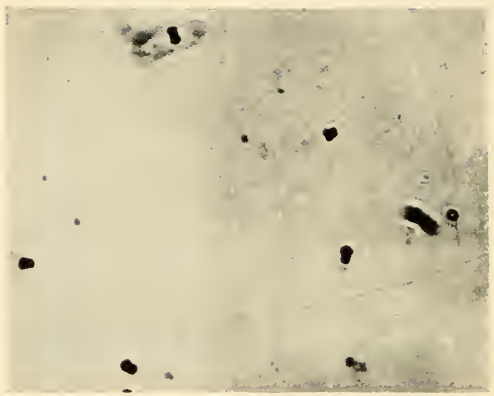

S. aureus, penicillin-inhibited cells. Prepared by Foster and Woodruff

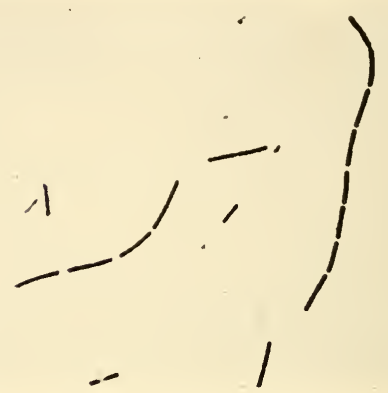

B. subtilis, penicillin-inhibited cells. Prepared by Foster and Woodruff

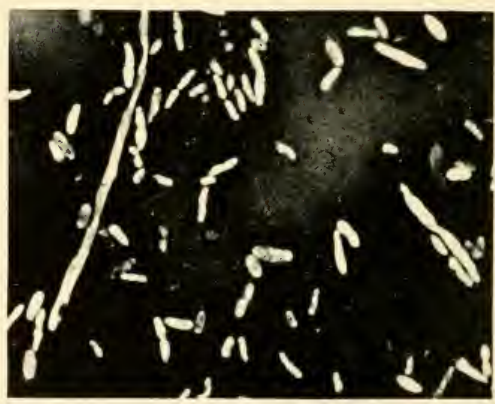

Az. vinelandï, actinomycin-inhibited cells. Prepared by Starkey

FigURE 27. Influence of antibiotic substances upon the morphology of bacteria. 
this phenomenon is due to the production and accumulation of metabolic products injurious to growth. Nonspecific antibiotic substances were demonstrated (692) in filtrates of bacteria. They not only injured growth of other bacteria but prevented the production of the ectoplasmic antigen. These substances could be partly removed by the use of adsorbents.

The morphology of bacteria is greatly influenced by the presence of other organisms or their antibiotic substances. In the case of diphtheria bacteria this is accompanied by a reduction in virulence $(4 \mathrm{r} 7)$. The specific effect of the antagonistic $B$. mesentericus upon the morphology of antagonized bacteria has also been established (73I). The antibiotic substances produced by actinomycetes were shown (76) to affect the growth of $B$. mycoides as follows: cell division is delayed; the cells become elongated, reaching enormous size and assuming most peculiar forms; spore formation or, with lower concentrations of agent, the active substance is repressed; delayed nonspore-forming variants are produced with a modified type of growth on nutrient media (Table 4I). The cells of bacteria subject to the action of streptothricin are greatly enlarged, due to incomplete fission (287, IO3I).

Gardner (3II) reported that concentrations of penicillin lower than those required for full inhibition caused a change in the type of growth of $\mathrm{Cl}$. welchii in liquid media. The majority of the cells became greatly elongated, giving rise to unsegmented filaments ten to twenty times longer than the average normal cells. The same was found to be true of a number of other bacteria (Figure 27). Even gram-negative bacteria, which are relatively resistant to penicillin, showed the same effect. Many bacteria produced giant forms as a result of the autolytic swelling and bursting of the elongated cells. It was recognized that these changes were due to a failure of fission. Cell growth not accompanied by cell division underwent autolysis. Br. abortus and Br. melitensis, which were not inhibited by penicillin even at $\mathrm{I}$ : I,000 dilution, gave no enlargement of the cells but showed vacuolation even in lower dilutions. $\mathrm{Cl}$. welchii, which was inhibited by $\mathrm{r}: 60,000$ penicillin, showed filament formation in a dilution of $I: I, 500,000$. These observations were fully confirmed. All sensitive bacteria were shown (9r3) to undergo lysis to a greater or less extent in cultures containing peni- 
NATURE OF ANTIBIOTIC ACTION

TABLE 4I. INFLUENCE OF CULTURE FILTRATE OF STREPTOMYCES SP. ON MORPHOLOGY OF BACILLUS MYCOIDES

\begin{tabular}{ccccc}
\hline & MORPHOLOGY OF & MACROSCOPIC & & \\
DAYS OF & ANTAGONIZED & GROWTH IN & SPORE & ROD \\
INCUBATION & BACTERIUM & BROTH & FORMATION & FORMATION
\end{tabular}

MEdium PLUS IO PER CENT CULTURE FILTRATE

$\begin{array}{lllll}2 & \text { Long filaments } & \text { x } & - & + \\ 4 & \begin{array}{l}\text { Filaments have divided } \\ \text { into elongated cells }\end{array} & \text { x } & - & + \\ 45 & \begin{array}{l}\text { Cells altered } \\ \text { Cell fragments of vari- } \\ \text { ous shape and length }\end{array} & \text { x } & - & +\end{array}$

Medium plus 5 Per Cent CUlture filtrate

$\begin{array}{rllll}2 & \text { Elongated cells } & \mathbf{x} & - & + \\ 4 & \text { Elongated cells } & \mathbf{x} & - & + \\ 17 & \text { Greatly deformed cells } & + & - & + \\ 45 & \text { Greatly deformed cells } & + & - & +\end{array}$

Control medium

\begin{tabular}{rrrrr}
2 & & $H$ & - & + \\
4 & & $H$ & + & + \\
17 & & $H$ & + & + \\
45 & Deformed cells rare & + & + & - \\
\hline
\end{tabular}

From Borodulina $(76)$.

$x$ indicates growth of $B$. mycoides in the shape of fluffy small balls inside liquid.

cillin. Before lysis, the culture becomes more turbid, thus pointing to the fact that multiplication is essential before death or lysis of the cells.

The phenomena of swelling and lysis were said (86I) to be associated with the active growth of the bacterial cell. Suspensions of fully grown bacterial cells showed neither of these effects when added to concentrations of penicillin many times higher. It was suggested that penicillin either has some action on the cellular wall of $S$. aureus or that it interferes with the assimilation of one or more growth factors necessary for the fission of the growing cell.

In a study of the effect of penicillin on bacterial spores, Gardner (3I2) observed that the spores gradually lose their high refractivity and become empty ghosts. Weaker concentrations of penicillin allow the germination of the spores to occur, the spores swelling up and be- 
coming spherical coccoids which burst; in the case of some bacteria, not all the spores are killed; however, the great majority of them become nonviable. In non-nutrient media the spores are little affected, even by strong concentrations of penicillin. The conclusion was reached, therefore, that the action of penicillin on sensitive bacteria has little or no connection with multiplication or division, although some abnormal divisions were observed in certain sensitive organisms. The majority of $S$. aureus and $S$. pyogenes growing on agar are checked or killed before any visible growth or division has occurred.

A growth-depressing substance, which altered the type of growth of both fungi and bacteria, was also isolated ( I5I) from yeast. Fungi treated with this substance produced thick gnarled mycelia and formed no conidia or pigment. Increasing the concentrations of the depressing agent changed the nature of the colony of $E$. coli from smooth to rough and finally to grainy; this was associated with an increase in the length of the cell and the formation of filaments. When the cultures thus modified were placed in media free of the agent, normal, highly motile cells were again produced.

The mechanism of disintegration of the hyphae of a plant pathogenic fungus $R$ hizoctonia by an antagonistic fungus Trichoderma as well as by the antibiotic product of the latter has been described by Weindling (989). The hyphae are usually killed in less than io hours, as shown by loss of the homogeneous appearance of the protoplasm and of the vacuolate structure of the hyphae, which become empty or appear to be filled with granular material. This is brought out in Figure 29, p. 302.

\section{ANTIBIOTIC SUBSTANCES AND THE PHYSIOLOGY OF THE BACTERIAL CELL}

Half a century ago Smith (867) emphasized that bacteria growing in mixed cultures undergo temporary and even permanent physiological modifications. Aside from cell proliferation, the important metabolic processes commonly considered to be affected by antibiotic agents were oxygen uptake, acid production, and dehydrogenase activity. Some agents apparently can inhibit cell growth without destroying the viability of the cells and their capacity for taking up oxygen. 
Gramicidin and tyrocidine were believed to affect bacteria by depressing the surface tension of aqueous solutions. This effect was favored by the addition of organic solvents such as glycerin, which increases the solubility of gramicidin. The addition of serum resulted in a decrease in activity of tyrocidine, to a less extent, however, than of gramicidin. Heat destroyed the bacterial and hemolytic effects of gramicidin, but the property of altering surface tension was heat-stable. It has further been shown (405) that gramicidin, after an initial stimulation, inhibited oxygen consumption of bovine spermatozoa and rendered them immobile; aerobic as well as anaerobic glycolysis was depressed by about 40 per cent and motility of the spermatozoa impaired. Tyrocidine, however, caused a small reduction in the oxygen consumption and in glycolysis. The action of gramicidin upon the metabolic activities of $S$. aureus and $S$. hemolyticus was shown (210) to be influenced by the composition of the medium, the presence of potassium and phosphate ions giving a prolonged stimulation of metabolism, whereas ammonium ions favored a depression in oxygen uptake.

The specific effects of basic proteins, such as protamine and histone, upon the activity of selective inhibitors offered a possible explanation for the difference in the action of tyrothricin upon gram-positive and gram-negative bacteria (645). These basic proteins also possess antibacterial properties. They have the capacity of sensitizing gram-negative bacteria by means of substances which otherwise act only on grampositive forms.

Pneumococci grown in media containing the specific enzymes which hydrolyze their capsular material are deprived of these capsules and fail to agglutinate in the specific antiserum. The enzymes do not interfere with the metabolic functions of the cells, but their action is directed essentially against the capsule. These enzymes were found not only to exhibit great selectivity but to be highly specific against the particular polysaccharides.

The respiratory enzymes of bacteria, such as $S$. aureus, that are sensitive to citrinin were found (643) to be inhibited by this antibiotic, but not the corresponding enzymes of resistant bacteria, such as $E$. coli.

The possible interference of penicillin with the metabolism of bacteria has attracted considerable attention due to the great practical im- 
portance of this antibiotic. The effect was believed to involve the metabolism of nucleotides and nucleic acids (530). Penicillin had no effect on the release of glucose from polysaccharides or on the oxidation of glucose or pentose to acetic acid. However, when yeast sodium nucleinate was added to a suspension of cells, a rate curve was obtained which was similar to the endogenous curve; the acceleration appeared two to four hours earlier, and the maximum oxidation was higher and was maintained for a longer period. Penicillin was completely inhibitory to this reaction.

\section{INHIBITION OF BACTERIOSTATIC AND BACTERICIDAL ACTION}

The formation of specific chemical compounds capable of inhibiting, inactivating, or even destroying bacteriostatic and bactericidal substances of microbial origin has been established for a number of antibiotic agents.

Yeasts were found to contain a substance which inhibits the action of sulfanilamide against $S$. hemolyticus as well as other streptococci and pneumococci. This substance has been identified with the $p$-amino-benzoic acid referred to above. $B r$. abortus and certain other bacteria also contain (360) a factor, designated as "p," which specifically inhibits the bacteriostatic action of sulfanilamide. This factor stimulates markedly the growth of many bacteria, and is not specific. The sensitivity of sulfanilamide depends on the rate of release of the factor from the bacterial cell and not on the total amount produced. This factor was believed to stimulate some enzyme reaction concerned with bacterial reproduction, whereas sulfanilamide inhibits this reaction. Similar factors have been isolated from other microorganisms.

To what extent antibiotic substances can be inhibited in their action against bacteria still remains to be determined. Certain few facts have so far been established.

Bacteria not inhibited by penicillin were found (4, 570, 1027) capable of producing a substance which destroys the growth-inhibiting property of the antibiotic. The substance is enzymatic and was designated as penicillinase. It is produced by various bacteria, especially members of the $B$. subtilis $(22 \mathrm{I}, 922)$ and $E$. coli groups. It is precipi- 
tated from the medium with acetone, alcohol, dioxane, sodium tungstate, and saturated ammonium sulfate solution. Highly purified preparations have been prepared from $B$. cereus, I mg. of the product destroying completely I 65,000 units of crystalline penicillin in 3 hours at $p \mathrm{H} 7.0$ and $30^{\circ} \mathrm{C}$. (44). In a dry state, penicillinase is thermostable; in solution, it is more readily inactivated by heat. In a purified state, it is labile; at $45^{\circ} \mathrm{C}$., 66 per cent of it is destroyed in 20 minutes and 95 per cent in an hour (6I I). The inactivation of penicillin by penicillinase is accompanied by the evolution of $\mathrm{CO}_{2}$ from the bicarbonate in solution, thus pointing to acid formation (279). The optimum $\mathrm{pH}$ for the action of the enzyme is between 8.0 and 9.0.

Penicillinase can be utilized for the purpose of testing the sterility of penicillin preparations (550). The penicillin, which would otherwise cause inhibition of growth of the contaminating organism in the test medium, is destroyed by the enzyme previous to the test. There is no apparent relation between the resistance of an organism to penicillin and its ability to produce penicillinase ( 1027 ).

Certain bacteria, as $E$. coli, produce a thermostable fungistatic factor which must be differentiated from penicillinase; the effect of this factor consists in reducing the rate of growth of the fungus, rather than in destroying the penicillin (I009).

Bacterial extracts, pus fluids, peptone, and p-amino-benzoic acid, which interfere with the action of sulfonamides, do not affect penicillin.

Cephalin and extracts of gram-negative bacteria, of milk, and of blood serum were found to inhibit the action of gramicidin. Because of this, cephalin is capable of reviving bacterial cells killed with gramicidin. This phenomenon is similar to the inhibition by phospholipins of the action of synthetic detergents upon bacterial metabolism. Mucin inhibits the action of tyrothricin, especially on meningococci and pneumococci ( 192 ).

Tannic acid is able to neutralize the antibiotic action of actinomycin. Humus compounds of the soil have a similar capacity. This effect was believed to be responsible for rendering harmless, to living plant and animal forms, the actinomycin produced in the soil (976). Ascorbic acid also has an effect in reducing the activity of this substance. Since vitamin $C$ is a strong reducing agent and actinomycin is a reversible 
oxidation-reduction system, it is conceivable that actinomycin may be reduced through the action of the vitamin. Such an effect should be greatly increased under anaerobic conditions, where no reoxidation due to atmospheric oxygen could occur. Twenty-five to 50 times as great a neutralizing effect of ascorbic acid upon actinomycin was obtained under anaerobic conditions with $\mathrm{Cl}$. butyricum as a test organism as under aerobic conditions with $B$. mycoides. Reduced actinomycin was inactive. It was concluded, therefore, that the neutralizing action of ascorbic acid upon actinomycin was due merely to its reducing properties. As far as the common growth factors are concerned, the action of actinomycin, like that of penicillin, differs from the mechanism proposed by Woods (IO32) and others for sulfanilamide inhibition.

Among the phenomena of inhibition of antibiotic substances, the action of cysteine offers some important practical applications. This substance inhibits the antibacterial action of penicidin (29), penicillin, citrinin, gliotoxin, clavacin, pyocyanin ( I I6), and streptomycin (327). It was suggested that this is due to the fact that the mode of action of certain antibiotics involves their ability to interfere with the normal functions of the sulfhydryl groups in bacterial metabolism. The rate of inactivation of penicillin was found ( 136 ) to be dependent on the concentration of penicillin and on the $\mathrm{pH}$ of the medium; since thioglycolic acid was somewhat less effective and other amino acids, like cystine and methionine, had no effect, it was suggested that the process of penicillin inhibition involves both the sulfhydryl and the amino groups of cysteine. Since I mg. of cysteine was sufficient to inactivate about 270 to 4 IO O.U. of penicillin, it was suggested (423) that advantage be taken of this fact in testing for sterility of penicillin preparations.

\section{ADAPTATION OF BACTERIA TO ANTIBIOTICS}

Different strains of bacteria vary greatly in their susceptibility to the same antibiotic substance (75). This is true particularly of penicillin (267) and streptomycin (965). By growing an organism in media containing increasing concentrations of the antibiotic, more resistant strains can be obtained. The rate and degree of acquired resistance vary for each antibiotic. For example, certain bacteria showed no resistance to 
aspergillic acid, slight resistance to gliotoxin, and marked resistance to penicillin, streptomycin, and pyocyanin; resistance was attained more rapidly and was lost more slowly for streptomycin. An increase in resistance to one did not affect the sensitivity to other antibiotics ( $5 \mathrm{IOa}$ ).

The resistance of staphylococci to penicillin, or penicillin-fastness, was found to be reversible; strains were shown to change frequently to the sensitive state when they were cultured in antibiotic-free media. It has even been suggested that the reversion may be more rapid in vivo than in vitro (914). Strains of staphylococci possessing increasing resistance to penicillin were isolated from infections treated with this substance (756).

In a study of I I 5 strains of staphylococci, I 3.9 per cent proved to be resistant to penicillin; the resistant strains produced penicillinase, but not the susceptible ones ( 72 ). Of 128 strains collected from various sources before the advent of penicillin treatment, 123 were inhibited by one-eighth unit or less of penicillin per ml., 2 were inhibited by onefourth unit, and 3 by half a unit. The 5 strains showing slightly increased resistance were nonpathogenic. Thirty-one strains from hospital wards in which penicillin had been used extensively, particularly in local application to wounds, were found to be largely penicillin resistant. These strains showed no cultural differences from normal strains. Whether they developed from sensitive parent organisms in the same wound or were the result of cross infection, either from carriers or air borne, was not determined (682). When staphylococci were made resistant to penicillin by cultivation in penicillin-containing medium, this acquired resistance or "fastness" was lost when the cultures were grown in plain medium. Pneumococci, however, acquired resistance less readily and maintained it even when subcultured in plain media (9I4). Patients treated with penicillin gave a much larger proportion of resistant strains of $S$. aureus than patients not so treated (725).

Bacterial cells that have become adapted to resist the action of a particular antibiotic substance are not resistant to the action of others. However, bacteria "trained" to resist one substance may also acquire resistance to another by a process of adaptation. This was brought out by Davies et al. ( 170 ) in studies on sulfonamides and proflavine. Adaptation of bacteria to an antibacterial agent has been explained as follows: 
I. By natural selection from an initially heterogeneous population. This concept, however, has lost much support, since variations have been found to occur in strains derived initially from a single cell.

2. By actual modification of the individual cells. This may be due (a) to the establishment in the cells of a mechanism alternative to that normally in use or (b) to the quantitative modification of existing mechanisms.

3. By a change in some center of organization of the cell.

Demerec (I77) suggested that the development of strains of $S$. aureus resistant to penicillin is due to the formation of mutants, the nonresistant cells being eliminated by the penicillin. The degree of resistance can be increased by exposure to larger doses of the antibiotic; this increase was considered to be a summation of several independent genetic factors for resistance which undergo considerable mutation. Resistant strains retained that property after many transfers.

There are apparently several mechanisms whereby organisms such as staphylococci develop resistance to penicillin. One consists in the development of a penicillin inhibitor; in other cases, however, no inhibitor can be demonstrated (7I7).

The adaptation of staphylococci to mycophenolic acid is not an easily reversible phenomenon, thus suggesting that the adaptation consists in the development of an alternative mode of growth, comprising a modification of the enzyme systems of the bacteria (2). The ending of the lag of growth of $S$. aureus is due to a diffusible growth intermediate produced by the cells; the primary action of the antibiotic consists partly in hindering the utilization of this substance. The effect of the antibiotic consists in a failure of the dividing cells to separate in the normal manner. These changes do not occur in "trained" cells.

\section{DIFFERENTIATION OF BACTERIA BY MEANS}

\section{OF ANTIBIOTIC SUBSTANCES}

Because of their selective action upon different bacteria, antibiotic substances can be utilized for separating bacteria from one another. Fleming (264) utilized penicillin to isolate Pfeiffer's bacillus and the pertussis organism of various cocci, diphtheria, and neisseria organisms; 
the substance was found to behave as the mirror image of tellurite in inhibiting specific bacteria. Penicillin was also utilized for the separation of acne bacilli from accompanying staphylococci (158) and for the separation of streptococci from staphylococci (262); also for the isolation of Trichomonas vaginalis and of animal viruses (803).

Actinomycin was used to separate gram-negative from gram-positive bacteria (974).

Tyrothricin has been utilized (886) for the isolation of $N$. gonorrhoeae from contamination with gram-positive bacteria. Usually a I : 1 5,000 dilution of the substance in "chocolate" agar was found quite satisfactory for this purpose. By the use of tyrothricin, gram-negative microorganisms have been isolated from the nasopharynx even in the presence of overgrowth by gram-positive cocci. Hemophilus infuenzae is resistant to the action of tyrothricin, and its isolation is facilitated by adding to the media on which it is cultured tyrothricin in a dilution which inhibits the cocci $(842)$.

Streptothricin was found to help in distinguishing $B$. mycoides from B. subtilis (979).

\section{SUMMARY}

Comparatively little is yet known of the mode of action of antibiotic substances. This field offers great opportunities for research and utilization of bacterial activities. The solution to such important problems as the morphology of the bacterial cell; taxonomic relations of bacteria; various physiological reactions of microorganisms, especially the phenomenon of adaptation of bacteria to antibiotics and the problem of bacterial resistance; the mechanism of causation of disease; and the very control of disease-producing microorganisms-all fundamental problems in microbiology - will be furthered by knowledge of the action of specific antibiotic substances upon bacteria and other microorganisms. 


\section{UTILIZATION OF ANTIBIOTIC SUBSTANCES FOR DISEASE CONTROL}

Whether gramicidin or any other product of microbic origin will eventually be found to fulfill certain purposes better than either sulphonamides or any other class of antiseptic remains to be seen. That several classes of reagent should be competing for supremacy in different aspects of a task which not long ago was considered impossible of any real fulfilment is a truly remarkable position (35 I).

Microorganisms and products of their metabolism have been utilized for the control of disease in man, animals, and plants with varying degrees of success. On the basis of the observations mentioned above (p. 36), Pasteur may be considered as the first to advance the subject of bacteriotherapy. Emmerich (233) reported that anthrax can be controlled by the use of streptococci such as the erysipelas organism; these bacteria were, therefore, looked upon as agents useful in bringing about immunity against all bacterial infections. Pawlowsky (7I I) obtained immunity against anthrax by inoculation with Friedländer's bacillus. Bouchard (78) was successful in the control of anthrax by means of Ps. aeruginosa. This organism, however, did not impart any immunity to the animals, but by the use of a sterilized ten-day-old culture of the antagonist, healing action was obtained against anthrax infection or at least its development was delayed ( IO26a). It was soon demonstrated (64, I3I) that filtrates of Ps. aeruginosa could destroy $B$. anthracis. The pressed extract of Ps. aeruginosa was also found to have a protective effect when injected in the animal simultaneously with the pathogen (534a).

Emmerich and Löw later employed a cell-free preparation of Ps. aeruginosa, concentrated to one-tenth its original volume, to treat rabbits infected with $B$. anthracis (898). This preparation also destroyed in vitro a number of other bacteria, including various staphylococci, streptococci, pneumococci, gonococci, C. diphtheriae, V. comma, and Sh. 
paradysenteriae. These studies led to the development of pyocyanase preparations of varying degrees of activity. Pyocyanase has been used in the treatment of a variety of diseases including diphtheria and meningitis. In some of these cases, especially of anthrax, treatment was rather successful (278), in others it was not, due largely to the low potency of the product $(529,80 \mathrm{I})$.

The lack of recognition of the existence of more than one antibiotic agent in the culture of Ps. aeruginosa led to the disrepute of pyocyanase. It was soon reported (69), for example, that a Berkefeld filtrate of the culture had only a weak therapeutic effect, an observation later confirmed by Wagner (938). The facts that some strains of $P$ s. aeruginosa do not form any pyocyanase and that even active strains may lose the capacity to produce this antibiotic (529) were other contributing factors to the gradual disappearance of pyocyanase as a chemotherapeutic agent.

Various methods of treating severe infections, like anthrax or malignant tumors, with mild infective agents have been suggested. The reduction in pathogenicity of one organism by the presence of others has thus been well recognized. Nonpathogenic organisms apparently have specific effects upon the pathogens, the development of which was prevented or even suppressed. The very occurrence of specific types of pneumococci in healthy individuals and the causation of specific forms of pneumonia were found to be controlled by the antagonistic effects of other microorganisms (37I).

It was thus definitely established that the growth of $B$. anthracis could be inhibited by antagonists (49). Guinea pigs survived large injections of washings from soil previously contaminated by $B$. anthracis through the slaughtering of a diseased cow. When cultures of this organism were isolated from the soil and injected, however, characteristic disease symptoms resulted. It was suggested that the anthrax spores are digested by the leucocytes which have been attracted to the site of injection by the accompanying bacteria (32).

Seitz (849), in discussing the problem of mixed infections, cited many cases not only of decreased but also of increased virulence of the pathogen as a result of accompanying bacteria. He warned, therefore, against too sweeping generalizations concerning the healing effect of 
antagonistic bacteria. He believed that in many cases of artificial infection, the favorable action of the antagonist may have been due entirely to increased body resistance. Nevertheless, he accepted the possibility of utilizing the antagonistic effects of microorganisms, for the treatment of skin surfaces, including those of the intestinal canal and the vagina, but not for tissue or blood infection.

Until very recent years, attempts to utilize the activities of antagonistic microorganisms for the control of disease did not always meet with success. This failure may have been due to an insufficient understanding of the nature of the chemical agent produced by the antagonist, to a lack of knowledge concerning the mechanism of its action, especially as regards the production of the active antibacterial substance or antibiotic.

\section{MICROBIAL ANTAGONISTS AND DISEASE CONTROL}

In 1885 , Cantani treated a tubercular patient with a culture of a saprophytic organism, designated as Bacterium termo; the results were highly favorable (I09). He expressed the hope that other infectious diseases readily accessible and of a local nature could be effectively treated with saprophytic bacteria which are antagonistic to the pathogens. Following this work of Cantani, Zageri (I043) inoculated S. pyogenes into animals suffering from anthrax; the rise in temperature caused by the streptococcus reduced the viability of the anthrax. The growth of an antagonistic organism was found to change the environmental conditions favorable to the pathogen, thus causing its attenuation.

These results received the immediate attention of other investigators. In most instances saprophytic organisms such as lactic acid bacteria or beer yeasts were used, in other cases mild pathogens were employed. Lorenz and Ravenel (582a), for example, sprayed the throats of diphtheria carriers with cultures of $S$. aureus; although the treatment was successful in eliminating the pathogens, the staphylococci sometimes caused sore throat.

Gaté and Papacostas (323) observed that mixed infections were usually mild, a phenomenon later confirmed. Mixed cultures of the Fried- 
länder bacillus and of $C$. diphtheriae gradually gave a predominance of the former on repeated transfer; the morphology of the diphtheria organism changed toward a more homogeneous state on staining. The use of culture filtrates gave no evidence that the diphtheria toxin was neutralized by the antagonist, either in vivo or in vitro; however, when the two organisms were grown together no toxin was formed, nor was toxin produced when the filtrate of the culture of the antagonist was used to grow $C$. diphtheriae. The therapeutic use of filtrates was, therefore, suggested. Lactic acid bacteria were also employed successfully $(678)$ in the treatment of diphtheria.

By allowing an antagonist to act upon a disease-producing organism that has previously been heated to $56^{\circ} \mathrm{C}$., a hydrolyzate was obtained which could be employed as a vaccine. Bezançon (54) treated typhoid sufferers with a culture of $E$. typhosa lysed by means of $P$ s. aeruginosa. Gratia (354) said, however, that this type of hydrolyzate brings about heat production, but the use of a preparation obtained by means of an actinomyces, designated as a mycolysate, does not. The use of living proteolytic bacteria (neocolysin) for treatment of chronic purulent conditions, such as osteomyelitis, gave favorable results; the bacteria were believed to continue growing as long as there was dead tissue available (98).

Besredka (52) used culture filtrates of bacteria for the treatment of various diseases in man. A filtrate of the anthrax organism was employed for dressings or for intracutaneous injections; the results were at least as good as those obtained with the bacterial vaccine. Staphylococci and streptococci were also utilized for similar purposes. Besredka believed that a substance, designated as antivirus, was secreted by the bacteria into the filtrate. This was said to check further growth of the bacteria. The mode of action of the antivirus was considered to be different from that of antibodies: the first affects the cells locally by stimulating their resistance; the second acts upon the organism as a whole and, through it, against the infecting agents. Antivirus was prepared by allowing bacteria to grow in ordinary bouillon for a long time, until the medium became unfavorable for further development of the bacteria. Staphylococcus antivirus prevented the growth of the staphylococcus organism in a medium in which it had grown previously. In the presence 
of the homologous antivirus, the organisms underwent active phagocytosis, this action being specific. The antivirus was nontoxic and could withstand a temperature of $100^{\circ} \mathrm{C}$. It imparted to certain tissues a local immunity against the specific bacteria.

The favorable therapeutic results obtained from the use of antivirus have been confirmed, largely in France, Austria, and Germany. The antivirus apparently acts not upon the bacterium but upon the tissue of the host in such a way as to produce local immunization, thus preventing infection. Nonspecific filtrates may cause an occasional increase of resistance, but the protection produced by specific filtrates is said to be more intense and more dependable $(689,775)$. Antivirus therapy was believed to offer some promise, although it was said not to give consistent results $(385)$. Further studies of antivirus led to suggestions that its favorable effects were due entirely to the culture medium ( 8 ). The whole question thus appears to be still debatable, with proponents and opponents of the specific nature of the antivirus effect ( 119,627$)$.

The application of bacteriotherapy for the treatment of chronic infections of the middle ear (739) and actinomycosis in man has also been suggested. Filtrates of E. typhosa and of E. coli were found (844) to check the growth of the typhoid organism, whereas $E$. coli grew readily in such filtrates; the more sensitive typhoid bacterium was checked earlier in its growth than the colon organism. In general, E. typhosa was found to be readily inhibited by the growth of antagonistic bacteria. Because of this, it was believed that pasteurized milk contaminated with a pathogenic organism presents a particular danger, since no antagonists are present to inhibit the rapid multiplication of the pathogen. Metchnikov (635) suggested utilization of the antagonistic relations between lactic acid bacteria and proteolytic bacteria for repressing the growth of the latter. Thus, pure cultures of the former are introduced into the food system of man, in order to repress in the intestinal canal the proteolytic organisms that are supposed to bring about intoxication in the system. In recent years, L. acidophilus, an inhabitant of the human intestine possessing antagonistic properties against pathogenic intestinal bacteria, has come into general use (778). The problem of combating pathogenic intestinal bacteria by means of nonpathogenic forms (737) has thus been given wide consideration. The utilization of yeasts 
for combating streptococci and staphylococci may also be classified among the phenomena of antagonism. On the basis of the rapid destruction of pathogenic bacteria added to natural water, the storage of drinking water in large reservoirs was recommended as an important safeguard against the water's becoming a carrier of bacterial diseases (293295).

Clinical methods have been proposed for evaluating the results obtained by treating tooth gangrene by means of antagonists (333). Donaldson ( 190) found that $\mathrm{Cl}$. sporogenes or a closely related form had a marked effect in suppressing the growth of pathogenic organisms in septic wounds. He believed the antagonistic anaerobe is present in the majority of gunshot wounds, but that its activities are held in abeyance by the method of wound-dressing. This antagonist acts by virtue of its proteolytic enzymes which hydrolyze the dead protein, from which the pathogenic organisms operate, as well as the toxic degradation products of other organisms.

Dack ( I65) reported that $C l$. sporogenes formed in the soil was responsible for destroying the toxin of $\mathrm{Cl}$. botulinum.

\section{ANTIBIOTIC SUBSTANCES AS CHEMO-}

\section{THERAPEUTIC AGENTS}

Numerous attempts were made, before the advent of tyrothricin which was soon followed by penicillin, to utilize the products of different organisms for the control of bacterial infections in man and in animals. Attention has already been called to the use of various pyocyanase preparations through nearly half a century, beginning with the work of Emmerich and Löw $(235,236)$, through the work of Nissle on mutaflor (680a), and finally the recent studies of Bergström and associates (50a). There was no question of the efficacy of many of these preparations. Attention has also been called to the work of Vaudremer (934) and others who attempted to utilize fungus preparations for the control of bacterial infections. It is only within the last seven years, that is, with the introduction of tyrothricin, that a new chapter has been opened in chemotherapy.

Of the numerous antibiotics so far isolated, only a very few have 
found practical application in chemotherapy. Among these, penicillin, streptomycin, and tyrothricin occupy a leading place. In a study of the relative susceptibility of different staphylococci to the bacteriostatic action of three different antibiotics it was found $(676)$ that no one agent parallels necessarily the action of another; a strain resistant to one antibiotic may be sensitive to another. Also, different staphylococcus strains may vary in sensitivity to the same antibiotic, some being inhibited by O. I unit of penicillin and others being resistant even to IO units. Hence a knowledge not only of species sensitivity but also of strain sensitivity is essential in selecting an antibiotic for the treatment of a given infection (3I0).

In any attempt to evaluate an antibiotic substance as a chemotherapeutic agent, one must consider the interaction between the drug and the parasite, on the one hand, and the drug and the host, on the other (6or).

\section{Penicillin}

Nature of Action. Since the publication of the first edition of this book, much work has been done on the in vivo activity of penicillin and the chemotherapeutic use of this important antibiotic agent. The appearance of the monographs by Herrell (410), Kolmer (522), and Fleming (262a) make a detailed discussion of this problem unnecessary here; discussion is therefore limited to the fundamental principles involved.

The antibacterial action of penicillin is selective, susceptibility being, however, one of degree rather than of kind. Some bacteria are inhibited by very low concentrations of the drug; others are not inhibited at all or only by high concentrations. On the basis of clinical experience (494), it has been suggested that organisms inhibited by O.I O.U. or less per $\mathrm{ml}$. are susceptible to penicillin therapy; some organisms do not respond at all or respond only on occasions. Pyogenic cocci, anaerobic clostridia, and certain pathogenic gram-negative cocci (Gonococcus, Meningococcus, and Micrococcus catarrhalis) are sensitive, whereas the colon-typhoid, hemophilic chromogenic bacilli and certain micrococci (Micrococcus flavus) are resistant to its action; it has no effect upon $M$. tuberculosis (863), Trypanosoma equiperdum, and the 
influenza virus (789). The purest preparation of penicillin so far available completely inhibited (275) the growth of $S$. aureus in a dilution of between $\mathrm{I}: 24,000,000$ and $\mathrm{I}: 30,000,000$. Partial inhibition was obtained up to I: I60,000,000. Salmonella organisms were also sensitive. Certain strains of Brucella are sensitive to penicillin in vitro, this effect being enhanced by the presence of small amounts of sodium sulfathiazole (918). The sensitivity of most strains of $S$. hemolyticus is similar to that of the majority of staphylococci and meningococci; pneumococcus and alpha streptococcus strains fall, in sensitivity, between the beta streptococci and the meningococci (628). Similar variations in sensitivity to penicillin of different strains of the same organism have been observed for various other bacteria, such as $C$. diphtheriae.

A partial list of the organisms susceptible to penicillin is given in Table 42.

The antibacterial activity of penicillin is not interfered with by substances that inhibit sulfonamides, namely, bacterial extracts, pus fluids, tissue autolysates, peptones, and p-amino-benzoic acid. It is nontoxic in concentrations far greater than those required for therapeutic purposes. It is rapidly excreted through the kidneys and frequent administration is essential in order to maintain a proper blood concentration.

In its biological properties, penicillin has been found, in general, to resemble sulfonamide drugs, with certain significant differences (5):

The bacteriostatic power of penicillin against streptococci and staphylococci is greater than that of sulfonamides, even when the tests are made under conditions optimum for the action of the latter. Saturated solutions of sulfapyridine and sulfathiazole showed no complete inhibition of bacteria on the assay plate, whereas penicillin, even in a dilution of $1: 500,000$, gave considerable inhibition.

The action of penicillin on streptococci and staphylococci, unlike that of the sulfonamides, is influenced very little by the number of bacteria to be inhibited. Bacterial multiplication can be completely prevented by as low a concentration of penicillin as $I: I, 000,000$, even if the inoculum contains several million bacterial cells. In the case of smaller inocula, inhibition occurs in even higher dilutions. This property of penicillin is believed to be of great importance in the treatment of heavily infected wounds, on which the sulfonamide drugs seem to have little beneficial action. 


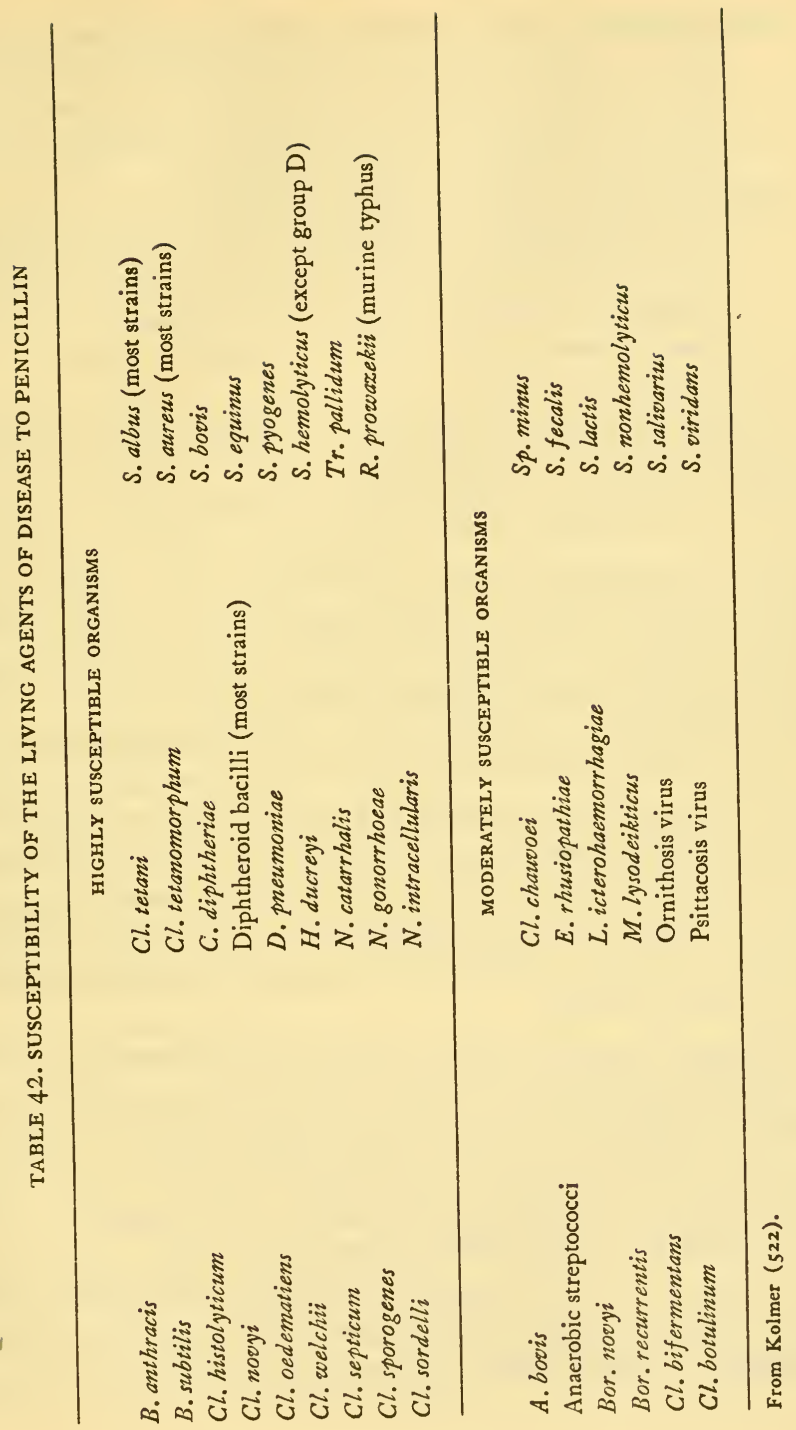


The bacteriostatic power of penicillin against streptococci and staphylococci is not inhibited to any extent by protein breakdown products or by pus, which neutralize the bacteriostatic action of sulfonamide drugs. The leucocytes remain active in any concentration of penicillin usually employed in intravenous injection.

Penicillin is active against strains of bacteria that are resistant to the action of sulfonamides. It is effective in the treatment of hemolytic streptococcus, pneumococcus, and gonococcus infections, which are resistant to sulfonamides. It has not been found effective, however, in the treatment of subacute bacterial endocarditis $(782)$.

On repeated passage through broth containing penicillin, pneumococcus cultures as well as Staphylococcus sp. and S. pyogenes (604) increased in resistance to penicillin. This was accompanied by a proportional loss of virulence. Small colony variants ( $G$ forms) of $S$. albus showed a specially high resistance to penicillin (840). Two strains of pneumococcus developed resistance to penicillin as a result of serial passage through mice treated with it. The degrees of resistance developed and acquired varied significantly with the strains. In the case of one strain, resistance was not impaired by 30 serial passages through normal mice. The development of resistance in vivo was accompanied by an increase in resistance to penicillin in vitro. The response of the pneumococci to sulfonamides was not altered by the development of resistance to penicillin. The mechanisms whereby staphylococci become resistant to sulfonamides and to penicillin appear to be distinctly different. This increase in resistance may be one of the dangers of using "homemade" penicillin.

Survival of a certain number of cells of staphylococci in a culture treated with penicillin may be due to the fact that these cells are temporarily in a nondividing state, since the antibiotic kills the bacteria that are about to divide. Such cells were designated "persisters" (57); their descendants are easily killed by the antibiotic. This concept led to the recommendation of intermittent treatment by penicillin: treatment to be interrupted to permit the bacteria to multiply and thus become again vulnerable. This concept has not been universally accepted (32 I), some investigators actually warning against too early interruption of peni- 
cillin therapy. Among the gonococci, no naturally resistant strains have been encountered (544).

Toxicity. As to the toxicity of penicillin, it was found (5) that mice were little affected by the intravenous injection of $10 \mathrm{mg}$. of penicillin; they became ill from the use of $20 \mathrm{mg}$. but recovered shortly. One hundred milligrams of crude penicillin given intravenously to man caused a shivering attack with a rise of temperature in about an hour. The latter was due to the presence of a pyrogenic substance in the preparation. Certain isolated fractions of penicillin had no such pyrogenic effect. Penicillin was toxic to mice when given intravenously in single doses of 0.5, I.0, I.5, and 2.0 gm. per kilogram. More highly purified preparations were less toxic. Higher concentrations were required for lethal effect from subcutaneous administration. The toxic dose is 64 times greater than the effective dose (789).

The relative toxicity of various salts of penicillin was found (997) to be, in increasing order, $\mathrm{Na}, \mathrm{Li}, \mathrm{NH}_{4}, \mathrm{Sr}, \mathrm{Ca}, \mathrm{Mg}$, and $\mathrm{K}$. Based on milligrams of the cation at the $\mathrm{LD}_{50}$ dose of salts of penicillin, the relative toxicity was $\mathrm{Na}, \mathrm{Sr}, \mathrm{NH}_{4}, \mathrm{Ca}, \mathrm{K}$, and $\mathrm{Mg}$. It was concluded that the toxicity of the salts of penicillin is primarily due to the cations used in their preparation.

Penicillin is rapidly absorbed and is excreted in the urine, usually within one hour (755). It does not appear to undergo any change in passing through the animal body. This fact was taken advantage of, in the early days when there was a shortage of penicillin, by recovering it from the urine. An average yield of 30 per cent of the amount administered was obtained (872).

The degree of the antibacterial action of penicillin is proportional to its concentration in the serum, maximum effects against hemolytic streptococci being produced by concentrations of 0.019-0.156 Oxford units in I ml. of serum. The $\mathrm{LD}_{50}$ for an $\mathrm{I} 8$-gram mouse was $32 \mathrm{mg}$. of the sodium salt (437). The cardinal symptoms of toxicity were choking, gasping, and rapid respiration. However, it is relatively nontoxic in doses used for therapeutic purposes.

Penicillin was thus found to combine the two most desirable qualities of a chemotherapeutic agent, namely, a low toxicity to tissue cells 
and a highly bacteriostatic action against some of the most common and destructive bacteria with which man may become infected. It was possible to maintain a bacteriostatic concentration of penicillin in the blood without causing any toxic symptoms.

Animal Experiments. In animal experiments it was established that penicillin is an effective chemotherapeutic agent against pneumococci, including sulfonamide-resistant types. It is superior, in staphylococcus infections, to bacteriophage, sulfa drugs, and specific antitoxins (468). In experiments with $S$. aureus, a survival ratio of $2:$ I was obtained in favor of penicillin as compared with sulfathiazole, correction being made for the survival of control mice. Penicillin, when administered subcutaneously, intravenously, or intraperitoneally, was also found to be effective against hemolytic streptococci. Generalized staphylococcal infections were cured by penicillin and local lesions healed during parenteral administration. The best method for administering penicillin is by the intramuscular route at 3 -hour intervals; the blood should contain enough penicillin ( I 5,000 O.U. dose) to inhibit the growth of the infecting agent. Intraocular infection caused by $D$. pneumoniae was checked by local treatment with penicillin in solutions of 0.25 and O.I per cent; the application was continued for 2 to 4 days ( 8 I 7 ).

Since penicillin readily loses its activity in an acid solution, it is used in the form of the sodium salt. Rabbits excreted in the urine as much as 50 per cent of the penicillin after intravenous injection, but less than 20 per cent after administration into the intestine; some excretion took place in the bile. The penicillin could not be detected in the blood within one-half hour after administration. Cats differed in this respect from rabbits, since they maintained an antibacterial concentration of penicillin in the blood for at least 1.5 hours after subcutaneous or intravenous injection, and for at least 3 hours after intestinal administration. They differed also in excreting about 50 per cent of the penicillin in the urine, even when the substance was injected into the intestine. In this respect man appeared to resemble cats more closely than rabbits.

A comparison of antibiotic agents against the anaerobes causing gas gangrene placed tyrothricin in first place, followed successively by penicillin, the sulfa drugs, and other antibiotic agents; however, in vivo 
treatment of mice infected intramuscularly with $C l$. perfringens placed penicillin first, with tyrothricin and aspergillic acid at the bottom of the list. Penicillin also proved superior to sulfonamides and amino acridines in experimental infection with $\mathrm{Cl}$. welchii and $\mathrm{Cl}$. oedematiens $(603)$.

The in vivo activity of penicillin against $C l$. septicum and other anaerobes, as well as many other bacterial pathogens, is brought out in Table 43. A single subcutaneous treatment of mice with 50 units of penicillin at the time of intramuscular inoculation with $\mathrm{Cl}$. welchii protected 98 per cent of the infected animals, and repeated small doses gave as good protection as a single large dose. Delay in the institution of therapy lowered the survival rate, but not appreciably unless the delay was over 3 hours. Local lesions were completely healed within 3 weeks if penicillin was injected repeatedly into the site of infection.

The effectiveness of penicillin has also been tested against various other infections in experimental animals, with varying degrees of success. It was found, for example, that the administration to mice of penicillin in relatively large doses after injection with murine typhus rickettsiae resulted in marked reduction in mortality, particularly when the initial dosage of the rickettsiae was relatively small (654). Its favorable effect on infections due to the ornithosis virus was also indicated (400). It is also effective in the treatment of leptospirosis in experimental animals ( 17,547$)$.

It has been brought out in recent studies that the effects of different forms of penicillin against the same bacteria are different in the animal body and in the test tube. Penicillin $\mathrm{K}$ gave one-quarter to one-eleventh in the blood (injected $0.6 \mathrm{mg} . / \mathrm{kg}$.) and persisted in demonstrable levels for only a short time, as compared to $F, G$, and $X$. The recovery of $\mathrm{K}$ in the urine was 30 to 35 per cent, as compared to 74 to $9 \mathrm{I}$ per cent in the case of the other forms. In the treatment of experimental infections, $\mathrm{K}$ was one-sixth to one-eleventh as active as $\mathrm{G}$, and one-eighth to one-thirteenth as active as $\mathrm{X}$. These data point to the more rapid inactivation of penicillin $\mathrm{K}$ in the body, resulting in a lower therapeutic activity (224).

Although the evidence concerning the effectiveness of different forms of penicillin is still very limited, the conclusions were reached 


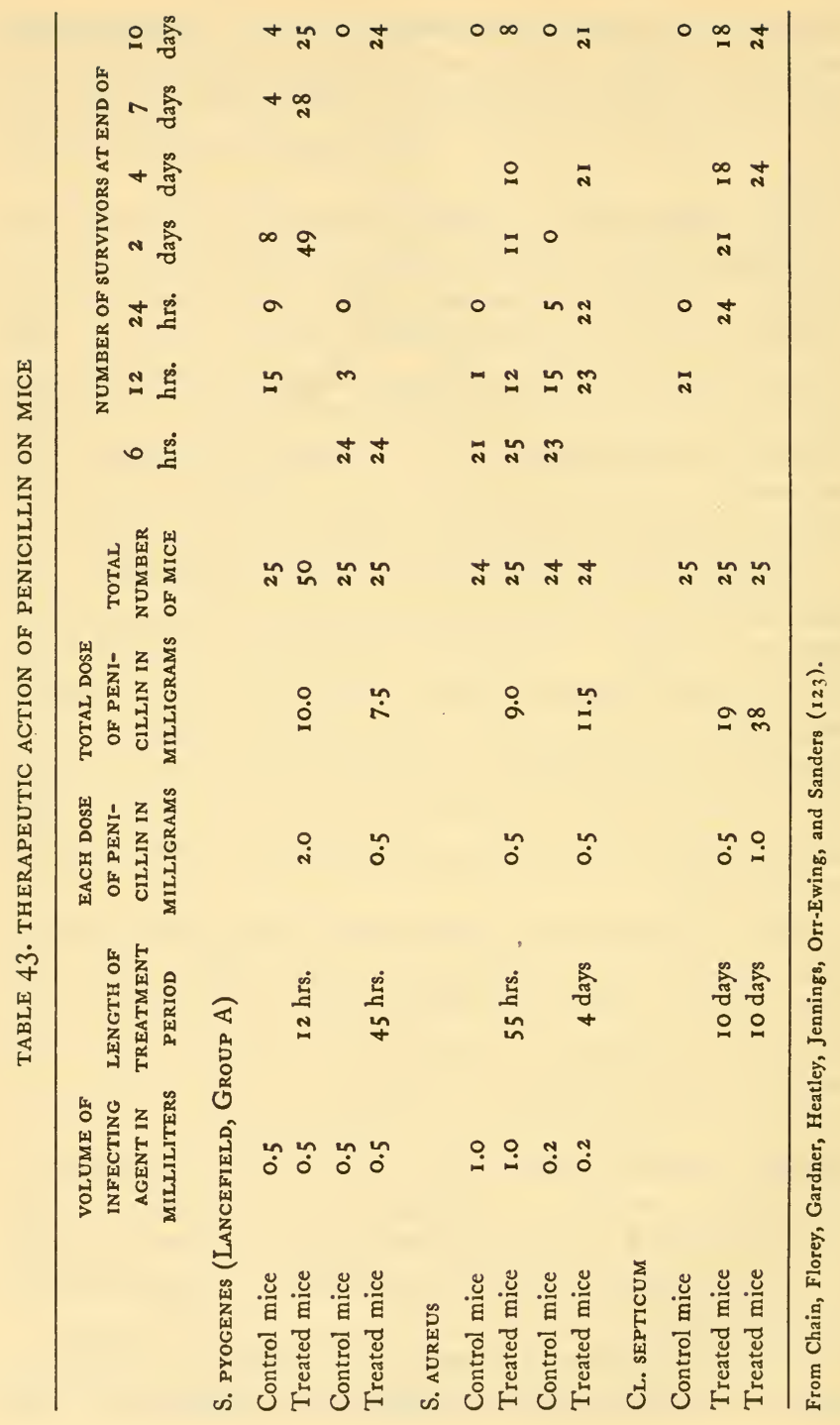


( $147 \mathrm{a}$ ) that (a) penicillin $\mathrm{K}$ is very unstable in the body, so that its parenteral effectiveness is open to question; (b) penicillins $\mathrm{G}$ and $\mathrm{X}$ are stable but they are rapidly excreted, which is a limiting factor in maintaining a therapeutic level; (c) penicillin $\mathrm{X}$ is more active against certain hemolytic streptococci, where its specific use is indicated.

Chemotherapeutic Action. Penicillin has also found an important place in the treatment of local and generalized infections in man. Fleming was the first $(261,262)$ to recommend that it be employed for dressing septic wounds. It appeared to be superior to dressings containing purely chemical agents. Isolated penicillin in a dry state was many times more powerful than the most potent of the sulfonamide compounds. Local applications include those to lesions of the eye produced by $S$. aureus, in which early treatment resulted in the elimination of the organism from the flora of the conjunctival sac (797). Weight for weight, penicillin was found to be four times as potent as sulfathiazole and 100 times as potent as sulfanilamide for the treatment of wound infections $(5,269)$.

Penicillin proved to be an especially effective agent for the treatment of staphylococcal and hemolytic streptococcal infections in man (755), including streptococcal meningitis and others. Many cases of infected war wounds treated with penicillin gave, in 24 hours, a uniform drop in the number of gram-positive organisms, including clostridia, staphylococci, streptococci, and corynebacteria; the gram-negative bacteria were not affected. Excellent therapeutic effects were also obtained in surgical infections. Even crude culture filtrates of $P$. notatum, applied locally, gave good results. It can be used in topical application and has proved to be an ideal agent for the treatment of genito-urinary infections. It is readily absorbed and excreted following intravenous, subcutaneous, and oral administration; a part of it is inactivated in the body.

In order to lessen the frequency of effective invasion of the nose by bacteria and the subsequent infection of the nasopharynx, the local use of penicillin has been suggested. The material acts as a prophylactic against bacterial infections of the upper respiratory tract; the course of a cold can thus be checked by preventing secondary bacterial infection. The curing of nasal carriers of staphylococci or even the reduction of 
the number of vegetative organisms was considered important in order to reduce the danger of the carrier as a source of infection to others. It has found application in oral infections, in acute infections of the ear, nose, eyes, in bone infections, meningitis, human anthrax, subacute bacterial endocarditis, and many other infections, such as rat-bite fever. In the case of some infections, such as those caused by $\mathrm{Cl}$. welchii, penicillin must be used in conjunction with good surgical principles. Penicillin can also find application in certain chronic cases, as in the treatment of chronic dermatitis and in preparing infected surfaces of hands for skin-grafting and infected stumps for amputation.

Penicillin is an effective agent in the treatment of clinical infections due to sulfonamide-resistant bacteria. Several strains of $N$. gonorrhoeae isolated from patients in whom the infection was resistant to treatment with sulfonamide preparations were found to be inhibited completely by penicillin. The number of organisms decreased greatly at the end of I or 2 hours' contact with the substance, and no viable organisms were found after 3 to 4 hours' contact. The complete absence of toxicity following the intravenous administration of penicillin, the lack of discomfort to the patient, and the rapid disappearance of clinical symptoms were observed in cases of sulfonamide-resistant gonorrheal infections. In all the cases reported, in addition to the clinical response noted, negative bacterial cultures were obtained some time between 7 and 48 hours after the institution of penicillin therapy. Sulfonamide-resistant gonorrhea cases responded to injections of 100,000 to 160,000 O.U. Favorable responses have also been obtained in the treatment of sulfonamideresistant strains causing staphylococcal pneumonia and empyema and other diseases. The susceptibility of various bacteria to penicillin can be determined by means of a very simple technique.

A favorable therapeutic response was obtained by administering penicillin intravenously to patients with staphylococcal infections and by mouth to a baby with a persistent staphylococcal urinary infection. In patients suffering from meningitis, penicillin was found to be absorbed more rapidly than in normal persons, and a larger part of the dose was excreted in the urine.

Penicillin has not been found to be effective in trypanosome infec- 
tions, but has been used successfully in the treatment of relapsing fever, although excessive doses were required (223).

Treatment of early syphilis cases with penicillin (6r4) indicated that the therapy was responsible for the rapid and complete disappearance of the infecting agent from the blood stream, as determined by various tests. Penicillin was found to be actively spirocheticidal (225). A comparative study has been made of the action of penicillin and of other antibiotic agents upon Treponema pallidum ( 2 I 7 ). The immobilization of spirochetes in vitro by penicillin preparations was found to be due to the impurities present ( 218$)$. The amount of penicillin required to produce bacteriostatic titers in rabbits infected with $T r$. pallidum is five times greater than that needed for adult man by intramuscular injection. Although highly favorable effects were obtained in the treatment of various types of syphilis in man, the need for more careful observations was indicated.

Penicillin was also found to have an effect upon experimental typhus rickettsiae $(36 \mathrm{r}, 654)$, bovine mastitis $(857)$, and a variety of other infections.

As a result of treatment with penicillin of 300 patients, it has been concluded (782) that this material is far superior to any of the sulfonamides in the treatment of $S$. aureus infections with and without bacteriemia, including acute and chronic osteomyelitis, cellulitis, carbuncles of the lip and face, pneumonia and empyema, infected wounds and burns.

A study of 500 cases of infections treated with penicillin led to the following conclusions $(494,588)$ : Penicillin can be administered intravenously, intramuscularly, or topically, but is ineffective when given by mouth. As it is excreted rapidly in the urine, it must be injected continuously or at intervals of 3 to 4 hours. Penicillin was found to be particularly effective in the treatment of staphylococcic, gonococcic, pneumococcic, and hemolytic streptococcus infections, especially sulfonamideresistant gonococcic infections, but not bacterial endocarditis. The usual patient requires a total of 500,000 to $1,000,000$ Oxford units, the best results being obtained when treatment is continued for 10 to I4 days, Io,000 units to be given every 2 to 3 hours at the beginning of treat- 
ment, either by continuous intravenous injection or by interrupted intravenous or intramuscular injections. Good results were obtained by injections of 100,000 to 160,000 units over a period of 2 to 3 days. In the treatment of empyema or meningitis it was found advisable to use penicillin topically by injecting it directly into the pleural cavity or the subarachnoid space. Toxic effects were extremely rare. Occasional chills with fever or headache and flushing of the face were noted.

A summary of the response of different bacteria in septic gunshot fractures is given in Table 44. Staphylococci and streptococci are rapidly responsive to penicillin therapy. Anaerobic cellulitis due to the proteolytic bacteria of putrid wound infection responds to penicillin, but the bacteria may persist in the presence of devitalized tissue or wound exudates. The pyocyaneus organism is not susceptible to penicillin, but it is considered to be relatively unimportant as a single pathogen in the surgical management of the wounds (269).

A summary of the results of extensive use of penicillin in the North African campaign of World War II led to the conclusion that in the treatment of recent soft-tissue wounds penicillin brought about the virtual elimination of infection and saved much hospitalization time. Treatment of fractures also gave good results, though some penicillinresistant cocci appeared. Favorable results were also obtained in various

TABLE 44. RESPONSE OF DIFFERENT BACTERIA FOUND IN WOUNDS TO PENICILLIN TREATMENT

\begin{tabular}{lcc}
\hline & \multicolumn{2}{c}{ PENICILlin RESPONSE } \\
TYPE of INFECTION & Systemic & Local \\
Putrid: & $+($ large dosage $)$ & + \\
$\quad$ Proteolytic clostridia & 0 & 0 \\
$\quad \begin{array}{l}\text { Proteus vulgaris } \\
\text { Nonhemolytic streptococci: } \\
\quad \text { Mesophilic }\end{array}$ & + & + \\
$\quad$ Thermophilic (S. faecalis) & 0 & O (or slight) \\
Staphylococci & $+(3-5$ days $)$ & + (often necessary) \\
Hemolytic streptococci & $+(1-3$ days $)$ & + (not essential) \\
Pseudomonas aeruginosa & 0 & 0 \\
\hline
\end{tabular}

From Lyons' $\left(5^{8} 7\right)$. 
other infections. It is suggested that an average of 750,000 units of sodium penicillin be allowed for systemic treatment and 50,000 units of the calcium salt for local treatment $(275,319)$.

Penicillin is thus found to form a valuable addition to the growing list of chemotherapeutic agents, to help man combat disease-producing bacteria. It is commonly used not as a pure acid but as either a calcium or a sodium salt, the former for local applications and the latter for intramuscular or intravenous treatments $(275,494)$. Since penicillin solutions are quite unstable, especially in the form of salts, the dry preparations are stored and are dissolved either in water or in saline just before required for use. Certain of the esters (e-butyl) of penicillin which are inactive in vitro can, when given by the oral route, become highly active against hemolytic streptococci $(639,640)$.

In some cases, penicillin failures have been experienced; these may be due to too brief treatment or too small doses, to need for surgical drainage, or to other complications. Toxic effects may also be produced due to the penicillin itself or to some of the accompanying impurities. Sensitivity is often in the nature of allergy $(159,592)$. Further details on the toxicity and in vivo activity of penicillin are reported by Herrell (4I0).

In place of penicillin preparations, crude culture filtrates are occasionally used. Such crude preparations have been designated as vivicillin, hypholin, etc. (500).

This is not the place to discuss in detail the pharmacology and chemotherapy of penicillin. An extensive literature has already accumulated on this subject. Reference is here made to the detailed summaries (274, 495) and books recently published, where indications for penicillin are listed under infections due to staphylococci, clostridia, hemolytic streptococci, anaerobic streptococci, pneumococci, gonococci, anthrax, chronic pulmonary suppuration, meningococci, bacterial endocarditis, murine erysipelas, Vincent's syphilis, actinomycosis, diphtheria, and certain others. It is not effective in mixed infections where a gram-negative flora predominates, in urinary infections due to $E$. coli and other gramnegative bacteria, in tuberculosis, in other diseases caused by gramnegative bacteria, viruses, or pathogenic fungi, in malaria, or in a variety of other diseases, such as cancer. The manner and extent of ad- 
ministration and amounts required depend largely upon the susceptibility of the infecting strain of the organism.

\section{Clavacin (Claviformin, Patulin)}

The treatment of common colds that were prevalent in an English naval establishment by the use of clavacin in the form of nasal sprays or snuffed up by hand gave 57 per cent complete recovery in 48 hours, as compared with 9.4 per cent for the controls; no ill effects were observed (744). These results were not confirmed, however, the conclusion having been reached that, compared with the natural evolution of the disease, clavacin has no demonstrable effect on the course of a cold (876). This substance also proved to be unsatisfactory for the treatment of bovine mastitis by udder infusion (718). In general, it is too toxic to be of therapeutic use; it acts as a tissue poison and has other undesirable pharmacological effects (90). To what extent the antifungal action of clavacin can be utilized for controlling fungus infections remains to be determined, since it is known to inhibit the growth of Trichophyton gypseum in concentrations of 0.02 per cent and in certain cases even 0.0 I per cent. It had only a slight effect upon other fungi in 0.04 per cent concentration (4I6).

\section{Tyrothricin}

Dubos (203) reported that $0.002 \mathrm{mg}$. of gramicidin, one of the two chemical constituents of tyrothricin, when injected intraperitoneally into white mice, exerted a therapeutic action against experimental peritonitis caused by pneumococci and streptococci (Table 45). This substance was found to be effective against five different types of pneumococci, eleven types of group A streptococci, and three strains of group C streptococci. It was, however, almost completely ineffective when administered into animal tissues by the intravenous, intramuscular, or subcutaneous route, because of its lack of activity under these conditions.

Tyrothricin exerted a lethal action in vitro on 1 8-hour broth cultures of $S$. hemolyticus, $S$. aureus, and $C$. diphtheriae, in a final dilution of I : I,000,000; freshly isolated strains of meningococcus were affected in a dilution of $\mathrm{r}: 100,000$ (84I). Two monkeys which carried in the nasopharynx and throat gram-positive hemolytic streptococci and gram- 
TABLE 45. BACTERICIDAL EFFECT OF TYROTHRICIN UPON DIFFERENT BACTERIA

TYROTHRICIN IN MILLIGRAMS PER MILLILITER OF CULTURE
$0.040 \quad 0.020$
$0.010 \quad 0.004$
0.002
$0.001 \quad 0.0$

Diplococcus pneumoniae, Type I

$\begin{array}{lrrrrrrr}\text { Viability* } & - & - & - & - & - & + & +1+ \\ \text { Reductase } \dagger & \text { NR } & \text { NR } & \text { NR } & \text { NR } & \text { NR } & \text { NR } & \text { CR } \\ \text { Lysis§ } & \mathrm{C} & \mathrm{C} & \mathrm{C} & \mathrm{C} & \mathrm{C} & \mathrm{P} & \mathrm{N}\end{array}$

Streptococcus hemolyticus, Group A, Type 6

Viability*

Reductase $\dagger$

Lysis§

$\begin{array}{rrr}- & \\ N & N R\end{array}$

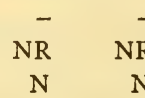

$\mathrm{N} \quad \mathrm{N}$

NR

$\begin{array}{rrr}- & H+ & +H+ \\ N R & \text { PR } & \text { CR } \\ \mathrm{N} & \mathrm{N} & \mathrm{N}\end{array}$

STAPHYLOCOCCUS AUREUS

Viability*

Reductase $\dagger$

Lysis§

$\begin{array}{rr}- & - \\ \mathrm{NR} & \mathrm{NR} \\ \mathrm{C}\end{array}$

$\begin{array}{rrrrr}- & H+1+ & H+ & H+1 & H+ \\ N R & \text { CR } & \text { CR } & \text { CR } & \text { CR } \\ \mathrm{N} & \mathrm{N} & \mathrm{N} & \mathrm{N} & \mathrm{N}\end{array}$

From Dubos and Cattaneo (208).

* - no growth on blood agar, + reduced growth, H+ abundant growth.

$\dagger N R$ no reduction of methylene blue, PR partial reduction, CR complete reduction.

$\S \mathrm{N}$ no lysis, $\mathbf{P}$ partial lysis, C complete lysis.

negative hemolytic bacilli showed disappearance of these bacteria within 2 hours following the administration of tyrothricin. Five days after a single treatment no hemolytic organisms were found in one monkey, and, in the other, only throat cultures were positive. A second application of the material gave completely negative cultures within 3 hours. No local or general reactions to these treatments were observed. This material was also administered to 5 human carriers of hemolytic streptococci, 2 of whom were persistent nasal carriers for two months following scarlet fever and the other three convalescent in the third week of this disease. In only one case was an immediate reduction in the number of streptococci obtained; a striking reduction or complete disappearance of the organisms occurred in the others on the fifth day, after 3 to 4 sprayings. These observations were said to be sufficiently encouraging to justify the use of the material against carriers harboring streptococci, diphtheria organisms, meningococci, and pneumococci. Injection of 3 to 40 $\mathrm{mg}$. tyrothricin into the pleural cavity of rabbits with hemolytic streptococcal empyema brought about the sterilization of the pleural cavity and 
enabled the animals to survive. The injection of $\mathrm{ro} \mathrm{mg}$. of tyrothricin into the pleural cavity of normal rabbits produced certain local tissue reactions. More than ro mg. produced adhesions, thickening of the pleura, sterile abscesses, and other disturbances (753).

The susceptibility of fecal streptococci to tyrothricin varies from strain to strain. Oral administration of the substance may produce inhibition of the growth of streptococci in the intestines of mice. This inhibition was most readily demonstrated when sulfasuxidine was administered together with the tyrothricin (799). Application of tyrothricin to ulcers brought about sterilization and healing of local infections. Application to the mastoid cavity following mastoidectomy also gave favorable results. In staphylococcic infections, resistant strains may develop during therapy. Certain sulfonamide-resistant strains of $S$. pyogenes were eradicated by application of gramicidin (29I).

Tyrothricin and tyrocidine exert a bactericidal effect, and gramicidin is largely bacteriostatic (Figure 28); the first two are affected by blood and serum, but not the last. In order to be effective against bacteria, the organisms must be in contact with the material (790). Gramicidin is more toxic than tyrocidine, the toxic dose being larger, however, than the dose necessary to kill most gram-positive cocci.

Both tyrothricin and tyrocidine cause hemolysis of erythrocytes, and both are leucocytolytic, gramicidin being less so. Both tyrothricin and gramicidin cause local and general toxic effects when injected into closed cavities of the body. Small amounts may bring about the sterilization of local infections without producing general toxic effects, giving only minimal local reactions. When injected into the skin, tyrothricin and gramicidin produce local reaction, the latter to a lesser degree. Oral administration is ineffective in reducing or destroying organisms which are susceptible in vitro. Local application of these substances has not been attended by toxic reactions even when large amounts were applied (758). Tyrothricin in high concentrations caused cytoplasmic and nuclear disintegration of the exudative rabbit polymorphonuclear leucocytes; in lower concentrations, it brought about altered staining reactions. When there was no apparent microscopic injury to the cells, phagocytosis of pneumococci took place. The presence of serum brought 


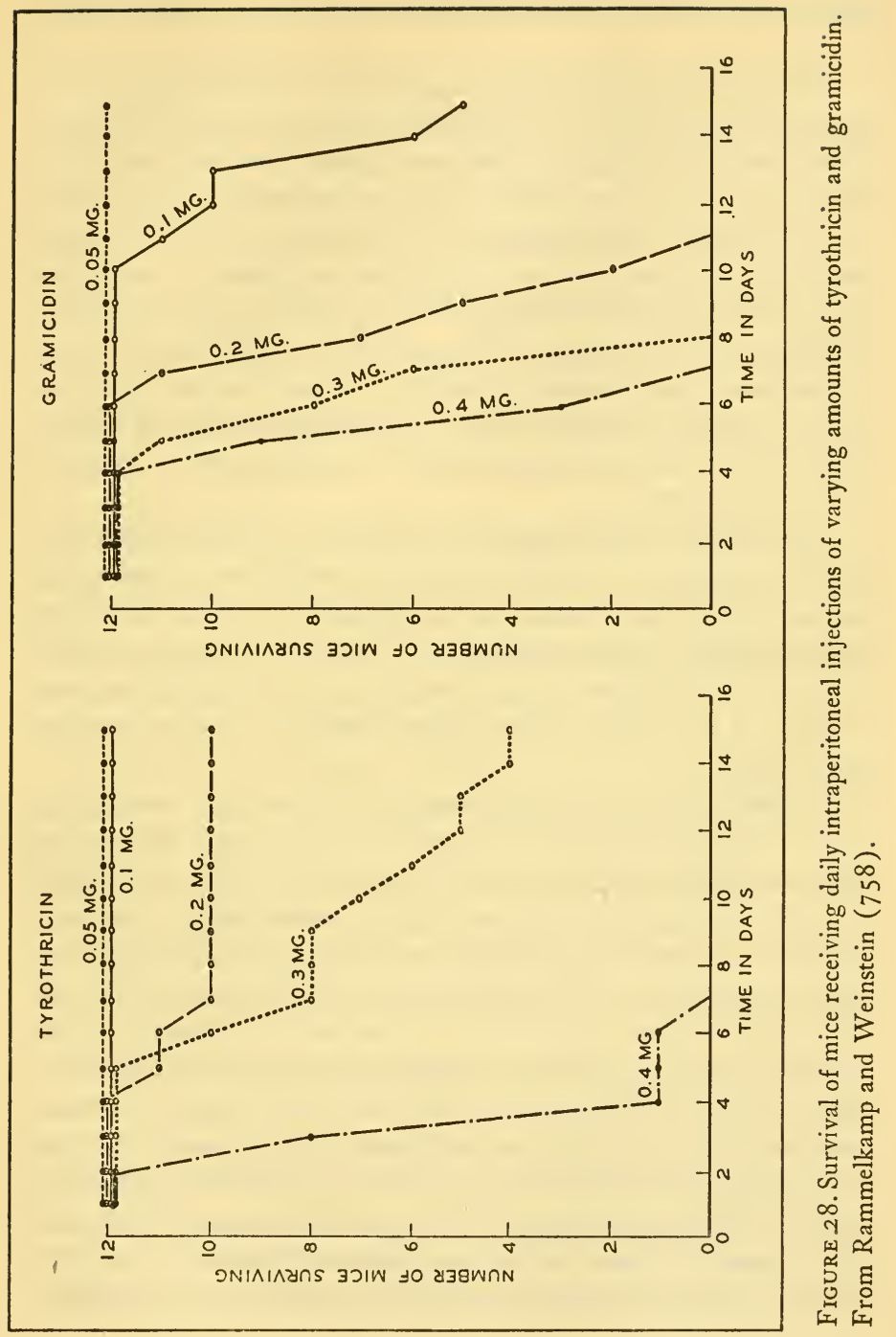


about some protection of the cells from the effects of these substances (I44).

When given intravenously in a 9.5 per cent alcoholic solution, tyrothricin was found (896) to be effective in the treatment of chickens infected with Plasmodium gallinaceum. It has a marked parasiticidal effect, especially on the extracellular merozoites produced at segmentation. Prolonged daily treatment of $100 \mathrm{gm}$. chickens with $0.2 \mathrm{mg}$. of material from the beginning of infection lengthens the incubation period of blood-induced infections, lowers the peak of acute infection, and prevents fatal relapses. When given in 12 daily doses, it has a quinine equivalent of about 4, the effective dose being, however, near the toxic level. Whereas tyrothricin is parasiticidal, quinine is parasitistatic, the first being also more effective in inhibiting oxygen consumption of the parasites.

Tyrothricin is limited, because of its toxicity, to topical applications; for that purpose, it has advantages over certain other antibacterial agents, such as the sulfonamides and penicillin, because of its stability, its wider range of antibacterial action, its activity in presence of blood and serum, its low tissue toxicity, and its lack of sensitizing properties (403a). It is ineffective when incorporated into common ointment bases (I9).

Particularly favorable results were obtained from the use of gramicidin in the treatment of chronic mastitis (576). Several cows received treatment with increasing amounts of gramicidin diluted with distilled water. Following the morning milking, the residual milk in the cistern and in the teat was flushed out with 100 to $200 \mathrm{ml}$. of the gramicidin solution, containing 60 to $240 \mathrm{mg}$. in I, $000 \mathrm{ml}$. water; 800 to $900 \mathrm{ml}$. were then injected under pressure into the quarter and allowed to remain until the next milking. Within one hour after the injection, the treated quarter became distended and rectal temperature began to increase, reaching $4 \mathrm{I}^{\circ} \mathrm{C}$. at the fifth or sixth hour. The temperature returned to nearly normal in about 3 hours thereafter, the acute swelling having subsided at the next milking. The streptococci disappeared from most of the quarters treated, without an appreciable decrease in milk production. The fact that streptococci had been eliminated was established 
by daily bacteriological examination of the milk over periods ranging from 15 to 8 I days.

Sterile mineral oil was later found (577) to be a suitable, nonirritating medium for the administration of the gramicidin, though some of the cows thus treated gave severe reactions. An alcoholic solution ( 2 to $3 \mathrm{ml}$.) of 80 to $120 \mathrm{mg}$. gramicidin was emulsified in $15 \mathrm{ml}$. sterile distilled water, and the emulsion mixed with $25 \mathrm{ml}$. of heavy mineral oil. The mixture was injected into the cistern shortly after the morning milking and allowed to remain until the evening milking. The treatment was repeated for several days in succession. Of 3 I quarters naturally infected with Streptococcus agalactiae and treated by the gramicidin-oil mixture, 26 seemed to have responded by a complete disappearance of the streptococci. The infection in some of the cases was of severe chronic nature.

Less satisfactory results were obtained in the treatment of bovine mastitis caused by Streptococcus uberis; of 4 cases treated, only one responded satisfactorily. The final recommendation was the daily use for four consecutive days of 20 to $40 \mathrm{mg}$. gramicidin in oil. These results were confirmed by various investigators, who reported 60 to 90 per cent cure after two or three treatments $(622)$.

A comparison of tyrothricin, trypaflavin, and novoxil for eradicating S. agalactiae from infected udders showed best results for the first. Infections with $S$. uberis and Streptococcus dysgalactiae also responded well, but not staphylococcic infections (829). The efficacy of the treatment is influenced by several factors, namely, (a) site of chronic infection, (b) selection of suitable cases, and (c) stage of lactation. In some experiments, as many as 90 per cent of the cases were cleared up with tyrothricin (96).

Gramicidin-like preparations were also used successfully in the treatment of local infections in man. The active material must be used locally on infected cavities which do not communicate with the blood stream (4I2). Tyrothricin has also been used ( 160 ) successfully in the treatment of acute otitis media, acute and chronic mastoiditis, and acute and chronic sinusitis. The substance does not damage the tissue or interfere with wound healing. The growth of most staphylococci, strepto- 
cocci, and pneumococci is inhibited or the organisms are killed. When applied locally, tyrothricin does not reach the blood stream. It has also been found that tyrothricin has an excellent therapeutic effect when used for urethral irrigations in the male (198). In a recent summary, it was reported (528) that tyrothricin can be used successfully as a wet dressing in surgical infections; it was most effective in hemolytic streptococcal lesions and next in $S$. aureus and $S$. albus lesions. It actually encouraged the growth of Ps. aeruginosa and $C$. diphtheriae.

Tyrothricin possesses several limitations, from the point of view of practical utilization: (a) development of bacterial, notably staphylococcus, variants, which become resistant to this agent; (b) inhibition of its action by phospholipins; (c) hemolytic action, which prevents its intravenous use.

The filtrate of $B$. mesentericus was found (984) to have a specific bactericidal action on $C$. diphtheriae in a dilution of $\mathrm{I}: \mathrm{I}, 250$. When injected parenterally into guinea pigs, it inhibited the toxic effect of the diphtheria organism. The filtrate of the antagonist was found useful in the treatment of diphtheria carriers.

Gramicidin S appears to be quite different from tyrothricin, since it crystallizes readily when an alcoholic extract of the acid precipitate of the bacterial culture is allowed to evaporate. It is four times more efficient in the killing of staphylococci than tyrothricin, although both have similar toxicity. It is effective against various gram-negative bacteria, such as $E$. coli and $P$. vulgaris. Aqueous solutions ( 0.4 to $0.8 \mathrm{mg}$. per $\mathrm{ml}$.) were applied daily for 4 to 5 days to gunshot wounds of soft tissues at the stage of necrosis, to severe burns, abscesses of the abdominal wall, and anaerobic infections; this was followed by gramicidin ointments every 2 to 3 days, with highly favorable results. There was no loss in potency in the presence of pus, no tissue irritation, with a favorable effect on regeneration and epithelization $(324,589,850)$. The possible relation of the last phenomenon to cell malignancy has been suggested (546).

\section{Subtilin and Bacitracin}

The toxicity index of subtilin has been defined (8I6) as the ratio of the highest dilution of this antibiotic that kills embryonic chick heart 
tissue after an exposure period of Io minutes at $37^{\circ} \mathrm{C}$. to the highest dilution that kills $S$. aureus under the same conditions. A unit of subtilin has been defined as that amount present in I ml. of the highest dilution (expressed in mg.) capable of killing $S$. aureus in Io minutes at $37^{\circ} \mathrm{C}$.

It is relatively nontoxic when tested by the tissue culture method; it is about 20 times more toxic to $S$. aureus than to chick heart tissue. It exerted a suppressive effect upon experimental tuberculosis in guinea pigs, and protected animals against infection with pneumococcus Type III and $B$. anthracis.

Bacitracin appears to have chemotherapeutic potentialities.

\section{Pyocyaneus Preparations}

Although, as pointed out previously, pyocyanase, the first antibiotic to be isolated, came into disrepute as a potential chemotherapeutic agent, various preparations of $P_{s}$. aeruginosa have continued to receive attention. One must differentiate among the lipoidal products and other antibiotics isolated either from the culture medium or from the bacterial cells of this organism (50a). The lipoid products obtained by chloroform extract of bacterial cells were found to be active against various gram-positive bacteria including $M$. tuberculosis in concentrations of I:500 (I 5 minutes) to I:500,000 ( 5 hours); it was effective not only in vitro but also in vivo. a-oxy-phenazine obtained in a crystalline state was active against various gram-positive and gram-negative bacteria. It was effective against bovine mastitis and $\mathrm{Br}$. abortus in guinea pigs ( 1053 ).

\section{Streptothricin and Streptomycin}

Among the antibiotic substances that are active against gram-negative bacteria both in vitro and in vivo, streptothricin and streptomycin occupy a prominent place. Their toxicity is low enough to make possible the administration of doses sufficient to destroy the pathogens in the living tissues $(792,794)$. In the very first experiments, using chicken egg embryos, mice, and other experimental animals, they gave favorable results in the treatment of $\mathrm{Br}$. abortus, bacillary dysentery, typhoid fever, and food poisoning produced by Salmonella organisms and 
other pathogens. Mycobacteria are readily inhibited by both streptothricin ( 1029) and streptomycin (232, 83I). Different strains of $M$. tuberculosis vary greatly in their sensitivity to the same substance. The same is true of the sensitivity to streptomycin of different strains of Erysipelothrix and various saprophytic and parasitic actinomycetes.

When given parenterally, streptomycin, injected daily in doses of 50,000 units ( $50 \mathrm{mg}$. of pure base) per $\mathrm{kg}$. for one month, was well tolerated by mice, rats, and monkeys. Injected subcutaneously, Ioo $\mu \mathrm{g}$ gave protection to mice against I0,000 lethal doses of the pathogen. Feces of mice fed streptomycin was sterile as far as lactose-fermenting bacteria were concerned; the total population was considerably reduced. Seventy per cent of the streptomycin was excreted in the urine in 5 to 6 hours. In order to maintain proper blood concentration it has to be administered, therefore, by frequent intramuscular injections or by continuous intravenous drip (746, 791, 795).

Streptomycin was found to be effective in the treatment of a variety of experimental infections caused by various gram-negative bacteria, including Br. abortus (478), Sh. gallinarum (478), S. schottmülleri (795), P. tularensis (397), the Friedländer bacillus or Klebsiella (398), D. pneumoniae (795), M. tuberculosis (249), and a number of others, especially the organisms commonly found in urinary infections (4OI). In a comparative study of several human strains of $M$. tuberculosis, the bacteriostatic concentration of streptomycin was shown to vary from 0.095 to $0.78 \mu \mathrm{g}$ per $\mathrm{ml}$; the effect was not influenced greatly by either the number of organisms or the presence of human plasma (Table 46). The bactericidal action of streptomycin upon human tubercle bacilli was slight as compared with its bacteriostatic action, nearly $100 \mu \mathrm{g} / \mathrm{ml}$. being required to kill o.I $\mathrm{mg}$. of virulent bacterial cells ( I039).

In the treatment of mice infected with the tularemia organism (Table 47), the controls died within 96 hours after inoculation, those receiving I,O0O units or I $\mathrm{mg}$. of pure streptomycin daily, for Io days, survived; smaller amounts of streptomycin gave incomplete protection (397). Infections caused by various other organisms, such as Borrelia novyi and Leptospira icterohaemorrhagiae (Table 48), can also be treated with streptomycin (399). Streptomycin is not effective in the 
treatment of avian malaria (848), and has little activity upon fungi and anaerobic bacteria.

TABLE 46. EFFECT OF NUMBER OF ORGANISMS AND PRESENCE OF PLASMA ON THE BACTERIOSTATIC ACTION OF STREPTOMYCIN ON

M. TUBERCULOSIS VAR. H. 37

INOCULUM

CONCENTRATION OF STREPTOMYCIN, MCG. PER ML.
1.56
0.78
0.39
0.19
0.095

Without Human Plasma

$\begin{array}{llllll}0.1 \mathrm{mg} . & \mathrm{O} & \mathrm{O} & \mathrm{O} & \mathrm{S} & \mathrm{M} \\ 0.5 \mathrm{mg} . & \mathrm{O} & \mathrm{O} & \mathrm{S} & \mathrm{S} & \mathrm{M} \\ & \mathrm{O} & \mathrm{O} & \mathrm{S} & \mathrm{M} & \mathrm{M} \\ 1.0 \mathrm{mg} . & \mathrm{O} & \mathrm{O} & \mathrm{S} & \mathrm{M} & \mathrm{M} \\ & \mathrm{O} & \mathrm{O} & \mathrm{M} & \mathrm{M} & \mathrm{M} \\ & \mathrm{O} & \mathrm{O} & \mathrm{M} & \mathrm{M} & \mathrm{M}\end{array}$

Ten Per Cent Human Plasma Added

\begin{tabular}{|c|c|c|c|c|}
\hline O.I mg. & $\mathrm{O}$ & $\mathrm{O}$ & $\mathrm{O}$ & M \\
\hline & $\mathrm{O}$ & $\mathrm{O}$ & $\mathrm{O}$ & M \\
\hline $0.5 \mathrm{mg}$. & $\mathrm{O}$ & $\mathrm{O}$ & G & G \\
\hline & $\mathrm{O}$ & $\mathrm{O}$ & G & G \\
\hline $1.0 \mathrm{mg}$. & $\mathrm{O}$ & $\mathrm{O}$ & G & G \\
\hline & 0 & $\mathrm{O}$ & G & G \\
\hline
\end{tabular}

From Youmans (1039).

Note. O indicates no growth; S, slight growth; $M$, moderate growth; G, profuse growth.

TABLE 47. EFFECT OF STREPTOMYCIN ON MICE INOCULATED WITH PASTEURELLA TULARENSIS

\begin{tabular}{|c|c|c|c|c|c|c|c|}
\hline \multirow{4}{*}{ DOSAGE } & NUMBER & & MORTALITY \\
\hline & OF MICE & \multirow{2}{*}{\multicolumn{5}{|c|}{$\begin{array}{l}\text { NUMBER OF MICE THAT } \\
\text { DIED AFTER INOCULATION }\end{array}$}} & RATE PER \\
\hline & TREATED & & & & & & 100 \\
\hline & & $\begin{array}{c}3 \\
\text { days }\end{array}$ & $\begin{array}{c}4 \\
\text { days }\end{array}$ & $\stackrel{5}{\text { days }}$ & $\begin{array}{c}8-23 \\
\text { days }\end{array}$ & Total & \\
\hline Iooo $\mu \mathrm{g}$ per day & 30 & 0 & 0 & o & 0 & 0 & o \\
\hline $500 \mu \mathrm{g}$ per day & 12 & 0 & 0 & 4 & I & $5^{*}$ & 42 \\
\hline None & 30 & 13 & 17 & o & 0 & 30 & 100 \\
\hline
\end{tabular}

From Heilman (397).

* Two other mice died of pneumonia on the twenty-sixth and thirty-second days. 
Some very striking results have been obtained in the treatment of experimental tuberculosis in guinea pigs (Table 49). On the basis of an arbitrarily established index of infection, microscopically determined, roo represented the maximum possible amount of tuberculosis. The control animals, sacrificed after 61 days, exhibited an index of 67 as contrasted to 5.8 for those which had received streptomycin. In another experiment, the corresponding values were $8 \mathrm{I} .9$ for the untreated and 2.8 for the treated animals. The daily administration of streptomycin per pig varied from 1,387 to $6,000 \mathrm{mg}$. Two different strains of the human tubercle bacillus were equally sensitive to streptomycin in vivo (250).

Streptomycin was pronounced to be "the most effective in vivo tuberculochemotherapeutic agent which we have studied and which we have seen reported in the literature." It has been repeatedly shown that antibacterial agents active against $M$. tuberculosis in vitro may be of little value in combating the infection in vivo; since experimental tuberculosis in guinea pigs may be quite distinct from that produced by the same organism in man, the application of results obtained in animals to its possible effect in humans is largely speculative.

The ability of streptomycin to check and retard the normal course of tuberculosis infection in guinea pigs has been confirmed. By combining streptomycin and promin, it was possible to obtain results unlike anything heretofore obtained in the treatment of experimental tuberculosis infections (862). The combination was also found (1040) to have a marked suppressive effect on experimental pulmonary tuberculosis in mice.

Both the toxicological and pharmacological properties of streptomycin readily allow its use in the treatment of diseases in man. Pure streptomycin, as well as many impure concentrated preparations, have been given at therapeutic levels, in doses as high as 4 gm. daily, without any unfavorable reactions.

Blood levels following intravenous injections can be better maintained with streptomycin than with penicillin, detectable amounts of the first being present for 6 hours compared with 2.5 to 3 hours for the second. Following parenteral administration, most of the streptomycin is excreted in the urine. It is distributed throughout the body fluids: 
blood, urine, ascitic fluid, pleural fluid, aqueous humor, vitreous humor, amniotic fluid, and bile. Small amounts of the drug appear in the spinal fluid in healthy individuals, but in a single case of Hemophilus influenzae meningitis the spinal fluid contained $25 \mu \mathrm{g}$ per cc.

TABLE 48. COMPARISON OF THE EFFECT OF STREPTOMYCIN AND PENICILLIN ON INFECTION WITH LEPTOSPIRA

ICTEROHAEMORRHAGIAE IN HAMSTERS

\begin{tabular}{|c|c|c|c|c|c|}
\hline \multirow{4}{*}{ DOSAGE* } & \multirow{4}{*}{$\begin{array}{l}\text { NUMBER OF } \\
\text { HAMSTERS } \\
\text { TREATED }\end{array}$} & \multirow{3}{*}{\multicolumn{3}{|c|}{$\begin{array}{l}\text { NUMBER OF HAMSTERS THAT } \\
\text { DIED AFTER INOCULATION }\end{array}$}} & \multirow{4}{*}{$\begin{array}{c}\text { MORTALITY } \\
\text { RATE PER } \\
\text { IOO }\end{array}$} \\
\hline & & & & & \\
\hline & & & & & \\
\hline & & $\begin{array}{l}7-14 \\
\text { days }\end{array}$ & $\begin{array}{c}15-22 \\
\text { days }\end{array}$ & Total & \\
\hline \multicolumn{6}{|l|}{250 units per day: } \\
\hline Streptomycin & 6 & 5 & I & 6 & 100 \\
\hline Penicillin & 6 & 0 & 6 & 6 & 100 \\
\hline \multicolumn{6}{|c|}{500 units per day: } \\
\hline Streptomycin & 6 & 4 & 0 & 4 & 67 \\
\hline Penicillin & 6 & 0 & 0 & 0 & 0 \\
\hline \multicolumn{6}{|c|}{800 units per day: } \\
\hline Streptomycin & 6 & 0 & 0 & 0 & 0 \\
\hline Penicillin & 6 & 0 & 0 & 0 & o \\
\hline None & I 2 & 12 & o & 12 & 100 \\
\hline
\end{tabular}

From Heilman (399).

* Streptomycin and penicillin are measured by totally different systems: a streptomycin unit is a milliliter dilution unit against $E$. coli; an Oxford unit of penicillin is $1: 50,000$ against $S$. aureus.

TABLE 49. EFFECT OF STREPTOMYCIN UPON THE DEVELOPMENT OF HUMAN TUBERCULOSIS IN GUINEA PIGS

\begin{tabular}{lccc}
\hline & $\begin{array}{c}\text { DURATION OF } \\
\text { INFECTION, } \\
\text { IN DAYS }\end{array}$ & $\begin{array}{c}\text { DURATION OF } \\
\text { TREATMENT, } \\
\text { IN DAYS }\end{array}$ & $\begin{array}{c}\text { INDEX OF INFECTION } \\
\text { DETERMINED } \\
\text { MICROSCOPICALLY }\end{array}$ \\
$\begin{array}{l}\text { EXPERIMENT I } \\
8 \text { control animals }\end{array}$ & $43-60$ & 0 & 81.9 \\
4 treated animals & 54 & $39-54$ & 2.8 \\
EXPERIMENT 2 & $6 \mathrm{I}$ & 0 & 67 \\
9 control animals & $6 \mathrm{I}$ & $47-6$ I & 5.8 \\
9 treated animals & & & \\
\hline
\end{tabular}

From Feldman, Hinshaw, and Mann (250). 
Relatively little transfer of streptomycin occurs between the blood and the lumen of the gastro-intestinal tract in either direction. Following oral administration, levels as high as $9 \mathrm{mg}$. per gm. were found in the feces. Because of the poor transfer of the drug across the walls of the alimentary tract, it was suggested that the drug be used both orally and parenterally in the treatment of infections such as those in which the pathogenic organisms are found both in the gastro-intestinal tract and in the blood stream $(230,393,1049)$.

When fed to mice in their diet streptothricin and especially streptomycin produced a very rapid reduction in the numbers of coliform and nonlactose-fermenting organisms in the feces. The amount of streptothricin required for effective reduction of the intestinal bacteria was one-half the toxic dose. Due to the lower toxicity of streptomycin the dose required was much below the toxic one and maintained the reduced number of organisms as long as therapy was continued. A distinct change in the intestinal flora was thus produced without increasing the resistance of the organisms (859).

In order to produce toxic manifestations in animals, it is necessary to administer either extraordinarily large amounts of the pure material or smaller amounts of certain impure preparations containing a histaminelike substance. No correlation was obtained between the acute toxicity of different lots to experimental animals and clinical tolerance by human beings. The behavior of the material in man cannot, therefore, be foretold if antibacterial potency alone is assumed to be the criterion of purity; highly concentrated material has on occasion been unsatisfactory clinically, whereas considerably less active preparations have often produced no undesirable effects.

Two distinctly different types of toxicity are possible. One, which is observed only with certain impure preparations, is due to a histaminelike substance. The general syndrome produced in man consists essentially of nausea, throbbing headache, general malaise, skin rash, pain in the joints, flushed face, vomiting, and drug fever, the last appearing two or three days after treatment and therefore not due to bacterial pyrogen. Local reactions at the sites of injection have also been encountered. These toxic manifestations are entirely absent when crystalline streptomycin, as well as many impure preparations, are used. By 
employing only pure streptomycin or impure concentrates which do not possess this factor it is possible to eliminate the undesirable side-reactions. The second kind of toxicity, which results in a fatty metamorphosis of the liver and kidney of animals, is an inherent property of streptomycin itself. However, this organ pathology has not been observed in man.

Streptomycin has been administered to man intramuscularly (every 3 to 4 hours, a daily total of $\mathrm{I}$ to $4 \mathrm{gm}$.), intravenously (intermittent or continuous, the latter comprising a daily dose of $\mathrm{I}$ to $4 \mathrm{gm}$.), and subcutaneously ( $100 \mathrm{mg}$. per I $\mathrm{ml}$., at 6-hour intervals). It has also been given orally ( 0.5 to $4 \mathrm{gm}$. per day in 4 doses) and by nebulization into the tracheobronchial tree ( 25 to $50 \mathrm{mg}$. per I ml., for a total of 500 mg. daily) as well as by intrathecal administration (4I4). By the intravenous route a high serum concentration is produced very rapidly, whereas the same level is obtained but more slowly after intramuscular or subcutaneous injection. However, the blood level falls rapidly following a single dose and must be maintained by repeated administrations. When given orally or by nebulization into the tracheobronchial tree, no appreciable amount of streptomycin is absorbed into the general circulation.

The intravenous injection of single doses of $200 \mathrm{mg}$. of streptomycin gives an immediate concentration in the serum of $32 \mu \mathrm{g}$ per $\mathrm{ml}$. This falls rapidly to $8 \mu \mathrm{g}$ at the end of two hours and to $\mathrm{I}$ or $2 \mu \mathrm{g}$ at the end of twelve hours. Intramuscular injection of the same amount gives a peak serum level of $\mathrm{i} 6 \mu \mathrm{g}$ at the end of one hour, followed by a slower drop in serum concentration, with detectable amounts after 12 hours. Streptomycin appears quickly in the urine, 20 to 35 per cent being recovered in 2 hours and 50 to 70 per cent in the 12 -hour period after administration of a single dose. The total recovery varies from 15 to 85 per cent of the daily dose, with an average of 53 per cent. When given parenterally, small amounts of streptomycin appear in the spinal fluid, namely, I to $2 \mu \mathrm{g}$ as compared to $25 \mu \mathrm{g}$ in the serum. Following oral administration, very little streptomycin reaches the serum, and only 0.2 to 0.5 per cent is found in the urine; however, there is a high concentration in the feces.

An intravenous injection of $600 \mathrm{mg}$. gave $32.8 \mu \mathrm{g}$ per ml. of blood 
in 15 minutes with a decrease to $4.9 \mu \mathrm{g}$ in six hours. Following a similar intramuscular injection, the rise was slower, with $26.5 \mu \mathrm{g}$ at 3 hours and $8 \mu \mathrm{g}$ at 6 hours per $\mathrm{ml}$. of blood. The recovery of the streptomycin in the urine varied during the first 24 hours, between 29 and 89 per cent, with an average of 66 per cent.

In the treatment of chronic infections of the urinary tract in man, streptomycin was found to be effective in destroying such gram-negative bacteria as $P$. vulgaris, $A$. aerogenes, $E$. coli, Ps. aeruginosa, and Eberthella sp. Four hours after commencement of streptomycin therapy ( $\mathrm{I} \mathrm{gm}$. of streptomycin daily in 8 divided doses given intramuscularly), urinary cultures were negative for $P$. vulgaris and, after 8 hours, for coliform organisms. In one case, the urine became negative for $E$. coli two hours after treatment. Though infections of the normal urinary tract were permanently cleared up, reinfection was likely to occur in damaged tracts, the catheter serving as the portal of entry for the new infection.

Streptomycin has also proved effective for the treatment of enteric and systemic diseases. In five severe to moderately severe cases of typhoid studied by Reimann (772), streptomycin was not administered until late in the development of the disease. Nevertheless, the clinical improvement of three patients coincided with the period of streptomycin therapy. Of the two unsuccessful cases, the treatment of one was prematurely discontinued because of the limited quantity of streptomycin available.

In a study of 45 patients suffering from a variety of infections, it was found (4I4) that good results were obtained in Io of 13 cases of moderately severe and severe infections of the urinary tract due to various pathogenic bacteria. Of 5 cases of infection involving the tracheobronchial tree, satisfactory results were obtained in 4. In some miscellaneous infections, comprising cases of typhoid fever, undulant fever, osteomyelitis, cellulitis, peritonitis, cholangitis, meningitis, and ozena, the results could be considered satisfactory. Of 8 cases of bacteriemia, 6 showed recovery. Doubtful results were obtained in 2 cases of undulant fever associated with bacteriemia. In 4 cases of syphilis it was doubtful whether treatment with streptomycin was effective, although 
failure may have been due to the small amount of streptomycin administered.

Salmonella as well as $E$. coli infections lend themselves readily to treatment with streptomycin. A patient with a colony count of 23 million Salmonella in the stool gave a negative stool after 4 days' oral therapy with I gm. streptomycin daily, the number of $E$. coli was reduced simultaneously to about 1,$000 ; S$. faecalis disappeared and the clostridia were reduced from 75,000 to 8,000 . $P$.tularensis is one of the most sensitive organisms in vitro to the bactericidal action of streptomycin. Parenteral administration of relatively low doses proved successful in human tularemia. One patient who began to receive streptomycin on the eighth day of the disease was sent home as cured on the seventeenth day. In another case with perisplenitis and generalized infection of the peritoneal cavity, the peritoneal fluid was noninfective on the sixth day after treatment, whereas usually such fluid is infective for at least nine months. Seven patients who had received streptomycin all responded promptly.

In a study of 34 tuberculous patients treated with streptomycin for nine months, streptomycin exerted a limited suppressive effect, especially on some of the more unusual types of pulmonary and extrapulmonary tuberculosis. The reproduction of $M$. tuberculosis may have been temporarily inhibited by the treatment; there was no evidence, however, of rapidly effective bactericidal action. It was suggested that studies be made of early pulmonary tuberculosis, tuberculosis of the genito-urinary tract, suppurative tuberculous lymphadenitis, and early miliary and extensive hematogenous forms of tuberculosis (429).

In a recent summary (494a) of a thousand cases treated with streptomycin, the following results were recorded: In urinary tract infections ( 409 cases), the over-all recovery rate was 42 per cent. Of roo cases of H. influenzae meningitis, recovery was obtained in 79 per cent; the I 7 fatal cases received treatment too late. Of 14 cases of meningitis caused by other gram-negative organisms, 4 died. In 91 bacteremia cases, 49 recovered, 12 improved, 26 died; again, the fatal cases were treated too late. Striking results were seen in tularemia ( 63 recoveries 
out of 67 cases) and otitis media ( 7 immediate recoveries out of 8 cases). In pulmonary infections (44 cases), recovery or improvement was obtained in 6I per cent; streptomycin is extremely effective against acute Friedländer bacillus infections. No dramatic effects were seen in acute brucellosis ( 45 cases). In typhoid (5 I cases), streptomycin, if given early, accelerated return of temperature to normal. Of 26 cases with Salmonella infection, I 2 recovered, 8 died. Encouraging results were obtained in peritonitis ( 39 recoveries out of 53 cases).

Preliminary evaluation of streptomycin in tuberculosis was based on 75 cases. The results that have been observed in miliary tuberculosis, in tuberculosis of the meninges, and in tuberculosis of the larynx, skin, and renal tract were considered as highly suggestive that streptomycin exerts a bacteriostatic effect on the growth of the tubercle bacillus in man. The same can be said for exudative pulmonary tuberculosis. It was recommended that a minimum period of treatment should be three to six months with doses of I. 5 to $3.0 \mathrm{gm}$. a day. The over-all incidence of untoward side effects was 20.5 per cent. The commonest reactions in order of frequency were headache, fever, skin eruptions, flushing of the skin, and vertigo, alone or in various combinations.

For the treatment of tubercular meningitis, intrathecal administration of IOO mg. daily has given encouraging results, especially when combined with parenteral administration ( I 52a).

Failures of streptomycin therapy were attributed to the following factors: treatment of infections not susceptible to streptomycin; inadequate dosage; development of resistance to streptomycin in vivo; change in the species of infecting organism during treatment; and localization of infection in an inaccessible area. In view of the development of resistance of bacteria to streptomycin, as can easily be demonstrated in urinary tract infections, it was recommended ( 5 I Ia) that high initial doses be used.

\section{Other Agents}

The protective action of the specific enzyme (polysaccharidase) of a soil bacterium against type III pneumococcus infection has also been established (3ra). The specific protection induced in experimental animals is determined by the nature of the polysaccharide of the pneu- 
mococcus type. The polysaccharidase destroys the protective capsular substance of the pneumococcus, thus rendering it susceptible to phagocytosis.

The toxicity of many other antibiotics to animal tissues prevents their consideration as potential chemotherapeutic agents. The range of toxicity and type of effect vary considerably, from the highly toxic actinomycin (796) to those which are characterized by lesser but still considerable toxicity, such as citrinin (I8).

Virulent strains of $M$. tuberculosis were found to lose their virulence in the presence of certain other organisms or their products. According to Vaudremer, this phenomenon occurs when the tubercle organism is kept for 24 hours at $39^{\circ} \mathrm{C}$. in contact with a filtered extract of $A$. fumigatus, and a similar effect can be exerted by certain bacteria. On the other hand, extracts of $A$. fumigatus were used for the treatment of 200 tuberculous patients, with rather inconclusive results $(740,934)$.

Treatments of intestinal disturbances by the use of antagonistic microorganisms, although highly promising, have not been sufficiently investigated as yet. It may be of interest to note, in this connection, that the presence in human intestines of $E$. coli with a high antagonistic index is considered as important evidence of immunity of certain individuals to intestinal disturbances $(387,618,66 \mathrm{I}, 68 \mathrm{I})$.

\section{ANTIFUNGAL ACTION OF ANTIBIOTIC SUBSTANCES}

The ability of certain antibiotic substances to inhibit the growth of various fungi has been brought out previously. For test purposes, a strain of Trichophyton mentagrophytes (T. gypseum) is used (240). The fungus is grown on a peptone-glucose agar medium of $p \mathrm{H} 5.6$ to 5.8 , and a spore suspension prepared from ten-day-old mycelial growth by shaking with glass beads. The spore suspension is then streaked over agar plates containing varying concentrations of the antibiotic, or added to a series of tubes containing graded concentrations of the agent, in a manner similar to determination of phenol coefficient.

- Although a large number of substances are thus found to have definite activity, they vary greatly in their usefulness because of variation in toxicity. Some, like actinomycin, are extremely toxic; others, 
like clavacin, less so. Only a few appear to offer definite promise (77I, 883) for the practical control of fungus infections, notably hemipyocyanin, gliotoxin, and streptothricin. In addition to clavacin and gliotoxin, certain other fungus products appear to show some promising action against fungi pathogenic to man. These include mycophenolic acid and aspergillic acid (8 8 8).

The possibility of utilizing antagonistic bacteria for the control of fungi causing skin infections has also been suggested (I29).

\section{TOXICITY OF ANTIBIOTIC SUBSTANCES}

The various antibiotic substances obtained from microorganisms vary greatly in their toxicity to animals. The therapeutic use of many of these agents, like actinomycin and clavacin, which are highly bacteriostatic, may be considered as either entirely excluded for the present or limited to local applications. Some substances, as pyocyanase, penicillin, and streptomycin, are relatively nontoxic (790); others, like tyrothricin (793), streptothricin, and fumigacin (788), are slightly toxic; and still

TABLE 5O. MAXIMAL TOLERATED DOSE FOR MICE OF VARIOUS ANTIBIOTICS

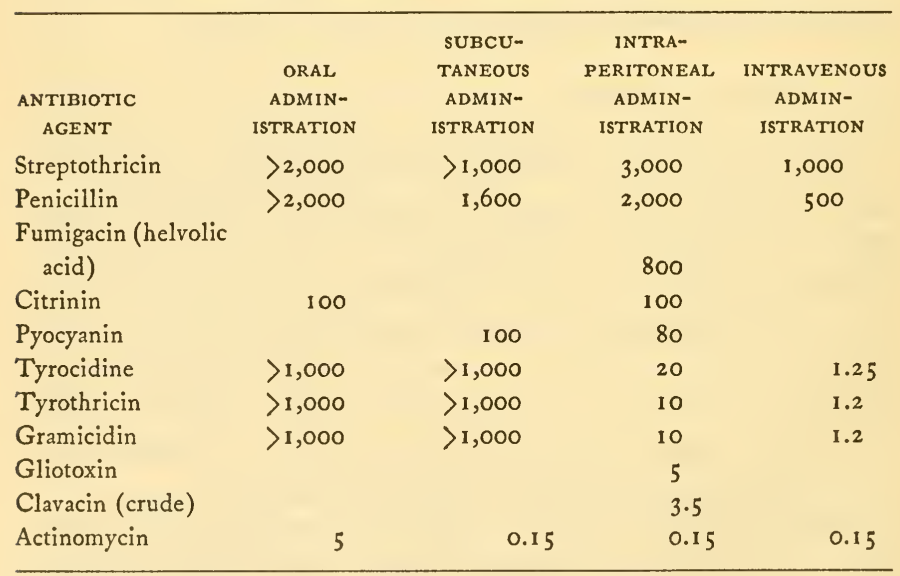

From Robinson (788).

Note: Figures represent maximal tolerated dose in $\mathrm{mgm} . / \mathrm{kgm}$. 
others, like actinomycin and clavacin, are highly toxic (796, 966). Some, like tyrothricin, are hemolytic (396, 6r 7); others, like penicillin, streptomycin, and streptothricin, are not (Table 50).

A great deal of additional information has recently accumulated on the problem of toxicity and chemotherapy of antibiotic substances. Reference need only be made to the discussions of penicillin, streptomycin, and some of the more recently isolated antibiotics, such as subtilin and bacitracin. 


\section{MICROBIOLOGICAL CONTROL OF SOIL-BORNE PLANT DISEASES}

$T_{H E}$ possibility of controlling microorganisms, especially fungi, in the soil by favoring the development of antagonistic microorganisms is significant for several reasons: Fungi are causative agents of some of the most important diseases of plants and are added constantly and often quite extensively to the soil, in plant residues and in diseased plant products; fungi capable of causing certain diseases of animals and of man also find their way sooner or later into the soil; many soil-inhabiting fungi have a marked antagonistic effect against fungus and bacterial plant pathogens.

Some fungi that produce plant diseases are able to survive in the soil for only short periods of time; others become established in the soil saprophytically and remain capable of attacking living plants when proper conditions arise. Some of these fungi are specific, their ability to attack different plants being limited, whereas others can cause diseases of a great variety of plants and many survive in infected soil for long periods. Some plant diseases, as in the case of virus infections, are transmitted by specialized means, as by insect carriers. This complicates further the interrelationship among the different organisms, in relation to plant and animal diseases.

Microorganisms causing diseases of plants may either reduce the vigor and productivity of the plants or destroy them completely. Plants appear to develop at times a certain degree of resistance to microbial infection. Whether this is in the nature of a phenomenon of immunization, similar to that of animals, is still a matter of speculation. Whatever the nature of the reaction, the degree of resistance depends to a certain extent upon the imperviousness of the outer layers of the plant tissues to penetration by the parasites, as well as upon the chemical composition of the plants. It is believed that an acid plant reaction, combined with the presence of tannins and lignins, retards the growth of many disease-producing agents. The survival of the pathogens outside 
the host plant is due to the formation of resistant spores which remain viable in the soil for long periods. Because of this, the growth of many plants requires a long rotation if this system is to be used as a means of controlling the specific diseases.

Many fungi and bacteria causing plant diseases were at first thought capable of surviving in the soil for an indefinite time, even in the absence of the hosts. It has since been established, however, that, although the majority of these pathogens are facultative saprophytes, some are obligate parasites. The first can be grown easily on sterile soil and on artificial culture media, whereas the second, such as Plasmodiophora brassicae and Synchytrium endobioticum, have not been cultivated so far upon any artificial media and are known to die out in the soil in the absence of host plants.

Certain soil-borne plant diseases may be caused by more than one organism. In the pink-root of onions (376), Phoma terrestris is followed by $F$ usarium malli; in the take-all disease of wheat, O. graminis is followed by Fusarium culmorum. This type of sequence occurs with other diseases, where the primary parasite first attacks the root and is followed by a succession of other fungi, both parasites and saprophytes. By means of the direct microscopic technique, the sequence of microorganisms can be demonstrated in the infected roots of the plants. Certain less specialized parasites are able to live saprophytically on the dead tissues, whereas the saprophytes are found only in the later stages of decomposition.

It has been suggested $(316,317,774)$ that root-infecting fungi be classified ecologically as soil inhabitants and soil invaders. The first may be looked upon as primitive or unspecialized parasites with a wide host range, their parasitism being considered incidental to their saprophytic existence in the soil. The second group comprises a majority of rootinfecting fungi, the more highly specialized parasites. The presence of these in the soil is closely associated with the occurrence of the host plants: in the absence of a host, these fungi die out in the soil, because of their inability to compete with the soil saprophytes. The close association between this group of organisms and their host plants is believed to be enforced by competition with the microbiological population of the soil. 


\section{ANTAGONISM OP SOIL-INHABITING MICRO- ORGANISMS TO PLANT PATHOGENS}

The antagonistic interrelationships among the members of the microbiological population of the soil have received particular attention from the point of view of modifying the virulence of those plant pathogens, especially the fungi, that find temporary or permanent habitat in the soil.

In the infection of wheat seedlings by $O$. graminis, a number of fungi and bacteria are able to exert a marked antagonistic action against the pathogen ( 822 ). Not only the living cultures of the antagonists, but, in many cases, the culture filtrates are also effective $(542,1024)$. The growth of $H$. sativum and $F$. graminearum upon sterilized soil was completely suppressed (407) by the addition of small amounts of unsterilized soil or by the simultaneous inoculation with harmless fungi and bacteria, with the result that no infection occurred when wheat seeds were inoculated with this soil. Although $H$. sativum is able to sporulate readily in sterilized soil, this does not take place in nonsterilized soil, sporulation being inhibited by the soil microorganisms. Virulence of $H$. sativum on wheat seedlings was reduced by i I to 57 per cent by certain cultures of Penicillium; Trichoderma reduced virulence by 50 to 58 per cent, Absidia glauca by 39 per cent, and A. nidulans by 30 per cent. Many fungi, however, had no effect on the virulence of the pathogen, and some even increased it (823). The fact that root-rot diseases are less severe on wheat grown on summer-fallowed land than on land cropped to wheat for several years was believed to be due to the soil saprophytic microorganisms, which in bare fallow have an advantage over the pathogenic organisms in competition for food (Figures 29 and 30 ).

The infection of wheat seedlings by $O$. graminis in sterile soil was found to fall off rapidly with the reestablishment of the original soil microflora (87). It was emphasized, however, that the effect of various organisms upon the pathogen grown in artificial culture media is no proof that the same organisms will be able to suppress the virulence of the pathogen on wheat in soil. An inverse correlation was shown (656) to exist between the degree of infection and the protective effect of the 


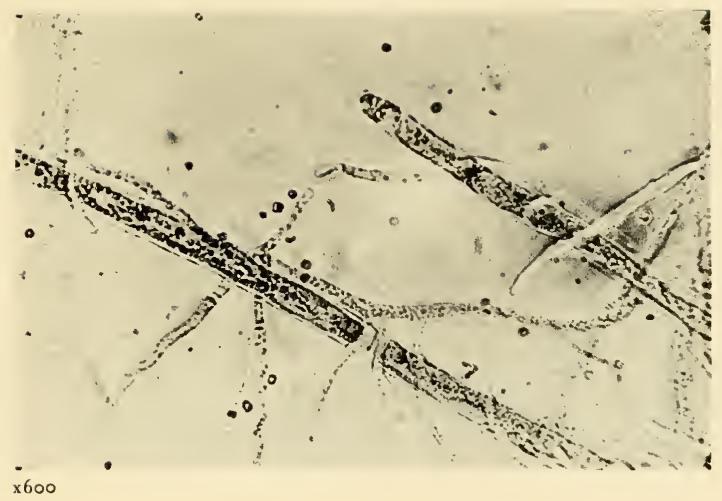

FigUre 29. An antagonistic fungus, Trichoderma, attacking a plant pathogenic fungus, $S$. rolfsii, showing one break of a septum. From Weindling (990).

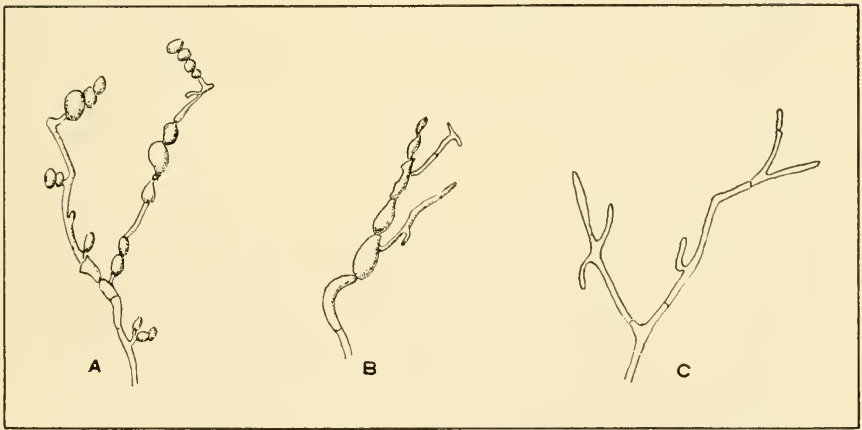

Figure 30. Influence of antagonists upon the growth of Helminthosporium. Distortion of mycelium by Bacterium sp. (A) and B. ramosus (B). C is a normal mycelium. From Porter (729). 


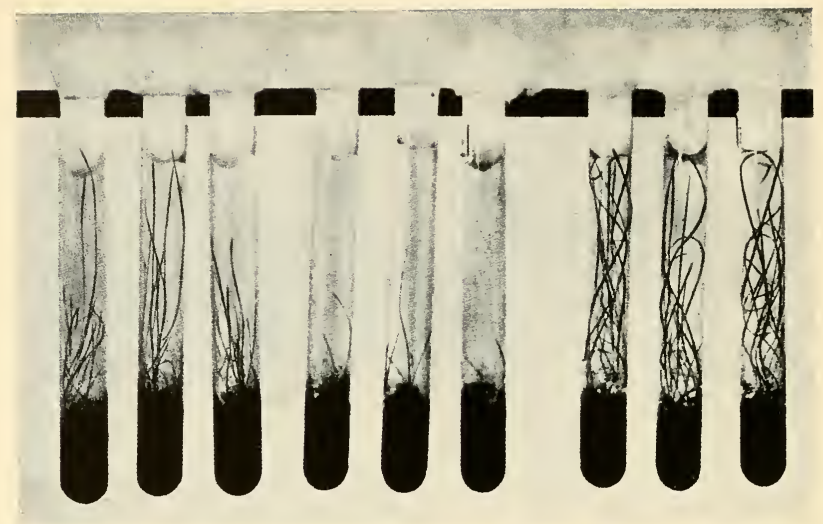

Figure 3I. Antagonism of soil organisms against parasitism of $P$. volutum on Agrostis. From van Luijk (930).

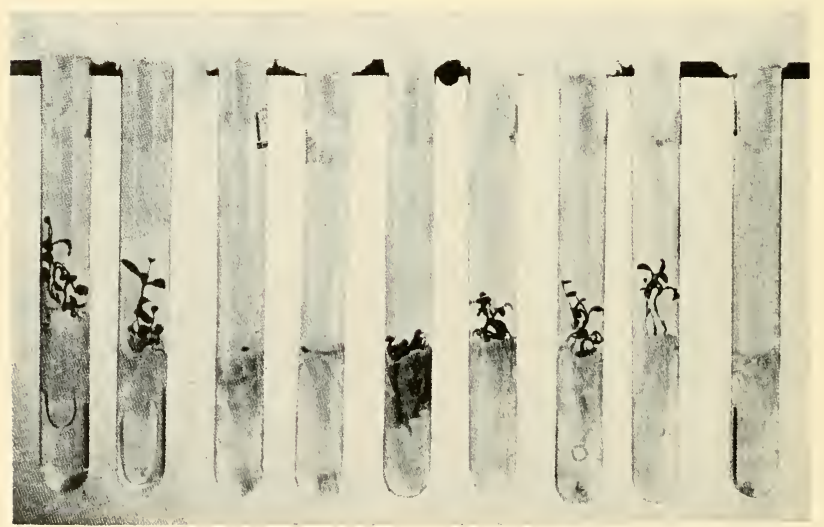

Figure 32. Inhibiting effect of sterilized liquid medium of $P$. expansum versus Pythium de Baryanum on lucerne. From van Luijk (930). 
general soil microflora; this was determined by comparing infection in an unsterilized soil with that obtained in a sterilized soil. An increase in soil temperature was found (408) to increase the antagonistic action of the soil microflora against the parasitic fungi causing cereal root rot.

Various actinomycetes were shown to be antagonistic (908) to species of Pythium, a root parasite of sugar cane. The phenomenon of antagonism was independent of the $\mathrm{pH}$ changes; it has been ascribed to the formation of a toxic, partly thermostable, principle. A marked influence of the soil microflora on grass diseases caused by Pythium is illustrated in Figures 31 and 32. Clavacin (patulin) was found capable of inhibiting the growth of various species of Pythium (the cause of damping-off disease of seedlings) in dilutions of about $r: 400,000$, and of exerting a strong fungicidal action upon Ceratostomella ulmi, the causative agent of the Dutch elm disease; the last effect could be overcome partly by certain nutrients in the medium, especially peptone (949).

Numerous soil microorganisms are moderately or strongly antagonistic to such pathogens as Hypochnus centrifugus, Hypochnus sasakii, and Sclerotium oryzae sativae (24I); culture filtrates from some of the antagonistic fungi were also able to reduce the damage caused by the pathogens. Phytophthora cactorum was found ( $\mathrm{IOO}_{3}$ ) to be inhibited in rotted tissues by the antagonistic effects of secondary organisms. In many cases, the rotting of fruits was suppressed by mixtures of organisms but not by the pathogens alone; the type of rot was also modified, depending on the temperature and the specific nature of the antagonists (827). Phytomonas tumefaciens, the causative agent of crown gall in plants, can be controlled by means of crude penicillin ( 92 ).

The stimulating effect of mycorrhizal fungi on the host plant has been attributed (297) to the capacity of the fungi to inactivate, destroy, or absorb certain plant-retarding principles found among the organic constituents of peat and other humus materials, or produced by fungi. On the other hand, the toxicity of certain soils to mycorrhiza has been explained (83) as due to the accumulation of antibiotic substances by the fungus population of the soil. This concept is purely hypothetical and is not based upon experimental evidence.

Certain fungi are also known (340) to be antagonistic to ants and 
their fungal symbionts. These antagonists are distributed by the insects, thus spreading agents that are destructive to themselves and to their fungus gardens.

\section{GENERAL METHODS OF CONTROL OF SOIL-BORNE DISEASES}

Soil sterilization by heat and chemicals has long been practiced as a method of controlling soil-borne fungus diseases. This phenomenon is usually designated as partial sterilization of soil, since not all microorganisms are killed by these treatments. However, once a soil thus treated becomes reinfected with a disease-producing organism, the infection may become much more severe. It has, therefore, been suggested (383) that partially sterilized soil be reinoculated with a mixture of saprophytic microorganisms before it is used as a seedbed, so as to counterbalance the injurious effect of the parasites (Table $5 \mathrm{I}$ ).

The importance of the soil microflora in modifying plant diseases caused by soil-borne pathogens is being realized more and more clearly. One of the earliest attempts to control a plant disease by microbiological agents was made in 1908 by Potter (73I). He found that Pseudomonas destructans, the cause of rot of turnip, produces a potent, heat-resistant toxin. The bacteria failed to grow in the presence of this toxin, and were completely killed by the substance. By spraying turnips with this mate-

\section{TABLE 5I. EFFECT OF A BACTERIAL ANTAGONIST ON DAMPING-OFF} OF PLANTS IN THE SOIL

\begin{tabular}{lcc}
\hline & $\begin{array}{c}\text { PERCENTAGE OF SEEDS PLANTED } \\
\text { PRODUCING NORMAL SEED- }\end{array}$ \\
TREATMENT of soil & LINGS IN 2 WEEKS & Peas \\
Control soil & 35 & 52 \\
Fresh medium added & 65 & 55 \\
Diluted medium added & 61 & 77 \\
Washed bacterial cells added & 58 & 75 \\
Culture of bacterial antagonist added & 55 & 80 \\
Diluted culture added & 87 & 90 \\
Culture added continuously & 81 & 90 \\
\hline
\end{tabular}

From Cordon and Haenseler (154). 
rial, the disease could be checked; the toxin was more or less specific for the particular organism. Certain bacteria commonly found in soils were shown (306) to have a deleterious effect on the growth, in artificial media, of Ps. citri, which causes citrus canker. This effect was brought about by inhibiting the growth of and by killing the pathogen. By the use of an antagonistic bacterium, wheat seedlings were protected from infection by Helminthosporium sp. (729). In a similar manner, flax seedlings were protected from Fusarium sp.

A watermelon disease, caused by Phymatotrichum omnivorum, was considerably reduced when certain specific fungi and bacteria were present in the soil together with the pathogen (105); T. lignorum was observed to attack and kill the hyphae of Phymatotrichum in culture. The severity of the seedling blight of flax, caused by Fusarium lini, was diminished when the pathogen was accompanied in the soil by various other fungi (90I). The pathogenicity of $H$. sativum on wheat seedlings was suppressed by the antagonistic action of Trichothecium roseum, this effect being due to a toxic substance produced by the latter (359). T. lignorum prevented infection of wheat (63) by H. sativum and Fusarium culmorum (Table 52). Novogrudsky (685) obtained protection against infection of wheat with Fusarium by inoculating the soil with the bacteria isolated by Chudiakov ( I43), provided the bacteria were introduced simultaneously with the fungus or preceded it.

TABLE 52. EFFECT OF TRICHODERMA LIGNORUM ON GERMINATION AND GROWTH OF BARLEY INFECTED WITH HELMINTHOSPORIUM SATIVUM IN STERILIZED SOIL

STRAIN OF H. SATIVUM

\begin{tabular}{lccccccccc} 
& $\mathrm{H}$ & $\mathrm{H}+\mathrm{T}$ & $\mathrm{H}+\mathrm{SI}$ & $\mathrm{H}$ & $\mathrm{H}+\mathrm{T}$ & $\mathrm{H}+\mathrm{SI}$ & $\mathrm{H}$ & $\mathrm{H}+\mathrm{T}$ & $\mathrm{H}+\mathrm{SI}$ \\
$\mathbf{2 1}$ & 84 & 94 & 94 & 46 & 12 & 6 & 52 & 32 & 15 \\
22 & 88 & 94 & 98 & 33 & 8 & 6 & 57 & 27 & 14 \\
23 & 86 & 88 & 96 & 25 & 17 & 8 & 78 & 31 & 21 \\
24 & 88 & 98 & 94 & 10 & 4 & 3 & 17 & 15 & 10 \\
\hline
\end{tabular}

From Christensen (14I).

Notes. Results are based on randomized duplicate pots, each sown with 50 seeds. $\mathrm{H}$, seeds inoculated with a spore suspension of $H$. sativum; H T , seed inoculated with H. sativum plus T. lignorum; H SI, seed inoculated with $H$. sativum and soil with $T$. lignorum. 
The role of microbiological antagonism in the natural control of soil-borne fungus diseases of plants has been well emphasized (408, $82 \mathrm{I}$ ). Methods for combating plant pathogenic fungi by the use of bacteria and other antagonists have been suggested by various investigators $(46,869)$.

The principles underlying the biological control of soil-borne plant diseases were outlined by Garrett (316) in terms of the soil population in a state of dynamic equilibrium. When a given crop is grown continuously in the same soil, the parasitic organisms capable of attacking the roots of that crop multiply. Organic manures stimulate the development of saprophytic organisms in the soil, and are thus able to check the activity of the pathogens, which are destroyed by the saprophytes. Either the metabolic processes of the saprophytes check the growth of the pathogens, or the saprophytes actually attack and destroy the mycelium of the pathogens. The microbiological control of plant diseases was said to be most effective against those organisms which have become highly adapted to a parasitic form of life. The pathogenic Ophiobolus, when present in the form of mycelium inside the infected wheat stubble buried in the soil, is able to tolerate adverse physical soil conditions. Those soil treatments which favor increased activities of the microbiological population, such as addition of organic matter, partial sterilization followed by reinoculation with fresh soil, and improvement in soil aeration, favored loss of viability of the pathogen.

Van Luijk (930) recommended the control of plant parasites by inoculating the soil with specific microorganisms selected for their antagonistic capacity, or by the addition of the growth products of these microorganisms. Living soil fungi, including Trichoderma viridis and Absidia spinosa, exerted an adverse influence upon Rhizoctonia solani and reduced its pathogenicity to cabbage seedlings (458). Broadfoot (87) and others (247), however, emphasized that the antagonism of a saprophyte to a plant pathogen, determined on artificial culture media, is not a reliable measure of the actual control of the parasite in the soil. A lack of specific microorganisms in the soil is not a sufficient factor limiting biological control under natural conditions. Therefore, no inoculation of soil with an antagonistic organism, such as $T$. lignorum, can have more than a temporary effect in changing the micro- 



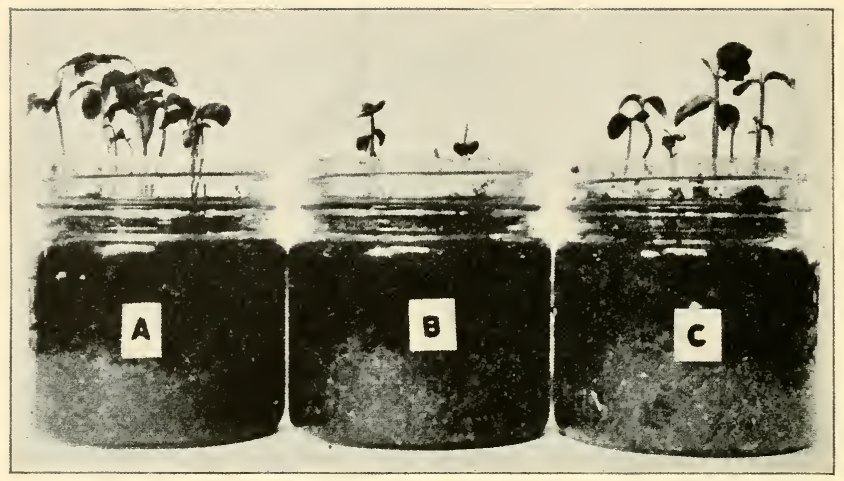

Figure 33. Sweet-orange seedlings in nonsterilized soil. A, control; $\mathrm{B}$, Rhizoctonia inoculated into soil layer in bottom of jar; C, Rhizoctonia as in B, plus Trichoderma in top layer of peat. From Weindling and Fawcett (992). 
biological balance of the soil population. Similar results have been obtained (992) in efforts to control $R$. solani, or the damping-off of citrus seedlings (Figure 33 ), by the use of $T$. lignorum, and in the action of B. simplex upon Rhizoctonia in the soil (154).

A number of antagonistic bacteria were found (502) to be able to prevent scab formation by $S$. scabies on potatoes. Daines ( 167 ) found that T. lignorum produces a diffusible substance which is toxic to $S$. scabies in an artificial liquid medium. However, the toxic principle added to potato soils is rapidly destroyed there by aeration; it can be removed from solution by charcoal and by soil, where it is destroyed. It was suggested, therefore, that it is highly doubtful whether antagonists will be found to be of much assistance in combating potato scab in soil. The physical and biological environments encountered in many cultivated soils offer an important barrier against the establishment of the antagonist. When the latter was added to a 5 -day-old culture of $S$. scabies, it was greatly inhibited by the scab organism. Soil bacteria are also able to produce substances toxic to both Trichoderma and Streptomyces alike. In such a complex physical, chemical, and biological environment as the natural soil, these antagonistic relationships may thus be modified or even entirely destroyed.

The application to the soil of organic materials which favor the development of antagonists has given much more favorable results than the use of pure cultures. Fellows (25I) obtained field control of the take-all disease of wheat in Kansas by the application of chicken and horse manure, alfalfa stems and leaves, boiled oats and barley, as well as potato flour. Garrett believed $(316,317)$ that the factor chiefly controlling the spread of pathogenic fungus along the roots of the wheat plant was the accumulation of carbon dioxide, with a corresponding lowering of oxygen tension in the microclimate of the root zone. A high rate of soil respiration was, therefore, said to check the growth of $O$. graminis. This can best be maintained, of course, by periodic additions of organic manures. Materials low in nitrogen were found to be more effective than those high in nitrogen. Garrett, therefore, postulated the hypothesis that the soil microflora used the mycelium of the pathogen as a source of nitrogen, in the process of decomposition of the nitrogenpoor materials. The addition of nitrogenous substances, in either an or- 
ganic or an inorganic form, was believed to protect the pathogenic organism against attack by the soil microflora, by offering a more readily available source of nitrogen. Tyner (920) suggested that the differences in the microflora associated with the decomposition of different plant residues are largely responsible for differences in persistence and virulence of pathogens causing root rot of cereals.

Against some plant pathogens, however, high nitrogenous materials were found to be very effective. Considerable reduction in the slimedisease of tomato plants resulted from the addition of green manures to the soil before planting (928); organic materials high in nitrogen, as well as the supplementary addition of nitrogenous materials suffcient for complete decomposition of the organic matter, brought about greater reduction of the disease. Organic matter was found to be most effective during the process of decomposition; after it has undergone extensive decomposition and reached a stage of slow decomposition, when it is usually designated as humus, it becomes comparatively inert.

It has been recommended $(767)$ that organic composts be used in forest soils in order to overcome the infertility resulting from the accumulation of toxic substances. The addition of the compost changes the microbiological population of the soil, followed by the destruction of the toxins.

The antagonistic action of soil microorganisms has been utilized for the control of $P$. omnivorum, the root rot of cotton. This pathogen can be inactivated when organic manures are added to the soil before the crop-growing season (506). By the use of the contact slide technique, microbiological antagonism was found (226) to represent the true mechanism of the control process; the growth of saprophytic organisms was most profuse in the slides buried in the manured plots, whereas the mycelium of the pathogen was most abundant on the slides kept in the unmanured plots. The conclusion was reached that manuring definitely controls cotton root rot, as a result of the parasitism by bacteria of the fungal strands of the causative agent of the disease. Continuous growth of cotton on certain neutral or alkaline soils in southern United States was believed to bring about an unbalanced soil population in which $P$. omnivorum became a dominant organism; this was accompanied by the absence or only the sporadic presence of Trichoderma and other molds 
(903). The application of organic matter to such soils results in the destruction of most of the sclerotia and mycelium of the pathogen (649). Microbial antagonists rather than food exhaustion were, therefore, considered to be responsible for the destruction of the pathogen.

The Sclerotium rot of sugar beets was found (552) to be controlled by the application of nitrogenous fertilizers. This effect was believed to be due largely to a change in the metabolism of the fungus or of the host. It was also suggested, however, that suppression may possibly be due to a change in the balance of the soil microbiological population.

The possibility of suppressing the growth and eliminating the infectivity of plant pathogens by utilizing the activities of the soil microflora was demonstrated also for a number of other diseases. It is sufficient to cite the suppression of Monilia fructigena on apples by various fungi and bacteria (933), of F. culmorum and H. sativum on wheat (408, 729), and of species of Rhizoctonia on citrus seedlings. These pathogens are markedly influenced by $T$. lignorum, a common soil saprophyte. A species of Trichoderma was also found to cause a reduction in the amount of Texas root rot of watermelons caused by $P$. omnivorum (105).

The damping-off of citrus seedlings, caused by a number of fungi, could be suppressed by $T$. lignorum, which parasitizes the fungi ( 989 , 992). When T. lignorum was inoculated into pots containing Helminthosporium sp. and Fusarium sp., the pathogenic action of these organisms was checked and rendered harmless to plants $\left(6_{3}\right) . T$. lignorum was also decidedly antagonistic to Rhizoctonia and Pythium, organisms responsible for seed decay and damping-off of cucumbers (I4).

The presence of Gibberella on corn inhibited infection due to $T$. viridis; seed grains inoculated with the former gave more vigorous growth than uninoculated seed grains (227). On the other hand, $T$. viridis was found able to attack and to destroy the sclerotia as well as the mycelium of such pathogenic fungi as Corticium rolfsii, Corticium sadakii, and Sclerotinia libertiana. The utilization of this organism for the biological control of plant diseases has, therefore, been suggested (427).

Henry (407) believed that the biological control by the soil microflora could even be directed against internal seed infection, since appre- 
ciable damage to surface-sterilized flax seed was found to occur in sterilized but not in unsterilized soil.

A very interesting application of the phenomenon of antagonism is also found in the use of harmless fungi (Pullularia pullulans) for the inhibition of harmful ones growing on paper pulp (7).

\section{CONTROL OF PATHOGENIC FUNGI IN SOIL BY INOCULATION WITH ANTAGONISTIC MICROORGAN ISMS}

Despite the favorable results obtained from the action, in artificial culture, of antagonistic bacteria and fungi upon plant pathogens, the field results have often been rather disappointing. The soil microflora seems to have no marked effect on certain diseases, such as the seedling blight of barley; the antagonistic action of the soil population appears to be insufficient to suppress the injury caused by diseased seed (I4I). The addition of $T$. lignorum and certain other fungi and bacteria to infected seed or to sterilized soil inoculated with $H$. sativum often prevented seedling injury, increased the stand, and decreased the number of deformed seed. Chudiakov ( I43) suggested inoculation of seed with bacteria for the control of flax against infection with Fusarium. It has been said that wheat seedlings were protected from attack by the simultaneous introduction of lytic bacteria with the pathogenic fungus, but when the bacteria were introduced 24 hours after the fungus they were unable to protect the wheat sown 3 days later.

On the basis of extensive studies on the control of plant-disease-producing fungi by means of antagonistic soil microorganisms, Novogrudsky $(683,685)$ came to the following conclusions: The distribution and vigor of parasitic fungi are a result, on the one hand, of resistance and immunity of plants to infection, and, on the other, of the antagonism between soil microorganisms and pathogenic fungi. Among the numerous forms of antagonism existing between soil microorganisms and pathogens, those bacteria which produce lysis of fungi deserve particular attention. The bacteria are widely distributed in nature; they are able to destroy and to dissolve the mycelium and the spores of different phytopathogenic fungi, not only in artificial media but also in the soil. 
The inoculation of sterilized soil with $F$. graminearum led to the inevitable death of wheat plants, but additional inoculation of the soil with lysogenic bacteria protected the wheat from the disease. The addition of bacteria to unsterilized soil which has been made sick by continuous growth of flax markedly lowered the percentage of plants diseased by $F$. lini.

The term "bacterization" was suggested by the Russian investigators $(46,673)$ to designate the process of treatment of seed with lysogenic bacteria, whereby the plants are protected against pathogenic fungi. The susceptibility of plant seedlings to infection by fungi could be decreased not only by the specific antagonistic bacteria, but also by the presence of other bacteria which are able, in one way or another, to retard the development of the fungi. The conclusion was reached that the effect of bacteria on germinating seeds is due to the metabolic products liberated by the bacteria, which are capable of depressing the development of parasitic fungi. By treating flax seeds with the culture filtrate of the antagonistic bacteria, a similar or even greater decrease in the number of diseased seedlings was obtained. The nature of the active substance produced by the antagonists was not investigated further. It was said to accumulate in 5-to-IO-day-old cultures. Heating at $80^{\circ} \mathrm{C}$. for Io minutes had no effect upon the substance, but heating at $100^{\circ} \mathrm{C}$. brought about its inactivation.

Jensen $(467)$ concluded that the beneficial result of bacterization is due not to nitrogen-fixation by Azotobacter or to production of growthpromoting substances by microorganisms, but to the protection of the seedlings against plant pathogens by specific bacterial antagonists.

Although it has now been definitely established that certain organisms can repress or even destroy disease-producing fungi, the utilization of specific microbial products for the control of plant diseases has made comparatively little progress so far. Leemann (556) tested the action of various secretions and extracts of microorganisms upon $H$. sativum. He concluded that microorganisms, pathogenic or nonpathogenic, can supply substances useful as preventive measures against plant pathogens. No favorable effects upon the development of Rhizoctonia disease in plants could be observed, however, from the application to soil of certain bacterial and fungus products. 
The only important procedure which has thus far found a practical application is the treatment of the soil in such a manner as to modify its microbiological population, which in its turn can destroy or in other ways control the activities of plant pathogens. Many such instances can be cited for illustrative purposes. In the case of root rots of the strawberry, it was found that carbohydrate decomposition induces a favorable change in the soil microflora from pathogenic or potentially harmful organisms to beneficial or rather innocuous types (424). Studies of the eradication of cotton root rot led to recommendations of treatments of soil with organic materials, especially during the period of increased microbial activity (650). The survival of the fungus is considered to be limited by microbial interrelationships rather than by food exhaustion. During the early stages of incubation, viable sclerotia are destroyed more rapidly than dead sclerotia in soils treated with organic matter. It was suggested, therefore, that the germination of the sclerotia is an important factor for their elimination from the soil. Field application of organic materials, accompanied by early October plowing, results in an increase in microbial activity. This brings about a reduction of the incidence of dead cotton in the succeeding crop and greater difficulty of finding sclerotia.

It was reported recently (65) that $R$. solani is able to cause roo per cent damping-off of radish seedlings planted at a distance of $4 \mathrm{~cm}$. from the inoculum; when the seeds were planted at a distance of $9 \mathrm{~cm}$. the damage was 40 per cent. The addition of I per cent ground wheat straw or dried grass to the soil had a marked depressing effect upon the growth of the fungus. This was ascribed to the nitrogen starvation of the mycelium, accompanied by the rapid utilization of the available soil nitrogen by the cellulose-decomposing microorganisms multiplying at the expense of the fresh organic material; carbon dioxide produced by the cellulose-decomposers was believed to cause a marked fungistatic action on the Rhizoctonia.

Treatment of the soil with organic materials, which results in the destruction of certain plant pathogens by stimulating the development of saprophytic microorganisms, may be designated as "partial disinfection." To what extent antibiotic agents produced by plants, such as 
tomatin of tomato plants, serve to protect the plant against invasion by fungi and other pathogens still remains to be determined (456a).

SOIL MICROORGANISMS IN RELATION TO

\section{LEGUME BACTERIA}

The possible injury caused to leguminous plants by the antagonistic action of soil bacteria upon the root nodule bacteria has been but little investigated (524). Certain bacteria belonging to the Pseudomonas and Achromobacter groups exercise a strong influence upon the nodule bacteria in the root zone or rhizosphere of the legumes. Some stimulate, others depress, and still others have no effect at all upon the growth of the legume bacteria. The stimulating effect of non-nodule bacteria upon the nodule bacteria often is very striking (533). 


\section{THE OUTLOOK FOR THE FUTURE}

THE production of antibiotic substances by microorganisms under controlled laboratory or factory conditions and the utilization of these substances for disease control are very recent developments. It has been known for more than half a century that certain microbes are capable of combating others, and it has even been suggested that saprophytic microorganisms may in time be utilized for controlling the growth of pathogenic forms. Until recently, however, these suggestions were largely speculative. Such positive facts as were available were merely isolated items, the full significance of which was not sufficiently well recognized. This is true, for example, of the claims and counterclaims concerning pyocyanase and pyocyanin, two antibiotics of bacterial origin, the antibacterial properties of which have long been known. It is true, also, of certain antibiotics produced by fungi, such as gliotoxin and the $A$. fumigatus factor; by actinomycetes, such as actinomycetin and lysozyme; as well as by various other bacteria, such as $B$. mesentericus factor, $B$. simplex factor. The existing confusion is due largely to the fact that the utilization of these antibiotic substances for disease control gave varying results that were frequently rather disappointing.

In 1929, Fleming observed that the growth of a mold, which was later identified as $P$. notatum, on a plate seeded with staphylococci prevented the growth of these bacteria. In liquid media, this mold produced a soluble substance, designated as penicillin, that inhibited pyogenic cocci and members of the diphtheria group but not gram-negative rods. Fleming, however, did not go beyond the suggestion that this substance be utilized for disease control or beyond the statement that it might prove useful because of these antibacterial properties. This contribution received no further attention for more than a decade, with the exception of very few experiments that served to prove Fleming's original observations. The full realization of the fact that we are dealing here with an entirely new field of biology and chemotherapy that is 
bound to enrich the subject of control of disease came only a little more than half a decade ago.

In 1939, Dubos announced that new antibacterial agents can be isolated from soil microorganisms that are active not only in vitro but also in vivo. He proceeded with the isolation of such substances in a novel and unique manner, which consisted in enriching the soil with pathogenic bacteria, isolating from such soil specific antagonistic organisms capable of destroying the pathogens, and finally producing the specific antibacterial substance by cultivating the organism on suitable media. This work pointed to a new method of approach to the isolation of antibiotic substances and attracted the immediate attention of bacteriologists, chemists, and medical investigators. One no longer had to depend for the isolation of antagonistic organisms upon mere air contaminations of exposed bacterial plates, or upon accidental observations of the destructive action of one microbe upon another. One could now proceed systematically with the isolation of microorganisms capable of destroying specific disease-producing bacteria. The mechanisms whereby such destruction was brought about were found to be due to the production of characteristic substances, known as antibiotics. The isolation of each antibiotic required special methods, because of its specific chemical nature. Since most of the antibiotics are selective in their action upon different bacteria, affecting some and not others, the method proved to be of great importance in pointing a way to the isolation of a variety of chemical agents active upon gram-positive bacteria as well as gramnegative forms.

It was not sufficient, however, merely to isolate these protoplasmic poisons from the cultures of the antagonistic microorganisms. It was essential to determine the effect of animal tissues upon the action of these agents and to establish their selective activity upon the bacteria in the animal body as compared to the test tube. However, once it was recognized that some of these antibiotics act in vivo against a variety of diseases, the branch of medical science known as chemotherapy acquired a new group of tools. This work led to a reexamination of the potentialities of penicillin, which in turn led to the second important contribution, namely, the work of Chain and Florey and their co-workers. These in- 
vestigators succeeded in obtaining crude active preparations of penicillin which, they demonstrated, had a marked effect upon various gram-positive and certain other bacteria in the animal body. The importance of this discovery was accentuated by the great need of the moment and the urgency for new methods of combating infections resulting from World War II. These investigations immediately attracted universal attention, and were soon followed by remarkable development in the manufacture, isolation, and study of the chemical nature of this highly important antibiotic agent. Penicillin fully deserves the designation "Wonder Drug" given to it by the popular press.

These two epoch-making contributions were rapidly followed by a series of investigations that resulted in the isolation of a number of other antibiotics. Among these, streptomycin deserves special consideration because of its activity against various gram-negative bacteria and $M$. tuberculosis, which are not affected by tyrothricin or penicillin, and because of its limited toxicity to animals and its activity in vivo.

It was soon recognized that one is not dealing here with only three or more types of chemical compounds capable of destroying various pathogenic bacteria and fungi, but that a new field of science bordering on microbiology, chemistry, pharmacology, pathology, and chemotherapy was being opened that was bound to result in many practical applications. The fact that many of these agents, including penicillin, are produced by several different organisms and, further, the fact that many of these compounds are formed in several chemical modifications open to the chemist new fields for the synthesis of types of compounds heretofore unknown, and point out to the medical world new ways of combating infections and epidemics.

The rapid progress made in the utilization of antibiotics in so brief a period of time can best be illustrated by the following two citations:

On May 4, 1940, Garrod (318), in discussing the use of antiseptics in wounds, wrote: "Only a few years ago it was thought impossible to kill bacteria within the body with chemicals and likely always to remain so. This belief was shaken by the discovery of a urinary antiseptic which really worked, and it was shattered by the introduction of Prontosil, with all its manifold consequences. Are we still to deny the possibility of killing bacteria which are merely lying on a body surface?" 
Less than four years later, Florey (274) summarized the value of penicillin: "I. As a preventive of infection in wounds, enabling a potentially septic wound to be treated in much the same way as an aseptic one, 2. in the promotion of healing in burns and for ensuring the success of skin grafts, 3. in infections (due to sensitive organisms) either (a) chronic, or (b) of such severity as to render the prospect of death likely, which have not responded to other forms of treatment, 4 . in acute infections due to sensitive organisms, 5 . in the rapid curing of gonorrhoea including sulphonamide-resistant cases, 6. in pneumonia, 7. probably in gas gangrene, but here numbers have been few and methods not fully tried out."

In commenting upon the remarkable developments in the use of penicillin, Keefer (493a) stated: "It can be said without reservation that penicillin is the most remarkable chemotherapeutic agent that has been discovered up to the present time. In the first place, it is a substance of extremely great antibacterial power. One $\mathrm{mg}$. of crystalline penicillin is capable of inhibiting the growth of staphylococci in 82.5 liters of broth. It is non-toxic in maximum therapeutic doses in man. It is highly effective against a wide variety of microorganisms of the gram-positive group. It is effective in both gonorrhea and syphilis. It is responsible for the reduction of the fatality rate in more diseases than any other chemotherapeutic agent; it shortens the clinical course of many infectious disorders, and it saves many days of illness and disability. When one realizes that this can be accomplished by an agent that destroys bacteria and other microorganisms such as the Treponema pallidum without injury to the tissues of the host, it deserves to be called remarkable. No other known agent can do as much."

Only one year later, the remarkable effectiveness of streptomycin was summarized by Waksman and Schatz (970) as follows:

"In vivo streptomycin has sucessfully controlled experimental infections due to Salmonella schottmülleri, Pseudomonas aeruginosa, Proteus vulgaris, Shigella gallinarum, Brucella abortus, Klebsiella pneumoniae, Pasteurella tularensis and Mycobacterium tuberculosis. Against the gram-positive Diplococcus pneumoniae and Staphylococcus aureus protection was afforded by somewhat larger doses. Streptomycin has also protected against spirochetal infections due to Borrelia 
novyi and Leptospira icterohaemorrhagica. Following the oral or parenteral administration of streptomycin, no unfavorable effects have been encountered which could not be attributed largely to the presence of impurities in the preparations. To date, streptomycin has been administered for infections of the urinary tract, typhoid, brucellosis, Klebsiella infections, tularemia, tuberculosis, and wounds."

It appears, therefore, that certain generalizations concerning possible future developments in the field of antibiotic substances are justified.

\section{A SEARCH FOR NEW ANTIBIOTIC AGENTS:}

\section{A PROBLEM FOR THE MICROBIOLOGIST}

Although more than sixty compounds or preparations possessing bacteriostatic and fungistatic properties have already been isolated from microorganisms, there is sufficient evidence that a great many others can be obtained without too great difficulty, if enough organisms are studied in greater detail. In this connection, three methods of approach have been followed: (a) testing organisms found in culture collections for antibacterial activity in general, followed by a detailed study of one or more substances produced by one or more organisms; (b) isolating specific organisms, such as members of the $P$. notatum $-P$. chrysogenum groups, from different soils and from moldy food materials and testing them for the production of penicillin, in the hope of finding more active organisms than those now known to exist; (c) enriching the soil with specific bacteria, followed by the isolation of organisms capable of inhibiting the growth of or of destroying such bacteria.

A summary of the various steps essential to the isolation of a suitable chemotherapeutic agent are given in Figure 34. A number of surveys have now been made concerning the distribution of organisms capable of producing antibiotics among bacteria, actinomycetes, and fungi. Only very few such organisms were selected for more detailed investigation, chiefly because of the great amount of time and experimentation required for the isolation of any new type of substance. The selection of a particular antibiotic for isolation and further study is largely governed by its specific antimicrobial spectrum, its action upon particular 
1. Isolation of antagonistic organisms from soils, composts, manures, and sewage

a. Common agar media; colonies isolated at random from plates

b. Washed agar-bacterial media; zone-forming or other colonies selected

c. Low dilutions; colonies producing inhibition of other organisms selected

d. Special selective media

2. Testing of isolated colonies

a. Streak method; tested against gram-positive and gram-negative bacteria

b. Agar plugs removed from plates in which antagonist is growing

c. Liquid media containing bacterial suspension inoculated with antagonist

d. Agar media inoculated with test culture, followed by inoculation with antagonist

3. Production of antibiotic substances

a. Synthetic and organic media used

b. Filtrate tested by convenient method

c. Study of surface $v$ s. submerged culture

4. Determination of antibacterial spectrum and general properties of type substance produced

a. Bacteriostatic spectrum by suitable methods

b. Chemical and physical properties of crude preparation

c. Pharmacological properties and in vivo activity

5. Recognition of type substance on basis of antibacterial properties

a. Bacteria: pyocyanase, pyocyanin, tyrothricin, and subtilin types

b. Fungi: penicillin, gliotoxin, clavacin, and penicillic acid types

c. Actinomycetes: actinomycetin, actinomycin, streptothricin, and streptomycin types

6. Isolation of antibiotic substance

a. By use of organic solvents

b. By adsorption on charcoal, and removal by acid solutions or solvents

c. Other methods

7. Isolated antibiotics

a. Antibacterial, physical, chemical, and pharmacological properties

8. Chemotherapeutic uses

FIGURE 34. Isolation and preparation of antibiotic substances. 
bacteria, its toxicity to animals, and its activity in vivo. The following illustrations will suffice:

Of all the aerobic spore-forming bacteria known to produce antibiotic substances, only $B$. brevis and $B$. subtilis have been utilized for the isolation of tyrothricin, bacitracin, and subtilin. It is known, for example, that various strains of $B$. mesentericus, $B$. mycoides, $B$. simplex, and other spore-forming bacteria are capable of producing antibiotics, some of which are markedly different chemically, biologically, or in selective activity. It is sufficient to call attention to such preparations as bacillin, simplexin, and others. A more detailed study of these organisms and the substances produced by them is bound to enlarge greatly our knowledge of this group of chemical compounds and their therapeutic potentialities.

Of all the nonspore-forming bacteria possessing antagonistic properties found in soils and water basins, only two have been studied in detail: Ps. aeruginosa has been utilized for the production of pyocyanase, pyocyanin, and the various pyo-compounds, and Ch. iodinum for the production of iodinin. It is known, however, that a large number of other nonspore-forming bacteria are capable of producing a variety of antibiotic substances, the chemical nature and biological activities of which are still but little understood.

Only very few of the antibiotic substances produced by actinomycetes have so far been investigated, isolated, or concentrated; namely, actinomycin, proactinomycin, streptothricin, and streptomycin. Even these few substances, however, differ markedly in chemical nature and in biological activity. In view of the fact that as many as 20 to 40 per cent of all the actinomycetes are known to be capable of producing antibiotic substances, many of which undoubtedly differ from those already isolated, the wealth of material that is awaiting investigation can only be surmised. Some of these possibilities have been definitely indicated.

The production of antibiotic agents by fungi likewise has been but insufficiently studied. The following pertinent facts may direct attention to the many problems still awaiting investigation:

(a) Some antibiotics, like penicillin, gliotoxin, clavacin, aspergillic acid, penicillic acid, and citrinin, are produced by a number of different 
organisms; the nature of the organism often influences not only the yield of the substance but also its chemical nature and its biological activity. A number of other substances have been added to this list, namely, fumigacin, viridin, penicidin, and others.

(b) The mode of nutrition and the manner of growth of a single organism have often been found to influence the concentration and the nature of the antibiotic substance, which may be formed in one medium and not at all or in much lower amounts in another medium. Some organisms are greatly favored in the production of antibiotic substances by the presence in the medium of certain vitamin-like complexes. Moreover, the formation of a substance is usually associated with a certain stage of growth of the organism, since the substance is produced at one time and then rapidly destroyed, the range of its accumulation often being very narrow. These facts point to certain fundamental aspects in the physiology of the organism producing the antibiotic substance that are still little understood.

(c) Certain organisms, such as members of the Fusarium group, produce bacteriostatic substances, the action of which, however, is rapidly overcome by the bacteria. This points to problems on the stability of the antibiotic substance and on the adaptation of bacteria to the substance.

(d) Although it is known that certain yeasts produce antibiotic substances, either of an adaptive or of a nonadaptive kind, very little is known concerning the nature and mode of action of such substances.

(e) Different strains of the same group of organisms, especially under different conditions of culture, may produce the same type of substance which varies both chemically and biologically. This is brought out by the formation of different penicillins. The same principle no doubt holds for other antibiotics.

These and many other problems are awaiting solution. The microbiologist is faced with a new field of research second only to that of the very discovery of the causation of disease by microorganisms.

\section{THE OPPORTUNITY FOR THE CHEMIST}

'The chemist has been searching far and wide for new chemotherapeutic agents. He has synthesized many thousands of compounds, only 
a few of which have proved to be of practical value. The chemist has started from a certain lead, such as the arsenical group in the salvarsan type of compounds and the sulfa-radical in the sulfanilamides. The discovery of new chemical agents possessing antibacterial or antifungal properties offers the chemist many new models to draw upon for varied types of syntheses.

Although only very few antibiotics have so far been isolated and their chemical nature determined, it is already well established that we are dealing here with a great variety of chemical compounds. It is sufficient to mention, first of all, the penicillins and other sulfur-bearing compounds, such as gliotoxin; the organic bases, notably streptomycin and streptothricin; the polypeptides, especially tyrothricin; the oxidation-reduction systems, namely pyocyanin and actinomycin; the ketones and quinones, such as clavacin and many others. Compounds like actinomycin, which are highly active against bacteria but also highly toxic to animals, may possibly be modified in such a manner as to reduce their toxicity without impairing their activity. This is also true of simpler compounds, such as the less toxic but also less active clavacin and gliotoxin. The solution of the chemical nature of penicillin offers many tempting opportunities for the synthetic chemist.

Doubtless most of the compounds that prove to be useful as chemotherapeutic agents will sooner or later be synthesized. The contribution of the bacteriologist may be all but forgotten in the light of the forthcoming chemical developments, but even the bacteriologist will be grateful for new tools to help combat disease-producing agents.

\section{THE FIELD OF CHEMOTHERAPY}

The utilization of the activities of antagonistic microorganisms for the control of human and animal diseases has only begun. Many practices in surgery and many old-time remedies are based on the creation of conditions favorable to the development of antagonistic microbes. Plaster treatment of wounds, without the use of antiseptics, has often given marvelous results. Such wounds have been found to contain aerobic bacteria with no one group predominating, except that Ps. aeruginosa tends to become more numerous when the healing process has 
been established. It still remains to be determined whether this organism exerts a favorable effect due to its antagonistic properties or is only another wound-infecting agent.

Of particular importance is the development of the manufacture of antibiotic substances. Largely because of the stimulus given by World War II when the need for new antibacterial agents became very acute, an intensive study was made of the practicability of utilizing some of the agents already known, and search was made for new ones. Among these, penicillin occupies a leading place. A large number of great concerns in this country, in Great Britain, and elsewhere are engaged in the manufacture of this drug by utilizing several strains of $P$. notatum and $P$. chrysogenum. An intensive search for new strains resulted in the isolation of cultures that have increased a hundred-fold the yield of penicillin from the same lot of medium. The development of deep culture technique greatly reduced the labor involved. New agents capable of inhibiting the growth of and destroying other pathogens resistant to the action of penicillin have been isolated. Most significant of these is streptomycin.

The progress made in the isolation of antibiotic substances from many microorganisms has not kept pace with their evaluation as chemotherapeutic agents. In discussing antimicrobial agents of biological origin, Dubos (200) emphasized that students of infectious diseases are primarily concerned with the action of these substances upon certain strains and stages of the parasites, with the mechanism of their action upon the susceptible cells, and with physiologic and pathologic effects on the host. McIlwain (600), on the other hand, suggested that animal testing in chemotherapy is not necessarily much nearer to the conditions under which the drug will be finally used than are properly chosen in vitro conditions; although in vitro testing does not reproduce all the conditions of the normal environment of the parasite, it is less likely, under present conditions of testing, to introduce new and unknown factors than is testing in another host. The in vitro and in vivo studies of an agent are considered as complementary.

The utilization of fungi and bacteria against plant diseases has also been variously attempted. The main difficulty involved is to establish the antagonist in the soil. This can be done by modifying soil 
conditions, as by the addition of stable manure or other plant and animal residues, in order to favor the development of the antagonist.

The activities of antagonistic microorganisms are also utilized for combating injurious insects and other lower animal forms destructive to plants and to animals. Among the insects, the Japanese and other Asiatic beetles have been treated rather successfully by the use of nematodes and certain specific bacteria. Extensive use has already been made of these bacteria, by inoculating the soil with grubs heavily infected with them.

Comparatively little is yet known of the ability to control, by means of antibiotic agents, diseases caused by protozoa, such as malaria and trypanosomes, as well as virus infections. The hope of finding antibiotics active against such resistant diseases as tuberculosis has recently gained much ground with the discovery that streptomycin has a remarkable tuberculostatic effect and that it may find a place in the treatment of certain forms of tuberculosis.

These instances suffice to arouse hope that even greater progress can be expected in the control of disease by utilization of the activities of antagonistic microorganisms. So far, most energies have been directed to the treatment of acute infections caused by bacteria. Less is known of chronic infections. Whether or not man will ever be able to control all diseases caused by the numerous microscopic and ultramicroscopic forms of life through the utilization of the activities of antagonistic microorganisms and antibiotics, he will have gained sufficient knowledge from the mode of action of these organisms, and of the substances produced by them, to justify further hope in the possibilities thus opened.

\section{MODE OF ACTION OF ANTIBIOTIC SUBSTANCES:}

A FIELD FOR THE PHYSIOLOGIST

Finally, there remains the fourth important group of problems involved in the study of antibiotics, namely, the mode of action of these substances upon bacteria and other microorganisms. The fact that different agents vary greatly in their bacteriostatic and bactericidal action upon different organisms is well established. A number of mechanisms 
have been propounded, some of which hold true for one substance and some for more than one. Each of these mechanisms involves some extremely puzzling physiological problems. To take only two illustrations:

(a) If a given substance interferes with the utilization by the bacteria of a certain metabolite in the medium, as in the relation of sulfa-drugs to $p$-amino-benzoic acid, one must assume that the sensitive bacteria require the metabolite in question and the resistant forms do not, or that the resistant bacteria synthesize larger concentrations of the particular metabolite than the sensitive forms. Since the sensitivity of the bacteria to an antibiotic is often more of degree than of kind, the assumption would be that the metabolite is either required in different concentrations by the various organisms or is synthesized to a different extent.

(b) The adsorption of the antibiotic substance by the bacterial cell, rendering the cell incapable of multiplying or dividing, points to another type of mechanism that may be rather common. This may often express itself in the abnormal enlargement of the cell. A clear understanding of this phenomenon will have to await a better knowledge of the mechanism of cell fission. Should one assume that the resistant cells and the sensitive cells divide by different mechanisms?

All these and many other problems point directly to the fact that a better understanding of the physiology of the microbial cell will be gained from a clearer appreciation of the mode of action of antibiotics upon the cell.

It is thus to the smallest of living systems, the microbes, that we must look for the solution of some of the most important problems that have faced man as well as his domesticated and friendly animals and plants. 

CLASSIFICATION OF ANTIBIOTIC SUBSTANCES GLOSSARY

BIBLIOGRAPHY

INDEX OF MICROORGANISMS

GENERAL INDEX 



\section{CLASSIFICATION OF ANTIBIOTIC SUBSTANCES}

\section{PRODUCED BY BACTERIA}

\author{
Bacillin (B. subtilis) \\ Bacitracin (B. subtilis) \\ Colicine ( $E$. coli) \\ Colistatin (aerobic spore-formers) \\ Diplococcin (Streptococci) \\ Endo-subtilysin (B. subtilis) \\ Eumycin (B. subtilis) \\ Gramicidin (B. brevis) \\ Iodinin ( $C h$. iodinum) \\ Phthiocol ( $M$. tuberculosis) \\ Prodigiosin (S. marcescens) \\ Pyo compounds (Ps. aeruginosa)
}

\section{PRODUCED BY ACTINOMYCETES}

Actinomycetin (S. albus)

Actinomycin (S. antibioticus)

Litmocidin (N. cyanea)

Micromonosporin (Micromonospora sp.)

\section{PRODUCED BY LOWER FUNGI}

Aspergillic acid (A. flavus)

Aspergillin (A. niger)

Chaetomin ( $C h$. cochliodes)

Citrinin ( $P$. citrinin, A. canäidus)

* Clavacin ( $A$. clavatus)

* Clavatin (A. clavatus)

* Claviformin (P. claviforme)

$\S$ Corylophillin (P. corylophylum)

$\S E$. coli factor ( $P$. notatum)

* Expansin ( $P$. expansum)

$\dagger$ Flavacidin ( $A$. flawus)

$\dagger$ Flavatin (A. flarus)

$\dagger$ Flavicin (A. flaous)

\$ Fumigacin (A. fumigatus)

Fumigatin (A. fumigatus)

$\dagger$ Gigantic acid ( $A$. giganteus)

Gladiolic acid ( $P$. gladioli)

Gliotoxin (Trichoderma, Gliocladium, A. fumigatus)

Glutinosin ( $M$. glutinosum)

\author{
Pyocyanase ( $P$ s. aeruginosa) \\ Pyocyanin (Ps. aeruginosa) \\ Pyolipic acid (Ps. aeruginosa) \\ Simplexin (B. simplex) \\ Subtilin ( $B$. subtilis) \\ Subtilysin ( $B$. subtilis) \\ Toxoflavin ( $B$. cocovenenans) \\ Trypanotoxin (B. subtilis) \\ Tyrocidine (B. brevis) \\ Tyrothricin (B. brevis) \\ Violacein (Ch. violaceum)
}

Mycetin (S. violaceus)
Proactinomycin ( $N$. gardneri)
Streptomycin (S. griseus)
Streptothricin (S. lavendulae)

Notr. Terms marked with the same symbol are synonyms. 
PRODUCED BY HIGHER FUNGI

Clitocybin ( $\mathrm{Cl}$. gigantea)

Polyporin ( $P$. sanguineus)

PRODUCED BY ALGAE

Chlorellin (Chlorella sp.)

Although the antibacterial products of higher forms of life are not in a strict sense antibiotic substances, they can be mentioned here because of their similar properties.

PRODUCED BY HighER PLANTS (PHYTONCIDES)

Allicin (Allium sativum)

Pinosylvin (Pinus silvestris)

Crepin (Crepis tarakacifolia)

Flour protein

Protoanemonin (Anemone pulsatilla)

Inhibin (honey)

Tomatin (tomato plant)

PRODUCED BY ANIMALS

Erythrin (red blood cells)

Lactenin (milk)

Lysozyme (eggs, tears, and various organs) 


\section{GLOSSARY}

Antagonism. The phenomenon of a living organism inhibiting the growth or interfering with the activities of another living organism as a result of the creation of unfavorable conditions in the medium or the production of a specific antimicrobial substance.

Antagonist. An organism having the capacity to inhibit the growth or interfere with the activity of another organism.

Antagonistic substance. A term frequently used to designate a substance that neutralizes the bacteriostatic action of an antibiotic substance.

Antibacterial index. The ratio of concentration of an inhibitor sufficient to inhibit the growth of an organism to the concentration of a metabolite.

Antibiosis. The inhibition of growth of one organism by another.

Antibiotic or antibiotic substance. A chemical substance produced by microorganisms which has the capacity to inhibit the growth of bacteria and other microorganisms and even to destroy them.

Antidotic or antidotic substance. A chemical substance produced by microorganisms which has the capacity to inactivate the injurious effect of bacterial toxins.

Anti-inhibitor, inhibitor, suppressor are terms of similar significance to antagonistic substance.

Bactericidal. Causing the death of bacteria.

Bacterioantagonistic. Inhibiting the growth of bacteria.

Bacteriolytic. Causing not only the death of bacteria but also their lysis or disintegration.

Bacteriostatic. Inhibiting the growth of bacteria.

Bacteriostatic or antibiotic spectrum. A range of inhibition of growth of different bacteria by different concentrations of an antibiotic substance. It may be expressed graphically, the bands of the spectrum representing the concentrations of the substance.

Bacteriotherapy. The use of living bacteria for the treatment of infectious diseases.

Bipstatic complex. The sum total of factors that limit microbial development in a medium. The absence of such factors may result in the formation of toxic products. 
Chemotherapy. The use for the treatment of infectious diseases of chemical agents that are effective against the parasites and are tolerated by the host.

Fungicidal. Causing the death of fungi.

Fungistatic. Inhibiting the growth of fungi.

Inactivator, nontoxic. A substance that inactivates plant viruses and is not detrimental to most forms of life.

Inhibitor or inhibitive substance. A term variously applied, but usually used to designate a substance that inhibits the growth of bacteria and other microorganisms.

Lysogenesis. The production by an organism of substances that cause the lysis of bacterial cells.

Lysozyme. A substance produced by living tissues (white of egg, tears, and also certain microorganisms) that is capable of dissolving living bacterial cells, especially certain micrococci.

Mycocidal. A substance having tuberculocidal properties.

Mycoin. A term suggested to designate antibiotics of fungal and actinomycete origin.

Oxford unit (O.U.). A standard for penicillin adopted by international agreement and often designated as international unit (I.N.). One $\mathrm{mg}$. of crystalline penicillin is equivalent to r.650 O.U. One unit inhibits the growth of a standard strain of $S$. aureus in $50 \mathrm{ml}$. of meat broth.

Phytoncide. A chemical substance produced by higher green plants which has the capacity to inhibit the growth of bacteria and other microorganisms.

Streptomycin unit (S.U.). A dilution unit against E. coli as test organism, or the amount of material that will inhibit the growth of $E$. coli in I ml. of medium; equivalent to I $\mu \mathrm{g}$ of streptomycin base.

Trypanotoxin. A substance that has a destructive effect upon trypanosomes.

Tuberculocidin. An antibiotic substance having tuberculocidal properties.

Tuberculostatic. A substance having a bacteriostatic effect upon members of the $M$. tuberculosis group. 


\section{BIBLIOGRAPHY}

1. Aвraham, E. P. Mode of action of chemotherapeutic agents. Lancet 2: $761-762$ ( I 941).

2. Abraham, E. P. The effect of mycophenolic acid on the growth of Staphylococcus aureus in heart broth. Biochem. J. 39:398-408 (1945).

3. Abraham, E. P. The effect of proactinomycin on Staphylococcus aureus in heart broth. Brit. J. Exper. Path. 26:339-356 (1945).

4. Abraham, E. P., and Chain, E. An enzyme from bacteria able to destroy penicillin. Nature 146:837 (1940).

5. Abraham, E. P., Chain, E., Fletcher, C. M., Gardner, A. D., HeatLey, N. G., Jennings, M. A., and Florey, H. W. Further observations on penicillin. Lancet 2:177-188 (194I).

6. Abraham, E. P., Chain, E., and Holiday, E. R. Purification and some physical and chemical properties of penicillin; with a note on the spectrographic examination of penicillin preparations. Brit. J. Exper. Path. 23: 103-1 20 (1942).

7. Airola, E. V. Control of the microorganisms responsible for damage to moist paper pulp. Finnish Paper Timer J. 23:1 1 2-1 14, 1 16-1 1 8, 1 20122, 124, 126, 128-129 (1941); abstract in Chem. Abstr. 35:5312 (194I).

8. Aldershoff, H. Untersuchungen in vitro über die Art des Besredkaschen Antivirus. Zentralbl. f. Bakteriol., I, Or., 112:273-281 (1929).

9. Alexandre, A., and $\mathrm{CACCH}_{\mathrm{A}}, \mathrm{R}$. Recherches sur quelques facteurs probables déterminant l'antagonisme entre le B. coli dans la phase "s" et le L. bulgaricum. Soc. internaz. di microbiol., Boll. d. sez. ital. 10:291-298 (1938).

10. Alexopoulos, C. J. Studies in antibiosis between bacteria and fungi; species of actinomyces inhibiting the growth of Colletotrichum gloeosporoides Penz. in culture. Ohio J. Sc. 41:425-430 (1941).

11. Alexopoulos, C. J., Arnett, R., and McIntosh, A. V. Studies in antibiosis between bacteria and fungi. Ohio J. Sc. 38:221-235 (1937).

12. Alexopoulos, C. J., and Herrick, J. A. Studies in antibiosis between bacteria and fungi; inhibitory action of some actinomycetes on various species of fungi in culture. Bull. Torrey Bot. Club 69:257-261 (1942).

13. Alivisatos, G. P. Ueber Antagonismus zwischen Pneumokokken und Staphylokokken. Centralbl. f. Bakteriol., I, Or., 94:66-73 (1925).

14. Allen, M. C., and Haenseler, C. M. Antagonistic action of Trichoderma on Rhizoctonia and other soil fungi. Phytopath. 25:244-252 (1935).

15. Allen, W. E. Cutthroat competition in the sea. Scient. Monthly 49: I I I119 (1939).

16. Alsberg, C. L., and Black, O. F. Contribution to the study of maize deterioration; biochemical and toxicological investigations of Penicillium puberulum and Penicillium stoloniferum. U.S.D.A., Bur. of Plant Industry, Bull. 270 ( 1913 ). 
17. Alston, J. M., and Broom, J. C. The action of penicillin on leptospira and on leptospiral infections in guinea-pigs. Brit. M. J. No. 4378, pp. 718719 (1944).

18. Ambrose, A. M., and DeEds, F. Pharmacological properties of citrinin. Federation Proc. 5:162 (1946).

19. Anderson, H. E. Tyrothricin in cutaneous infections. Arch. Dermat. \& Syph. 53:20-25 (1946).

20. Anderson, H. H., Villela, G. G., Hansen, E. L., and Reed, R. K. Some physical and biologic properties of subtilin and other antibiotics. Science 103:419-420 (1946).

21. Anderson, T.F. The activity of bacteriostatic substances in the reaction between bacterial virus and host. Science I01:565-566; J. Cell. \& Comp. Physiol. 25: I-1 5, 1 7-26 (1 945).

22. ANDREws, C. H. Interference by one virus with the growth of another in tissue-culture. Brit. J. Exper. Path. 23:214-220 (1 942).

23. Anslow, W. K., and Raistrick, H. Studies in the biochemistry of microorganisms; fumigatin (3-hydroxy-4-methoxy-2:5-toluquinone) and spinulosin (3:6-dihydroxy-4-methoxy-2:5-toluquinone), metabolic products respectively of Aspergillus fumigatus Fresenius and Penicillium spinulosum Thom. Biochem. J. 32:687-696 (1938).

24. Anslow, W. K., Raistrick, H., and Smith, G. Anti-fungal substances from moulds; patulin (anhydro-3-hydroxymethylene-tetrahydro-1:4-pyrone-2-carboxylic acid), a metabolic product of Penicillium patulum Bainier and Penicillium expansum (Link) Thom. J. Soc. Chem. Ind. 62:236-238 (1943).

25. ARK, P. A., and Hunt, M. L. Saprophytes antagonistic to phytopathogenic and other microorganisms. Science 93:354-355 (I94I).

26. Arnstein, H.R. V., Cook, A.H., and Lacey, M.S. An antibacterial pigment from Fusarium javanicum. Nature 1 57:333-334 (1946).

27. Asheshov, I. M., and Strelitz, F. An antibiotic substance active against Mycobacterium tuberculosis. Science I OI : I I 9-I 20 (1945).

28. Asthana, R. P., and Hawker, L. E. The influence of certain fungi on the sporulation of Melanospora destruens Shear and some other Ascomycetes. Ann. Bot. 50:325-344 (1936).

29. Atrinson, N. Antibacterial substances produced by moulds. Australian J. Exper. Biol. \& M. Sc. 20:287-288 (1942) ; $21: 1$ 5-16, I 27-1 31, 249-257 (1943); 22:223-226, 227-230 (1944); M. J. Australia 1:359-362 (1943).

30. Atrinson, N. Toadstools and mushrooms as a source of antibacterial substances active against Mycobacterium phlei and Bact. typhosum. Nature I 57:441 (1946).

31. Auerswald, H. Welche Mikroorganismen wirken auf Diphtherie- und Pseudodiphtheriebazillen antagonistisch? Zentralbl. f. Bakteriol., I, I 42: 32-41 (1938).

31a. Avery, O. T., and Dubos, R. The protective action of a specific enzyme against type III pneumococcus infection in mice. J. Exper. Med. 54:73-89 (1931). 
32. BaIL, O. Versuche an Bakterienpopulationen. Arch. f. Hyg. $95: 1$ (1925); Ztschr. f. d. ges. exper. Med. 50: I I (1926); Deutsche med. Wchnschr. p. I 289 (1929); Ztschr. f. Immunitätsforsch. u. exper. Therap. 60:1-22 (1929).

33. Bailey, J. H., and Cavallito, C. J. Production of citrinin. J. Bact. 45: 30-3 I ( I 943).

34. Baker, G. E. Heterokaryosis in Penicillium notatum. Bull. Torrey Bot. Club 71:367-373 (1944); Science 99:436 (1944).

35. Bamberg, R. H. Bacteria antibiotic to Ustilago zeae. Phytopath. 20:140 (1930); 2 I:88 I-890 (1931).

36. Barriev, A. R. Contribution à l'étude du rôle des associations microbiennes; les bacilles sporulés aérobies; leur action pathogène probable dans les plaies de guerre. Thesis, Paris (1919); Presse méd. 28:40 (1919); abstract in Abstr. Bact. 4:1 140 (1920).

37. Bawden, F. C., and Kassanis, B. The suppression of one plant virus by another. Ann. App. Biol. 32:52-57 (1945).

38. Beadle, G. W., Mitchell, H. K., and Bonner, D. Improvements in the cylinder-plate method for penicillin assay. J. Bact. 49:101-104 (I 945).

39. Beard, P. J. Longevity of Eberthella typhosus in various soils. Am. J. Pub. Health 30:1077-1082 (1940).

40. Beard, R. L. Competition between two entomogenous bacteria. Science IO3:371-372 (1 946).

4I. Behrens, J. Wechselwirkungen zwischen verschiedenen Organismen (Symbiose, Metabiose, Antagonismus). Lafars Handb. techn. Mykol. Jena 1: $501-513$ (1904).

42. Beijerinck, M. W. Ueber Chinonbildung durch Streptothrix chromogena und Lebensweise dieser Microben. Centralbl. f. Bakteriol., Abt. II, 6: 2-1 2 (1900).

43. Belozersky, A. N., and Paschina, T.S. On the chemical nature of gramicidin S. Biokhimiya 10:344-352 (1945).

44. Benedict, R. G., Schmidt, W. H., and Coghill, R. D. Penicillin; penicillinase. Arch. Biochem. 8:377-384 (1945).

45. Berdnikoff, A. Les milieux de culture dits "vaccinés" et l'antagonisme des microbes in vitro. Compt. rend. Soc. de biol. 91:859-861 (1924).

46. Berezova, E. F. Bacteriological method of combating fungus diseases of agricultural plants. Microbiologia (U.S.S.R.) 8:1 86-197, 695-699 (1939).

47. Bergel, F., Morrison, A. L., Moss, A. R., Klein, R., Rinderknecht, H., and WARD, J. L. An antibacterial substance from Aspergillus clavatus and Penicillium claviforme and its probable identity with patulin. Nature I52:750 (1943).

48. Berger, F. M. Extraction and purification of penicillin. Nature 154: 459 (1944).

49. Bergonzini, C. Contributo sperimentale allo studio dei mezzi che l'organismo oppone all'infezione. Rassegna di scienze mediche 5:551-568 (1 890). 
50. Bershova, O. I. The dependence of the development of ammonifying bacteria on the soil bacteriophage. Mikrobiol. Zhur. 7:97-I I9 (1940).

50a. Bergström, S., Theorell, H., and Davide, H. On a metabolic product of Ps. pyocyanea, pyolipic acid, active against Mycobact. tuberculosis Arkiv. Kimi. Min. Geo., 23A (13):1-12; Arch. Biochem. 10:165-166 (1946).

51. Bertarelli, E. Untersuchungen und Beobachtungen über die Biologie und Pathogenität des Bacillus prodigiosus. Centralbl. f. Bakteriol., I, Or. 34: 193-202, 312-322 (1903).

52. Besredka, A. Les immunités locales. Paris, Masson et Cie, $1925,1937$.

53. Besta, B., and KuHN, $H$. Untersuchungen über Antagonismus zwischen Diphtheriebacillen und anderen Bakterien. Ztschr. f. Hyg. u. Infektionskr. I16:520-536 (1934).

54. Bezançon, F., Duchon et Duruy. Les difficultés du problème de la vaccinothérapie de la fièvre typhoide. Presse méd. 41:1941-1942 (1933).

55. Bienstock, Dr. Untersuchungen über die Aetiologie des Eiweissfäulnis; Milchfäulnis, Verhinderung der Fäulnis durch Milch, Darmfäulnis. Arch. f. Hyg. 39:390-427 (1901).

56. Biourge, Ph. Les moisissures du groupe Penicillium Link. Etude monographique. La cellule 33:5-33 I (1923).

57. Bigger, J. W. Treatment of staphylococcal infections with penicillin by intermittent sterilisation. Lancet 2:497-500 (1944).

58. Bigger, J. W. Inactivation of penicillin by serum. Lancet 2:400-402 (I 944).

59. Birch-Hirschfeld, L. Versuche zur Analyse der Pyocyanase. Ztschr. f. Hyg. u. Infektionskr. I 16:304-314 (1934).

6o. Birkinshaw, J. H., Bracken, A., and Raistrick, H. Studies in the biochemistry of micro-organisms; metabolic products of Aspergillus fumigatus Fresenius. Biochem. J. 39:70-85 (1945).

61. Birkinshaw, J. H., Oxford, A. E., and Raistrick, H. Studies in the biochemistry of microorganisms; penicillic acid, a metabolic product of Penicillium puberulum Bainier and P. cyclopium Westling. Biochem. J. 30: 394-4 I I (1936).

62. Birkinshaw, J. H., and Raistrick, H. Studies in the biochemistry of micro-organisms; puberulic acid $\mathrm{C}_{8} \mathrm{H}_{6} \mathrm{O}_{6}$ and an acid $\mathrm{C}_{8} \mathrm{H}_{4} \mathrm{O}_{6}$, new products of the metabolism of glucose by Penicillium puberulum Bainier and Penicillium aurantio-virens Biourge. Biochem. J. 26:441-453 (1932).

63. Bisby, G. R., James, N., and Timonin, M. Fungi isolated from Manitoba soils by the plate method. Canad. J. Research 8:253-275 (1933).

64. Blagovestchensky, N. Sur l'antagonisme entre les bacilles du charbon et ceux du pus bleu. Ann. Inst. Pasteur 4:689-7 I 5 ( I 890).

65. Blair, I. D. Behaviour of the fungus Rhizoctonia solani Kühn in the soil. Ann. App. Biol. 30: I I 8-1 27 (1943).

66. Blair, J. E., and Hallman, F. A. The effect of actinomycin, clavacin, and tyrothricin on staphylococcal toxin. J. Infect. Dis. 72:246-252 (1943).

67. Blinnikova, E. I. Mechanism of tyrothricin action. Biokhimiya ro: 15 I- $^{-}$ 154 (1945). 
68. Buss, C. I. Relative potency as applied to the assay of penicillin. Science I00: $577-578$ (1 944).

69. Bocchia, I. Die Pyocyanase. Centralbl. f. Bakteriol., I, Or. 50:220-225 (1909).

70. Военм, M. M., and Kopaczewski, W. Etudes sur les phénomènes électrocapillaires; l'antagonisme microbien et la thérapeutique du cancer. Protoplasma 6:302-320 (1929).

71. Bogendörfer, L. Hemmungsstoffe aus Bakterien und ihren Kultursubstraten. Ztschr. f. d. ges. exper. Med. 41:620 (1924); abstract in Centralbl. f. Bakteriol., I, Ref. 77:372 (1924).

72. Bondi, A., and Dietz, C. C. Relationship of penicillinase to the action of penicillin. Proc. Soc. Exper. Biol. \& Med. 56:1 35-1 37 (1 944); 60:55-58 ( 1945 ).

73. Bonét-Maury, P., and PÉrault, R. Photometric record of the mode of action of sulphonamides and penicillin. Nature I 55:701-702 (1945).

74. Bordet, J. Apparition spontanée du pouvoir lysogène dans les cultures pures. Compt. rend. Soc. de biol. 90:96-98 (1924); 93:1054-1056 (1925).

75. BoRnstein, S. Action of penicillin on enterococci and other streptococci. J. Bact. 39:383-387 (1940).

76. Borodulina, J.A. Interrelations of soil actinomyces and B. mycoides. Microbiologia (U.S.S.R.) 4:56I-586 (1935).

77. Bose, S. R. Antibacterial action of "polyporin" against typhoid, cholera, dysentery and B. coli. Nature I 56:17 I (1945); Current Sci. I 3:233-234 (1944).

77a. Bose, S. R. Antibiotics in a polyporus (Polystictus sanguineus). Nature 158:292-296 (1946).

78. Bouchard, C. Influence, qu'exerce sur la maladie charbonneuse l'inoculation du bacille pyocyanique. Compt. rend. Acad. d. sc. I08:713-714 (I 889).

79. Bowser, B. M. A study of the action of certain soil bacteria on Mycobacterium tuberculosis, varieties Hominis and Bovis. Thesis, Univ. Pittsburgh (1942).

80. Boyle, C. Studies in the physiology of parasitism; the growth reactions of certain fungi to their staling products. Ann. Bot. 38:113-135 (1924).

8oa. Brazhnikova, M. G. The isolation, purification, and properties of litmocidin. J. Bact. 51 :655-657 (1946).

8I. Brewer, C. M. Use and abuse of Staphylococcus aureus as a test organism. Am. J. Pub. Health 32:401-405 (1942).

8ia. Brian, P. W., Curtis, P. J., Grove, J. P., Hemming, H. G., and McGowan, J. C. Gladiolic acid; an antifungal and antibacterial metabolic product of Penicillium gladioli. Nature 157:697-698 (1946).

8 ib. Brian, P. W., Curtis, P. J., Hemming, H. G., and McGowan, J. C. The production of viridin by pigment-forming strains of Trichoderma viride. Ann. App. Biol. 33:190-200 (1946).

82. Brian, P. W., and Hemming, H. G. Gliotoxin, a fungistatic metabolic product of Trichoderma viride. Ann. App. Biol. 32:2 I 4-220 (1945). 
83. Brian, P. W., Hemming, H. G, and McGowan, J. C. Origin of a toxicity to Mycorrhiza in Wareham Health soil. Nature 155:637-638 (1945).

83a. Brian, P. W., and McGowan, J. C. Biologically active metabolic products of the mould Metarrhizium glutinosum S. Pope. Nature 157:334 (I946).

84. Brian, P. W., and McGowan, J. C. Viridin; a highly fungistatic substance produced by Trichoderma viride. Nature 156:144-1 45 (1945).

85. Brink, N. G., Kuehl, F. A., Jr., and Folkers, K. Streptomyces antibiotics; degradation of streptomycin to streptobiosamine derivatives. Science 1 02:506-507 ( I 945).

86. Briscoe, C. F. Fate of tubercle bacilli outside the animal body. Illinois Agr. Exper. Sta. Bull. I61:279-375 (1912).

87. Broadfoot, W. C. Studies on foot- and root-rot of wheat; effect of age of the wheat plant upon the development of foot- and root-rot. Canad. J. Research 8:483-491, 545-552 (1933).

88. Brodski, A. L. Antagonism between soil infusoria and (plant) pathogenic fungi. Compt. rend. Acad. d. sc. (U.S.S.R.), n.s. 33:8 I-83 (I 94 I).

89. Brömmelhues, M. Die wechselseitige Beeinflussung von Pilzen und die Bedeutung der Pilzkonkurrenz für das Ausmass der Schädigung an Weizen durch Ophiobolus graminis Sacc. Zentralbl. f. Bakteriol., II, 92:8 I-I I6 (1935).

90. Broom, W. A., Bulbring, E., Chapman, C. J., Hampton, J. W. F., Thomson, A. M., Ungar, J., Wein, R., and Woolfe, G. The pharmacology of patulin. Brit. J. Exper. Path. 25:195-207 (1944).

91. Brown, A. J. The influences regulating the reproductive functions of Saccharomyces cerevisiae. J. Chem. Soc. Trans. 87: 1395-I41 2 (1905).

92. Brown, J. G., and Boyle, A. M. Effect of penicillin on a plant pathogen. Phytopath. 34:760-761 (1944).

93. Brown, W. Experiments on the growth of fungi in culture media. Ann. Bot. 37:105-129 (1923); Bot. Rev. 2:236-281 (1936).

94. Brues, A. M. Chemical treatment of tumors; reactions of four patients with advanced malignant tumors to injection of a polysaccharide from Serratia marcescens culture filtrate. J. Nat. Cancer Inst. 5: 195-208 (1 944).

95. Brues, C. T., and DunN, R. C. The effect of penicillin and certain sulfa drugs on the intracellular bacteroids of the cockroach. Science IOI:336337 (1945).

96. Bryan, C. S., Weldy, M. L., and Greenberg, J. The results obtained with tyrothricin in the treatment of 157 cows with streptococcic mastitis. Vet. Med. 37:364-369 (1942).

97. Bülthuis, G. Welche Bakteriengruppen wirken auf Typhusbazillen antagonistisch? Zentralbl. f. Bakteriol., I, Or. 145:462-469 (1940).

98. Bumm, R. Behandlung chronisch-eiteriger Prozesse mit toten Gewebsrückständen durch Dauerpräparate von proteolytischen Bakterien. Arch. f. klin. Chir. I 38: I I I (1925); abstract in Centralbl. f. Bakteriol., I, Ref. 81:41 7 (1926).

99. Burkholder, P. R. Some growth patterns of bacteria in cylinder plate tests for promoting and inhibiting substances. Am. J. Bot. 31:555-558 (1944). 
100. Burkholder, P. R., and Evans, A. W. Further studies on the antibiotic activity of lichens. Bull. Torrey Bot. Club 72:157-163 (1945).

IoI. Burkholder, P. R., Evans, A. W., McVeigh, I., and Thornton, H. K. Antibiotic activity of lichens. Proc. Nat. Acad. Sc. 30:250-255 (1944).

102. Bush, M. T., Dickison, H. L., Ward, C. B., and Avery, R. C. Antibiotic substances active against $M$. tuberculosis. Federation Proc. 4:II3; J. Pharmacol. \& Exper. Therap. 85:237-246 (1945).

103. Bush, M. T., and Gotн, A. Flavicin; an antibacterial substance produced by an Aspergillus flavus. J. Pharmacol. \& Exper. Therap. 78:164-169 (1943) ; Fed. Proc., Am. Soc. Exper. Biol. 2:75 (1943).

I04. Bush, M. T., Goth, A., and Dickison, H. L. Flavicin. J. Pharmacol. \& Exper. Therap. 84:262-277 (1945).

105. Butler, K. D. The cotton root rot fungus Phymatotrichum omnivorum, parasitic on the watermelon, Citrillus vulgaris. Phytopath. 25:559-577 (1935).

i 06. Butterfield, C. T., and Purdy, W. C. Some interrelationships of plankton and bacteria in natural purification of polluted water. Ind. \& Eng. Chem. 23:213-218 (1931).

107. Callow, R. K., and Hart, P. D. Antibiotic material from Bacillus licheniformis (Weigmann, emend, Bigson) active against species of mycobacteria. Nature 1 57:334-335 (1946).

108. Campbeli, A. H., Foss, M. E., Hirst, E. L., and Jones, J. K. N. Nitrogenous substances synthesized by molds. Nature 155:141 (1945).

109. Cantani, A. Tentativi di bacterioterapia. Riforma Medica, Napoli, 147 (1885); abstract in Centralbl. medicin. Wissensch. 23:513-514 (I 885).

I Io. Cantan1, F. Sulle antibiose microbica. Ann. d'ig. 40:257-271 (1930); abstract in Jior. di Immunol., p. 665 (1930).

II I. Carlson, H. J., Ridenour, G. M., and McKhann, C. F. Effect of the activated sludge process of sewage treatment on poliomyelitis virus. Am. J. Pub. Health 33:1083-1087 (1943).

I I 2. Carpenter, C. W. Antibacterial properties of yeasts, Fusarium sp., onion, and garlic. Hawaiian Planters' Rec. 49:4 I-67 (1945).

I 13. CARR, J. G. Action of notatin on the Rous No. I Sarcoma virus. Nature 1 55:202 (1945).

II 4. Carter, H. E., Clark, R. K., Dickman, S. R., Loo, Y. H., Meek, J.S., Skell, P. S., Strong, W. A., Alberi, J. T., Bartz, Q. R., BinkLeY, S. B., Crooks, H. M., JR., Hooper, I. R., and Rebstock, M. Degradation of streptomycin and the structure of streptidine and streptamine. Science 103:53-54 (1946).

I1 5. Carter, H. E., Clark, R. K., Dickman, S. R., Loo, Y. H., Skell, P.S., and Strong, W. A. Isolation and purification of streptomycin. J. Biol. Chem. 160:337-342 (1945).

II5a. CARTER, J. C. The fusible nature of the inhibitory agent produced by fungi. Phytopath. 25:1031-1034 (1935).

I I 5b. Cavallito, C. J. Relationship of thiol structures to reaction with antibiotics. J. Biol. Chem. 164:29-34 (1946). 
1 16. Cavallito, C. J., and Bailey, J. H. Preliminary note on the inactivation of antibiotics. Science 100:390 (1944).

I 1 7. Cavallito, C. J., and Bailey, J. H. Allicin, the antibacterial principle of Allium sativum; isolation, physical properties and antibacterial action. J. Am. Chem. Soc. 66: 1950-1951, 1952-1954 (1944).

i 18. Cavallito, C. J., Bailey, J. H., Haskell, T. H., McCormick, J. R., and WARNER, W.F. The inactivation of antibacterial agents and their mechanism of action. J. Bact. 50:6I-69 (I 945); J. Am. Chem. Soc. 67: I 99I-I 994 (I 945).

I 19. Chaillot, L. Etude in vitro sur les antivirus. Compt. rend. Soc. de biol. 103:206-207 (1930).

1 20. Chain, E. Mode of action of chemotherapeutic agents. Lancet $2: 761-762$ (I94I).

121. Chain, E., and Duthie, E. S. Bactericidal and bacteriolytic action of penicillin on the staphylococcus. Lancet $1: 652-657$ (1945).

1 22. Chain, E., and Forey, H. W. Antibacterial substances produced by bacteria and fungi. Ann. Rep. Prog. Chem. for I943; Chem. Soc. 40:180I 97 ( 1944 ).

123. Chain, E., Florey, H. W., Gardner, A. D., Heatley, N. G., Jennings, M. A., Orr-Ewing, J., and Sanders, A. G. Penicillin as a chemotherapeutic agent. Lancet 2:226-228 (I940).

1 24. Chain, E., Florey, H. W., and Jennings, M. A. An antibacterial substance produced by Penicillium claviforme. Brit. J. Exper. Path. 23:202205 ( I 942 ).

1 25. Chain, E., Florey, H. W., and Jennings, M. A. Identity of patulin and claviformin. Lancet I: I I 2-I I 4 ( I 944).

126. Chain, E., Florey, H. W., Jennings, M. A., and Williams, T. I. Helvolic acid, an antibiotic produced by Aspergillus fumigatus, mut. helvola Yuill. Brit. J. Exper. Path. 24:108-1 i9 (1943).

127. Challinor, S. W. Production of penicillin. Nature 150:688 (1942).

128. Challinor, S. W., and MacNaughtan, J. Production of penicillin. J. Path. \& Bact. 55:441-446 (1943).

129. Chambers, S. O., and Weidman, F. D. A fungistatic strain of Bacillus subtilis isolated from normal toes. Arch. Dermat. \& Syph. I 8:568-572 (1928).

130. Chandler, V. L., Price, C. W., and Randall, W. A. Control and evaluation of blood serum assays for penicillin. Science 102:355-356 (1945).

131. Charrin, M., and Guignard, L. Action du bacille pyocyanique sur la bactéridie charbonneuse. Compt. rend. Acad. d. sc. 108:764-766 (1889).

132. Chatterjee, G. C. On a new test for differentiation of the bacilli of the typhoid group. Centralbl. f. Bakteriol., I, Or. 48:246-249 (I 909).

133. Chatton, E. and M. L'influence des facteurs bactériens sur la nutrition, la multiplication et la sexualité des infusoires. Compt. rend. Acad. d. sc. 1 76: 1 262-1265 (1923); 1 88:1315-1317 (1929); Compt. rend. Soc. de biol. $93: 675-678$ (1925). 
134. Chatton, E. and M. Sur le pouvoir cytolytique immédiat des cultures de quelques bactéries chromogènes. Compt. rend. Soc. de biol. 97:289-292 (1927).

135. Chaze, J., and Sarazin, A. Nouvelles données biologiques et expérimentales sur la môle maladie du champignon de couche. Ann. sc. nat., bot. 18 (10): $1-86(1936)$.

136. CHow, B. F., and $\mathrm{MCK}_{\mathrm{EE}}, \mathrm{C} . \mathrm{M}$. Inactivation of the antibiotic activity of penicillin by cysteine hydrochloride; chemical aspects of inactivation. Proc. Soc. Expcr. Biol. \& Med. 58:1 75-177 (1945); Science 101:67-68 (1945).

137. Christensen, H. N. The configuration of valylvaline in gramicidin. J. Biol. Chem. 154:427-436 (1944).

138. Christensen, H.N. The free chemical groups of tyrocidine. J. Biol. Chem. 160:75-82 (1945).

139. Christensen, H. N., and Hegsted, D. M. The course of the acid hydrolysis of gramicidin. J. Biol. Chem. 158:593-600 (1945).

140. Christensen, H. N., Uzman, L., and Hegsted, D. M. A note on the amino acid composition of tyrocidine. J. Biol. Chem. 158:279-28 I (1945).

141. Christensen, J. J. Associations of microorganisms in relation to seedling injury arising from infected seed. Phytopath. 26:1091-1105 (1936).

142. Christensen, J. J., and Davies, F. R. Variation in Helminthosporium sativum induced by a toxic substance produced by Bacillus mesentericus. Phytopath. 30: 1017-1033 (1940).

143. Chudiakov, J. P. The lytic action of soil bacteria on parasitic fungi. Microbiologia (U.S.S.R.) 4:193-204 (1935).

144. CLAPP, M. P. In vitro effect of tyrothricin and tryocidine hydrochloride on polymorphonuclear leucocytes. Proc. Soc. Exper. Biol. \& Med. 51:279281 (1942).

145. Clayton, J. C., Hems, B. A., Robinson, F. A., Andrews, R. D., and Hunwicke, R. F. Preparation of penicillin; improved method of isolation. Biochem. J. 38:452-458 (1944).

146. Clutterbuck, P. W., Lovell, R., and Raistrick, H. Studies on the biochemistry of microorganisms; the formation from glucose by members of the Penicillium chrysogenum series of a pigment, an alkali-soluble protein and penicillin-the antibacterial substance of Fleming. Biochem. J. 26: 1907-1918 (1932).

147. Clutterbuck, P. W., Oxford, A. E., Raistrick, H., and Smith, G. Studies in the biochemistry of microorganisms; the metabolic products of the Penicillium brevi-compactum series. Biochem. J. 26:1441-1 458 (1932).

147a. Coghill, R. D., Osterberg, A. E., and Hazel, G. R. The relative effectiveness of pure penicillins $G, X$, and K. Science 103:709-710 (1946).

178. Conradi, H., and Karpjuweit, O. Ueber die Bedeutung der bakteriellen Hemmungsstoffe für die Physiologie und Pathologie des Darmes. München. med. Wchnschr., pp. 522, 1761, 2164, 2228 (1 905); abstract in Centralbl. f. Bakteriol., I, Ref. 38:69-70 (1906). 
149. Cook, A. H., and Lacer, M. S. An antibiotic from Aspergillus parasiticus. Nature 153:460 (1944).

150. Cook, A. H., and LaceY, M. S. Kojic acid and the antibiotic action of species of Aspergillus. Nature 155:790-79 I (I945).

I 5 I. Cook, E. S., Kreke, C. W., Giersch, M. C., and Schroeder, M. P. A growth-depressant substance from yeast. Science 93:616-617 (I94I).

152. Cooke, J.V. A simple clinical method for the assay of penicillin in body fluids and for the testing of penicillin sensitivity of bacteria. J.A.M.A. I 27:445-449 (I 945).

152a. Cooke, R. E., Dumphy, D. L., and Blake, F. G. Streptomycin in tuberculous meningitis; report of its use in one year old infant. Yale J. Biol. \& Med. I 8:22 I-226 (1946).

153. Cooper, E. A., and Mason, J. Studies of selective bactericidal action. J. Hyg. 26: I I9-1 26 (1927).

154. Cordon, T. C., and Haenseler, C. M. A bacterium antagonistic to Rhizoctonia solani. Soil Sc. 47:207-2 I 5 ( I939).

155. Cornil, A. V., and Babes, V. Concurrence vitale des bactéries; atténuation de leurs propriétés dans des milieux nutritifs modifiés par d'autres bactéries; tentatives de thérapeutique bactériologique. J. conn. méd. prat. Paris 7:321-323 ( 1885 ).

156. Cornman, I. Survival of normal cells in penicillin solutions lethal to malignant cells. Science 99:247 (1944); J. Gen. Physiol. 28: I I3-1 I 8 (1944).

I 57. Coulthard, C. E., Michaellia, R., Short, W. F., Sykes, G., Skrimshire, G. E. H., Standfast, A. F. B., Birkinshaw, J. H., and RaisTRICK, H. Notatin; anti-bacterial glucose-aerodehydrogenase from Penicillium notatum Westling and Penicillium resticulosum sp. nov. Biochem. J. 39:24-36 (1945).

158. CRADDOCK, S. Use of penicillin in cultivation of the acne bacillus. Lancet I : $55^{8-559}$ ( I 942).

159. CRIEP, L. H. Allergy to penicillin. J.A.M.A. I 26:429-430 (I944).

160. Crowe, S. J., Fisher, A. M., Ward, A. T., Jr., and Foley, M. K. Penicillin and tyrothricin in otolaryngology. Ann. Otol. Rhin. \& Laryng. 52: $541-572$ (1943).

161. Crowfoot, D. M., and Low, B. W. Note on crystallography of helvolic acid and methyl ester of helvolic acid. Brit. J. Exper. Path. 24:120 ( 1943 ).

162. Curran, H. R., and Evans, F. R. Penicillin as a sporicidal agent. Proc. Soc. Exper. Biol. \& Med. 58:262-265 (1945).

163. Cutler, D. W., and Bal, D. V. Influence of protozoa on the process of nitrogen fixation by Azotobacter chroococcum. Ann. App. Biol. 1 3:516-534 (1926).

164. Dack, G. M. Food poisoning. Chicago, Univ. Chicago Press, 1943.

165. DACK, G. M. Influence of anaerobic species on toxin of $\mathrm{Cl}$. botulinum with special reference to Cl. sporogenes. J. Infect. Dis. 38:165-1 73 (1926).

166. D'Aетн, H. R. X. A survey of interaction between fungi. Biol. Rev. 14: I05-13 I (1939). 
167. Dalnes, R. H. Antagonistic action of Trichoderma on Actinomyces scabies and Rhizoctonia solani. Am. Potato J. I 4:85-93 (1937).

168. Dale, H. Uniform standard for penicillin. Brit. M. J. No. 4373, p. 572 (1944).

169. Dalldorf, G., Douglass, M., and Robinson, H. E. The sparing effect of canine distemper on poliomyelitis in Macaca mulatta. J. Exper. Med. 67: 333-343 (1938).

170. Davies, D. S., Hinshelwoods, C. N., and Pryce, J. M. Studies in the mechanism of bacterial adaptation. Trans. Faraday Soc. 40:397-419 (1944).

I 7 I. Dawson, M. H., Hobby, G. L., Meyer, K., and Chaffee, E. Penicillin as a chemotherapeutic agent. Ann. Int. Med. 19:707-717 (1943).

172. DeBary, A. Die Erscheinungen der Symbiose. Strassburg, I 879.

173. DE BeER, E. J., and SHerwood, M. B. The paper-disc agar-plate method for the assay of antibiotic substances. J. Bact. 50:459-468 (I 945).

174. DeLBRÜCK, M. Interference between bacterial viruses; the mutual exclusion effect and the depressor effect. J. Bact. 50: I 5 I-I 70 ( I 945).

175. DelbrücK, M., and Luria, S. E. Interference between bacterial viruses; interference between two bacterial viruses acting upon the same host, and the mechanism of virus growth. Archiv. Biochem. I: I I I-1 43 (1942).

176. Demelenne-Jaminon, G. A propos d'un cas de variation microbienne. Compt. rend. Soc. de biol. 1 33:440-442 (1940).

177. Demerec, M. Production of staphylococcus strains resistant to various concentrations of penicillin. Proc. Nat. Acad. Sc. 31:16-24 (1945); Ann. Missouri Bot. Garden 32: 13 I-I 38 ( I 945).

178. Demolon, A., and Dunez, A. Nouvelles observations sur le bactériophage et la fatigue des sols cultivés en luzerne. Ann. Agron. 6:434-454 (1936).

179. Denkewalter, R., Cook, M., and Tishler, M. The effect of cysteine on streptomycin and streptothricin. Science IOI: I 2 ( I 945).

180. Deschiens, R. Considérations relatives à la destruction des larves de Nématodes parasites par des Hyphomycètes prédateurs. Bull. Soc. path. exot. 32:459-464 (1 939); Compt. rend. Acad. d. sc. 2 I 5: 1 48-I 5 I (1941).

181. Diмiск, K. P. A quantitative method for the determination of tyrothricin. J. Biol. Chem. I 49:387-393 (I943).

182. Dimitrijević-Speth, V. Die Schwärmkultur insbesondere Schwärmhemmung, Antagonismus und Farbindikatoren. Zentralbl. f. Bakteriol., I, Or. I $16: 332-338$ ( 1930 ).

183. Dixon, K. Penicillin and fibrinolysis. Brit. M. J. No. 4397, pp. 514-516 (1945).

184. Dmitrevskaya, N. A., and TChebotarewitch, M. F. On the phenomenon of antagonism among microorganisms. Arch. biol. nauk (U.S.S.R.) 43 : 337-344 (1936).

185. Dmitrieff, S., and Souteeff, G. Sur les phénomènes de dissociation et de lyse observés dans les cultures de l'Actinomyces bovis Bostroem; essais d'application des filtrats de cultures lysées au traitement de l'actinomycose. Ann. Inst. Pasteur 56:470-476 (1936). 
I 86. Doebelt, H. Beiträge zur Kenntnis eines pigmentbildenden Penicilliums. Ann. Mycol. 7:315-338 (1909).

I 87. Doenle, Dr. Beobachtungen über einen Antagonisten des Milzbrandes. Habilitationschr. Kiel, I 889 .

188. Doering, W. E., Dubos, R. J., Noyce, D. S., and Dreyfus, R. Metabolic products of Aspergillus ustus. J. Am. Chem. Soc. 68:725-726 (1946).

189. Dold, H., and DEck, F. W. The antibacterial inhibition substances (inhibins) in normal fresh human urine. Ztschr. Hyg. Immunität. 123:383 (1941); Klin. Wchnschr. 2 I : 823 ( I 942).

190. Donaldson, R. Character and properties of the "Reading" bacillus, on which a new method of treatment of wounds has been based. J. Path. \& Bact. 22: I 29-I 5I (I 918).

191. Donovick, R., Hamre, D., Kavanagh, F., and Rake, G. A broth dilution method of assaying streptothricin and streptomycin. J. Bact. 50:623628 (1 945 ).

192. Downs, C. M. The effect of bactericidal agents on gram-negative cocci. J. Bact. 45: 1 37-1 42 (1 943 ).

193. Drake, C. H. Action of penicillin on several genera of actinomycetales. J. Bact. 51:199-204 (1946).

194. DrechsLer, C. Some hyphomycetes parasitic on free-living terricolous nematodes. Phytopath. 31:773-802 (I94I); Biol. Rev. 16:265-290 (I 94I).

195. Drechsler, C. Several additional phycomycetes subsisting on nematodes and amoebae. Mycologia 37:1-31 (1 945).

196. DreChSLER, C. Two hyphomycetes parasitic on oöspores of root-rotting oömycetes. Phytopath. 28:81-103 (1938).

197. Dresel, E. G. Bakteriolyse durch Fettsäuren und deren Abkömmlings. Centralbl. f. Bakteriol., I, Or. 97:1 78-181 (1926).

198. Duв, L. Urethral tyrothricin irrigations in the male; an experimental and clinical study. Am. J. Syph., Gonor. \& Ven. Dis. 28:325-333 (1944).

199. Duвos, R. J. The adaptive production of enzymes by bacteria. Bact. Rev. 4: $1-16$ (1 940).

200. Dubos, R. Antimicrobial agents of biological origin. J.A.M.A. 124:633636 ( I 944).

20I. Dubos, R. J. Bactericidal effect of an extract of a soil bacillus on grampositive cocci. Proc. Soc. Exper. Biol. \& Med. 40:3 II-3I 2 (I939); J. Exper. Med. 70: 1-10, 1 1-1 7 (1939).

202. Dubos, R. The bacteriostatic action of certain components of commercial peptones as affected by conditions of oxidation and reduction. J. Exper. Med. 52:331-345 (1930).

203. Dubos, R. J. The effect of specific agents extracted from soil microorganisms upon experimental bacterial infections. Ann. Int. Med. 13:2025-2037 (1940).

204. Dusos, R. Factors affecting the yield of specific enzyme in cultures of the bacillus decomposing the capsular polysaccharide of type III pneumococcus. J. Exper. Med. 55:377-391 (1932). 
205. Duros, R. J. Studies on the mechanism of production of a specific bacterial enzyme which decomposes the capsular polysaccharide of type III pneumococcus. J. Exper. Med. 62:259-269 (1935).

206. Duвos, R. J. The mode of action of chemotherapeutic agents. Bull. New York Acad. Med. 2 1:27-36 (1945).

207. Dubos, R. J., and Avery, O. T. Decomposition of the capsular polysaccharide of pneumococcus type III by a bacterial enzyme. J. Exper. Med. 54: 5 I-7I (I93I).

208. Dubos, R. J., and Cattaneo, C. Studies on a bactericidal agent extracted from a soil bacillus; preparation and activity of a protein-free fraction. J. Exper. Med. 70:249-256 (1 939).

209. Dusos, R. J., and Hотснкiss, R. D. The production of bactericidal substances by aerobic sporulating bacilli. J. Exper. Med. 73:629-640 (I94I).

2io. Dubos, R. J., Нотснкiss, R. D., and Coburn, A. F. The effect of gramicidin and tyrocidine on bacterial metabolism. J. Biol. Chem. 146:42 I-426 (1942).

2I I. Duchesne, E. Contribution à l'étude de la concurrence vitale; antagonisme entre les moisissures et les microbes. Thesis, Lyon (1897).

212. Duclaux, E. Réaction sur le microbe des produits de sa vie cellulaire. Traité de Microbiologie. Paris, Masson, 1898. Vol. 1, pp. 236-249.

213. Dujardin-Beaumetz, E. Action antibiotique excercée "in vitro" par certains streptocoques et en particulier par un microcoque saprophyte. Compt. rend. Soc. de biol. I 1 7:1 1 78-1 1 80 (1934).

21 4. Dujardin-Beaumetz, E. Propriété antibiotique du pneumocoque. Compt. rend. Soc. de biol. 1 24:890-891 (1937).

21 5. Duliscouet, R. Action probiotique et antibiotique des staphylocoques chez les porteurs des germes diphtériques. Compt. rend. Soc. de biol. I I 8: I 2771280 (1935); Arch. méd. pharm. colon. I 29:410-443 (1939).

216. Duncan, J. T. On a bactericidal principle present in the alimentary canal of insects and arachnids. Parasitology 1 8:238-252 (1926).

21 7. Dunham, W. B., Hamre, D. M., McKee, C. M., and Rake, G. W. Action of penicillin and other antibiotics on Treponema pallidum. Proc. Soc. Exper. Biol. \& Med. 55:158-160 (1944).

218. Dunham, W. B., and Rake, G. The relative activity of partially purified penicillin and of crystalline penicillin $G$ on Treponema pallidum. Am. J. Syph., Gonor., \& Ven. Dis. 29:2 I 4-228 (1945).

21 . Duran-Reynals, F. Bactériophage et microbes tués. Compt. rend. Soc. de biol. 94:242-243 (1926).

220. Dutcher, J. D., and Wintersteiner, O. The structure of aspergillic acid. J. Biol. Chem. 1 55:359-360 (1944); Federation Proc. 4:88 (1945).

221. Duthie, E. S. The production of penicillinase by organisms of the Subtilis group. Brit. J. Exper. Path. 25:96-100 (1944).

222. Dutky, S. R. Two new spore-forming bacteria causing milky diseases of Japanese beetle larvae. J. Agr. Research 61:57-68 (1940).

223. Eagle, H., Magnuson, H. J., and Musselman, A. D. The therapeutic efficacy of penicillin in relapsing fever infections in mice and rats. Pub. Health Rep. 59:583-588 (1944). 
224. Eagle, H., and Musselman, A. The low therapeutic activity of penicillin $\mathrm{K}$ relative to that of penicillins $\mathrm{F}, \mathrm{G}$, and $\mathrm{X}$, and its pharmacological basis. Science 103:61 8-620 (1946).

225. Eagle, H., and Musselman, A. D. The spirocheticidal action of penicillin in vitro (Treponema pallidum-Reiter strain). J. Bact. 47:428; J. Exper. Med. 80:493-505 (1944).

226. EATon, E. D., and KING, C. J. A study of the cotton root rot fungus (Phymatotrichum omnivorum) in the soil by the Cholodny method. J. Agr. Research 49: Iro9-III3 (I934).

227. Edwards, E. T. The biological antagonism of Gibberella fujikuroi and Gibberella fujikuroi var. subglutinans to Trichoderma viride, with notes on the pathological effects of the latter fungus on maize. J. Australian Inst. Agr. Sc. 6:91-100 (1940).

228. Ehrismann, O. Pyocyanin und Bakterienatmung. Zentralbl. f. Bakteriol., I, Ref. I1 2:285-286 (1934).

229. Eisler, M., and JAcoBsohn, I. Über die antagonistische Wirkung steriler Bouillonextrakte aus Bacterium prodigiosus. Ztschr. Hyg. Immunität. I I 7: 76-91 (1936).

230. Elias, W. F., and Durso, J. Blood, urine and fecal levels of streptomycin in the treatment of human infections of E. typhosa. Science I01:589-59I (1945).

231. Ellis, E. L., and Spizizen, J. The rate of bacteriophage inactivation by filtrates of Escherichia coli cultures. J. Gen. Physiol. 24:437-445 (I 94 I).

232. Emmart, E. W. The tuberculostatic action of streptothricin and streptomycin with special reference to the action of streptomycin on the chorioallantoic membrane of the chick embryo. Pub. Health Rep. 60:1415-1421 (1945).

233. Emmerich, R. Die Heilung des Milzbrandes. Arch. f. Hyg. 6:442-50 I (1886).

234. Emmerich, R. Sind alle Einwände gegen die Natur und Wirkungsweise der sogenannten Nukleasen widerlegt? Centralbl. f. Bakteriol., I, Or. 3 I : 585-588 (1 902).

235. ЕммеRich, R., and Löw, O. Bakteriologische Enzyme als Ursache der erworbenen Immunität und die Heilung von Infektionskrankheiten durch dieselben. Ztschr. Hyg. Immunität. 31: 1-65 (1899).

236. ЕммеRich, R., and Löw, O. Die künstliche Darstellung der immunisierenden Substanzen (Nukleasen-Immunproteide) und ihre Verwendung zur Therapie der Infektionskrankheiten und zur Schutzimpfung an Stelle des Heilserums. Ztschr. f. Hyg. u. Infektionskr. 36:9 (1901); abstract in Centralbl. f. Bakteriol. 29:577-579 (1901).

237. Емmerich, R., Löw, O., and Korschun, A. Die bakteriolytische Wirkung der Nucleasen und Nucleasen-Immunproteidine als Ursache der natürlichen und künstlichen Immunität. Centralbl. f. Bakteriol., I, Or. 3 I : I-25 ( 1902$)$.

238. EMmerich, R., and SAIDA, DR. Ueber die morphologischen Veränderungen der Milzbrandbacillen bei ihrer Aufösung durch Pyocyanase. Centralbl. f. Bakteriol., I, Or. 27:776-787 (1 900). 
239. Emmerich, R., and Tromsdorf, R. Ueber die erfolgreiche Behandlung tödlicher intraperitonaler Streptokokkeninfektion beim Kaninchen durch präventive Pyocyanase-Immunproteiden-Injektionen. Centralbl. f. Bakteriol., 1, Or. 33:627-633 (1903).

240. Emmons, C. W. Fungicidal and fungistatic agents; proposed method for testing fungicides against Trichophyton. Am. J. Pub. Health $35: 844-846$ (1945).

241. Endo, S. Studies on the antagonism of microorganisms; growth of $\mathrm{Hy}-$ pochnus sasakii Shirai as influenced by the antagonistic action of other microorganisms. Bul. Miyazaki Coll. Agr. For. 3:95-119 (1931); 4:133-1 58, 1 59-185 (1932); 5:51-73 (1933).

242. Epste1n, L. A., and $\mathrm{Chain}_{\text {, }}$ E. Some observations on the preparation and properties of the substrate of lysozyme. Brit. J. Exper. Path. $21: 339-355$ (1940).

243. Etinger-Tulczinska, R. Ueber Bakterienantagonismus. Ztschr. f. Hyg. u. Infektionskr. I 1 3:762-780 (1932); 116:72-80 (1934).

244. Fadeeva, T. D., and Tchernobaiev, V. S. Bacillus pestis in mixed cultures; antagonism of various species of bacteria towards plague bacilli. Viestnik mikr. epidemiol. i parasitol. I4:346-356 (1935). Cited by $\mathrm{Na}$ khimovskaia (670).

245. Fainshmidt, O. I., and Koreniako, A. I. Method of obtaining concentrates of the antibacterial substance, produced by Actinomyces violaceus. Biokhimiya 9:147-153 (1944).

246. Faltin, R. Studien über Hetero- und Isantagonismus, mit besonderer Berücksichtigung der Verhältnisse bei infektiösen Erkrankungen der Harn. wege. Centralbl. f. Bakteriol., I, Or., 46:6-20, 109-128, 222-229 (1908).

247. FAWCETT, H.S. The importance of investigations on the effects of known mixtures of microorganisms. Phytopath. 21:545-550 (1931).

248. FDA reveals penicillin assay methods. Drug Trade News 1 8:33-42 (1 943 ).

249. Feldman, W. H., and Hinshaw, H. C. Effects of streptomycin on experimental tuberculosis in guinea pigs; a preliminary report. Proc. Staff Meet., Mayo Clinic 19:593-599 (1944).

250. Feldman, W. H., Hinshaw, H. C., and Mann, F. C. Streptomycin in experimental tuberculosis. Am. Rev. Tuberc. 52:269-298 (1945).

251. Fellows, H. Studies of certain soil phases of the wheat take-all problem. Phytopath. 19:103 (1929).

252. Fernbach, A. Sur un poison élaboré par la levure. Compt. rend. Acad. d. sc. 149:437-439 (1909).

253. FILDES, P. A rational approach to research in chemotherapy. Lancet I: 955-957 (1940).

254. Fildes, P. The mechanism of the anti-bacterial action of mercury. Brit. J. Exper. Path. 21:67-73 (1940).

255. Findlay, G. M., Fleming, A., and others. The mode of action of chemotherapeutic agents. Biochem. J. 36:1-17 (1942).

256. Fischer, R. A., Thornton, H. G., and MacKenzie, W. A. The accuracy of the plating method of estimating the density of bacterial populations. Ann. App. Biol. 9:325-359 (1922). 
257. Fleming, A. Chemotherapy and wound infection. Lancet 1:278 (1941).

258. Fleming, A. In vitro tests of penicillin potency. Lancet 1:732-733 (1942).

259. Fleming, A. Lysozyme; president's address. Proc. Roy. Soc. Med. (London) $26: 71-84$ (1932).

260. Fleming, A. On a remarkable bacteriolytic element found in tissues and secretions. Proc. Roy. Soc. (London), s.B. 93:306-317 (1922).

261. Fleming, A. On the antibacterial action of cultures of a Penicillium, with special reference to their use in the isolation of B. influenzae. Brit. J. Exper. Path. 10:226-236 (1929).

262. Fleming, A. On the specific antibacterial properties of penicillin and potassium tellurite; incorporating method of demonstrating some bacterial antagonisms. J. Path. \& Bact. 35:831-842 (1932).

262a. Fleming, A. Penicillin; its practical application. Philadelphia, Blakiston, 1946.

263. Fleming, A. Selective bacteriostasis. Proc. Second Internat. Cong. Microbiol. (1 936), pp. 33-34.

264. FLEMING, A. A simple method of using penicillin, tellurite, and gentian violet for differential culture. Brit. M. J. I:547-548 (1942).

265. FlemiNG, A. Streptococcal meningitis treated with penicillin; measurement of bacteriostatic power of blood and cerebrospinal fluid. Lancet $2: 434-438$ (1943).

266. Fleming, A. Micro-methods of estimating penicillin in blood serum and other body fluids. Lancet 2:620-62 I (I 944); Am. J. Clin. Path. I 5: I-6 (I 945).

267. Fleming, R. S., and Queen, F. B. Penicillin resistance; of bacteria; strain variations in penicillin sensitivity among bacterial species encountered in war wounds and infections. Am. J. Clin. Path. 16:63-65, 66-67 ( 1946 ).

268. Florey, H. W. The use of micro-organisms for therapeutic purposes. Brit. M. J. No. 4427 , pp. 635-642 (1945); Brit. Med. Bull. 4:248-258 ( I 946).

269. Florey, H. W., and Cairns, H. Penicillin in war wounds; a report from the Mediterranean. Lancet 2:742-745 (1943).

270. Florey, H. W., Heatley, N. G., Jennings, M. A., and Williams, T. I. Penicillin-like antibiotics from various species of moulds. Nature 1 54:268 (1944).

271. Florey, H. W., Jennings, M. A., Gilliver, K., and Sanders, A. G. Mycophenolic acid; an antibiotic from Penicillium brevi-compactum Dierckx. Lancet $1: 46-49$ (1946).

272. Florey, H. W., Jennings, M. A., and Philpot, F. J. Claviformin from Aspergillus giganteus Wehm. Nature 153:139 (1944).

273. Florey; H. W., Jennings, M. A., and Sanders, A. G. Biological investigations on proactinomycin. Brit. J. Exper. Path. 26:337-349 (1945).

274. Florey, M.E. Clinical uses of penicillin. Brit. Med. Bull. 2:9-13 (1944). 
275. FloREY, M. E., and FloREY, H. W. General and local administration of penicillin. Lancet 1:387-397 (1943); 2:638, 639 (1943).

276. Flosdorf, E. W. Drying penicillin by sublimation in the United States and Canada. Brit. M. J. No. 4389, pp. 2 I6-2 I 8 (1 945 ).

277. Fordos, M. Recherches sur la matière colorante des suppurations bleues; pyocyanine. Compt. rend. Acad. d. sc. 51:2 I 5-2 I 7 (1860).

278. Fortineau, L. Note sur le traitement du charbon par la pyocyanase. Ann. Inst. Pasteur 24:955-972 ( 19 I0).

279. Foster, J.W. Acid formation from penicillin during enzymatic inactivation. Science ror:205 (1945).

280. Foster, J. W. Quantitative estimation of penicillin. J. Biol. Chem. 144: 285-286 (1942).

28I. Foster, J. W., and Karow, E. O. Microbiological aspects of penicillin; penicillin from different fungi. J. Bact. 49:19-29 (1945).

282. Foster, J. W., McDaniel, L. E., Woodruff, H. B., and Stokes, J. L. Microbiological aspects of penicillin; conidiospore formation in submerged cultures of Penicillium notatum. J. Bact. 50:365-368 ( I 945).

283. Foster, J. W., and Wilker, B. L. Microbiological aspects of penicillin; turbidimetric studies on penicillin inhibition. J. Bact. 46:377-389 (1943).

283a. Foster, J. W., and Woodruff, H. B. Antibiotic substances produced by bacteria. Ann. New York Acad. Sc. 48:87-98 (1946).

284. Foster, J. W., and Woodruff, H. B. Bacillin, a new antibiotic substance from a soil isolate of Bacillus subtilis. J. Bact. 51:363-369, 371-380 (I 946).

285. Foster, J. W., and Woodruff, H. B. Microbiological aspects of penicillin; methods of assay. J. Bact. 46:1 87-202 (1943).

286. Foster, J. W., and Woodruff, H. B. Microbiological aspects of penicillin; procedure for the cup assay for penicillin. J. Bact. 47:43-58 (1944).

287. Foster, J. W., and Woodruff, H. B. Microbiological aspects of streptothricin; antibiotic activity of streptothricin. Arch. Biochem. 3:24I-255 ( 1943 ).

288. Foster, J. W., Woodruff, H. B., and McDaniel, L. E. Microbiological aspects of penicillin; production of penicillin in surface cultures of Penicillium notatum. J. Bact. 46:42 I-433 (1943).

289. Fox, S. W., Fling, M., and Bollenback, G. N. Inhibition of bacterial growth by $d$-leucine. J. Biol. Chem. I 55:465-468 (1944).

290. Francillon, M. Einfluss der aeroben Mischinfektion auf Entwicklung und Toxinbildung des Bacillus botulinus. Arch. f. Hyg. 95:121-139 (1925).

291. Francis, A. E. Sulphonamide-resistant streptococci in a plastic-surgery ward. Lancet I : 408-409 ( I 942).

292. Franke, H., and Ismet, A. Ueber Cytolyse. Centralbl. f. Bakteriol., I, Or., 99: 570-576 (1926).

293. Frankland, P. F. The bacteriology of water; its present position. J. Soc. Chem. Ind. 30:319-334 (1911). 
294. Frankland, P. F. Microorganisms in water. New York, Longmans, I 894.

295. Frankland, P. F., and Ward, H. M. The vitality and virulence of Bacillus anthracis and its spores in potable waters. Proc. Roy. Soc. (London), 53:164-317 (1893).

296. Frazier, C. N., and Frieden, E. H. Action of penicillin, especially on Treponema pallidum. J.A.M.A. I 30:677-683 (1 946).

297. Freisleben, R. Weitere Untersuchungen über die Mykotrophie der Ericaceen. Jahrb. wiss. Bot. 82:413-459 (1935).

298. Freudenreich, E. DE. De l'antagonisme des bactéries et de l'immunité qu'il confère aux milieux de culture. Ann. Inst. Pasteur 2:200-206 (1888); abstract in Jahresber. path. Mikroorg. 5:530 (1889).

299. Fried, J., Koerber, W. L., and Wintersteiner, O. The chemical nature of flavacidin. J. Biol. Chem. 163:341-342 (1946).

300. Fried, J., and Wintersteiner, O. Crystalline reineckates of streptothricin and streptomycin. Science Ior:613-615 (1945).

300a. Frieden, E. H. The nature and action of the antibiotics. Texas Rep. Biol. \& Med. 3:569-646 (1945).

301. Friedenwald, J., and Leitz, T. F. Experiments relating to the bacterial content of the feces, with some researches on the value of certain intestinal antiseptics. Am. J. M. Sc. 1 38:653-66 I (1909).

302. Friedmann, E. Pyocyanine an accessory respiratory enzyme. J. Exper. Med. 54:207-221 (1931).

303. Frost, W. D. The antagonism exhibited by certain saprophytic bacteria against Bacillus typhosus Gaffky. J. Infect. Dis. I: 599-640 (1 904).

304. Fukuhara, Y. Ueber die Wirkung einiger lipoider Stoffe auf die invisiblen Virusarten. Ztschr. Immunität. u. exp. Ther. 9:75-78 (I 91 I).

305. Fuller, A. T. Antibacterial action and chemical constitution in long-chain aliphatic bases. Biochem. J. 36:548-558 (r 942).

306. Fulton, H. R. Chemotropism of fungi. Bot. Gaz. 4I:8I-I08 (r908).

307. Fulton, R. W. The sensitivity of plant viruses to certain inactivators. Phytopath. 33:674-682 (1943).

308. Gabritschewsky, G., and Maljutin, E. Ueber die bakterienfeindlichen Eigenschaften des Cholerabacillus. Centralbl. f. Bakteriol. I3:780-785 (1893).

308a. Gailey, F. B., Stefaniak, J. J., Olson, B. H., and Johnson, M. J. A comparison of penicillin-producing strains of Penicillium notatum-chrysogenum. J. Bact. 52:1 29-140 (1946).

309. Gale, E. F., and TAYLoR, E. S. Action of tyrocidin and detergents in liberating amino-acids from bacterial cells. Nature 157:549-550 (1946).

310. Gallardo, E. Sensitivity of bacteria from infected wounds to penicillin; results in one hundred and twelve cases. War Med. 7:100-103 (1945).

311. Gardner, A. D. Morphological effects of penicillin on bacteria. Nature I 46: $837-838$ (1940).

312. Gardner, A. D. Microscopical effect of penicillin on spores and vegetative cells of bacilli. Lancet 1 :658-659 ( 1945 ). 
3 13. Gardner, A. D., and Chain, E. Proactinomycin; a "bacteriostatic" produced by a species of Proactinomyces. Brit. J. Exper. Path. 23:123-127 (1942).

31 4. Garrard, E. H., and Lochhead, A. G. Relationships between soil microorganisms and soil-borne plant pathogens. Sc. Agr. 18:719-737 (1938).

315. Garré, C. Über Antagonisten unter den Bakterien. Centralbl. f. Bakteriol. 2: 3 I 2-3 I 3 ( I 887 ).

316. Garretr, S. D. Root disease fungi. Waltham, Mass., Chronica Botanica Co., 1944.

317. Garretr, S. D. Soil conditions and the root-infecting fungi. Biol. Rev. 13:159-185 (1938); Imp. Bur. Sc. Tech. Commun. No. 38 (1939), No. 41 (1942).

318. Garrod, L. P. Action of antiseptics on wounds. Lancet I:798-802, 845848 (1 940).

3I9. GarRoD, L. P. The treatment of war wounds with penicillin. Brit. M. J. No. 4327 , pp. 755-756 (1943).

320. Garrod, L. P. The action of penicillin on bacteria. Brit. M. J. No. 4386 , pp. IO7-I IO (I 945).

32I. Garrod, L. P. The therapeutic use of penicillin. Practitioner 152:318323 (1944).

322. Gasperini, G. Recherches morphologiques et biologiques sur un microorganisme de l'atmosphère, le Streptothrix Foersteri Cohn. Ann. Microgr. I0: $449-474$ (1890).

323. Gaté, J., and Papacostas, G. Antagonisme biologique entre le Bacille de Löffler et le Pneumobacille de Friedländer. Compt. rend. Soc. de biol. 85 : 859-86I, 1038-1040 (I92I); 86:929 (1922); Paris méd. 61:205-210 (1926).

323a. Gause, G. F. Colistatin; a new antibiotic substance with chemotherapeutic activity. Science 104:289-290 (1946).

323b. GaUse, G. F. Litmocidin; a new antibiotic substance produced by Proactinomyces cyaneus. J. Bact. 51 :649-653 (1946).

324. Gause, G. F., and Brazhnikova, M. G. Gramicidin S and its use in the treatment of infected wounds. War Med. 6: I 80-I 8I (1944); Lancet 2: 715-716; Nature 1 54:703 (1944); Compt. rend. Acad. d. sc. (U.S.S.R.) 43:2 17-219 (1944); abstract in Chem. Abstr. 39: I I95 (1945).

325. Geiger, W. B., and Conn, J. E. The mechanism of the antibiotic action of clavacin and penicillic acid. J. Am. Chem. Soc. 67:1 12-1 I6 (I945).

326. Geiger, W. B., Conn, J. E., and Waksman, S. A. Chaetomin, a new antibiotic substance produced by Chaetomium cochliodes; isolation and concentration. J. Bact. 48:53 I-536 (I 944).

327. Geiger, W. B., Green, S. R., and Waksman, S. A. The inactivation of streptomycin and its practical application. Proc. Soc. Exper. Biol. \& Med. $61: 187-192$ (1946).

328. Gerber, I. E., and Gross, M. Inhibition of growth of Mycobacterium tuberculosis by a mold product. Science I01:616-617 (1945); 103:167169 (1946).

329. Gessard, C. De la pyocyanine et son microbe. Thesis, Paris (1 882). 
330. Gessard, C. Diagnose pigmentaire du bacille pyocyanique. Ann. Inst. Pasteur 33:241-260 (1919).

331. Gessard, C. Nouvelles recherches sur le microbe pyocyanique. Ann. Inst. Pasteur 4:88-102 (1890).

332. Gildemeister, E. Untersuchungen über das Lysozym. Centralbl. f. Bakteriol., I, $136: 408-412$ (1936).

333. Gilerson, C., and Levinson, A. Clinical evaluation of the treatment of gangrene of teeth pulp on the basis of bacterial antagonism. Modern Problems of Somatology (U.S.S.R.), M.L. 533 (1933).

334. Gilmour, R. T. Further notes on the isolation of the Micrococcus melitensis from peripheral blood; and experiments on the duration of life of this microbe in earth and in water. Reports of the Commission for the Investigation of Mediterranean Fever, I 906. Part IV, pp. 3-7.

335. Glaser, R. W. Studies on Neoaplectana glaseri, a nematode parasite of the Japanese beetle (Popillia Japonica). N.J. Dept. Agr., Cir. 2 I I, pp. 1-34 (1932) ; J. N.Y. Ent. Soc. 43:345-371 (1935).

336. Glasgow, H. The gastric caeca and the caecal bacteria of the Heteroptera. Biol. Bull. 26: 101-155 (1914).

337. Glathe, H. Über die Rotte des Stalldüngers unter besonderer Berücksichtigung der Anaeroben-Flora. Zentralbl. f. Bakteriol., II, 91:65-101 (1934).

338. Glister, G. A. A new antibacterial agent produced by a mould. Nature I 48:470 (194I).

339. Glister, G. A., and Williams, T. I. Production of gliotoxin by Aspergillus fumigatus mut. helvola Yuill. Nature 1 53:6 5 I-652 ( 1 944).

340. Goetsch, W., and Grüger, R. Die Pilze der Blattschneider-Ameisen und ihre Vernichtung. Naturwiss. 28:764-765 ( 1940 ).

341. Goidanich, G., Borzini, G., Mezzetti, A., and Vivani, W. Ricerche sulle alterazioni e sulla conservazione della pasta di legno destinata alla fabbricazione della carta. Rome, Ministre delle Corporazioni, Commissario dell' Ente Nazionale per la cellulosa e per la carta, 1938.

342. Goldie, H. Absorption et destruction des substances inhibitrices de filtrats microbiens. Compt. rend. Soc. de biol. 108:762-764 (1931).

343. Goldie, H. Pathogenic bacteria in sewage; bacteriolysis. Rev. d'hyg. 55: 5-23 (1933); abstract in Chem. Abstr. 27:1929 (1933).

344. Goldman, W. Untersuchungen über den Coli-Milzbrandantagonismus. Zentralbl. f. Bakteriol., I, Or., 1 36:345-352 (1936).

345. Gordon, A. H., Martin, A. J. P., and Synge, R. L. M. The amino-acid composition of gramicidin. Biochem. J. 37:86-92, 313-3 I 8 ( I 943).

346. Goris, A., and Liot, A. Importance des sels ammoniacaux organiques dans la production de la pyocyanine par le bacille pyocyanique. Compt. rend. Acad. d. sc. 1 76: 191-193 (1923).

347. Goss, R. W. The influence of various soil factors upon potato scab caused by Actinomyces scabies. Res. Bull. Nebraska Agr. Exper. Sta. 93 ( 1937).

348. Gотн, A. The antitubercular activity of aspergillic acid and its probable mode of action. J. Lab. \& Clin. Med. 30:899-902 (1945). 
349. Gотн, A. The effect of cobalt on the antituberculosis activity of aspergillic acid. Federation Proc. 5:180 (1946).

350. Goth, A., and Bush, M. T. Rapid method for estimation of penicillin. Ind. \& Eng. Chem. (Anal. Ed.) 16:451-452 (1944).

351. Gramicidin (Editorial). Brit. M. J. 2:1 7-1 8 (1942).

352. Gratia, A. Antagonisme microbien et "bactériophagie." Ann. Inst. Pasteur 48:413-437 (1932).

353. Gratia, A. Des relations numériques entre bactéries lysogènes et particules de bactériophage. Ann. Inst. Pasteur 56:307-31 5; 57:652-676 (1936).

354. Gratia, A. La dissolution des bactéries et ses applications thérapeutiques. Bull. Acad. roy. de méd. de Belgique, May 19, 285-295 (1934).

355. Gratia, A. Sur un remarquable exemple d'antagonisme entre deux souches de colibacille. Compt. rend. Soc. de biol. 93: 1040 (1925).

356. Gratia, A., and Alexander, J. Sur la "mycolyse" par le streptothrix. Compt. rend. Soc. de biol. 106:1 288-1 289 (1931).

357. Gratia, A., and Dath, S. De l'action bactériolytiques des streptothrix. Compt. rend. Soc. de biol. 91 : 1 442-1 443 (1 924); 92:1 1 25-1 I 26 (I925); 93:45 I (1 925); 94: I 267-1 268 (1926).

357a. Gratia, A., and Frederice, P. Pluralité et complexité des "colicines." VII Congrès Chim. Biol., Liége; Résumés des Commun., IV:2 (1946).

358. Graves, A. H. Chemotropism in Rhizopus nigricans. Bot. Gaz. 62:337369 (1916).

359. Greanex, F. J., and Machaceк, J. E. Studies on the control of the rootrot diseases of cereals caused by Fusarium culmorum (W.G.Sm.) Sacc. and Helminthosporium sativum P.K. and B.; pathogenicity of Helminthosporium sativum as influenced by Cephalothecium roseum Corda in greenhouse pot tests. Sc. Agr. 15:377-386 (1 935 ).

360. Green, H. N., and Bielschowsky, F. A factor ("P" factor) in bacterial extracts stimulating bacterial growth and inhibiting the action of sulphanilamide. Chem. \& Ind. 59: 1 35, 850 (1940); Brit. J. Exper. Path. 23: I-I 2 (1942).

36I. GreifF, D., and Pinkerton, H. Inhibition of growth of typhus rickettsiae in the yolk sac by penicillin. Proc. Soc. Exper. Biol. \& Med. 55:116-1 19 (I 944).

362. GREIG, E. D. W. The invasion of the tissues by the cholera vibrio and further observations on pneumonia in cases of cholera. Indian J. M. Research 2: 1-27 (1914-1915).

363. Greig, M. E., and Hoogerheide, J. C. Evaluation of germicides by a manometric method. J. Bact. 41:557-562 (I94I).

364. Greig-Smith, R. Contributions to our knowledge of soil fertility; the action of certain microorganisms upon the numbers of bacteria in the soil. Proc. Linn. Soc. N.S. Wales, 42:162-166 (1917).

36\%. Greig-Smith, R. Contributions to our knowledge of soil fertility; the agricere and bacteriotoxins of soil. Proc. Linn. Soc. N:S. Wales, 36:679699 (1912); 40:631-645 (1915). 
366. Gruber, Th. Die Bakterienflora von Runkelrüber, Steckrüben, Karotten, von Milch während der Stallfütterung und des Weideganges einschlieszlich der in Streu, Gras und Kot vorkommenden Mikroorganismen und deren Mengenverhältnisse in den 4 letzten Medien. Centralbl. f. Bakteriol., II, 22:401-416 (1909).

367. Gundel, M. Ueber den Antagonismus von Coli-Bakterien auf Milzbrandbazillen. Centralbl. f. Bakteriol., I, Or., 104:463-473 (1927).

368. Gundel, M., and Himstedt, H. Ueber den Antagonismus zwischen Bakterien in künstlichen Nährmedien. München. med. Wchnschr. 72:16741676 (1925).

369. Gundel, M., and Kliewe, H. Experimentelle Untersuchungen über das antagonistisch wirksame Prinzip der Coli- gegenüber Milzbrandbazillen. Zentralbl. f. Bakteriol., I, Or., I 24:519-528 (1932).

370. Gundel, M., and MAyer, U. Ueber den Bakterienantagonismus innerhalb einer Art bei den Pneumokokken. Zentralbl. f. Bakteriol., I, Or., I 29:305323 (1933).

371. Gundel, M., and Okura, G. Untersuchungen über das gleichzeitige Vorkommen mehrerer Pneumokokkentypen bei Gesunden und ihre Bedeutung für die Epidemiologie. Ztschr. f. Hyg. u. Infektionskr. I 14:678704 (1933).

372. Gundel, M., and Wagner, W. Weitere Studien über Bakterienlipoide. Ztschr. Hyg. Immunität. 69:63-76 (1930).

373. Hall, I. C., and Peterson, E. The effect of certain bacteria upon the toxin production of Bacillus botulinus in vitro. J. Bact. 8: 319-341 (1923).

374. Hall, R. P. Vitamin deficiency as one explanation for inhibition of protozoan growth by conditioned medium. Proc. Soc. Exper. Biol. \& Med. 47: 306-308 (194I).

375. Hallauer, C., and Faust, B. Über den Einfluss von Aspergillin und Penicillin. Schweiz. Ztschr. f. Path. u. Bakt. 7:380-387 (1 944).

375a. Halpern, P. E., Siminovitch, D., and McFarlane, W. D. The effect of specific amino acids on the yield of penicillin in submerged culture. Science IO2:230-231 (1945).

376. Hansen, H. N. Etiology of the pink-root disease of onions. Phytopath. I 9:69I-704 (1929).

377. Hansen, H. N., and SNyder, W. C. Relation of dual phenomenon in Penicillium notatum to penicillin production. Science 99:264-265 (1 944 ).

378. Hanson, H. J., Mrers, W. G., Stahly, G. L., and Birkeland, J. M. Variation in Penicillium notatum induced by the bombardment of spores with neutrons. J. Bact. 51:9-18 (1946).

379. Happold, F. C., and Waters, J. W. The action of clavatin on certain enzyme systems. Biochem. J. 38: 1 7-I 8 (1 944).

380. Harder, R. Über das Verhalten von Basidiomyceten und Ascomyceten in Mischkulturen. Naturw. Ztschr. Forst. Landw. 9: I 29-160 (1911).

381. Hardin, G. Physiological observations and their ecological significance; a study of the protozoan, Oikomonas termo. Ecology 25:192-201 (1944).

382. Hardin, G. Symbiosis of Paramecium and Oikomonas. Ecology 25:3043 II (1944). 
383. Hartley, C. Damping-off in forest nurseries. U.S.D.A. Bull. 934 ( 192 I), pp. I-99.

384. Hartley, P. World standard and unit for penicillin. Science $101: 637-$ 638 (1945).

385. HaRtoch, O., and Joffe, V. Ueber die Wirkung von Bakterienfiltraten in vitro und in vivo. Arb. a. d. Staats. Inst. f. exper. Therap., Hft. 2 r, pp. 83-97 (1928).

386. Harvey, H. W. Biological chemistry and physics of sea water. New York, Macmillan, I 928.

387. Hasнimoto, K. Wachstumhemmende Wirkung von Coli-Bazillen pathogenen Darmbakterien gegenüber. Centralbl. f. Bakteriol., I, Or., I 03: 1-9 (1927).

388. Havens, L. C., and Dehler, S. A. The effect of Gambusia affinis on the B. coli index of pollution of water. Am. J. Hyg. 3:296-299 (r923).

389. Hays, E. E., Wells, I. C., Katzman, P. A., Cain, C. K., Jacobs, F. A., Thayer, S. A., Doisy, E. A., Gaby, W. L., Roberts, E. C., Muir, R. D., Carroll, C. J., Jones, L. R., and Wade, N. J. Antibiotic substances produced by Pseudomonas aeruginosa. J. Biol. Chem. I 59:725-750 (1945).

390. Heatley, N. G. A method for the assay of penicillin. Biochem. J. 38 : 6I-65 (r 944$)$.

391. Heatley, N. G. An antibiotic from Crepis taraxacifolia (Thuill). Brit. J. Exper. Path. 25:208-2 12 (1944).

392. Heilman, D. H. A method for standardizing penicillin. Am. J. M. Sc. 207:477-483 (1944).

393. Heilman, D. H., Heilman, F. R., Hinshaw, H. C., Nichols, D. R., and Herrell, W. E. Streptomycin; absorption, diffusion, excretion and toxicity. Am. J. M. Sc. 210:576-584 (1945).

394. Heilman, D. H., and Herrell, W. E. Comparative antibacterial activity of penicillin and gramicidin; tissue culture studies. Proc. Staff Meet., Mayo Clinic 17:321-327 (1942).

395. Heilman, D. H., and Herrell, W. E. Comparative bacteriostatic activity of penicillin and gramicidin. J. Bact. 43: 1 2-1 3 ( I 942).

396. Heilman, D. H., and Herrell, W. E. Hemolytic effect of gramicidin. Proc. Soc. Exper. Biol. \& Med. 46:182-184 (1941).

397. Heilman, F. R. Streptomycin in the treatment of experimental tularemia. Proc. Staff Meet., Mayo Clinic 19:553-559 (1944).

398. Heillanan, F. R. Streptomycin in the treatment of experimental infections with microorganisms of the Friedlander group (Klebsiella). Proc. Staff Meet., Mayo Clinic 20:33-39 (1945).

399. Heilman, F. R. Streptomycin in the treatment of experimental relapsing fever and Leptospirosis icterohaemorrhagica (Weil's Disease). Proc. Staff Meet., Mayo Clinic 20:169-1 76 (1945).

400. Heilman, F. R., and Herrell, W. E. Penicillin in the treatment of experimental ornithosis. Proc. Staff Meet., Mayo Clinic 19:57-65 (1944).

401. Helm holz, H. F. The effect of streptomycin on bacteria commonly found in urinary infections. Proc. Staff Meet., Mayo Clinic 20:357-362 (1945). 
402. Helmholz, H. F., and Sung, C. Bacterial action of penicillin on bacteria commonly present in infections of urinary tract, with especial reference to streptococcus faecalis. Am. J. Dis. Child. 68:236-242 (1944).

403. Helander, S. Detection of chemotherapeutics in thin sections of tissue by the aid of fluorescence microscopy. Nature 155:109 (1945).

403a. Henderson, J. The status of tyrothricin as an antibiotic agent for topical application. J. Am. Pharm. A. 35: I 4I-I 47 (I 946).

404. Henle, W., and Henle, G. Interference of inactive virus with the propagation of virus of influenza. Science 98:87-89 (1943).

405. Henle, G., and $Z_{1 T t h e}$, C. A. Effect of gramicidin on metabolism of bovine spermatozoa. Proc. Soc. Exper. Biol. \& Med. 47: 193-I 98 (I94I).

406. Henrici, A. T. Characteristics of fungous diseases. J. Bact. 39:113-1 38 ( I 940).

407. Henry, A. W. The influence of soil temperature and soil sterilization on the reaction of wheat seedlings to Ophiobolus graminis. Canad. J. Research 7:198-203 (1932).

408. Henry, A. W. The natural microflora of the soil in relation to the root-rot problem of wheat. Canad. J. Research 4:69-77 (1931); 5:407-413 (1931).

409. Henry, R. J., and Henry, M. D. The effect of penicillin on eggs of the sea urchin, Arbacia punctulata. J. Gen. Physiol. 28:405-413, 41 5-419 (1945).

410. Herreld, W. E. Penicillin and other antibiotic agents. Philadelphia, Saunders, 1945.

4i i. Herrell, W. E., Cook, E. N., and Thompson, L. Use of penicillin in sulfonamide resistant gonorrheal infections. J.A.M.A. 122:289-292 (1943).

41 2. Herrell, W. E., and Heilman, D. Experimental and clinical studies on gramicidin. J. Clin. Investigation 20:433, 583-591 (1941); J.A.M.A. I I 8:1401-1402 (1942).

413. Herrell, W. E., and Heilman, D. Tissue culture studies on cytotoxicity of bacterial agents; cytotoxic and antibacterial activity of gramicidin and penicillin; comparison with other germicides. Am. J. M. Sc. 206:22 1-226 (1943).

4I 4. Herreli, W. E., and Nichols, D. R. The clinical use of streptomycin; a study of forty-five cases. Proc. Staff Meet., Mayo Clinic 20:449-462 (I945).

41 5. Herrell, W. E., Nichols, D. R., and Heilman, D. H. Penicillin. J.A.M.A. 125 : 1003-1010 (1944).

416. Herrick, J. A. Antifungal properties of clavacin. Proc. Soc. Exper. Biol. \& Med. 59:41-42 (1945).

4 7. Hetrcie, H. O. Der Einfluss der Umwelt auf die Form der Diphtheriebazillen. Zentralbl. f. Bakteriol., I, Or., 1 34:433-438 (1934).

4I8. Heтtche, H. O., and Vogel, W. Vergleichende Untersuchungen über die antagonistische Wirkung von Bacterium fluorescens und Bacterium pyocyaneum. Arch. f. Hyg. 1 17:234-244 (1937). 
419. Hettche, H. O., and Weber, B. Die Ursache der bakteriziden Wirkung von Mesentericus-filtraten. Arch. f. Hyg. 123:69-80 (1939).

420. Heтtсhe, O. Untersuchungen über die bakteriziden und anthrakoziden Bestand teile von Bacillus pyocyaneus und Bacillus prodigiosus. Arch. f. Hyg. I 07:337-353 (1932).

421. Hetтche, O. Untersuchungen über die Natur der bakteriziden und hämolitischen Bestandteile der Pyocyaneuslypoiden. Ztschr. f. Hyg. u. Immunitätsforsch u. exper. Therap. 83:499-505, 506-5 I I (I934).

422. Heukelekian, H., and Schulhoff, H. B. Studies on the survival of B. typhosus in surface waters and scwage. New Jersey Agr. Exper. Sta. Bull. 589 ( 1935 ).

423. Hickey, R. J. Sterility test for penicillin employing cysteine for inactivation. Science 101:232-234 (1945).

424. Hildebrand, A. A., and West, P. M. Strawberry root rot in relation to microbiological changes induced in root rot soil by the incorporation of certain cover crops. Canad. J. Research I 9: I 83-I 98, I 99-2 I0 (194 I).

425. Himmelweit, F. Combined action of penicillin and bacteriophage on staphylococci. Lancet 2:104-105 (1945).

426. Hino, I. Antagonistic action of soil microbes with special reference to plant hygiene. Trans. Third Internat. Cong. Soil Sc. I: I 73-1 74 (I935).

427. Hino, I., and Endo, S. Trichoderma parasitic on sclerotial fungi. Ann. Phytopath. Soc. Japan I0:23 I-24I (1940).

428. Hegarty, C. P., Thiele, E., and Verwey, W. F. The in vitro and in vivo activity of streptomycin against Hemophilus pertussis. J. Bact. 50: $651-654$ (1945).

429. Hinshaw, H. C., and Feldman, W. H. Streptomycin in treatment of clinical tuberculosis; a preliminary report. Proc. Staff Meet., Mayo Clinic 20:3 I3-318 (1945).

430. Hinshaw, H. C., and Feldman, W. H. Streptomycin; a summary of clinical and experimental observations. Ann. New York Acad. Sc. 48: 175I 8 I ( I 946).

43 I. Новву, G. L. The antibacterial action of penicillin against gram-negative organisms. Science IO0:500-50 I (1944).

432. Hoвby, G. L., and Dawson, M. H. Bacteriostatic action of penicillin on hemolytic streptococci in vitro. Proc. Soc. Exper. Biol. \& Med. 56:178181 ( 1944 ).

433. Новвy, G. L., and Dawson, M. H. Effect of rate of growth of bacteria on action of penicillin. Proc. Soc. Exper. Biol. \& Med. 56:181-184 (1944).

434. Hobby, G. L., Meyer, K., and Chaffee, E. Activity of penicillin in vitro. Proc. Soc. Exper. Biol. \& Med. 50:277-280 (1 942).

435. Hobry, G. L., Meyer, K., and Chaffee, E. Chemotherapeutic activity of penicillin. Proc. Soc. Exper. Biol. \& Med. 50:285-288 (1942).

436. Новby, G. L., Meyer, K., and Chaffee, E. Observations on the mechanism of action of penicillin. Proc. Soc. Fxper. Biol. \& Med. 50:281-285 (1942). 
437. Ноbby, G. L., Meyer, K., Dawson, M. H., Chaffee, E., and FalkNER, D. The antibacterial action of penicillin. J. Bact. 43:1 I-1 2 (1942).

438. Hogeboom, G. H., and $\mathrm{C}_{\mathrm{RAlG}}, \mathrm{L}$. C. Identification by distribution studies; isolation of antibiotic principles from Aspergillus ustus. J. Biol. Chem, 162: 363-368 ( I 946 ).

439. Hollande, A. C. Lyse massive des bacilles de Koch chez le cobaye après traitement à la clitocybine; pouvoir inhibiteur de ce produit vis-à-vis du bacille typhique, du colibacille, de Brucella abortus etc. Compt. rend. Acad. d. sc. $221: 361-363$ (1 945$)$.

440. Holman, W. L. Bacterial associations. In The newer knowledge of bacteriology and immunology, edited by E. O. Jordan and I. S. Falk. Chicago, University of Chicago Press, 1928, pp. I02-I 19.

441. Holst, E. C. An antibiotic from a bee pathogen. Science 102:593-594 (1945).

442. Hoogerheide, J. C. An agent, isolated from a soil bacillus, which inhibits encapsulation of Friedländer's bacterium and is highly bactericidal for grampositive microorganisms. J. Franklin Inst. 229:677-680 (1940).

443. Hoogerheide, J. C. Antibiotic substances produced by soil bacteria. Bot. Rev. I 0: 599-638 (1944).

444. Hoogerheide, J. C. Studies on capsule formation; inhibition of capsule formation of Klebsiella pneumoniae (Friedländer's bacterium) by an agent produced by a soil bacillus. J. Bact. 40:41 5-422 (I940).

445. Hooper, I. R., Anderson, H. W., Skell, P., and Carter, H. E. The identity of clavacin with patulin. Science 99: 16 (1944).

446. Horrocks, W. H. On the duration of life of the Micrococcus melitensis in unsterilized soil. Reports of the Commission for the Investigation of Mediterranean Fever, I 906, Part IV, pp. 27-3I.

447. Hoskins, M. A protective action of neurotropic against viscerotropic yellow fever virus in Macacus rhesus. Am. J. Trop. Med. 15:675-680 (1935).

448. Hosoya, S. Sur la nature de la pyocyanase. Compt. rend. Soc. de biol. 49: $771-773$ (1928).

449. Нотснкіss, R. D. Gramicidin, tyrocidine, and tyrothricin. In Advances in enzymology, vol. 4, pp. 1 53-199. New York, Interscience, 1944.

450. Нотснкіss, R. D., and Duвos, R. J. Fractionation of the bactericidal agent from cultures of a soil bacillus. J. Biol. Chem. I 32:79I-792, 793794 (1940); I 36:803-804 (I940); I 4 I: I 55-I62 (I94I).

451. Houston, A. C. Report on inoculation of soil with particular microbes, pathogenic and other. Local Govt. Board, Rep. Med. Officer 28:41 3-438 (1 898-1 899).

45 Ia. Hughes, G. C., and Kierman, R. A. A product of Pseudomonas aeruginosa active in vitro against $M$. tuberculosis. Nature 159:197 (1947).

452. Hüntemüller, O. Vernichtung der Bakterien im Wasser durch Protozoen. Arch. f. Hyg. 54:89-100 (1905).

453. Humfeld, H., and Feustel, I. C. Utilization of asparagus juice in microbiological culture media. Proc. Soc. Exper. Biol. \& Med. 54:232-235 (1943).

454. Hunter, A. C., and Randall, W. A. Standardization of assay of penicillin. J. Assoc. Off. Agr. Chem. 27:430-438 (I 944). 
455. Hutchinson, D., Weaver, R. H., and Scherago, M. The incidence and significance of microorganisms antagonistic to Escherichia coli in water. J. Bact. 45:29 (1943).

455a. Hutner, S. H., and ZahL, P. A. Action of bacterial toxins on tumors; distribution of tumor-hemorrhage agents among bacterial species. Proc. Soc. Exper. Biol. \& Med. 52:364-368 (1943).

456. Hutrer, S. Les substances antibiotiques du Penicillium notatum Westling. Contribution à l'étude de la notatine et mise en évidence d'un principe bactériolytique nouveau: la notalysine. J. suisse Med. 75 (I9):4I I-434 (1945).

456a. Irving, G. W., Fontaine, T. D., and Doolittle, S. P. Partial antibiotic spectrum of tomatin, an antibiotic agent from the tomato plant. J. Bact. 52:601-607 (1946).

457. Isabolinski, M. P., and Sobolewa, R. M. Ueber den Antagonismus der Bakterien. Zentralbl. f. Bakteriol., I, Or., I 33:107-1 IO (1934).

458. JaArsveld, A. Der Einfluss verschiedener Bodenpilze auf die Virulenz von Rhizoctonia solani Kühn. Phytopath. Ztschr. 14:1-75 (1942).

459. JacoBson, K. A. Untersuchungen über die Lebensfähigkeit der Choleravibrionen im Meerwasser. Centralbl. f. Bakteriol., I, Or., 56:201-207 (1910).

460. Jansen, E. F., and Hirschmann, D. J. Subtilin; an antibacterial product of Bacillus subtilis, culturing conditions and properties. Arch. Biochem. 4: 297-309 ( I 944).

461. Jelinek, B., and HoF, T. L'influence de la nature des aliments azotés sur le pouvoir pigmentaire du bacille pyocyanique. Ann. Ferment. 4: I 41160 (1938).

462. JenEy, A. von. Experimentelle Untersuchungen über antagonistische Wirkung innerhalt der Typhus-Coli Gruppe. Ztschr. f. Hyg. u. Infektionskr. I OO: 47-58 (1923).

463. Jenkins, S. H. Organic manures. Imp. Bur. Soil Sc. (England), Tech. Commun. 33 (1935).

464. Jennings, M. A. Activity of helvolic acid against Mycobacterium tuberculosis. Nature 1 56:633 (I 945).

465. Jennings, M. A., and Williams, T. I. Production of kojic acid by Aspergillus effusus Tiraboschi. Nature I 55:302 (I 945).

466. Jennison, M. W., and Irvine, J. W. The effect of beta radiation on the production of penicillin. J. Bact. 51:37 (1946).

467. Jensen, H. L. Bacterial treatment of non-leguminous seeds as an agricultural practice. Australian J. Exper. Biol. \& M. Sc. 4:1 17-I 20 (1942).

468. JERn, H. Z., and MELEnEy, F. L. The superiority of penicillin over bacteriophage, sulfathiazole and certain other antibacterial substances as indicated by experimental staphylococcal infections in chick embryos. Surg., Gynec. \& Obst. 80:27-34 (1945).

469. Johnson, B. A., Anker, H., and Meleney, F. L. Bacitracin; a new antibiotic produced by a member of the B. subtilis group. Science $102: 376-377$ (1945). 
470. Johnson, D. E. The antibiosis of certain bacteria to smuts and some other fungi. Phytopath. 21:843-863 (1931); Sixth Internat. Bot. Cong. 2: $221-222$ (1935).

471. Johnson, E. A., and Burdon, K. L. Eumycin-a new antibiotic active against pathogenic fungi and higher bacteria, including bacilli of tuberculosis and diphtheria. J. Bact. 51:30 (1946).

472. Johnson, G., Trussell, M., and Jahn, F. Isolation of Trichomonas vaginalis with penicillin. Science 102: 1 26-1 28 ( I 945).

473. Johnson, J. Plant virus inhibitors produced by microorganisms. Science 88:552-553 (I938); Phytopath. 31:679-701 (I941).

474. Johnson, J. R., Bruce, W. F., and Dutcher, J. D. Gliotoxin, the antibiotic principle of Gliocladium fimbriatum; production, physical and biological properties. J. Am. Chem. Soc. 65:2005-2009 (1943); 66:501, 6 1 4-6 16, 6 1 7-6 19, 6 I 9-62 I ( 1944).

474a. Johnson, M. J. Metabolism of penicillin-producing molds. Ann. New York Acad. Sc. 48:57-66 (1946).

475. Johnson, M. J., Stefaniak, J. J., Gailey, F. B., and Olson, B. H. Penicillin production by a superior strain of mold. Science 103:504-505 (1946).

476. JonEs, D. The effect of antibiotic substances upon bacteriophage. J. Bact. 50:341-348 (1945).

477. Jones, D., Beaudette, F. R., Geiger, W. B., and Waksman, S. A. A search for virus-inactivating substances among microorganisms. Science I01: $665-668$ (1945).

478. Jones, D., Metzger, H. J., Schatz, A., and Waksman, S. A. Control of gram-negative bacteria in experimental animals by streptomycin. Science 100: 103-105 (1944).

479. Jones, D., and Schatz, A. Methods of study of antiphage agents produced by microorganisms. J. Bact. 52:327-335 (1946).

480. Jones, H., Rake, G., and Hamre, D. M. Studies on Aspergillus flavus; biological properties of crude and purified aspergillic acid. J. Bact. 45: 46 I-469 ( I 943 ).

481. Jordan, E. O., Russell, H. L., and ZEIT, F. R. The longevity of the typhoid bacillus in water. J. Infect. Dis. $1: 641-689$ (1904).

482. Joslyn, D. A. Penicillin assay; outline of four-hour turbidimetric method. Science 99:2 I-22 (1943).

483. Jungeblut, C. W., and Sanders, M. Studies of a murine strain of poliomyelitis virus in cotton rats and white mice. J. Exper. Med. 72:407-436 (1940); 76:127-142 (1942).

484. KaHN, M. C. Anaerobic spore-bearing bacteria of the human intestine in health and in certain diseases. J. Infect. Dis. 35:423-478 (1924).

485. Kamada, K. Antagonismus und Mutation in Mischkulturen. Zentralbl. f. Bakteriol., I, Or., I I 8: 316-330 (1930).

486. Karow, E. O., and Foster, J. W. An antibiotic substance from species of Gymnoascus and Penicillium. Science 99:265-266 (1944). 
487. Karow, E. O., Woodruff, H. B., and Foster, J.W. Penicillic acid from Aspergillus ochraceus, Penicillium Thomii, and Penicillium suavolens. Arch. Biochem. 5:279-282 (1944).

488. Katser, A. Ein Beitrag zur Anwendung des Antagonismus als biologische Bekämpfungsmethode unter besonderer Berücksichtigung der Gattungen Trichoderma und Phytophthora. Boll. Staz. Pat. veg. Roma, N.S. 18: I-I 34 (I938); 19:75-86 (I 939).

489. Katzman, P. A., Hayes, E. E., Cain, C. K., Van WyK, J. J., Reithel, F. J., Thayer, S. A., Doisy, E. A., Gaby, W. L., Carroll, C. J., Muir, R. D., Jones, L. R., and WADE, N. J. Clavacin, an antibiotic substance from Aspergillus clavatus. J. Biol. Chem. I 54:475-486 (I 944).

490. Katznelson, H. Bacteriophage in relation to plant diseases. Bot. Rev. 3: 499-52I (1937).

491. Katznelson, H. Inhibition of microorganisms by a toxic substance produced by an aerobic spore-forming bacillus. Canad. J. Research 20:169I 73 (1942).

492. KatzNelson, H. Survival of microorganisms introduced into the soil. Soil Sc. 49:2 I-35, 83-93, 2 I I-2 I 7, 283-293 (1940).

493. Kayukova, N. I., and Kremer, T.A. Development and toxin formation of Bacillus botulinus in mixed cultures. Microbiologia (U.S.S.R.) 9:585593 (I 940).

493a. KeEfer, C. S. Penicillin-its present status in the treatment of infections. Am. J. M. Sc. 2 10:1 47-1 $5^{8}$ (1945).

494. Keefer, C. S., and Anderson, D. G. Penicillin in the treatment of infections. In Oxford Medicine, vol. 4:938 [201-249], 1 946. New York, Oxford University Press.

4942. Keefer, C. S., Blake, F. G., Lockwood, J. S., Long, P. H., MarSHALL, E. K., JR., and Wood, W. B., JR. Streptomycin in the treatment of infections; a report of one thousand cases. J.A.M.A. 132:4-10, 70-77 (1946).

495. Keefer, C. S., Herwick, R. P., Van Winkle, W., Jr., and Putnam, L. E. New dosage forms of penicillin; statement concerning certifiable penicillin products, including recommended indications, dosages and precautions. J.A.M.A. 1 28: 1 161-1 164 (1945).

496. Keeney, E. L., Ajella, L., and Lankford, E. Studies on common pathogenic fungi and on Actinomyces bovis; in vitro effect of penicillin. Bull. Johns Hopkins Hosp. 75:410-41 6 (1 944).

497. Kelner, A. A survey of antibiotic production by representative Aspergilli, Penicillia, and other fungi from a culture collection. J. Bact. 51:29 (1946).

498. Kelner, A., Kocholaty, W., Junowicz-Kocholaty, R., and Morton, H. E. Two antibiotics produced by actinomyces isolated from soil. J. Bact. 5 I :30-3 I (1946).

499. Kempner, W. Ueber den vermeintlichen Antagonismus zwischen dem Choleravibrio und dem Bacterium coli commune. Centralbl. f. Bakteriol. 1 7:32-35 (1895). 
500. Kenyon, J., Segar, H. R., Cran, J., and Wallersteiner, W. K. S. Antipenicilliums in relation to penicillium therapy. M. Press 2 I $3: 70-78$ (1945); abstract in Chem. Abstr. 39:2339 (1945).

501. Kent, J., and Heatley, N. G. Antibiotics from moulds. Nature i 56: 295-296 (1945).

502. Kiessling, L. E. Biologische Masznahmen zur Unterdrückung des Kartoffelschorfes. Kühn Archiv 38:184-201 (1933).

503. Kieweg, H. Production and use of penicillin. Tr. Am. Inst. Chem. Eng. 40:767-772 (1 944).

504. Kimmelstiel, P. Ueber einige biologische Eigenschaft eines Wurzelbazillus. Centralbl. f. Bakteriol., I, Or., 89: I I 3-I I 5 (I923).

505. Kimmelstiel, P. Weitere Versuche über die bakteriolytische Fähigkeiten des Bacillus mycoides. Med. Klinik 20:419-42 I (1924).

506. King, C. J., Hope, C., and EAton, E. D. Some microbiological activities effected in manurial control of cotton root-rot. J. Agr. Research 49: 1093I 107 (I 934); U.S.D.A. Circular 425 (1937).

507. KIRBY, W. M. M. Bacteriostatic and lytic action of penicillin on sensitive and resistant staphylococci. J. Clin. Investigation 24:165-169 (1945).

508. KIRBY, W. M. M., and RANTZ, L. A. Methods of measuring penicillin concentrations in body fluids. J. Bact. 48:603-608 (1944).

509. Klein, B. I. Theory of bacterial lysis. Microbiologia (U.S.S.R.) I 3:708 I (I 945).

5IO. Kligler, I. J. Investigation on soil pollution and the relation of the various types of privies to the spread of intestinal infections. Mon. 15, Rockefeller Inst. Medical Research (192 I).

5ioa. Klimek, J. W., Cavallito, C. J., and Bailey, J. H. Induced resistance of Staphylococcus aureus to antibiotics. J. Bact. 5 I : I9-20 (1946).

5 I I. Klinger, R. Zur Oetiologie der Aktinomykose. Centralbl. f. Bakteriol., I, Or., 85:357-359 (192 I).

5 I I a. Knop, C. Q. Experimental study of the development of resistance to streptomycin by some bacteria commonly found in urinary infections. Proc. Staff Meet., Mayo Clin. 21:273-276 (1946).

5 I 2. KNox, R. Effect of penicillin on cultures in liquid and solid media. Lancet I : 559-56 I ( I 945).

513. Knudsen, L. F. Penicillin assay. Science ior:46-48 (1945).

514. Knudsen, L. F., and Randall, W. A. Penicillin assay and its control chart analysis. J. Bact. 50:1 87-200 (1945).

5 I 5. Koch, F. E., and Kraemer, E. Ueber den Antagonismus von Colibakterien gegen Typhusbakterien, Staphylokokken und Streptokokken. Untersuchungen in vitro. Zentralbl. f. Bakteriol., I, Or., I23:308-318 (1932).

516. Kocholatr, W. Cultural characteristics of Penicillium notatum in relation to the production of antibacterial substance; indication of the dual nature of the antibacterial substance. J. Bact. 44:469-477 (1942).

517. Kocholatr, W. Purification and properties of the second antibacterial substance produced by Penicillium notatum. Science 97:186-187 (1943); Arch. Biochem. 2:73-86 (1943). 
518. KodiceK, E., and WORdeN, A. N. Effect of unsaturated fat acids on Lactobacillus helveticus and other gram-positive microorganisms. Chem. Abstr. 39:5280-528I (1945).

519. Koffler, H., Emerson, R. L., Perlman, D., and Burris, R. H. Chemical changes in submerged penicillin fermentations. J. Bact. 50:517-548 (1945).

520. Koffler, H., Knight, S. G., Emerson, R. L., and Burris, R. H. The effect of certain chemicals on penicillin production and mold metabolism in shake flask fermentations. J. Bact. 50:549-559 (1 945).

521. Конм, H. L. The effect of propamidine on bacterial growth. Science 98: 224 (1943).

522. Kolmer, J.A. Penicillin therapy, including tyrothricin and other antibiotic therapy. New York, Appleton-Century, 1945.

523. Konikova, A. S., Asarkh, R. M., Blinnikova, E. I., and Dobbert, N. N. A contribution to the biochemistry of the sporulating gramicidinproducing bacteria. Microbiologia (U.S.S.R.) I 3: I 7 I-1 79 (1945).

523a. Konikova, A. S., Urasova, A. P., and Asarkh, R. M. Bacteriostatic substances of animal origin. Compt. rend. Acad. d. Sc. (U.S.S.R.) 47:565-567 (1946).

524. Konishi, K. Effect of soil bacteria on the growth of the root nodule bacteria. Mem. Col. Agr., Kyoto Imp. Univ. 16 (1931); J. Sc. Soil Man. Japan 9:75-82 (1935).

525. Kopaczewski, W. Conditions physico-chimiques de la vitalité microbienne. Arch. microb. 2:187-244 (1931).

526. Kopeloff, N. Lactobacillus acidophilus. Baltimore, Williams \& Wilkins, 1926.

527. Korinek, J. De l'influence des microbes banaux du sol sur les plantes. Faculté Sci. Univ. Charles 60 (1926).

528. Korolev, P.A. Symbiosis and antagonism of bacteria of the Brucella group with yellow sarcinae and white staphylococci. Zhur. Microb. Epid. Immun. 22 (4):35-39 (1939).

528a. Kozoll, D. D., Meyer, K. A., Hoffman, W. S., and Levine, S. The use of tyrothricin in surgical infections. Surg., Gynec. \& Obst. 83:323-342 (1946).

529. Kramer, H. Neue Untersuchungen über antagonistische Wirkung des Bacillus pyocyaneus. Ztschr. f. Immunitätsforsch. u. exp. Therap. 84:505534 (1935).

530. Krampitz, L. O., and Werkman, C. H. On the mode of action of penicillin. Federation Proc. 5:142 (1946).

531. Krassilnikov, N.A. The phenomenon of autolysis in Actinomycetales. Microbiologia (U.S.S.R.) 7:708-720, 829-837 (1938).

532. Krassilnikov, N.A., and Koreniako, A. I. Antibacterial properties of Aspergillus niger. Microbiologia (U.S.S.R.) I 4:347-352 (1 945).

533. Krassilnikov, N. A., and Koreniako, A. I. Influence of soil bacteria on the virulence and activity of Rhizobium trifolii. Microbiologia (U.S.S.R.) 13:39-44 (1945). 
533a. Krassilnikov, N. A., and Koreniako, A. I. Mycetin and its bactericidal properties. Microbiologia (U.S.S.R.) I 4:80-85 (1945).

534. Krassilnikov, N. A., and Koreniako, A. I. The bactericidal substance of the actinomycetes. Microbiologia (U.S.S.R.) 8:673-685 (1939).

534a. Krause, P. Ueber durch Pressung gewonnenen Zellsaft des Bacillus pyocyaneus. Centralbl. f. Bakteriol., I, Or., 31:673-678 (1902).

535. KREBS, H. A. Enzymic hydrolysis of patulin. Biochem. J. 38:xxix-xxx (1944).

536. Kriss, A. E. The lysozyme in actinomycetes. Microbiologia (U.S.S.R.) 9:32-38 (1940).

537. Krueger, A. P., et al. Attempts to protect against influenza virus with various sulfonamides, acridines and antibiotics. Science 98:348-349 (1943).

537a. Kuehl, F. A., Jr., Peck, R. L., Hoffhine, C. E., Jr., Graber, R. P., and Folkers, K. Streptomycin antibiotics; isolation of streptomycin. J. Am. Chem. Soc. 68: 1460-1462 (1946).

538. Kuehl, F. A., Jr., Peck, R. L., Walti, A., and Folkers, K. Streptomyces antibiotics; crystalline salts of streptomycin and streptothricin. Science I 02:34-35 (1945).

539. Kurung, J. M. Aspergillus ustus. Science I02:II-1 2 (I945).

540. Kunkel, L. O. Immunological studies on the three peach diseases, yellows, rosette and little peach. Phytopath. 26:201-2 I9 (1936).

541. Küster, E. Keimung und Entwicklung von Schimmelpilzen in gebrauchten Nährlösungen. Ber. Deut. Bot. Gesell. 26a:246-248 (1908).

542. LAL, A. Interaction of soil microorganisms with Ophiobolus graminis Sacc., the fungus causing the take-all disease of wheat. Ann. App. Biol. 26:24726I (1939).

543. Langer, M. Der antagonistische Index der Colibazillen. Deutsche med. Wchnschr. 43:1317-1320 (1917).

544. LAN KFord, C. E. The in vitro tolerance of gonococcus for penicillin. Am. J. Syph., Gonor. \& Ven. Dis. 29:56-63 (1945).

545. Lapage, G. Antibacterial activity of amoebae. Nature 155:182-183 (1945).

546. Lapage, G. Gramacidin S. Nature 155:246 (1945).

547. Larson, C. L., and Griffitts, J. J. A comparison of the effect of penicillin and immune serum in the treatment of experimental leptospirosis in young white mice and in hamsters. Pub. Health Rep. 60:317-323 (1945).

548. Lasseur, Ph., and Marchal, J. G. Associations bactériennes. Antagonisme-Antibiose. Trav. lab. microbiol. faculté pharm. Nancy 7:75-89 ( I934); 9:49-53 (1936).

549. Laszlo, D., and Leuchtenberger, C. A rapid test for tumor growth inhibitors. Cancer Research 3:401-410 (1943).

550. Lawrence, C. A. Sterility test for penicillin. Science 98:413-414 (1943); 99:15-16 (1944); J. Bact. 49:47-55, 57-63 (1945).

551. LAws, J.P., and Andrews, F. W. Report on the result of investigations of the microorganisms of sewage. Reports to the London County Council, Dec. I 3, 1894 . 
552. LeAch, L. D., and Davey, A. E. Reducing southern Sclerotium rot of sugar beets with nitrogenous fertilizers. J. Agr. Research 64:1-18 (1942).

553. Ledingham, R. J. Antagonism in inoculation tests of wheat with Helminthosporium sativum P.K. \& B. and Fusarium culmorum. Sc. Agr. 22: 688-697 (1942).

554. Lee, S. W., Foley, E. J., Epstein, J. A., and Wallace, J. H., Jr. Improvements in the turbidimetric assay for penicillin. J. Biol. Chem. I52: 485-486 (1944).

555. Lee, S. W., Foley, E. J., and Epstein, J. A. Plant growth substances and Penicillium notatum. Nature I 55:333-334 (1 945).

556. Leemann, A. C. The problem of active plant immunity. Zentralbl. f. Bakteriol., I1, 85:360-376 (1931).

557. Legroux, R., and DJemil, K. Sur la lyse du bacille de la morve et du Bac. pyocyanique. Compt. rend. Acad. d. sc. I93: II I7-III9 (1931); Ann. Ferment. 1: 193 (1935).

558. Lennette, E. H., and Koprowski, H. Interference between viruses in tissue culture. J. Exper. Med. 83:195-2 I9 (1946).

559. Lentz, J. W., Ingraham, N. R., Beerman, H.; and Stokes, J.H. Penicillin in the prevention and treatment of congenital syphilis. J.A.M.A. I 26:408-413 (I 944).

560. Levaditi, C., and Twort, C. Mécanisme de la toxo-résistance à la trypanosome du subtilis. Compt. rend. Soc. de biol. 70:927-929, 962-964, 1024-1025 (I9II).

561. Levaditi, C., and Twort, C. Sur la trypanotoxine du Bacillus subtilis. Propriétés de la toxine. Compt. rend. Soc. de biol. 70:645-647, 753-755 (I9I I) ; 7I: I27-128 (I9II).

562. Levitov, M. M., Wyshepan, E. D., and Nenasheva, A. M. A new method for the determination of penicillin. Biokhimiya I0:49I-498 (1945).

563. LEwEK, T. Ueber den Wachsthumseinfluss nichtpathogener Spaltpilze auf pathogene. Beitr. path. Anat. 6:277-298 (1890); abstract in Centralbl. f. Bakteriol. 7: 107-109 (I 890).

564. Lewis, J. C., Dimick, K. P., and Feustel, I. C. Production of tyrothricin in cultures of Bacillus brevis. Indust. \& Engin. Chem. (Indust. Ed.) 37:996-1004 (1945).

565. Lewis, J. C., Dimick, K. P., Feustel, I. C., Fevold, H. L., Olcott, H. S., and Fraenkel-ConRat, H. Modification of gramicidin through reaction with formaldehyde. Science 102:274-275 (1945).

566. Lewis, J. M. Bacterial antagonism with special reference to the effect of Pseudomonas fluorescens on spore-forming bacteria in soils. J. Bact. I 7:89I 03 (1929).

567. LEwis, M. R. The failure of purified penicillin to retard the growth of grafts of sarcoma in mice. Science $100: 3$ I 4-3 I 5 (1944).

568. Lrbir, R. L., and Holmberg, N. L. The activity of penicillins G and X in vitro. Science 102:303-304 (1945).

568a. Lichstein, H. C., and VAN DE SAND, V.F. The antibiotic activity of violacein, prodigiosin, and phthiocol. J. Bact. 52:145-146 (1946). 
569. Lichstein, H. C., and VAN de Sand, V. F. Violacein, an antibiotic pigment produced by Chromobacterium violaceum. J. Infect. Dis. 76:47-5 I (1945).

570. Liebmann, A. J., McQuarrie, E. B., and Perlstein, D. A standard penicillinase preparation. Science 100:527-528 (1944).

571. LiesKe, R. Morphologie und Biologie der Strahlenpilze. Leipzig, Borntraeger, I 921 , Pp. I $38-143$.

572. Linford, M. B., Yap, F., and Oliveira, J. M. Reduction of soil populations of the root-knot nematode during decomposition of organic matter. Soil Sc. 45: 1 27-1 40 (1938).

573. Liot, A. Culture du Bac. pyocyanique sur milieux chimiquement définis. Ann. Inst. Pasteur 37:234-274 (1923).

574. Lisbonne, M., and Carrère, L. Antagonisme microbien et lyse transmissible. Compt. rend. Soc. de biol. 86:569-570 (1922); 87:101 (1922).

575. Lissauer, M. Über den Bakteriengehalt menschlicher und tierischer Fäces. Arch. f. Hyg. 58:1 36-1 49 (1906).

576. Little, R. B., Dubos, R. J., and Нотснкiss, R. D. Action of gramicidin on streptococci of bovine mastitis. Proc. Soc. Exper. Biol. \& Med. 44:444445 (1940); 45:462-463 (1940); Vet. Digest. 3: I I I (194I).

577. Little, R. B., Dubos, R. J., and Нотснкiss, R. D. Gramicidin, novoxil, and acriflavine for the treatment of chronic form of streptococcic mastitis. J. Am. Vet. M.A. 98:1 189-1 99 (1 94I).

578. Lochhead, A. G., Chase, F. E., and Landerkin, G. B. Production of claviformin by soil penicillin. Canad. J. Research 24: I-9 (1946).

579. Lodge, R. M., and Hinshelwood, C. N. Physicochemical aspects of bacterial growth; conditions determining stationary populations and growth rates of Bact. lactis aerogenes in synthetic media. J. Chem. Soc. 2:16831697 (1939).

580. LöDE, A. Experimentale Untersuchungen über Bakterienantagonismus. Centralbl. f. Bakteriol., I, Or., 33:196-208 (1902); Verhandl. deut. Naturf. Aerzte (1 902).

58I. Lohrisch, H. Der Vorgang der Cellulose- und Hemicellulosenverdauung beim Menschen und der Nährwerth dieser Substanzen für den menschlichen Organismus. Ztschr. exper. Path. u. Ther. 5:478-539 (1 908).

582. Loo, Y. H., Skell, P. S., Thornberry, H. H., Ehrlich, J., McGuire, J. M., Savage, G. M., and Sylvester, J. C. Assay of streptomycin by the paper disc-plate method. J. Bact. 50:701-709 (1945).

582a. Lorenz, W. F., and Ravenel, M. R. The treatment of diphtheria carriers by over-riding with Staphylococcus aureus. J.A.M.A. 59:690 (1912).

583. Lucas, E. H., and Lewis, R. W. Antibacterial substances in organs of higher plants. Science 100:597-599 (1944).

584. Luck, M. J., Sheets, G., and Thomas, J. O. The role of bacteria in the nutrition of protozoa. Quart. Rev. Biol. 6:46-58 (I93I).

585. Lumb, G. D., and Wilson, J. M. Penicillin assay methods. J. Roy. Army M. Corps $84: 247-254$ (1945). 
586. Luria, S. E., and Delbrück, M. Interference between inactivated bacterial virus and active virus of same strain and of different strains. Arch. Biochem. I :207-2 I 8 ( 1942 ).

587. Lyons, C. Penicillin therapy of surgical infections in the U.S. Army. J.A.M.A. 1 23: 1007-101 8 (1 943).

588. Lyons, C. Symposium on management of Cocoanut Grove burns at Massachusetts General Hospital; problems of infection and chemotherapy. Ann. Surg. 1 I 7:894-902 (1943).

589. Manevich, A. A., and Pitskhelauri, G. Z. The treatment of wounds and ulcers with gramicidin. Am. Rev. Soviet Med. 2:143-1 48 (I 944).

590. Mason, H. C. Food-poisoning staphylococci and the order of their resistance to penicillin; inhibition of coagulase production. J. Immunol. $5 \mathrm{I}$ : 307-315 (1945).

591. Mathieson, C. A. Preliminary experiments on the effect of the relation between the $\mathrm{C}$ and $\mathrm{N}$ source on penicillin production. Australian J. Sc. 7: 20-23 (1944).

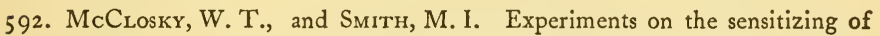
penicillin. Proc. Soc. Exper. Biol. \& Med. 57:270-275 (1944).

593. McCormack, R. B. The associative action of some species of actinomyces. Thesis, Cornell Univ. (1935).

594. MacGregor, A. B., and Long, D. A. Action of penicillin on the rate of fall in numbers of bacteria in vivo. Nature 1 55:201-202 (1945).

595. MachaceK, J. E. Studies on the association of certain phytopathogens. Macdonald Col. McGill Univ. Tech. Bull. 7 (1928).

596. Mcllwain, H. Antibacterial action of two bacterial products of known structure. Nature 1 48:628, 758 (194I).

597. McIlwain, H. The anti-streptococcal action of iodinin; naphthaquinones and anthraquinones as its main natural antagonists. Biochem. J. 37:265-27 I (1943).

598. McIlwain, H. Bacterial inhibition by aminosulfonic analogs of some natural aminocarboxylic acids. Brit. J. Exper. Path. 22:148-155 (I94I).

599. Mcllwain, H. Biochemical characterization of the actions of chemotherapeutic agents; measurement of growth of streptococcal cultures through their gaseous metabolism, and the effects of pantothenate and pantoyltaurine upon the metabolism and growth. Biochem. J. 38:97-105 (1944).

600. McIlwain, H. Biochemistry and chemotherapy. Nature I 51:270-272 (1943); 1 53:300-304 (1944); Trans. Faraday Soc. 39:359-367 (1943).

601. Mcllwain, H. Theoretical aspects of bacterial chemotherapy. Biol. Rev. I 9:135-I 49 (1944).

602. McIlwain, $H$. Biochemical characterization of the actions of chemotherapeutic agents. Biochem. J. 39: I 33-139 (1945).

603. McKee, C. M., Hamre, D. M., and Rake, G. The action of antibiotics on organisms producing gas gangrene. Proc. Soc. Exper. Biol. \& Med. 54: 2I I-2 I 3 ( I 943 ). 
604. McKeE, C. M., and Houck, C. L. Induced resistance to penicillin of cultures of staphylococci, pneumococci and streptococci. Proc. Soc. Exper. Biol. \& Med. 53:33-34 (1943).

605. McKee, C. M., and MacPhillany, H. B. An antibiotic substance produced by submerged cultivation of Aspergillus flavus. Proc. Soc. Exper. Biol. \& Med. 53:237-248 (1 943).

606. McKee, C. M., Rake, G., and Houck, C. L. Studies on Aspergillus flavus; the production and properties of a penicillin-like substance-flavacidin. J. Bact. 47:187-197 (1943).

607. McKeen, J. E. The production of penicillin. Tr. Am. Inst. Chem. Eng. 40:747-758 (1944).

608. MCKinney, H. H. Virus-antagonism tests and their limitations for establishing relationship between mutants, and nonrelationship between distinct viruses. Am. J. Bot. 28:770-778 (I94I).

609. McLeod, J. W., and Govenzock, P. The production of bactericidins by microorganisms. Lancet 200:900-903 (I 92 I).

6Io. McMahan, J. R. An improved short time turbidimetric assay for penicillin. J. Biol. Chem. I 53:249-258 (1 944).

6i i. McQuarrie, E. B., Liebmann, A. J., Kluener, R. G., and Venosa, A. T. Studies on penicillinase. Arch. Biochem. 5:307-316 (1944).

6I 2. McWhorter, F. P. The antithetic virus theory of tulip-breaking. Ann. App. Biol. 25:254-270 (1938).

6I 3. MAdDock, E. C. G. Studies on the survival time of the bovine tubercle bacillus in soil, soil and dung, in dung and on grass, with experiments on the preliminary treatment of infected organic matter and the cultivation of the organism. J. Hyg. 33:103-1 17 (1933).

6i 4. Mahoney, J. F., Arnold, R. C., and Harris, A. Penicillin treatment of early syphilis. Am. J. Pub. Health 33:1387-1391 (1943).

6I 5. Mahoney, J. F., and VAN SLYKe, C. J. The chemotherapy of gonorrhea. Bull. New York Acad. Med. 21:18-26 (1945).

6I6. MarR, W. Experiments on the survival of B. typhosus in sterilized and unsterilized soil. J. Hyg. 8:37-47 (1908).

6i 7. Mann, F. E., Heilman, D., and Herrell, W. E. Effect of serum on hemolysis by gramicidin and tyrocidine. Proc. Soc. Exper. Biol. \& Med. 52: 31-33 (1943).

618. Manolov, D. Antagonism between B. coli and B. typhi in mixed cultures in vitro. Zhur. Microb. Epid. Immun. 14:524 (1935). Cited by $\mathrm{Na}$ khimovskaia (670).

619. Marie, A. C. Virus rabique et Bacillus subtilis. Compt. rend. Soc. de biol. $92: 561-562$ (1925).

620. Marmorek, A. La toxine streptococcique. Ann. Inst. Pasteur 16:169-1 78 (1902).

621. Marshall, M. S., and Hrenoff, A. K. Bacteriostasis. J. Infect. Dis. $6 \mathrm{I}: 42-54$ ( I 937).

622. Martin, F. E. The eradication of streptococcic mastitis by treatment with tyrothricin. J. Am. Vet. M. A. 101:23-25 (1942); 102:267-268 (1942); Vet. Med. 38:174-176 (1943). 
623. Martin, S. Growth of the typhoid bacillus in soil. Local Govt. Board, Rep. Med. Officer 27:308-317 (I $897-1898$ ); 28:382-4I2 (I8981899); 29:525-548 (1 899-1900).

624. Masera, E. Fenomeni di antagonismo e antibiosi fra "Bacillus prodigiosus Flügge" e "Beauveria Bassiana Vuill." Ann. speriment. agri. I 5: I I 7-I 50 (1934).

625. MatTick, A. T. R., and Hirsh, A. A powerful inhibitory substance produced by group $\mathrm{N}$ streptococci. Nature 1 54:55 I (1944).

626. Matzuschita, T. Untersuchungen über die Mikroorganismen des menschlichen Kotes. Arch. f. Hyg. 41:210-255 (1901).

627. Maurin, C. Konservierung des Antivirus in Verbindung mit verschiedenen chemischen Substanzen. Zentralbl. f. Bakteriol., I, Or., I30:129-137 (1933).

628. Meads, M., OrY, E. M., Wilcox, C., and Finland, M. Penicillin sensitivity of strains of six common pathogens and of hemophilus hemolyticus. J. Lab. \& Clin. Med. 30:725-730 (1945).

629. Meleney, F. L. Recent experiences with penicillin in the treatment of surgical infections. Bull. New York Acad. Med. 20:51 7-537 (1944).

630. Melin, E. Zur Frage des Antagonisms zwischen freilebenden Mikroorganismen. Untersuchungen an Holzschliff. Arch. f. Mikrobiol. 4:5095 I 3 (1933); Svensk Skogsv. Tidskr. 3-4:397-6 I6 (1934).

630a. MELIN, E., and WiKEN, T. Antibacterial substances in water extracts of pure forest litter. Nature I 58:200 (1946).

631. Menzel, A. E. O., Wintersteiner, O., and Hoogerheide, J. C. The isolation of gliotoxin and fumigacin from culture filtrates of Aspergillus fumigatus. J. Biol. Chem. 1 52:419-429 (1944).

632. Mercier, J. Experimenteller Beitrag zur Aufklärung der Ursachen des Coliantagonisms. Zentralbl. f. Bakt., I, 1 49:295-303 (1943).

633. Meredith, C. H. The antagonism of actinomyces to Fusarium oxysporum cubense. Phytopath. 33:403 (1 943); 34:426-429 (1 944).

634. Metalnikoff, M. S. Utilisation des méthodes bactériologiques dans la lutte contre les insectes nuisibles. Compt. rend. Soc. de biol. I I 3:169-1 72 (1933) ; 134:66-68 (1940); Acad. Agr. France Proc. Verb., Jan. 17, pp. I-7 (1 940).

635. Metchnikoff, E. The prolongation of life. New York, Putnam, 1908.

636. Metzger, H. J., WaKsman, S. A., and Pugh, L. H. In vivo activity of streptothricin against Brucella abortus. Proc. Soc. Exper. Biol. \& Med. 5 I : $251-252$ (1942).

637. Meyer, J. R. Ação bacteriostática da "orelha de pau" vermelha (Polyporus cinnabarinus). Biológico 10:165-168 (1944); abstract in Biol. Abstr. 19:1 845 (1945).

638. Meyer, K., Chaffee, E., Hobby, G. L., Dawson, M. H., Schwenk, E., and Fleischer, G. On penicillin. Science 96:20-2 I (1942).

639. Meyer, K., Новby, G. L., and Chaffee, E. On esters of penicillin. Science 97:205-206 (1 943).

640. Meyer, K., Hobby, G.L., and Dawson, M. H. The chemotherapeutic effect of esters of penicillin. Proc. Soc. Exper. Biol. \& Med. 53:100-104 (1943). 
641. Meyer, K., Thompson, R., Palmer, J. W., and Khorazo, D. The purification and properties of lysozyme. J. Biol. Chem. I I3:303-309, 479-486 (1 936).

642. Meyer, K. F., and Dubovsky, B. J. The distribution of the spores of B. botulinus in California. J. Infect. Dis. 31:41-55, 56-58, 59-94, 95-99, 100-109 (1923).

643. Michaelis, M., and Thatcher, F.S. The action of citrinin on some respiratory enzymes of Staphylococcus aureus and Escherichia coli. Arch. Biochem. 8:177-1 82 (1945).

644. Millard, W. A., and TAYLoR, C. B. Antagonisms of microorganisms as the controlling factor in the inhibition of scab by green manuring. Ann. App. Biol. 14:202-215 (1927).

645. Miller, B. F., Abrams, R., Dorfman, A., and Klein, M. Antibacterial properties of protamine and histone. Science 96:428-430 (1942).

646. Miller, C. P., and Boor, A. K. Protection of mice against lethal action of gonococcal endotoxin by penicillin. Proc. Soc. Exper. Biol. \& Med. 6r: I 8-20 (1946).

647. Miller, D. K., and Rekate, A. C. Inhibition of growth of Mycobacterium tuberculosis by a mold. Science $100: 172-173$ (1944).

648. Miller, W. S., Green, C. A., and Kitchen, H. Biphasic action of penicillin and other sulphonamide similarity. Nature I55:210-2II (1945).

649. Mitchell, R. B., Adams, J. E., and Thom, C. Microbial responses to organic amendments in Houston black clay. J. Agr. Research 63:527-534 (1941).

650. Mitchell, R. B., Hooton, D. R., and $\mathrm{C}_{\text {Lark, }}$ F. E. Soil bacteriological studies on the control of the Phymatotrichum root rot of cotton. J. Agr. Research 63:535-548 (194I).

65I. MoHR, W. Untersuchungen über antagonistische Vorgänge zwischen Varianten desselben Stammes. Ztschr. f. Hyg. u. Infektionskr. I 16:288-294 (1934); Arch. f. Hyg. 116:197 (1936).

652. Molitor, H. Pharmacology of streptothricin and streptomycin. Ann. New York Acad. Sc. 48:101-117 (1946).

653. Мом, С. P., and Schaeffer, C. O. Typhoid bacteria in sewage and in sludge. Sewage Works J. 12:715-737 (1940).

654. Moragues, V., Pinkerton, H., and Greiff, D. Therapeutic effectiveness of penicillin in experimental murine typhus infection in dba mice. J. Exper. Med. 79:431-437 (1944); 80:56I-574 (1944).

655. Morgan, J. C., and Harvey, D. An experimental research on the viability of the Bacillus typhosus as excreted under natural conditions by the "chronic carrier." J. Roy. Army M. Corps 12:587-598 (1 909).

656. Moritz, O. Weitere Studien über die Ophiobolose des Wiezens. Arb. Biol. Reichsanst. Land. Forstw. 20:27-48 (1932).

657. Moriya, G. Ueber die Umwandlungshypothese und Lebensdauer des Tuberkelbacillus. Centralbl. f. Bakteriol., I, Or., 5 1:480-493 (1909).

658. Morris, C. S. Presence in raw cow's milk of a bactericidal substance specific for certain strains of coliform organisms. Nature 1 55:22 (1945). 
659. Mortara, F., Feiner, R. R., and Levenkron, E. Activity of penicillin against Hemophilus ducreyi in vitro. Proc. Soc. Exper. Biol. \& Med. 56: 163-166 (1944).

66o. Morton, H. E., Kocholaty, W., Junowicz-Kocholaty, R., and KelNER, A. Toxicity and antibiotic activity of kojic acid produced by Aspergillus luteo-virescens. J. Bact. 50:579-584 (1945).

66 I. Mostova, P. On the antagonistic index of B. coli in colitis. Zhur. Microb. Epid. Immun. 44:533 (1935). Cited by Nakhimosskaia (670).

662. Moyer, A. J., and Coghill, R. D. Penicillin; production of penicillin in surface cultures. J. Bact. 51:57-78 (1946).

663. Moyer, A. J., and Coghill, R. D. Penicillin; the laboratory scale production of penicillin in submerged culture by Penicillium notatum Westling (NRRL 832). J. Bact. 5 1:79-93 (1 946).

664. Much, H., and Sartorius, F. Über die neuartige Lysine des Mycoides "Much." München. med. Klinik 20:345-348 (I924).

665. Mull, R. P., Townley, R. W., and Scholz, C. R. Production of gliotoxin and a second active isolate by Penicillium obscurum Biourge. J. Am. Chem. Soc. 67:1626-1627 (1945).

666. Murtaugh, J. J., and Levy, G. B. Chemical method for the determination of penicillin. J. Am. Chem. Soc. 67:1042 (1945).

667. Myers, W. G., and Hanson, H. J. New strains of Penicillium notatum induced by bombardment with neutrons. Science 101:357-358 (1945).

668. Nadson, A., and Adamovic, M. Über die Beeinflussung der Entwicklung des Bacillus mycoides Flügge durch seine Stoffwechselprodukte. Bull. Jard. Bot., St. Petersbourg, 10:154-165 (1910); abstract in Centralbl. f. Bakteriol., II, 31:287-288 (1910).

669. Nadson, G. A., and Zolk1ewicz, A. 1. Spicaria purpurogenes n. sp. Concerning the question of microbial antagonism. Bull. Jard. Bot. Repub. Russe, Sup. I, 21:1-12, 13-18 (1922).

670. NAKHimovsKaIA, M. I. Antagonism among bacteria. Microbiologia (U.S.S.R.) 7:238-264 (1938); 8: 1014-1032 (1939).

671. Nakhimovskaia, M. I. The antagonism between actinomycetes and soil bacteria. Microbiologia (U.S.S.R.) 6:131-I 57 (I937).

672. NakhimovsKaia, M. I. The influence of bacteria on the germination of rust spores. Microbiologia (U.S.S.R.) 8: 116-121 (1939).

673. Naumova, A. N. The influence of grain bacterization on the infection degree of the seedlings of summer wheat by parasitic moulds and on the yield. Microbiologia (U.S.S.R.) 8: 1 98-205 (1939).

6732. Nauta, W. Th., Oosterhuis, H. K., Linden, A. C., Van Duyn, P., and Dienske, J.W. The structure of expansin, a metabolic product of Penicillium expansum with antibiotic properties. Rec. trav. chim. 64:254255 (1945).

674. Nenck1, M. Über Mischkulturen. Centralbl. f. Bakteriol. I 1:225-228 (1892).

675. Neter, E. Effects of tyrothricin and actinomycin A upon bacteriophage and bacterial toxins and toxin-like substances. J. Bact. 43:10-I 1 (I942); Proc. Soc. Exper. Biol. \& Med. 49:163-167 (1942); Science 96:209-210 (1942). 
676. Neter, E. Relative susceptibility of staphylococci to the bacteriostatic action of antibiotics. Proc. Soc. Exper. Biol. \& Med. 58:1 26-1 28 (1945).

677. Neufeld, F., and Kunn, H. Untersuchungen über "direkten" Bakterienantagonismus. Ztschr. f. Hyg. u. Infektionskr. I 16:95-1 10 (1934).

678. Nicholson, S. T., and Hogan, J. F. Effect of lactic acid bacilli on diphtheria. J.A.M.A. 62:510 (1914).

679. Nicol, H., and Thornton, H. G. Competition between related strains of nodule bacteria and its influence on infection of the legume host. Proc. Roy. Soc. 130:32-59 (1 941).

680. Nicolle, M. Action du "Bacillus subtilis" sur diverses bactéries. Ann. Inst. Pasteur 21:613-62 I (1907).

680a. Nissle, A. Die Heilung der chronischen Obstipationen mit Mutaflor, ihre Grundlagen und ihre Bedeutung. München. med. Wchnschr. 76:1745I 748 (1929).

681. Nissle, A. Ueber die Grundlagen einer neuen ursächlichen Bekämpfung der pathologischer Darmflora. Deutsche med. Wchnschr. 42: I I 8 I-I I 84 (1916); Med. Klinik 2:29 (1918).

682. North, E. A., and Christie, R. Observations on sensitivity of staphylococci to penicillin. M. J. Australia 2:44-46 (I 945).

683. Novogrudsky, D. M. Antagonistic interrelations among microbes, and biological methods of combating fungus discases of cultivated plants. Adv. Mod. Biol. (U.S.S.R.) 5: 509-536 (1936).

684. Novogrudsky, D. M. Pyronema confluens Tul. et ses rapports réciproques avec les microorganismes du sol. Bull. Soc. Nat. Moscow, S. Biol. 45:384403 (1936).

685. Novogrudsky, D. M. The use of microbes in the fight against fungous diseases of cultivated plants. Bull. Acad. Sc. (U.S.S.R.) 1:277-293 (1936).

686. Novogrudsky, D. M., Berezova, E., Nakhimovskaia, M., and PerviaKova, M. The influence of bacterization of flax-seed on the susceptibility of seedlings to infection with parasitic fungi. Compt. rend. Acad. d. sc. (U.S.S.R.) I 4:385-388 (1937).

687. Novogrudsky, D. M., Koronenko, E., and Rybalkina, A. The change of bacteria after their introduction into the soil. Bull. Microb. Inst. Acad. Sc. (U.S.S.R.), pp. 1089-1 II 3 (1936).

688. Novy, F. G. Ein neuer anaërober Bacillus des malignen Oedems. Ztschr. f. Hyg. u. Infektionskr. 1 7:209-232 (1894).

689. Oesterlin, E. J. Experimental studies with pyocyaneus filtrates. J. Immunol. 16:359-367 (1929).

690. OkunukI, K. Über die Beeinflussung des Wachstums der Schimmelpilze durch die von Rosa-hefen gebildeten Stoffe. Jap. J. Bot. 5:401-455 (1931).

691. Olitski, L. Ueber die antagonistischen Wirkungen des Bacillus fluorescens liquefaciens und seine hygienische Bedeutung. Inaug. Diss., Berne (1891).

692. Olitski, L. Ueber die das Ektoplasma schädigenden Substanzen und ihre Beziehungen zu anderen hemmenden Substanzen in Filtraten alter Kulturen. Zentralbl. f. Bakteriol., I, Or., 1 1 9:223-238 (1930). 
693. Olivier, H. R. Biological properties of Bacillus subtilis. Nature I57: 238-239 (1 946).

694. Orla-Jensen, S., and Snog-KJaer, A. Über Faktoren, welche aktivierend oder hemmend auf die Entwickelung der Milchsäurebakterien wirken. Det. Kongelige Danske Videnskabernes Selskab. Biol. Skr. 1 :5-1 9 (1940).

695. Ory, E. M., Meads, M., and Finland, M. Penicillin X; comparison with penicillin $G$ with respect to sensitivity of pathogenic organisms and serum levels. J.A.M.A. I 29:257-26I (I 945).

696. OsBorn, E. M. On the occurrence of antibacterial substances in green plants. Brit. J. Exper. Path. 24:227-231 (1943).

697. Oxford, A. E. Anti-bacterial substances from moulds; the bacteriostatic powers of the methyl ethers of fumigatin and spinulosin and other hydroxy-, methoxy-and hydroxymethoxy-derivatives of toluquinone and benzoquinone. Chem. \& Ind. 61: 189-192 (1942).

698. OxFord, A. E. Anti-bacterial substances from moulds; the bacteriostatic powers of the mould products citrinin and penicillic acid. Chem. \& Ind. 6r: 48-51 (1942).

699. OxFord, A. E. Diplococcin, an anti-bacterial protein elaborated by certain milk streptococci. Biochem. J. 38:178-182 (1944); 39:xiii (1945).

700. OxFord, A. E. On the chemical reactions occurring between certain substances which inhibit bacterial growth and the constituents of bacteriological media. Biochem. J. 36:438-444 (1942).

701. Oxford, A. E. The chemistry of antibiotic substances other than penicillin. Ann. Rev. Biochem. 14:749-772 (1945).

702. Oxford, A. E., and Raistrick, H. Anti-bacterial substances from moulds; spinulosin and fumigatin, metabolic products of Penicillium spinulosum Thom and Aspergillus fumigatus Fresenius. Chem. \& Ind. 61:128-129 (1942).

703. Oxford, A. E., Raistrick, H., and Smith, G. Anti-bacterial substances from moulds; penicillic acid, a metabolic product of Penicillium puberulum Bainier and Penicillium cyclopium Westling. Chem. \& Ind. 6I:22-34 (1942).

704. Oxford, A. E., Raistrick, H., and Smith, G. Anti-bacterial substances from moulds; puberulic acid, $\mathrm{C}_{8} \mathrm{H}_{6} \mathrm{O}_{6}$, and puberulonic acid, $\mathrm{C}_{8} \mathrm{H}_{4} \mathrm{O}_{6}$, metabolic products of a number of species of Penicillium. Chem. \& Ind. 61: 485-487 (1942).

705. Paley, T., and Osicheva, P. Reciprocal action of Aspergillus niger and Penicillium luteum purpurogenum Thom and Church. Trudi NauchnoIzslied. Inst. Pischtch. Promish. 3 (4): 1 46-1 56 (1936).

706. Papacostas, G., and Gaté, J. Les associations microbiennes, leurs applications thérapeutiques. Paris, Doin, 1928.

707. Parker, R. F., and Diefendorf, H. W. Effect of penicillin on certain viruses. Proc. Soc. Exper. Bicl. \& Med. 57:35 I-354 (I 944).

708. Passini, F. Ueber die Lebensdauer der Tuberkelbazillen in Kulturen anaerober Fäulnissbakterien. Wien. klin. Wchenschr. 38: 1182-1184 (1925); abstract in Centralbl. f. Bakteriol., I, 81:447 (1926). 
709. Pasteur, L. Nouvel exemple de fermentation déterminée par des animalcules infusoires pouvant vivre sans gas oxygène libre, et en dehors de tout contact avec l'air de l'atmosphère. Compt. rend. Acad. d. sc. 56:416-42 I, I I 89-I I 94 ( I 863).

7 Io. Pasteur, L., and Joubert, J. Charbon et septicémie. Compt. rend. Acad. d. sc. 85:101-105 (1877).

7 I I. Pawlowsky, A. Heilung des Milzbrandes durch Bakterien und das Verhalten der Milzbrandbacillen im Organismus. Archiv. pathol. Anat. Physiol. I 08:494-52 I ( I 887).

71 2. PeCk, R. L., Brink, N. G., Kuehl, F. A., Jr., Flynn, E. H., Walti, A., and Folkers, K. Streptomyces antibiotics; crystalline streptomycin trihydrochloride-calcium chloride double salt. J. Am. Chem. Soc. 67: I 866-I 867 (I 945).

713. Peck, R. L., Graber, R. P., Walti, A., Peel, E. W., Hoffhine, C. E., and Folkers, K. Streptomyces antibiotics; hydrolytic cleavage of streptomycin to streptidine. J. Am. Chem. Soc. 68:29-3 I (1945).

7 I 3 a. Peck, R. L., Walti, A., Graber, R. P., Flynn, E., Hoffhine, C. E., Allfrey, V., and Folkers, K. Streptomyces antibiotics; isolation of streptothricin. J. Am. Chem. Soc. 68:772-776 (1946).

7 1 4. PECK, S. M., and Hewitr, W. L. The production of an antibiotic substance similar to penicillin by pathogenic fungi (Dermatophytes). Pub. Health Rep. 60:148-I 53 (1945).

715. Penicillin, chemistry of. Science 102:627-629 (1945).

716. Perault, R. The antipenicillin of Bacillus subtilis. Compt. rend. soc. de biol. I 39:61 8-619 (1945); abstract in Chem. Abstr. 40:5091 (1946).

71 7. Perlman, D., and McCoy, E. Some effects of induced streptothricin resistance on Lactobacillus casei. J. Bact. 49:271-275 (1945).

718. Peterson, E. H., and Graham, R. Studies on bovine mastitis; a note on clavacin therapy in bovine mastitis. Am. J. Vet. Research 5:316-317 ( 1944 ).

7 19. Pfalz, G. J. Ueber den Einfluss von Bacterium coli auf pathogene Darmkeime. Ztschr. f. Hyg. u. Infektionskr. 106:504-514 (1926).

720. Phillips, R. L., and Barnes, L. H. Development of resistance in staphylococci to natural inhibitory substances (gramicidin). J. Franklin Inst. 233: 396-40I (1942).

721. Philpot, C. H. Growth of paramecium in pure cultures of pathogenic bacteria and in the presence of soluble products of such bacteria. J. Morphol. 46:85-129 (1928).

722. Phılpot, F.J. A penicillin-like substance from Aspergillus giganteus Wehm. Nature 1 52:725 (1943).

723. Pinoy, E. Rôle des bactéries dans le développement de certaines Myxomycètes. Ann. Inst. Pasteur 21:622-656, 686-700 (1907).

724. Pinschmidt, N. W., and Levy, B. A simple method for the routine search for antibiotic substances produced by molds. J. Pharmacol. \& Exper. Therap. 82:19-22 ( 1944 ).

725. Plough, H. H. Penicillin resistance of Staphylococcus aureus and its clinical implications. Am. J. Clin. Path. 1 5:446-45 I (1945). 
726. Pontecorvo, G. Assay of the rates of secretion of antibiotics in different regions of a growing mold colony. Nature 1 55:515-5 I6 (1945).

727. Pontecorvo, G., and Gemmeli, A. R. Colonies of Penicillium notatum and other molds as models for the study of population genetics. Nature 154 : 532-534 (1944).

728. Poole, E. A., and Hinshelwood, C. N. Physicochemical aspects of bacterial growth; the influence of toxic substances on growth rate, stationary population, and fermentation reactions of Bact. lactis aerogenes. J. Chem. Soc., Dec. $1565^{-1} 57^{2}$ (1940).

729. Porter, C. L. Concerning the characters of certain fungi as exhibited by their growth in the presence of other fungi. Am. J. Bot. I I: 168-188 (1924); Proc. Indiana Acad. Sc. 41: 149-152 (1932).

730. Porter, C. L., and Carter, J. C. Competition among fungi. Bot. Rev. 4: $165-182$ (1938).

731. Potter, M. C. On a method of checking parasitic diseases in plants. J. Agr. Sc. 3:102-107 (1908).

732. Pratt, C. A. The staling of fungal cultures; general and chemical investigation of staling by Fusarium. Ann. Bot. 38:563-594, 599-615 (1924).

733. Pratt, R. Influence of the proportions of $\mathrm{KH}_{2} \mathrm{PO}_{4}, \mathrm{MgSO}_{4}$, and $\mathrm{NaNO}_{3}$ in the nutrient solution on the production of penicillin in surface cultures. Am. J. Bot. 32:528-535 (1945); 33:149-I 56 (1946).

734. Pratr, R., et al. Chlorellin, an antibacterial substance from Chlorella. Science 99:35 I-352 (1944).

735. Pratt, R., and Dufrenox, J. Physiological comparison of two strains of Penicillium. Science 102:428-429 (1945).

736. Prausnitz, W. Die Hygiene des Bodens. Handb. der Hygiene I:520562 ( I 91 I).

737. Prell, H. Zur Frage der biologischen Bekaempfung pathogener Darmbakterien durch apathogene. Centralbl. f. Bakteriol., 1, Or., 80:225-242 (1918); Ztschr. Hyg. Immunität. 88:507-528 (1919).

738. Pringsheim, E. G. Über die gegenseitige Schädigung und Förderung von Bakterien. Centralbl. f. Bakteriol., II, 51:72-85 (1920).

739. Pshenitchnikov. On the question of bacteriotherapy of chronic putrefactive infections of the middle ear. Ural Med. J. 6:6I (1921). Cited by Nakhimorskaia (670).

739a. Puetzer, B., and GrubB, T. C. The action of clavacin, a clavacin isomer and related compounds on tetanus toxin. J. Infect. Dis. 78:253-256 (1946).

740. Puntoni, V., and Favia, N. La perte de la virulence du b. tuberculeux comme suite de son association avec le b. tuberculophile. Soc. internaz. di microbiol., Boll. d. sez. ital. 6: I 58-160 (1934).

741. Purdy, W. C., and Butterfield, C. T. The effect of plankton animals upon bacterial death-rates. Am. J. Pub. Health 8:499-505 (1918).

742. Quortrup, E. R., and Holt, A. L. Detection of potential botulinustoxin-producing areas in western duck marshes with suggestions for control. J. Bact. 4I:363-372 (194I). 
743. Raistrick, H. The production of quinones by "moulds." J. Soc. Chem. Ind. 16:293-294 (1938).

744. Raistrick, H., Birkinshaw, J. H., Michael, S. E., Bracken, A., Gye, W. E., and Hopkins, W. A. Patulin in the common cold; collaborative research on a derivative of Penicillium patulin Bainier. Lancet 2:625-635; comment p. 684 ( 1943 ).

745. Raistrick, H., and Smith, G. Anti-bacterial substances from moulds; citrinin, a metabolic product of Penicillium citrinum Thom. Chem. \& Ind. 60:828-830 (I 94 I).

746. Rake, G., Hamre, D., Kavanagh, F., Koerber, W. L., and Donovick, R. On the toxicity of streptothricin. Am. J. M. Sc. 210:6 I-66 (I945).

747. Rake, G., and Jones, $H$. A rapid method for estimation of penicillin. Proc. Soc. Exper. Biol. \& Med. 54:189-190 (1943).

748. Rake, G., Jones, H., and MCKeE, C. M. Antiluminescent activity of antibiotic substances. Proc. Soc. Exper. Biol. \& Med. 52:136-1 38 (1943).

749. RaKe, G., McKeE, C. M., and Jones, H. A rapid test for the activity of certain antibiotic substances. Proc. Soc. Exper. Biol. \& Med. 51:273-274 (1942).

750. Rakieten, M. L., Rakieten, T. L., and Doff, S. Inhibition of staphylococcus bacteriophage and the virus of vesicular stomatitis. J. Bact. 3 I : 55-56 (1 936).

751. Rammel Kamp, C. H. A method for determining the concentration of penicillin in body fluids and exudates. Proc. Soc. Exper. Biol. \& Med. 5 1:95-97 (1942).

752. Rammelkamp, C. H. Observations on resistance of Staphylococcus aureus to action of tyrothricin. Proc. Soc. Exper. Biol. \& Med. 49:346-350 (1942).

753. Rammelkamp, C. H. Tyrothricin therapy of experimental hemolytic streptococcal empyema. J. Infect. Dis. 7 1 :40-46 (1942).

754. Rammelkamp, C. H. Use of tyrothricin in the treatment of infection. War Med. 2:830-846 (1942).

755. Rammelkamp, C. H., and Keefer, C. S. The absorption, excretion and toxicity of penicillin administered by intrathecal injection. Am. J. Med. Sc. 205:342-350 (1943); J. Clin. Investigation 22:425-438, 649-657 (1943).

756. Rammelkamp, C. H., and Maxon, T. Resistance of Staphylococcus aureus to the action of penicillin. Proc. Soc. Exper. Biol. \& Med. 51:386389 (1942).

757. Rammelkamp, C. H., and Weinstein, L. Hemolytic effect of tyrothricin. Proc. Soc. Exper. Biol. \& Med. 48:21 I-214 (I94I).

758. Rammelkamp, C. H., and Weinstein, L. Toxic effects of tyrothricin, gramicidin, and tyrocidine. J. Infect. Dis. 7 I: I66-173 (1942).

759. Ramon, G., Richou, R., and Ramon, P. Sur la production de ferments protéolytiques très actifs par le $\mathrm{B}$. subtilis, cultivé dans des milieux à base de matières végétales; conséquences. Compt. rend. Acad. d. sc. 220:341$343,543-546,802-805 ; 22$ I: 165-167, 213-21 7, 271-274; $222: 621-$ $622(1946)$. 
760. Randall, W. A., Welch, H., and Hunter, A. C. The stability of penicillin sodium held at various temperatures. J. Am. Pharm. A. (Scient. Ed.) 34:110-1 13 (1945).

761. Rantz, L. A., and Kirby, W. M. M. The absorption and excretion of penicillin following continuous intravenous and subcutaneous administration. J. Clin. Investigation 23:789-794 (1944).

762. RaO, S. S., and DE, S. P. Production of penicillin. Current Sc. 1 2:209 (1943).

763. RAPER, K. B. The development of improved penicillin producing molds. Ann. New York Acad. Sc. 48:41-56 (1946).

764. Raper, K. B., and Alexander, D.F. Penicillin; mycological aspects of penicillin production. J. Elisha Mitchell Sc. Soc. 61:74-1 I I (1945).

765. Raper, K. B., Alexander, D. F., and Coghill, R. D. Penicillin; natural variation and penicillin production in Penicillium notatum and allied species. J. Bact. 48:639-659 (1944).

766. Raubitscheк, H., and Russ, V.K. Zur Kenntnis der bakteriziden Eigenschaften der Pyocyanase. Centralbl. f. Bakteriol., I, Or., 48: 1 I 4-122 (I 909).

767. Rayner, M. M. C., and Jones, W. N. Problems in tree nutrition. London, Faber, 1944 .

768. Regna, P. P. The stability of penicillin during the stages of recovery. Tr. Am. Inst. Chem. Eng. 40:759-765 (1944).

769. Regnier, J., and Lambin, S. Etude d'un cas d'antagonisme microbien. Compt. rend. Acad. d. sc. 199:1682-1686 (1934).

770. REID, R. D. Some properties of a bacterial-inhibitory substance produced by a mold. J. Bact. 29:215-220 (1935).

771. Reilly, H. C., Schatz, A., and Waksman, S. A. Antifungal properties of antibiotic substances. J. Bact. 49:585-594 (1945).

772. Reimann, H. A., Elias, W. F., and Price, A. H. Streptomycin for typhoid; a pharmacologic study. J.A.M.A. I 28:175-1 80 (1945).

773. Reinhardt, M. O. Das Wachstum der Pilzhyphen. Jahrb. wiss. Bot. 23: $479-563$ ( 1892 ).

774. Reinking, O. A., and Manns, M. M. Parasitic and other Fusaria counted in tropical soils. Ztschr. Parasitenk. 6:23-75 (I933); Zentralbl. f. Bakteriol., II, 89:502-509 (1934).

774a. Remlinger, P., and Bailly, J. Action des filtrats de cultures de Bacillus subtilis sur le virus de la rage. Compt. rend. Acad. d. sc. 223:118-120, 267-268 (1946).

775. Renaux, E. Sur l'antivirus staphylococcique. Compt. rend. Soc. de biol. 104: 1 29-130 (1930).

776. Rennerfelt, E. Beobachtungen über den gegenseitigen Einfluss einiger Pilze aufeinander. Svensk Botan. Tidskr. 32:332-345 (1938).

777. Rettger, L. F. The antagonism of bacteria and their products to other bacteria. J. Infect. Dis. 2:562-568 (1905).

778. Rettger, L.F., and Cheplin, H. A. Treatise on the transformation of the intestinal flora, with special reference to the implantation of Bacillus acidophilus. New Haven, Yale University Press, 1921. 
779. Rhines, C. The longevity of tubercle bacilli in sewage and stream-water. Am. Rev. Tuberc. 31:493-497 (1935).

780. Rhines, C. The persistence of avian tubercle bacilli in soil and in association with soil microorganisms. J. Bact. 29:299-3 I I (1935).

781. Rhines, C. The relationship of soil protozoa to tubercle bacilli. J. Bact. 29:369-381 (1935).

782. Richards, A. N. Penicillin; statement released by the Committee on Medical Research. J.A.M.A. 122:235-236 (1943).

783. Rizzı, I. Untersuchungen über die antagonistische Wirkung von Colibazillen verschiedener Herkunft. Ztschr. Hyg. Immunität. 82:380-385 ( 1934 ).

784. Robbins, B. H. Effect of penicillin and patulin on fowl pox. Proc. Soc. Exper. Biol. \& Med. 57:21 5-216 (1944).

785. Robbins, W. J., Hervey, A., Davidson, R. W., MA, R., and Robins, W. C. A survey of some wood-destroying and other fungi for antibacterial activity. Bull. Torrey Bot. Club 72:165-190 (1945).

785a. Robbins, W. J., Kavanagh, F., and Hervey, A. Production of antibiotic substances by basidiomycetes. Ann. New York Acad. Sc. 48:67-72 (1946).

786. Roberts, E. C., Cain, C. K., Muir, R. D., Reithel, F. J., Gaby, W. L., VanBruggen, J. T., Homan, D. M., Katzman, P. A., Jones, L. R., and Dorsy, E. A. Penicillin B, an anti-bacterial substance from Penicillium notatum. J. Biol. Chem. I 47:47-58 (1943).

787. Robertson, I. M. Penicillin in bone infections. Brit. M. J. 4345:51952 I ( 1944 ).

788. Robinson, H. J. Some toxicological, bacteriological and pharmacological properties of antimicrobial agents produced by soil microorganisms. 'Thesis, Rutgers Univ. (1943).

789. Robinson, H. J. Toxicity and efficacy of pencillin. J. Pharmacol. \& Exper. Therap. 77:70-79 (1943).

790. Robinson, H. J., and Graessle, O. E. In vitro and in vivo studies of gramicidine, tyrothricin and tyrocidine. J. Pharmacol. \& Exper. Therap. 76:316-325 (1942).

79i. Robinson, H. J., Graessle, O. E., and Smith, D. G. Chemotherapeutic properties of streptomycin. Am. J. Med. Sc. 209: I 28-I 29 (1 945 ).

792. Robinson, H. J., Graessle, O. E., and Smith, D. G. Studies on the toxicity and activity of streptothricin. Science 99:540-542 (1944).

793. Robinson, H. J., and Molitor, H. Some toxicological and pharmacological properties of gramicidin, tyrocidine and tyrothricin. J. Pharmacol. \& Exper. Therap. 74:75-82 (1942).

794. Robinson, H. J., and Smith, D. G. Streptothricin as a chemotherapeutic agent. J. Pharmacol. \& Exper. Therap. 81:390-40 I (1944).

795. Robinson, H. J., Smith, D. G., and Graessle, O. E. Chemotherapeutic properties of streptomycin. Proc. Soc. Exper. Biol. \& Med. 57:226-23I ( 1944 ).

796. Robinson, H. J., and Waksman, S. A. Studies on the toxicity of actinomycin. J. Pharmacol. \& Exper. Therap. 74:25-32 (1942). 
797. Robson, J. M., and ScotT, G. I. Local chemotherapy in experimental lesions of the eye produced by Staph. aureus. Lancet I:100-103 (1943); Nature I 49: 581-582 (1942).

798. Rochaix, A., and Vieux, G. Antagonisme du Bacille pyocyanique et du Colibacille dans l'eau d'alimentation. Compt. rend. Soc. de biol. I24: 1 i $18-$ I I 19 ( 1937 ).

799. Rodaniche, E. C., and Palmer, W. L. The action of tyrothricin on fecal streptococci in vitro and in vivo. J. Infect. Dis. 72:154-156 (1943).

80o. Rodionova, E. A. The influence of metabolism products of micro-organisms on the development of others. Arch. biol. nauk 30:335-344 (1930).

80oa. Romansky, M. J., and Rittman, S. E. Penicillin; prolonged action in beeswax-peanut oil mixture; single injection treatment of gonorrhea. Bull. U.S. Army M. Dept. (No. 8I) pp. 43-49 (1944).

801. Rösler, F. Die wachstumshemmende bezw. bakterizide Wirkung der Pyocyanase auf verschiedene tierpathogene Bakterien. Prager Archiv. Tiermed. vergl. Pathol. A 6:21 7-232 (1926).

802. Rogers, L. A. The inhibiting effect of Streptococcus lactis on Lactobacillus bulgaricus. J. Bact. 16:321-325 (1928).

803. Rose, H. M., Molloy, E., and O'Neill, E. Effect of penicillin on bacterial contamination of eggs and tissue cultures inoculated with unfiltered sputums. Proc. Soc. Exper. Biol. \& Med. 60:23-25 (1945).

804. Rosen, H. R., and Shaw, L. Studies on Sclerotium rolfsii, with special reference to the metabolic interchange between soil inhabitants. J. Agr. Research 39:41-6I (1929).

805. Rosenthal, L. La lyse des Bacilles diphtériques effectuée par un streptothrix. Compt. rend. Soc. de biol. 93:77-78 (1925).

806. Rosenthal, L. Sur les lysobactéries thermophiles. Compt. rend. Soc. de biol. 92:78-79, 472-473 (1925); 93:1569-1570 (1926); Proc. Soc. Exper. Biol. \& Med. 46:448-449 (I 94 I).

807. Rosenthal, L. Antagonistic action of red mould pigment against bacteria of the typhoid-paratyphoid-dysentery group. Science 102:176-177 (1945).

808. Rosenthal, L., and Ilitch, Z. Sur le pouvoir lytique des filtrats de Tyrothrix scaber. Compt. rend. Soc. de biol. 95:10-1 I (1926).

809. Ruchioft, C. C. Studies on the longevity of Bacillus typhosus (Eberthella typhi) in sewage sludge. Sewage Works J. 6:1054-1067 (1934).

810. Ruehle, G. A. A., and Brewer, C. M. United States food and drug administration methods of testing antiseptics and disinfectants. U.S.D.A. Circular 198 ( I931).

811. Ruschmann, G. Natürlicher und künstlicher Stalldünger. Jauche und Gülle. Handb. Pflanzenern. Düngerl. (Honcamp) 2:I62-234 (I93I).

8 I 2. Russell, E. J., and Hutchinson, H. B. The effect of partial sterilization of soil on the production of plant food. J. Agr. Sc. 3: III-I 44 (1909); 5:152-221 ( I913).

81 3. Rybalkina, A. V. On the toxic substances in soils and their action upon soil bacteria. Microbiologia (U.S.S.R.) 7:91 7-932 (1 938). 
814. Rybalkina, A. V. The vitality of cultures of Azotobacter chroococcum Beij. in peat. Microbiologia (U.S.S.R.) 7:933-935 (1938).

8 I 5. Rysнко, W. L., and Suкноv, K. S. Influence of substances related to enzymatic action on the necrotic reaction produced by Nicotiana virus $\mathbf{I}$. Biokhimiya 9: 1 54-160 ( 1944 ).

8I 5a. Saint-Rat, L. D., and Olivier, H. R. Extraction et purification de l'endo-subtilysine. Compt. rend. Acad. d. Sc. 222:297-300 (1946).

8I6. SALle, A. J., and JANN, G. J. Subtilin-an antibiotic produced by Bacillus subtilis; action on various organisms. Proc. Soc. Exper. Biol. \& Med. 60:6064 (1945); 61:23-24 (1946); J. Bact. 51:591 (1946).

8I 7. Sallmann, L. von. Penicillin and sulfadiazine in treatment of experimental intraocular infection with pneumococcus. Arch. Ophth. 30:426 (1943).

8I 8. Sanders, A. G. Effect of some antibiotics on pathogenic fungi. Lancet i : 44-46 ( 1946 ).

819. Sanfelice, F. Der Antagonismus des Milzbrandbacillus gegenüber dem "B. coli." Arch. f. Hyg. 1 10:348-354 (1933).

820. Sanford, G. B. Some factors affecting the pathogenicity of Actinomyces scabies. Phytopath. 16:525-547 (1926).

82 I. Sanford, G. B. Some soil microbiological aspects of plant pathology. Sc. Agr. 13:638-641 (1933).

822. Sanford, G. B., and Broadfoot, W. C. Studies of the effects of other soil-inhabiting microorganisms on the virulence of Ophiobolus graminis Sacch. Sc. Agr. I I: 512-528 (I93I).

823. SANFORD, G. B., and CORMACK, M. W. Variability in association effects of other soil fungi on the virulence of Helminthosporium sativum on wheat seedlings. Canad. J. Research 18:562-566 (1940).

824. Sartorius. Neuartige Lysine bei Mycoidesbakterien. Centralbl. f. Bakteriol., I, Or., 93: 162-167 (1924).

825. Sartory, A. De l'influence d'une bactérie sur la production des périthèces chez un Aspergillus. Compt. rend. Soc. de biol. 79:174 (1916).

826. Saтон, S. Studien über die Wirkungen der durch Ophiobolus miyabeanus gebrauchten Nährlösungen auf die Keimung und Entwicklung eines andern Pilzes. Mem. Col. Agr., Kyoto Imp. Univ. 13 ( I93 I).

827. Savastano, G., and Fawcett, H. S. A study of decay in citrus fruits produced by inoculations with known mixtures of fungi at different constant temperatures. J. Agr. Research 39: 163-198 (1929).

828. Schalk, A. F. Results of some avian tuberculosis studies. J. Am. Vet. M. A. $72: 852-864$ (1928).

829. Schalm, O. W. Treatment of bovine mastitis. J. Am. Vet. M. A. 99: 196 (I 94 I) ; 100: 323-334 (1942).

830. Schatz, A., Bugie, E., and Waksman, S. A. Streptomycin, a substance exhibiting antibiotic activity against gram-positive and gram-negative bacteria. Proc. Soc. Exper. Biol. \& Med. 55:66-69 (1944).

830a. Schatz, A., Magnuson, H. J., Waksman, S. A., and Eagle, H. Isolation of an antibiotic agent derived from a Phycomyces active in vitro against Trypanosoma equiperdum. Proc. Soc. Exper. Biol. \& Med. 62:143-145 (1946). 
831. Schatz, A., and Waksman, S. A. Effect of streptomycin and other antibiotic substances upon Mycobacterium tuberculosis and related organisms. Proc. Soc. Exper. Biol. \& Med. 57:244-248 (1 944).

832. Schatz, A., and Waksman, S. A. Strain specificity and production of antibiotic substances; variations and mutations among actinomycetes, with special reference to Actinomyces griseus. Proc. Nat. Acad. Sc. 31:129-137 (1945).

833. Scheffler, W. Bakteriologisch-chemische Untersuchungen über den Stalldünger, speziell über den Einfluss verschiedener Konservierungsmittel auf die Bakterienflora und die Gärungsvorgänge. Landw. Jahrb. 42:429547 (1912).

834. Schenck, J. R., and Spielman, M. A. The formation of maltol by the degradation of streptomycin. J. Am. Chem. Soc. 67:2276-2277 (1945).

835. Schiller, I. Über erzwungene Antagonisten. Centralbl. f. Bakteriol., I, Or., 91:68-72 (1924); 92:124-129 (1924); 94:64-66 (1925); 96: 54-56 (1925); 103:304-314 (1927); Compt. rend. Soc. de biol. 105: $423-425,550-552$ (1930).

836. Schilling, C. Antagonismus bei Bacterien. Zentralbl. f. Bakteriol., I, Or., $127: 276-279$ (1933).

837. Sснмidt, B. Untersuchungen über das Myzelwachstum der Phycomyceten. Jahrb. wiss. Bot. 64:509-586 (1925).

838. Schmidt, W. H., and Moyer, A. J. Penicillin; methods of assay. J. Bact. 47: 199-209 (1944).

839. Sснмidt, W. H., WARd, G. E., and Coghill, R. D. Penicillin; effect of dissociation phases of Bacillus subtilis on penicillin assay. J. Bact. 49:4I I412 (1945).

840. Schnitzer, R. J., Camagni, L. J., and Buck, M. Resistance of small colony variants ( $G$-forms) of a Staphylococcus towards the bacteriostatic activity of penicillin. Proc. Soc. Exper. Biol. \& Med. 53:75-78 (1943).

841. Schoenbach, E. B., Enders, J. F., and Mueller, J. H. The apparent effect of tyrothricin on Streptococcus hemolyticus in the rhino-pharynx of carriers. Science 94:2 I 7-2 I 8 (194I).

842. Schoenbach, E. B., and Seidman, L. R. A selective medium for isolation of Hemophilus influenzae. Proc. Soc. Exper. Biol. \& Med. 49:108-1 10 (1942).

843. Schoental, R. The nature of the antibacterial agents present in Pseudomonas pyocyanea cultures. Brit. J. Exper. Path. 22:137-147 (1941).

844. Schweinburg, F. Ueber Kulturversuche mit Antivirus. Wien. klin. Wchnschr. 40:8 I I-8I 3 (1927).

845. Schweizer, G. Bacillus hirudinis ein spezifischer Symbion des Blutegels. Arch. f. Mikrobiol. 7:235-240 (1936).

845a. Scudi, J. V. A colorimetric method for the determination of penicillin. J. Biol. Chem. 164:183-194 (1 946).

846. Sedgwick, W. T., and Winslow, C.-E. A. Experiments on the viability of typhoid fever bacilli in earth at various temperatures. Mem. Am. Acad. Arts \& Sc. 12:508-515 (1902). 
847. Seegal, B. C., and Holden, M. The antibiotic activity of extracts of Ranunculaceae. Science IOI:4I3-4I4 (1945).

848. Seeler, A. I., Malanga, C., and Pierson, J. Effect of streptomycin on avian malaria. Proc. Soc. Exper. Biol. \& Med. 59:291-292 (I 945).

849. SEitz, A. Misch- und Sekundärinfektion. In Kolle, Kraus and Ullenhut, Handbuch der pathogenen Mikroorganismen. 3d ed., vol. I, pt. I, pp. 505522, Jena, Fischer, 1929.

850. Sergiev, P. G. Clinical use of gramicidin S. Lancet 2:717-718 (1944).

85 I. Sherman, J. M., and Hodge, H. M. The bactericidal properties of certain plant juices. J. Bact. 31:96 (1936).

852. Shwartzman, G. Inhibition of E. coli by penicillin. Science 100:477478 (1944); IOI:276-277; 102:1 48-150 (1945); J. Exper. Med. 83: 65-88 ( ( 946 ).

853. Silberschmidt, W., and $\mathrm{S}_{\mathrm{l}} \mathrm{Hoch}, \mathrm{E}$. Contribution à l'étude de microbes antagonistes de la bactéricide charbon (Bacillus anthracis). Ann. Inst. Pasteur 34:669-683 (1920).

854. Simmons, S. W. A bactericidal principle in excretions of surgical maggots which destroys important etiological agents of pyogenic infections. J. Bact. 30:253-267 (1935).

855. Singh, B. N. Selection of bacterial food by soil flagellates and amoebae. Ann. App. Biol. 29:18-22 (1942); Brit. J. Exper. Path. 26:316-325 (1945).

856. Skinner, C. E., and Murray, T. J. The viability of B. coli and B. aerogenes in soil. J. Infect. Dis. 38:37-4I (1926).

857. Slanetz, L. W., and Allen, F. E. Treatment of bovine mastitis with penicillin. J. Am. Vet. M. A. 107:18-20 (1945).

858. Sмiтh, D. G. A method for the detection of streptothricin in the presence of streptomycin. Proc. Soc. Exper. Biol. \& Med. 61:214-216 (I946).

859. Smith, D. G., and Robinson, H. J. The influence of streptomycin and streptothricin on the intestinal flora of mice. J. Bact. 50:6 I3-62 I (1945).

860. Smith, F. R., and Sherman, J. M. The hemolytic streptococci of human feces. J. Infect. Dis. 62:186-189 (1938).

861. Sмiтh, L. D., and $\mathrm{H}_{A Y}$, T. The effect of penicillin on the growth and morphology of Staphylococcus aureus. J. Franklin Inst. 233:598-602 (1942).

862. SMith, M. I., and MC $C_{\text {LOSKY }}$, W. T. The chemotherapeutic action of streptomycin and promin in experimental tuberculosis. Pub. Health Rep. 60: I 129-1 I 38 (1945).

863. Smith, M. I., and Emmart, E. W. The action of Penicillium extracts in experimental tuberculosis. Pub. Health Rep. 59:4 I 7-423 (I 944).

864. Sмiтн, O. The antagonistic action of Bacillus thermophilus, Bacillus subtilis, Escherichia coli-communis and Alcaligenes fecalis on Sarcina lutea. J. Bact. 36:659-660 (1938).

865. Smith, R., and Kilbourne, I. L. Investigations into the nature, causation and prevention of Southern cattle fever. U.S.D.A., Bur. of Animal Industry, Bull. I ( 1893 ). 
866. Sм1тH, R. P. The influence of B. coli on the growth of B. typhosus with special reference to enrichment by brilliant green in typhoid carriers. J. Path. \& Bact. 26:122-123 (1923).

867. Sмiтh, T. Modification, temporary and permanent of the physiological characters of bacteria in mixed cultures. Trans. Am. Assn. Physicians 9:85IO9 ( 1894 ).

868. Sokoloff, V. P., and Klotz, L. J. A bacterial pathogen of the citrus red scale. Science 94:40-4I (1 94I).

869. Solntzeva, L. I. On the lysis of phytopathogenic bacteria caused by Myxobacteriales. Microbiologia (U.S.S.R.) 8:700-705 (1939).

870. Soltys, M. A. Antibiotic action of Aspergillus fumigatus upon Mycobacterium tuberculosis. Nature I 54:550-55 I (1 944).

871. Soo-Hoo, G., and Schnitzer, R. J. The activity of penicillin combined with other anti-streptococcal agents towards $\beta$-hemolytic streptococci in vivo. Arch. Biochem. 5:99-106 (1944).

87 Ia. Soparkar, M. B. The vitality of the tubercle bacillus outside the body. Indian J. M. Research 4:627-650 ( 1917 ).

872. Sophian, L. H. A method for the recovery of penicillin from the urine. J. Lab. \& Clin. Med. 29:769-771 (1944).

873. Speakman, H. B., and Phillips, J. F. A study of a bacterial association; the biochemistry of the production of lactic acid. J. Bact. 9:183-197 (1924).

874. SPINK, W. W., and FERRIS, V. Quantitative action of penicillin inhibitor from penicillin-resistant strains of staphylococci. Science 102:221-223 (1945).

875. Stanley, N. F. Aspergillin, a stable antibacterial substance of high potency produced by a species of Aspergillus. Australian J. Sc. 6:151-1 52 (I 944); abstract in Chem. Abstr. 38:4642 (1944).

876. Stansfield, J. M., Francis, A. E., and Stuart-Harris, C. H. Laboratory and clinical trials of patulin. Lancet $2: 370-372,373-375$ (1944).

877. Starkey, R. L. Some influences of the development of higher plants upon the microorganisms in the soil. Soil Sc. 27:319-334, 355-378, 433-444 (1929); 32:367-393 (1931); 45:207-249 (1938).

878. Stebins, R. B., Graessle, O. E., and Robinson, H. J. Studies on the absorption and excretion of streptomycin in animals. Proc. Soc. Exper. Biol. \& Med. 60:68-72 (1945).

879. Stebbins, R. B., and Robinson, H. J. A method for determination of streptomycin in body fluids. Proc. Soc. Exper. Biol. \& Med. 59:255-259 (1945).

880. Steiner, M. Gram-negative bacilli susceptibility to penicillin; experiments in vitro. U.S. Nav. M. Bull. 44:486-489 (1 945 ).

881. Steinhaus, E. A. The microbiology of insects; with special reference to the biologic relationships between bacteria and insects. Bact. Rev. 4: I 7-57 (1 940).

882. Stewart, A. G., and Ghosal, S. C. The germicidal action of the activated sludge process. Indian J. M. Research 16:989-992 (1929).

883. Stokes, J. L., Peck, R. L., and Woodward, C. R., Jr. Antimicrobial action of pyocyanine, hemipyocyanine, pyocyanase, and tyrothricin. Proc. Soc. Exper. Biol. \& Med. 51 : 1 26-1 30 (1942). 
884. Stokes, J. L., and Woodward, C. R., JR. Formation of tyrothricin in submerged cultures of Bacillus brevis. J. Bact. 45:29-30 (1 943); 46:83-88 (1943).

885. Stokes, J. L., and Woodward, C. R., Jr. The isolation of soil bacteria that produce bactericidal substances. J. Bact. 43:253-263 (1942).

886. Stokinger, H. E., Ackerman, H., and Carpenter, C. M. The use of tyrothricin in culture medium as an aid in the isolation of Neisseria gonorrhoeae. J. Bact. 45:31 (1943).

887. Stone, R. W., Patterson, H. T., and Farrell, M. A. Chemical adjuvants affecting penicillin yields on synthetic media. J. Bact. 5 1:37 (1946).

888. Strong, F. M. Isolation of violacein. Science 100:287 (1944).

889. Stuart, L. S., and Harris, T. H. Bactericidal and fungicidal properties of a crystalline protein isolated from unbleached wheat flour. Cereal Chem. 19:288-300 (1942).

890. Suter, C. M. Relationships between the structure and the bactericidal properties of phenols. Chem. Rev. 28:269-300 (1941).

891. Sweetman, H. L. The biological control of insects. Ithaca, N. Y., Comstock Publishing Co., 1936.

892. Synge, R. L. M. Analysis of a partial hydrolysate of gramicidin by partition chromatography with starch. Biochem. J. 38:285-294 (1944); 39: 35 I-355 (1 945).

893. Synge, R. L. M. The hydroxyamino component of gramicidin hydrolysates. Biochem. J. 39:355-362 (1945).

894. Synge, R. L. M. "Gramicidin S"; over-all chemical characteristics and amino-acid composition. Biochem. J. 39:363-367 (I 945).

895. Takahashi, W. N. A virus inactivator from yeast. Science $95: 586-587$ (1942); 104:377 (1946).

896. Taliaferro, L. G., Coulston, F., and Silverman, M. The antimalarial action of tyrothricin against Plasmodium gallinaceum. J. Infect. Dis. 75: 179-2 I I (1944).

897. Tatum, E. L., Peterson, W. H., and Fred, E. B. Effect of associated growth on forms of lactic acid produced by certain bacteria. Biochem. J. 26:846-852 (1932).

898. Tavernari, L. Die Pyocyanase Emmerich's und Loew's bei dem experimentellen Milzbrand. Centralbl. f. Bakteriol., 31:786-793 (I g02).

899. TAYLOR, C. B. The ecology and significance of the different types of coliform bacteria found in water. J. Hyg. 42:23-45 (1942).

900. TAYlor, C. V., and Strickland, A. G. R. Reactions of Colpoda duodenaria to environmental factors; factors influencing the formation of resting cysts. Physiol. Zoöl. 1 2:2 19-230 (1939).

901. Tervet, I. W. Effect of mixed inocula on the production of seedling blight in flax. Phytopath. 28:21 (1938).

902. Thaysen, A. C., and Butlin, K. R. Inhibition of the development of Fusarium oxysporum cubense by a growth substance produced by Meredith's actinomycetes. Nature 1 56:781-782 (1945).

903. Тном, С., and Morrow, M. B. Experiments with mold inoculation in cotton root-rot areas. Proc. Soil Sc. Soc. Amer. 1:223 (1 936). 
904. Thomas, A. R., Jr., and Levine, M. Some effects of penicillin on intestinal bacteria. J. Bact. 49:623-628 (1945).

905. Thompson, R. Lysozyme and its relation to the antibacterial properties of various tissues and secretions. Arch. Path. 30: 1096-11 34 (1940).

905a. Thorneerry, H. H. Nutrient requirements of an antibiotic soil fungus, Streptomyces griseus (Krainsky) Waksman and Henrici. Phytopath. 36: 412 (1946).

906. Timonın, M. I. Another mould with anti-bacterial ability. Science 96: $494(1942)$.

907. Timonin, M. I., and Rouatt, J. W. Bacteriostatic activity of citrinin in vitro. Canad. J. Pub. Health 35:396-406 (1944).

908. Tıмs, E. C. An actinomycete antagonistic to a Pythium root parasite of sugar cane. Phytopath. 22:27 (1932).

909. Tishler, M. Process for isolation of gramicidin. U.S. 2,365,499. Off. Gaz. U.S. Pat. Off. 569:475 (1944).

910. Tishler, M. Extraction of actinomycin A and manufacture of its diacetates. U.S. 2,378,449. Off. Gaz. U.S. Pat. Off. 575:438 (1945).

9i I. Tishler, M., Stokes, J. L., Trenner, N. R., and Conn, J. B. Some properties of gramicidin. J. Biol. Chem. I41:197-206 (194I).

912. Tissier, H., and Martelly. Recherches sur la putréfaction de la viande de boucherie. Ann. Inst. Pasteur, 16:865-903 (1902).

913. Todd, E. W. Bacteriolytic action of penicillin. Lancet $\mathrm{I}: 74-78 ; 2: 172-$ 175 (1945).

914. Todd, E. W., Turner, G. S., and Drew, L. G. W. The temporary character of "fastness" of staphylococci to penicillin. Brit. M. J. No. 4386, pp. I I I-1 I 3, No. 4426, pp. 603-604 (I 945 ).

915. Trawinski, A. Etudes sur la vitalité des bacilles pathogènes du groupe colityphique dans l'eau de mer. Bull. de l'Inst. oceanograph. No. 542, pp. I-3 (I929).

916. Trumper, M., and Hutter, A. M. Prolonging effective penicillin action. Science 100:432-434 (1944).

917. Trussell, P. C., and Sarles, W. B. Effect of antibiotic substances upon Rhizobia. J. Bact. 45:29 (1942).

918. T'UNG, $T$. In vitro action of penicillin alone, and in combination with sulfathiazole, on Brucella organisms. Proc. Soc. Exper. Biol. \& Med. 56: 8-1 I (1944).

919. Tyndall, J. The optical deportment of the atmosphere in relation to the phenomenon of putrefaction and infection. Phil. Trans. Roy. Soc. London, 166:27-74 (1876).

920. TYNeR, L. E. The effect of crop debris on the pathogenicity of cereal rootrotting fungi. Canad. J. Research 1 8:289-306 (1940).

92 r. UNGAR, J. Synergistic effect of para-aminobenzoic acid and sulphapyridine on penicillin. Nature 152:245-246 (1 943).

92 2. UNGAR, J. Penicillinase from B. subtilis. Nature 154:236-237 (1944).

923. URBAin, A., and KowARsKI, T. Sur l'antagonisme entre divers germes et la bactéridie charbonneuse. Compt. rend. Soc. de biol. 115:1085-1087 (1934). 
924. VACEK, B. Examination of some conditions necessary for the survival of the typhoid bacillus in water. Water Pollution Research 6 (8):272-273 (1933).

925. Vallée, M. Bacteriolytic power of Bacillus subtilis. Compt. rend. Soc. de biol. I 39: 1 48-1 49 (1945).

926. Van Bruggen, J. T., and others. Penicillin B; preparation, purification, and mode of action. J. Biol. Chem. 1 48:365-378 (1943).

927. Van Canneyt, J. Action du B. subtilis et de ses sécrétions sur le bacille de la tuberculose. Compt. rend. Soc. de biol. 95:878-881 (1926).

928. VAN DER Poel, J. Overzicht van de thans verkregen resultaten bij het onderzoek naar den invloed van verschillende meststoffen op de slijmziekte. Mededel. Deli-Proefst. 2:99 (1938).

929. VAN DER Reis. Der Antagonismus zwischen Coli- und Diphtheriebacillen und der Versuch einer praktischen Nutzanwandung. Ztschr. f. d. ges. exper. Med. 30: I (1922); abstract in Centralbl. f. Bakteriol., I, Ref., 75:446447 (1922).

930. VAN LUiJK, A. Antagonism between various microorganisms and different species of the genus Pythium, parasitizing upon grasses and lucerne. Mededel. Lab. Willie Com. Schol. Baarn. 14:43-83 (1938).

931. VAN VEEN, A. G., and BAARs, J. K. The constitution of toxoflavin; provisional communication. Rec. trav. chim. 57:248 (1938).

932. Van VeEn, A. G., and Mertens, W. K. On the isolation of a toxic bacterial pigment. K. Akad. Wetensch. Amsterdam 36:666-670 (1933); Rec. trav. chim. 53:257-266, 398-404 (1938).

933. Vasudeva, R. S. Studies in the physiology of parasitism; on the effect of one organism in reducing the parasitic activity of another. Ann. Bot. 44: 557-564 (1930); Indian Jour. Agr. Sc. 6:904-916 (1936); 11:422-431 (1941).

934. Vaudremer, A. Action de l'extrait filtré d'Aspergillus fumigatus sur les bacilles tuberculeux. Compt. rend. Soc. de biol. 74:278-280, 752-754 ( 1913 ).

935. Vellinger, E. Sur les propriétés spectrales de la pyoflavine qui accompagne normalement la pyocyanine dans les cultures du bacille de Gessard. Compt. rend. Soc. de biol. I I 2:306-308 (1933).

935 a. Verner, A. R., and Altergot, V. F. On the phenomenon of mycophagy. Compt. rend. Acad. d. sc. (U.S.S.R.) 15:219-224 (1937).

936. Vignat1, J. Beitrag zur Kenntnis des Typhus-Coli-Antagonismus und seiner Ausnützung zur Anreicherung der Typhusbazillen. Centralbl. f. Bakteriol., 1, Or., 107:54-69 (1928); Compt. rend. Soc. de biol. 94:21 2213 (1926); 96:212 (1926).

937. Vincent, J. G., and Vincent, H.W. Filter paper disc modification of the Oxford cup penicillin determination. Proc. Soc. Exper. Biol. \& Med. $55: 162-164$ (1944).

938. WAGNER, W. Untersuchung der bacteriziden Bestandteile des Bac. pyocyaneus. Ztschr. Hyg. Immunität. 63:483-49I (I929).

939. Wagner-Jauregg, Von Th. Die neueren biochemischen Erkenntnisse und Probleme der Chemotherapie. Naturwiss. 31:335-344 (1943). 
940. Waksman, S. A. Antagonistic relations of microorganisms. Bact. Rev. 5: 231-291 (1941).

94I. Waksman, S. A. Associative and antagonistic effects of microorganisms; historical review of antagonistic relationships. Soil Sc. 43:51-68 (1 937).

942. WAKSMAN, S. A. Humus; origin, chemical composition, and importance in nature. 2 d ed. rev. Baltimore, Williams \& Wilkins, 1938.

943. Waksman, S. A. Microbes in a changing world. Scient. Monthly 51:422427 (1940).

944. Waksman, S. A. Microbial antagonisms and antibiotic substances. Ist ed. New York, Commonwealth Fund, I 945.

945. Waksman, S. A. Principles of soil microbiology. 2d ed. Baltimore, Williams \& Wilkins, 1932.

946. Waksman, S. A. Production and activity of streptothricin. J. Bact. 46: 299-3 IO (1943).

947. WAKsman, S. A. Standardization of streptomycin. Science 102:40-4I (1945).

948. Waksman, S. A., and Bugie, E. Chaetomin, a new antibiotic substance produced by chaetomium cochliodes; formation and properties. J. Bact. 48: 527-536 (1944).

949. Waksman, S. A., and Bugie, E. Action of antibiotic substances upon Ceratostomella ulmi. Proc. Soc. Exper. Biol. \& Med. 54:79-82 (1943).

950. WAKSMAN, S. A., and Bugre, E. Strain specificity and production of antibiotic substances; Aspergillus flavus-oryzae group. Proc. Nat. Acad. Sc. 29: 282-288 (1943).

95 I. Waksman, S. A., Bugie, E., and Reilly, H. C. Bacteriostatic and bactericidal properties of antibiotic substances, with special reference to plant pathogenic bacteria. Bull. Torrey Bot. Club 71:107-221 (1944).

952. WaKsman, S. A., Bugie, E., and Schatz, A. Isolation of antibiotic substances from soil microorganisms, with special reference to streptothricin and streptomycin. Proc. Staff Meet., Mayo Clinic I 9:537-548 (I 944).

953. Waksman, S. A., Cordon, T. C., and Hulpoi, N. Influence of temperature upon the microbiological population and decomposition processes in composts of stable manure. Soil Sc. 47:83-113 (1939).

954. Waksman, S. A., and Foster, J. W. Associative and antagonistic effects of microorganisms; antagonistic effects of microorganisms grown on artificial substrates. Soil Sc. 43:69-76 (1937).

955. Waksman, S. A., and Geiger, W. B. The nature of the antibiotic substances produced by Aspergillus fumigatus. J. Bact. 47:39I-397 (I944).

955a. Waksman, S. A., Geiger, W. B., and Reynolds, D. M. Strain specificity and production of antibiotic substances; production of actinomycin by different actinomycetes. Proc. Nat. Acad. Sc. 32: I 1 7-1 20 (1946).

956. WaKsman, S. A., and Horning, E. S. Distribution of antagonistic fungi in nature and their antibiotic action. Mycologia 35:47-65 (1943).

957. Waksman, S. A., Horning, E. S., and Spencer, E. L. The production of two antibacterial substances, fumigacin and clavacin. Science 96:202-203 (1942); J. Bact. 45:233-248 (1943). 
958. Waksman, S. A., Horning, E. S., Welsch, M., and Woodruff, H. B. The distribution of antagonistic actinomycetes in nature. Soil Sc. 54:28I296 (1 94 I).

959. Waksman, S. A., and Нотснкiss, M. Viability of bacteria in sea water. J. Bact. 33:389-400 (1937).

960. Waksman, S. A., and Hutchings, I. J. Associative and antagonistic effects of microorganisms; associative and antagonistic relationships in the decomposition of plant residues. Soil Sc. 43:77-92 (1 937).

961. Waksman, S. A., and Nissen, W. On the nutrition of the cultivated mushroom, Agaricus campestris, and the chemical changes brought about by this organism in the manure compost. Am. J. Bot. I9:514-537 (1932).

962. Waksman, S. A., and Reilly, H. C. Strain specificity and production of antibiotic substances; Penicillium notatum-chrysogenum group. Proc. Nat. Acad. Sc. 30:99-105 (1944).

963. Waksman, S. A., and Reilly, H. C. Bactericidal action of antibiotic substances. J. Infect. Dis. 75:1 50-I 59 (1944).

964. Waksman, S. A., and Reilly, H. C. The agar streak method for assaying antibiotic substances. Ind. Eng. Chem. (Anal. Ed.) 17:556-558 (1945).

965. Waksman, S. A., Reilly, H. C., and Schatz, A. Strain specificity and production of antibiotic substances; strain resistance of bacteria to antibiotic substances, especially to streptomycin. Proc. Nat. Acad. Sc. 31:157-164 (1945).

966. Waksman, S. A., Robinson, H., Metzger, H. J., and Woodruff, H. B. Toxicity of actinomycin. Proc. Soc. Exper. Biol. \& Med. 47:26I-263 (I94I).

967. Waksman, S. A., and Schatz, A. Soil enrichment and development of antagonistic microorganisms. J. Bact. 51:305-316 (1946).

968. Waksman, S. A., and Schatz, A. Strain specificity and production of antibiotic substances. Proc. Nat. Acad. Sc. 29:74-79 (1 943 ).

969. Waksman, S. A., and Schatz, A. Strain specificity and production of antibiotic substances; strain variation and production of streptothricin by Actinomyces lavendulae. Proc. Nat. Acad. Sc. 31:585-594 (1945).

970. WAKsman, S. A., and Schatz, A. Streptomycin; origin, nature and properties. J. Am. Pharm. A. (Scient. Ed.) 34:273-291 (1945).

97 I. Waksman, S. A., Schatz, A., and Reilly, H. C. Metabolism and the chemical nature of Streptomyces griseus. J. Bact. 5 I:753-759 (1946).

97 I a. Waksman, S. A., Schatz, A., and Reynolds, D. M. Production of antibiotic substances by actinomycetes. Ann. New York Acad. Sc. 48:73-85 (I946).

972. Waksman, S. A., and Starkey, R. L. Partial sterilization of soil, microbiological activities and soil fertility. Soil Sc. I6: 1 37-1 57, 247-268, 343358 (1923).

973. WAKSMAN, S. A., and Tishler, M. The chemical nature of actinomycin, an antimicrobial substance produced by Actinomyces antibioticus. J. Biol. Chem. 142:519-528 (1942). 
974. Waksman, S. A., and Woodruff, H. B. Actinomyces antibioticus, a new soil organism antagonistic to pathogenic and non-pathogenic bacteria. J. Bact. 42:23I-249 (194I).

975. Waksman, S. A., and Woodruff, H. B. Bacteriostatic and bactericidal substances produced by a soil actinomyces. Proc. Soc. Exper. Biol. \& Med. 45 :609-61 4 (1940).

976. WaKsman, S. A., and WoodRUfF, H. B. The occurrence of bacteriostatic and bactericidal substances in the soil. Soil Sc. 53:233-239 (1942).

977. Waksman, S. A., and Woodruff, H. B. Selective bacteriostatic and bactericidal action of various substances of microbial origin. J. Bact. 43:9-10 (1942); 44:373-384 (1942).

978. WaKsman, S. A., and Woodruff, H. B. The soil as a source of microorganisms antagonistic to disease-producing bacteria. J. Bact. 40:581-600 (1940).

979. WaKsman, S. A., and Woodruff, H. B. Streptothricin, a new selective bacteriostatic and bactericidal agent, particularly active against gram-negative bacteria. Proc. Soc. Exper. Biol. \& Med. 49:207-2 10 (1942).

980. Waksman, S. A., and WoodrufF, H. B. Survival of bacteria added to soil and the resultant modification of soil population. Soil Sc. 50:42I-427 ( 1940 ).

98I. WaLKER, E. L. Some new aspects of the etiology and endemiology of leprosy. J. Prev. Med. 3:167-195 (1929).

982. Ward, H. M. Symbiosis. Ann. Bot. 13:549-562 (1899).

983. WATHELET, M. Recherches bactériologiques sur les déjections dans la fièvre typhoide. Ann. Inst. Pasteur 9:252-257 (1895).

983a. Wehmer, C. Die Pilzgattung Aspergillus. Mem. Soc. Phys. d'Histoire Nat. de Genère. Vol. 33, pt. 2, no. 4 (I90I).

984. Weiland, P. Bakterizide Wirkung von Mesentericusfiltraten auf Diphtheriebazillen. Zentralbl. f. Bakteriol., I, Or., I 36:45 I-456 (I936); I 47: 32 I-334 (I 94 I).

985. Weinberc, M., and Otelesco, I. B. proteus des plaies de guerre. Compt. rend. Soc. de biol. 84:535-536 (1921).

986. Weindilng, R. Association effects of fungi. Bot. Rev. 4:475-496 (1938).

987. Weindling, R. Experimental consideration of the mold toxins of Gliocladium and Trichoderma. Phytopath. 31:991-1003 (194I).

988. WeindLing, $R$. Isolation of toxic substances from the culture filtrates of Trichoderma and Gliocladium. Phytopath. 27:1175-1177 (1937).

989. Weindling, R. Studies on a lethal principle effective in the parasitic action of Trichoderma lignorum on Rhizoctonia solani and other soil fungi. Phytopath. 24:1153-1 179 (1934).

990. Weindling, R. Trichoderma lignorum as a parasite of other soil fungi. Phytopath. 22:837-845 (1932).

991. Weindling, R., and Emerson, O. H. The isolation of a toxic substance from the culture filtrate of Trichoderma. Phytopath. 26:1068-1070 (1936). 
992. Weindling, R., and Fawcett, H. S. Experiments in the control of Rhizoctonia damping-off of citrus seedlings. Hilgardia 10:1-16 (1936).

993. WeINMAN, D. Effects of gramicidin and tyrocidine on pathogenic protozoa and a spirochete. Proc. Soc. Exper. Biol. \& Med. 54:38-40 (1 943).

994. WELCH, A. D. Interference with biological processes through the use of analogs of essential metabolites. Physiol. Rev. 25:687-7 I 5 (1945).

995. Welch, H., Grove, D. C., Davis, R. P., and Hunter, A. C. The relative toxicity of six salts of penicillin. Proc. Soc. Exper. Biol. \& Med. $55: 246-248$ (1944).

996. Welch, H., Price, C. W., Chandler, V. L., and Hunter, A. C. The thermostability of pyrogens and their removal from penicillin. J. Am. Pharm. A. (Scient. Ed.) 34: I I3-I I 8 (1945).

997. Welch, H., Price, C. W., Nielsen, J. K., and Hunter, A. C. The acute toxicity of commercial penicillin. J. Lab. \& Clin. Med. 29:809-8 I 4 (1944).

998. Welch, H., Putnam, L. E., Randall, W. A., and Herwick, R. P. Penicillin $\mathrm{X}$; successful treatment of gonorrhea with a single intramuscular injection. J.A.M.A. 1 26:1024 (1944).

999. WeLD, J. T. The antibiotic action of Tillandsia usneoides (Spanish moss). Proc. Soc. Exper. Biol. \& Med. 59:40-4I (1945).

I000. WELSCH, M. Bactericidal substances from sterile culture-media and bacterial cultures, with special reference to bacteriolytic properties of actinomycetes. J. Bact. 42:801-814 (1941).

100I. Wersch, M. Bacteriolytic properties of actinomyces. Proc. Third Internat. Cong. for Microbiol. (I939), pp. 260-261; J. Bact. 43:10 (1942); 44:571-588 (1942).

1002. WeLsCh, M. La dissolution des germes vivants par les Streptothrix. Compt. rend. Soc. de biol. I 24:573-577 (1937).

I0O2a. Welsch, M. Production d'actinomycine ou d'une substance voisine par un Streptomyces distinct de S. antibioticus Waksman et Woodruff. Bull. Soc. chim. biol. 28:557-566 (I 946).

I003. WELSH, M. F. Studies of crown rot of apple trees. Canad. J. Research 20:457-490 (1942).

1004. White, A. G. C., Krampitz, L. O., and Werkman, C. H. On a synthetic medium for the production of penicillin. Arch. Biochem. 8:303310 (1 945).

1005. White, E. C. Antibacterial filtrates from cultures of Aspergillus flavipes. Proc. Soc. Exper. Biol. \& Med. 54:258-259 (1943).

I006. White, E. C., and HiLl, J. J. Studies on antibacterial products formed by molds; aspergillic acid, a product of a strain of Aspergillus flavus. J. Bact. 45:433-442 (I 943 ).

1007. WhiteheAd, H. R. A substance inhibiting bacterial growth, produced by certain strains of lactic streptococci. Biochem. J. 27:1 793-1800 (1933).

1008. Wibaut, N. L., and Moens, I. Het verdwijnen van typhus-bacillen met water. K. Akad. Wetensch. Amsterdam, Natuurk. 36:1 29-1 39 (1927). 
1009. Wiedling, S. Antibacterial effects of iodinin, 2-methyl-quinoxaline di$\mathrm{N}$-oxide and 2,6-Dimethoxybenzo-quinone in vitro. Acta path. et microbial Scandinav. 22:379-391 (1945).

I0IO. Wiedling, S. The production of antibiotics by Penicillium species. Bot. Notiser 433-443 (1 944); Nature I 56:204 (1 945).

IOI I. Wieringa, K. T., and Wiebols, G. L. W. De aardappelschurft en de heterolyse der schurftparasiet. Tijdschr. Plantenziekten 42:235-240 (1936).

IOI 2. Wiesner, B. P. Bactericidal effect of Aspergillus clavatus. Nature 149: 356-357 (1942).

IOI 3. WIKULLIL, L. voN. Wachstumsverhältnisse in Bakterienmischpopulationen. Zentralbl. f. Bakteriol., I, Or., I26:488-508 (I932).

IOI 4. WILKIns, W. H. Investigation into the production of bacteriostatic substances by fungi. Brit. Mycol. Soc. Trans. 28: I I0-I I4 (I945).

I OI 5. WILKINS, W. H., and Harris, G. C. M. Estimation of the antibacterial activity of fungi that are difficult to grow on liquid media. Nature I 53: 590-591 (1944).

IoI6. WILKINs, W. H., and Harris, G. C. M. A modification of the method for estimating the antibacterial activity of fungi that are difficult to grow on liquid media. Nature 154:578-579 (1944).

IOI 7. Wilkins, W. H., and Harris, G. C. M. Investigation into the production of bacteriostatic substances by fungi; preliminary examination of 100 fungal species. Brit. J. Exper. Path. 23:166-169 (1942); 24:141-1 43 (1943) ; 25:135-137 (1944); Ann. App. Biol. 30:226-229 (1943).

IOI 8. WILK1Ns, W. H., and HARRIS, G.C.M. Investigation into the production of bacteriostatic substances by fungi; preliminary examination of the third 100 fungi with special reference to strain variation among species of Aspergillus. Brit. Mycol. Soc. Trans. 27: I I 3-I I 8 (I 945).

IoI9. Wilkins, W. H., and Harris, G. C. M. Investigation into the production of bacteriostatic substances by fungi; examination of the larger $\mathrm{Ba}$ sidiomycetes. Ann. App. Biol. 31:26 I-270 (1 944).

1020. Williams, R. S., and Hoy, W. A. The viability of B. tuberculosis (bovinus) on pasture land, in stored faeces and in liquid manure. J. Hyg. 30: 413-4I 9 (1930).

iO2 I. Wilson, S. D., Winfield, G. F., Chen, S. C., and Chao, T. Y. Control of fecal-borne diseases in North China; chemical nature of Shantung farm manure. Soil Sc. 49:379-392 (1940).

1022. WILson, U. A new rapid method for penicillin assay. Nature 152:475476 (1943).

1023. WiNF1ELD, G. F. Studies on the control of fecal-borne diseases in North China. Chinese Med. J. 51:217-236, 502-518, 643-658, 919-926 (1937) ; Supplement, pp. 463-486 (1938); 54:233-254 (1938); 56: 265-286 (1939).

1024. Winter, G. Untersuchungen über den Einfluss biotischer Faktoren auf die Infektion des Weizens durch Ophiobolus graminis. Ztschr. Pflanzenk. I : I I 3-I 34 ( I 940). 
1025. Wolf, J. E. Beiträge zur Biologie des Pfeifferschen Influenzabazillus. Mischkulturen-Mischinfektion. Centralbl. f. Bakteriol., I, Or., 84:24I255 (1920).

1026. Wood, F. C. Studies on "damping-off" of cultivated mushrooms and its association with Fusarium species. Phytopath. 27:85-94 (1937); 29:728739 ( I 939).

1026a. Woodhead, M. M., and Wood, C. De l'action antidotique exercée par les liquides pyocyaniques sur le cours de la maladie charbonneuse. Compt. rend. Acad. d. sc. I09:985-988 (1889).

1027. Woodruff, H. B., and Foster, J. W. Bacterial penicillinase. J. Bact. 47:I 9 (I944); 49:7-I 7 (I945).

1028. Woodruff, H. B., and Foster, J. W. Cultivation of actinomycetes under submerged conditions, with special reference to the formation of streptothricin. J. Bact. 45:30 (1943).

1029. Woodruff, H. B., and Foster, J. W. In vitro inhibition of mycobacteria by streptothricin. Proc. Soc. Exper. Biol. \& Med. 57:88-89 (I 944).

1030. Woodruff, H. B., and Foster, J. W. Antibacillin, a naturally occurring inhibitor of bacillin. J. Bact. $51: 37$ I-380 (I946).

103I. Woodruff, H. B., and Foster, J. W. Microbiological aspects of streptothricin; metabolism and streptothricin formation in stationary and submerged cultures of Actinomyces lavendulae. Arch. Biochem. 2:301-315 (1943).

1032. Woods, D. D. The relation of p-aminobenzoic acid to the mechanism of the action of sulphanilamide. Brit. J. Exper. Path. 21:74-90 (1940); Chem. \& Ind. 59: 133-I 34 (1940).

1033. Woolley, D. W., and Krampitz, L. O. Reversal by phosphatides of the antimicrobial action of a crystalline protein from wheat. J. Biol. Chem. I 46:273-274 (1942).

1034. Worpenberg, H. Sind die Grundlagen fuer eine Unterscheidung von stark und schwach antagonistischen Colibacillen experimentell begruendet? Tierarzt. Rund. 30:601-603 (1 924 ).

1035. WREDE, F., and RothhaAs, A. Über das Prodigiosin, den roten Farbstoff des Bacillus prodigiosus. VI. Ztschr. f. physiol. Chem. 226:95-107 (I 945 ).

1036. Wrede, F., and Strack, E. Über das Pyocyanin, den blauen Farbstoff des Bacillus pyocyaneus. Ztschr. f. physiol. Chem. 140:I-I5 (1924); I8I: 58-76 (1929).

1037. Wyss, O., Ludwig, J., and Jorner, R. R. The fungistatic and fungicidal action of fatty acids and related compounds. Arch. Biochem. 7:41 5-425 (1945).

I038. Yermolieva, Z., Kaplun, T., and Levitov, M. Penicillin crustosin. Am. Rev. Soviet Med. 2:247-250 (1945).

1039. Youmans, G.P. The effect of streptomycin in vitro on M. tuberculosis var. Hominis. Quart. Bull., Northwest. Univ. M. School 19:207 (1945).

1040. Youmans, G.P., and McCarter, J. C. Streptomycin in experimental tuberculosis. Am. Rev. Tuberc. 52:432-439 (I 945). 
1041. Youmans, G. P., Williston, E. H., Feldman, W. H., and Hinshaw, H. C. Increase in resistance of tubercle bacilli to streptomycin; a preliminary report. Proc. Staff Meet., Mayo Clinic 21:126-127 (1946).

1042. Youmans, G. P., Williston, E. H., and Simon, M. Production of small colony variants of Staphylococcus aureus by action of penicillin. Proc. Soc. Exper. Biol. \& Med. 58:56-57 (1945).

1043. Zageri, G. Esperienze sulla concorrenza vitale dei microorganismi e sopra un nuovo mezzo di profilassi carbonchiosa. Gior. Intern. Scienz. Med. Napoli 9:61 7-623 (1887).

1044. ZAHL, P.A., and HutNer, S. H. The occurrence among bacteria of agents inducing hemorrhage in transplanted tumors. J. Bact. 45:8 I (1943).

1045. Zamenhof, S. A specific lytic substance in Escherichia coli. J. Bact. 49: 413 (1945).

1046. Zeller, S. M., and Schmitz, H. Studies on the physiology of fungi; mixed cultures. Ann. Missouri Bot. Garden 6:183-192 (1919).

1047. Ziegler, J. E., Jr., and Horsfall, F. L., JR. Interference between the influenza viruses; the effect of active virus upon the multiplication of influenza viruses in the chick embryo. J. Exper. Med. 79:361-377 (1944).

1048. Ziegler, J. E., JR., Lavin, G. 1., and Horsfall, F. L., JR. Interference between the influenza viruses; the effect of virus rendered non-infective by ultraviolet radiation upon the multiplication of influenza viruses in the chick embryo. J. Exper. Med. 79:379-400 (1944).

1049. Zintel, H. A., Flippin, H.F., Nichols, A. C., Wiley, M. M., and RHoAds, J. E. Studies on streptomycin in man; absorption, distribution, excretion and toxicity. A. J. M. Sc. $210: 42$ 1-430 (1945).

1050. ZoBeli, C. E. Bactericidal action of sea water. Proc. Soc. Exper. Biol. \& Med. 34:113-116 (1936).

1051. Zorzoli, G. Influenza dei filtrati di alcuni miceti sul Bacillo tubercolare umano e bovino. Ann. Inst. Carlo Forlanini 4: 208-220, 22 I-237 (1940).

1052. Zukerman, I., and Minkewitsch, I. Zur Frage des bakteriellen Antagonismus. Wratschebnoje Delo, No. 7 (1925); abstract in Centralbl. f. Bakteriol., 1, Ref., 80:483-484 (1925).

1053. ZweIG, J. Ps. pyocyanea; study in vitro and in vivo of the bactericidal and therapeutic properties of $\alpha$-oxyphenazine and a lipoidal product. Vet. J. 102:55-70 (1946). 



\section{INDEX OF MICROORGANISMS}

Absidia glauca, 302

Ab. spinosa, 306

Achromobacter, 151, 313

A. lipolyticum, 105

A. stutzeri, 120

Acrostalagmus, 59, 148

Actinomyces, 108, 220

See also Streptomyces

A. albus, I I 3, 269

A. boois, 76, 124, 127, 236, 269

Actinomycetaceae, 108

Actinomycetales, 108

Actinomycetes. See General Index

Aerobacter, 236

$A$. aerogenes, 10, I 2, 21, 32, 86, 96, 99, 100, 102, I20, 123,124 , I64, 220, 244, 294

Agrostis, 303 (Fig. 31)

Algae, 6, 9

Alkaligenes fecalis, 106, 151

Allium sativum, 21 7, 225, 330

Alternaria, 59, 148

A. tenuis, 148

Amebae, 9, 23

Anemone pulsatilla, 330

Anthrax organism. See General Index Arctium minus, 225

Argas, 16 I

Armillaria, 148

Asarum canadense, 225

Ascaris, 26

Ascomycetes, 1 31, 132, 147

Aspergilli, 42, I 3 I, I32, I 42, I 46, I 47 Aspergillus, 9, 47, 131, 140, 146, 147, I $48,153,2$ I I

A. albus, 133

A. candidus, 140, 171, 329

A. clavatus, 57, 74, 130 (Fig. I2), I $31,132,133,143,144,148$, I 71, 329

A. effusus, 173, 213

A. flaripes, 140
Aspergillus (cont.)

A. flavus, 56, 57, 70, 133, 1 40, I41, $148,170,172,207,208,329$

A. flavus-oryzae, 1 31 , 1 40, 329

A. fumigatus, 56, 57, 70, 130 (Fig. 12) $131,133,142,143,145$, 170, 171, I72, 173, 175, 210, 2 II, 244, 297, 3I 4

A. nidulans, 140, 302

A. niger, 49, 100, I31, I33, 140, I46, I48, 150, 164, I7 I, 176, 214,329

A. oryzae, 140, 173, 213, 214, 329

A. parasiticus, I 40, 1 72, 329

A. schiemannii, I $3 \mathrm{I}$

A. spinulosum, 329

A. terreus, I 3 I, 144

A. ustis, I 43, 175, 329

Asymmetrica, 132

Azotobacter, 15, 42, II 5, 31 I

Az. agile, 123

Az. chroococcum, I 5, I I 2, I 23

$A z$. indicum, 123

$A z$. vinelandii, 11 2, 120, 123, 251 (Fig. 27)

Bacillus " $D$," I 5 I

Bacillus, 21,86

$B$. anthracis, $36,50,76,85,86,88$, $93,96,97,100,102,103,105$, I24, I26, I 30, I51, 179, 181, $200,246,250,261,262,269$, 287

B. brevis, 48, 56, 57, 70, 71, 87, 88, $92,170,173,175,185,219$, 320,329

$B$. hirudenses, 95

B. lentimorbus, 95, 160

$B$. licheniformis, 94

B. macerans, 120,123

B. megatherium, $86,100,112,120$, I 23, I 24, I 28, 220

B. mesentericus, $21,48,51,87,88$, 
Bacillus (cont.)

$89,90,91,94,112,120,151$, $152,158,180,181,216,251$, $286,314,320$

B. mesentericus-øulgatus, 88,90

B. mucosus-capsulatus, 85

B. mycoides, 5 1, 58, 59 (Fig. 4), 72, $87,88,89,90,100$, I I I, I I 2, I $14,116,120,123,124,144$, $151,152,175,200,220,223$, $251,252,257,260,320$

B. mycoides-cytoliticus, 88, 90

$B$. petasites, 21

B. polymyxa, 120,123

B. popillae, 95, 160

$B$. prodigiosus, 158

B. putrificus verrucosus, 106

$B$. pyocyaneus. See Ps, aeruginosa

B. ramosus, 302 (Fig. 30)

B. simplex, 57, 94, I 5 I, 1 52, I75, I $88,307,314,320,329$

B. subtilis, $21,51,57,58,59,72$, $74,75,77,78,83,86,87,88$, $89,90,92,93,94$, I о0, I 12 , I 20, I 2 I, I 23, I 24, I 42, I 44, $151,158,163,169,171,172$, I 75, 176, I 88, 192, 204, 207, $209,215,216,217,220,223$, $234,236,239,243,250,251$ (Fig. 27), 255, 260, 269, 320, 329

B. suipestifer, 88

$B$. thermophilus, 88

$B$. tumescens, I I 2

B. vulgatus, 100

Bacteria, 36

Bacterium, 5, 15 I, 160, 302 (Fig. 30)

$B$. acidi lactici, 105

$B$. aroideae, $15 \mathrm{I}$

B. cazaubon, 160

B. cocovenenans, 188,329

$B$. ephestiae, 160

B. gelechiae, 160

$B$. lactis aerogenes, 105

$B$. pyocyane1um. See $P$ s. aeruginosa

B. solanacearum, 128
Bacterium (cont.)

B. termo, 263

$B$. tyrogenes, 95

$B$. violaceum, 49

Bacteroides, 2 I

Basidiomycetes, I 3 I, I 32, I 46, 147

Basisporium, I $5 \mathbf{I}$

B. gallarum, 150

\section{Beauveria, I 5 I}

Blastomycoides dermatitidis, I 50, I 83

Boophilus bovis, 17

Borrelia gallinarum, 158

Bor. novyi, 269, 288, 3 I 7

Bor. recurrentis, 269

Botrytis, I 48

B. allii, 148

B. cinerea, 148

Botulinus organism, 27

Brucella, 106, 235, 268

Br. abortus, 58, 76, 106, I 20, 123 , I 24, 146, 220, 25 I, 255, 287, 288, 317

Br. melitensis, 34, 76, 97, 104, 106, $25 \mathrm{I}$

Br. suis, 106, I 24

Cephalosporium, 9, I 3 I

Cephalothecium roseum, I 48, I 5 I

Ceratostomella, I 53

C. ulmi, 83, 242, 303

Chaetomium, 131, 133, 213

Ch. cochliodes, I 71, 213,329

Chlorella, I 7 I, 330

Chromobacterium, I 81

Ch. iodinum, 173, 182, 320, 329

Ch. violaceum, 86, 100, 175, 182, 329

Citromyces, 147

Cladosporium, 9

Clitocybe candida, 146

C. gigantea, $146,172,330$

Clostridium acetobutylicum, 42

Cl. bifermentans, 269

Cl. botulinum, 106, 266, 269

Cl. butyricum, 106, 1 23, 124, 257

Cl. chaneoei, 27, 96, 99, 269 
Clostridium (cont.)

Cl. fallax, $2 \mathrm{I}$

Cl. granulobacter-pectinovorum, 42

Cl. histolyticum, 269

Cl. nosyi, 269

Cl. oedematiens, 76, 106, 273

Cl. oedematis, $21,106,269$

Cl. perfringens, 106, 273

Cl. sepicum, $21,76,134,269,273$, 274

Cl. sordelli, 269

Cl. sporogenes, 97, 106, 266, 269

Cl. tetani, 27, 76, 1 24, 269

Cl. tetanomorphum, 269

Cl. welchii, 21, 76, 106, 120, 162, I 82, 220, 25 I, 269, 273, 276

Colletotrichum, 148

C. gloeosporioides, I I 8

Colpidium, 22

Colpoda, 158

Coniophora cerebella, 149

Corticium rolfsii, 309

C. sadakii, 309

Cortinarius, 146

Corynebacteria, 104

Corynebacterium, I I 2

C. diphtheriae, 76, 88, 90, 91, 93, $96,97,98,102,124,179,227$, $246,261,264,268,269,280$, 286

Crepis taraxacifolia, 217,330

Cryptochilum nigricans, 22

Cryprococcus neoformans, 74

Cunninghamella, 43, 44

C. elegans, 148

Dematiaceae, 149

Dematium, 148

Deuterophoma, 148

Dictyostileum discoideum, I 57

D. mucoroides, 49

Diplococci, 95, 97, 104

Diplococcus pneumoniae, 124, 126 , $237,269,272,288,317$ Diplococcus pneumoniae I, 28 I D. pneumoniae III, 233
Dothiorella, I 5 I

Dysentery bacteria, 28

Eberthella, 86, 294

E. rhusiopathiae, 269

E. typhi, 100, I 23

E. typhosa, 30, 31, 32, 49, 59, 70, $85,86,88,89,95,96,97$, I о I, $104,105,113,146,174,213$, $220,233,236,246,264,265$

Entamoeba histolytica, 234

Erwinia carotovora, I 20

Erysipelothrix, 288

Er. muriseptica, 124

Er. rhusipathiae, 236

Escherichia coli, 10, 21, 29, 30, 31, $32,43,45,49,57,58,59,72$, $74,76,85,86,87,89,91,93$, $94,95,96,98,99$, 100, 101, 102, 103, 105, 106, I I 2, I 13 , I I 4, I I 7, I 20, I 2 I, I 23, I 24, I 26, I $31,133,142,144,146$, $158,165,172,181,192,194$, $201,207,208,210,220,223$, $227,233,234,235,236,240$, $244,246,247,248,253,254$, $255,256,265,279,286,29 \mathrm{I}$, $294,295,297,329,332$

Flavobacterium, 2 1, 31

Fluorescent bacteria, 95

Friedländer's bacillus, 92

Fusarium, 9, 38, 59, 62, 74, I I 1 , 1 1 8, I 3 I, I 45, I 48, I 50, I 5 I, I 52, 157, 305, 309, 310, 32 I

F. conglutinans, 152

F. culmorum, 301, 305, 309

F. graminearum, 302, 3 II

$F$. javanicum, I 4I, I 73, 329

F. lateritium, 148

F. lini, 305, 3 I I

F. malli, $30 \mathrm{I}$

F. moniliforme, I 50

$F$. oxysporum cubense, I I 8 , I 45

F. sambucinum, 150 (Fig. 17)

$F$. vasinfectum, 149 
Gaffkya tetragena, 120

Gambusia, 96

Gas-gangrene organisms, 27

Gibberella, 309

Gleosporium, 59

Gliocladium, 57, 131, 133, 144, 148, I 50, 1 73, 2 I1, 329

Gonococcus, 133, 267

Gymnoascus, 144

Hartmanella castellanii, 157

Helminthosporium, 62, 148 , I 51 , I 52 , 302 (Fig. 30), 305, 309

H. sativum, 95, 148, I 49, I 5 I, I 52 , $302,305,309,310,311$

$H$. teres, 148

Hemophilus, 220, 235

H. ducreyi, 235, 269

$H$. influenzae, $123,124,200,291$, 295

$H$. pertussis, I 20, 124

H. suis, 123

Heterodera marioni, 162

Hyphomycetes, 149

Hypochnus centrifugus, 303

H. sasakii, 303

Klebsiella, 288, 3 I 8

$K$. pneumoniae, 75, 76, 80, 97, 100, I $05,124,244,317$

Lactobacillus, 189

L. acidophilus, 103,107, 265

L. arabinosus, $\mathbf{I} 86$

L. bulgaricus, 50, 97, 103, 105,107

L. casei, I $23,24 \mathrm{I}$

Leishmania, 158

Leptospira, I 58,2 I 3

L. icterohaemorrhagiae, 76, 269, 288, 29I, 3 I 8

Listerella monocytogenes, I 24

Lonicera tartarjia, 217

Lucilia sericata, 162

Macrophomina phaseoli, 150
Malleomyces mallei, 124

Melanospora pampeana, 149

Meningococci, 98, 230

Meningococcus, 267

Metarrhizium glutinosum, 173, 2 I4, 329

Micrococci, 95, 97, I 15

Micrococcus, 31

$M$. antibioticus, 104

$M$. candicans, 2 I, 112

M. catarrhalis, 267

$M$. conglomeratus, 233

M. flavus, 100, 267

$M$. luteus, 21 , 112

M. lysodeikticus, 59, 72, 112,123 , 223,269

$M$. roseus, I 12

$M$. tetragenus, 104

Micromonospora, 57, 108, I10, III, I $7,173,329$

M.vulgaris, 108 (Fig. 10)

Monascus, 148

Monilia albicans, 146 .

M. fructigena, 309

Mucor, 9, 148

Mucorales, 147

Mycobacteriaceae, 108

Mycobacterium, 108

$M$. avium, 124

$M$. citreum, I I 2

M. phlei, 72, 94, I 1 2, 123, 124

$M$. ranae, 143

M. rubrum, II 2

$M$. smegmae, I I 2

M. tuberculosis, $21,33,76,88,90$, $93,94,95,96,97,98,102,104$, 1 05, I 06, I 1 2, I 1 3, 1 20, I 24, $130,133,141,143,146,174$, $175,176,208,234,244,245$, $267,287,288,289,290,295$, $297,317,329,332$

Mycococcus ruber, I I 2

Mycogone, I 50

Myxobacteria, 97

Myxobacteriales, 105

Myxobacterium, 59, I 5 I 
Neisseria, 86, I $33,220,235$

$N$. catarrhalis, 100, I 20, 232, 235, 269

N. flava, 235

N. gonorrhoeae, 76, I 24, 235, 260, 269, 276

$N$. intracellularis, 235,269

N. meningitidis, 76, 126,200

Neoaplectana glaseri, 160

Nocardia, I08, I I O, I I 4, I I 5, I I 7, 245

N. alba, I 12

$N$. asteroides, 124

$N$. corallina, I 12

N. cyanea, 1 26, 173,329

N. gardneri, 57, I I I, I I 9, I 25, I 74, 200, 239

N. rubra, 112

\section{Oidium, 2 I}

Oikomonas, I 57

O. termo, I 56

Ophiobolus, 39, I 48, I 5 I

O. graminis, I 49, 302, 307

O. miyabeanus, 150

\section{Paramecium, 157}

Paratyphoid bacteria, 91, 96

Pasteurella, 220, 233

P. avicida, 97

$P$. pestis, 76, 91, 96, 97, 98, 103, I05, I 24, I 6I

$P$. tularensis, I 24, 288, 289, 295

Pectinophora gossypiella, 160

Penicillia, I 3 I, I 32 , I 46, 147

Penicillium, 9, 36, 62, I 30, I 3 I, I 33 , I 40, I 44, I 47, I 48, I 49, I 5 I,

I $53,157,174,2$ I 3,302

$P$. africanum, 49

P. brevi-compactum, 1 73, 2 I 3

P. brunneoviolaceum, I 3 I

$P$. chloro-leucon, I 3 I

P. chrysogenum, I 30 (Fig. I 2), I 3 I, 136, 137 (Fig. 1 4), I 38, I 39, I 73, I 74, 200, 205, 323, 329

$P$. cinnabarinus, 147
Penicillium (cont.)

$P$. citreo-roseum, 140

P. citrinum, 130 (Fig. I2), 131, 133, I 71, 208, 329

P. claviforme, I3 I, 133, 144, I7I, 329

P. corylophylum, 329

P. crustosum, 140

P. cyclopium, I 31, I 33, 174, 209, 329

P. cyclopium-claviforme, I $3 \mathbf{I}$

$P$. expansum, 131, I44, I7I, 303

(Fig. 33), 329

P. funiculosum, I 3 I

$P$. gladioli, 1 49, 1 72, 329

$P$. griseo-roseum, I 3 I

P. luteum, 49, I 47

$P$. luteum-purpurogenum, I 31 , 148

$P$. notatum, 54, 56, 57, 70, I30 (Fig. 12), I31, 132, 133, I34, I $35,136,139,146,169,170$, $173,174,200,201,205,207$, 223, 225, 275, 314, 323, 329

P. notatum-chrysogenum, I 3 I, I32, I 33, I 34, 136, I 38,3 1 8

$P$. obscurum, I 45,2 I I

P. patulum, I 44, I 7 1, 329

P. puberulum, 133, 174, 209, 2 I 2 , 329

$P$. resticulosum, I 33

$P$. sanguineus, 174

P. spinulosum, 175

P. urticae, 144

Pestalozzia, 62

Peziza, I47, 148

P. sclerotiorum, 148

$P$. trifoliorum, 148

Pfeifferella mallei, 95

Phoma terrestris, $30 \mathrm{I}$

Phycomyces, I 59

Phycomycetes, I 3 I, I 32, I 47

Phymatotrichum, 305

Ph. omnivorum, 305, 308

Phytomonas, 86

Ph. bowlesii, 100

Ph. pruni, I 24 


\section{Phytomonas (cont.)}

Ph. tumefaciens, 97, 103, 104, 303

Phytophthora, I 51 , I 52

Ph. cactorum, 303

Ph. erythroseptica, 132

Pinus silvestris, 330

Plasmodiophora brassicae, $30 \mathrm{I}$

Plasinodium, I 58

Pl. gallinaceum, 284

Pneumococci, 92, 97, I 04, I I I, I I 4,

$$
230,244,254,258
$$

Pneumococcus, 76, 91, 238

Pneumococcus, Type I, 236

Pneumococcus, Type II, 236

Pneumococcus, Type III, 296

Polystictus sanguineus, I 46, 213,330

Polytoma uvella, 22

Proteus vulgaris, 21, 76, 86, 89, 91, 97,98, I 05, I06, I I 2, I 24, I 5 I, I $52,227,235,236,278,286$, 294, 317

Psalliota, I 46

Ps. compestris, 150

Pseudoeurotium zonatum, I50 (Fig. 17)

Pseudomonas, 21, 31, 85, 3 I 3

Ps. aeruginosa, 31, 42-43, 48, 50, $51,56,57,70,76,86,91,95$, 96, 97, 98, 1 00, 105 , I 1 0, I I I , I I $2,113,120,124$, I 3 I, I 46 , I $51,157,158,174,175,178$, I 79, I $81,183,219,261,262$, $264,278,286,287,294,317$, $320,322,329$

Ps. aviseptica, 105

Ps. citri, I 57, 305

Ps. destructans, 304

Ps. fluorescens, 9, 13,2 I, 43, 44, $51,85,86,96,97,100,103,112$, I 2O, I 23, I 24, I $28,152,153$, 220

Ps. hyacinthi, 157

Ps. juglandis, $15 \mathrm{I}$

Ps. phaseoli, I 5 I

Ps. putida, 2 1, 85

Ps. pyocyaneus. See $P$ s. aeruginosa
Pseudomonas (cont.)

Ps. translucens, I 5 I

Pullularia pullulans, 310

Pyronema, 16

$P$. confluens, 153

Pythium, I I I, 148, I 49, 242, 303, 309

P. de Baryanum, 303 (Fig. 32)

$P$. volutum, 303 (Fig. $3 \mathrm{I}$ )

Radiobacter, I I 2

Ranunculus, 2 I 7

Rhizobium, 45, II5

$R h$. leguminosarum, 112

Rhizoctonia, 38, I 48, 15 1, I 52, 212 , $253,307,309,311,312$

$R$. solani, 94, 150, 306, 307, 312

Rhizopus, 9, 43, 47, 153

Rhodococcus, 86

$R$. cinnebareus, 100

$R$. roseus, 100

Rickettsia prowazekii, 269

Saccharomyces, 15 I

Sac. cereviseae, 97, 15 I

Sac. ellipsoideus, 100

Sac. marianus, 100

Sac. pastorianus, 100

Salmonella, 86, 235, 268, 287, 295

S. abortivoequina, 123

S. aertrycke, 220

S. cholerasuis, 123

S. enteritidis, $2 \mathrm{I}, 100, \mathrm{I} 24$

S. gärtneri, 76

S. paratyphi, 76, 126, 233

S. pullorum, 100

S. schottmülleri, 1 23, I 24, 220, 288, 317

S. suipestifer, 100

S. typhi, 75, 76, 126

S. typhimurium, I 26

Sarcina, 2 1, 3 I, 86

S. flava, 2 I

S.lutea, 49, 57, 58, 59 (Fig. 4), 72, 88 , I 00 , I IO, I I 2, I 20, I 23, I 24, I 52, 220, 223 
Sarcina (cont.)

S. ureae, 152

Sclerotinia, 59, I 5 I

S. americana, 150

S. libertiana, 309

Sclerotium, 309

S. oryzae sativae, 303

S. rolfsii, 148, 302 (Fig. 29)

Serratia, 34, 99

S. marcescens, $51,85,86,87,96$, 97, 99, 100, I10, 112, 120, 123, I 24, I 5 I, I $52,157,174,181$, 220,329

Shiga bacillus, 87 , 101

Shigella, 91, 126, 236

Sh. dysenteriae, 76, 93, 100

Sh. gallinarum, 120, 123, 220, 288, 3 I 7

Sh. paradysenteriae, 124, 261-262

Spicaria purpurogenes, 49

Spirillum, 158

Sp. minus, 269

Sporotrichum, 16

Staphylococci, 45, 92, 95, 96, 97, 102, I 04, I I 1, I I 2, $120,172,225$, 230, 232, 258, 260, 268, 270, 278

Staphylococcus, 209, 249, 250, 270

S. albus, 21, 91, 1 79, 238, 269, 270, 286

S. aureus, 58, 59, 63, 72, 73, 75, 76, $77,80,81,83,84,85,91,94$, 98, 100, 102, 106, I I 0, I 1 2, I $17,124,126,131,134,142$, $146,147,162,165,166,172$, $179,182,201,204,207,208$, $209,213,217,220,232,233$, $235,236,237,240,243,244$, $250,252,253,254,258,259$, $263,268,269,272,274,275$, $277,280,281,286,287,291$, 317,332

S. citreus, 91, 100

S. muscae, 123

S. viridis, 9 I

Sierigmatocystis, $\mathbf{1} 48$
Stontoxys, 161

Streptococci, 76, 97, 103, 104, I I I, 230, 231, 260, 268, 269, 270, 278,329

Streptococcus Group A, 236

Streptococcus Group B, 236

Streptococcus Group C, 236

S. agalactiae, 285

S. bovis, 269

S. cremoris, 103,172

S. dysgalactiae, 285

S. enteritidis, 244

S. faecalis, 235, 237, 269, 278, 295

S. hemolyticus, 75, 91, 98, 1 24, 182, 208, 221, 223, 227, 235, 238, $240,254,255,268,269,280$, 281

S. lactis, $97,103,269$

S. mastidis, 103

S. mucosus, 91, 103

S. nonhemolyticus, 269

S. pyogenes, $21,76,82,103,110$, I 26, I 34, 147, 237, 244, 253 , $263,269,270,274,282$

S. salivarius, 237,269

S. septicemiae, 21

S. thermophilus, 106

S. uberis, 285

S. viridans, 59, 75, 76, I 24, I46, 269

Streptomyces, 43, 44, 108 (Fig. I0), I IO, III, II 4, I I 7, I 2 I, I 28 , 245,307

S. albus, 98, 100, 102, I I I, I 18 , 1 $19,123,126,171,329$

S. antibioticus, 56, 57, 59 (Fig. 4), I 8 (Fig. 10), I I I, I I 9, I 24, I 27, I 7 1, 1 89, 329

S. aurantiacus, 112

S. californicus, 120

$S$. cellulosae, 120

S. equinus, 269

S. globisporus, I I 2

S. griseus, 57, 108 (Fig. 10), I I I , I I 2, I 1 9, 1 24, I 25, I 27, I 75, $193,194,329$ 
Streptomyces (cont.)

S. lavendulae, 57, 108 (Fig. 10), I I I, I I 9, I 2 I, I 22, I 23,124 ,

$$
175,191,192,329
$$

S. praecox, I I I , 128

S. scabies, I I I, I 28, 129, 307

S. violaceus, I 1 2, I 16, 1 25, I 73 , 329

S. violaceus-ruber, 123

Streptomycetaceae, 108

Streptothrix, I IO

Synchitrium endobioticum, $30 \mathrm{I}$

Tetramitus rostratus, 22

Thamnidium elegans, 148

Torula sphaerica, 100

T. suganii, 148, I 50, 2 I 4

Torulopsis, 148 , 149

Torulospora utilis, var. major, 2 I 5

Treponema pallidum, 235, 269, 277 , 317

Trichoderma, 9, 43, 44, 72, I 3 I, I33,

$144,145,150,153,173,211$, 21 2, 253, 302, 302 (Fig. 29), $307,308,309,329$

T. lignorum, I48, I50, I 50 (Fig. 1 7), 305, 306, 307, 309, 310

T. viridis, I 45, I 75, 212, 306, 309, 329

Trichomastric, $21-22$
Trichomonas, 22

$T$. vaginalis, 260

Trichophyton gypseum, 280, 297

T. mentagrophytes, 74, I 46, 297

Trichothecium, $\mathbf{I}_{48}$

$T$. roseum, 305

Trypanosoma, 158

T. equiperdum, I 59, 234, 267

Tylenchus tritici, 162

Typhoid bacteria. See General Index

Tyrothrix, 87

\section{Ustilago, I 48, I 5 I}
$U$. avenae, $\mathbf{I} 52$
$U$. hordei, $\mathbf{I} 52$
U. nuda, 152
$U . z e a e, 59,151,152$

Verticillium, 148

$V$. dahliae, 158

Vibrio comma, 34, 49, 76, 85, 86, 87, $89,95,96,97,98,100,103$, 104, 1 24, 1 26, 146, 179,213 , $26 \mathrm{I}$

V. metchnikovi, 98

Y-bacillus, 9I

Yeasts. See General Index

Zygorhynchus, 59

Zygorsaccharomyces priorianus, I0O 


\section{GENERAL INDEX}

See also Index of Microorganisms, page 395

Abortion of cattle, survival of organism in soil, 28

Acridine, 181,182

Actinomyces lysozyme, I 16

Actinomycetes, 108-1 10

antagonistic properties of, I IO-I I 8 as antagonists, Fig. 4 (p. 59), 108I 29

against actinomycetes, $\mathbf{1} \mathbf{2} 8$

against agents producing plant diseases, 12 8-1 29

against bacteria, $110-118$

against fungi, I I 8, I 5 I-1 53, 303

in soil, 1, 6, 8, 9, 110 , I I 5-118

physiology, 108

substances produced by, 53-54, I I9-

I 27, 1 98-200, 251, 329

in vivo activity, 129

types, Fig. 10 (p. 108)

Actinomycetin, I 1 3-1 I 4, I I 9, I 26, I 29, I 7 I, 3 I 4, 319, 329

chemical and biological properties, 17 I

effect on bacteria, 1 26, 228

therapeutic value, $\mathbf{I} 29$

toxicity, 178

Actinomycin, 83, 1 19-1 20, 165, I 7 I,

$219,228,241,242,298,299$,

$319,320,329$

antiluminescent activity, 81,82

bactericidal action, 246-248

bacteriostatic action, Fig. 4 (p. 59), 220

chemical nature, 189-191

compared with other antibiotics, 74,

219-223

compared with proactinomycin, 126 compared with tyrothricin, 242

crystals, Fig. 20 (p. 209)

differentiation of bacteria, 260

effect on bacteria, Fig. 5 (p. 62),

Fig. 27 (p. 251)

effect on fungi, 74, I 53
Actinomycin (cont.)

in vivo activity, I 29

neutralizing agent, 256-257

toxicity, 1 78, 241, 298-299

Actinomycosis, 27, 127

Adaptation of bacteria to antibiotics, 257-259

Adaptive enzymes, 184

Aerobic bacteria as antagonists, 105I 06

Agar diffusion method, 63, 75-78, 84

Agar method for testing antagonistic action, $6 \mathrm{I}-63$

Agar streak-dilution method, 72-73

Alfalfa, decomposition of, 43-44

Alfalfa-sick soils, 18

Algae, 6, 9, 330

Allicin, 1 70, 217,330

Amebae, 9, I 57

Anaerobic bacteria, 21, 105-107, 266, 272,273

Anaxogramic method, 6 I

Animal excreta. See Human and animal wastes

Animal pathogens, survival of, 26-35

Animals, microscopic

as antagonists, 154-162

in soil, 6

substances produced by, $215-216$, 330

Antagonism, 1 3, 53-59

defined, 331

effect on organisms, $38-39$

metabolite, 227

types, $45,47-48$

Antagonist, defined, 33 I

Antagonistic action, 50-52, Fig. 5 (p. 62)

Antagonistic index, IOI, $\mathrm{IO}_{2}$

Antagonistic interrelationships among microorganisms, 36-39, 44-49

Antagonistic microorganisms

isolation and cultivation, 53-69 
Antagonistic microorganisms (cont.) production of antibiotic substances, $49,64-69$

measurement of activity of substances, 69-83

measurement of bactericidal action, $83-84$

measurement of in vivo activity, 83-84

methods of growing organisms, 64-69

utilization for disease control, 263266

See also Actinomycetes; Animals, microscropic; Bacteria; Fungi

Antagonistic substance, defined, 33 I

Anthrax, 85, 87, 88, 95

survival of organism in soil, 17,27

treatment, 26 I

use of culture filtrate in treating in-

fections, $26 \mathrm{I}$

Antibacillin, 94

Antibacterial action, inhibition of, $225-228$

Antibacterial index, 227, 331

Antibacterial spectrum, 3 I 9

Antibiosis, 37-39, 33I

Antibiotic, defined, 170,331

Antibiotic action, mechanism of, 223228

Antibiotic spectrum, defined, 33I

Antibiotic substances

as means of differentiation of bacteria, 259-260

antifungal action, 297-298

bactericidal action, $22 \mathrm{I}, 245-250$

bacteriostatic spectra, 220

chemical nature. See Chemical nature of antibiotic substances

classification, 170, 228-229, 329330

compared with chemical antiseptics, $218-223$

crystalline preparation, 197

defined, 69-70, 33 I

disease control. See Disease control

inhibition, 255-257

in vivo activity, 315

isolation, 319

manufacture, 3 I 9
Antibiotic substances (cont.)

mode of action, 70, 2 1 8, 228, 324325

produced by actinomycetes, 53, I I 91 27, $189-200$

produced by bacteria, I 78-1 89 produced by fungi, 200-2 I 4 produced by yeasts, 2 I 4-2 I 5 production, 51, 70-72, 319 structural formulae, I 82

See also specific substances

Antidotic, 189, 331

Antifungal substances, 107, 297-298

Anti-inhibitors, 227-228, 33 I

Antiluminescent test, 81,82

Anti-penicillin, 240

Antiphage agents, 166

Antiseptics, 21 8-2 23, 228, 3 I 6-3 I 7

Antivirus, 263-264

Ants, fungi antagonistic to, 303

Aromatic oils as bacteriostatic agents, I 83

Ascaris, 26

Ascomycetes, 147, I 50

Ascorbic acid, effect on actinomycin, 256

Aspergillic acid, 70, I 33, 140, I 4I, I 70, I 7 I, 208, 2 I 3, 244, 258, $273,320,329$

antiluminescent activity, $8 \mathbf{2}$

chemical nature, I 7 I, 208

effect on bacteria, 82, 224, 244

in experimental infection with $\mathrm{Cl}$. perfringens, 273

toxicity, 178

Aspergillin, 133, 165, 329

Assay value, 77

Associative interrelationships among microorganisms, $4 \mathrm{I}-44$

Autolysin, 234

Autolysis, 25 I

Autolytic substance, 127

Autophage, $\mathrm{IO}_{2}$

Autotoxins, 103

Bacillin, 92, 94, 171, 233, 320, 329

Bacillus mesentericus filtrate, bactericidal action of, 286 
Bacitracin, 92, 94, 1 71, 1 88, 286-287, 299, 320, 329

Bacteremia, treatment, 295

Bacteria

aerobic and anaerobic, 9, 105-107

agents destructive to, $245-250$

actinomycetes, I I O-I I 8

insects, I 59-16 I

fungi, 107

maggots, 162

protozoa, $21-22$, I $54^{-1} 58$

substance found in milk, 2 I 6

substance produced by yeast, 2 I 4-

215

ticks, I6 I

as antagonists, Fig. 2 (p. 58), 85107

against agents producing plant diseases, 15 I-1 53

against bacteria, 85-107

against fungi, 57, 58, 94-95,

151-153, Fig. 30 (p. 302), 307

against insects, 159-161

against protozoa, 157

against viruses, $16_{3}-16_{4}$

cocci, $\mathrm{IO}_{3-1} \mathrm{O}_{4}$

colon-typhoid group, 30-32, 99103

differentiation by means of antibiotic substances, 259-260

effect on tumors, 168-169

enzymes, 224-225

fastness, 258

fluorescent bacteria, 95-99

in fecal matter, 19-22

in soil, 7-10, 26-35

lysis, $83,87,88,91$

metabolism, 224

nonspore-forming bacteria, 95-104

spore-forming bacteria, 87-95

substances produced by, 178-179, 329

survival in soil, $26-35$

virulence, 297

Bacterial agar plate method, 55-56, 57

Bacterial cell division, interference by

antibiotic substances, 224

Bactericidal, defined, $33 \mathrm{I}$
Bactericidal action

methods of measuring, $79,82,83$

of insects, $16 \mathrm{I}$

Bacterioantagonistic, defined, 33 I

Bacteriolytic agents in soil, 9

Bacteriolytic, defined, $33 \mathrm{I}$

Bacteriophage, 101, 161, 166, 168, 250

Bacteriostatic action, 69-72 inhibition, 255-257

Bacteriostatic and bactericidal agents.

See Bacteria, agents destructive to

Bacteriostatic, defined, 331

Bacteriostatic spectrum, defined, 59, 319,331

Bacteriostatics, 47, 229

Bacteriotherapy, 26 I, 265, 33 I

Bacterization, 3 I I

Basidiomycetes, antibiotics produced by, $1_{3} 1,132,146,147$

Biological conditioning, 224

Biological control of insects, 16 I

Biological control of plant diseases, 306-3 13

Biostatic complex, defined, 33 I

Blackleg organism in soil, 17,27

Blood cells, hemolysis of, 84

as test of antibiotic activity of tyrothricin, 8 I

by gramicidin, 231, 254

by tyrocidine, 231

by tyrothricin, 23I, 299

Blue staining of pulp, 149

Botulinus, 27, I 89

Bovine mastitis

survival of organism, 28

treatment with clavacin, 280

treatment with gramicidin, $284-285$

Bovine spermatozoa, 254

Bovine tuberculosis in manure, 33

Bran as a medium, 67

Bromo-aspergillic acid, 208

Brucella organism, survival of, 34

Bubonic plague organism, survival of, 28

Cationic detergent, 232

Cattle tick, relation to Texas fever, 17

Cellulose decomposing organisms, 43

Cephalin, 256 
Cevitamic acid, effect on streptomycin, 24 I

Chaetomin, 74, I33, I 53, I 71, 213 , 329

Cheese as a source of antagonistic organisms, 92

Chemical composition of soils, 4-5

Chemical nature of antibiotic substances, I 70-2 I 7

classification of substances, $170-178$ substances produced by actinomycetes, I 89-200

substances produced by animals, 2 I 5 216

substances produced by bacteria, I $78-189$

substances produced by fungi, 200214

substances produced by higher plants, 216-2 17

substances produced by yeasts, 2 I 42 I 5

Chemist, problems for, $32 \mathrm{I}-322$

Chemotherapy, 266-297, 322-324, 332

Chlorellin, I 7 I, 330

Chlororaphin, I 8 I-I 82

Cholera bacteria

as antagonists, 103

survival, 28,34

Cholera immune soils, 35

Chromogenic bacteria as antagonists, 99

Citrinin, I33, I40, I 71 , I 82, 208209, 245, 254, 298, 320, 329

chemical nature, I 7 I, 177

crystals, Fig. 20 (p. 209)

structural formula, $\mathbf{1} 82$

toxicity, 178,298

Citrus canker, 305

Clavacin, 83, I 33, I 40, I69, I 7 I, I 82, $210,219,242-243,298,299$, $303,319,320,329$

antiluminescent activity, $8 \mathbf{2}$

bactericidal action, 243

bacteriostatic spectrum, 220

chemical nature, 171,177

compared with other antibiotics, 74, 2 I 9-22 I

effect on bacteria, 74, $210,223,242$, 243
Clavacin (cont.)

effect on fungi, 242

effect on virus, 165

production, 144,210

structural formula, I 82

therapeutic value, 280

toxicity, 1 78, 280, 298

Clavatin. See Clavacin

Claviformin. See Clavacin

Clitocybin, 1 46, 172,330

Clover-sick soils, I 8

Coagulase, 225

Cocci, 259

as antagonists, $\mathrm{IO}_{3}-\mathrm{IO}_{4}$

Coccidiosis organism, survival in soil, 17

Colds

treatment with clavacin, 280

treatment with penicillin, 275

Colicines, 102, 172, 329

Coliform bacteria in soil, 10,29

Colistatin, 94, 1 72, 329

Collodion sac method of testing antagonistic action, 60-6 I

Colon index, 96

Colon-typhoid bacteria, 245

as antagonists, 99-103

in manure, $2 \mathrm{I}$

in soil, $30-32$

Competition among microorganisms, 44-45

Corylophillin. See Penatin

Cotton root rot, control of, 3 I 2

Crepin, 330

Crowded plate method, 56-57

Cultivation of antagonistic microorganisms, methods, $64-69$

Cup method, $63,75-78$

Cylinder method, $63,75-78$

Cysteine, effect on streptomycin, 24 I

Cytolytic bacteria, 9 I

Damping-off disease, 27, 94, 309, 312

Definitions of terms, $331-332$

Dehydrogenases, 8I, 248-249, 253

Dermatophytes, 146

Differentiation of bacteria by means of antibiotic substances, 259-260

Dilution method, 73-74, 84

Diphtheria, 48, 88, 90, 91, 259 survival of organism, 28 
Diphtheria (cont.)

treatment of carriers with filtrate of B. mesentericus, 286

Diplococcin, 1 72, 1 89, 329

Direct antagonism, 46,48

Direct microscopic method, 7

Direct soil inoculation method, 5759

Disease control

of fecal-borne diseases in China, 2526

of plant disease. See under Plants

of soil-borne diseases, $14^{-1} 5,304^{-}$ 3 I 3

toxicity of antibiotic substances, 298 use of antibiotic substances, 26I-299 use of microbial antagonists, $263-$ 266

Disinfectant spectrum, 222

Disinfectants, chemical, compared with antibiotic substances, 2 I 8-223

Double plate method, $61-63$

Dyes as bacteriostatic agents, 245

Dysentery bacteria, survival of, 28

\section{E. coli}

antagonists of, $3 \mathrm{I}-32$

influence of enrichment of soil with organism, 29-30

survival of organism, 29, 31-32

$E$. coli factor. See Penatin

Endo-subtilysin, 92, 1 73, 329

Enzyme action, inhibition by antibiotics, 50,254

Enzymes acting on polysaccharides, I $83-184$

Equilibrium among soil microorganisms, 38-39

Erythrin, 330

Eumycin, 172, 188, 329

Fastness of bacteria to antibiotics, 258

Fecal-borne diseases, 25-26

Fecal residues, 20-23

Fertilizer

effect on microbial population, 8,26 vse for disease control, 309

Fibrinolysis, 237

Flavacidin. See Flavicin

Flavatin. See Flavicin
Flavicin, 70, 1 33, I 41, 1 72, 207

chemical nature, 172,207

toxicity, 178

Flax blight, 305

Flax-sick soils, I 52

Flour protein, $170,217,330$

Fluorescent bacteria as antagonists, 9599

Fluorescin, I 80

Food competition, 44

Forced antagonism, 53, 58, 214

Formulae, structural, of antibiotic substances, I 82

Freudenreich's method of testing antagonistic action, 60

Fumigacin, 70, 133, 1 70, 172, $210-$ 2 I I, 244, 298, 32 I, 329

antiluminescent activity, $8 \mathrm{I}, 82$

chemical nature, I 72, I 77, 2 I0-2 I I

crystals, Fig. 20 (p. 209)

effect on bacteria, 74, 244

production, $142-143,144$

toxicity, 178,298

Fumigatin, 70, I 33, I 42, I 70, 1 72, I 82, 209-210, 329

chemical nature, 172,177

structural formula, 182

Fungi

agents destructive to, $83,99,147^{-}$ I 53

actinomycetes, I I 8, I 5 I-I 53, 303

bacteria, 63, 83, 94, 130-147,

I 5 I-I 53

substance produced by yeast, $6 \mathbf{2}$,

253

as antagonists, 56, Fig. 2 (p. 58),

Fig. 17 (p. I 50), I 30-1 53

against agents producing plant dis-

eases, I 5 I-I 53

against bacteria, I 30-1 47

against fungi, 62, 147-1 50, Fig.

29 (p. 302)

against insects and other animal

forms, I 60-I 6 I

in fecal matter, 22

in soil, $1,6,8,9,15-16,301$

pathogenic to plants, control of, 306-3 13

relation to protozoa, 158 


\section{Fungi (cont.)}

substances produced by, I, I 30, 200-

214,329

survival in soil, 300

Fungicidal, defined, 332

Fungistatic, defined, 332

Fungistatic factor, 256

Fungistatic properties, 58

Fungus infections of animals, 16

\section{Gangrene, 27, 266}

Garbage disposal, 215

Garré's method of testing antagonistic action, $6 \mathrm{I}$

Gigantic acid. See Flavicin

Gladiolic acid, I 49, I 72, 329

Gliotoxin, 70, I 33, I42, I44-1 45, I 70, I 73, 2 I I-2 I 2, 213,244 , $258,298,314,319,320,329$ antiluminescent activity, $8 \mathbf{1}, 82$ chemical nature, I 73, I 78, 2 I I-2 I 2 compared with other antibiotics, 74,

222

crystals, Fig 20 (p. 209)

effect on bacteria, 73, 21 2, 223, 244

effect on fungi, 73, I 50 , I 53

medium, I 44

production, 72, I 44-1 45

toxicity, I 78, 244, 298

Glucose-oxidase, 225

Glutinosin, I 73, 214,329

Gonorrhea, treatment with penicillin, 276

Gramicidin, 70, 92, 170, 1 73, 228, $242,261,298$

antiluminescent activity, 81,82

chemical nature, I 73, I 78, I 85-1 86 compared with other antibiotics, 74 ,

22 I

compared with penicillin, 221, 222 ,

237,239

compared with tyrocidine, 22 I, 230

crystals, Fig. 20 (p. 209)

effect on bacteria, $8 \mathbf{2}, \mathbf{2} 32$

hemolytic action, 23I, 254

inhibition, 256

mode of action, 226, 230, 248, 254

therapeutic value, $23 \mathbf{I}, \mathbf{2} 80$
Gramicidin (cont.)

toxicity, I $78,230,280,282,283$, 298

Gramicidin S, 92, 188,286

Gramidinic acid, 82

Gram-negative bacteria in soil, 28-32

Gram stain and sensitivity to antibiotic substances, 223

Growth-promoting substances, 46, 63, I 50,224

Helvolic acid. See Fumigacin

Hemipyocyanin, 82, I53, I 79, I 81 , 219

Hemolysin production method of measuring antibiotic activity, 83

Hemolytic action. See Blood cells, hemolysis of

Hetero-antagonism, 47

Heterotrophic bacteria in manure, 2 I

Histone, 254

Human and animal wastes, I 9-35

composting of, 308

destruction of microorganisms, 2526

garbage, 25

manure and fecal residues, 20-22 composition and decomposition, 22-23

microbial population, 20-22, 92

sewage, 24-25

survival of pathogens, 26-35

Humic acids, 4

Humus compounds, effect on actinomycin, 256

Hydrogenase, 225

Hypholin, 229

Hyphomycetes, antibiotics produced by, I 49

Inactivator, nontoxic, defined, I63164, 332

In activators of viruses, $163-166$

Indirect antagonism, 46, 48

Infections, wound, 316-3I 7

treatment, 275,278

Influenza organisms, 28,86

Infusoria, lysis of, 99

Inhibins, 330 
Inhibition

of antibacterial action, 255-257

of antibiotic action, 255-257,259

Inhibitive substance, defined, 332

Inhibitor, defined, 33 I-332

Inner antagonism, 226

Inorganic constituents of soil, 4-5

Insects

activity of fungi against, I 59-16 I

bactericidal action of, I6 I

control of, I 59-16 I

in soil, 6, 9, 17

Interference phenomenon, 167

Intestinal disturbances, treatment of, 265,298

In vivo activities of antibiotic substances, methods of testing, $83-84$

Iodinin, 1 73, I $81-182,320,329$

chemical nature, 173,177

structural formula, 182

Iron utilization, 224

Iso-antagonism, 47, 250

Isolation of antagonistic microorganisms, methods. See Methods of isolating antagonistic microorganisms

Japanese beetle, control of, 160,324

Javanicin, 145, 1 73, 329

Ketones, 24I

Kojic acid, I 73, 182, 213,329

Lactenin, 170,330

Lactic acid bacteria, 107, 265

Lactose fermenting bacteria, I I I

Lauryl sulfate, 82

Leeches, 94

Leguminous plants, 3 I 3

Leprosy, 17, 28

Lichens, 217

Lipoids, 103, 104, 287

Liquid media for testing antagonistic action, 60-6I

Litmocidin, I 1 9, 1 26, 173,329

Lysin of bacteria, 90, 226

Lysis

of actinomycetes, 127

of bacteria, $56,57,83,87,88,91$,

I05, I 27, $251-252$

of fungi, 152
Lysobacteria, 89

Lysogenesis, defined, 332

Lysogenic bacteria, 57-58

Lysozyme, 161, 170, 21 5-216, 245, 250, 314,330

defined, 332

effect on bacteria, $215-216$

of actinomycetes, 116

Lytic action

of actinomycetes, I 10-I I 4, I 26127

of antibiotic substances, 93, 98, 105, 225,249

Maggots, bactericidal action of, 162

Malarial parasites, I 58-159

Maltol, I 99

Manure. See Human and animal wastes

Manuring of soils, 308

Mastitis. See Bovine mastitis

Measurement of antibiotic activity, methods. See Methods of measuring antibiotic activity

Mechanical separation method of determining abundance of organisms in soil, 7

Mechanism of antibiotic action. See under Antibiotic substances

Medium, 6o-63, 64-69 effect of aeration on antibacterial activity of fungi, I $37,138-139$ staling, 47

Meningitis, treatment of, 275, 278, 295,296

Metabiosis, 13

Metabolic processes of cells, interference by antibiotic substances, $252-$ 255

Metabolic products, effect of, 60

Metabolite antagonism, 227

Methods of determining abundance of microorganisms in soil, 6-9

Methods of growing organisms for production of antibiotic substances, $64-69$

Methods of isolating antagonistic microorganisms, 53-59, 319

bacterial agar plate, 55-56

crowded plate, 56

direct soil inoculation, $57-58$ 
Methods of isolating antagonistic microorganisms (cont.)

"forced antagonism," 53, 58, 214

soil enrichment, 54-55

Methods of measuring antibiotic activity, 69-83

agar diffusion or "agar cup," 78

agar streak-dilution, $72-73$

antiluminescent test, 82

lysis of red blood cells, 84

serial dilution, $73-75$

turbidimetric, 78-8 I

Methods of measuring bactericidal action, $82-83$

Methods of testing antagonistic action of microorganisms, 59-69

Methods of testing in vivo activity of antibiotic substances, $83-84$

Microbial cell, physiology of, 325

Microbiological equilibrium, I 56

Microbiological population, 3-4

Microbiologist, problems for, 31 8-321

Micrococci as antagonists, 104

Micromonosporin, I 19, 329

Microorganisms

disease-producing, I 3-1 5

in animal excreta, 20-23, 85-87

in soil, $1-2,6-9,31,32,33-35$

nutrition of, $11-12$

See also Actinomycetes; Animals, microscropic; Antagonistic microorganisms; Bacteria; Fungi;

Mixed cultures

Microscopic methods of determining abundance of microorganisms in soil, 7

Milk, bactericidal action of, 2 I 6

Milky disease of larvae, 94, I60

Mixed culture inoculation for testing antagonistic action, 63

Mixed cultures, 86, 104

antagonistic interrelationships, 45-

associative interrelationships, $4 \mathrm{I}-44$ competitive interrelationships, 44-45 growth of microbial cells, I 2-I 3, 40 mutualistic relationships, 36-39, 4I42

nature, $40-4 \mathrm{I}$

Mixed infections, $263-264$
Mixed population. See Mixed cultures

Mode of action of antibiotic substances, 70, 218, 228, 324325

Morphology, 103, 223, 250-253

Much-lysin, 90

Mushroom fungi, 9

Mutaflor, 266

Mutants of $P$. notatum, I 36, I 39

Mutations of bacteria, 259

Mutualistic relationships among microorganisms, 36-4I

Mycetin, I I 9, I 26, I 73, 329

Mycobacteria and streptomycin, 288, 289-291, 296

in soil, 17

inhibition by streptomycin and streptothricin, 288

Mycocidal, defined, 332

Mycoin, defined, 332

Mycolysate, 53, I13, I 29, 265

Mycophagy, I 30

Mycophenolic acid, 1 30, I 73, 21 3, 259

Mycorrhizal fungi, 303

Mytogenetic rays, 5 I

Natural selection of bacteria, 259

Nematodes, I 58, I 59, I60, I 62

Neocolysin, 265

Nitrite production method for measuring activity of penicillin, $8 \mathrm{I}$

Nitrogenous materials, effect on fungi, 307-308

Nonspore-forming bacteria, 95-104

Notalysin, 173

Notatin. See Penatin

Nutrition of microorganisms, I I-I 2, 223

Organic matter of soil, 4

Organic media, 64

Otitis media, 295, 296

Oxford unit, 77, 204, 332

Oxygen supply of soil, 3

Oxyphenazine, 1 79, 287

Pantoyltaurine, 226

Paper-disc method, 63, 75-78

Paper-pulp fungi, 1 50, 310 
Para-amino-benzoic acid, effect on penicillin, 226-227, 229, 239$240,256,325$

Paracolon bacteria, 102

Parasiticin, 329

Parasitism, 1 3, 37-38

Paratyphoid bacteria, 93

Partial disinfection of soil, 3 I 2

Partial sterilization of soil, I55, 304

Passive antagonism, 48

Pathogenic organisms

in fecal wastes, $\mathbf{2} \mathbf{I}-\mathbf{2} 2$

in soil, $14-15,16-18,26-35$

Patulin. See Clavacin

Penatin, 70, 133, I69, 1 70, 173, 207, 329

Penicidin, 133, I 40, 174, 213,320 , 329

Penicillamine, 207

Penicillic acid, I33, I40, I 74, I 82, 209, 228, 245, 319, 320, 329

chemical nature, 174,177

structural formula, 182

Penicillin, 81, I31, 163, 169, 170, I 74, $213,298,299,319,320$, 329

administration, 272

animal experiments, $272-275$

antiluminescent activity, 8 I, 82

as prophylactic, 275

assay, 204-205

bactericidal action, $221,234-235$,

$$
\text { 249-250 }
$$

bacteriostatic spectrum, $76,220,236$ chemical nature, 174, I78, 200207

chemotherapy, 274, 275-280

compared with

chemical substances, 70, 221-222

other antibiotics, 219, 222, 232,

237,242

sulfanilamide, 237

sulf athiazole, 235

sulfonamide, 237-240, 268, 269,

277

crystals, frontispiece

differentiation of bacteria by, 259260

discovery, I 32, 314-316
Penicillin (cont.)

effect of other agents, 226

effect of reaction, 234

effect on bacteria, 80, 225, 234, $236-237,247-248$, Fig. 27 (p. $251), 252$

effect on cell morphology, 25 I-253

effect on fungi, 236

effect on metabolism, 255

effect on phage, 165

effect on sea urchin eggs, 240

effect on virus, 165,166

failures, $\mathbf{2} 79$

inactivation, $239,240,255^{-256}$

inhibitor, 259

in wounds, 317

isolation, 202-204

lysis of bacteria by, 234

measurement, $73,75-78,80-85$

medium, 65-67

mode of action, 234-240

pharmacology, 279

production, 132-140, 200-201, 205

resistance of bacteria to, $235,257-$ 259,270

selective action, 267-269

sporocidal action, 235, 252

submerged culture for production, I $37^{-1} 39$

surface culture for production, 137I 38

therapeutic value, $266,267-280$, 317

toxicity, $178,267-269,271,272$, 276

Penicillin B. See Penatin

Penicillin F, I 39, 206, 272, 275

Penicillin G, 139, 206, 273, 275

Penicillin K, 139, 206, 273, 275

Penicillin X, 139, 140, 206, 236, 273, 275

Penicillinase, $82,147,226,230,255^{-}$ 256,258

Penicillin-like substances, 140

Peptones as bacteriostatic agents, I 83

Persisters, 270

Pfeiffer's bacillus, 259

Phage in soil, 6, 9 
Phage of bacteria, $163,165,166,226$, 250

Phenazine, 181 , 182

Phenol, 69, 70, 82, 222 coefficient, 70

Phthiocol, 1 05, I 74, 329

Phycomycetes, I 3 I, 132

Physiologist, field for, 324-325

Physiology of bacteria, effect of antibiotic agents, $87,253-255,325$

Pigment formation and antagonism, $42-43,95,99$

Pigments, 49, 108

Pinosylvin, 330

Plant viruses, 167

Plants

agents pathogenic to, $\mathbf{1} 8,300-301$ antibacterial agents produced by, $216-217,225,330$

bacteria pathogenic to, 93

bactericidal action of juice, 216

diseases of, control, 300-31 3

by fungi, 253, 305-310

by use of antagonistic microorganisms, 93, 304-3 13

fungi pathogenic to, $302-313$

influence on microbial population of soil, 5,8

Plate culture method, 6-7

Pneumococci as antagonists, 104, 105

Pneumonia organism, survival, 28

Poliomyelitis, 167

Polypeptides, I 85-1 89

Polyporin, 146, 1 74, I 78, 213,330

Polysaccharidases, I 83-I 84, 296-297

Potato scab, I 28-1 29, 307

Precursor for streptomycin, 68, I 25

Proactinomycin, I 1 9, I 26, I 74, 242, 320,329

chemical nature, 200

compared with actinomycin, I 26

Prodigiosin, I 74, I 81,329

Production of antibiotic substances, methods of growing organisms for, 64-69

Protamine, 228, 254

Protoanemonin, 217,330

Protozoa

in manure and urine, $2 \mathbf{I}-\mathbf{2 2}$

in soil, $6,9,42$
Protozoa (cont.)

relation to bacteria, 22, 32, I 54-1 57

relation to fungi, 158

Protozoan theory of soil fertility, I 55

Pseudodiphtheria, 48

Puberulic acid, 174, 2 1 2-2 1 3, 329

Puberulonic acid, 174,329

Pure cultures, I 2-1 3, 86

Pyo-compounds, 98, I 74, 1 83, 320, 329

Pyocyanase, 51, 70, 85, 97, 174, 258, $314,319,320,329$

antiluminescent activity, $8 \mathbf{2}$

bactericidal action, 246

chemical nature, 98, I 74, I 80

effect on bacteria, 82, $219,222,250$

isolation, I 78-1 80

practical value, $98,262,266,287$

toxicity, 298

virus inactivation, 164

Pyocyaneus organism as antagonist, 95, 96

Pyocyanic acid, 179

Pyocyanin, 70, 98, 153, 174, 298, $314,319,320,329$

antiluminescent activity, 82

chemical nature, $174,178,181,182$

effect on bacteria, 82, 98, 2 1 9, $222-$ 223, 249

inhibitory action, 225

isolation, I $78-180$

structural formula, 182

toxicity, 298

Pyolipic acid, 98, I 75, I 79, 329

Pyoxanthose, 180

Pyrogenic substances, 239

Quinine, r70, 209-210, 284

Quinones, 245

effect on bacteria, 22, 227, 246-247

Radiations, 5 I

Repressive antagonism, 48

Resistance of bacteria to antibiotics, $257-259,270$

Respiration of bacteria, 229

Respiratory infections, 275

Rhizosphere, 5, 313

Rickettsiae, affected by penicillin, I 66

Root-inhabiting fungi, 30 I

Rust spores, inhibition of, I 52 
Saliva, antibacterial action of, 2 I 6

Saprophytic organisms

for disease control, 263

in soil, $15-18$

Saprophytism, 38

Sarcoma cells, I69

Sea water, bactericidal action of, 32

Seed inoculation, 3 I I

Selective culture method, 7

Semisolid media, 63, 8 I

Serial dilution method, $73-74,84$

Sewage, 24-25, 85, 92

Silkworms, destruction of, I 59

Simplexin, 92, 94, 1 75, 1 89, 233, 320, 329

Simultaneous inoculation method, 60 , $6 \mathrm{I}, 102,106$

Skin diseases, 150

Slime disease, 308

Smuts, bacteria antagonistic to, I 5 I

Soil

actinomycetes in, 6, 8, 9, I I 5-1 18

as culture medium, I O-I I

as habitat of microorganisms, $1-2$

bacteria in, $6,8,9,11,92$

biological state, 5-6

chemical composition, 4-5

effect of heating, 304

effect on plant growth, Fig. 34 (p. 254)

fungi in, 1, 6, 8, 9-10, 149

invaders, $30 \mathrm{I}$

microbial population. See Soil microorganisms

pathogens in, I6-1 8, 27-36

physical properties, $2-4$

saprophytes in, I 5, I 8

treatment, effect on microorganisms, 8

Soil-borne diseases, 300-3 I 3

methods of control, I 4-I 5

Soil enrichment method, 53-55

Soil inoculation method, 57-59

Soil microorganisms, 6-9, 34-35

effect of bacteria, 29

equilibrium, 38

nature of, $16-18$

Solid media for testing antagonistic action, $61-6_{3}, 64$
Space antagonism among microorganisms, 44,50

Spectrum, bacteriostatic, 59, 76, 319, 331

Spinulosin, 70, 133, 142, 170, 175, 329

chemical nature, 175

Spirocheticidal action of penicillin, $235,247-248$

Spore-forming bacteria

antibiotics produced by, 233-234

as antagonists, 56, 87-95

Spore germination, 149

Spores, preparation of, 65,68

Sporicidal action of penicillin, 235

Spot inoculation method, 63

Stable manures, 20-23

Staling of medium, 47, I 52

Staphylococcus aureus infections, treatment with penicillin, 275,278

Staphylococci as antagonists, 104

Sterilization of soil, 304

effect on coliform bacteria, Io

partial, I 55, 304

Streptamine, 198, 199

Streptidine, 197-1 99

Streptococcal infections, treatment of, 275

Streptococci as antagonists, 103

Streptomycin, 75, 127, 128, 1 53, 165,

I 75, 299, 319, 326, 329

activity, I 93-1 94

administration, 290, 292, 293-294 agar, 78

agar diffusion method for measuring activity, 84

bacteriostatic spectrum, I 24

chemical nature, $175,178,193-200$

chemotherapy, 266, 287-296

compared with other antibiotics, 74

crystals, Fig. 19 (p. 196)

curve, 79

discovery, 316

effect on bacteria, 74, 1 24, 223,

$317-318$

effect on phage, 165

inactivation, 195, 199-200, 225,

240-24 I

in vivo activity, 83

isolation, I 94 
Streptomycin (cont.)

lysis of organism, 127

media, 68-69

precursor for, 125

production, I I 9, I 24-125, I 93

resistance of bacteria to, $241,257-$

259

toxicity, 178, 287, 290, 292-293

tuberculosis treatment, 288, 289296

tularemia treatment, 288,289

urinary infections, treatment, 288 , 294, 296

Streptomycin unit, defined, 332

Streptothricin, 75, 82, I 1 9-1 24, 129 ,

$153,165,175,240-241,298$,

299, 319, 320, 329

bacteriostatic spectrum, 220

chemical nature, I75, I91-193, 1 99-200

compared with other antibiotics, 74, $219-223,226$

differentiation of bacteria by, 260

effect on bacteria, 74, I 23, 223, 25 I

effect on fungi, 74, 124

media, 68-69

production, I I 9-1 24

resistance of bacteria to, $24 \mathrm{I}$

therapeutic value, $287,288,292$

toxicity, I 78,287

Structural formulae of antibiotic substances, I 82

Submerged growth, 65, 67, I 09

Subtilin, 88, 92, 163, 1 75, I 88, 233, 286-287, 299, 319, 320, 329

Subtilysin, 92, 188, 329

Successive inoculation method, 6 I

Sulfanilamide

antiluminescent activity, $\mathbf{8 2}$

compared with penicillin, 226-227,

$235,237-238$

effect on bacteria, 82

inhibition of antibacterial action, 255

Sulfhydryl groups, 255

Sulfonamide, 232,258

bacteria resistant to, 276

compared with penicillin, 268, 269,

277

Suppressor, defined, 33 I
Surface tension, 225,254

Surgical infections, treatment of, 275 , 278

Symbiosis, 1 3, 37-39, 42

Synergism, 39

Synthetic media, 64, 66-67, 68

Syphilis, treatment with penicillin, 277

Take-all disease, 39

Tannic acid, effect on actinomycin, 56

Temperature for growth of antagonists, 65

Testing antagonistic action, methods, 59-69

Testing in vivo activity, methods, 8384

Tetanus organisms, survival of, 27

Tetanus toxin, I 69

Texas fever, 17

Thermolabile substances, 46, 89

Thermophilic actinomycetes, I 27

Thermophilic bacteria, 89

Ticks, bactericidal action of, I 6 I

Tissue culture, $8 \mathrm{I}$

Tolu-p-quinone, 82

Tomatin, 330

Toxic substances, 46

Toxicity of antibiotic substances, 178 , 229,24 I, 286-287, 297, 298299

Toxin destruction, 169,233

Toxin of bacteria, 163

Toxin production, $42,47,106,304$

Toxoflavin, 189,329

True antagonism, 46, 48

Trypanosome parasites, I 58-1 59, 276277

Trypanotoxin, I 58, I 75, 329, 332

Tubercle bacillus, 28, 33-34

inhibition by microorganisms, 146 , 245

in human and animal wastes, $2 \mathbf{I}$

Tuberculocidin, 245, 332

Tuberculosis, chemotherapy of, 263, 289-296

Tuberculostatic, defined, 332

Tularemia, treatment of, 288,289

Tumors, I 68-169

Turbidimetric method, $78-81$ 
Typhoid organism, 85-86, 87, 88, 90, 93, I I I, 242

as antagonist, $\mathrm{IO}_{3}$

in soil, $28,30-32,85-86$

treatment of, 264, 265, 294, 295, 296

Typhus rickettsiae, 166,273

Tyrocidine, 70, 92, 170, 175, 298, 329

bactericidal action, 282

chemical nature, I 75, I78, I 86-I 87 compared with gramicidin, $22 \mathrm{I}-$ 222, 230

compared with penicillin, 239

crystals, Fig. 20 (p. 209)

effect on bacteria, 70, 225, 232

effect on protozoa, 158

hemolytic effect, 231

mode of action, 22 I, 230-233, 254

therapeutic value, $23 \mathrm{I}$

toxicity, 178,298

Tyrothricin, 65, 81, 88, 92, I53, I63, 175, 242, 266, 298, 316, 319, 320,329

adaptation of bacteria to, 232

administration, 282

antiluminescent activity, 82

bactericidal action, 28I, 282

chemical nature, 175

differentiation of bacteria by, 260

effect on bacteria, 82, 219, 230

hemolytic effect, 23 I, 299

inhibition, 230, 256

limitation, 286

mode of action, 229-233, 254

production, 71,92

therapeutic value, $272-273,280-$ 286
Tyrothricin (cont.)

toxicity, $178,230,282,284$

Udder infections. See Bovine mastitis

Ultramicroscopic forms in soil, 6

Urinary infections, 275, 294, 295, 296

Urine, bacterial composition of, 21

Ustin, 142, 1 75, 329

Utilization of antibiotic substances. See Disease control

Vaccination of medium, 47

Violacein, 175, 182, 329

Viridin, 145, 175, 21 2, 321, 329

Viruses antagonisms among, 163-169 inactivators of, 164-166

Vitamins, I I, 42

Vivicillin, 279

Wastes, human and animal. See Human and animal wastes

Water

as culture medium, IO-I I

as habitat of microorganisms, $\mathbf{1}-\mathbf{2}$

Wonder drug, 316

Worms, 9

Wound infections, 316-317

treatment, 275,278

Yeasts, 45

in soil, 9

substances produced by, 214-215, $253,255,32$ I

utilization, $68,265-266$

Yellow fever virus, 167 







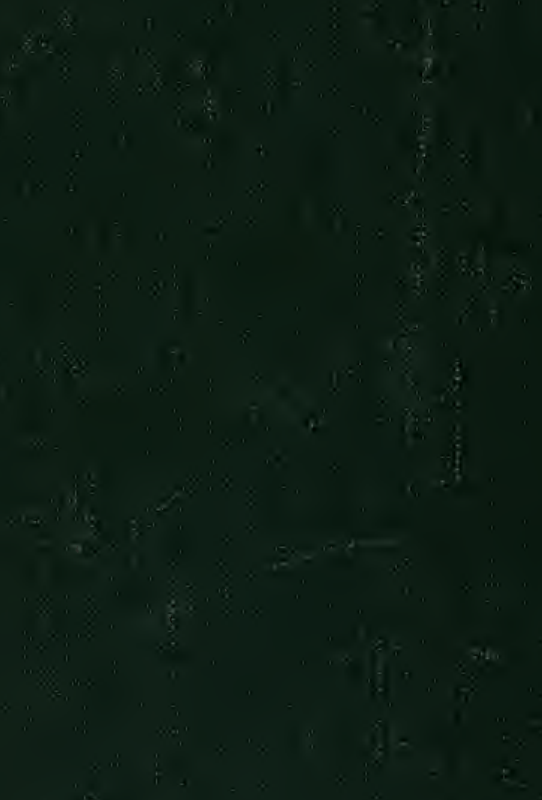